\title{
Aplicación de humedales artificiales para la depuración de purines de granjas porcinas
}

Iván Blanco Rubio

Directores de tesis:

Dra. Gemma Ansola González

Dr. Luis Enrique Sáenz de Miera Carnicer

Memoria presentada para optar al título de Doctor

Área de Ecología

Departamento de Biodiversidad y Gestión Ambiental

Universidad de León

León, Enero de 2014 
Esta tesis doctoral ha sido posible gracias a la beca de Formación de Personal Investigador cofinanciada por la Junta de Castilla y León y el Fondo Social Europeo concedida a D. Iván Blanco Rubio por Orden EDU/1817/2004, de 29 de noviembre. 
A mi madre 
Caminante, son tus huellas el camino, y nada más; caminante, no hay camino: se hace camino al andar.

Al andar se hace camino, y al volver la vista atrás se ve la senda que nunca se ha de volver a pisar.

Caminante, no hay camino, sino estelas en la mar.

Antonio Machado 


\section{Agradecimientos}

Al escribir estas últimas líneas me invaden muchas emociones: alegría, satisfacción, orgullo, alivio... pero sobre todo gratitud, ya que han sido muchas las personas que me han ofrecido su apoyo, sus consejos, su cariño y amistad a través de este largo camino. Esta sección es la más importante ya que esta tesis jamás podría haberse completado sin vuestra colaboración.

En primer lugar quiero agradecer la supervisión de Gemma Ansola y Luis E. Sáenz de Miera, mis directores de tesis. Gemma me aceptó como estudiante y me ha guiado a través de mi primera experiencia en el mundo de la ciencia. Las palabras se quedan cortas para agradecer su ánimo, su apoyo incondicional y confianza incluso durante mi periodo sabático en los Estados Unidos. Eres una persona excelente, gracias de corazón.

La redacción de la memoria no hubiera sido posible sin las frecuentes sugerencias y correcciones de Luis. ¡Ninguna frase pasiva ha escapado a su escrutinio! He tenido la suerte de poder trabajar con un científico ejemplar. Muchas gracias por tu paciencia y dedicación.

Quiero también expresar mi agradecimiento al Dr. Carlos Tejerina y los trabajadores de CENTROTEC que nos han brindado su asistencia durante el trabajo experimental.

Para crear y mantener una planta piloto experimental hace falta cavar, plantar, podar, cavar, conducir el viejo Lan, reparar el viejo Lan, retirar el viejo Lan, conducir la furgoneta, transportar depósitos, tomar muestras, cavar, analizar muestras, diseñar columnas de experimentación... es decir, hace falta Luis. Todos los problemas tienen solución cuando Luis está cerca. A ti te debo el haber llegado hasta aquí. Gracias por tu buen humor, tus consejos, tu ayuda y tu amistad.

Gracias a Merce y Héctor por ayudarme a analizar muchas de las muestras cuando menos tiempo disponía y a diseñar los experimentos en batch. Es un placer llegar al departamento y ser recibido con un buenos días y una sonrisa... iincluso cuando llevas trabajo extra!

No puedo olvidar a los compañeros del Instituto de Medio Ambiente con quienes he compartido tantas risas, cafés, cenas, salidas de campo, laboratorio, etc., en los inicios de la tesis. Gracias a Rubén, Roberto, Esther, Luis, Paula, Flanagan, Joselito, Patricia, Linda, Antonio, Rafa, Bea, Irene, Cristina, Saúl, Amando, Ricardo, Servi, Juan, Juan Carlos, etc., y muy especialmente a Nataluki, el alma máter del IMA.

También a mis compañeros del área de Ecología a los que no hacía falta convencer para bajar a tomar un café. Gracias a Carlos, Joselito, Bea, Rocío, Gemma, Alejandra, Manu, Bea, Lozano, Cynthia, etc. A Joselito le he nombrado dos veces y es que se lo merece, es un fenómeno.

Gracias especialmente a Piltri, Dinio, Tino y Julie, mis compañeros de piso, quienes me sufrieron a mí y a mi tesis sin entender a qué me dedicaba. Gracias también a Linux y Barny como visitas frecuentes y a Carlos y Daniel como vecinos, iqué recuerdos!

Dos grandes profesionales hicieron posible que disfrutase de mis estancias de investigación: Pascal Molle, que me enseñó sus experimentos sobre el fósforo en el Cemagref de Lyon, y el profesor Inoue, que me recibió en la Universidad de Hokkaido. Disfruté este tiempo gracias a mis compañeros de trabajo y amigos. Gracias a Najatte Harouiya, Maxime Chevalier, Stephane Troesch, Kunihiko Kato (Kato san), Pradeep Sharma, Dai Tokuhisa y Milyn Torres.

Los dos años que viví en Miami me permitieron aumentar conocimientos en el sector de las aguas residuales gracias a la Obra Social de la Fundación Caja Madrid y a todos mis profesores y compañeros de FIU, especialmente a los profesores Miralles y Gardinali y a Alberto Pissani y esas cervecitas de los viernes; y también al equipo de la Everglades Foundation, especialmente a 
Rosanna Rivero y cómo no a Melodie Naja, quien se aseguró de que finalizase mi proyecto fin de máster y me animó a completar la tesis en León.

Tengo gratos recuerdos de las aventuras y desventuras que viví con Georgina y mis compañeros de piso: Desirée, Amida (the coolest landlord in the world), Kurt y Junior que me permitieron conocer la cultura americana en Miami... ies posible!, y también de todos los becarios españoles que pasaron por South Beach, especialmente de Diego, Berta y Germán, el núcleo duro (menudo Halloween en Key West... ¡inolvidable!)

Y por supuesto no puedo dejar de mencionar a aquellos que me recibieron el primer día y me despidieron el último... iißla TUNA!!! Gracias a los Peluca, especialmente a Pedro (gracias calamar), a Tortilla, Pedro de Granada, Hortalizo, Cordobés, Rayman, Patán, Leroy, Vicente, Nani, Luis, Lausín, Mosca, Tarjetas, Purroy, Marlon, Kunta, Kinte, Inés, Armando, Mónica, Alexis, etc. y a toda la gente de Casa Juancho.

El año que viví en Narragansett no hubiera sido lo mismo sin Tamara, mi amiga y confidente, con quien compartí tan buenos momentos. Sin Tania que me ayudó a integrarme, sin las excursiones improvisadas y los cohetes de Kevin y sin las cervezas, canciones, barbacoas y casas quemadas de Antonio. Gracias a Erik, Erin, Naresh, Bea, Gemma, Daniel, Ben, Tayebeh, Amir Shirazi y Banari, Sina, Leila, Christian, Jeff, David Grote, y las familias Wood y Morrill que me recibieron como uno más. Gracias también a Naomi, Lisa y el resto de compañeros de la U.S. EPA.

El periodo en los Estados Unidos se hizo mucho más interesante con las visitas de mis amigos y las aventuras que vivimos en Miami, California, Las Vegas, Nueva York, Canadá, Chicago, Washington DC, Key West, Rhode Island y Massachusetts. Inolvidables recuerdos gracias a mis amigos de la infancia Chema y Nico y al resto de la panda: Diego, Tino, Raúl, Prada, Fer (242 forever), Oscarín, De la Rosa, Gelo, Óscar González, Lupe, Rebe, Edu, Chete, Kosko, Charles, Pelli, Centeno, Miche, Raquel... ¡me hizo mucha ilusión vuestra visita! Gracias también a Dani, Javi, Luisma, Maite, Miri, Iván, Rebo, Clau, Sergio, Susana, Musu, Ramón, Villalón y al resto de amigos que no he mencionado, $¡$ sois demasiados!

También quiero agradecer a todos aquellos con los que he compartido risas y charlas a la hora del café, durante la comida, los cortos de los viernes y las cenas de Navidad. Gracias a Luisfe, Paco, Raquel, Luz, Elena, Gustavo, Eloy, Reyes, Leo, Susana, Geli, Marga, Camino, Paula, Javi, etc. Gracias a Tanis que me recibió en el departamento como uno más y que ha dado la oportunidad de realizar una tesis a tantos becarios que han pasado por el área de Ecología. Y por supuesto gracias a las dos personas que hacen que salga el sol todas las mañanas en el departamento. Anna e Irena, ¿pensábais que me había olvidado de vosotras? Gracias por aguantarme durante el periodo de redacción, sois las mejores.

Quiero mandar un abrazo muy fuerte a todos los miembros de mi Tuna, la Tuna de la Universidad de León: Pipo, Getino, Lobo, Centella, Pin, Ses, Pica, Copi, etc. Demasiados para nombrarles aquí. Gracias por ese parche, esos viajes y esos compromisos que han sido la excusa perfecta para distraerme de mis deberes profesionales. Ya era hora de ir tocando Fonseca...

Y por supuesto gracias a mi familia que siempre me ha ayudado, me ha demostrado su cariño y apoyado mis decisiones aunque no fuesen las más acertadas. Gracias a mi abuela que se alegrará mucho de saber que soy doctor, a Victoria y Valentín, Jose Antonio, Susana, Pedro y Yolanda, a tía Pepa y Carlitos que siempre me pregunta a ver cuándo termino de estudiar, a mi nueva familia política, ahora puedo decir que soy un poco de Villaroañe, y a todos los demás. Y sobre todo a mis padres a quienes se lo debo todo y a mi hermana que siempre está pendiente de mí. Y a mi sobrinín Alejandro, que habrá cumplido un año cuando esta tesis haya sido defendida.

A todos vosotros, muchas, muchas gracias. 




\section{Índice}

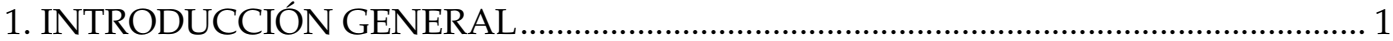

1.1. Problemática ambiental de los purines de cerdo .......................................................... 2

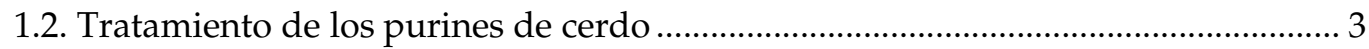

1.3. Sistemas naturales para el tratamiento de agua residual .......................................... 5

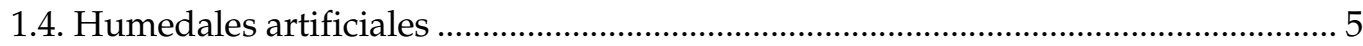

1.5. Mosaico jerarquizado de ecosistemas artificiales $\left(\right.$ MJEA $\left.^{\circledR}\right)$........................................ 8

1.6. Humedales artificiales para el tratamiento de agua residual de origen ganadero 8

3. FUNCIONAMIENTO DE UN SISTEMA DE FLUJO COMBINADO TIPO MJEA®

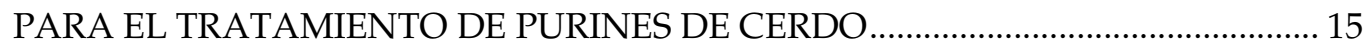

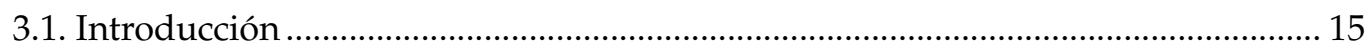

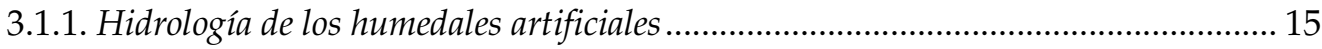

3.1.2. El papel de la vegetación en los humedales artificiales............................................. 16

3.1.3. Mecanismos de eliminación de sólidos en suspensión.................................................. 17

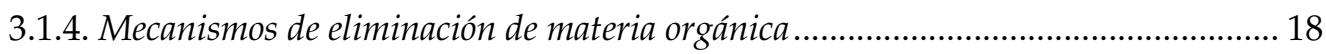

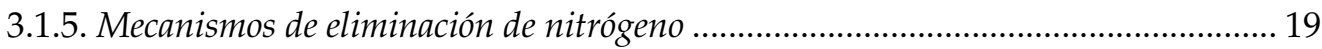

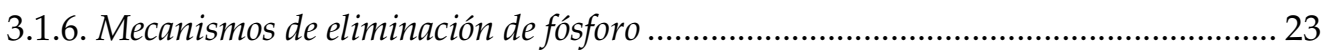

3.1.7. Eficiencia de los humedales artificiales para el tratamiento de agua residual de origen

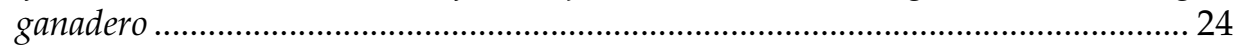

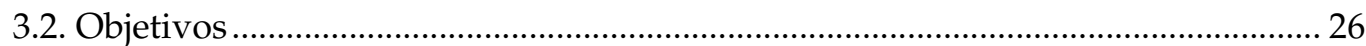

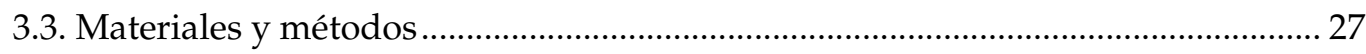

3.3.1. Planta piloto para el tratamiento de purines de cerdo .................................................. 27

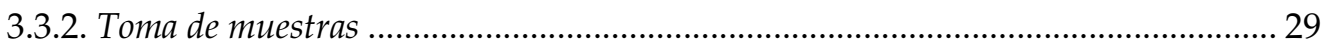

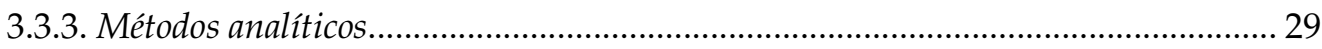

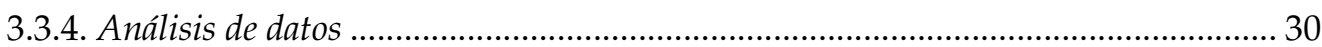

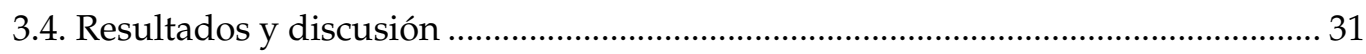

3.4.1. Características del agua residual......................................................................... 31

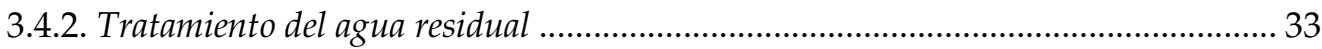

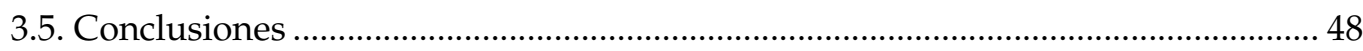

4. EVALUACIÓN DEL DIMENSIONADO DE UN SISTEMA DE FLUJO COMBINADO TIPO MJEA ${ }^{\circledR}$ PARA EL TRATAMIENTO DE PURINES DE CERDO …….................... 51

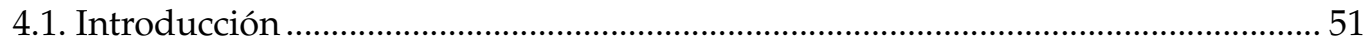

4.1.1. Influencia del balance hídrico en el funcionamiento de humedales artificiales ......... 51

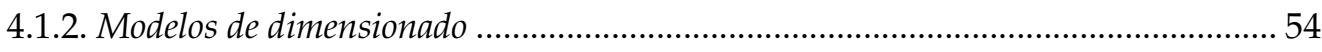

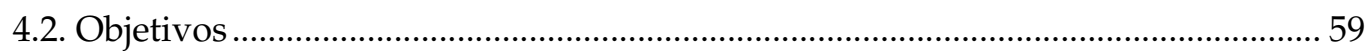

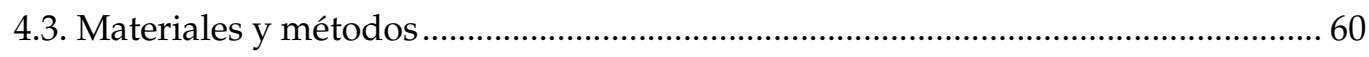

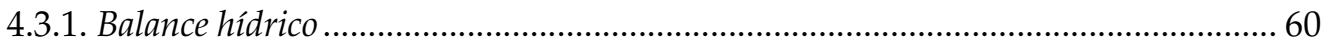

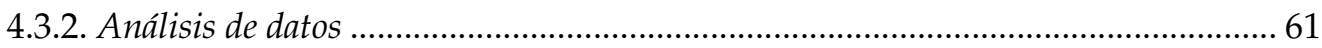

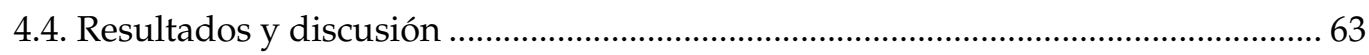

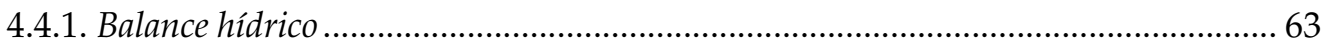

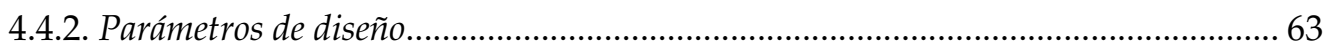

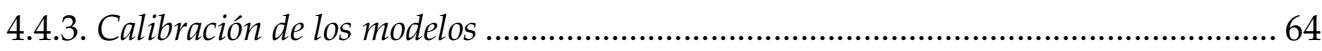




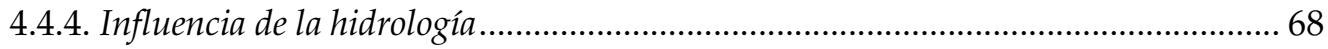

4.4.5. Calibración de los modelos con los datos corregidos ................................................... 70

4.4.6. Dimensionado de un sistema de flujo combinado tipo MJE $A^{\circledR}$.................................. 72

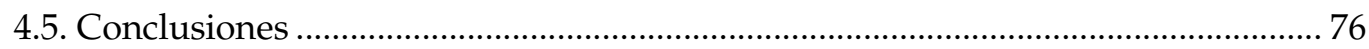

\section{ANÁLISIS FILOGENÉTICO DE LA COMUNIDAD BACTERIANA ASOCIADA A} LA RIZOSFERA DE MACRÓFITOS DE SISTEMAS DE FLUJO COMBINADO TIPO

MJEA $^{\circledR}$

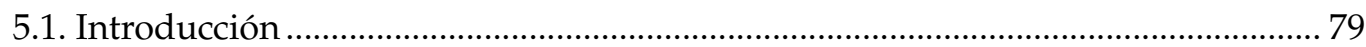

5.1.1. La comunidad microbiana en los humedales artificiales ........................................ 79

5.1.2. Técnicas para el estudio de las comunidades microbianas en humedales artificiales 80

5.1.3. Distribución de las comunidades microbianas en los humedales artificiales ............. 82

5.1.4. Efecto de los macrófitos en las comunidades microbianas de los humedales artificiales

5.1.5. Comunidades bacterianas asociadas a la rizosfera de humedales artificiales para el

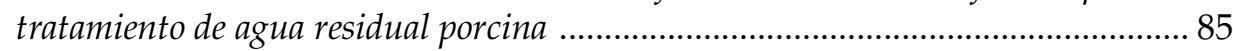

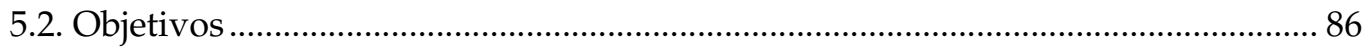

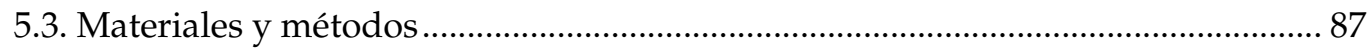

5.3.1. Planta a escala real para el tratamiento de agua residual urbana ............................. 87

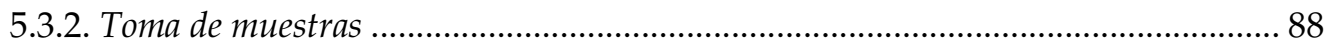

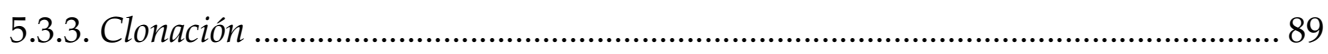

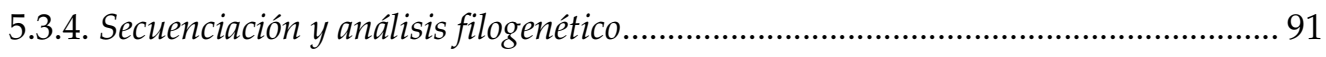

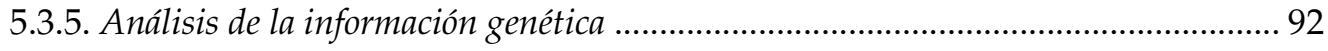

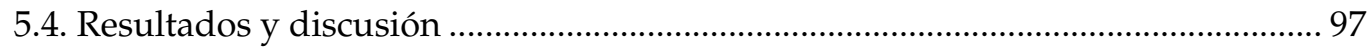

5.4.1. Composición de las comunidades bacterianas ......................................................... 97

5.4.2. Riqueza y diversidad $\alpha$ de las comunidades bacterianas ........................................ 117

5.4.3. Diversidad $\beta$. Análisis comparativo de las comunidades de bacterias .................... 121

5.4.4. Diversidad metabólica de las comunidades bacterianas .......................................... 125

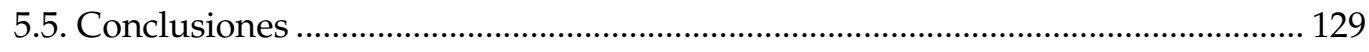

6. FILTROS DE ESCORIAS DE ACERÍA LD PARA LA RETENCIÓN DE FÓSFORO EN

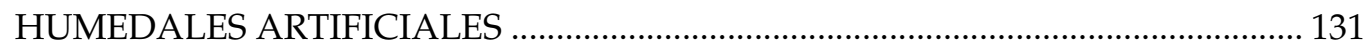

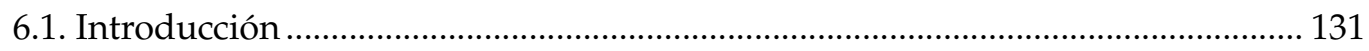

6.1.1. Mecanismos de retención de fósforo en humedales artificiales............................... 131

6.1.2. Filtros para la retención de fósforo en humedales artificiales.................................. 137

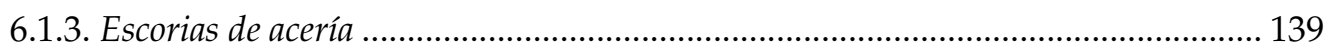

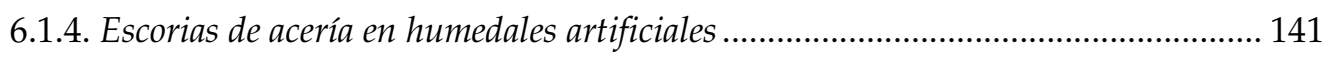

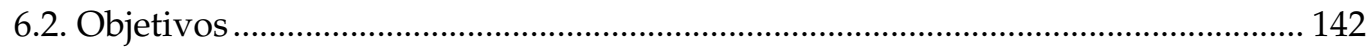

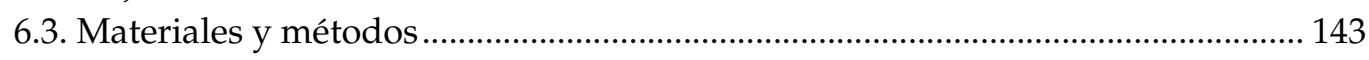

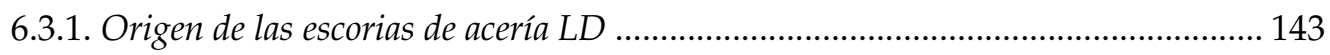

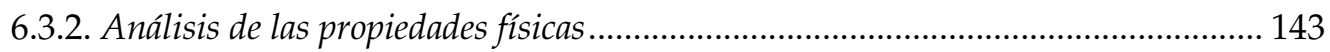

6.3.3. Análisis químicos y propiedades físicas del agua residual .................................... 144

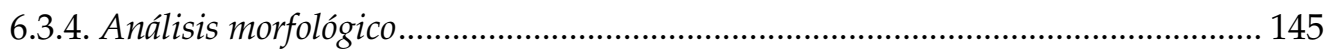

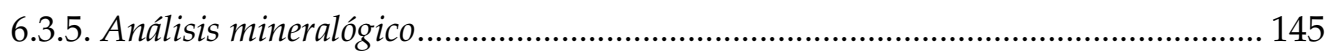

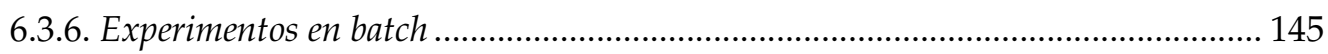




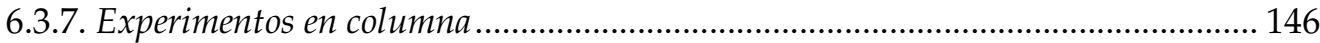

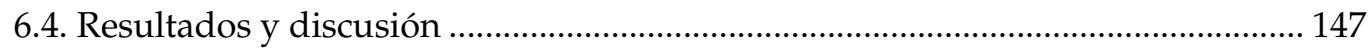

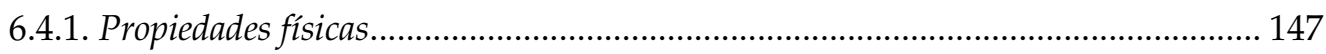

6.4.2. Composición química y mineralógica de las escorias de acería $L D$......................... 147

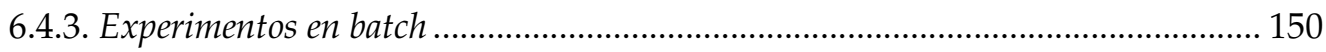

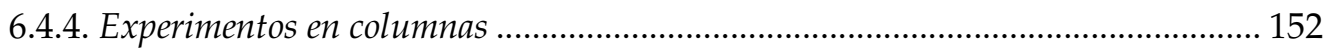

6.4.4. Volumen de un filtro de escorias de acería $L D$........................................................ 162

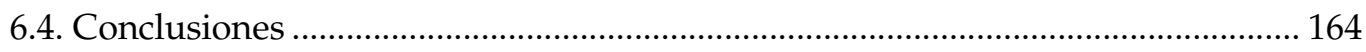

7. DISCUSIÓN GENERAL - RECOMENDACIONES DE DISEÑO PARA EL TRATAMIENTO DE PURINES DE CERDO CON HUMEDALES ARTIFICIALES 167

7.1. Recomendaciones de diseño para el tratamiento de nitrógeno .............................. 168

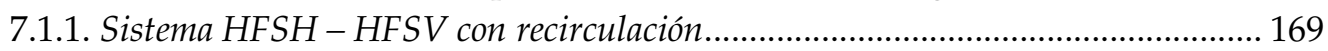

7.1.2. Sistema HFSV - HFSH con adición de carbono ................................................... 171

7.2. Recomendaciones de diseño para el tratamiento de fósforo.................................. 172

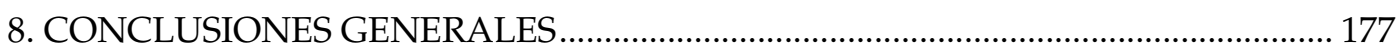

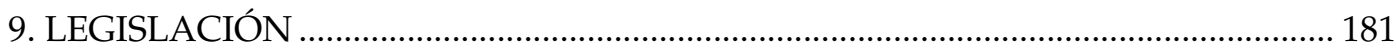

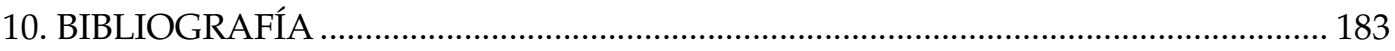




\section{Índice de Figuras}

Figura 1.1. Esquema de un Humedal de Flujo Superficial ................................................................ 6

Figura 1.2. Esquema de un Humedal de Flujo Subsuperficial Horizontal ................................................. 7

Figura 1.3. Esquema de un Humedal de Flujo Subsuperficial Vertical ...................................................... 8

Figura 3.1. Rutas metabólicas que regulan la degradación de la materia orgánica en suelos de humedales y la reducción de los aceptores de electrones inorgánicos en función del potencial redox del

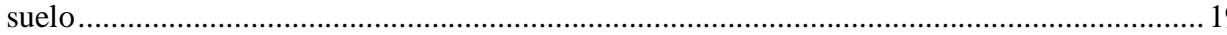

Figura 3.2. Reacciones realizadas por microorganismos en el ciclo del nitrógeno ................................2 21

Figura 3.3. Localización de Campo de Villavidel en España, localización de CENTROTEC en el municipio de Campo de Villavidel y localización de la balsa de purines y la nave principal en

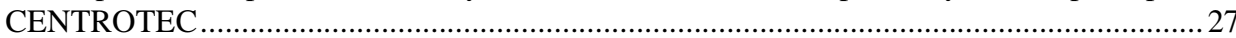

Figura 3.4. Fotografías de la balsa de purines y unidades FS y FSS .....................................................2 28

Figura 3.5. Localización de los puntos de muestreo en la planta a escala piloto.....................................29

Figura 3.6. Diagramas de caja de los resultados de los muestreos para los parámetros SST y SSV por año y punto de muestreo .......................................................................................................... 34

Figura 3.7. Diagramas de caja de los índices de eliminación por año y etapa del sistema ......................... 34

Figura 3.8. Concentración de entrada de SST frente a concentración de salida de SST y regresión lineal

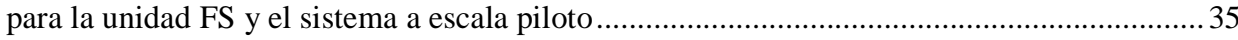

Figura 3.9. Concentración de entrada y salida de SST por muestreo .................................................... 35

Figura 3.10. Diagramas de caja de los resultados de los muestreos para los parámetros $\mathrm{DBO}_{5}$ y DQO por

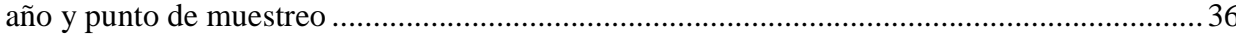

Figura 3.11. Diagramas de caja de los índices de eliminación por año y etapa del sistema para los

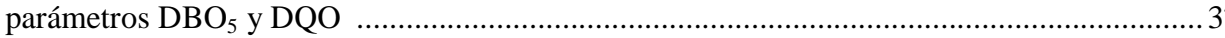

Figura 3.12. Concentración de entrada frente a concentración de salida y regresión lineal de los parámetros $\mathrm{DBO}_{5}$ y DQO en la unidad FS, las unidades FSS y el sistema a escala piloto ....... 38

Figura 3.13. Concentración de entrada y salida de $\mathrm{DBO}_{5}$ y DQO por muestreo ......................................39

Figura 3.14. Diagramas de caja de los resultados de los muestreos para los parámetros $\mathrm{NTK}, \mathrm{NH}_{4}{ }^{+}$, NT y

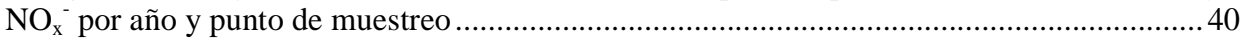

Figura 3.15. Valores promedio de composición de NT en los puntos de muestreo.................................. 41

Figura 3.16. Diagramas de caja de los índices de eliminación por año y etapa del sistema para el parámetro NT

Figura 3.17. Concentración de entrada frente a concentración de salida del parámetro NT y regresión lineal para la unidad FS, las unidades FSS y el sistema a escala piloto MJEA ${ }^{\circledR}$.................... 42

Figura 3.18. Concentración de entrada y salida de $\mathrm{NO}_{\mathrm{x}}{ }^{-}$y $\mathrm{NT}$ por muestreo ........................................... 43

Figura 3.19. Concentración de entrada y salida de nitrógeno orgánico en la unidad FS por muestreo ..... 44

Figura 3.20. Diagramas de caja de los resultados de los muestreos para el parámetro PT por año y punto de muestreo.

Figura 3.21. Diagramas de caja de los índices de eliminación por año y etapa del sistema para el parámetro PT

Figura 3.22. Concentración de entrada frente a concentración de salida del parámetro PT y regresión lineal para la unidad FS, las unidades FSS y el sistema a escala piloto....

Figura 3.23. Concentración de entrada y salida de PT por muestreo........................................................ 47

Figura 3.24. La función ideal de eliminación de primer orden................................................................54

Figura 3.25. Localización de la estación meteorológica y de CENTROTEC en la provincia de León .......61

Figura 3.26. Promedio de precipitación y evapotranspiración por muestreo............................................63

Figura 3.27. Concentraciones de salida esperadas mediante el ajuste de los modelos $k-C^{*}, k C T, P-k-C^{*} \mathrm{y}$

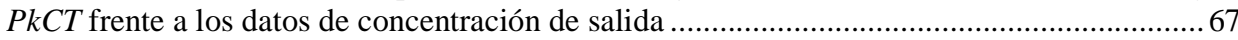

Figura 3.28. Relación entre la Pérdida de agua y la constante de eliminación de NT en la unidad FS .......69

Figura 3.29. Concentración de $\mathrm{NO}_{\mathrm{x}}{ }^{-}$nitrificado y no consumido en las unidades FSS frente a la evapotranspiración en el sistema para cada muestreo ......................................................... 70

Figura 3.30. Concentraciones de salida esperadas mediante el ajuste de los modelos $k-C^{*}, k C T, P-k-C^{*}$ y $P k C T$ con los datos corregidos frente a los datos de concentración de salida corregidos ........ 73

Figura 3.31. Área por habitante equivalente de un sistema de flujo combinado tipo MJEA ${ }^{\circledR}$ calculada con las constantes de eliminación de los datos originales y corregidos para los modelos $k-C^{*}, k C T$, $P-k-C^{*}$ y $P k C T$ frente a una concentración de salida objetivo ............................................ 74 
Figura 3.32. Métodos moleculares comunes para el estudio de las comunidades bacterianas en humedales artificiales

Figura 3.33. Condiciones de reducción-oxidación en la rizosfera de macrófitos de humedales artificiales

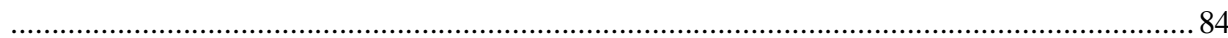

Figura 3.34. Localización de Bustillo de Cea y de CENTROTEC en la provincia de León .......................8 87

Figura 3.35. Vista cenital y de perfil de la planta a escala real.............................................................. 88

Figura 3.36. Árbol filogenético esquemático de las secuencias indicando los filos Proteobacteria, Bacteroidetes, Firmicutes, Actinobacteria y Acidobacteria ............................................ 98

Figura 3.37. Segmento del árbol filogenético correspondiente al filo Proteobacteria ............................. 100

Figura 3.38. Segmento del árbol filogenético correspondiente a la clase Beta-Proteobacteria ................ 101

Figura 3.39. Segmento del árbol filogenético correspondiente a la clase Beta-Proteobacteria, orden Burkholderiales, familia Comamonadaceae y otras secuencias sin afiliar a familias, así como las secuencias de bacterias más similares obtenidas del GenBank 102

Figura 3.40. Segmento del árbol filogenético correspondiente a la clase Beta-Proteobacteria, orden Burkholderiales, familia Oxalobacteraceae y orden Rhodocyclales, familia Rhodocyclales, así como las secuencias de bacterias más similares obtenidas del GenBank ............................ 104

Figura 3.41. Segmento del árbol filogenético correspondiente a la clase Gamma-Proteobacteria ........... 105

Figura 3.42. Segmento del árbol filogenético correspondiente a la clase Gamma-Proteobacteria, orden Xanthomonadales, así como las secuencias de bacterias más similares obtenidas del GenBank

Figura 3.43. Segmento del árbol filogenético correspondiente a la clase Gamma-Proteobacteria, orden Pseudomonadales, así como las secuencias de bacterias más similares obtenidas del GenBank

Figura 3.44. Segmento del árbol filogenético correspondiente a la clase Gamma-Proteobacteria, órdenes Alteromonadales, Enterobacteriales, Aeromonadales, Chromatiales y Methylococcales, así como las secuencias de bacterias más similares obtenidas del GenBank

Figura 3.45. Segmento del árbol filogenético correspondiente a la clase Alpha-Proteobacteria ............. 110

Figura 3.46. Segmento del árbol filogenético correspondiente a la clase Delta-Proteobacteria, órdenes Syntrophobacterales, Myxococcales, Desulfomonadales y Desulfovibrionales así como las secuencias de bacterias más similares obtenidas del GenBank

Figura 3.47. Segmento del árbol filogenético correspondiente a la clase Delta-Proteobacteria, orden Syntrophorhabdales así como las secuencias más similares obtenidas del GenBank ............ 113

Figura 3.48. Segmento del árbol filogenético correspondiente al filo Bacteroidetes ............................. 114

Figura 3.49. Segmento del árbol filogenético correspondiente al filo Firmicutes ................................ 116

Figura 3.50. Curvas de rarefacción de las comunidades bacterianas muestreadas para cada distancia genética considerada

Figura 3.51. Representación proporcional de las comunidades bacterianas analizadas con respecto al total de secuencias de cada muestra.

Figura 3.52. Diagramas biplot con los ejes 1 y 2 del Análisis de Coordenadas Principales de la matriz de distancias generada por el estimador Jest

Figura 3.53. Diagramas biplot con los ejes 1, 2 y 3 del Análisis de Coordenadas Principales de la matriz de distancias generada por el estimador Thetayc

Figura 3.54. Diagramas biplot con los ejes 1 y 2 del Análisis de Coordenadas Principales de la matriz de distancias generada por los algoritmos UniFrac unweighted y weighted

Figura 3.55. Mapa de frecuencias relativas para cada comunidad e histograma de abundancias de las secuencias asignadas para cada OTU

Figura 3.56. Efecto del $\mathrm{pH}$ en las diferentes formas de fósforo

Figura 3.57. Diagrama de solubilidad de diversos fosfatos de $\mathrm{Fe}, \mathrm{Al}$ y $\mathrm{Ca}$ en función del pH calculados para una concentración de $\mathrm{Ca}^{2+}$ de $10^{-3} \mathrm{M}$

Figura 3.58. Zona estable, metaestable e inestable para la cristalización de los fosfatos de calcio en función del pH y la concentración de ortofosfatos .............................................................. 136

Figura 3.59. Distribución en equilibrio de las especies $\mathrm{H}_{2} \mathrm{CO}_{3}, \mathrm{HCO}_{3}{ }^{-}$y $\mathrm{CO}_{3}{ }^{2-}$ en disolución ................. 137

Figura 3.60.Curvas granulométricas de dos materiales con distinto coeficiente de uniformidad............. 139

Figura 3.61. Localización de la acería LD-II en España ....................................................................... 143

Figura 3.62. Esquema del experimento en columnas para la retención de fósforo.................................. 146 
Figura 3.63. Curvas granulométricas de las muestras estudiadas

Figura 3.64. Observación SEM a 500, 1.500 y 10.000 aumentos y espectro de elementos obtenidos mediante un MRX de la superficie de una partícula de escoria antes de los experimentos de retención de $\mathrm{P}$

Figura 3.65. Difractograma del análisis de DRX para la muestra de escoria ........................................ 149

Figura 3.66. Cinética de la retención de fósforo, liberación de iones $\mathrm{Ca}^{2+}$ y cambio del valor de $\mathrm{pH} \ldots 150$

Figura 3.67. Concentraciones de $\mathrm{Ca}^{2+}$ y $\mathrm{P}$ y valores de $\mathrm{pH}$ para disoluciones con diferentes concentraciones iniciales de $\mathrm{P}$

Figura 3.68. Isotermas de Langmuir y Freundlich frente a los datos experimentales

Figura 3.69. Caudal de salida de las dos columnas a lo largo del periodo de estudio 152

Figura 3.70. Fotografía del fondo de la columna A al finalizar el experimento y foto de las columnas experimentales y sus conductos de vertido

Figura 3.71. Observación SEM a 30, y 500 aumentos de cristales de pequeño y gran tamaño y espectro de elementos obtenidos mediante un MRX de la superficie del precipitado procedente del conducto de vertido de la columna B

Figura 3.72. Difractograma del análisis DRX para la muestra de precipitado procedente del conducto de vertido de la columna $\mathrm{B}$

Figura 3.73. Concentración de $\mathrm{Ca}^{2+}$ y valores de $\mathrm{pH}$ y conductividad en la entrada y salida de la columna

Control

Figura 3.74. Concentraciones de ortofosfatos de entrada, puntos de muestreo y salida de la columna B 156

Figura 3.75. Concentraciones de ortofosfatos de entrada, puntos de muestreo y salida de la columna B 158

Figura 3.76. Relación molar Ca/P para diferentes secciones de la columna durante el experimento ...... 159

Figura 3.77. Fotografía cenital y lateral de la parte superior de la columna B después del experimento. 160

Figura 3.78. Observación SEM a 500, 1.500 y 10.000 aumentos de la superficie de la escoria de la columna B después de los experimentos y espectro de elementos obtenidos mediante un MRX del aglomerado esferoidal

Figura 3.79. Observación SEM a 500 y 1.500 aumentos de la superficie de la escoria de la sección Entrada - $5 \mathrm{~cm}$ de la columna B después de los experimentos y espectro de elementos obtenidos mediante análisis MRX de los cristales

Figura 3.80. Porcentaje de caudal de entrada afectado por la influencia de evapotranspiración y precipitación

Figura 3.81. Area de un sistema de flujo combinado tipo MJEA ${ }^{\circledR}$ frente al índice de eliminación........... 168

Figura 3.82. Esquema de un sistema de flujo combinado tipo HFSH - HFSV para el tratamiento de agua residual de una explotación porcina de 150 plazas

Figura 3.83. Area de un sistema de flujo combinado tipo $\mathrm{MJEA}^{\circledR}$ frente al índice de eliminación...... 


\section{Índice de Figuras}

Tabla 1.1. Composición típica de las fracciones sólida y líquida de las deyecciones de cerdo. 2

Tabla 3.1. Capacidad de tratamiento de contaminantes analizados en varios humedales artificiales para el tratamiento de agua residual de origen ganadero

Tabla 3.2. Protocolos utilizados para el análisis de los parámetros del agua residual 30

Tabla 3.3. Valores promedio y desviación estándar de las características físicas del agua residual y de los contaminantes físicos, químicos y biológicos monitorizados en el sistema de tratamiento a escala piloto

Tabla 3.4. Concentraciones de entrada de contaminantes analizados en varios humedales artificiales para el tratamiento de agua residual de origen ganadero

Tabla 3.5. Índices de eliminación promedio para la unidad FS, las unidades FSS y el sistema a escala piloto $\left(\right.$ MJEA $\left.^{\circledR}\right)$

Tabla 3.6. Coeficientes de macrófito de Typha latifolia, Salix atrocinerea y coeficiente de macrófito total

60

Tabla 3.7. Parámetros $C^{*}, k, k_{20}$ y $\theta$ obtenidos para los modelos $k-C^{*}$ y $k C T$ para el sistema a escala piloto .

Tabla 3.8. Parámetros $C^{*}, k, k_{20}$ y $\theta$ de humedales artificiales para el tratamiento de agua residual de origen ganadero disponibles en la bibliografía...

Tabla 3.9. Parámetros $C^{*}, k, k_{20}$ y $\theta$ obtenidos para los modelos $P-k-C^{*}$ y $P k C T$ para el sistema a escala piloto.

Tabla 3.10. Coeficientes de determinación y resultados del análisis AIC

Tabla 3.11. Parámetros $C^{*}$ cor,$k_{-}$cor,$k_{20}$ cor $\mathrm{y} \theta_{\text {cor }}$ obtenidos para los modelos $k-C^{*}$ y $k C T$ utilizando los datos corregidos por los efectos de dilución y concentración para el sistema a escala piloto... 71

Tabla 3.12. Parámetros $C^{*}$ _cor, $k_{-}$cor, $k_{20 \_ \text {cor }}$ y $\theta_{\text {ccor }}$ obtenidos para los modelos $P-k-C^{*}$ y $P k C T$ utilizando los datos corregidos por los efectos de dilución y concentración para el sistema a escala piloto... 71

Tabla 3.13. Coeficientes de determinación y Criterio de Información Akaike para los datos corregidos por los efectos de dilución y concentración.

Tabla 3.14. Parámetros utilizados para calcular las dimensiones de un sistema de flujo combinado tipo MJEA $^{\circledR}$

Tabla 3.15. Afiliación a nivel de filo de las secuencias de las comunidades de bacterias muestreadas de acuerdo con la base de datos RDP.

Tabla 3.16. Afiliación a nivel de clase de las secuencias de las comunidades de bacterias muestreadas correspondientes al filo Proteobacteria de acuerdo con la base de datos RDP

Tabla 3.17. Afiliación a nivel de orden de las secuencias de las comunidades de bacterias muestreadas correspondientes a la clase Beta-Proteobacteria de acuerdo con la base de datos RDP

Tabla 3.18. Afiliación a nivel de orden y familia de las secuencias de las comunidades de bacterias muestreadas correspondientes a la clase Gamma-Proteobacteria de acuerdo con la base de datos RDP

Tabla 3.19. Afiliación a nivel de orden y familia de las secuencias de las comunidades de bacterias muestreadas correspondientes a la clase Alpha-Proteobacteria de acuerdo con la base de datos RDP.

Tabla 3.20. Afiliación a nivel de orden y familia de las secuencias de las comunidades de bacterias muestreadas correspondientes a la clase Delta-Proteobacteria de acuerdo con la base de datos RDP .

Tabla 3.21. Afiliación a nivel de orden y familia de las secuencias de las comunidades de bacterias muestreadas correspondientes al filo Bacteroidetes de acuerdo con la base de datos RDP .... 115

Tabla 3.22. Afiliación a nivel de orden y familia de las secuencias de las comunidades de bacterias muestreadas correspondientes al filo Firmicutes de acuerdo con la base de datos RDP....

Tabla 3.23. Número de OTUs observados, riqueza estimada, índice de diversidad de Shannon-Wiener e índice de dominancia de Simpson para las comunidades de bacterias estudiadas ....

Tabla 3.24. Valor de significancia del análisis comparativo de cada comunidad con el resto de comunidades estudiadas mediante los algoritmos UniFrac unweighted y UniFrac weighted con corrección de Bonferroni

Tabla 3.25. Valor de significancia del análisis por parejas de las comunidades de bacterias mediante los algoritmos UniFrac unweighted y UniFrac weighted con corrección de Bonferroni..... 
Tabla 3.26. Procesos metabólicos de las especies y géneros de referencia de las secuencias de las muestras CF y BL

Tabla 3.27. Procesos metabólicos de las especies y géneros de referencia de las secuencias de las muestras CT, BT, CS y BS

Tabla 3.28. Relación de Ca y $\mathrm{P}$ y constantes de producto de solubilidad a $25^{\circ} \mathrm{C}$ de diferentes fosfatos de calcio

Tabla 3.29. Tipo de partículas de un suelo en función de su tamaño

Tabla 3.30. Composición química promedio de las escorias de horno alto, de horno de arco eléctrico y de horno de oxígeno básico

Tabla 3.31. Luz de los tamices UNE utilizados en el análisis granulométrico.....

Tabla 3.32. Propiedades físicas de las muestras estudiadas.

Tabla 3.33. Composición química de la escoria de acería LD.

Tabla 3.34. Composición centesimal de $\mathrm{P}$ y distintos elementos metálicos del precipitado del conducto de salida de la Columna B

Tabla 3.35. Características y fósforo acumulado en la columna B y otros experimentos en columna con escorias de acería presentes en la bibliografía

Tabla 3.36. Fósforo acumulado en función de la masa de material en las diferentes secciones de la columna B

Tabla 3.37. Fósforo acumulado por volumen de sección desde la entrada hasta el punto de muestreo hasta el momento de liberación de $\mathrm{P}$.....

162

Tabla 3.38. Parámetros obtenidos en la calibración del modelo $k-C^{*}$ para los contaminantes $\mathrm{DBO}_{5}$ y $\mathrm{NH}_{4}{ }^{+}$ en las unidades FSS 




\section{INTRODUCCIÓN GENERAL}

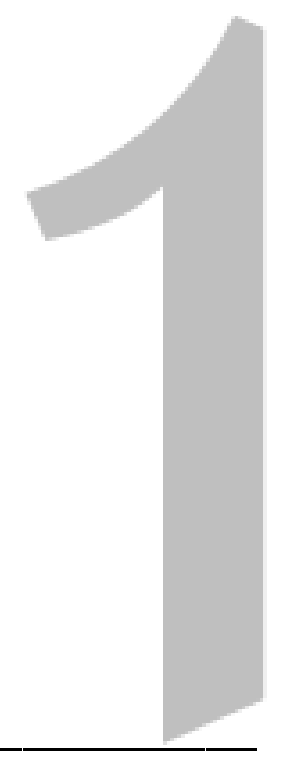

\subsection{PROBLEMÁTICA AMBIENTAL DE LOS PURINES DE CERDO}

Tradicionalmente las explotaciones agrícola-ganaderas de tipo familiar originaban unos estiércoles con un bajo contenido acuoso, constituidos casi exclusivamente por las heces, los orines y la cama, por lo que eran fácilmente apilables en los estercoleros. En estos estercoleros se iniciaban los procesos de descomposición originados por los microorganismos y eran utilizados como fertilizantes cuando la tierra de cultivo los podía necesitar.

El paso a la ganadería intensiva, enfocada a la máxima producción, conjuntamente con la importación de productos alimenticios para el ganado ha dado lugar a unas grandes cantidades de deyecciones ganaderas que han descompensado la relación entre la producción de estiércoles y los requerimientos de abonos para la agricultura. Esto ha originado que pasasen a tener la connotación de materiales excedentarios y, por tanto, residuales.

El caso más importante se ha producido en las ganaderías porcina y vacuna, en las que las estabulaciones con cama que producían estiércoles sólidos han sido sustituidas, gradualmente al principio y más rápidamente después, por los sistemas de emparrillados o "slats" con fosa inferior y por la limpieza de las naves con agua a presión. Este hecho lleva a la aparición de un nuevo tipo de estiércol: el purín, constituido fundamentalmente por una mezcla de las deyecciones sólidas y líquidas de los animales, materiales usados en la estabulación, restos de alimentos y agua de limpieza (y de lluvia si son acumulados en el exterior).

Los purines de cerdo son una fuente de múltiples constituyentes minerales: macroelementos primarios o nutrientes $(\mathrm{N}, \mathrm{P}, \mathrm{K})$, secundarios $(\mathrm{Mg}, \mathrm{Ca}, \mathrm{Na})$ y oligoelementos $(\mathrm{Cu}, \mathrm{Zn}, \mathrm{Mn}, \mathrm{Fe}$, $\mathrm{S}, \mathrm{B}, \mathrm{Mo}$ ). La disponibilidad de macroelementos del purín para los cultivos es buena (N, P) incluso comparable a la de los abonos minerales. El comportamiento agronómico de los oligoelementos sin embargo, parece ser menos conocido (Levasseur, 1998). 
Debido a su poder fertilizante la aplicación de estos residuos sobre el terreno es una práctica habitual. Las dosis de volumen que son aplicadas han de ser adecuadas según las necesidades de los cultivos, los suelos y las características del purín a fin de reducir el riesgo de contaminación del medio.

Pouliot y col. (2005) presentan una composición típica de las deyecciones de cerdo de una explotación de cerdos de engorde. En su estudio, el residuo es separado en deyecciones sólidas y líquidas, en ausencia de agua de lavado o precipitaciones. Como puede apreciarse en la Tabla 1.1, las concentraciones de materia seca, carbono orgánico, materia orgánica, nitrógeno total, fósforo y metales son más elevadas en la fase sólida que en la fase líquida. Además de un alto contenido de carbono orgánico, materia orgánica y óxidos de potasio, la fase líquida del purín porcino se caracteriza por un alto contenido de nitrógeno total constituido típicamente entre un $60-75 \%$ por nitrógeno amoniacal, mientras que el nitrógeno orgánico equivale a la fracción restante (Levasseur, 1998). El fósforo presente en el purín porcino proviene principalmente de las heces y se encuentra ligado a la fracción sólida. En torno a un $80 \%$ del fósforo total del purín se encuentra en forma mineral, mientras que el resto se encuentra en forma orgánica (Levasseur, 1998). En la fracción líquida este elemento se encuentra en la forma de fosfatos disueltos $\left(\mathrm{PO}_{4}{ }^{3-}\right)$, mientras que en la sólida se encuentra en la forma mineral y poco soluble de los fosfatos de calcio.

Tabla 1.1. Composición típica de las fracciones sólida y líquida de las deyecciones de cerdo (Pouliot y col., 2005).

\begin{tabular}{lccc}
\hline \multicolumn{1}{c}{ Parámetros } & Unidades & Fracción Sólida & Fracción Líquida \\
\hline Materia seca & $\%$ & 33,7 & 2,5 \\
Carbono orgánico & $\mathrm{kg} \mathrm{t}^{-1}$ & 167,6 & 8,1 \\
Materia orgánica & $\mathrm{kg} \mathrm{t}^{-1}$ & 286,4 & 14,0 \\
Nitrógeno total & $\mathrm{kg} \mathrm{t}^{-1}$ & 16,0 & 6,0 \\
Nitrógeno amoniacal & $\mathrm{kg} \mathrm{t}^{-1}$ & 4,05 & 5,02 \\
$\mathrm{P}_{2} \mathrm{O}_{5}$ & $\mathrm{~kg} \mathrm{t}^{-1}$ & 14,46 & 1,07 \\
$\mathrm{~K}_{2} \mathrm{O}$ & $\mathrm{kg} \mathrm{t}^{-1}$ & 10,06 & 4,95 \\
$\mathrm{~S}$ & $\mathrm{~kg} \mathrm{t}^{-1}$ & 1,52 & 0,68 \\
$\mathrm{Mg}$ & $\mathrm{kg} \mathrm{t}^{-1}$ & 2,83 & 0,19 \\
$\mathrm{Ca}$ & $\mathrm{kg} \mathrm{t}^{-1}$ & 6,42 & 0,29 \\
$\mathrm{Na}$ & $\mathrm{kg} \mathrm{t}^{-1}$ & 1,61 & 0,71 \\
$\mathrm{Al}$ & $\mathrm{ppm}_{\mathrm{B}}$ & 185,0 & 7,4 \\
$\mathrm{Cu}$ & $\mathrm{ppm}$ & 10,6 & 6,7 \\
$\mathrm{Fe}$ & $\mathrm{ppm}$ & 36,3 & 1,4 \\
$\mathrm{Mn}$ & $\mathrm{ppm}$ & 658,7 & 25,6 \\
$\mathrm{Zn}$ & $\mathrm{ppm}$ & 72,9 & 2,1 \\
& $\mathrm{ppm}$ & 332,2 & 8,1 \\
\hline
\end{tabular}

La aplicación sobre el terreno del purín implica riesgos debido a la acumulación de ciertos elementos. La aportación de $\mathrm{Mg}$ y $\mathrm{K}$ no parece entrañar riesgos hacia el medio ambiente, aunque sí suponen un problema desde el punto de vista agronómico. En la información aportada por Pouliot y col. (2005) el Mg está parcialmente disuelto en la fracción líquida del purín, mientras que el $\mathrm{K}$ se encuentra soluble en torno a un $40 \%$. Otras composiciones típicas indican que el $\mathrm{K}$ puede llegar a encontrarse soluble hasta un $80 \%$ en la orina en forma de sales minerales (Levasseur, 2004). La acumulación excesiva de K supone un problema al entrar en competición con otros cationes por la absorción radicular, lo que puede provocar carencias en los cultivos, especialmente en Mg (Levasseur, 2004). Por otro lado, los oligoelementos se encuentran en proporciones importantes en el purín, especialmente en el caso de $\mathrm{Cu}$ y $\mathrm{Zn}$ debido a que su presencia en los piensos de alimentación es superior a las necesidades nutricionales de los cerdos. Aquellas superficies de terreno que reciban fuertes dosis de purines presentarán 
mayores concentraciones de oligoelementos y por tanto un mayor riesgo de aparición de fenómenos de toxicidad para los cultivos o para invertebrados en caso de elevadas concentraciones en los medios acuáticos (Levasseur, 1998).

La aplicación excesiva o en periodo desfavorable (fuerte pluviometría) de purín sobre el terreno puede implicar pérdidas de nitrógeno y fósforo por percolación y escorrentía hacia los cuerpos de agua superficiales y subsuperficiales. El exceso de fósforo y nitrógeno en forma de amonio $\left(\mathrm{NH}_{4}^{+}\right)$, nitrato $\left(\mathrm{NO}_{3}^{-}\right)$y nitrito $\left(\mathrm{NO}_{2}{ }^{-}\right)$, en las aguas puede acelerar el envejecimiento de los ecosistemas acuáticos. Este exceso de nutrientes produce una proliferación de biomasa que debido a la respiración nocturna y los procesos de descomposición, disminuye drásticamente el contenido de oxígeno en el ecosistema, afectando por igual a fauna y vegetación. Este proceso es conocido como eutrofización.

En condiciones adversas la concentración de nitrógeno en forma de nitratos de las aguas superficiales o subsuperficiales puede sobrepasar los $50 \mathrm{mg} \mathrm{L}^{-1}$, lo que supone el umbral máximo de potabilidad de agua fijado por la Directiva 91/676/CEE, de 12 de diciembre, relativa a la protección de las aguas contra la contaminación producida por nitratos de origen agrícola. Esta Directiva impone a los Estados miembro europeos la obligación de identificar las aguas que se hallen afectadas por la contaminación de nitratos de esta procedencia, cuyas concentraciones deberán ser vigiladas en una serie de estaciones de muestreo. Por otra parte, establece criterios para designar como zonas vulnerables aquellas superficies territoriales cuyo drenaje da lugar a la contaminación por nitratos. Una vez determinadas tales zonas, se deben realizar y poner en funcionamiento programas de actuación, coordinados con técnicas agrícolas, con la finalidad de eliminar o minimizar los efectos de los nitratos sobre las aguas. Por último, la Directiva establece la obligación de emitir periódicamente informes de situación sobre este tipo de contaminación.

La Directiva 91/676/CEE afecta especialmente al sector porcino español. Según datos del Ministerio de Agricultura Pesca y Alimentación (MAPA, 2006), este sector ha experimentado en España un aumento progresivo desde los años 70, llegando a situarse como segundo productor europeo tras Alemania con un $16,7 \%$ del censo total de la cabaña porcina en la Unión Europea de los 27. En la producción interna, Castilla y León junto con Cataluña y Aragón destacan como las principales comunidades autónomas productoras de porcino. La incorporación de la Directiva en la legislación española se ha realizado a través del Real Decreto 261/1996, de 16 de febrero, que impone a su vez a los órganos competentes de las Comunidades Autónomas las mencionadas obligaciones. La problemática ambiental de los purines de cerdo en Castilla y León se refleja en la designación de cinco zonas vulnerables, todas ellas en la provincia de Segovia, según expone el Decreto 109/1998, de 11 de Junio de CyL.

\subsection{TRATAMIENTO DE LOS PURINES DE CERDO}

El Real Decreto 324/2000, de 3 de marzo, con revisión vigente desde el 5 de agosto de 2009, por el que se establecen normas básicas de ordenación de las explotaciones porcinas, contempla la gestión de los estiércoles mediante la utilización de cualquiera de los siguientes procedimientos:

a. Valorización como abono orgánico-mineral, en cuyo caso las explotaciones han de disponer de balsas de estiércol cercadas e impermeabilizadas para poder almacenar la producción de al menos tres meses. Deberán disponer de suficiente superficie agrícola para la utilización de los estiércoles como fertilizantes. Además, de acuerdo con el Real Decreto 261/1996, deberán cumplir con una cantidad de estiércol aplicado anual máximo de $170 \mathrm{~kg} \mathrm{~N}$ por hectárea en las zonas vulnerables o $210 \mathrm{~kg} \mathrm{~N}$ por hectárea en zonas no vulnerables. 
b. El tratamiento de estiércoles mediante compostaje, secado artificial y otros, según lo establecido en la Ley 22/2011, de 28 de julio, de residuos y suelos contaminados.

c. Eliminación de estiércoles mediante vertido, que estará regulada por el Real Decreto 606/2003, de 23 de mayo, por el que se modifica el Real Decreto 849/1986, de 11 de abril, por el que se aprueba el Reglamento del Dominio Público Hidráulico.

d. Entrega a centros de gestión de estiércoles para su gestión bien como abono orgánicomineral o para tratamiento.

La última alternativa es utilizada frecuentemente ya que una correcta gestión de los residuos supone una carga de trabajo adicional para el empresario ganadero. Existen numerosas empresas dedicadas a la gestión de los residuos, especialmente en zonas de mayor concentración de explotaciones porcinas, lo que permite reducir los costes de transporte del residuo. De modo general, se pueden distinguir tres tipos de sistemas de tratamiento empleados por las empresas dedicadas a la gestión del purín:

a. Acondicionamiento y desodorización del purín para su reutilización como fertilizante agrícola. Ésta es la solución más sencilla y de menor coste que además permite una revalorización del purín. Sin embargo, necesita la disponibilidad de superficie agrícola y autonomía de almacenamiento en función de la climatología y de la temporalidad de los cultivos para una correcta aplicación según el Código de Buenas Prácticas Agrarias. En este sector existen empresas dedicadas a gestionar la utilización del purín como fertilizante en los campos, requiriendo la colaboración de los agricultores e incrementando el coste debido a la logística de transporte (de granjas a planta y de planta a parcelas) y la gestión de las salidas (calendario, recogida, aplicaciones, recorridos, etc.).

b. Los sistemas de cogeneración consisten en la producción conjunta de energía eléctrica y energía calorífica útil, a partir de una fuente de energía primaria que, en la mayoría de los casos, es el gas natural. Los recursos producidos se utilizan para autoconsumo de la planta y para deshidratar los purines, los cuales se someten a un tratamiento para eliminar los elementos contaminantes y convertirlos en compost para fabricar fertilizantes. La energía excedentaria se exporta a la red eléctrica general (Mateu, 2005). La rentabilidad económica de estos sistemas se basa en la producción energética que depende de subvenciones y del precio variable de los combustibles fósiles en el mercado.

c. Los tratamientos biológicos buscan la depuración de la fracción líquida del purín para su vertido directo en el cauce o pueden encontrarse como parte de los métodos anteriores, con el objeto de reducir el contenido de nitrógeno para ajustar el residuo a la baja disponibilidad de tierras de cultivo. La digestión metanogénica es un proceso biológico fermentativo en el que la materia orgánica es decompuesta por diversos grupos de bacterias heterótrofas, obteniéndose biogás, un gas combustible que puede cubrir las necesidades energéticas de las instalaciones. El elevado contenido de agua, nutrientes y la capacidad tampón de los purines hacen de éstos un sustrato adecuado para la digestión metanogénica (García, 2007). Los procesos de nitrificacióndesnitrificación permiten la transformación de nitrógeno orgánico y amoniacal a nitrógeno atmosférico. Para ello se requiere de dos etapas: la etapa de nitrificación permite la transformación aerobia de estos compuestos a nitrato, en la etapa de desnitrificación se produce la transformación anaerobia de nitrato a nitrógeno atmosférico. El objetivo es reducir la concentración de nitrógeno de los residuos para poder ser utilizado como fertilizante. El proceso genera unos lodos biológicos que también pueden ser aplicados al terreno. 
La aplicación de estos métodos de tratamiento de purines de cerdo puede no ser viable debido a las necesidades técnicas y económicas, como es el caso de granjas que se encuentren alejadas de aquellas zonas con grandes concentraciones de explotaciones porcinas. En este marco resulta interesante la investigación de métodos alternativos para el tratamiento de los purines de cerdo con el fin de reducir los costes asociados a su gestión.

\subsection{SISTEMAS NATURALES PARA EL TRATAMIENTO DE AGUA RESIDUAL}

Los sistemas naturales de tratamiento de agua residual, también llamados sistemas blandos, extensivos o no convencionales, son tecnologías que imitan los ecosistemas naturales para la depuración del agua residual. El propósito de estos sistemas es reducir la dependencia de reactivos y/o energía de los sistemas convencionales requerida para aireación y desplazamiento de grandes volúmenes de agua residual. Esta ausencia de aporte energético permite la reducción del coste económico, aunque implica mayores tiempos de permanencia del agua residual en el sistema, debido a que los procesos de depuración tienen lugar a velocidades ambientales (Salas y col., 2007), y por lo tanto requiere mayores superficies de terreno para lograr la misma capacidad de depuración que los sistemas de tipo intensivo. Estos sistemas suelen ser menos costosos y sofisticados en cuanto a construcción, operación y mantenimiento, y requieren menos personal especializado que los sistemas convencionales (Fernández y col., 2005).

A este tipo de sistemas pertenecen los filtros verdes, zanjas, pozos y lechos filtrantes, que emplean el suelo para la depuración del agua residual. Destacan particularmente los sistemas de lagunaje, que imitan los procesos que tienen lugar en los lagos, y los humedales artificiales, que están diseñados para simular las interacciones y procesos que tienen lugar entre la vegetación, el sustrato y los microorganismos de los humedales naturales en un ambiente controlado (Vymazal, 2005).

\subsection{HUMEDALES ARTIFICIALES}

Los humedales artificiales son ecosistemas que imitan a los humedales naturales con el objeto de utilizar los procesos físicos, químicos y biológicos que ocurren de forma natural para la depuración pasiva del agua residual. Generalmente los humedales artificiales están constituidos por canales de profundidad inferior a $1 \mathrm{~m}$ excavados en el terreno, impermeabilizados y rellenos total o parcialmente de material filtrante en el que son plantados macrófitos acuáticos, especies vegetales propias de zonas húmedas o encharcadas. Una ligera pendiente permite el flujo del agua residual a través del lecho, que actúa como un reactor en el que tienen lugar los procesos de depuración.

El origen de esta tecnología se remonta a las investigaciones de Käthe Seidel en el Instituto Max Planck de Alemania Occidental (Seidel, 1953), y el trabajo de Reinhold Kickuth en la década de los 70 (Kickuth, 1977). La implementación de la tecnología se ha acelerado desde 1985, debido principalmente a que los humedales artificiales, aunque mecánicamente simples, son complejos sistemas biológicos capaces de conseguir altos niveles de tratamiento. Además, los humedales artificiales pueden ser construidos utilizando materiales y mano de obra locales, lo que supone una ventaja importante para los países en vías de desarrollo (Kadlec y Wallace, 2009). El uso más común de los humedales artificiales es la depuración de agua residual urbana (USEPA, 1988), aunque esta tecnología ha demostrado ser mucho más versátil. Los humedales artificiales se han utilizado para la depuración de drenajes ácidos de minas (Wieder, 1989), agua residual de origen industrial (industria química, petroquímica, textil, de alimentación, de papel y de tinción entre otras), agua residual de origen animal (animales de granja, piscicultura), lixiviados de vertederos y escorrentía de zonas agrarias por un lado y de infraestructuras de transporte y urbanas por otro lado (Vymazal, 2009).

Los diferentes diseños de humedales artificiales pueden clasificarse en función de dos características principales; el tipo de flujo hidráulico y el tipo de vegetación. En función del tipo 
de flujo hidráulico pueden distinguirse dos grupos: los humedales de flujo superficial (HFS) y los de flujo subsuperficial. Dentro de este último grupo se incluyen los humedales artificiales de flujo subsuperficial horizontal (HFSH) y vertical (HFSV).

Los humedales artificiales de flujo superficial están diseñados de modo que la superficie del agua entre en contacto directo con la atmósfera. Son sistemas de poca profundidad, con una capa inferior de sustrato, generalmente suelo o grava, de unos 20-30 cm de espesor sobre la que fluye la columna de agua, de unos $40 \mathrm{~cm}$ de altura (Figura 1.1). Brix (1993) clasifica estos sistemas según el tipo de vegetación dominante en el sistema. De este modo pueden encontrarse HFS con vegetación de macrófitos flotantes, los cuales pueden estar enraizados al sustrato como el nenúfar blanco (Nymphaea alba) o libres como la lenteja de agua (Lemna minor), de macrófitos no emergentes, en cuyo caso el organismo se encuentra completamente sumergido (Isoetes lacustris, Lobelia dortmanna) o de macrófitos emergentes, que es el tipo de vegetación más común y la forma de vida dominante en humedales y pantanos de aguas someras

Los macrófitos emergentes están morfológicamente adaptados a crecer en sustratos saturados de agua o completamente sumergidos. Poseen un extenso sistema de raíces y rizomas que se desarrolla en el sedimento, mientras que la parte vegetativa se desarrolla sobre la superficie del agua. Este es el caso de especies tales como enea (Typha latifolia), junco (Scirpus lacustris) o carrizo (Phragmites australis).

La aplicación más común de los HFS es el tratamiento avanzado de los efluentes de procesos secundarios y terciarios de otros sistemas convencionales de depuración. También suelen ser utilizados en el tratamiento de agua de escorrentía, drenaje ácido de minas, lixiviados de vertedero y remediación de agua subterránea (Kadlec y Knight, 1996).

La poca profundidad, los tallos de las plantas y la baja velocidad del agua regulan su paso por el humedal y aseguran las condiciones de flujo pistón, particularmente en canales largos y estrechos (Reed y col., 1988). Los procesos de sedimentación, filtración, oxidación, reducción, adsorción y precipitación se encargan de tratar el agua residual en el humedal (Kadlec y Wallace, 2009).

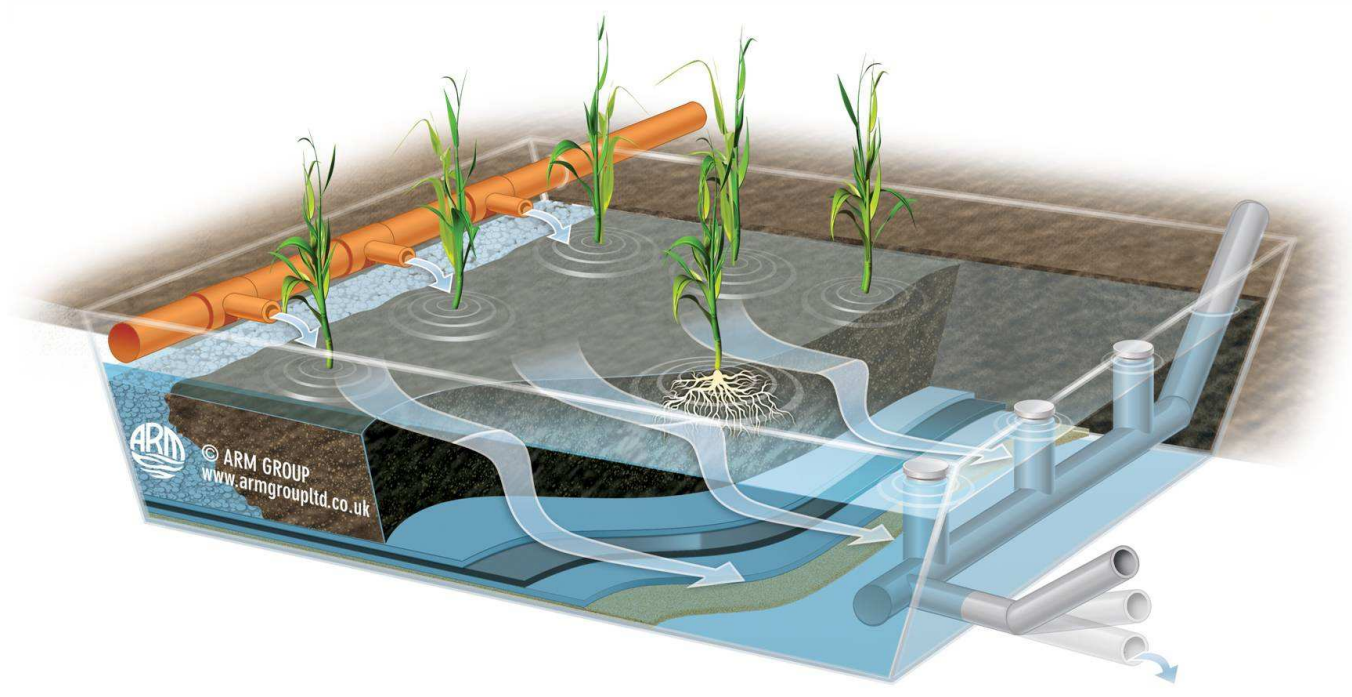

Figura 1.1. Esquema de un Humedal de Flujo Superficial (HFS) (ARM, 2011).

Los humedales artificiales de flujo subsuperficial horizontal (HFSH) son lechos de grava o suelo plantados con macrófitos emergentes herbáceos como el carrizo (Phragmites australis) o leñosas como el sauce (Salix spp.). El agua residual fluye horizontalmente por el sistema a 
través del lecho filtrante hasta la salida, donde un sifón permite regular la altura de la columna de agua. Normalmente el nivel de agua se encuentra $5 \mathrm{~cm}$ por debajo de la superficie del lecho, saturando completamente el humedal. Las plantas desarrollan su sistema radicular hasta una profundidad máxima de $60 \mathrm{~cm}$ y ayudan a mantener la conductividad hidráulica del sistema (Figura 1.2). En un HFSH prevalecen las condiciones anaerobias debido a la saturación del lecho, aunque la liberación de oxígeno por las raíces permite la existencia de zonas de condiciones aerobias y anóxicas en la rizosfera (Brix, 1997). Los procesos de depuración predominantes en este tipo de sistemas son biológicos y físicos, favorecidos por el contacto entre el sustrato, el sistema radicular y el biofilm formado por la comunidad microbiana.

Estos sistemas pueden proporcionar tratamiento secundario y terciario de aguas residuales agrícolas, industriales y urbanas. La mayoría de estos sistemas se encuentran operativos en Europa (más de 10.000), aunque también pueden ser encontrados en gran cantidad en los Estados Unidos de América (USA), Australia, Asia y África (Vymazal, 2003b).

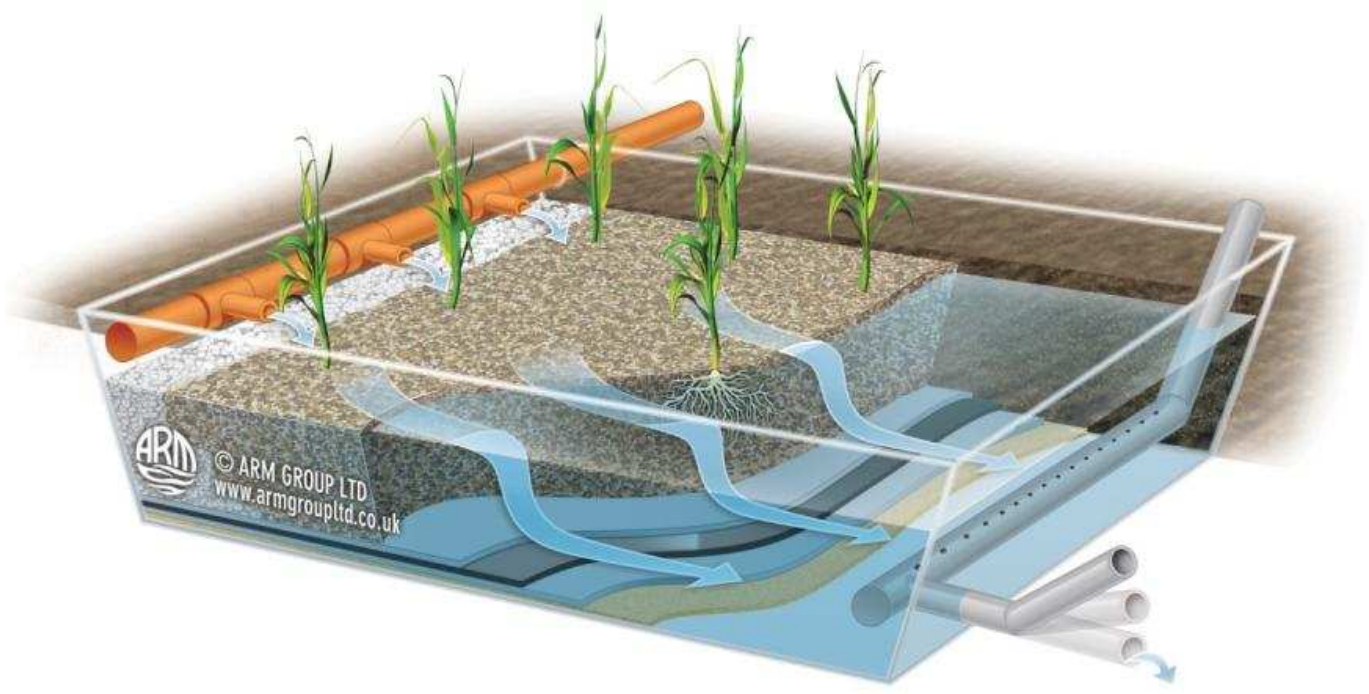

Figura 1.2. Esquema de un Humedal de Flujo Subsuperficial Horizontal (HFSH) (ARM, 2011).

Los lechos de los humedales artificiales de flujo subsuperficial vertical (HFSV) están formados por varias capas de sustrato de granulometría creciente sobre los que se desarrolla la biomasa microbiana. La superficie está plantada con macrófitos emergentes, generalmente Phragmites australis. La alimentación del sistema se realiza mediante la alternancia de aplicaciones sucesivas o batchs y periodos de reposo. El agua percola por gravedad a través del sustrato filtrante, estableciendo contacto con la biomasa aerobia y llega hasta el fondo, donde es recolectada por un sistema de drenaje en la base (Figura 1.3). Los periodos de reposo permiten una buena oxigenación del lecho y una degradación óptima de los contaminantes. El principal motivo de la presencia de los macrófitos es mantener la conductividad hidráulica del sistema. Muchos de los sistemas HFSV tienen diversas unidades en serie o en paralelo. En ocasiones hay lechos en paralelo que son alimentados en rotación durante 1 o 2 días para posteriormente dejarlos descansar durante periodos de 3 a 6 días (Cooper y col., 1996).

Los distintos tipos de humedales artificiales pueden ser combinados con el objeto de obtener un mayor nivel de tratamiento del agua residual. Estos sistemas son denominados humedales artificiales híbridos (Vymazal, 2005). Es común la combinación de HFSH deficitarios en oxígeno con HFS o HFSV que tienen una mayor capacidad de aireación del sistema. En cualquier caso, la combinación de los distintos tipos de humedales artificiales dependerá de los contaminantes que han de ser eliminados (Vymazal, 2009). 


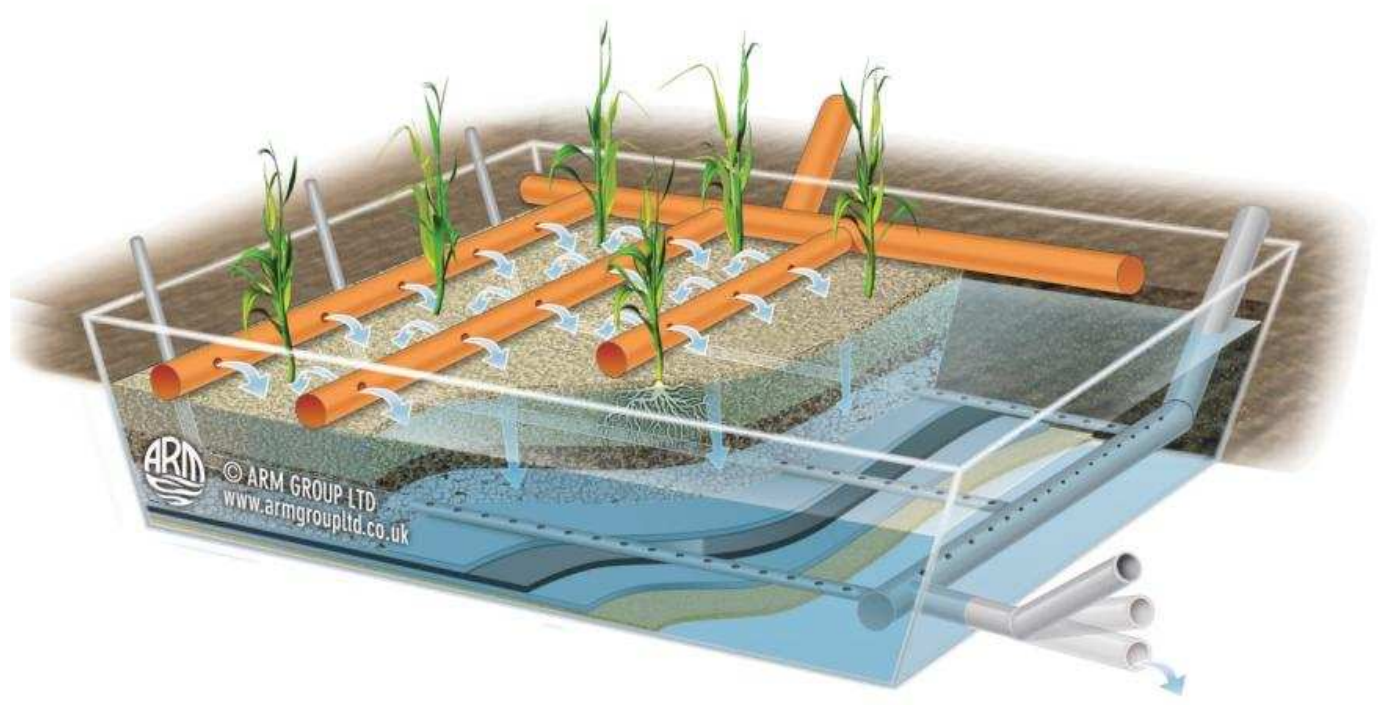

Figura 1.3. Esquema de un Humedal de Flujo Subsuperficial Vertical (HFSV) (ARM, 2011).

\subsection{MOSAICO JERARQUIZADO DE ECOSISTEMAS ARTIFICIALES (MJEA $\left.{ }^{\circledR}\right)$}

La tecnología de depuración de agua residual MJEA $^{\circledR}$ fue desarrollada originariamente por el profesor Michel Radoux (Fundación Universitaria Luxemburguesa) a finales de los años 70 (Radoux y Kemp, 1982). El principio en el que se basa esta tecnología consiste en que las plantas utilizadas en los sistemas naturales para el tratamiento del agua residual no pueden ofrecer rendimientos de depuración óptimos para todos los contaminantes presentes en el agua residual de forma aislada; sólo una combinación de ecosistemas acuáticos y semiacuáticos pueden lograr este objetivo.

El MJEA ${ }^{\circledR}$ busca organizar y estructurar de un modo artificial las especies acuáticas vegetales con el objetivo de alcanzar el rendimiento de depuración óptimo del sistema. Para ello combina ecosistemas acuáticos (lagunaje) con ecosistemas semiacuáticos dominados por macrófitos emergentes (HFS) y ecosistemas terrestres dominados por macrófitos emergentes leñosos (HFSH). Se ha demostrado la eficacia de esta tecnología para tratar aguas residuales de tipo urbano en climas de tipo oceánico en Bélgica y el noroeste de Francia (Radoux y Kemp, 1982; Radoux y col., 1997), mediterráneo en Marruecos (Radoux y col., 2003; Ezzahri y col., 2010) y mediterráneo continentalizado en Bustillo de Cea (León, España) (Ansola y col., 2003), aunque hasta la fecha no se ha estudiado su aplicación a purines de cerdo.

\subsection{HUMEDALES ARTIFICIALES PARA EL TRATAMIENTO DE AGUA RESIDUAL DE ORIGEN GANADERO}

En la definición de agua residual de origen ganadero se pueden incluir tanto las explotaciones de ganado porcino como de ganado vacuno, ya que en ambos casos el agua residual se caracteriza por tener altas concentraciones de nitrógeno, fósforo y materia orgánica en comparación con el agua residual de origen urbano.

La utilización de los humedales artificiales para tratar agua residual de origen ganadero es un concepto relativamente nuevo. Knight y col. (2000) realizaron un análisis bibliográfico para la creación de una base de datos de humedales artificiales para el tratamiento de agua residual de origen animal en USA (Livestock Wastewater Treatment Database o LWTD). Encontraron información de 68 lugares, de los cuales 38 recibían agua residual procedente de lecherías, 19 
trataban agua residual procedente de explotaciones porcinas y 8 recibían agua residual procedente de explotaciones de vacuno para la obtención de carne. El sistema más antiguo data de 1930 y no hay información sobre otros humedales hasta 1989. El resto de sistemas incluidos en la revisión comenzaron su operación entre 1993 y 1994. Cronk (1996) identificó 10 humedales artificiales para el tratamiento de agua residual de lecherías y 6 para el tratamiento de agua residual porcina. La revisión de Hunt y Poach (2001) incluye 5 humedales artificiales para el tratamiento de agua residual de lecherías y 3 para el de agua residual porcina.

Durante los últimos tres lustros se ha creado un importante número de sistemas de humedales artificiales por todo el mundo. En el caso de HFS aplicados a la depuración de agua residual procedente de lecherías, se encuentran ejemplos en Australia (Geary y Moore, 1999) o USA (Karpiscak y col., 1999; Newman y col., 2000; Schaafsma y col., 2000), y más recientemente en Irlanda, donde por ejemplo, en el valle de Anne (condado de Wexford) existen en funcionamiento 16 HFS desde 2004, ocupando un área total de 15 ha con un promedio de 120 $\mathrm{m}^{2}$ por vaca (Harrington y McInnes, 2009). Lee y col. (2010b) presentan un ejemplo reciente de aplicación de este tipo de humedal artificial a purines de cerdo, aunque el estudio más extenso sobre esta materia se ha realizado en Carolina del Norte (USA). En este estudio se ha analizado la capacidad depuradora de una planta de tratamiento compuesta por 2 HFS dispuestos en paralelo alimentados por agua residual procedente de una explotación porcina de 2.600 madres y pretratada por un sistema de lagunaje anaerobio. El sistema ha estado en funcionamiento desde 1992 hasta la actualidad, y los análisis se han centrado en distintos aspectos del tratamiento del nitrógeno: procesos de nitrificación y desnitrificación, volatilización, modelización y otros (Szogi y Hunt, 2001; Stone y col., 2002; Hunt y col., 2003; Poach y col., 2003; Hunt y col., 2009).

Los HFSH también han sido utilizados para el tratamiento de agua residual de origen ganadero. Tanner y Kloosterman (1997) recomiendan la utilización de este tipo de humedales como complemento a los HFS, presumiblemente debido al potencial de colmatación de los lechos de grava frente a vertidos directos de agua residual. Si el HFSH se va a utilizar como una unidad independiente entonces el área requerida será superior. Ejemplos de este tipo de sistemas como unidades independientes se pueden encontrar a escala real en Italia (Mantovi y col., 2003) o a escala piloto en Taiwán (Lee y col., 2004), Bélgica (Meers y col., 2005), México (González y col., 2009) o Vietnam (Dan y col., 2011). Vymazal (2009) hace mención a la aplicación de HFSH para el tratamiento de agua residual de origen ganadero, citando hasta 7 casos de agua residual porcina y 9 casos de agua residual procedente de lecherías.

En la actualidad la investigación se está dirigiendo a sistemas híbridos que permiten la combinación de los HFSH con sistemas HFS o HFSV. Estas combinaciones pueden encontrarse en sistemas complejos de hasta 11 unidades en serie con recirculación para el tratamiento de purines de cerdo como es el caso de los denominados Ecological Treatment Systems o ETS (Lansing y Martin, 2006; Morgan y Martin, 2008) o en humedales híbridos de varias etapas sucesivas (Lian-sheng y col., 2006; Meers y col., 2008; Xinshan y col., 2010). La utilización de estos sistemas híbridos ha sido investigada incluso en condiciones extremas de temperatura, como es el caso del norte de Japón con una temperatura media anual de 5 a $8^{\circ} \mathrm{C}$, donde se han utilizado combinaciones de dos o tres unidades HFSV seguidas por una unidad HFSH con recirculación para depurar concentraciones de entrada de DQO de 2.400 a $5.000 \mathrm{mg} \mathrm{L}^{-1}$ promedio, procedente de lecherías, y $10.100 \mathrm{mg} \mathrm{L}^{-1}$ procedente de purines de cerdo (Sharma y col., 2012; Kato y col., 2013). Borin y col. (2013) también presentan resultados para un humedal artificial de similares características, con concentraciones de entrada promedio de $1.278 \mathrm{mg} \mathrm{L}^{-1}$ y resume las concentraciones de entrada y salida de 18 humedales artificiales utilizados para el tratamiento de purines de cerdo, aunque no proporciona información sobre el tipo de flujo de los sistemas.

Otro tipo de humedal artificial híbrido presente en la bibliografía es el denominado MarshPond-Marsh o MPM, que consiste en un humedal con una primera sección de flujo superficial 
de $15 \mathrm{~cm}$ de profundidad seguida por una sección de lagunaje de $80 \mathrm{~cm}$ de profundidad y finalmente otra sección de flujo superficial de $15 \mathrm{~cm}$ de espesor. La importancia de este tipo de sistemas radica en la continuidad de los estudios realizados en la Universidad de North carolina $A \& T$ State University (USA), centradas en el tratamiento de agua residual de origen porcino, aunque este tipo de sistema también se ha utilizado para el tratamiento de agua residual de lecherías en Canadá (Jamieson y col., 2007). Los estudios realizados en Carolina del Norte comenzaron en 1995 y continúan en la actualidad. Se centran en aspectos tales como la depuración de diferentes cargas de nitrógeno, el efecto en la depuración de diferentes regímenes de inundación, procesos de desnitrificación y su modelización (Reddy y col., 2001; Poach y col., 2004; Stone y col., 2004; Hunt y col., 2006; Poach y col., 2007).

A pesar de la relativa abundancia de información presente en la bibliografía referente al tratamiento de agua residual ganadera mediante humedales artificiales, no ha sido posible encontrar referencias a la aplicación de sistemas de flujo combinado tipo MJEA ${ }^{\circledR}$. En este contexto se plantea la línea de investigación de esta tesis doctoral. 




\section{OBJETIVOS GENERALES}

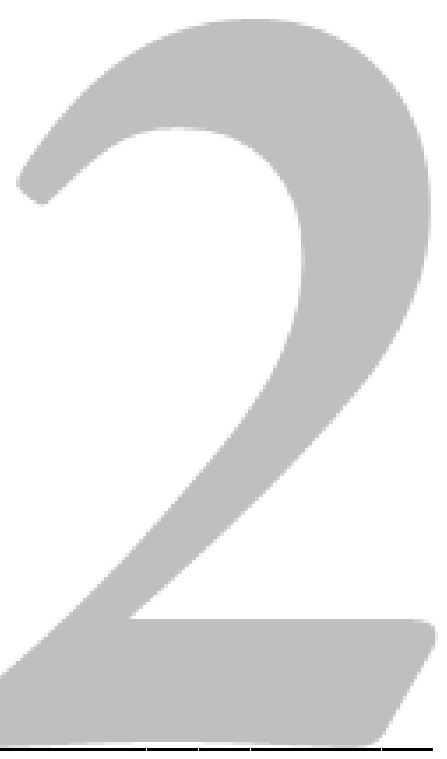

El principal objetivo de este trabajo es proporcionar información relevante sobre el funcionamiento y dimensionado de los sistemas de flujo combinado tipo MJEA ${ }^{\circledR}$ para el tratamiento de purines de cerdo. Para ello se plantean los siguientes objetivos generales:

a. Determinar la capacidad de tratamiento de un sistema de flujo combinado tipo MJEA ${ }^{\circledR}$ para el tratamiento de los sólidos en suspensión, la materia orgánica, el nitrógeno y el fósforo del agua residual porcina.

b. Evaluar la capacidad de ajuste de los modelos de dimensionado de humedales artificiales y la influencia de la temperatura en el dimensionado de un sistema de flujo combinado tipo MJEA ${ }^{\circledR}$.

c. Caracterizar las comunidades bacterianas del sedimento de una fosa de purines y de la rizosfera de los macrófitos Typha latifolia y Salix atrocinerea de un sistema de flujo combinado tipo $\mathrm{MJEA}^{\circledR}$ para el tratamiento de agua residual porcina y compararlas con las de un sistema análogo para el tratamiento de agua residual urbana.

d. Evaluar la capacidad de retención de fósforo de un filtro de escorias de acería LD para su utilización en el tratamiento de aguas residuales de origen porcino en combinación con sistemas de humedales artificiales.

e. Recomendar alternativas de diseño para mejorar la funcionalidad de los humedales artificiales en el tratamiento de purines de cerdo. 


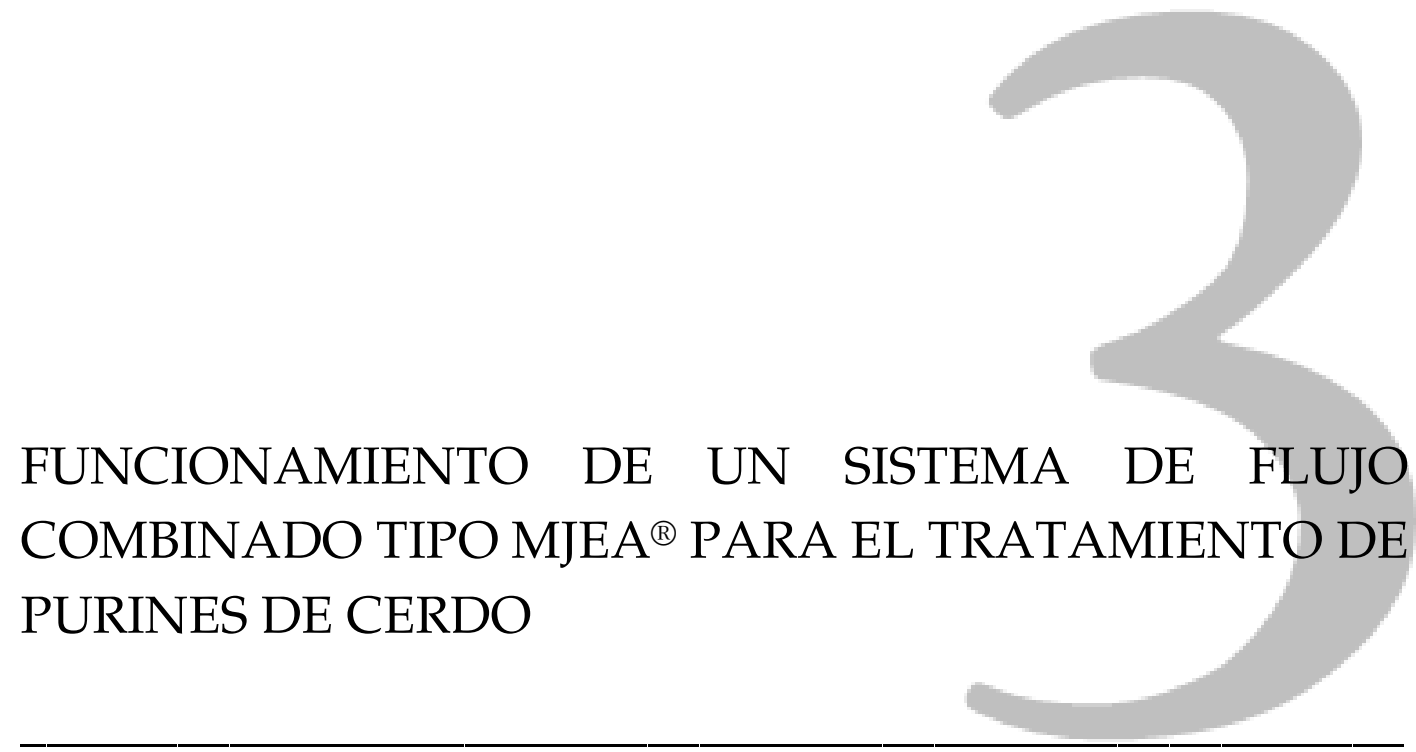

\subsection{INTRODUCCIÓN}

Los humedales artificiales son sistemas complejos con características únicas que determinan la capacidad de tratamiento para cada tipo de contaminante que entra en el sistema. La eficiencia de un humedal artificial para tratar un contaminante determinado dependerá de factores tales como la composición del agua residual, la especie de macrófito o el tipo de humedal artificial.

\subsubsection{Hidrología de los humedales artificiales}

Las características de mayor importancia en un humedal artificial son aquellas que determinan su capacidad para reducir los contaminantes presentes en el agua residual. En el caso de la hidrología de los humedales artificiales las características más relevantes son las que determinan la duración de las interacciones entre el agua residual con los macrófitos, los microorganismos y el sustrato. Es importante definir conceptos tales como la tasa de carga hidráulica y el tiempo de retención hidráulico que son utilizados en el diseño de humedales artificiales.

\subsubsection{Tasa de Carga Hidráulica}

La tasa de carga hidráulica $(q)$ hace referencia al caudal de agua residual que entra al humedal artificial por unidad de área del humedal. No implica una distribución física uniforme del agua sobre la superficie del humedal (Kadlec y Wallace, 2009). La ecuación que la define es:

donde

$$
q=\frac{Q}{A}
$$

$q=$ tasa de carga hidráulica, $\mathrm{m} \mathrm{día}^{-1}$

$Q=$ caudal, $\mathrm{m}^{3}$ día ${ }^{-1}$

$A=$ área del humedal, $\mathrm{m}^{2}$ 


\subsubsection{Tiempo de Retención Hidraúlico}

El tiempo de retención hidráulico (TRH) se define como el volumen de agua del humedal artificial dividido por el caudal de agua residual. Para un humedal artificial de flujo superficial (HFS), el TRH es definido por el volumen delimitado por la superficie del agua, el fondo y los lados del humedal. En el caso de un humedal artificial de flujo subsuperficial horizontal (HFSH), se trata de ese mismo volumen multiplicado por la porosidad del lecho (Kadlec y Wallace, 2009).

$$
T R H=\frac{V}{Q}=\frac{\varepsilon h A}{Q}
$$

donde

$$
\begin{aligned}
& \text { TRH = tiempo de retención hidráulico, día } \\
& V=\text { volumen del humedal } \mathrm{m}^{3} \\
& Q=\text { caudal, } \mathrm{m}^{3} \text { día }^{-1} \\
& \varepsilon=\text { porosidad, sin unidades } \\
& h=\text { profundidad de la columna de agua, } \mathrm{m} \\
& A=\text { área del humedal, } \mathrm{m}^{2}
\end{aligned}
$$

\subsubsection{El papel de la vegetación en los humedales artificiales}

La presencia de vegetación tiene un efecto regulador sobre las características hidráulicas de los humedales artificiales. Los tallos de las plantas distribuyen y reducen la velocidad del agua favoreciendo la sedimentación de sólidos en suspensión, reduciendo el riesgo de erosión y de resuspensión e incrementando el tiempo de contacto entre el agua y la superficie de la planta. El dosel formado por la parte aérea de los macrófitos emergentes reduce la velocidad del viento en la superficie del agua lo que afecta a la sedimentación y resuspensión de los sólidos y a la aireación de la columna de agua. Además, la cobertura del dosel atenúa la luz que llega a la superficie del agua, por lo que se disminuye la producción de algas. La presencia de vegetación previene la congelación del sustrato durante el invierno y lo mantiene fresco durante la primavera (Brix, 2003). Por último, también ejerce un efecto de filtración y actúa como sustrato para microorganismos y macroinvertebrados.

El metabolismo de estas plantas interviene en la eliminación de contaminantes en los humedales artificiales mediante la captación de nutrientes que la planta toma a través de su sistema radicular para su crecimiento y reproducción. Estos nutrientes son retirados del agua residual y pasan a formar parte de los tejidos de la planta, pero si no se realiza una cosecha periódica la mayor parte de los nutrientes incorporados volverán al agua después de su descomposición.

El aspecto metabólico de los macrófitos emergentes que más importancia tiene en los humedales artificiales es la liberación de oxígeno a través de su sistema radicular. Los macrófitos están enraizados en sustratos saturados de agua en condiciones anóxicas o anaerobias. El sistema radicular está forzado a obtener oxígeno de sus partes aéreas mediante un transporte por el interior de las plantas (Brix, 2003). Este transporte interno fue descrito por Armstrong y col. (1992) como un flujo convectivo en el transporte de los gases gracias a la diferencia de presión, proceso influido principalmente por la radiación solar. También encontraron un segundo tipo de transporte propiciado por un efecto Venturi. En este proceso el viento fuerza al aire a pasar a través de los tallos huecos de las plantas que asoman por encima de la superficie. La liberación de oxígeno depende de la concentración interna de oxígeno, la demanda de oxígeno del medio circundante y la permeabilidad de las paredes de la raíz (Sorrell y Armstrong, 1994). Este aporte de oxígeno en un medio de condiciones anaerobias permite la creación de zonas donde los organismos aerobios pueden llevar a cabo su metabolismo. El aporte de oxígeno a través de este mecanismo es muy superior en comparación con la 
aportación de oxígeno por aireación superficial, que es apreciable sólo en una estrecha capa de la superficie del humedal.

La aireación superficial tiene importancia en los HFS, donde la superficie de contacto entre el aire y el agua es máxima, mientras que en los HFSH la superficie de contacto es menor debido al lecho de grava. Según McGechan y col. (2005) la transferencia de oxígeno por difusión molecular se produce al existir un gradiente a través de una masa de agua causado por el consumo de oxígeno en una zona particular. El movimiento por difusión molecular a través del agua no es tan rápido como por otros mecanismos, por lo que puede ser ignorado. La aireación superficial tiene lugar principalmente por procesos de difusión y convección provocados por el contacto del viento con la superficie de la masa de agua.

\subsubsection{Mecanismos de eliminación de sólidos en suspensión}

Las características de los sólidos en suspensión presentes en el agua residual pueden variar según sea su origen. Así, los sólidos en suspensión del agua residual de origen urbano son característicos por su naturaleza orgánica, mientras que las aguas de escorrentía pueden contener altas proporciones de materia mineral y otras aguas residuales pueden llevar materiales coloidales (como es el caso del agua residual procedente de salas de ordeño). La mayor parte de los nutrientes orgánicos presentes en la fracción líquida de los purines de cerdo se encuentran asociados a los sólidos en suspensión (Vanotti y Hunt, 1999). La fracción orgánica de los sólidos en suspensión totales (SST) se mide como sólidos en suspensión volátiles (SSV) y en los purines de cerdo su composición puede suponer entre un 50 y un $80 \%$ de los SST (Lim, 2008). La diferencia entre SST y SSV proporciona información sobre la fracción mineral restante que se denomina sólidos en suspensión no volátiles (SSNV) (Fonder, 2010).

En todos los tipos de humedales artificiales, la mayor parte de los sólidos en suspensión presentes en el agua residual sedimentan y son filtrados en los primeros metros tras la entrada al sistema (USEPA, 1993). La acumulación de sólidos en suspensión puede suponer un problema a largo plazo para la eficiencia de algunos sistemas, particularmente para los HFSH, que pueden llegar a colmatarse (Pedescoll, 2010).

La sedimentación es el principal mecanismo de eliminación de sólidos en suspensión en humedales (Schmid y col., 2005) y está relacionado con el tamaño de las partículas, el tiempo transcurrido y la distancia recorrida. Así, las partículas de mayor tamaño y densidad serán eliminadas en primer lugar, mientras que el resto irá sedimentando progresivamente al aumentar la distancia y el tiempo (Tchobanoglous, 2003). Los largos tiempos de retención hidráulicos típicos de estos sistemas favorecen este proceso.

Los procesos de filtración e intercepción favorecen la eliminación de los sólidos en suspensión. El término filtración hace referencia a la captura de partículas por el sustrato o por detritos vegetales presentes en la superficie del agua. Las partículas pueden quedar retenidas en el sustrato o planta al impactar sobre su superficie, su movimiento puede ser redirigido hacia una parte más profunda del humedal o pueden ser interceptadas por el biofilm formado en el lecho del humedal artificial o sobre la superficie de las plantas (Kadlec y Wallace, 2009).

Las partículas retenidas pueden volver a la columna de agua mediante el fenómeno conocido como resuspensión que puede producirse debido a fuerzas de fricción que liberan partículas del lecho sedimentado, por el efecto del viento en la superficie del agua en HFS o a causa de la actividad biológica (Kadlec y Wallace, 2009). Aquellas partículas que no son afectadas por la resuspensión pasan a formar parte del sedimento del humedal artificial. El ciclo de los compuestos orgánicos e inorgánicos asociados a estas partículas no termina en el sedimento. Procesos de asimilación por parte de los microorganismos y el sistema radicular de los macrófitos pueden reintroducir estos compuestos de nuevo en el sistema.

\subsubsection{Mecanismos de eliminación de materia orgánica}


El agua residual presenta un amplio espectro de compuestos orgánicos que pueden estar presentes en forma soluble o particulada, y pueden ser desde altamente biodegradables a completamente refractarios en función de su naturaleza. Existen diferentes técnicas analíticas para medir la cantidad de materia orgánica en el agua residual. La demanda biológica de oxígeno (DBO) mide el oxígeno consumido por los microorganismos en el proceso de la oxidación de la materia orgánica biodegradable en un ambiente estanco. Este test se realiza tras 5 días de incubación en condiciones controladas, por lo que se denomina $\mathrm{DBO}_{5}$. La demanda química de oxígeno (DQO) mide la cantidad de oxígeno disuelto requerido por un oxidante químico, generalmente dicromato potásico, para la degradación química de la materia orgánica presente en una muestra. Este parámetro no diferencia entre materia orgánica biodegradable y no biodegradable, por lo que los valores de $\mathrm{DQO}$ son siempre mayores que los de $\mathrm{DBO}_{5}$ para una misma muestra de agua residual.

Los compuestos orgánicos particulados son rápidamente eliminados en los humedales artificiales mediante procesos de sedimentación y filtración (Vymazal y col., 1998), mientras que los microorganismos se encargan de eliminar el resto de la materia orgánica. Aquellos compuestos más fácilmente biodegradables se eliminan en primer lugar, por lo que los valores de $\mathrm{DBO}_{5}$ disminuyen rápidamente en las primeras etapas del humedal artificial (Kadlec, 2003a). La composición de la materia orgánica en el efluente será sustancialmente diferente de la composición a la entrada del humedal artificial (Wallace y Knight, 2006).

La materia orgánica sirve como fuente de carbono y energía para la síntesis de biomasa. Antes de ser utilizados como sustrato por los microorganismos, muchos compuestos orgánicos de alto peso molecular necesitan una etapa previa de ruptura que se lleva a cabo por enzimas extracelulares producidas por los microorganismos. Los procesos de hidrólisis son reacciones de superficie que requieren un estrecho contacto entre los organismos que proporcionan las enzimas y la materia orgánica.

Después de la hidrólisis, los organismos heterótrofos utilizan compuestos orgánicos de bajo peso molecular como fuente de carbono y obtienen su energía de una serie de reacciones de reducción-oxidación en las que los electrones son transferidos desde el sustrato de las reacciones catabólicas hasta un aceptor final. Diferentes microorganismos pueden estar relacionados con esta última etapa del proceso de descomposición, que depende fuertemente de la disponibilidad del aceptor final de electrones que puede ser el oxígeno (respiración aerobia) o, en ausencia de oxígeno, pueden ser compuestos orgánicos (fermentaciones) o compuestos inorgánicos (respiración anaerobia) (Figura 3.1).

La degradación de la materia orgánica soluble está gobernada por bacterias heterótrofas que generan biomasa mediante la utilización de compuestos orgánicos como fuente de carbono y energía. La mineralización aerobia del carbono es hasta 3 veces más rápida que bajo condiciones anaerobias (D'Angelo y Reddy, 1999), por lo que los microorganismos aerobios son más eficientes que los anaerobios en la degradación de la materia orgánica. Energéticamente el $\mathrm{O}_{2}$ es el oxidante más favorable, por lo que los organismos aerobios obtienen más cantidad de energía por molécula de sustrato original. En condiciones de baja concentración de oxígeno, la respiración anaerobia es la principal responsable de la degradación de la materia orgánica (Cooper y col., 1996).

La respiración anaerobia tiene lugar cuando el potencial de oxido-reducción (Eh) disminuye por debajo de los $300 \mathrm{mV}$, una vez agotado el $\mathrm{O}_{2}$ en el sistema. Debido a diferencias energéticas, los aceptores de electrones son utilizados en el orden $\mathrm{O}_{2}>\mathrm{NO}_{3}{ }^{-}>\mathrm{Mn}^{4+}>\mathrm{Fe}^{3+}>\mathrm{SO}_{4}{ }^{2-}>\mathrm{CO}_{2}$ (Figura 3.1). En primer lugar tienen lugar los procesos de desnitrificación (reducción de $\mathrm{NO}_{3}{ }^{-}$) y de reducción del manganeso en potenciales de 300 a $100 \mathrm{mV}$. La reducción del hierro comienza cuando se ha consumido todo el nitrato y es completa en torno a los $-100 \mathrm{mV}$, seguida por la 
reducción de sulfato (de -100 a $-200 \mathrm{mV})$ y finalmente la del $\mathrm{CO}_{2}(\mathrm{Eh}<-200 \mathrm{mV})$ que es por tanto la que menos energía proporciona a los organismos (Reddy y col., 2000).

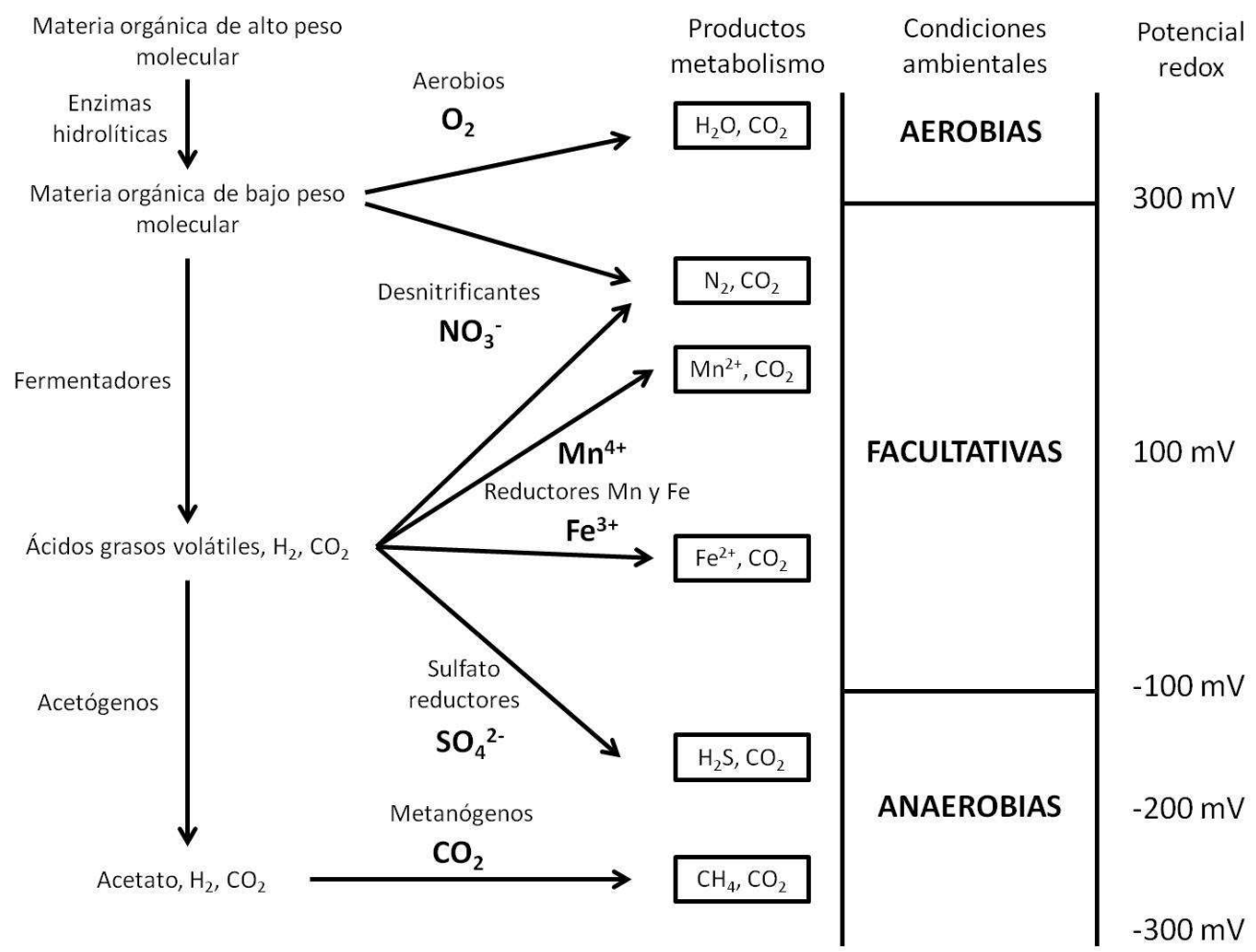

Figura 3.1. Rutas metabólicas que regulan la degradación de la materia orgánica en suelos de humedales y la reducción de los aceptores de electrones inorgánicos en función del potencial redox del suelo (los valores de Eh están calculados para un pH de 7). Adaptado de Reddy y col. (2000).

Los procesos de fermentación juegan un papel importante en la eliminación de la materia orgánica del agua residual llevada a cabo por bacterias facultativas o anaerobias heterótrofas. Durante la fermentación se produce la degradación de la materia orgánica hidrolizada en alcoholes y ácidos grasos (como acético, butírico y láctico) con coproducción de dióxido de carbono e hidrógeno (Vymazal y col., 1998). Los productos de las reacciones de fermentación pueden ser metabolizados posteriormente. Tanto acetato como dióxido de carbono e hidrógeno pueden ser transformados en metano por bacterias anaerobias estrictas. La reducción del sulfato en ácido sulfhídrico a partir de los subproductos formados en la fermentación es llevada a cabo por las bacterias sulfato reductoras, también anaerobias estrictas, y desempeña un papel fundamental en la descomposición de la materia orgánica y el ciclo del carbono en humedales artificiales (Vymazal y col., 1998).

\subsubsection{Mecanismos de eliminación de nitrógeno}

Los compuestos de nitrógeno presentes en el agua residual pueden ser orgánicos o inorgánicos, en forma particulada o soluble. Entre las formas orgánicas podemos encontrar urea, aminoácidos, aminas, purinas y pirimidinas (Vymazal, 2003a). Los compuestos de nitrógeno inorgánico más importantes en el agua residual son los nitratos $\left(\mathrm{NO}_{3}{ }^{-}\right)$, nitritos $\left(\mathrm{NO}_{2}{ }^{-}\right)$y amonio $\left(\mathrm{NH}_{4}{ }^{+}\right)$, que puede estar presente en su forma no ionizada como amoníaco $\left(\mathrm{NH}_{3}\right)$. El nitrito es un estado de oxidación (+3) del nitrógeno, intermedio entre el amonio (-3) y el nitrato $(+5)$. Debido a esta condición energética intermedia, el nitrito no es químicamente estable en humedales artificiales y se encuentra a muy bajas concentraciones. 
La presencia de estos compuestos en altas concentraciones hace que se les considere contaminantes. Este es el caso de los nitratos, responsables de episodios de eutrofización o del amoníaco, tóxico para peces e invertebrados acuáticos en concentraciones incluso inferiores a 2

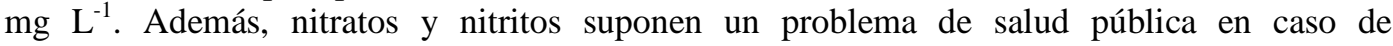
contaminación de aguas potables al estar relacionados con casos de metaglobinemia y carcinogénesis (USEPA, 2000). Las concentraciones de estos compuestos varían a lo largo de los humedales artificiales, fundamentalmente debido a procesos de transformación por parte de la comunidad bacteriana, aunque sus concentraciones también pueden ser afectadas por procesos de volatilización, adsorción al sustrato y asimilación.

La volatilización es un proceso físico-químico por el cual el amonio puede pasar como amoníaco a la atmósfera. El equilibrio entre las formas hidroxilo y gaseosa depende del valor de pH y la temperatura. Reddy y Patrick (1984) indicaron que las pérdidas de amoníaco por volatilización desde suelos y sedimentos saturados son insignificantes si el valor de $\mathrm{pH}$ es inferior a 7,5, y no son serias si el $\mathrm{pH}$ es inferior a 8. En valores de $\mathrm{pH}$ de 9,25 la relación entre amonio y amoníaco es 1:1 y las pérdidas vía volatilización son significativas.

Debido a su carga positiva, los iones amonio pueden ser adsorbidos mediante una reacción de intercambio catiónico con el sustrato o detritos presentes en el humedal. El proceso de adsorción es reversible, y los iones pueden liberarse fácilmente con cambios de las condiciones químicas del agua, por lo que no se considera un mecanismo de eliminación a largo plazo (Vymazal y col., 1998). Los lugares específicos de adsorción del sustrato o detrito son limitados por lo que la capacidad máxima de adsorción del amonio se alcanzará a una determinada concentración de amonio en el agua residual. Cuando la concentración de amonio se reduzca en la columna de agua, los iones se liberarán incrementando la concentración en el agua y manteniendo el equilibrio de intercambio (Vymazal, 2007). Los drenajes periódicos en el humedal permiten el contacto del sustrato con el oxígeno atmosférico, facilitando la oxidación del amonio adsorbido a nitrato (Kadlec y Knight, 1996).

El término asimilación hace referencia a los procesos biológicos empleados por macrófitos, microorganismos y algas para incorporar el nitrógeno inorgánico en biomasa (Vymazal, 2007). Las formas de nitrógeno utilizadas en los procesos de asimilación son amonio y nitrato. Los organismos prefieren el ión amonio frente al nitrato, ya que se encuentra más reducido energéticamente, aunque el nitrato puede ser una fuente importante de nitrógeno cuando se encuentra en altas concentraciones (Kadlec y Knight, 1996). El nitrógeno puede ser asimilado directamente de la columna de agua o de los sedimentos por el sistema radicular de los macrófitos. En climas templados, la captación de nitrógeno por macrófitos emergentes herbáceos es un fenómeno estacional, alcanza su máximo con el crecimiento de nuevos brotes en primavera y comienzos del verano, se reduce a finales de verano cuando la planta ha alcanzado su máximo crecimiento y se detiene por completo en otoño al producirse la senescencia de la planta (Kadlec y Knight, 1996). La senescencia tiene lugar cuando la acumulación de nutrientes disminuye, momento en el que comienza su translocación de la parte aérea al rizoma. Este proceso varía según la especie y las condiciones ambientales, y puede llegar a permitir la movilización de un 50\% del nitrógeno (Vymazal, 1995). Si la parte aérea no es retirada del humedal artificial su descomposición devolverá el nitrógeno de nuevo al sistema.

Los procesos de volatilización, adsorción y asimilación contribuyen de forma limitada a la eliminación de nitrógeno en los humedales artificiales. Las bacterias juegan un papel fundamental en la transformación de los compuestos nitrogenados hasta su liberación final en forma de nitrógeno atmosférico (Figura 3.2) en los procesos biológicos de nitrificacióndesnitrificación y anammox (Lee y col., 2009).

La amonificación es el proceso biológico de transformación del nitrógeno orgánico en amonio. El proceso de amonificación es esencialmente un catabolismo de aminoácidos que incluye varios tipos de reacciones de deaminación (Vymazal, 2007), aunque también incluye otros 
compuestos orgánicos como aminas, purinas, pirimidinas y urea. Cinéticamente, la amonificación es más rápida que la nitrificación (Kadlec y Knight, 1996), y es más rápida en condiciones aerobias que anaerobias (Reddy y Patrick, 1984). Su repercusión en la eliminación de la materia orgánica es limitada puesto que las bacterias heterótrofas tienen una tasa metabólica más rápida (Cooper y col., 1996). Este proceso es dependiente de la temperatura, el $\mathrm{pH}$, la relación $\mathrm{C} / \mathrm{N}$, la disponibilidad de nutrientes y las condiciones del suelo tales como textura y estructura (Reddy y Patrick, 1984). El rango óptimo de $\mathrm{pH}$ está entre 6,5 y 8,5 (Vymazal, 1995). Los géneros de bacterias que participan en los procesos de amonificación son Bacillus, Clostridium, Proteus, Pseudomonas y Streptomyces entre otros (Bisen y col., 2012).

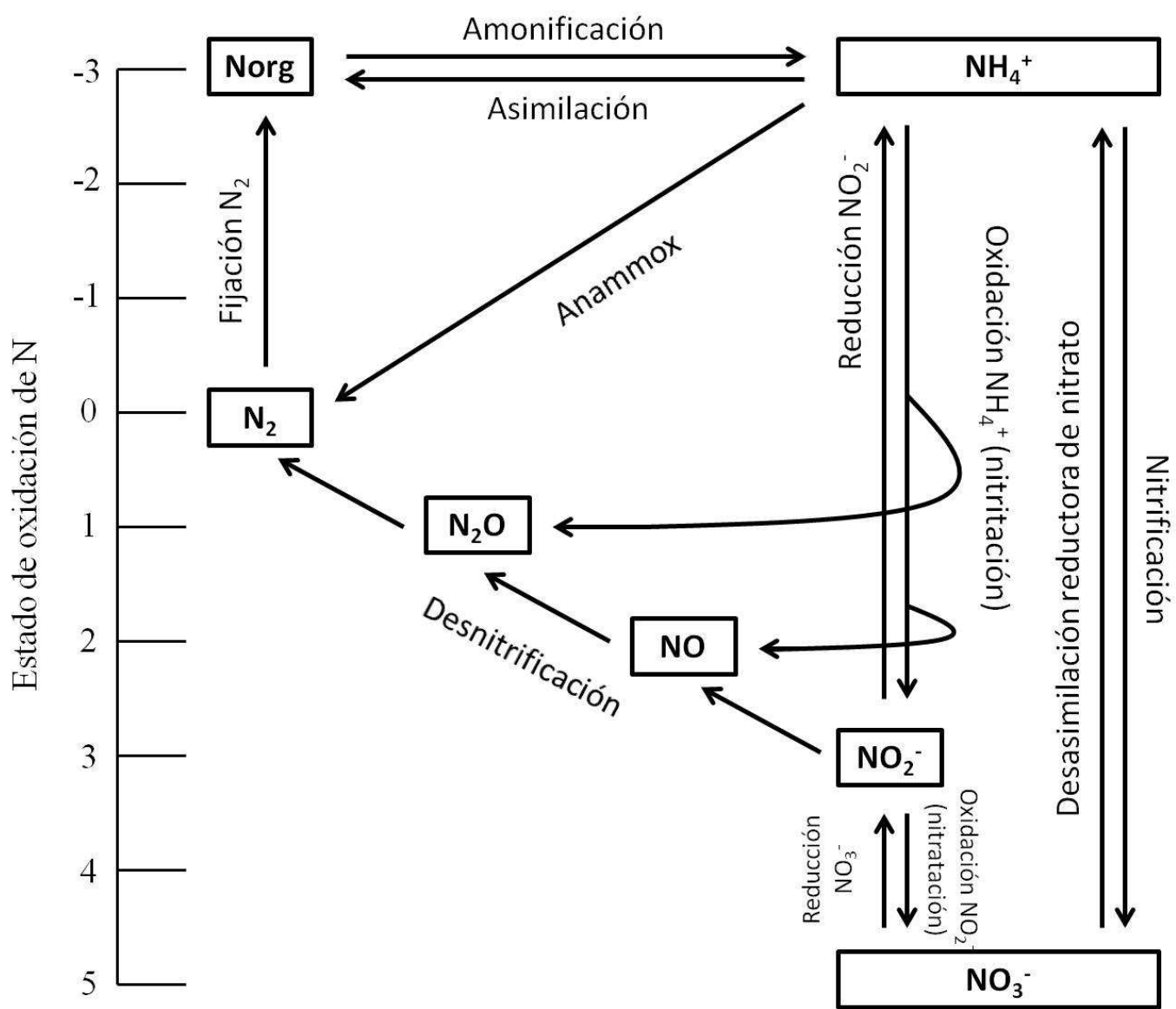

Figura 3.2. Reacciones realizadas por microorganismos en el ciclo del nitrógeno. Norg equivale a nitrógeno orgánico. Adaptado de Capone (2000).

La nitrificación se define generalmente como la oxidación biológica del amonio en nitrato con nitrito como intermediario. La nitrificación se asocia típicamente con las bacterias quimioautótrofas, aunque también puede ser llevada a cabo por bacterias heterótrofas (Paul y Clark, 1996). El proceso tiene lugar en condiciones estrictamente aerobias, y se produce a través de dos etapas oxidativas secuenciales denominadas nitritación y nitratación. La nitritación consiste en la oxidación de amonio a nitrito, con hidrógeno y agua como subproductos, mientras que en la nitratación se oxida el nitrito resultante a nitrato. Cada etapa es llevada a cabo por diferentes grupos de bacterias que utilizan el amonio o el nitrito como fuente de energía, oxígeno molecular como aceptor de electrones y una fuente externa de carbono (Ahn, 2006). El género bacteriano más conocido que lleva a cabo la oxidación del amonio es Nitrosomonas; sin embargo Nitrosococcus, Nitrosospira, Nitrosovibrio, y Nitrosolobus son también capaces de participar en este proceso. En la etapa de oxidación de nitrito encontramos varios géneros como Nitrospira, Nitrospina, Nitrococcus y Nitrocystis aunque Nitrobacter es el más conocido (Teske y col., 1994; Rittman y McCarty, 2001). 
Los humedales artificiales satisfacen las condiciones requeridas por el proceso de nitrificación. El rango de pH óptimo está entre 6,6 y 8 (Vymazal, 2007), rango de pH habitual en aguas residuales de origen urbano. El rango óptimo de temperatura para la nitrificación en suelos se encuentra entre 30 y $40{ }^{\circ} \mathrm{C}$ (Paul y Clark, 1996) y la temperatura mínima de crecimiento de Nitrosomonas y Nitrobacter se encuentra en torno a $5{ }^{\circ} \mathrm{C}$ (Cooper y col., 1996), por lo que el proceso de nitrificación tiene lugar durante la mayor parte del año en humedales artificiales de climas templados. Los procesos de nitrificación están limitados a las zonas de condiciones aerobias dentro del humedal artificial; se requieren $4,3 \mathrm{mg} \mathrm{O}_{2}$ por $\mathrm{mg}$ de amonio oxidado a nitrato (Cooper y col., 1996).

La desnitrificación es el proceso mediante el cual el nitrato es reducido a nitrógeno atmosférico, teniendo como intermediarios nitrito, óxido nítrico $(\mathrm{NO})$ y óxido nitroso $\left(\mathrm{N}_{2} \mathrm{O}\right)$. Esta reacción es irreversible, y requiere de la presencia de materia orgánica como donador de electrones, los cuales serán transportados a formas oxidadas de nitrógeno en condiciones anóxicas o anaerobias (zona de reducción del nitrato entre 300 y -100 mV) (Reddy y col., 2000; Vymazal, 2007), donde el nitrógeno es utilizado como aceptor de electrones. Los subproductos generados en esta reacción son dióxido de carbono y agua. En la desnitrificación clásica participan principalmente bacterias heterótrofas anaerobias facultativas. Entre los organismos desnitrificantes se encuentran bacterias de los géneros Pseudomonas, Alcaligenes, Paracoccus, Thiobacillus, Bacillus y Halobacterium (Zumft, 1992). La desnitrificación es un proceso fuertemente dependiente de la temperatura que tiene su óptimo entre 60 y $75{ }^{\circ} \mathrm{C}$, aunque también puede encontrarse a temperaturas por debajo de $\operatorname{los} 5^{\circ} \mathrm{C}$ (Bremner y Shaw, 1958). El rango óptimo de pH se encuentra entre 6 y 8, y el proceso se ralentiza por debajo de 5 (Paul y Clark, 1996). La estequiometría de la reacción de nitrato con metanol o glucosa como fuente de carbono se estima en 2,3 g DBO por g de nitrato (Gersberg y col., 1984).

La desasimilación reductora del nitrato es el proceso de reducción de nitrato en amonio. Las responsables de esta transformación son bacterias fermentativas que no dependen de la presencia de nitrato para su crecimiento en condiciones anaerobias. En ambientes con bajas concentraciones de nitrato estas bacterias serán capaces de competir con los microorganismos desnitrificantes que sí dependen de la presencia de nitrato para su supervivencia (Laanbroek, 1990). La transformación de nitrato en amonio en humedales artificiales a través de esta ruta está limitada a un 5\% (Van Oostrom y Russell, 1994).

Anammox (Anaerobic Ammonium Oxidation) u oxidación anaerobia del amonio es la transformación anaeróbica de amonio en nitrógeno atmosférico con la utilización de nitrito como aceptor de electrones (Vymazal, 2007). Se trata de un proceso autotrófico que no requiere carbono (Kadlec y Wallace, 2009), y que necesita $1,9 \mathrm{~g} \mathrm{O}_{2}$ por g de amonio, lo que incluye el oxígeno necesario para convertir amonio a nitrito (Sliekers y col., 2002). Uno de los puntos débiles de este proceso es la baja tasa de crecimiento bacteriano, con un tiempo de dos semanas para doblar la población. Se ha detectado metabolismo anammox tanto en HFS como en HFSH (Austin y col., 2006). Hasta la fecha solo se han identificado bacterias anammox dentro del filo Planctomycetes pertenecientes a los géneros bacterianos Brocadia, Kuenenia, Scalindua, Anammoxoglobus y Jettenia (Hu y col., 2012).

La fijación de nitrógeno es el proceso de conversión de nitrógeno atmosférico a amonio. La realizan géneros de actinomicetos simbióticos (Frankia), bacterias heterotróficas (Bacillus, Klebsiella, Clostridium) y cianobacterias (Nostoc, Anabaena). La fijación en sistemas saturados de agua es mayor en condiciones de reducción que en condiciones de oxidación. La mayor actividad de fijación de nitrógeno en suelos saturados se encuentra en el rango de potencial redox de -200 a -260 mV (Buresh y col., 1980). La descomposición de organismos fijadores de nitrógeno en un humedal puede contribuir a aumentar la concentración de compuestos de nitrógeno orgánico en la columna de agua. Sin embargo las tasas de fijación en humedales que 
reciben agua residual con alto contenido en nitrógeno son consideradas despreciables en comparación con las de otros procesos de transformación de nitrógeno (Vymazal, 2007).

De entre todos los procesos descritos, solo los de volatilización, adsorción, asimilación, desnitrificación y anammox eliminan nitrógeno del agua residual. El resto de procesos incorporan nitrógeno al sistema (fijación) o transforman el nitrógeno en otras formas de nitrógeno (amonificación, nitrificación y desasimilación reductora del nitrato). La volatilización no es considerada un mecanismo importante que permita la salida de nitrógeno del sistema a no ser que los valores de $\mathrm{pH}$ sean muy elevados. La adsorción es un proceso finito y reversible. Se estima que la cantidad de nitrógeno eliminado a través de la asimilación por macrófitos y su cosecha está limitado a un 5-10\% (Vymazal, 2007). El proceso de desnitrificación depende de la concentración de nitrato, que suele ser muy baja en el agua residual, por lo que la desnitrificación debe ser precedida por una etapa de nitrificación. Se estima que la combinación de nitrificación y desnitrificación es capaz de eliminar entre un 60 y un 95\% del nitrógeno presente en el agua residual (Lee y col., 2009). El mayor obstáculo para el rendimiento óptimo de este mecanismo es la presencia del oxígeno necesario para la nitrificación. El proceso anammox requiere menos oxígeno que el mecanismo de nitrificación-desnitrificación y no necesita materia orgánica como fuente de carbono. Sin embargo todavía se desconoce su importancia con respecto a la desnitrificación puesto que los métodos empleados para detectar su presencia y actividad son recientes ( $\mathrm{Li} \mathrm{y} \mathrm{Gu}, 2011)$. El proceso anammox merece especial atención en aquellos humedales artificiales en los que las concentraciones de amonio y nitratos se reducen en cantidades superiores a las estimadas según las necesidades teóricas de carbono y oxígeno de los procesos de nitrificación-desnitrificación (Austin y col., 2006).

\subsubsection{Mecanismos de eliminación de fósforo}

El fósforo es uno de los elementos más importantes en los ecosistemas. Es un nutriente requerido para el crecimiento de las plantas y además suele ser el principal nutriente limitante en los ecosistemas de agua dulce. Es por ello que la introducción de cantidades traza de este elemento en las aguas receptoras puede tener profundos efectos en la estructura de los ecosistemas acuáticos. Ya que no tiene componentes gaseosos en su ciclo biogeoquímico, el fósforo tiende a incorporarse al sedimento de los sistemas naturales, volviéndose escaso en el ecosistema. Su clasificación se basa en los métodos analíticos usados para su determinación y puede encontrarse en forma de compuestos orgánicos o inorgánicos.

El contenido de fósforo orgánico en el agua residual urbana procede fundamentalmente de las deyecciones humanas. Los compuestos de fósforo orgánico pueden ser insolubles (fosfolípidos, fosfoproteínas y fosfatos polisacáridos) o solubles (tales como glucosa-1-fosfato, adenosín difosfato, inositol mono- y hexa-fosfato, glicerofosfatos, fosfocreatina) (Roques, 1990). Las formas inorgánicas incluyen ortofosfatos, la única forma libre que puede ser utilizada directamente por algas y macrófitos, polímeros lineales o polifosfatos y polímeros cíclicos o metafosfatos (Vymazal, 2007). Los polifosfatos consisten en cadenas de fosfatos unidos entre sí por un átomo de oxígeno (Roques, 1990). Los fosfatos son generados en la hidrólisis y descomposición microbiológica de los polifosfatos y el fósforo orgánico.

El fósforo es esencial para el desarrollo de microorganismos y macrófitos. El uso del fósforo por parte de los microorganismos es muy rápido debido a sus altas tasas de crecimiento, pero la cantidad acumulada es muy baja. El ciclo completo a través de los procesos de crecimiento, muerte y descomposición devuelve la mayor parte del fósforo al sistema. En general el uso del fósforo por parte de los microorganismos no se considera un mecanismo de eliminación (Vymazal, 2003a), pero permite su transformación lo que facilita su eliminación a través de otros mecanismos.

El fósforo puede encontrarse tanto en forma particulada como soluble. El principal mecanismo de eliminación del fósforo particulado es la sedimentación sobre el sustrato, el entrampamiento 
en el tallo de los macrófitos y la intercepción sobre el biofilm (USEPA, 2000). Los principales mecanismos que reducen la concentración de fósforo soluble del agua residual son los procesos de adsorción y precipitación. Ambos fenómenos son reacciones de superficie que pueden ocurrir simultáneamente y que forman enlaces químicos similares difíciles de discernir entre sí (Molle y col., 2005).

La adsorción es un proceso rápido que permite la acumulación de solutos en la superficie del sustrato. Es un fenómeno de superficie en el que las moléculas de fósforo no se vuelven en ningún momento parte integrante de la estructura del sólido. La afinidad de $\mathrm{Al}, \mathrm{Fe}, \mathrm{Ca}$ o $\mathrm{Mg}$ por el fósforo depende del $\mathrm{pH}$ del sistema, de la concentración de fósforo en el agua residual y de la capacidad de adsorción del sustrato que es limitada, puesto que existe un número finito de lugares de adsorción en el sustrato (Richardson, 1999). La adsorción es un proceso reversible, por lo que la concentración de fósforo en el agua dependerá del equilibrio de adsorción y desorción entre el sustrato y la columna de agua.

El proceso de precipitación requiere más tiempo que el anterior. El proceso de adsorción puede favorecer una acumulación importante de partículas sobre la superficie del sustrato, facilitando la asociación molecular y la consiguiente formación de precipitados de fósforo a partir de elementos disueltos (Molle, 2003). La precipitación da lugar a sólidos cristalinos amorfos, resultado de la fijación de fósforo por $\mathrm{Al}$ y Fe en condiciones ácidas y $\mathrm{Ca}$ y $\mathrm{Mg}$ en condiciones alcalinas (Reddy y D'Angelo, 1994). La naturaleza de las reacciones de precipitación depende de la concentración de fósforo en el agua, el pH, la temperatura y las condiciones redox (Kadlec y Wallace, 2009).

Al igual que otros nutrientes, el fósforo es asimilado por los macrófitos a través del sistema radicular. La cantidad de fósforo tomada por las plantas es máxima al comienzo de la estación de crecimiento, que en climas templados coincide con el comienzo de la primavera,y se mantiene alta durante el resto del periodo vegetativo. Antes de la senescencia, la mayor parte del fósforo se transporta de la parte aérea a las raíces y rizomas para su acumulación hasta la siguiente estación de crecimiento. La descomposición de la materia muerta devuelve el fósforo al sistema (Reddy y col., 1999).

Algunas porciones de materia muerta procedente de microflora, microfauna y de las partes aérea y sumergida de los macrófitos son resistentes a la descomposición. Estos restos sedimentan y se acumulan en el lecho de los humedales formando parte de los sedimentos. Aunque la mayor parte del fósforo es liberado, entre un 10 y un $20 \%$ se acumula permanentemente (Kadlec y Wallace, 2009). Este es el único proceso, aparte de la cosecha de la parte aérea de los macrófitos, que permite una eliminación sostenible del fósforo en el propio humedal artificial, aunque solo sería efectivo en HFS con una alta producción de biomasa emergente y una columna de agua sobre el sedimento (Vymazal, 2007).

\subsubsection{Eficiencia de los humedales artificiales para el tratamiento de agua residual de origen ganadero}

La capacidad de tratamiento de distintos tipos de humedales artificiales y combinaciones de éstos presentes en la bibliografía para el tratamiento de SST, $\mathrm{DBO}_{5}, \mathrm{DQO}, \mathrm{NTK}, \mathrm{NH}_{4}{ }^{+}, \mathrm{NT}$ y PT se muestran en la Tabla 3.1. Los resultados muestran una gran variación aunque en general la capacidad de tratamiento es superior en el caso de sólidos en suspensión y materia orgánica en comparación con los parámetros de nitrógeno y fósforo. La capacidad de tratamiento y los mecanismos de eliminación de contaminantes de los humedales artificiales varía en función del tipo de sistema, las condiciones ambientales, las condiciones de operación y la composición del agua residual. 
Tabla 3.1. Capacidad de tratamiento (\%) de contaminantes analizados en varios humedales artificiales para el tratamiento de agua residual de origen ganadero. Los acrónimos indican: LWDB, Livestock wastewater treatment database; HFS, Humedal de flujo superficial; HFSH, Humedal de flujo subsuperficial horizontal; MPM, Marsh-Pond-Marsh.

\begin{tabular}{|c|c|c|c|c|c|c|c|c|}
\hline $\begin{array}{l}\text { Tipo de } \\
\text { humedal }\end{array}$ & SST & $\mathrm{DBO}_{5}$ & DQO & NTK & $\mathrm{NH}_{4}^{+}$ & NT & PT & Referencia \\
\hline \multicolumn{9}{|c|}{ Lecherías } \\
\hline LWDB & 47 & 68 & & & 60 & 51 & & Knight y col. (2000) \\
\hline HFS & 20,9 & 60,9 & & 42,8 & 25,6 & & 27,7 & Geary y Moore (1999) \\
\hline HFS & 29,6 & $-1,6$ & & 23,2 & 40,1 & & & $\begin{array}{l}\text { Karpiscak y col. } \\
\text { (1999) }\end{array}$ \\
\hline HFS & 90 & 76 & & 28 & & & 45 & Newman y col. (2000) \\
\hline HFSH & 90,8 & 93,7 & 91,9 & 48,5 & $-0,1$ & & 60,6 & Mantovi y col. (2003) \\
\hline \multicolumn{9}{|l|}{ Porcino } \\
\hline LWDB & 52 & 58 & & & 40 & 39 & & Knight y col. (2000) \\
\hline MPM & $66-69$ & & $43-53$ & $37-51$ & $43-59$ & & $31-44$ & Reddy y col. (2001) \\
\hline HFS & & & & & 86 & 84 & 38 & Stone y col. (2002) \\
\hline MPM & & 43 & 41 & & & 44 & 22 & Poach y col. (2004) \\
\hline HFSH & 96 & 91 & 84 & 24 & 22 & 24 & 47 & Lee y col. (2004) \\
\hline HFSH & & & $67-75$ & & & $73-83$ & 71-98 & Meers y col. (2005) \\
\hline
\end{tabular}

El estudio de los sistemas de flujo combinado tipo MJEA ${ }^{\circledR}$ para su aplicación al tratamiento de los purines de cerdo requiere conocer cuáles son los mecanismos que intervienen en la eliminación de contaminantes con el fin de optimizar la capacidad de tratamiento del sistema. Para ello se ha monitorizado el funcionamiento de una planta a escala piloto bajo unas condiciones de operación determinadas. 


\subsection{OBJETIVOS}

El seguimiento del funcionamiento de un sistema de flujo combinado tipo MJEA $^{\circledR}$ para el tratamiento de purines de cerdo tiene como objetivos:

a. Determinar la capacidad de este tipo de sistemas para tratar la fracción líquida de los purines de cerdo mediante la definición de los índices de eliminación para los contaminantes $\mathrm{SST}, \mathrm{DBO}_{5}, \mathrm{DQO}, \mathrm{NTK}, \mathrm{NH}_{4}{ }^{+}$, NT y PT y su comparación con los resultados obtenidos en estudios similares presentes en la bibliografía.

b. Determinar el límite inferior de la concentración de salida para definir el rango de valores de concentración de fondo de los contaminantes SST, DBO 5 , DQO, NT y PT.

c. Identificar los principales mecanismos de eliminación de contaminantes. 


\subsection{MATERIALES Y MÉTODOS}

\subsubsection{Planta piloto para el tratamiento de purines de cerdo}

Se ha construido un humedal artificial a escala piloto en el Centro Tecnológico de Inseminación Artificial Porcina CENTROTEC localizado en Campo de Villavidel, en la provincia de León, con latitud $42^{\circ} 25^{\prime}$ '44' $\mathrm{N}$ y longitud 5' 31 ' 33' ' O (Figura 3.3). CENTROTEC tiene naves con capacidad para un total de 150 verracos productores de semen. Las naves disponen de sistemas de emparrillado con fosa inferior donde se acumulan las deyecciones de los animales junto con el agua de limpieza. Las fosas son evacuadas periódicamente y los residuos son conducidos a una balsa de purines en el exterior del recinto.
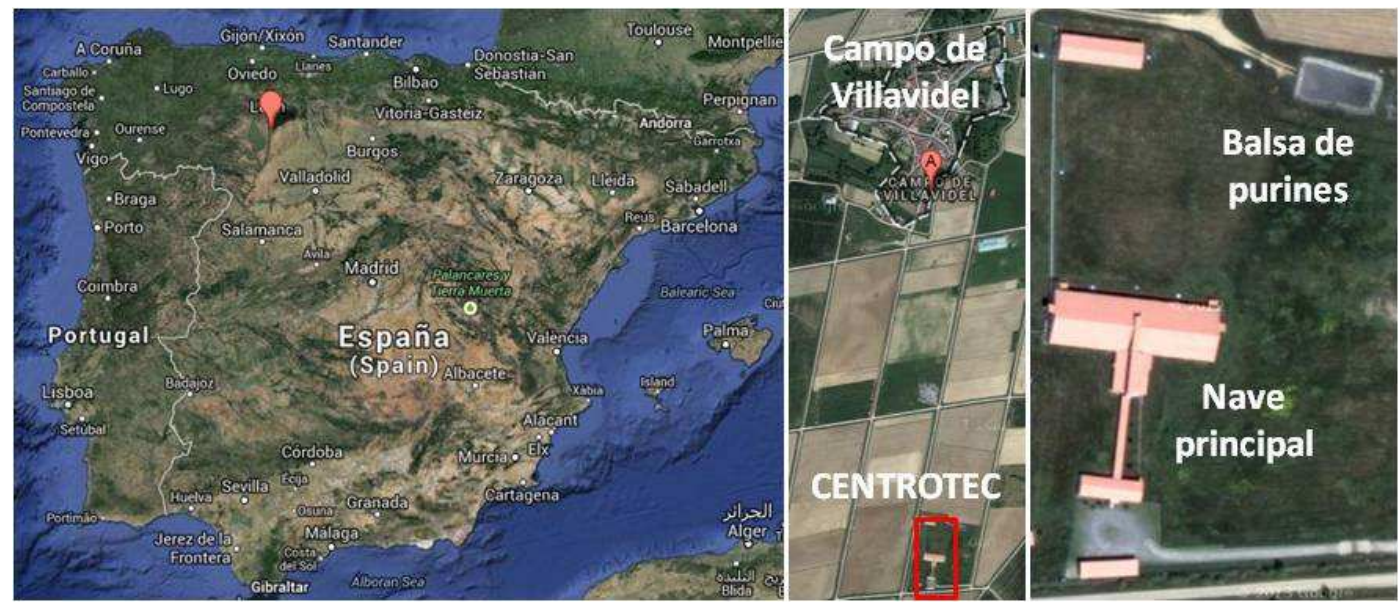

Figura 3.3. De izquierda a derecha. Localización de Campo de Villavidel en España, localización de CENTROTEC en el municipio de Campo de Villavidel y localización de la balsa de purines y la nave principal en CENTROTEC. Adaptado de Google (2013).

El diseño de este humedal artificial está inspirado en el trabajo de Ansola y col. (2003) con sistemas de tipo MJEA $^{\circledR}$. La planta piloto consta de tres unidades de fibra de vidrio de forma arriñonada de $3 \mathrm{~m}$ de longitud, 2,3 $\mathrm{m}$ de ancho máximo y 0,5 $\mathrm{m}$ de profundidad. El área de cada unidad es aproximadamente $4,54 \mathrm{~m}^{2}$, para un área total del sistema de $13,62 \mathrm{~m}^{2}$. Las tres unidades se encuentran dispuestas en serie, conectadas a través de arquetas para facilitar el muestreo y asentadas sobre una capa nivelada de arena machacada para crear una pendiente del $1 \%$ que permite el flujo del agua por gravedad. El espacio alrededor de las unidades se ha rellenado con grava para evitar tensiones en la estructura debido al peso del lecho de grava y exponer la parte inferior a la temperatura del aire. Las conducciones y arquetas se han forrado con Armaflex ${ }^{\circledR}$ de $2,5 \mathrm{~cm}$ de espesor como material aislante para evitar congelaciones (Figura 3.4).

El agua residual procedente de la balsa de purines es bombeada hasta un depósito de $1 \mathrm{~m}^{3}$ de volumen en donde se diluye con agua procedente del pozo que abastece a CENTROTEC. La alimentación del sistema se realiza a través de este depósito, que permite regular el flujo para obtener una carga hidráulica promedio de $14,4 \mathrm{~mm}_{\text {día }}{ }^{-1}$ y un tiempo de retención hidráulico (TRH) teórico promedio de 16 días.

La primera unidad constituye la primera etapa de depuración del sistema. El lecho de la unidad está ocupado por grava hasta una altura de $25 \mathrm{~cm}$, la alimentación se realiza por la parte más elevada y un aliviadero en la parte superior del extremo opuesto permite el flujo superficial (FS) del agua residual con un TRH teórico promedio de 8 días. El lecho de grava ha sido plantado con el rizoma del macrófito emergente Typha latifolia (enea o espadaña) con una densidad de $8-10$ brotes $\mathrm{m}^{-2}$ (Figura 3.4). 

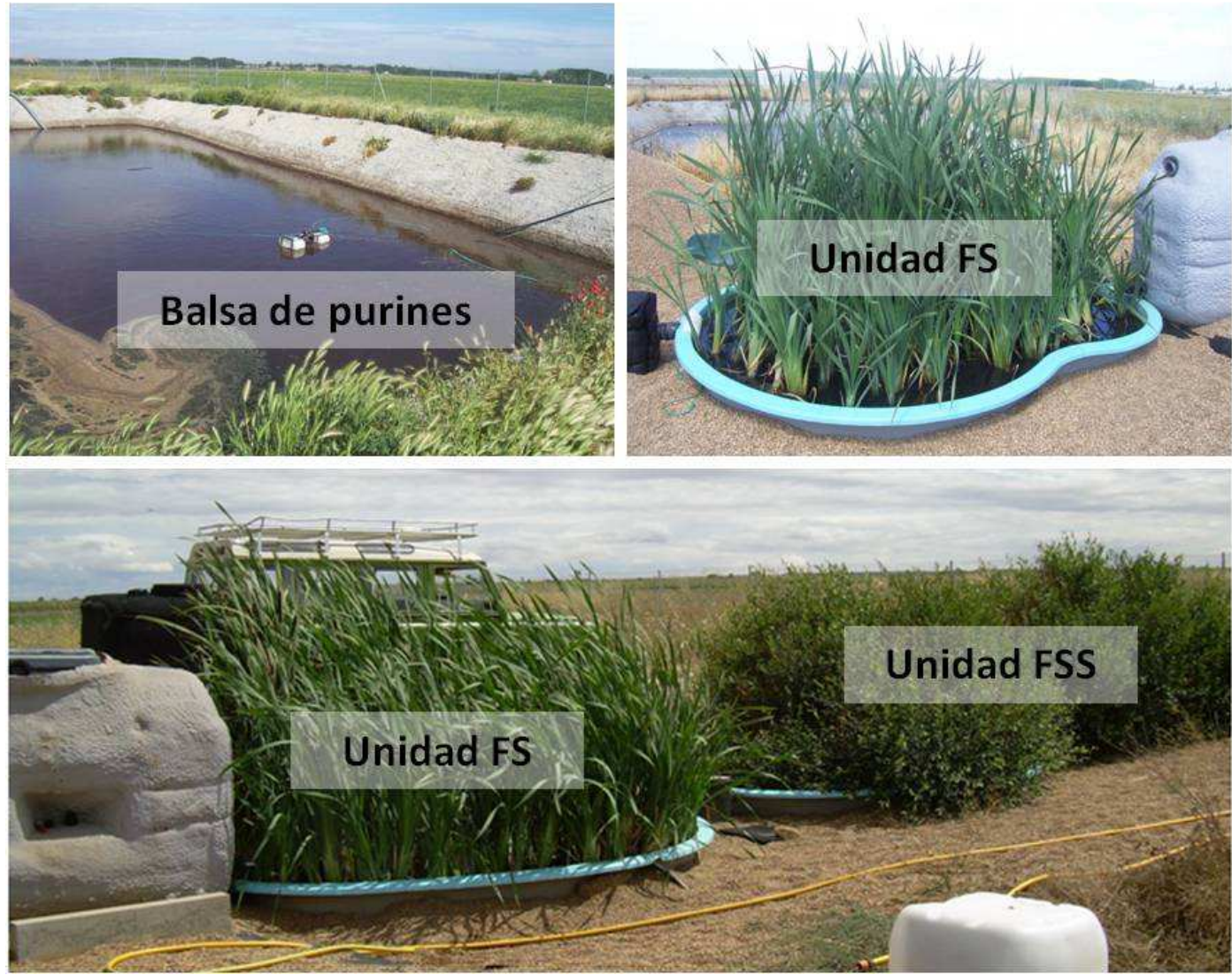

Figura 3.4. De izquierda a derecha y de arriba hacia abajo. Fotografías de la balsa de purines y unidades FS y FSS.

Las otras dos unidades constituyen la segunda etapa de depuración del sistema. El lecho está completamente ocupado por grava y un aliviadero en el fondo del extremo opuesto permite el flujo subsuperficial (FSS) del agua residual con un TRH teórico promedio de 8 días. El lecho de grava se ha plantado con individuos de Salix atrocinerea (sauce) a $20 \mathrm{~cm}$ de profundidad y con una densidad de 3-4 plantones $\mathrm{m}^{-2}$ (Figura 3.4).

La fase de construcción del sistema comienza en noviembre de 2005. Las plantas utilizadas fueron tomadas del humedal artificial localizado en Bustillo de Cea (León) a finales de febrero de 2006. En la recolección de Typha latifolia se podó la parte aérea y parte del rizoma respetando los brotes. Los plantones de Salix atrocinerea se podaron cuando la planta comenzaba a desarrollar los brotes y se tuvo cuidado en elegir aquellos más desarrollados. Una vez plantados, el sistema ha recibido una carga contaminante con una baja concentración de nitrógeno durante un periodo de aclimatación a fin de comprobar la viabilidad de los macrófitos.

La fase de operación comienza en abril de 2006. La carga de nitrógeno se redujo progresivamente durante esta fase mediante la dilución del purín bruto, estableciéndose la carga de nitrógeno objetivo en $3,0 \mathrm{~g} \mathrm{~m}^{-2}$ día $^{-1}$ en $2006,1,5 \mathrm{~g} \mathrm{~m}^{-2}$ día ${ }^{-1}$ en 2007 y $0,6 \mathrm{~g} \mathrm{~m}^{-2}$ día $^{-1}$ en 2008. El concepto de carga equivale a la masa de un contaminante que es añadida a un humedal artificial en función de la superficie y el tiempo, y se suele expresar como $\mathrm{g} \mathrm{m}^{-2}$ día $^{-1}$. Se eligió el nitrógeno debido a la importancia de este elemento en la composición de los purines de cerdo. 


\subsubsection{Toma de muestras}

Las muestras se han tomado teniendo en cuenta el tiempo de retención hidráulico de la planta piloto. Durante los meses de invierno la congelación del agua residual de la balsa de purines imposibilita el funcionamiento del sistema, por lo que los muestreos durante la fase de operación se limitan al periodo Abril - Noviembre.

En total se han realizado 54 muestreos durante los tres periodos experimentales: 14 muestras en 2006, 13 muestras en 2007 y 27 muestras en 2008, año en el que se duplica el esfuerzo de muestreo. Los muestreos se han realizado entre las 9:00 de la mañana y las 14:00 de la tarde y en todos ellos se han tomado muestras del agua residual que alimenta el sistema (Entrada), el agua residual a la salida de la primera etapa (Salida-FS), y el agua residual a la salida de la instalación (Salida) (Figura 3.5).

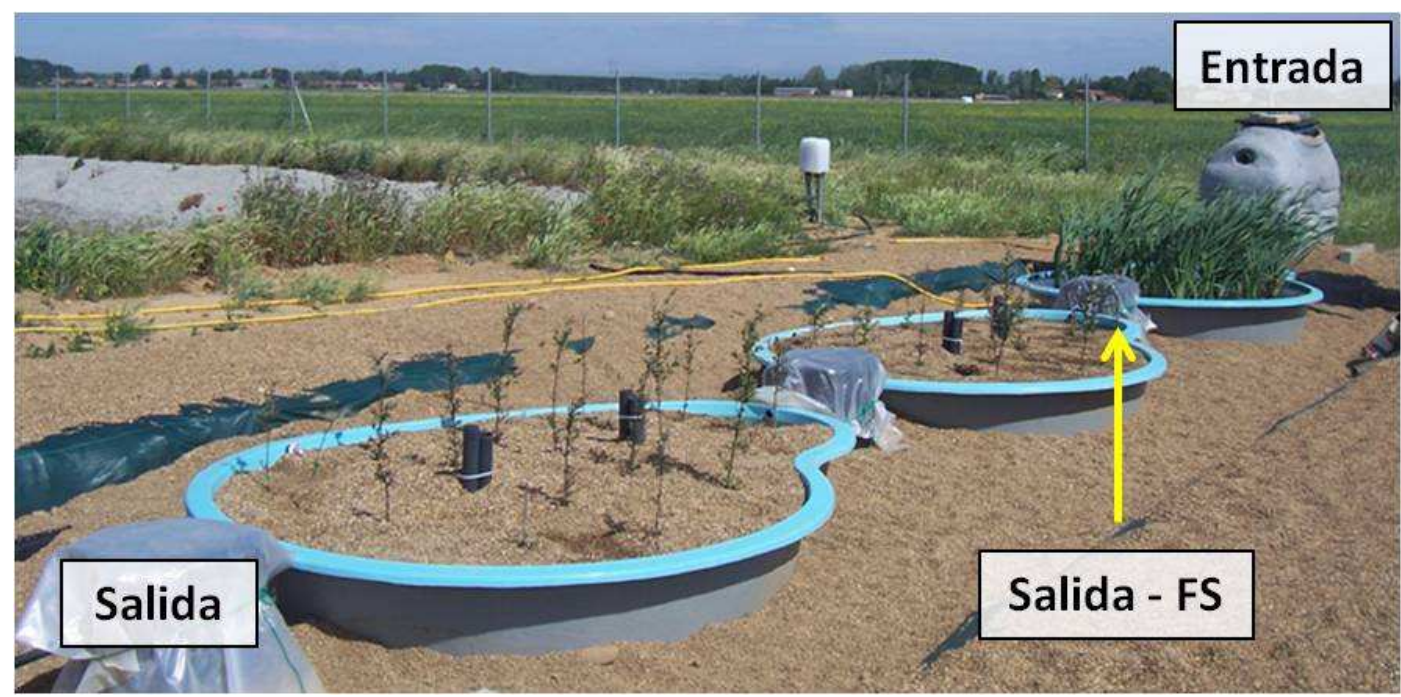

Figura 3.5. Localización de los puntos de muestreo en la planta a escala piloto.

La toma de muestras se ha realizado de acuerdo con las especificaciones recogidas en el manual de referencia "Standard methods for the examination of water and wastewater", método $1060 \mathrm{~A}$. Introduction, B. Collection of samples y C. Sample storage and preservation (APHA-AWWAWEF, 2005). Las muestras se han recogido en botes de polipropileno para aquellos análisis que han de ser realizados en un periodo de 24 horas o en botes de vidrio para aquellos contaminantes que pueden ser almacenados para un análisis posterior. En este caso, se ha realizado la fijación de la muestra mediante acidificación de $\mathrm{pH}$ hasta un valor de 1,5-2 con ácido sulfúrico (en el caso de muestras que han de ser analizadas por su contenido en nitrógeno) o ácido clorhídrico (en el caso de muestras que han de ser analizadas por su contenido en fósforo). El transporte de las muestras se ha realizado en neveras portátiles para asegurar condiciones de refrigeración, y el almacenamiento se ha realizado en una cámara frigorífica a $4{ }^{\circ} \mathrm{C}$ a la espera de realizar los análisis.

\subsubsection{Métodos analíticos}

Las propiedades físicas del agua residual $(\mathrm{pH}$, potencial de oxido-reducción (Eh), oxígeno disuelto (OD), conductividad eléctrica (CE) y temperatura (T)) han sido medidas in situ mediante el uso de una sonda YSI 556 MPS Multiprobe calibrada periódicamente.

Las muestras almacenadas se han analizado en los laboratorios del Instituto de Medio Ambiente, Recursos Naturales y Biodiversidad de la Universidad de León para los parámetros 
mostrados en la Tabla 3.2 siguiendo los protocolos establecidos en (APHA-AWWA-WEF, 2005).

Tabla 3.2. Protocolos utilizados para el análisis de los parámetros del agua residual (APHAAWWA-WEF, 2005).

\begin{tabular}{|c|c|c|c|}
\hline Parámetro & Técnica & Protocolo & Unidades \\
\hline $\begin{array}{l}\text { Sólidos en suspensión totales } \\
\text { (SST) }\end{array}$ & Gravimetría & $\begin{array}{l}2540-\mathrm{B} . \text { Total solids dried at } \\
103-105^{\circ} \mathrm{C}\end{array}$ & $\mathrm{mg} \mathrm{L}^{-1}$ \\
\hline $\begin{array}{l}\text { Sólidos en suspension } \\
\text { volatiles (SSV) }\end{array}$ & Gravimetría & $\begin{array}{l}2540-\mathrm{E} \text {. Fixed and volatile } \\
\text { solids ignited at } 550^{\circ} \mathrm{C}\end{array}$ & $\mathrm{mg} \mathrm{L}^{-1}$ \\
\hline $\begin{array}{l}\text { Demanda biológica de } \\
\text { oxígeno } 5 \text { días } 20^{\circ} \mathrm{C}\left(\mathrm{DBO}_{5}\right)\end{array}$ & Manométrica & 5210 - B. 5-Day BOD Test & $\mathrm{mg} \mathrm{O}_{2} \mathrm{~L}^{-1}$ \\
\hline $\begin{array}{l}\text { Demanda química de oxígeno } \\
\text { (DQO) }\end{array}$ & $\begin{array}{l}\text { Reflujo cerrado } \\
\text { dicromato }\end{array}$ & $\begin{array}{l}5220-\text { C. Closed reflux, } \\
\text { titrimetric method }\end{array}$ & $\mathrm{mg} \mathrm{O}_{2} \mathrm{~L}^{-1}$ \\
\hline $\begin{array}{l}\text { Nitrógeno total Kjeldahl } \\
\text { (NTK) }\end{array}$ & Titración & $\begin{array}{l}4500 \text { - Norg - B. Macro- } \\
\text { Kjeldahl method }\end{array}$ & $\operatorname{mg~N~L}{ }^{-1}$ \\
\hline Amonio $\left(\mathrm{NH}_{4}{ }^{+}\right)$ & Titración & $\begin{array}{l}4500-\mathrm{NH} 3-\mathrm{B} . \text { Preliminary } \\
\text { distillation step } \\
4500-\mathrm{NH} 3-\mathrm{C} . \text { Titrimetric } \\
\text { method }\end{array}$ & $\operatorname{mg~N~L}{ }^{-1}$ \\
\hline Fósforo total (PT) & Espectrofotometría & $\begin{array}{l}4500-\mathrm{P}-\mathrm{E} . \text { Ascorbic acid } \\
\text { method }\end{array}$ & $\mathrm{mg} \mathrm{P} \mathrm{L}^{-1}$ \\
\hline
\end{tabular}

Para el análisis de nitratos $\left(\mathrm{NO}_{3}^{-}\right)$y nitritos $\left(\mathrm{NO}_{2}^{-}\right)$, las muestras se han filtrado, fijado y congelado inmediatamente. Posteriormente las muestras se han analizado mediante electroforesis capilar en el Laboratorio de Técnicas Instrumentales de la Universidad de León.

\subsubsection{Análisis de datos}

Para determinar la eficiencia en la eliminación de contaminantes del agua residual se ha definido el Índice de eliminación:

$$
\text { Índice de eliminación }=\left[\left(C_{e}-C_{s}\right) / C_{e}\right] \times 100
$$

donde

$C_{e}=$ concentración de entrada en el sistema o etapa, $\mathrm{mg} \mathrm{L}^{-1}$

$C_{s}=$ concentración de salida del sistema o etapa, $\mathrm{mg} \mathrm{L}^{-1}$

El tratamiento de datos se ha realizado con el paquete estadístico R 2.15.1 (RCoreTeam, 2012) para Windows. En el caso de identificarse "outliers" éstos se han estudiado de forma individualizada y se han eliminado de los datos en los casos en los que se ha estimado oportuno. 


\subsection{RESULTADOS Y DISCUSIÓN}

\subsubsection{Características del agua residual}

Las características físicas del agua residual no han variado de forma importante durante el periodo de estudio (Tabla 3.3). La media de $\mathrm{pH}$ se ha mantenido próxima a un valor entre 7 y 7,5 a lo largo del humedal. El valor promedio de oxígeno disuelto (OD) se ha reducido desde un valor de entrada promedio de $5 \mathrm{mg} \mathrm{L}^{-1}$ y se ha mantenido estable en el resto de puntos de muestreo. El valor de la concentración de entrada se debe al contenido de oxígeno del agua de dilución que ha aumentado la concentración de OD original del agua residual.

Los potenciales promedio de oxido-reducción (Eh) a lo largo del humedal se han mantenido relativamente estables pero con una gran desviación estándar. Altos coeficientes de desviación estándar de Eh son frecuentes en humedales artificiales puesto que el equilibrio de oxidaciónreducción se alcanza muy pocas veces en suelos saturados de agua debido al continuo aporte de donadores de electrones como los que se encuentran en la materia orgánica (Bohn, 1971).

Los valores promedio de conductividad eléctrica (CE) han variado ampliamente a la entrada del sistema mostrando una elevada desviación estándar. Tanto la media como la desviación estándar se han reducido de forma importante a lo largo del sistema manteniéndose por encima del límite de $1000 \mu \mathrm{S} \mathrm{cm}^{-1}$ que define el agua útil para riego (Ayers y Westcot, 1994).

La temperatura media se ha mantenido constante y la desviación estándar ha aumentado ligeramente hacia la salida del sistema. En los humedales artificiales con elevado tiempo de retención hidráulico (TRH), existe una zona de entrada en la que las temperaturas del agua se ajustan a las condiciones meteorológicas, y una zona de salida en la que el ajuste es completo (Kadlec y Wallace, 2009). El agua residual objeto de estudio procede de una fosa de purines adyacente al sistema de tratamiento, por lo que ya se encontraba ajustada a las condiciones meteorológicas. El ligero incremento de las temperaturas en la salida es debido a la orientación Este del humedal que ha permitido el incremento de las temperaturas en este punto de muestreo por las mañanas, momento en el que se realiza la toma de muestras.

Tabla 3.3. Valores promedio y desviación estándar de las características físicas del agua residual y de los contaminantes físicos, químicos y biológicos monitorizados en el sistema de tratamiento a escala piloto. Número de muestras $(n)=54$.

\begin{tabular}{|c|c|c|c|}
\hline Parámetros & Entrada & Salida-FS & Salida \\
\hline $\mathrm{pH}$ & $7,5 \pm 1,1$ & $7,5 \pm 1,0$ & $7,0 \pm 1,0$ \\
\hline $\mathrm{OD}\left(\mathrm{mg} \mathrm{O}_{2} \mathrm{~L}^{-1}\right)$ & $5,0 \pm 3,2$ & $2,1 \pm 1,7$ & $1,7 \pm 1,6$ \\
\hline Eh $(\mathrm{mV})$ & $40,4 \pm 134,9$ & $16,4 \pm 151,9$ & $66,1 \pm 133,5$ \\
\hline $\mathrm{CE}\left(\mu \mathrm{S} \mathrm{cm} \mathrm{cm}^{-1}\right)$ & $1576 \pm 1761$ & $1409 \pm 1093$ & $1072 \pm 627$ \\
\hline $\mathrm{T}^{\mathrm{a}}\left({ }^{\circ} \mathrm{C}\right)$ & $16,1 \pm 3,6$ & $15,4 \pm 4,8$ & $16,2 \pm 5,0$ \\
\hline $\operatorname{SST}\left(\mathrm{mg} \mathrm{L}^{-1}\right)$ & $230,1 \pm 145,2$ & $37,1 \pm 23,5$ & $29,5 \pm 17,9$ \\
\hline $\operatorname{SSV}\left(\mathrm{mg} \mathrm{L}^{-1}\right)$ & $143,9 \pm 127,3$ & $22,9 \pm 26,4$ & $17,6 \pm 12,9$ \\
\hline $\mathrm{DBO}_{5}\left(\mathrm{mg} \mathrm{O}_{2} \mathrm{~L}^{-1}\right)$ & $69,1 \pm 40,8$ & $37,1 \pm 30,6$ & $10,4 \pm 7,6$ \\
\hline $\mathrm{DQO}\left(\mathrm{mg} \mathrm{O}_{2} \mathrm{~L}^{-1}\right)$ & $380,1 \pm 181,4$ & $211,9 \pm 81,0$ & $123,1 \pm 51,9$ \\
\hline NTK $\left(\mathrm{mg} \mathrm{N} \mathrm{L}^{-1}\right)$ & $104,7 \pm 78,9$ & $83,8 \pm 58,2$ & $41,4 \pm 31,2$ \\
\hline $\mathrm{NH}_{4}^{+}\left(\mathrm{mg} \mathrm{N} \mathrm{L}^{-1}\right)$ & $88,2 \pm 69,9$ & $75,3 \pm 52,2$ & $38,2 \pm 29,3$ \\
\hline $\mathrm{NT}\left(\mathrm{mg} \mathrm{N} \mathrm{L} \mathrm{L}^{-1}\right)$ & $118,1 \pm 81,9$ & $98,7 \pm 58,9$ & $54,2 \pm 33,9$ \\
\hline $\mathrm{NO}_{2}^{-}\left(\mathrm{mg} \mathrm{N} \mathrm{L}^{-1}\right)$ & $0,3 \pm 0,5$ & $1,1 \pm 1,1$ & $1,3 \pm 2,1$ \\
\hline $\mathrm{NO}_{3}^{-}\left(\mathrm{mg} \mathrm{N} \mathrm{L}^{-1}\right)$ & $3,9 \pm 4,4$ & $5,1 \pm 5,4$ & $9,8 \pm 12,1$ \\
\hline PT $\left(\mathrm{mg} \mathrm{P} \mathrm{L}^{-1}\right)$ & $19,7 \pm 9,0$ & $18,4 \pm 5,7$ & $10,1 \pm 5,9$ \\
\hline
\end{tabular}

La Tabla 3.3 también muestra los promedios y desviaciones estándar de los contaminantes a través de las distintas etapas del sistema de tratamiento. Las desviaciones estándar han sido muy elevadas en la entrada del sistema para todos los contaminantes y han disminuido progresivamente a lo largo del sistema de tratamiento. $\mathrm{NO}_{2}^{-}$y $\mathrm{NO}_{3}{ }^{-}$han sido la excepción, con 
un incremento de la media y la desviación estándar desde la entrada hasta la salida del humedal artificial debido a la generación de estos compuestos dentro del sistema.

El comportamiento de PT también ha diferido del resto de contaminantes en la salida, donde la desviación estándar se ha mantenido similar a la del punto Salida-FS aunque ha mostrado menores concentraciones promedio de salida del humedal artificial. Esta desviación estándar se ha debido a la pérdida de la capacidad de retención de PT en la última etapa del humedal, donde se ha registrado un amplio rango de concentraciones desde el comienzo del periodo de operación en el sistema (cuando la retención de PT ha sido elevada y la concentración de salida ha sido mínima) hasta el final del periodo de estudio (cuando la retención de PT ha disminuido y la concentración de salida ha sido máxima). Se han llegado a encontrar muestreos en los que la concentración de PT de salida es superior a la concentración de entrada.

Los valores promedio de entrada de los contaminantes se han situado por debajo del promedio de valores encontrados en otros estudios sobre la depuración del agua residual de origen ganadero mediante humedales artificiales (Tabla 3.4). Los valores promedio de entrada de los contaminantes NTK, $\mathrm{NH}_{4}{ }^{+}$, NT y PT (Tabla 3.3) han sido similares a los valores mínimos de entrada encontrados en la bibliografía y se sitúan por debajo del valor promedio (Tabla 3.4). Los valores de SST, $\mathrm{DBO}_{5}$ y DQO (Tabla 3.3) han sido en general inferiores a los encontrados en otros humedales, solo por encima de los aportados por Dan y col. (2011).

Las concentraciones promedio de salida de $\mathrm{SST}, \mathrm{DBO}_{5}$ y DQO se han encontrado por debajo de los valores límite de emisión establecidos en el Real Decreto 849/1986 (80, 40 y $160 \mathrm{mg} \mathrm{L}^{-1}$ respectivamente) cuando el caudal de vertido es superior a la décima parte del caudal mínimo circulante por el cauce receptor. Los valores promedio de $\mathrm{NO}_{3}^{-}$y PT (Tabla 3.3) se han encontrado justo en el límite establecido en el Real Decreto 849/1986 (10 $\mathrm{mg} \mathrm{L}^{-1}$ para ambos contaminantes), aunque la desviación estándar de la salida indica que se ha incumplido la legislación con frecuencia.

Tabla 3.4. Concentraciones de entrada $\left(\mathrm{mg} \mathrm{L}^{-1}\right)$ de contaminantes analizados en varios humedales artificiales para el tratamiento de agua residual de origen ganadero. Los acrónimos indican: LWDB, Livestock wastewater treatment database; HFS, Humedal de flujo superficial; HFSH, Humedal de flujo subsuperficial horizontal; MPM, Marsh-Pond-Marsh.

\begin{tabular}{|c|c|c|c|c|c|c|c|c|}
\hline Tipo humedal & $\mathrm{SST}$ & $\mathrm{DBO}_{5}$ & DQO & NTK & $\mathrm{NH}_{4}^{+}$ & NT & $\mathrm{PT}$ & Referencia \\
\hline \multicolumn{9}{|l|}{ Lecherías } \\
\hline LWDB & 1111 & 442 & & & 105 & 103 & & Knight y col. (2000) \\
\hline HFS & 2307 & 220 & & 227 & 126 & & 59,3 & Geary y Moore (1999) \\
\hline HFS & 911 & 242 & & 289 & 188 & & & Karpiscak y col. (1999) \\
\hline HFS & 1284 & 2683 & & 102,6 & & & 25,7 & Newman y col. (2000) \\
\hline HFS & 1645 & 1914 & & 164 & & & 52,6 & Schaafsma y col. (2000) \\
\hline HFS & 980 & 2629 & & & 48 & & 18,5 & Dunne y col. (2005) \\
\hline HFSH & 690 & 451 & 1219 & 64,7 & 22,4 & & 12,8 & Mantovi y col. (2003) \\
\hline MPM & 1450 & 1747 & & 237 & 188 & & 36,9 & Jamieson y col. (2007) \\
\hline \multicolumn{9}{|l|}{ Porcino } \\
\hline LWDB & 128 & 104 & & & 366 & 407 & & Knight y col. (2000) \\
\hline HFS & & & & & 118 & 134 & 30 & Stone y col. (2002) \\
\hline HFSH & 519 & 411 & 1160 & 204 & 185 & 208 & 40,3 & Lee y col. (2004) \\
\hline HFSH & & & 3167 & & & 230 & 265 & Meers y col. (2005) \\
\hline HFSH & & & 4413 & 709 & 615 & & 44 & González y col. (2009) \\
\hline HFSH & & 28 & 126 & & 163 & 478 & 135 & Dan y col. (2011) \\
\hline HFSH & & & 870 & & & 447 & 17 & Borin y col. (2013) \\
\hline
\end{tabular}

\subsubsection{Tratamiento del agua residual}


La eficiencia de las unidades de tratamiento del sistema a escala piloto y del sistema en su conjunto en el tratamiento del agua residual está representada en la Tabla 3.5 mediante los índices de eliminación para cada contaminante. Los valores de desviación estándar proporcionan información sobre la variación de la eficiencia del tratamiento durante el periodo de operación.

La unidad de flujo superficial (FS) ha demostrado ser efectiva y estable únicamente en la eliminación de los SST. Su eficacia ha resultado ser moderada y variable en el caso del tratamiento de $\mathrm{DBO}_{5}$ y DQO y nula en el caso del tratamiento de compuestos de nitrógeno y PT. Los altos valores de la desviación estándar para estos contaminantes, particularmente elevada en el caso del PT, indican que la capacidad de tratamiento de esta unidad ha cambiado de forma importante a lo largo del periodo de estudio.

Las unidades de flujo subsuperficial (FSS) han mejorado el nivel de tratamiento del agua residual de todos los contaminantes con la excepción de los SST para los que el índice de eliminación promedio negativo indica un incremento de la concentración de SST en la salida de la unidad, aunque este incremento no haya sido importante $\left(37,1 \pm 23,5 \mathrm{mg} \mathrm{L}^{-1}\right.$ en la salida-FS y $29,5 \pm 17,9 \mathrm{mg} \mathrm{L}^{-1}$ en la salida del sistema).

El tratamiento de $\mathrm{DBO}_{5}$ y DQO en las unidades FSS se ha mantenido en niveles similares a los de la unidad FS. La combinación de los dos tipos de unidades ha permitido un tratamiento de la materia orgánica promedio elevado y estable para todo el sistema MJEA ${ }^{\circledR}$. El tratamiento promedio de los compuestos de nitrógeno y el PT ha aumentado significativamente en las unidades FSS y los valores de desviación estándar se han reducido con respecto a los de la unidad FS. La combinación de los dos tipos de unidades ha permitido incrementar la capacidad de tratamiento promedio de los compuestos de nitrógeno en el sistema a escala piloto.

En general los índices de eliminación promedio para todo el sistema de tratamiento (MJEA ${ }^{\circledR}$ ) han sido similares a los encontrados en otros humedales artificiales para el tratamiento de agua residual de origen ganadero (Tabla 3.1).

Tabla 3.5. Índices de eliminación promedio para la unidad FS, las unidades FSS y el sistema a escala piloto $\left(\mathrm{MJEA}^{\circledR}\right)$.

\begin{tabular}{lccc}
\hline \multicolumn{1}{c}{ Parámetros } & Unidad FS & Unidades FSS & MJEA $^{(}$ \\
\hline SST $_{\text {DBO }}$ & $82,8 \pm 9,3$ & $-37,6 \pm 160,6$ & $82,8 \pm 15,9$ \\
DQO & $44,7 \pm 35,7$ & $52,8 \pm 56,9$ & $81,7 \pm 13,0$ \\
NTK & $36,1 \pm 31,2$ & $35,5 \pm 28,1$ & $64,2 \pm 15,6$ \\
$\mathrm{NH}_{4}{ }^{+}$ & $-6,8 \pm 42,7$ & $40,5 \pm 38,9$ & $43,1 \pm 34,6$ \\
NT & $5,5 \pm 44,3$ & $29,0 \pm 32,3$ & $47,7 \pm 44,3$ \\
PT & $1,7 \pm 33,6$ & $38,9 \pm 26,1$ & $43,9 \pm 28,9$ \\
\hline
\end{tabular}

\subsubsection{Tratamiento de sólidos}

Los resultados de los muestreos para SST y SSV en función del año de operación y el punto de muestreo se muestran en la Figura 3.6. La fracción orgánica de los SST, medida como la proporción de SSV en los SST, ha oscilado entre 0 y $100 \%$ durante todo el periodo de estudio. Ambos contaminantes han mostrado una disminución de la concentración de entrada entre 2006 y 2008 como consecuencia de las diluciones utilizadas cada año para alcanzar la carga de nitrógeno objetivo.

Tanto las concentraciones de SST como las de SSV se han reducido de forma importante tras el paso del agua residual por la unidad FS. Esta reducción de la concentración se ha debido probablemente a procesos de sedimentación e intercepción favorecidos por la baja carga 
hidráulica, la presencia de macrófitos y el elevado TRH. Como resultado se han obtenido unos índices de eliminación elevados para esta etapa durante todo el periodo de estudio (Figura 3.7). Los sólidos liberados por un HFS no están relacionados con los sólidos de entrada, sino que se deben a fenómenos de resuspensión o son generados en el interior del sistema como detritos de macrófitos (Kadlec y Wallace, 2009). Esta independencia entre las concentraciones de SST de entrada y salida explica la débil relación entre ambas variables que se ha encontrado en la unidad FS $\left(R^{2}=0,29\right)$ (Figura 3.8).

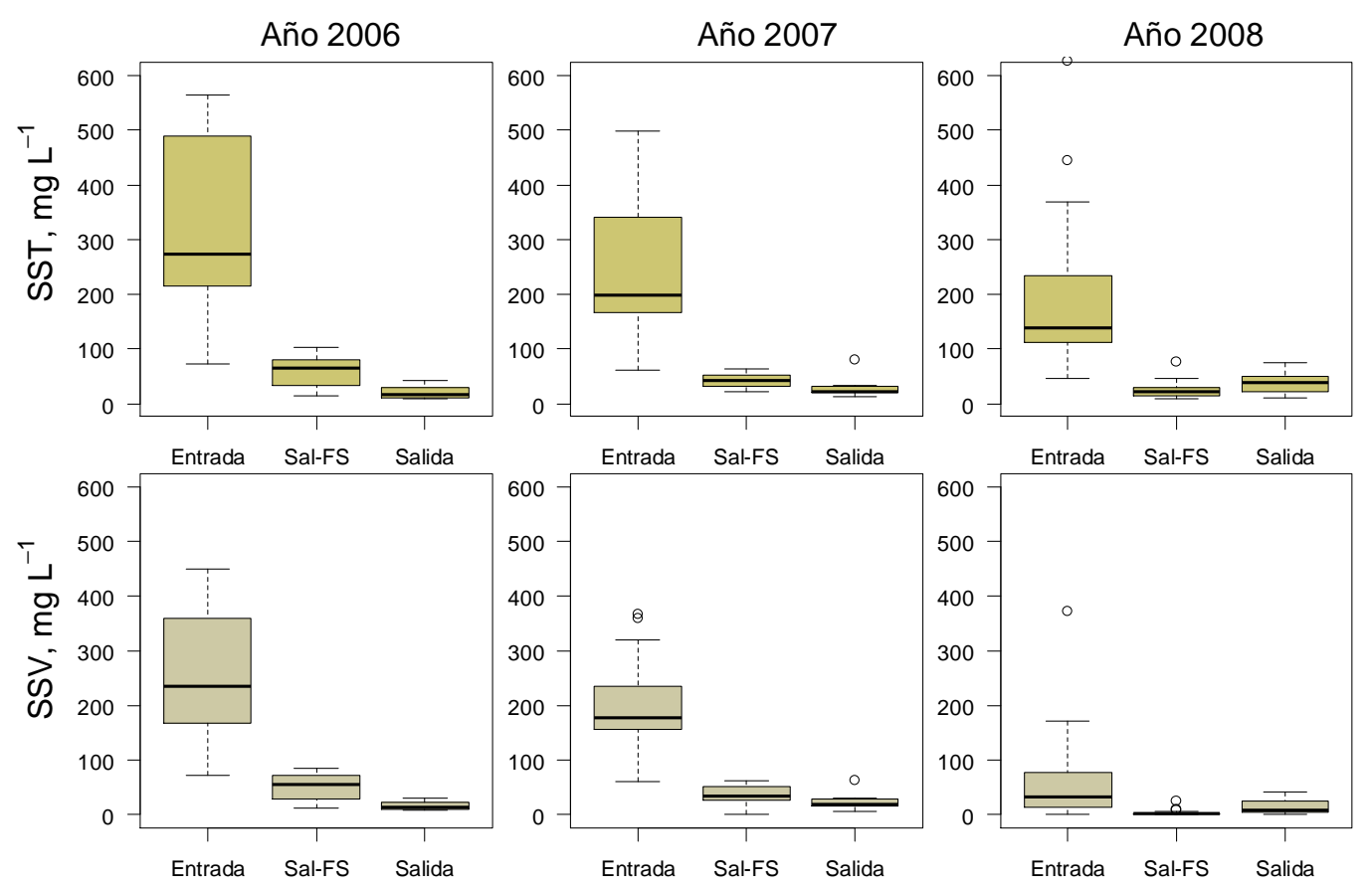

Figura 3.6. Diagramas de caja de los resultados de los muestreos para los parámetros SST y SSV por año y punto de muestreo.
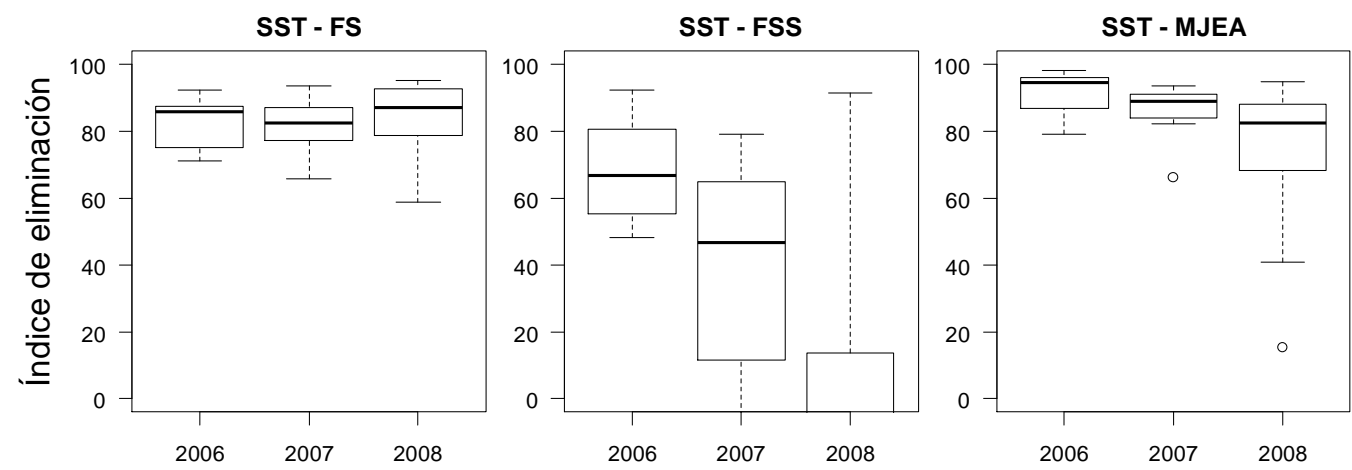

Figura 3.7. Diagramas de caja de los índices de eliminación por año y etapa del sistema.

El paso del agua residual por las unidades FSS ha permitido una mayor reducción de los sólidos durante 2006 y 2007. La capacidad de tratamiento de esta unidad se ha reducido progresivamente entre 2006 y 2008, año en el que los índices de eliminación pasan a ser negativos (Figura 3.7). Esta pérdida de la capacidad de tratamiento está producida por una reducción de la concentración de entrada en combinación con la existencia de una concentración de fondo cercana al valor promedio de $29,5 \mathrm{mg} \mathrm{L}^{-1}$ similar para todos los años de muestreo que puede apreciarse en las Figuras 3.6 y 3.9. 

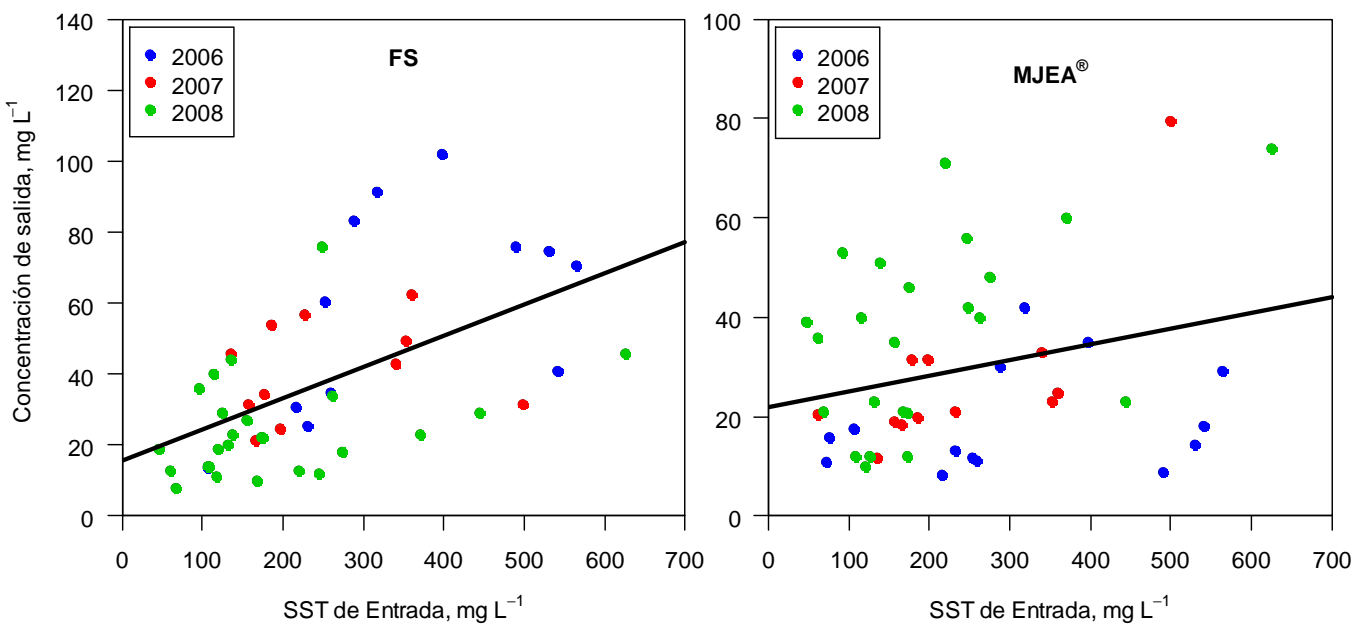

Figura 3.8. Concentración de entrada de SST frente a concentración de salida de SST y regresión lineal para la unidad FS $\left(R^{2}=0,29\right)$ y el sistema a escala piloto $\left(R^{2}=0,05\right)$.

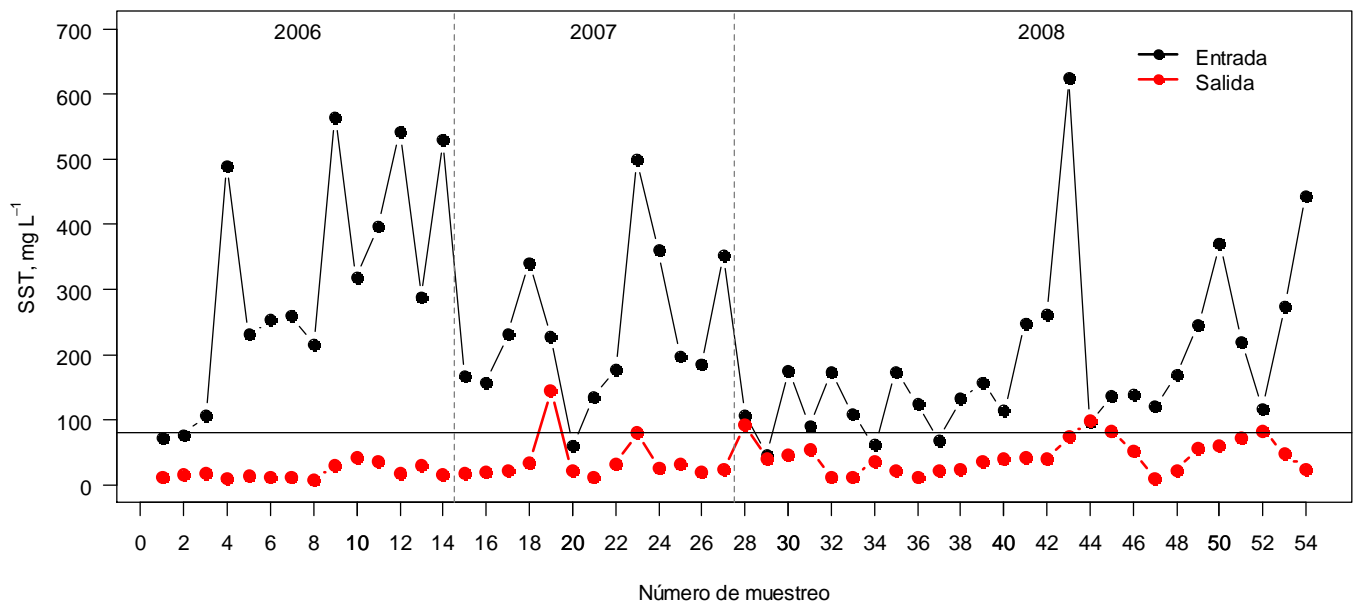

Figura 3.9. Concentración de entrada y salida de SST por muestreo. Las líneas de puntos verticales indican la separación entre los años de muestreo. La línea horizontal indica el límite de vertido de $80 \mathrm{mg} \mathrm{L}^{-1}$.

En el caso de los SST, la concentración de fondo representa los procesos de generación del contaminante dentro del humedal artificial tales como descomposición, resuspensión o la existencia de una fracción recalcitrante. La generación de sólidos en humedales de tipo HFSH es un fenómeno común que tiene su origen en la biomasa microbiana que se forma con la incorporación de materia orgánica y nutrientes en el agua residual. Los sólidos que salen de un humedal tipo HFSH no están relacionados con los sólidos de entrada, sino que están producidos por la descomposición y resuspensión de partículas de biomasa en el interior del sistema (Kadlec y Wallace, 2009).

Los índices de eliminación para el sistema en su conjunto han disminuido progresivamente entre 2006 y 2008 (Figura 3.7). La concentración de salida de los SST del sistema MJEA ${ }^{\circledR}$ a escala piloto es independiente de la concentración de entrada $\left(R^{2}=0,05\right.$; Figura 3.8), y se mantiene cercana al valor promedio de la concentración de fondo pese a las amplias variaciones del afluente (Figura 3.9). Esto sugiere que la reducción del valor de los índices de eliminación se debe al incremento de la dilución de la concentración de entrada entre 2007 y 2008. Las concentraciones de salida de SST se han mantenido por debajo del límite de vertido de 
$80 \mathrm{mg} \mathrm{L}^{-1}$ en la mayor parte de los muestreos, aunque este umbral se ha superado ligeramente y de forma puntual (Figura 3.9).

\subsubsection{Tratamiento de materia orgánica}

La materia orgánica analizada como $\mathrm{DBO}_{5}$ y $\mathrm{DQO}$ en la entrada del sistema se ha reducido entre 2006 y 2008 como resultado de las diluciones utilizadas durante el periodo de estudio. Tanto las concentraciones como los índices de eliminación de las distintas etapas del humedal han seguido un patrón similar para $\mathrm{DBO}_{5}$ y DQO (Figuras 3.10 y 3.11). Para ambos contaminantes la reducción de la concentración más importante ha tenido lugar en la unidad FS. (Figura 3.10).

En el caso de la $\mathrm{DBO}_{5}$, las concentraciones de salida de la unidad FS se han mantenido en un rango similar durante 2007 y 2008 (Figura 3.10). Unas concentraciones de salida estables indican la presencia de una concentración de fondo para la materia orgánica que el sistema no puede reducir. Las concentraciones de oxígeno disuelto a la entrada y la salida de la unidad FS sugieren que los organismos aerobios consumen el oxígeno rápidamente. El hecho de que los potenciales de oxido-reducción a lo largo del humedal hayan sido siempre inferiores a los $300 \mathrm{mV}$ indica que la degradación de la materia orgánica ha tenido lugar principalmente en condiciones anóxicas o anaerobias. El rango de potencial de oxidación-reducción registrado en la columna de agua del humedal artificial durante el periodo de estudio se ha encontrado entre 270 y $-250 \mathrm{mV}$, aunque se esperan valores superiores en la rizosfera de Typha latifolia, por lo que es probable que en la degradación de la materia orgánica hayan participado microorganismos con metabolismos muy diferentes (aerobios, desnitrificantes, reductores de Fe y Mn, sulfatoreductores y metanógenos).
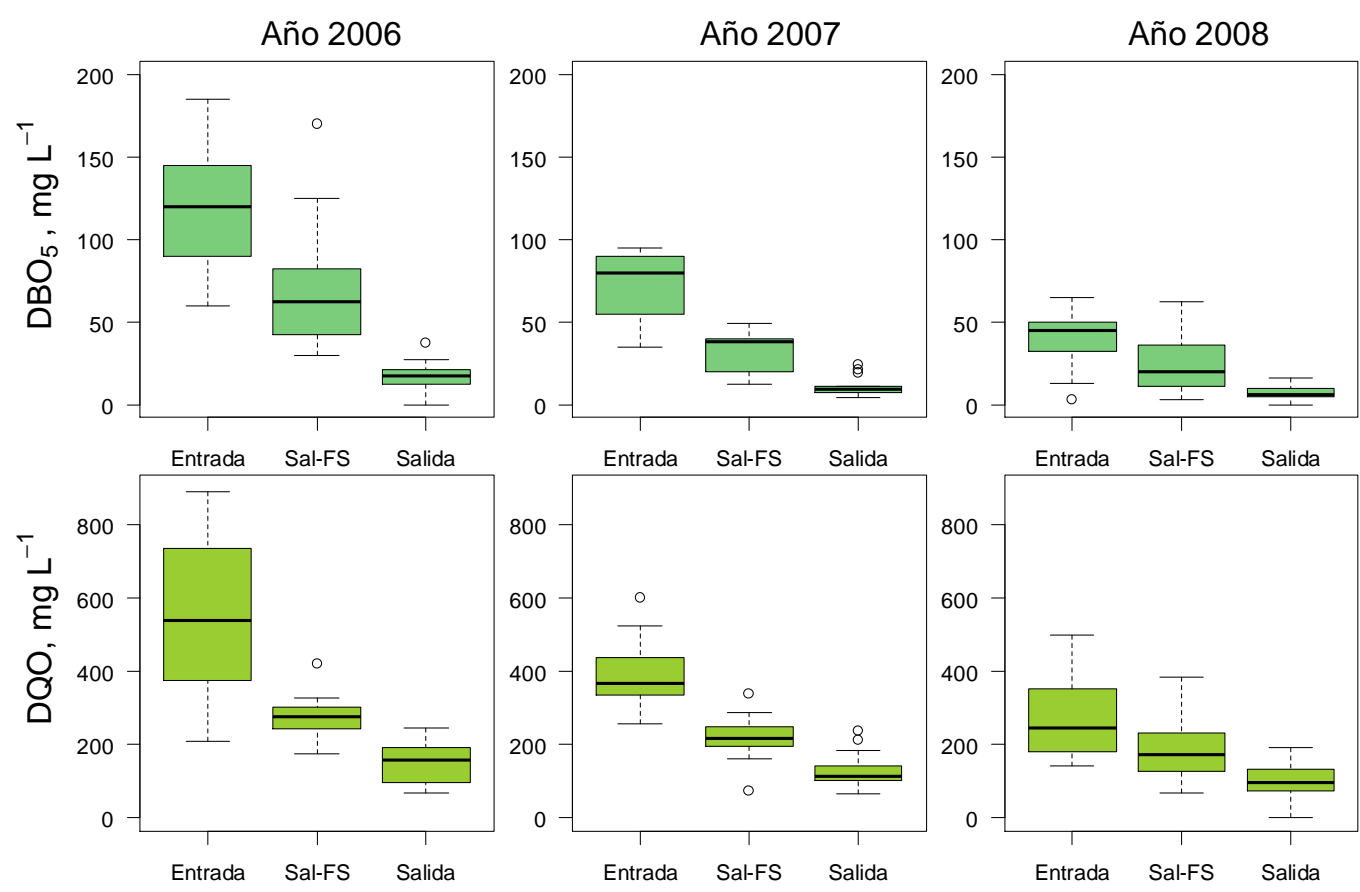

Figura 3.10. Diagramas de caja de los resultados de los muestreos para los parámetros $\mathrm{DBO}_{5}$ y DQO por año y punto de muestreo.

La relación entre las concentraciones de entrada y de salida de $\mathrm{DBO}_{5}$ en la unidad FS es directamente proporcional, con un coeficiente de correlación de 0,56 (Figura 3.12). Resulta complicado predecir la concentración de salida en función de la concentración de entrada 
cuando existe una comunidad bacteriana tan diversa que participa en la degradación de la materia orgánica.

La relación $\mathrm{DBO}_{5} / \mathrm{DQO}$ es un indicador de la degradabilidad de la materia orgánica. Un ratio de 0,5 o superior indica que la materia orgánica es fácilmente biodegradable mientras que un ratio inferior a 0,3 indica que la materia orgánica es difícilmente biodegradable en el tratamiento del agua residual (Tchobanoglous y col., 2003). En este sistema la relación $\mathrm{DBO}_{5} / \mathrm{DQO}$ de entrada promedio ha sido de 0,19 $\pm 0,07$ lo que indica que una alta proporción de materia orgánica medida como DQO en el agua residual es difícilmente biodegradable. El valor de la correlación de Pearson entre los índices de eliminación de DQO y SST ha sido de 0,70 en la unidad FS, lo que sugiere que gran parte de la DQO en la entrada del humedal se ha encontrado en forma particulada y ha seguido los mismos procesos de eliminación de los SST. Los sólidos de salida de un HFS son independientes de la concentración de entrada de sólidos, lo que explicaría la débil relación $\left(R^{2}=0,22\right)$ de la DQO entre las concentraciones de entrada y salida de la unidad FS (Figura 3.12).
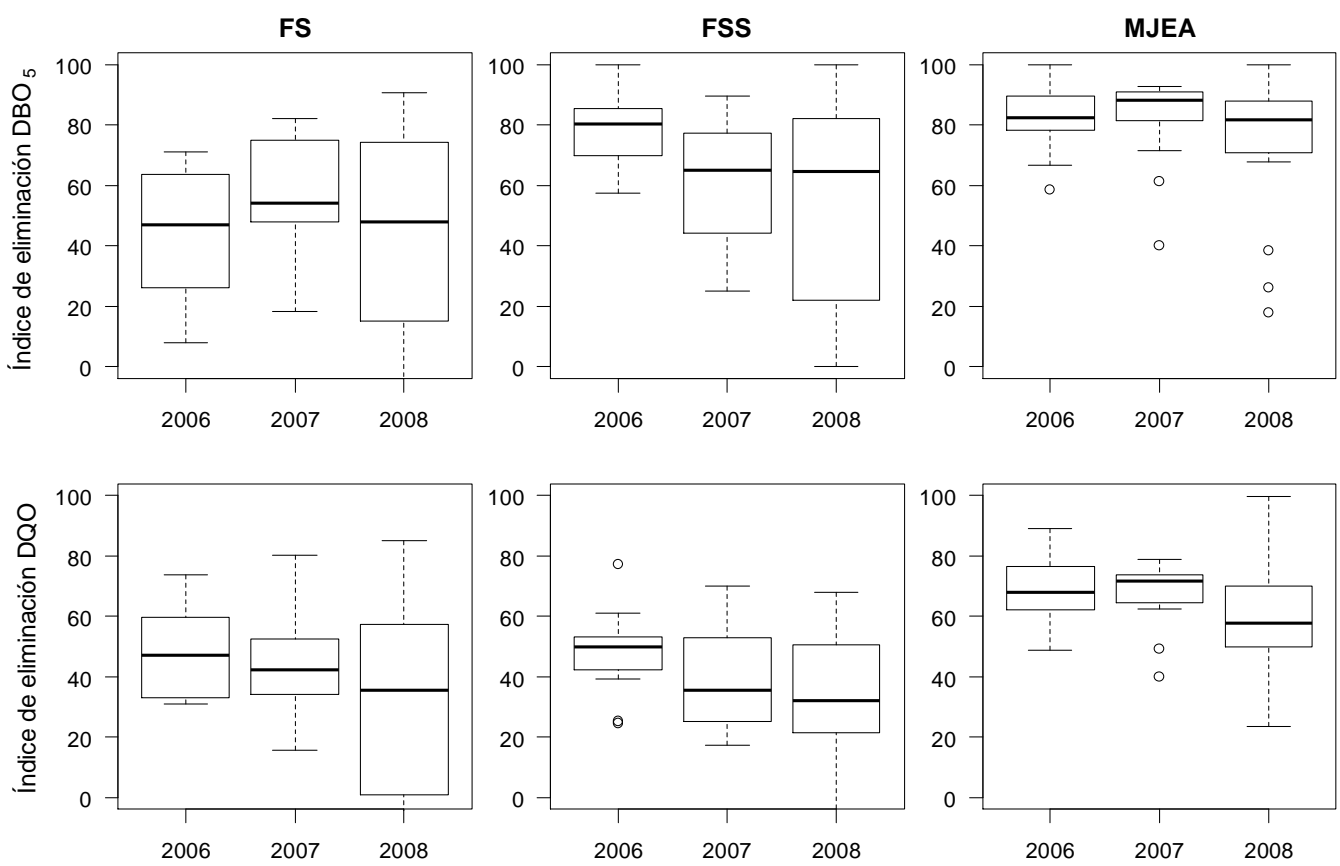

Figura 3.11. Diagramas de caja de los índices de eliminación por año y etapa del sistema para los parámetros $\mathrm{DBO}_{5}$ y DQO.

Los índices de eliminación de $\mathrm{DBO}_{5}$ han sido superiores a los de DQO tanto en las unidades FS y FSS como en el sistema al completo (MJEA), lo cual se puede atribuir a la mayor capacidad de degradación de la materia orgánica fácilmente biodegradable (Figura 3.11). En los tres casos se ha producido una reducción de los índices de eliminación de $\mathrm{DBO}_{5}$ y DQO, más evidente en 2008, que probablemente se debe al efecto combinado de la dilución de la concentración de entrada con la existencia de una concentración de fondo estable en la salida (Figuras 3.10 y $3.11)$.

La existencia de una concentración de fondo se aprecia claramente en el caso de la concentración de salida de $\mathrm{DBO}_{5}$ (Figura 3.12). En la unidad FS la concentración de salida de $\mathrm{DBO}_{5}$ se encuentra en el rango $0-50 \mathrm{mg} \mathrm{L}^{-1}$ para concentraciones de entrada inferiores a $100 \mathrm{mg} \mathrm{L}^{-1}$. En las unidades FSS y el sistema al completo (MJEA) la concentración de salida se encuentra en el rango $0-25 \mathrm{mg} \mathrm{L}^{-1}$ para concentraciones de entrada inferiores a $50 \mathrm{y}$ $100 \mathrm{mg} \mathrm{L}^{-1}$ respectivamente (Figura 3.12). 

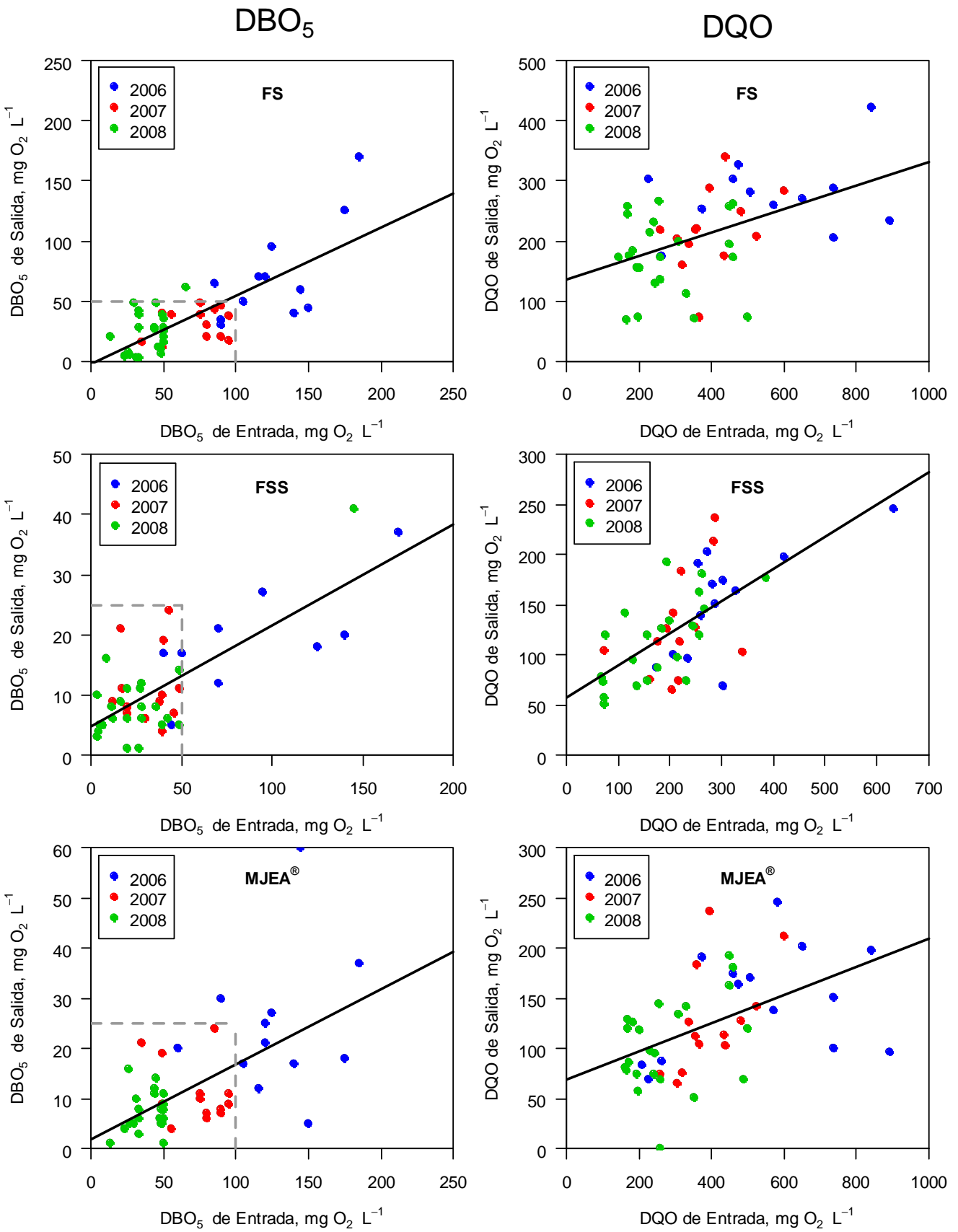

Figura 3.12. Concentración de entrada frente a concentración de salida de los parámetros $\mathrm{DBO}_{5}$ y DQO y regresión lineal para DBO $\mathrm{D}_{5}$ en la unidad FS $\left(R^{2}=0,56\right)$, DQO en la unidad FS $\left(R^{2}=0,22\right)$, $\mathrm{DBO}_{5}$ en las unidades FSS $\left(R^{2}=0,56\right)$, DQO en las unidades FSS $\left(R^{2}=0,43\right), \mathrm{DBO}_{5}$ en el sistema a escala piloto $\left(R^{2}=0,33\right)$ y DQO en el sistema a escala piloto $\left(R^{2}=0,22\right)$.

El valor de la correlación de la $\mathrm{DBO}_{5}$ entre las concentraciones de entrada y salida es similar en las unidades FS y FSS $\left(R^{2}=0,56\right)$, lo que indica que en ambas unidades se mantienen los mismos mecanismos de degradación de la materia orgánica. En el caso de la DQO la correlación entre entrada y salida ha aumentado en las unidades FSS $\left(R^{2}=0,43\right)$ con respecto a la unidad FS $\left(R^{2}=0,22\right)$ (Figura 3.12). 
Las correlaciones entre las concentraciones de entrada y salida han sido muy débiles para el conjunto del sistema a escala piloto para $\operatorname{DBO}_{5}\left(R^{2}=0,33\right)$ y DQO $\left(R^{2}=0,22\right)$ debido a que la combinación de las etapas FS y FSS enmascaran los resultados obtenidos por cada etapa de forma individual (Figura 3.12).

En general las concentraciones de salida de $\mathrm{DBO}_{5}$ se han mantenido por debajo del límite legal de vertido de $40 \mathrm{mg} \mathrm{L}^{-1}$ en la mayor parte de los muestreos, siendo ligeramente superado de forma puntual, mientras que en el caso de la DQO el límite de vertido de $160 \mathrm{mg} \mathrm{L}^{-1}$ ha sido superado de forma ligera en 12 de los 54 muestreos (máximo de diferencia con el límite legal de vertido de $20 \mathrm{mg} \mathrm{L}^{-1}$ ) incluso durante el año 2008 en el que la concentración de entrada era menor (Figura 3.13).
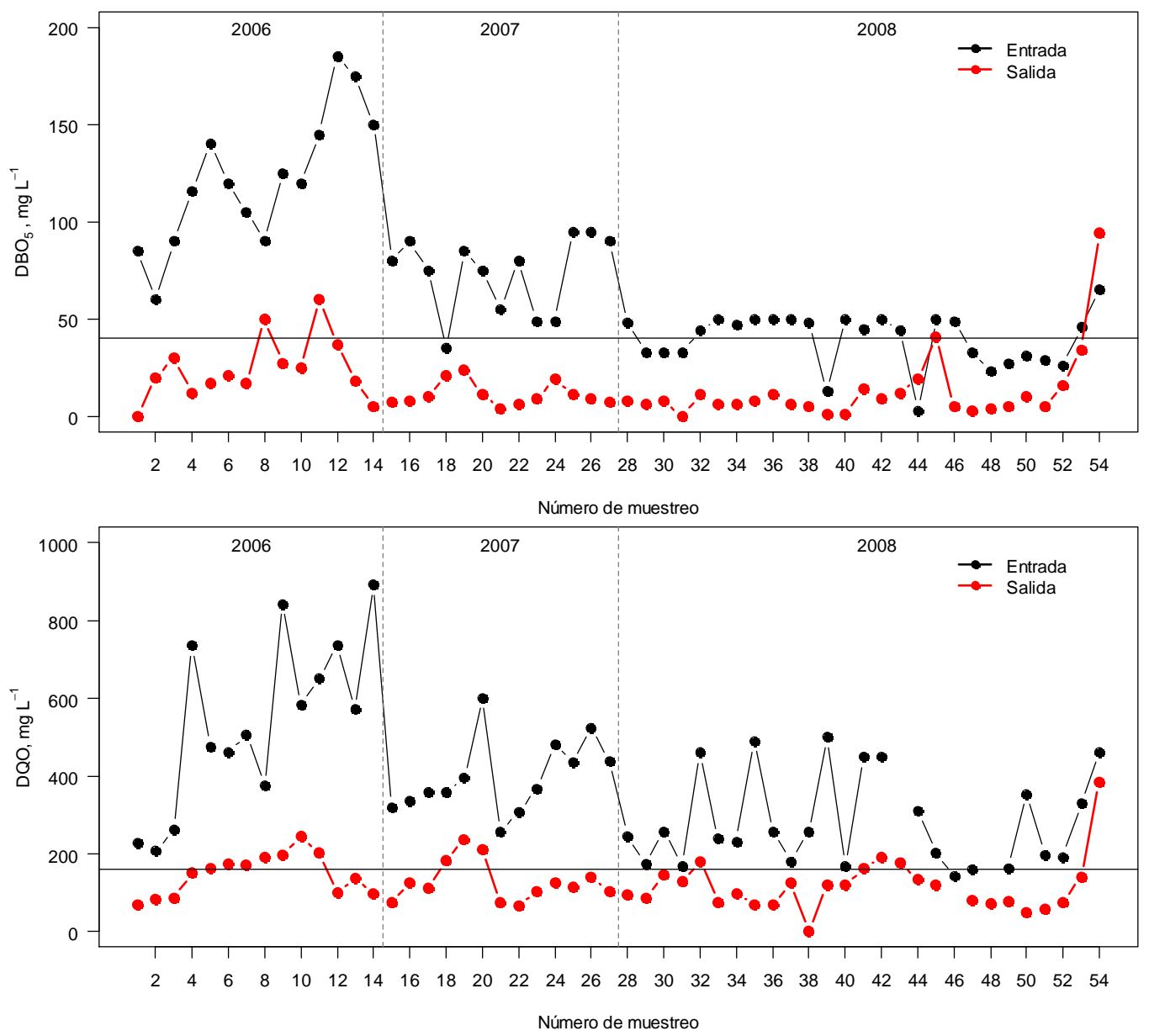

Figura 3.13. Concentración de entrada y salida de $\mathrm{DBO}_{5}$ y DQO por muestreo. Las líneas de puntos verticales indican la separación entre los años de muestreo. La línea horizontal indica el límite de vertido de $40 \mathrm{mg} \mathrm{L}^{-1}$ para $\mathrm{DBO}_{5}$ y $160 \mathrm{mg} \mathrm{L}^{-1}$ para DQO.

\subsubsection{Tratamiento de nitrógeno}

Los valores mínimo, máximo, los valores atípicos, los cuartiles y la mediana de las concentraciones de los compuestos de nitrógeno analizados son representados mediante diagramas de cajas en la Figura 3.14. Las concentraciones de entrada al sistema a escala piloto de NTK, $\mathrm{NH}_{4}{ }^{+}$y NT además de nitratos y nitritos representados conjuntamente como óxidos de nitrógeno $\left(\mathrm{NO}_{\mathrm{x}}^{-}\right)$han disminuido progresivamente cada año de operación como consecuencia de las diluciones empleadas para alcanzar la carga de nitrógeno objetivo. 

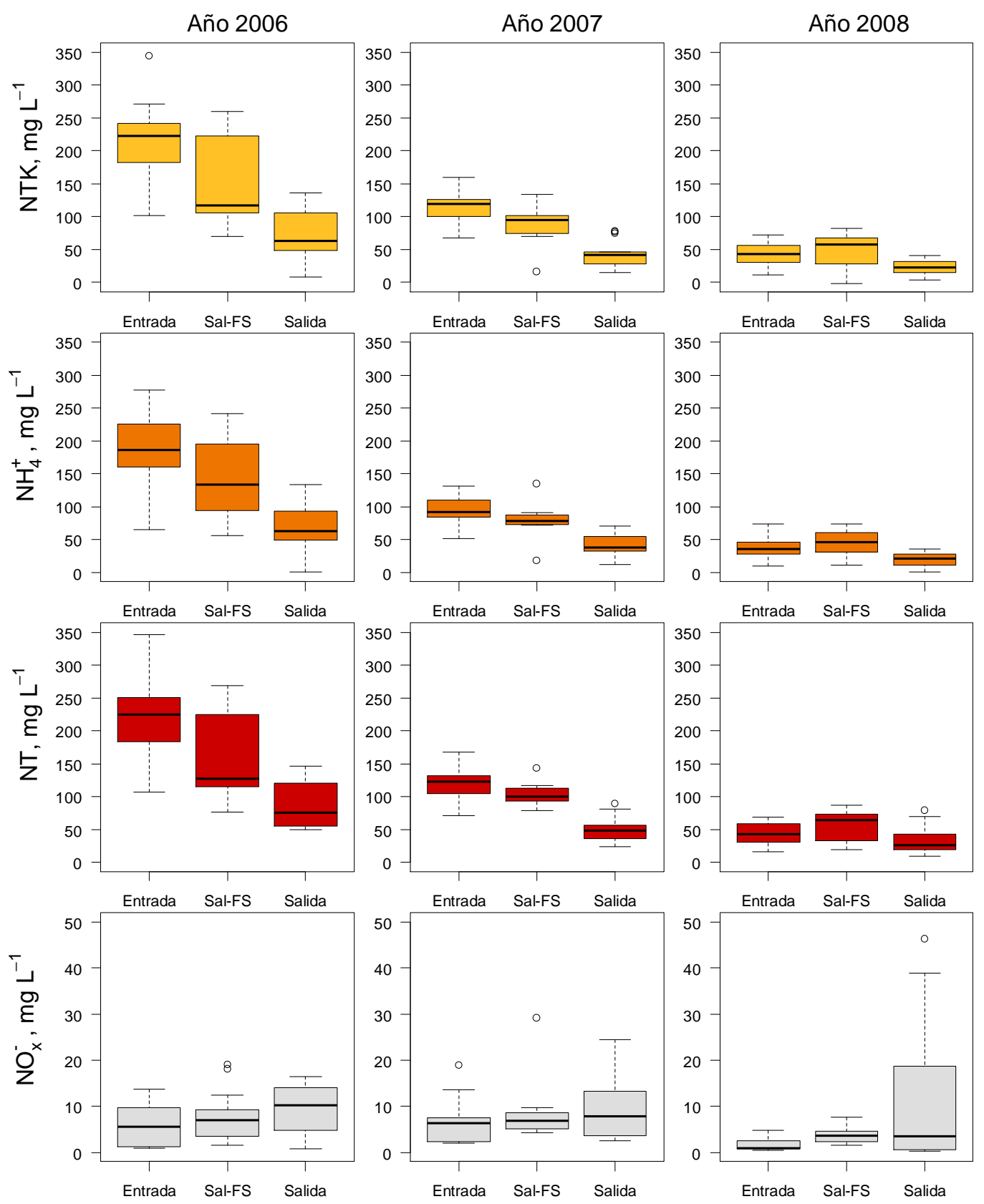

Figura 3.14. Diagramas de caja de los resultados de los muestreos para los parámetros $\mathrm{NTK}, \mathrm{NH}_{4}{ }^{+}$, NT y $\mathrm{NO}_{\mathrm{x}}^{-}$(suma de $\mathrm{NO}_{2}^{-} \mathrm{y} \mathrm{NO}_{3}^{-}$) por año y punto de muestreo.

El rango de concentraciones de salida de la unidad FS durante 2006 ha sido muy superior al de los años 2007 y 2008 como consecuencia de una concentración de entrada mucho más variable. La diferencia entre las concentraciones de entrada y salida de la unidad FS para NTK, $\mathrm{NH}_{4}^{+}$y NT se ha reducido entre 2006 y 2007, y ha sido negativa (la concentración de salida ha sido superior a la de entrada) en 2008.

La concentración de salida de $\mathrm{NO}_{\mathrm{x}}{ }^{-}$de la unidad FS ha sido superior a la concentración de entrada al sistema durante todo el periodo de muestreo aunque estas concentraciones no han sido una parte importante del contenido de NT (Figura 3.15). Los valores de salida del sistema completo siempre se han reducido con respecto a los valores de salida de la unidad FS para 
todos los compuestos de nitrógeno con la excepción de $\mathrm{NO}_{\mathrm{x}}{ }^{-}$que siempre se ha incrementado (Figura 3.14).

La Figura 3.15 muestra el contenido relativo de $\mathrm{NH}_{4}{ }^{+}$, nitrógeno orgánico y $\mathrm{NO}_{\mathrm{x}}{ }^{-}$como parte del NT. En el humedal artificial el nitrógeno se ha encontrado predominantemente en forma amoniacal, cuyo contenido promedio es superior al de la composición típica del agua residual porcina para NT, que suele encontrarse entre un 60 y un 75\% (Levasseur, 1998). La proporción de $\mathrm{NH}_{4}{ }^{+}$se ha mantenido en torno al $80 \%$, aunque disminuye ligeramente en la salida del sistema. El mayor cambio en la composición de NT en el sistema se produce en el descenso de nitrógeno orgánico y el aumento de $\mathrm{NO}_{\mathrm{x}}{ }^{-}$en la salida del sistema que llega a alcanzar el $20 \%$ del NT.

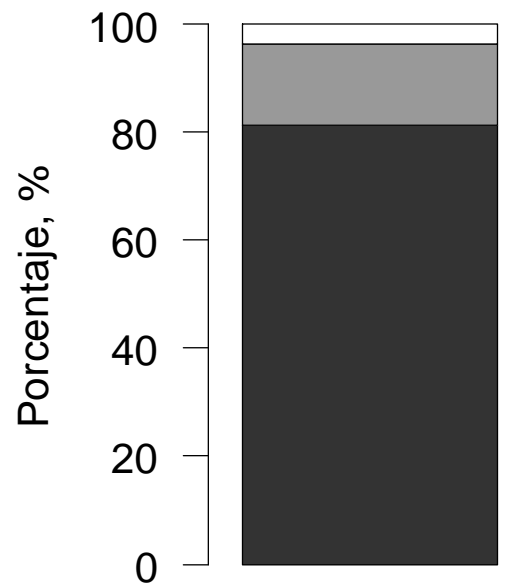

Entrada

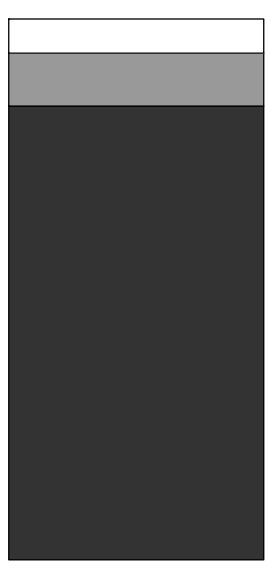

SalidaFS

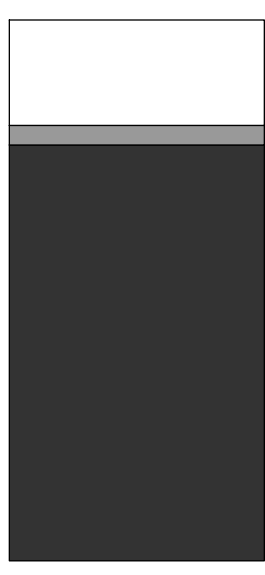

Salida

Figura 3.15. Valores promedio de composición de NT en los puntos de muestreo. Norg equivale a nitrógeno orgánico.

Los índices de eliminación para las concentraciones de $\mathrm{NT}$, que engloban $\mathrm{N}_{\mathrm{org}}, \mathrm{NH}_{4}{ }^{+} \mathrm{y} \mathrm{NO}_{\mathrm{x}}{ }^{-}$, se muestran en la Figura 3.16. En la unidad FS los índices de eliminación han sido muy bajos durante todo el periodo de estudio y se han reducido entre 2006 y 2008, año en el que algún componente del NT ha sido generado dentro de la primera etapa de tratamiento del purín. La mayor reducción de nitrógeno en el sistema ha tenido lugar en las unidades FSS con un índice de eliminación de NT relativamente estable para todo el periodo de estudio en torno a 49. La capacidad de tratamiento para el sistema en su conjunto se reduce entre 2006 y 2008 como consecuencia de la pérdida de la capacidad de tratamiento de la unidad FS.

Se ha encontrado una fuerte relación entre las concentraciones de entrada y de salida de NT en el sistema MJEA ${ }^{\circledR}$ y en las unidades FS y FSS (Figura 3.17). Los datos se dividen claramente en tres grupos correspondientes a cada año de muestreo. El grupo de muestreos del año 2006 indica cierta capacidad de tratamiento que disminuye en 2007 y es nula en 2008. En este año se alcanza la concentración de fondo de las distintas etapas del sistema que se sitúa en el rango 0 - $50 \mathrm{mg} \mathrm{L}^{-1}$ para la unidad FS y $0-25 \mathrm{mg} \mathrm{L}^{-1}$ para las unidades FSS y el sistema completo cuando las concentraciones de entrada se encuentran entre 0 y $50 \mathrm{mg} \mathrm{L}^{-1}$. 

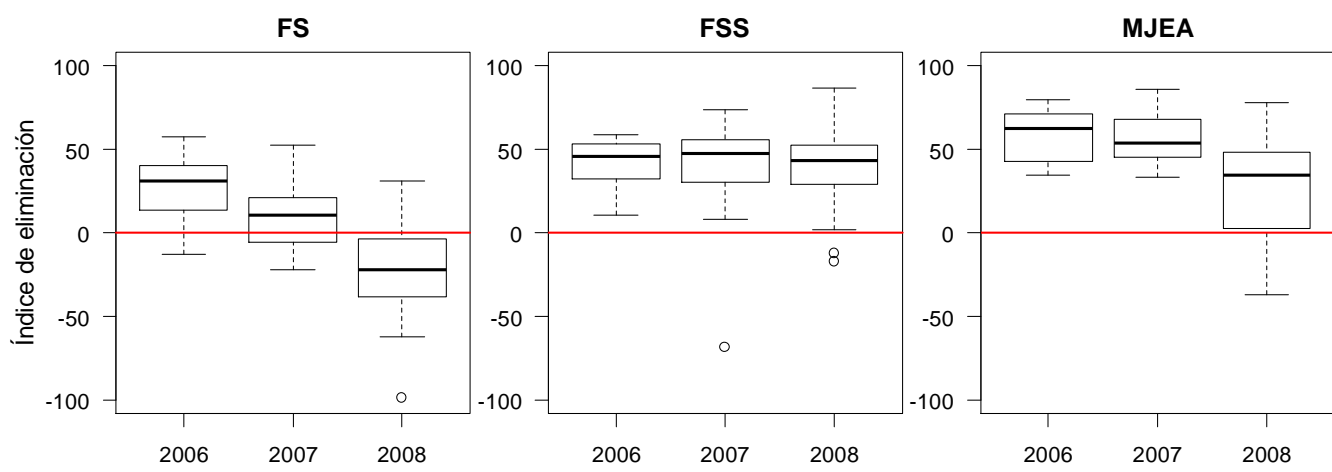

Figura 3.16. Diagramas de caja de los índices de eliminación por año y etapa del sistema para el parámetro NT.
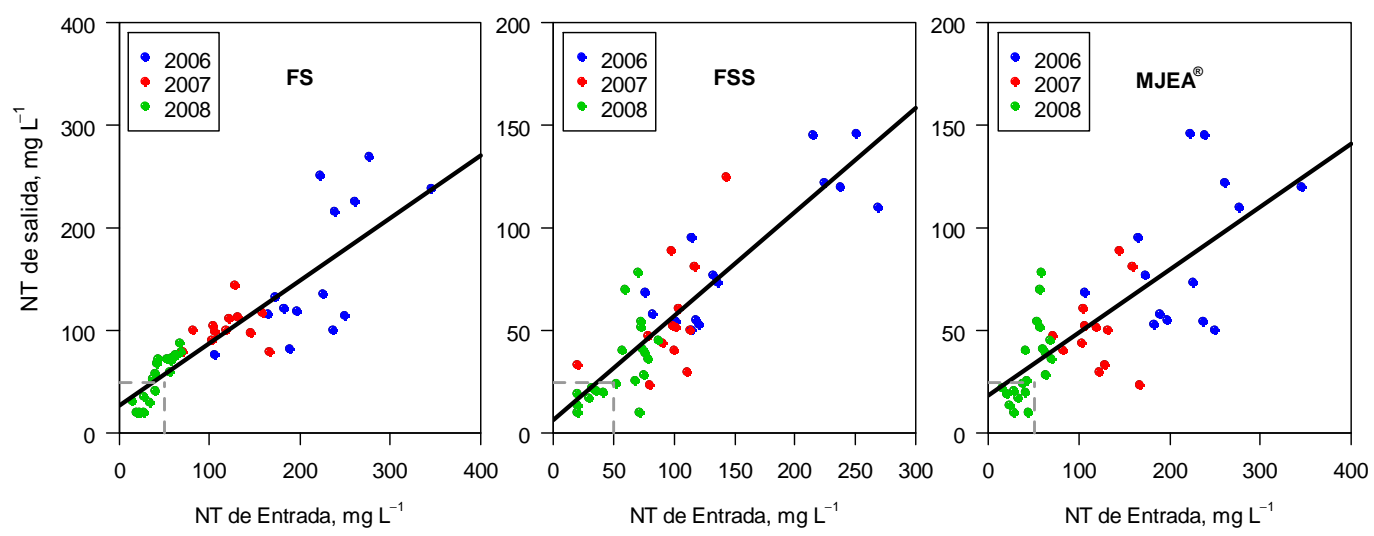

Figura 3.17. Concentración de entrada frente a concentración de salida del parámetro NT y regresión lineal para la unidad FS $\left(R^{2}=0,74\right)$, las unidades FSS $\left(R^{2}=0,73\right)$ y el sistema a escala piloto $\mathrm{MJEA}^{\circledR}\left(\boldsymbol{R}^{2}=0,55\right)$.

Las concentraciones de salida de $\mathrm{NO}_{\mathrm{x}}{ }^{-}$han sido superiores a las de entrada para la mayor parte de los muestreos y superan en varias ocasiones el valor límite de vertido de $10 \mathrm{mg} \mathrm{L}^{-1}$. En 6 muestreos que han tenido lugar durante los meses de julio y agosto el valor de salida supera los $20 \mathrm{mg} \mathrm{L}^{-1}$, el doble del valor límite de vertido (Figura 3.18).

Los mecanismos de eliminación más importantes en los humedales artificiales son volatilización, adsorción, asimilación por parte de macrófitos y la combinación de los procesos de nitrificación y desnitrificación. No es probable que las pérdidas de $\mathrm{NH}_{4}{ }^{+}$en el sistema puedan ser atribuidas a procesos de volatilización. La eliminación de $\mathrm{NH}_{3}$ mediante este mecanismo en suelos saturados de agua y sedimentos son insignificantes si el valor de pH está por debajo de 7,5, y no son serias si el pH está por debajo de 8 (Reddy y Patrick, 1984). Los valores promedio de $\mathrm{pH}$ se han encontrado siempre cercanos a 7,5 $\pm 1,1$ durante todo el periodo de estudio.

La liberación de nitrógeno en la unidad FS ha sido posiblemente debida a la combinación de los procesos de adsorción sobre el sustrato y asimilación por parte de macrófitos. La información existente sobre adsorción y asimilación en humedales artificiales es limitada y a menudo contradictoria (Sun y col., 2005). La capacidad de adsorción del nitrógeno amoniacal sobre grava ha sido estimado como $175 \mathrm{mg} \mathrm{kg}^{-1}$ por Sikora y col. (1995), $500 \mathrm{mg} \mathrm{kg}^{-1}$ de grava por Stein y col. (2003) o $769 \mathrm{mg} \mathrm{kg}^{-1}$ por Zhu y col. (2011). El amonio adsorbido se encuentra ligado al sustrato y se puede liberar fácilmente cuando cambian las condiciones químicas del agua (Vymazal, 2007). Cuando la concentración de entrada de $\mathrm{NH}_{4}{ }^{+}$se reduce en 2007 y 2008 
como consecuencia de la dilución empleada, el $\mathrm{NH}_{4}{ }^{+}$ligado al sustrato es liberado para alcanzar el equilibrio con la nueva concentración en la columna de agua.
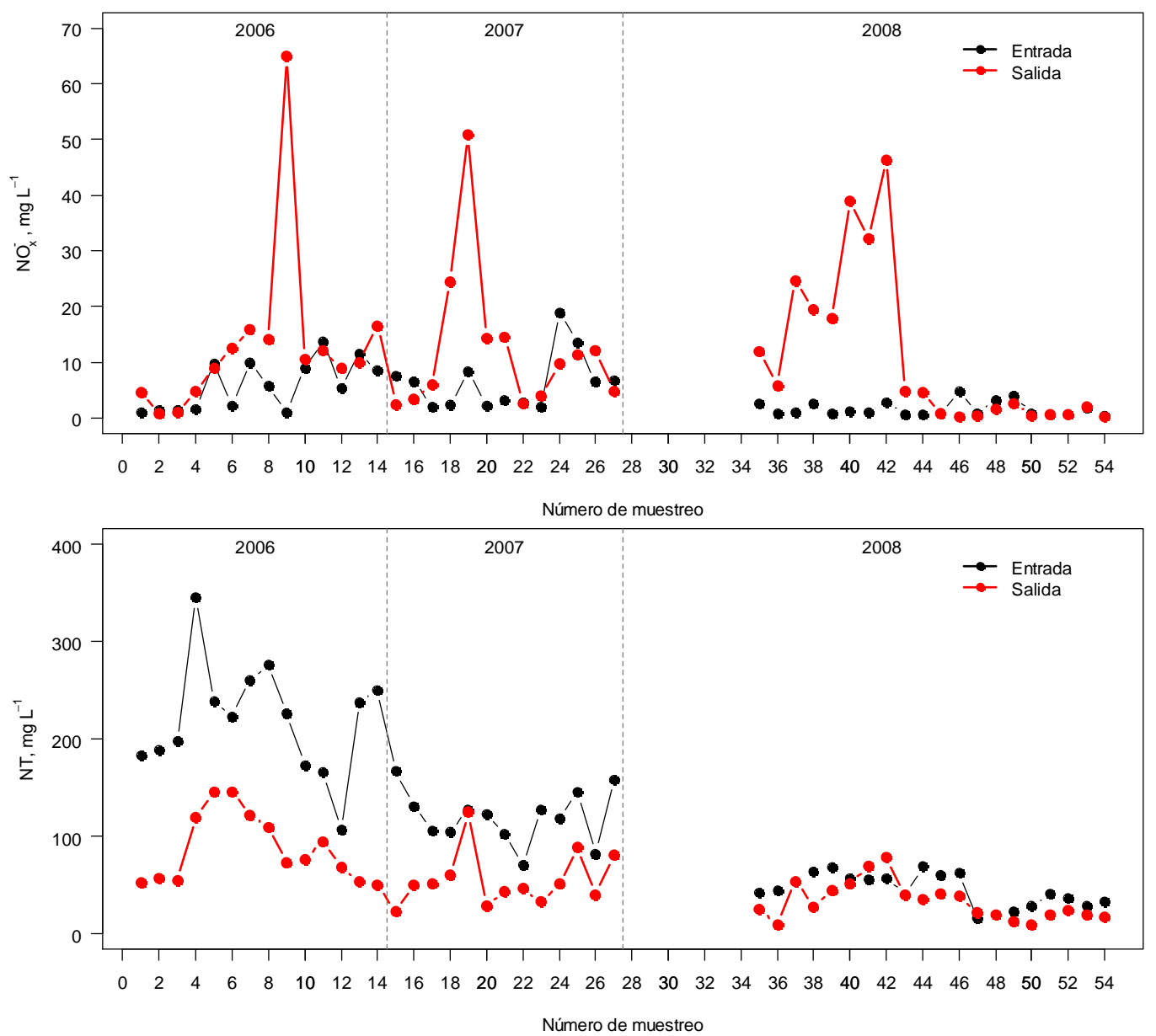

Figura 3.18. Concentración de entrada y salida de $\mathrm{NO}_{\mathrm{x}}^{-} \mathrm{y}_{\mathrm{NT}}$ por muestreo. Las líneas de puntos verticales indican la separación entre los años de muestreo.

Los macrófitos plantados en un humedal artificial requieren típicamente de un periodo de uno a tres años hasta su desarrollo definitivo. La cantidad de nutrientes que asimilan durante este periodo es importante en muchos casos y representa un mecanismo de eliminación que no es sostenible a largo plazo (Kadlec y Wallace, 2009). Las necesidades de nitrógeno de Typha latifolia son importantes en un HFS durante el establecimiento de la población en el primer año y durante el desarrollo de nuevos brotes en el segundo año. A partir de la primavera del segundo año el crecimiento neto de Typha latifolia cesa (Dubbe y col., 1988). La asimilación de nitrógeno por parte de Typha latifolia puede llegar a suponer el $60 \%$ del $\mathrm{NH}_{4}{ }^{+}$eliminado (Busnardo y col., 1992). Este mecanismo de eliminación habría colaborado en la eliminación de NT durante 2006 y 2007 en la unidad FS.

La descomposición de los rizomas podría haber contribuido a la liberación de nitrógeno orgánico durante el último año de operación. La parte aérea de los macrófitos fue cosechada al final de cada año pero los rizomas, que son capaces de acumular hasta un 50\% del contenido total de nitrógeno en la planta por traslocación en el periodo de senescencia (Vymazal, 1995), no fueron retirados del humedal artificial en todo el periodo de estudio. Durante 2007 la mayor parte de estos rizomas desarrollaron nuevos brotes mientras que otros permanecieron inactivos y sufrieron procesos de descomposición durante el periodo estival liberando nitrógeno en la 
columna de agua. En 2008 el número de rizomas inactivos aumentó con respecto a 2007, lo que habría supuesto una mayor descomposición y liberación de nitrógeno orgánico en la primera etapa del sistema.

En general, el nitrógeno orgánico a la salida de la unidad FS es inferior a las concentraciones de entrada en 2006 y 2007, lo que indica una actividad transformadora por parte de las bacterias amonificadoras. En 2008 no se aprecian diferencias importantes entre el nitrógeno orgánico de entrada y salida de la unidad FS, lo que sugiere que el nitrógeno orgánico liberado durante la descomposición de Typha latifolia es transformado en amonio dentro de la unidad FS (Figura 3.19).

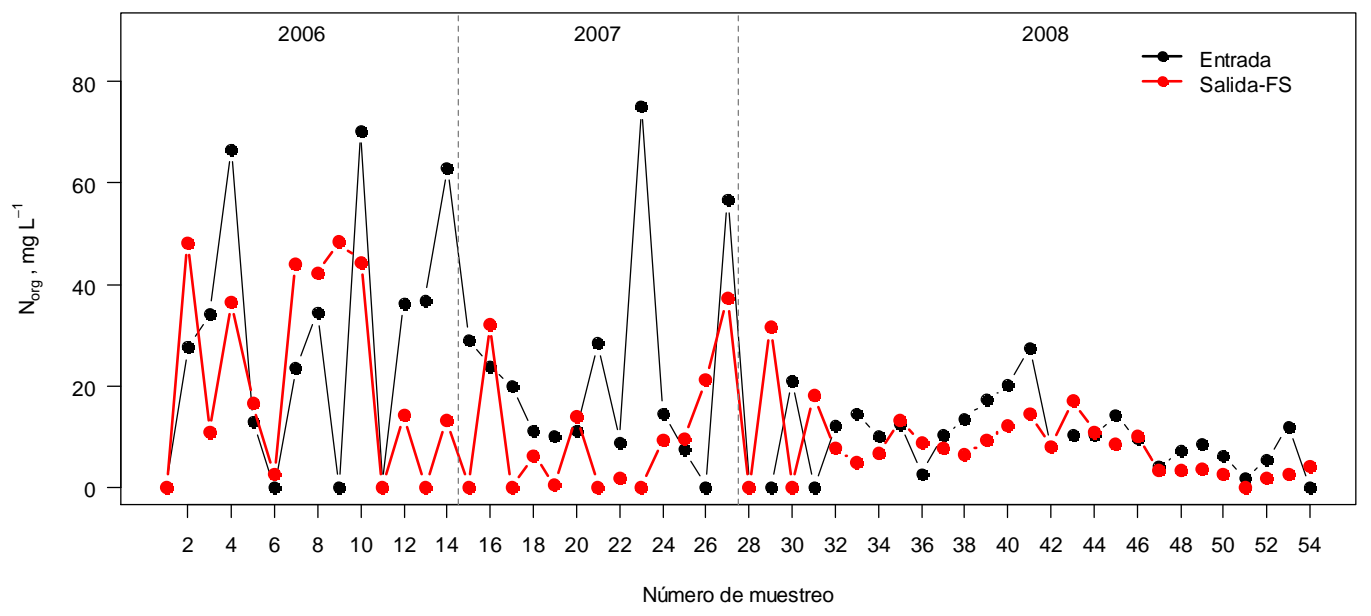

Figura 3.19. Concentración de entrada y salida de nitrógeno orgánico $\left(\mathbf{N}_{\text {org }}\right)$ en la unidad FS por muestreo. Las líneas de puntos verticales indican la separación entre los años de muestreo.

La asimilación por parte de Salix atrocinerea también ha contribuido a la eliminación de nitrógeno en las unidades FSS, sin embargo el mantenimiento de este macrófito leñoso ha sido muy diferente del de Typha latifolia. No se ha realizado cosecha de la parte aérea entre los diferentes años para Salix atrocinerea ya que este macrófito no tiene una época de senescencia, aunque sí se produce la caída de sus hojas sobre el lecho de las unidades FSS. El crecimiento de brotes y ramas de sauce es generalmente más lento durante el primer año y aumenta en el año siguiente hasta alcanzar un crecimiento estable que se mantiene durante el tercer año (Larsson y col., 2003). La asimilación constante por parte de este macrófito junto con la ausencia de un proceso de descomposición del rizoma en los tres años de operación del sistema a escala piloto contribuye a una eliminación de nitrógeno estable en las unidades FSS a diferencia de la que tiene lugar en la unidad FS. La asimilación de nitrógeno por especies del género Salix puede llegar a suponer entre un 6 y un 55\% de la concentración de entrada en filtros verdes alimentados con efluente del tratamiento primario de plantas de depuración de agua residual municipal (Larsson y col., 2003).

La nitrificación está limitada a las zonas de condiciones aerobias dentro del humedal artificial. Los potenciales de oxido-reducción en el agua residual de todo el sistema han sido siempre inferiores a los $300 \mathrm{mV}$ lo que indica que las condiciones anóxicas y anaerobias han predominado durante todo el periodo de estudio. La nitrificación ha estado por tanto limitada a la zona aerobia de la rizosfera de los macrófitos generada por la liberación de oxígeno por parte de raíces y rizomas (Brix, 1990). Se ha observado un ligero incremento de $\mathrm{NO}_{\mathrm{x}}{ }^{-}$en la salida de la unidad FS lo que indica que parte del amonio ha sido nitrificado, aunque su peso relativo no es importante en comparación con el resto de los compuestos de nitrógeno (Figura 3.15). Es posible que la nitrificación haya pasado inadvertida al haberse sucedido de la desnitrificación. 
La concentración de $\mathrm{NO}_{\mathrm{x}}{ }^{-}$en el efluente del sistema ha sido muy superior a la encontrada en el resto del humedal (Figuras 3.14 y 3.18) lo que indica que el proceso de nitrificación ha tenido lugar en las unidades FSS. El ratio DQO/N promedio de entrada a las unidades FSS durante el periodo de estudio ha sido de 2,9 $\pm 2,1$ dentro del rango $2-4$ en el cual los procesos de nitrificación y desnitrificación ocurren simultáneamente en HFSH (Ding y col., 2012). Las condiciones para la nitrificación en el agua residual a su paso por las unidades FSS han sido adecuadas, con concentraciones de $\mathrm{DBO}_{5}$ por debajo del umbral de $50 \mathrm{mg} \mathrm{L}^{-1}$ (Gray y col., 1996). La máxima transformación de amonio en nitrato puede tener lugar en concentraciones de oxígeno disuelto (OD) superiores a los $1,5 \mathrm{mg} \mathrm{L}^{-1}$, mientras que concentraciones de OD por debajo de los 1,2 $\mathrm{mg} \mathrm{L}^{-1}$ limitan este proceso (Xinshan y col., 2010). Durante el periodo de estudio la concentración de OD ha sido muy variable, lo que habría permitido ocasionalmente la nitrificación de amonio en el lecho de las unidades FSS. La concentración promedio de OD en la salida de la unidad FS ha sido de $2,1 \pm 1,7 \mathrm{mg} \mathrm{L}^{-1}$, mientras que en la salida del sistema a escala piloto ha sido de $1,7 \pm 1,6 \mathrm{mg} \mathrm{L}^{-1}$.

Bajos ratios de $\mathrm{DQO} / \mathrm{N}$ en el afluente junto con la acumulación de $\mathrm{NO}_{\mathrm{x}}{ }^{-}$en el efluente son indicativos de un proceso de desnitrificación incompleto (Ding y col., 2012). El proceso de desnitrificación depende de la disponibilidad de carbono, particularmente de $\mathrm{DBO}_{5}$ que es la forma de carbono orgánico utilizada preferentemente para reducir las formas oxidadas de nitrógeno en los humedales artificiales (Kadlec y Wallace, 2009). $\mathrm{La} \mathrm{DBO}_{5}$ en la salida del sistema se encontraba cercana a la concentración de fondo en 2007 y 2008 lo que indica que todo el carbono orgánico disponible en el sistema ha sido consumido.

\subsubsection{Tratamiento de fósforo}

Los resultados de PT han seguido un patrón similar al del NT, con una reducción progresiva entre la entrada y la salida del humedal y una reducción de la capacidad de tratamiento entre 2006 y 2007. En 2008 también se ha producido un incremento de la concentración entre la entrada y la salida de la unidad FS indicando la liberación de PT dentro del sistema que ha sido tratado posteriormente en las unidades FSS (Figura 3.20).
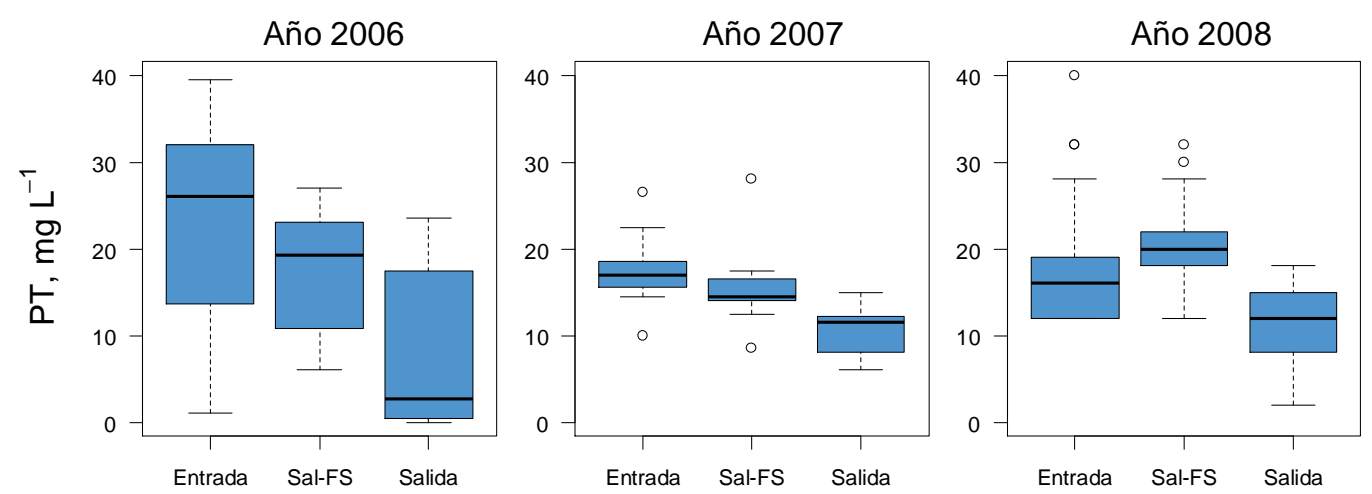

Figura 3.20. Diagramas de caja de los resultados de los muestreos para el parámetro PT por año y punto de muestreo.

Los índices de eliminación también han mostrado un comportamiento similar entre ambos contaminantes en la unidad FS con unos valores muy bajos en 2006 que se redujeron en 2007 y alcanzaron valores negativos en 2008 (Figura 3.21). Se ha encontrado una fuerte correlación entre los índices de eliminación de PT y NT en la unidad FS (coeficiente de correlación de Pearson de 0,71), lo que sugiere que la liberación de PT ha involucrado mecanismos similares a los de NT en esta etapa del sistema: adsorción sobre el sustrato y asimilación por macrófitos. Los procesos de adsorción y asimilación de fósforo tienen una capacidad finita y por tanto no pueden contribuir a una eliminación sostenible en el sistema (Dunne y Reddy, 2005; Kadlec y Wallace, 2009). 

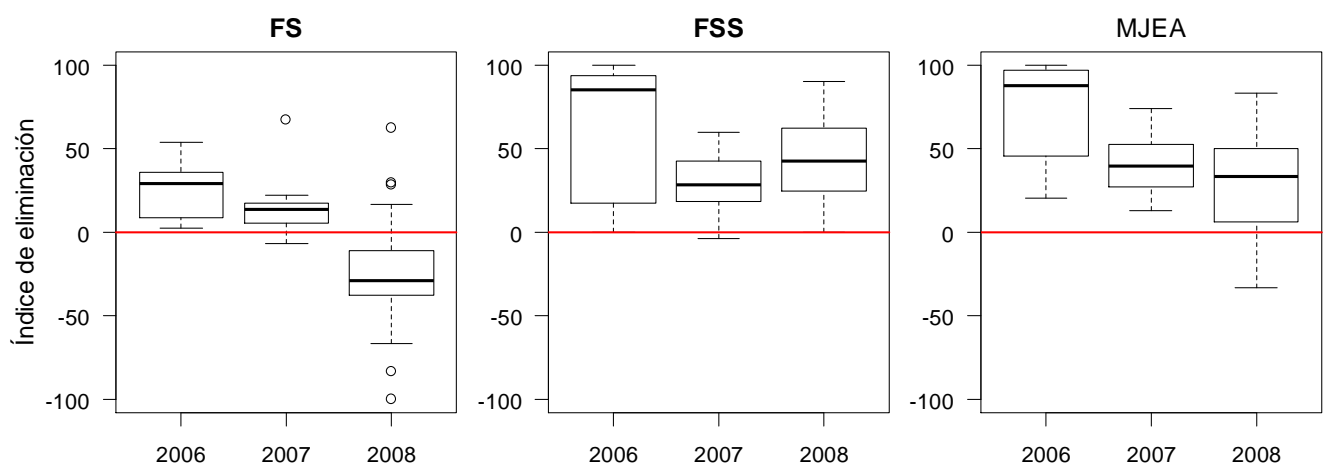

Figura 3.21. Diagramas de caja de los índices de eliminación por año y etapa del sistema para el parámetro PT.

La liberación de PT en la unidad FS puede ser atribuida a procesos de descomposición de Typha latifolia y al balance entre adsorción y desorción que mantiene el equilibrio de fósforo entre la fase sólida y el fósforo de la fase líquida, fenómeno similar a la capacidad tampón del pH en suelos (Barrow, 1983). El momento en el que se realiza la cosecha de la parte aérea de los macrófitos es importante puesto que la liberación de nutrientes puede alcanzar hasta un 30\% durante los primeros días del proceso de descomposición (Vymazal, 2007). La descomposición de rizomas puede haber contribuido de forma importante a la liberación de fósforo en la unidad FS, ya que en ellos se puede llegar a concentrar hasta el 50\% del fósforo de la planta debido a la traslocación de nutrientes (Martín y Fernández, 1992).

En el caso de las unidades FSS los principales mecanismos de eliminación de PT continuaron siendo adsorción y asimilación a diferencia de los mecanismos de NT que también incluyeron procesos biológicos, lo que explica las diferencias de comportamiento entre ambos contaminantes en esta parte del sistema. La asimilación por parte de Salix atrocinerea es constante durante el periodo de estudio ya que este macrófito no tiene periodo de senescencia. Sin embargo no se considera un mecanismo de eliminación de fósforo importante; la asimilación de especies del género Salix en filtros verdes puede suponer entre un 3 y un $12 \%$ del fósforo total retenido en el sistema (Larsson y col., 2003). Los mecanismos de adsorción y precipitación son por lo tanto los responsables de la retención de fósforo en las unidades FSS. Estos mecanismos son efectivos en HFSH en los que se favorece el contacto entre el agua residual y el sustrato. Sin embargo, la grava proporciona una capacidad muy baja de adsorción y precipitación (Vymazal, 2007). Los índices de eliminación de PT de las unidades FSS han sido muy superiores en 2006, cuando la unidad FS aún mantiene capacidad de retención de fósforo y se han estabilizado en 2007 y 2008 cuando los índices de eliminación de la unidad FS son mínimos (Figura 3.21). En conjunto, la capacidad de tratamiento del sistema MJEA ${ }^{\circledR}$ se ha visto afectada por el comportamiento de la unidad FS, reduciéndose progresivamente entre 2006 y 2008 (Figura 3.21).

Las altas concentraciones de entrada al humedal han provocado una rápida reducción de la capacidad de tratamiento, por lo que la relación entre las concentraciones de entrada y salida ha variado de forma importante entre los diferentes años. Por ello no es posible encontrar una relación entre las concentraciones de entrada y salida para las unidades o el sistema en su conjunto (Figura 3.22). La Figura 3.23 muestra cómo las concentraciones de salida han sido muy variables para este contaminante, superando en más de la mitad de los muestreos el límite de vertido de $10 \mathrm{mg} \mathrm{L}^{-1}$ presente en el Real Decreto 849/1986. 

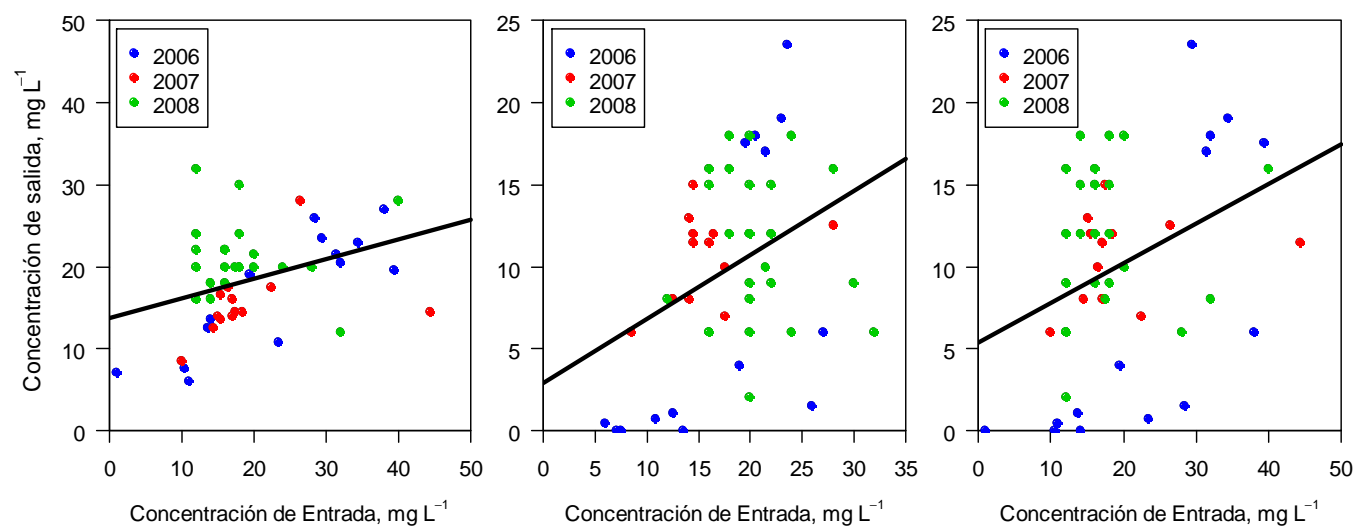

Figura 3.22. Concentración de entrada frente a concentración de salida del parámetro PT y regresión lineal para la unidad FS $\left(R^{2}=0,13\right)$, las unidades FSS $\left(R^{2}=0,13\right)$ y el sistema a escala piloto $\left(R^{2}=0,14\right)$.

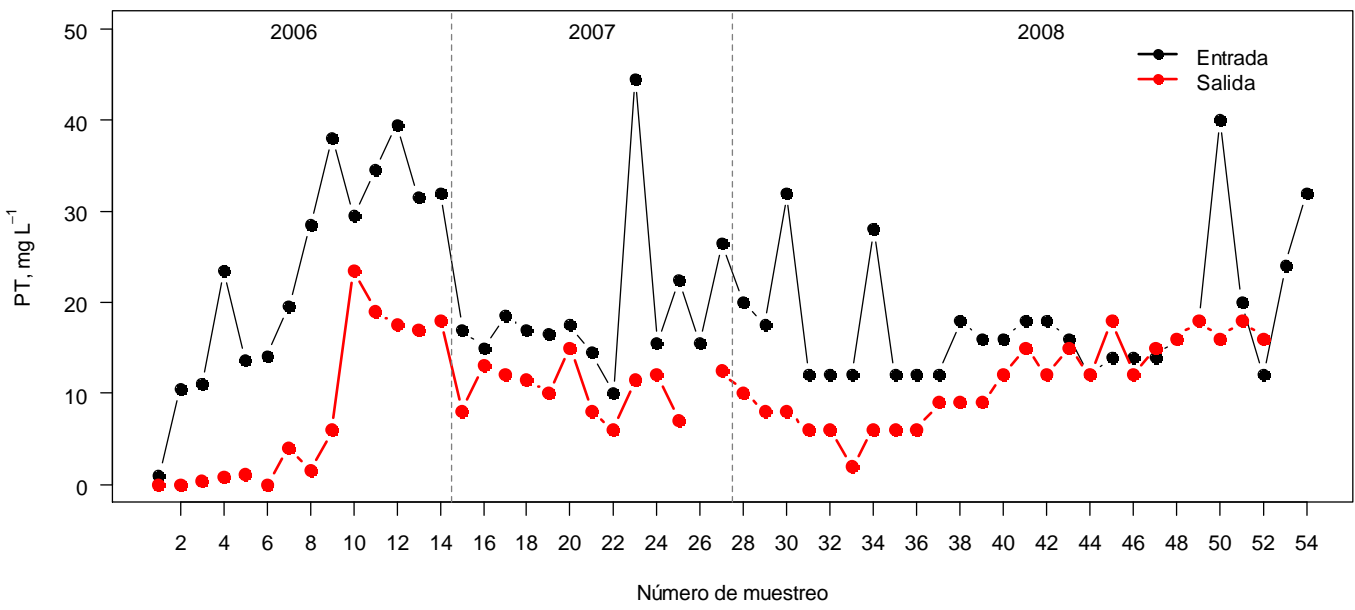

Figura 3.23. Concentración de entrada y salida de PT por muestreo. Las líneas de puntos verticales indican la separación entre los años de muestreo. La línea horizontal indica el límite de vertido de $10 \mathrm{mg} \mathrm{L}^{-1}$ para PT. 


\subsection{CONCLUSIONES}

Los sistemas de flujo combinado tipo MJEA $^{\circledR}$ son capaces de tratar eficientemente los sólidos en suspensión y la materia orgánica de la fracción líquida de los purines de cerdo con unos índices de eliminación promedio comparables a los presentes en la bibliografía. La reducción progresiva de las cargas de contaminantes aportadas al sistema ha permitido alcanzar las concentraciones de fondo de $\mathrm{SST}_{\text {y }} \mathrm{DBO}_{5}$ en este tipo de sistemas, aunque no se ha alcanzado para la DQO.

La capacidad de tratamiento de nitrógeno y fósforo de este tipo de sistemas es limitada, aunque similar a la publicada por otros estudios que utilizan sistemas de humedales artificiales para el tratamiento de agua residual ganadera. Debido a esta capacidad limitada de tratamiento para las distintas formas de $\mathrm{N}$ y $\mathrm{P}$ no se ha podido obtener valores de concentración de fondo.

La eliminación de SST puede atribuirse a procesos de sedimentación e intercepción favorecidos por la baja carga hidráulica, la presencia de macrófitos y el elevado tiempo de retención hidráulico. La degradación de la materia orgánica ha tenido lugar principalmente en condiciones reductoras en las que han podido participar microorganismos con metabolismos muy diversos (desnitrificantes, reductores de Mn y Fe, sulfatoreductores y/o metanógenos). El análisis de las comunidades bacterianas debería aportar información valiosa sobre estos metabolismos.

El tratamiento de nitrógeno en el sistema se ha producido mediante la combinación de procesos de adsorción, asimilación y nitrificación-desnitrificación. La desorción de amonio y la descomposición de los rizomas de Typha latifolia ha podido contribuir a aumentar notablemente la concentración de nitrógeno en la unidad FS, particularmente durante el último año de operación. La contribución de los procesos de nitrificación-desnitrificación parece haber sido más importante en las unidades FSS. El incremento de la concentración de $\mathrm{NO}_{3}{ }^{-}$indica que el proceso de nitrificación se ha llevado a cabo en el sistema seguido de una desnitrificación incompleta debido al efecto limitante de la materia orgánica.

La eliminación de PT ha seguido un patrón similar a la del nitrógeno. La retención de fósforo en el sistema y su posterior liberación puede deberse a la limitada capacidad de adsorción de la grava y a los procesos de asimilación de macrófitos. Se recomienda estudiar la utilización de sustratos alternativos para mejorar la capacidad de adsorción de fósforo en este tipo de sistemas. 




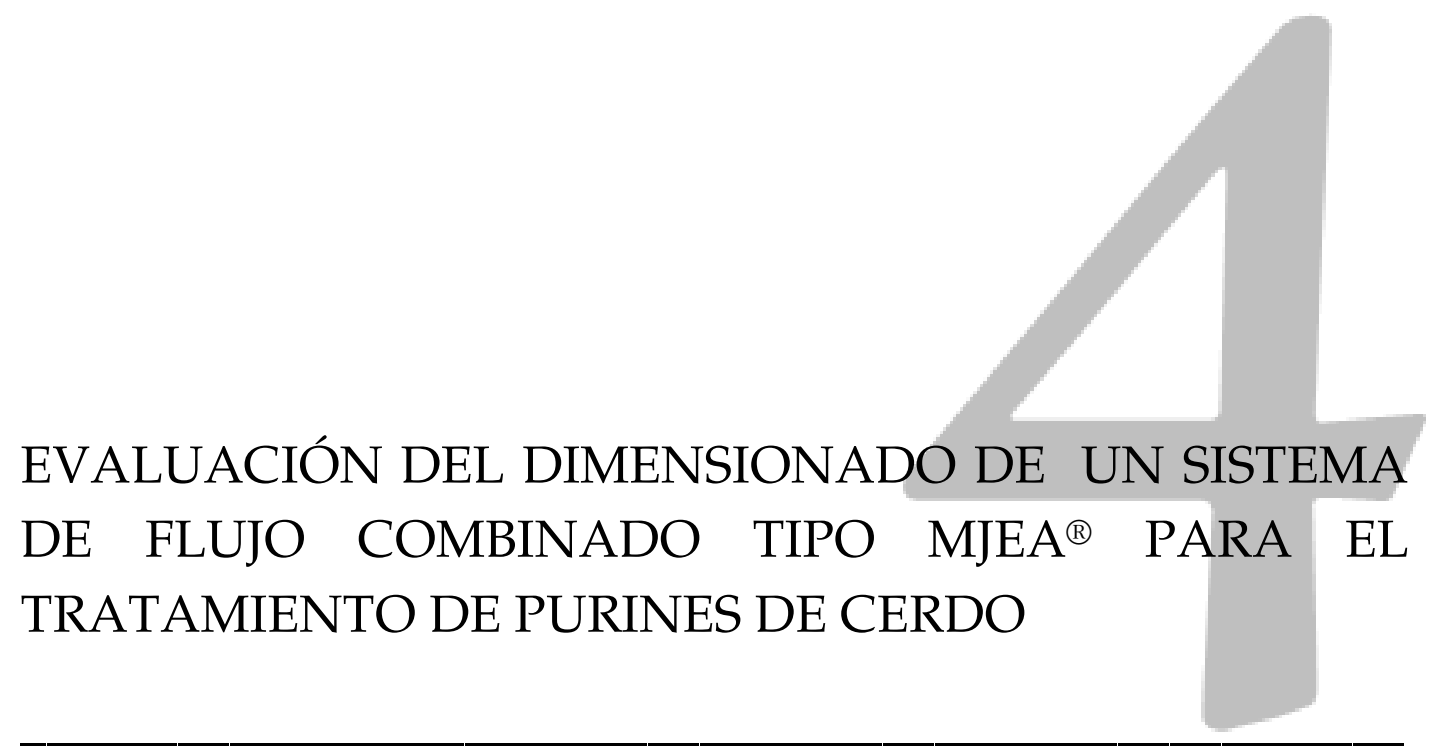

\subsection{INTRODUCCIÓN}

Desde el comienzo de la utilización de los humedales artificiales se han empleado diferentes métodos para estimar la superficie necesaria para el tratamiento del agua residual. Entre ellos podemos encontrar reglas de tres, regresiones lineales, modelos de primer orden y modelos determinísticos. Todas estas técnicas tienen limitaciones a la hora de representar aspectos importantes del funcionamiento de los humedales artificiales tales como hidráulica, meteorología, variabilidad estacional, variabilidad estocástica e interacciones entre macrófitos y microorganismos con el agua residual (Kadlec y Wallace, 2009).

\subsubsection{Influencia del balance hídrico en el funcionamiento de humedales artificiales}

La transferencia de agua desde y hasta un humedal natural sigue el mismo patrón tanto en humedales artificiales de flujo superficial (HFS) como en humedales artificiales de flujo subsuperficial horizontal (HFSH). El agua residual supone el componente dominante del flujo de entrada en los humedales artificiales aunque otras transferencias de agua pueden ser también importantes (Kadlec y Wallace, 2009). Según Mitsch y Gosselink (2007) los procesos hidrológicos juegan un papel principal en los humedales naturales, lo que determina sus condiciones bioquímicas y la composición de la comunidad ecológica. Como ecosistemas de transición entre ecosistemas terrestres y acuáticos los humedales naturales dependen también de sus características hidráulicas.

Los fenómenos atmosféricos de precipitación y evapotranspiración (ET) pueden modificar de forma importante el flujo del agua a través de un humedal, afectando significativamente a la calidad del agua. La evapotranspiración se define como la pérdida de agua del humedal a la atmósfera que puede tener lugar desde la superficie del agua y el suelo (evaporación) o a través de los tejidos emergentes de los macrófitos (transpiración). Ambos procesos suceden simultáneamente y no hay una manera sencilla de distinguir entre ellos (Allen y col., 2006). La 
pérdida de agua por evapotranspiración reduce el caudal a su paso por el humedal artificial, incrementa el tiempo de contacto y produce un incremento de la concentración de los contaminantes. La precipitación tiene el efecto contrario lo que supone un incremento del caudal en el humedal artificial, una reducción del tiempo de contacto y una dilución de la concentración de los contaminantes (Headley y col., 2012). La eficiencia del tratamiento de contaminantes en los humedales artificiales depende de la duración de la interacción entre el agua residual, los organismos y el sustrato, o lo que es lo mismo, depende del tiempo de retención hidráulico $(\mathrm{TRH})$.

En un humedal natural las entradas de agua al sistema proceden del caudal de entrada de otros cauces tales como ríos o arroyos, del agua de escorrentía, de la descarga del agua subterránea y de la precipitación, mientras que las pérdidas de agua del sistema se deben al caudal de salida, la recarga subterránea y la evapotranspiración (Fonder, 2010). En los humedales artificiales las recargas y descargas de agua subterránea son excluidas del sistema, generalmente mediante capas de materiales impermeables como arcilla o geotextiles en función de los materiales empleados en la construcción del sistema. Se excluyen también las aguas de escorrentía y se sustituye el caudal de agua de entrada de un cauce por un caudal de entrada de agua residual. Por lo tanto, el balance de agua de un humedal artificial para un momento determinado puede representarse mediante la siguiente ecuación (Headley y col., 2012):

$$
Q_{e n t}+P=Q_{\text {sal }}+E T
$$

donde

$$
\begin{aligned}
& Q_{\text {ent }}=\text { caudal de entrada o afluente } \\
& Q_{\text {sal }}=\text { caudal de salida o efluente } \\
& P=\text { precipitación } \\
& E T=\text { evapotranspiración }
\end{aligned}
$$

La gran mayoría de sistemas realizan una medición del caudal de entrada, mientras que un número menor de instalaciones disponen de la capacidad para medir independientemente los caudales de entrada y salida. La ecuación de balance hídrico se utiliza para calcular el flujo de salida estimado cuando no hay valores de caudal de salida disponibles (Kadlec y Wallace, 2009). La precipitación se suele medir en el propio emplazamiento o en estaciones meteorológicas cercanas.

La evaporación de una superficie de agua proporciona un índice del efecto integrado de la radiación, la temperatura del aire, la humedad del aire y del viento en la evapotranspiración (Allen y col., 2006). Los tanques de evaporación son utilizados para estimar la evapotranspiración observando la pérdida por evaporación de una superficie libre de agua. Se trata de tanques normalizados de los cuales el de tipo A, de $120 \mathrm{~cm}$ de diámetro y $25 \mathrm{~cm}$ de altura, es el más utilizado. En humedales naturales y HFS de gran superficie se considera que la evapotranspiración es similar a la evaporación lacustre, la cual corresponde a un $80 \%$ del tanque de evaporación tipo A (Kadlec y Wallace, 2009). Debido al coste económico y a la dificultad de obtener mediciones de campo precisas, la evapotranspiración se calcula generalmente con datos meteorológicos (Allen y col., 2006).

Existe una gran cantidad de ecuaciones desarrolladas para determinar la evapotranspiración utilizando datos meteorológicos. Algunos de los métodos son solamente válidos para condiciones climáticas y agronómicas específicas y no se pueden aplicar bajo condiciones diferentes de las que fueron desarrolladas originalmente. El método FAO Penman-Monteith se recomienda como el método estándar para la definición y el cálculo de la evapotranspiración de referencia $\left(\mathrm{ET}_{0}\right)$ (Allen y col., 2006): 


$$
E T_{0}=\frac{0,408 \Delta\left(R_{n}-G\right)+\gamma\left(\frac{900}{T+273}\right) u_{2}\left(e_{s}-e_{a}\right)}{\Delta+\gamma\left(1+0,34 u_{2}\right)}
$$

donde

$E T_{0}=$ evapotranspiración de referencia, $\mathrm{mm} \mathrm{día}^{-1}$

$R_{\mathrm{n}}=$ radiación neta en la superficie del cultivo, $\mathrm{MJ} \mathrm{m}^{-2}$ día $^{-1}$

$G=$ flujo del calor de suelo, $\mathrm{MJ} \mathrm{m}^{-2}$ día $^{-1}$

$T=$ temperatura media del aire a $2 \mathrm{~m}$ de altura, ${ }^{\circ} \mathrm{C}$

$u_{2}=$ velocidad del viento a $2 \mathrm{~m}$ de altura, $\mathrm{m} \mathrm{s}^{-1}$

$e_{\mathrm{s}}=$ presión de vapor de saturación, $\mathrm{kPa}$

$e_{\mathrm{a}}=$ presión real de vapor, $\mathrm{kPa}$

$\Delta=$ pendiente de la curva de presión de vapor, $\mathrm{kPa}^{\circ} \mathrm{C}^{-1}$

$\gamma=$ constante psicrométrica, $0,665 \times 10^{-3} \mathrm{kPa}^{\circ} \mathrm{C}^{-1}$

La pendiente de la curva de presión de vapor $(\Delta)$ es proporcionada por Tetens (1930) y Murray (1967):

$$
\Delta=4,098 \frac{\left[0,6108 e^{\left(\frac{17,27 T}{T+237,3}\right)}\right]}{(T+237,3)^{2}}
$$

donde

$\Delta=$ pendiente de la curva de presión de vapor, $\mathrm{kPa}^{\circ} \mathrm{C}^{-1}$

$T=$ temperatura media del aire, ${ }^{\circ} \mathrm{C}$

La ecuación 4.2 utiliza datos meteorológicos de radiación solar, temperatura del aire, humedad y velocidad del viento para representar los parámetros físicos que gobiernan el proceso de evapotranspiración. Para incluir los parámetros fisiológicos que intervienen en la evapotranspiración se utiliza la definición del cultivo de referencia:

"cultivo hipotético con una altura asumida de $0,12 \mathrm{~m}$, una resistencia superficial de $70 \mathrm{~s}$ $\mathrm{m}^{-1} \mathrm{y}$ un albedo de 0,23 y que representa a la evapotranspiración de una superficie extensa de pasto verde de altura uniforme, crecimiento activo y riego adecuado" (Allen y col., 2006).

En humedales tipo HFS de gran superficie se considera que la evapotranspiración es igual a la evapotranspiración de referencia. En el caso de sistemas de pequeña superficie se utiliza el coeficiente de macrófito $\left(k_{\mathrm{c}}\right.$ ) (Kadlec y Wallace, 2009) que representa el resumen de las diferencias físicas y fisiológicas (tales como dosel del cultivo y resistencia aerodinámica) entre la definición del cultivo de referencia y los macrófitos. De este modo la evapotranspiración de un humedal se estima en función del coeficiente de macrófito y la evapotranspiración de referencia (Allen y col., 2006):

$$
E T=E T_{0} \times k_{c}
$$

donde

$$
\begin{aligned}
& E T=\text { evapotranspiración, mm día }{ }^{-1} \\
& E T_{0}=\text { evapotranspiración de referencia, mm día }{ }^{-1} \\
& k_{\mathrm{c}}=\text { coeficiente de macrófito, sin unidades }
\end{aligned}
$$




\subsubsection{Modelos de dimensionado}

Rousseau y col. (2004) comparan distintos modelos para el diseño de HFSH entre los que se incluyen regresiones lineales, reglas de tres, el modelo $k-C^{*}$ de primer orden elaborado por Kadlec y Knight (1996) y un modelo determinístico desarrollado por Wynn y Liehr (2001) en el que se representan los ciclos del carbono y el nitrógeno, los balances de agua y oxígeno y el crecimiento, muerte y metabolismo de bacterias heterótrofas y autótrofas.

Rousseau y col. (2004) concluyen que las reglas de tres y las regresiones son modelos de diseño conservadores. Los humedales artificiales dimensionados mediante estos métodos permiten alcanzar buenos objetivos de depuración, pero requieren de grandes extensiones de terreno que pueden suponer un elevado coste económico. La calibración del modelo determinístico es muy compleja ya que requiere la estimación de 42 parámetros mediante 15 variables relacionadas con procesos físicos y biológicos. Estos tipos de modelos, entre los cuales se encuentran los utilizados por Langergraber (2008) para describir los procesos internos de los sistemas HFSH, son muy útiles para describir las interacciones que suceden dentro de los humedales artificiales pero no ofrecen una ayuda real en términos de diseño.

La conclusión principal a la que llegan Rousseau y col. (2004) es que el modelo $k$ - $C^{*}$ de primer orden es la mejor herramienta de dimensionado si el diseñador se asegura de cumplir con todos los supuestos y está al tanto de sus inconvenientes. A falta de un modelo estándar comúnmente aceptado, los modelos $k-C^{*}$ de primer orden son los más utilizados para predecir el rendimiento de los humedales artificiales (USEPA, 2000).

\subsubsection{Modelo $k-C^{*}$}

Los modelos de primer orden predicen que la concentración de entrada de un contaminante se aproxima a cero de forma asintótica a medida que el agua fluye por el humedal artificial. Todos los procesos físicos y biológicos que tienen lugar en la degradación o generación de dicho contaminante son agrupados en un único parámetro, la constante de eliminación $k$ (Stein y col., 2006) (Figura 4.1).

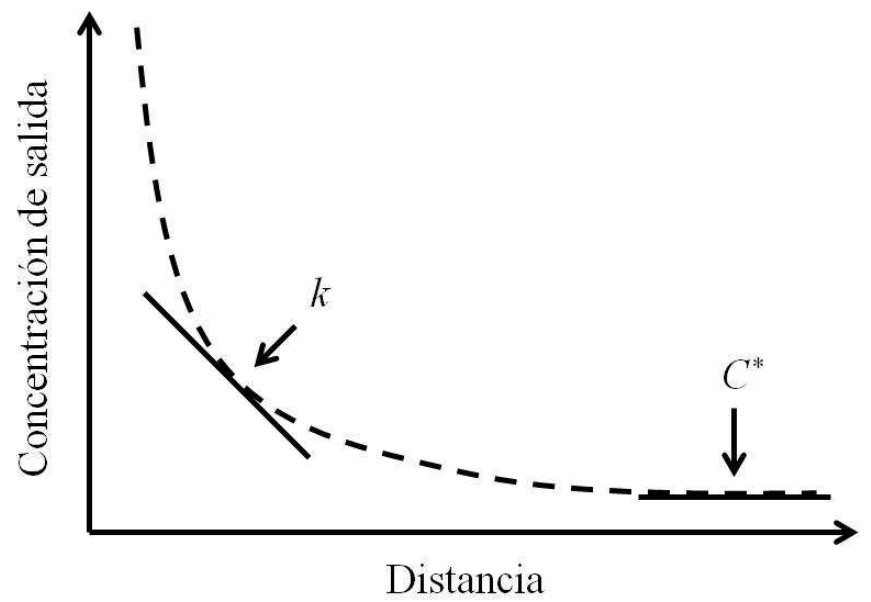

Figura 4.1. La función ideal de eliminación de primer orden. Adaptado de Kadlec y Knight (1996).

Kadlec y Knight (1996) propusieron un modelo de primer orden modificado, el denominado modelo $k$ - $C^{*}$. Este modelo asume la existencia de una concentración residual o de fondo $\left(C^{*}\right)$, un límite mínimo distinto de cero que se alcanza de forma asintótica sustituyendo el valor de cero original (Figura 4.1). El concepto de $C^{*}$ permite incluir en el modelo los procesos de generación del contaminante dentro del humedal (descomposición, resuspensión, desorción, etc), la 
incorporación atmosférica o subterránea y la existencia de una fracción recalcitrante en la concentración de entrada del contaminante. En ausencia de datos que puedan cuantificar cada uno de estos aportes del contaminante al humedal artificial, $C^{*}$ puede ser considerado un parámetro de ajuste empírico (Kadlec, 2000).

El modelo $k-C^{*}$ está basado en supuestos de flujo pistón y en condiciones de estado estacionario (Rousseau y col., 2004). Los modelos de primer orden pueden ser definidos en función de la constante de área, por lo que determinan el área necesaria para el humedal, o en función de la constante volumétrica, lo que proporciona el volumen requerido por el humedal artificial (Kadlec, 2000). El modelo de diseño $k-C^{*}$ en función de la constante de área es presentado como (Kadlec y Knight, 1996):

$$
\ln \left(\frac{C_{s a l}-C^{*}}{C_{e n t}-C^{*}}\right)=-\frac{k}{q}
$$

donde

$C_{\text {sal }}=$ concentración de salida o efluente, $\mathrm{mg} \mathrm{L}^{-1}$

$C_{\text {ent }}=$ concentración de entrada o afluente, $\mathrm{mg} \mathrm{L}^{-1}$

$C^{*}=$ concentración residual o de fondo, $\mathrm{mg} \mathrm{L}^{-1}$

$k=$ constante de área de eliminación ajustada por la temperatura, $\mathrm{m} \mathrm{día}^{-1}$

$q=$ tasa de carga hidráulica, $\mathrm{m} \mathrm{día}^{-1}$

Combinando las ecuaciones 3.1 y 4.5 se puede calcular el área como:

$$
A=\frac{Q \ln \left(\frac{C_{e n t}-C^{*}}{C_{s a l}-C^{*}}\right)}{k}
$$

El modelo de diseño $k-C^{*}$ en función del volumen es presentado como (Kadlec, 2000):

$$
\ln \left(\frac{C_{s a l}-C^{*}}{C_{e n t}-C^{*}}\right)=-k_{v} \frac{x}{L} \tau
$$

donde

$C_{\text {sal }}=$ concentración de salida o efluente, $\mathrm{mg} \mathrm{L}^{-1}$

$C_{\text {ent }}=$ concentración de entrada o afluente, $\mathrm{mg} \mathrm{L}^{-1}$

$C^{*}=$ concentración residual o de fondo, $\mathrm{mg} \mathrm{L}^{-1}$

$k_{v}=$ constante volumétrica de eliminación, día ${ }^{-1}$

$\mathrm{x} / \mathrm{L}=$ fracción de distancia en el humedal, sin unidades

$\tau=$ tiempo de retención hidráulico teórico, $\mathrm{L}_{\text {día }}{ }^{-1}$

Combinando las ecuaciones 3.2 y 4.7 se puede calcular el volumen como:

$$
V=\frac{L Q \ln \left(\frac{C_{e n t}-C^{*}}{C_{s a l}-C^{*}}\right)}{k_{v} x}
$$

La relación entre la constante volumétrica de eliminación $\left(k_{v}\right)$ y la constante de eliminación en función del área $(k)$ se define como (Kadlec, 2000):

$$
k=(\varepsilon h) k_{v}
$$

donde 


$$
\begin{aligned}
& k=\text { constante de área de eliminación, m día }{ }^{-1} \\
& \varepsilon=\text { porosidad del humedal, sin unidades } \\
& h=\text { profundidad del humedal, } \mathrm{m} \\
& k_{v}=\text { constante volumétrica de eliminación, día }{ }^{-1}
\end{aligned}
$$

La ecuación modificada de Arrhenius puede utilizarse para estimar los efectos de la temperatura en la constante de eliminación de las ecuaciones anteriores (Kadlec y Knight, 1996):

$$
k=k_{20} \theta^{(T-20)}
$$

donde

$k=$ constante de eliminación ajustada por la temperatura, $\mathrm{m} \mathrm{día}^{-1}$

$k_{20}=$ constante de eliminación a $20^{\circ} \mathrm{C}, \mathrm{m}_{\text {día }}{ }^{-1}$

$\theta=$ coeficiente de temperatura, sin unidades

$T=$ temperatura,${ }^{\circ} \mathrm{C}$

La calibración de los parámetros $k, C^{*}$ y $\theta$ se basa en las concentraciones de entrada y salida del humedal artificial. Existe un amplio rango de valores de estos parámetros publicados en otros estudios, debido a que agrupan un gran número de características que representan la compleja red de interacciones que tienen lugar en un humedal artificial además de influencias externas como las condiciones atmosféricas (Rousseau y col., 2004). También se debe a la variación existente entre los sistemas de humedales artificiales que reciben distintos tipos de agua residual y son sometidos a distintas condiciones meteorológicas, además de diferir en tipos de sustrato, dimensiones, tipo y densidad de plantas, profundidad, número de unidades de funcionamiento, etc. Por lo tanto es de esperar una distribución con un amplio rango de valores de $k$ para todos los contaminantes (Kadlec y Wallace, 2009).

Kadlec (2000) reconoce las deficiencias del modelo $k-C^{*}$ y propone un nuevo modelo para solucionarlas. En primer lugar demuestra que los parámetros $k$ y $C^{*}$ no son constantes, sino que dependen de la tasa de carga hidráulica y la concentración de contaminantes en el afluente. También cuestiona el supuesto de que el flujo pistón sea una aproximación razonable de las condiciones hidráulicas de un humedal artificial. Los sistemas de flujo continuo no son espacialmente uniformes, sino que macrófitos, algas y microorganismos varían en tipo y densidad a lo largo del humedal (Kadlec y Wallace, 2009). Esto permite la existencia de zonas de corto-circuito por las que el agua sin tratar o parcialmente tratada sale del sistema en tiempos inferiores al tiempo de retención hidráulico del humedal. También permite la existencia de zonas muertas o de aguas estancadas, donde el agua permanece por tiempos superiores al tiempo de retención hidráulico del humedal. Los dos tipos de zonas causan condiciones de flujo pistón no ideales, y limitan el uso del modelo $k-C^{*}$.

\subsubsection{Modelo TIS}

Con el objetivo de tener en cuenta los conceptos de corto-circuito y zonas muertas, Kadlec y Wallace (2009) incorporan el modelo de tanques en serie o TIS (Tanks-In-Series). Los humedales artificiales de flujo horizontal con flujo continuo no son espacialmente uniformes, por lo que el modelo TIS descompone el sistema en un número $N$ de tanques en serie, en cada uno de los cuales los contaminantes son parcialmente eliminados (Fonder, 2010). Para la secuencia completa de tanques, el modelo se define como:

$$
\frac{C_{s a l}-C^{*}}{C_{e n t}-C^{*}}=\left(1+\frac{k \tau}{N h}\right)^{-N}
$$

donde

$$
C_{\text {sal }}=\text { concentración de salida o efluente, } \mathrm{mg} \mathrm{L}^{-1}
$$


$C_{\text {ent }}=$ concentración de entrada o afluente, $\mathrm{mg} \mathrm{L}^{-1}$

$C^{*}=$ concentración residual o de fondo, $\mathrm{mg} \mathrm{L}^{-1}$

$k=$ constante de eliminación, $\mathrm{m}_{\text {día }}{ }^{-1}$

$\tau=$ tiempo de retención hidraúlico, días ${ }^{-1}$

$N=$ número de tanques

$h=$ profundidad del humedal artificial, $\mathrm{m}$

Se asume que la constante de eliminación para el total de tanques en serie no varía con el tiempo de exposición en el humedal. Este no es el caso de mezclas de contaminantes como la $\mathrm{DBO}_{5}$ donde las constantes de eliminación se reducen a medida que tiene lugar el proceso de tratamiento a lo largo del humedal artificial (Kadlec y Wallace, 2009).

\subsubsection{Modelo $P-k-C^{*}$}

El modelo TIS representa la reducción de un único compuesto a su paso por un humedal artificial de flujo horizontal. Muchos de las sustancias que son consideradas contaminantes en el agua residual son en realidad agrupaciones de compuestos químicos individuales de un mismo tipo. Estas distribuciones pueden ser discretas, en el caso de una cantidad pequeña y contable de compuestos individuales, o continuas, en el caso de un número elevado e incontable de compuestos como es el caso de las variables $\mathrm{SST}_{\mathrm{S}} \mathrm{DBO}_{5}$ y DQO. También hay combinaciones de ambos tipos de distribuciones como es el caso del nitrógeno total (NT), que consiste en un número definido de compuestos (nitrato, amonio) y una agrupación de compuestos incontable (nitrógeno particulado, nitrógeno orgánico). Lo mismo ocurre en el caso del fósforo total (PT) que incluye compuestos particulados, fósforo orgánico disuelto y fósforo inorgánico disuelto (Kadlec y Wallace, 2009).

Cuando la mezcla de compuestos pasa por el humedal artificial, las fracciones de la mezcla se degradan con diferentes constantes de eliminación. La composición de la mezcla cambia o, de acuerdo con Kadlec y Wallace (2009), se erosiona. Cada fracción de la mezcla posee su propio valor de $k$ y existe una distribución de valores de $k$ para el conjunto de la mezcla. El comportamiento de erosión en humedales artificiales bajo condiciones ambientales puede ser representado por un modelo TIS en el que la variable $N$ se convierte en un parámetro de ajuste (Kadlec, 2003a). El modelo TIS relajado o modelo $P-k-C^{*}$ se define como:

$$
\frac{C_{s a l}-C^{*}}{C_{e n t}-C^{*}}=\left(1+\frac{k}{P q}\right)^{-P}
$$

donde

$$
\begin{aligned}
& C_{\text {sal }}=\text { concentración de salida o efluente, } \mathrm{mg} \mathrm{L}^{-1} \\
& C_{\text {ent }}=\text { concentración de entrada o afluente, } \mathrm{mg} \mathrm{L}^{-1} \\
& C^{*}=\text { concentración residual o de fondo, } \mathrm{mg} \mathrm{L}^{-1} \\
& k=\text { constante de eliminación, } \mathrm{m} \mathrm{día}^{-1} \\
& q=\text { tasa de carga hidráulica, } \mathrm{m} \mathrm{día}^{-1} \\
& P=\text { número aparente de tanques }
\end{aligned}
$$

El modelo TIS divide el humedal artificial en un número $N$ de tanques o compartimentos donde los contaminantes son degradados independientemente de su composición, por lo que $N$ hace referencia a la hidráulica del agua residual y el tiempo de retención hidráulico. El modelo $P-k-C^{*}$ divide el humedal artificial en un número aparente de tanques $P$ en los que las mezclas de contaminantes se degradan más lentamente que los contaminantes individuales.

$N$ siempre es mayor que $P$ ya que los compuestos orgánicos se mueven más lentamente que el flujo de agua residual dentro del humedal (Fonder, 2010), por lo que se considera que $P$ hace referencia a la fracción de contaminantes degradados en cada tanque y el tiempo de retención 
hidráulico. La ecuación modificada de Arrhenius (Ecuación 4.10) se utiliza para estimar los efectos de la temperatura en la constante de eliminación.

Kadlec y Wallace (2009) comparan los modelos $k-C^{*}, T I S$ y $P-k-C^{*}$ e indican que no hay una gran diferencia entre los resultados de los mismos cuando los rendimientos de eliminación se encuentran por debajo del 50\%. Sin embargo la diferencia entre los resultados de los modelos es muy grande cuando los rendimientos de eliminación son elevados, llegando a haber un factor de orden 10 de diferencia cuando se alcanzan rendimientos del 99\%. Por lo general, el área requerida por un humedal artificial dimensionado con el modelo $P-k-C^{*}$ es superior a la de un humedal artificial dimensionado con el modelo TIS, y éste a su vez requiere de un área superior al compararse con un humedal artificial dimensionado con el modelo $k-C^{*}$. Esta alta sensibilidad al parámetro $P$ implica que no pueden tener lugar altas reducciones de contaminantes a menos que el humedal artificial sea muy eficiente hidráulicamente.

Para la calibración del modelo $P-k-C^{*}$ Kadlec y Wallace (2009) utilizaron datos de numerosos humedales artificiales tanto HSF como HSFH destinados generalmente al tratamiento de agua residual urbana, proporcionando rangos en la distribución de los parámetros de ajuste. Trabajos más recientes proporcionan información sobre la utilización de HSF para el tratamiento terciario de agua residual urbana (Kadlec y col., 2010; Kadlec y col., 2012) y para el tratamiento de agua potable (Kadlec y col., 2011). Al contrario de lo que ocurre con el modelo $k-C^{*}$, la información disponible sobre la aplicación del modelo $P-k-C^{*}$ para el tratamiento de agua residual de origen ganadero con humedales artificiales es escasa. Así mismo el estudio de la influencia de la temperatura en la degradación de contaminantes resulta interesante debido a los diferentes resultados obtenidos en humedales artificiales que tratan este mismo tipo de agua residual.

La aplicación de los modelos $k-C^{*}$ y $P-k-C^{*}$ a este tipo de agua residual permitiría obtener información comparable con la de otros estudios y también obtener nueva información útil para el diseño de humedales artificiales y más específicamente para el diseño de sistemas de flujo combinado tipo MJEA $^{\circledR}$. Se ha utilizado la denominación $k C T$ y $P k C T$ para distinguir a los modelos originales de aquellos a los que se ha incorporado la ecuación modificada de Arrhenius para el estudio de la influencia de la temperatura. 


\subsection{OBJETIVOS}

La evaluación del dimensionado de un sistema de flujo combinado tipo MJEA ${ }^{\circledR}$ para el tratamiento de purines de cerdo tiene como objetivos:

a. Determinar la influencia de la hidrología en el dimensionado del sistema.

b. Calibrar los modelos $k-C^{*}$ y $k C T$ con los datos experimentales analizados en el Capítulo 3 y comparar los parámetros de calibración con los disponibles en la bibliografía.

c. Calibrar los modelos $P-k-C^{*}$ y $P k C T$ con los datos experimentales analizados en el Capítulo 3 para obtener nuevos parámetros de calibración para el dimensionado de humedales artificiales.

d. Determinar qué modelo se ajusta mejor a los datos experimentales.

e. Determinar las dimensiones requeridas por un sistema de flujo combinado tipo MJEA ${ }^{\circledR}$ con los distintos modelos para tratar el agua residual generada por un habitante equivalente. 


\subsection{MATERIALES Y MÉTODOS}

\subsubsection{Balance hídrico}

El sistema de depuración a escala piloto descrito en el Capítulo 3 ha recibido una baja carga hidráulica $(q)$ con un promedio de $14,4 \mathrm{~mm} \mathrm{día}^{-1}$ de agua residual y un tiempo de retención hidráulico (TRH) de aproximadamente 16 días, lo que ha permitido que el balance hídrico del sistema haya estado condicionado por la precipitación y la evapotranspiración. La evapotranspiración ha sido estimada considerando la evapotranspiración de referencia y el coeficiente de macrófito $k_{c}$.

Los coeficientes de macrófito han sido obtenidos a partir de información experimental procedente de otros ensayos para Typha latifolia (Drexler y col., 2008) y Salix atrocinerea (Guidi y col., 2008). Los valores de $k_{c}$ varían a lo largo del periodo de crecimiento del macrófito por lo que se han utilizado los promedios mensuales de $k_{c}$ para el cálculo de la evapotranspiración de cada muestreo. Para el cálculo del coeficiente de macrófito total de la planta piloto $\left(k_{c T}\right)$ se han relativizado los valores de $k_{c}$ en función de la superficie ocupada por cada macrófito mediante la siguiente expresión:

$$
k_{c T}=0,33 k_{\text {cTypha }}+0,66 k_{\text {cSalix }}
$$

donde

$k_{c T}=$ coeficiente de macrófito total

$k_{c \text { Typha }}=$ coeficiente de macrófito de Typha latifolia

$k_{c \text { Salix }}=$ coeficiente de macrófito de Salix atrocinerea

En el caso de aquellos meses para los que no se ha encontrado información (abril, noviembre) se ha utilizado el valor de coeficiente del mes más cercano para calcular el valor de $k_{c T}$. Los valores utilizados para calcular $k_{c T y p h a}, k_{c S a l i x}$ y $k_{c T}$ se incluyen en la Tabla 4.1.

Tabla 4.1. Coeficientes de macrófito de Typha latifolia, Salix atrocinerea y coeficiente de macrófito total. (Drexler y col., 2008; Guidi y col., 2008).

\begin{tabular}{lccc}
\hline Mes & $k_{c T y p h a}$ & $k_{c \text { Salix }}$ & $k_{c T}$ \\
\hline Abril & - & 0,33 & 0,48 \\
Mayo & 0,80 & 0,57 & 0,64 \\
Junio & 0,92 & 1,03 & 0,68 \\
Julio & 1,02 & 2,19 & 2,09 \\
Agosto & 1,09 & 3,49 & 2,66 \\
Septiembre & 1,01 & 3,22 & 2,46 \\
Octubre & 0,90 & 1,43 & 1,24 \\
Noviembre & - & - & 1,24 \\
\hline
\end{tabular}

El caudal de salida estimado se ha calculado mediante la ecuación de balance hídrico. Para ello, se ha utilizado el método FAO Penman-Monteith para el cálculo de la evapotranspiración de referencia (Allen y col., 2006). Los datos meteorológicos se han obtenido a través de la Agencia Estatal de Meteorología (AEMET, 2012). Los datos utilizados corresponden a la estación meteorológica 2661 del aeropuerto de León ubicado en La Virgen del Camino que se encuentra a una altura de 916 metros, latitud $42^{\circ} 35^{\prime} 20^{\prime \prime} \mathrm{N}$ y longitud $-5^{\circ} 38^{\prime} 58^{\prime \prime} \mathrm{O}$, a unos $18 \mathrm{~km}$ en línea recta de la planta piloto (Figura 4.2). 


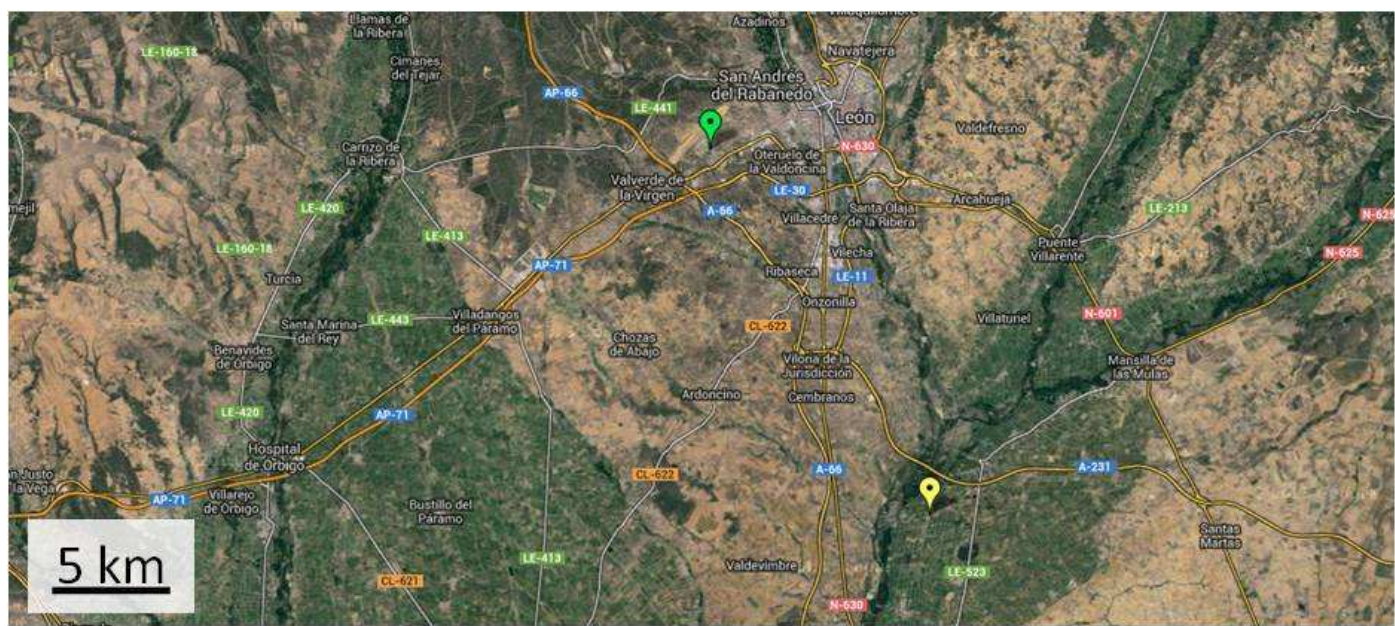

Figura 4.2. Localización de la estación meteorológica (etiqueta verde) y de CENTROTEC (etiqueta amarilla) en la provincia de León. Adaptado de Google (2013).

\subsubsection{Análisis de datos}

La calibración de los modelos $k-C^{*}$ y $P-k-C^{*}$ (Ecuaciones 4.5 y 4.12) con los datos experimentales del Capítulo 3 se ha realizado mediante el método de mínimos cuadrados. El método de mínimos cuadrados estima el valor de los parámetros al ajustar los valores esperados a los datos experimentales utilizando un proceso de prueba y error. Para ello se asume que el "mejor ajuste" es obtenido cuando los valores de los parámetros logran minimizar la suma de cuadrados de los residuos (diferencia entre los valores estimados y los observados).

Se ha utilizado el promedio de los valores de entrada y salida del caudal del sistema completo y de cada una de las etapas para realizar los cálculos del valor de $q$ y así tener en cuenta las influencias meteorológicas en la modificación del TRH.

Los valores de concentración de salida de los contaminantes han sido corregidos para tener en cuenta los efectos de la dilución o la concentración causados por influencias meteorológicas utilizando la siguiente ecuación:

$$
C_{\text {sal_cor }}=C_{\text {sal }}\left(\frac{V_{\text {sal }}}{V_{\text {ent }}}\right)
$$

donde

$$
\begin{aligned}
& C_{\text {sal_cor }}=\text { concentración de salida corregida, } \mathrm{mg} \mathrm{L}^{-1} \\
& C_{\text {sal }}=\text { concentración de salida, } \mathrm{mg} \mathrm{L}^{-1} \\
& V_{\text {sal }}=\text { volumen de salida durante el muestreo, } \mathrm{m}^{3} \\
& V_{\text {ent }}=\text { volumen de entrada durante el muestreo, } \mathrm{m}^{3}
\end{aligned}
$$

Para seleccionar el modelo que mejor explica los datos obtenidos se ha utilizado el criterio de información de Akaike (AIC), método probabilístico que compara modelos anidados creados al ir eliminando parámetros:

$$
A I C=2 p-2 \ln (L)
$$

donde

$L=$ función de verosimilitud

$p=$ número de parámetros independientes estimados en el modelo 
AIC mide la información que se pierde cuando se utiliza un modelo alternativo con distinto número de parámetros. El objetivo es buscar el modelo aproximado, partiendo del modelo completo, que proporcione la menor pérdida de información posible.

La función de verosimilitud es una medida de la capacidad de ajuste del modelo (probabilidad de obtener los datos observados), mientras que $2 p$ representa una penalización debida al número de parámetros (Burnham y Anderson, 1988; Sorensen y Gianola, 2002).

Todos los análisis estadísticos se han realizado con el paquete estadístico R 2.15.1 (RCoreTeam, 2012) para Windows. En el caso de identificarse "outliers", éstos se han estudiado de forma individualizada y se han eliminado de los datos en los casos en los que se ha estimado oportuno. 


\subsection{RESULTADOS Y DISCUSIÓN}

\subsubsection{Balance hídrico}

Los valores promedio de precipitación y evapotranspiración por muestreo se muestran en la Figura 4.3. La precipitación durante el periodo de estudio se ha encontrado en el rango $0-6,02$ $\mathrm{mm}$ día $^{-1}$ con una media de $1,04 \mathrm{~mm} \mathrm{día}^{-1}$. Los episodios de precipitación máximos han tenido lugar en primavera (mayo) y otoño (octubre), siendo junio, julio y agosto los meses de mínima precipitación.

La evapotranspiración calculada se ha encontrado en el rango 0,86 - 11,56 $\mathrm{mm}_{\text {día }}{ }^{-1}$, con una media de 5,67 mm día ${ }^{-1}$. Los periodos de máxima evapotranspiración han tenido lugar durante el periodo estival (junio, julio y agosto) coincidiendo con el periodo de mínima precipitación. La hidrología del humedal artificial durante el periodo de estudio ha estado dominada por la evapotranspiración. Mientras que el volumen de la precipitación ha llegado a suponer un aporte adicional promedio del 7,2\% con respecto al caudal de entrada, la evapotranspiración ha supuesto la pérdida promedio del $39,3 \%$ del caudal de entrada, hasta un $57,1 \%$ si solo se consideran los meses de verano.

La evapotranspiración estimada no ha tenido en cuenta la exposición de los pequeños humedales artificiales al microclima de los alrededores descrito por Kadlec y Wallace (2009). El "efecto oasis" supone un incremento de la evapotranspiración causado por un proceso de advección en el que el aire seco y caliente de los alrededores fluye entre las plantas. También existe el "efecto tendedero" en el que la altura de la vegetación del humedal es superior a la de la vegetación de los alrededores, lo que incrementa la pérdida por evapotranspiración. Por último el "efecto borde" debido a la distribución en serie de las unidades del propio humedal pudo haber incrementado la exposición al movimiento del viento y la intercepción de luz solar (Headley y col., 2012).

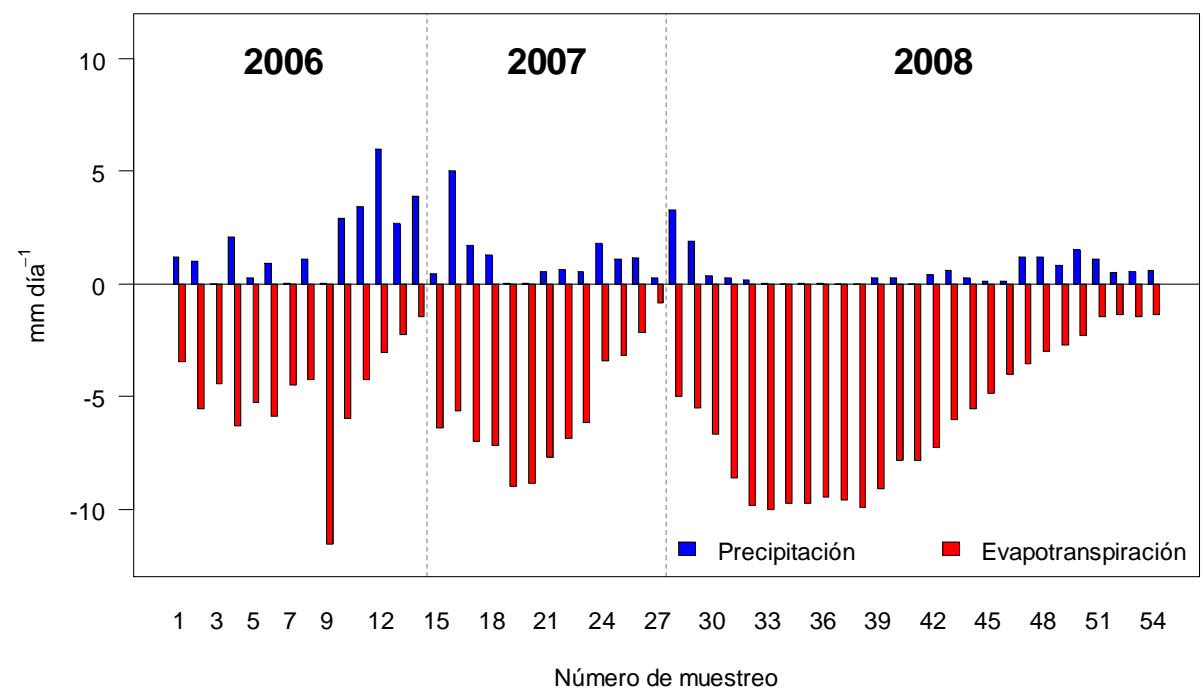

Figura 4.3. Promedio de precipitación y evapotranspiración por muestreo.

\subsubsection{Parámetros de diseño}

El diseño de los humedales artificiales está basado en un enfoque empírico y depende de datos experimentales para seleccionar los parámetros de diseño. Se sabe que la temperatura del agua influye en las constantes de eliminación de algunas de las variables (Knight y col., 2000). El valor del coeficiente de temperatura $\theta$ presente en los modelos $k C T$ y $P k C T$ indica el grado con el que la temperatura influye en la degradación de los contaminantes. Un valor de $\theta$ cercano a 1 
indica una influencia nula de la temperatura y produce valores muy similares entre las constantes de eliminación $k$ (pertenecientes a los modelos originales) y $k_{20}$ (pertenecientes a los modelos modificados con la ecuación de Arrhenius). Valores de $\theta$ superiores a la unidad indican una relación positiva entre la temperatura y la eliminación de un contaminante y generan valores de $k_{20}>k$. Valores de $\theta$ inferiores a la unidad indican que la eliminación se incrementa al disminuir la temperatura y generan valores de $k_{20}<k$ (Stein y col., 2006).

El mejor procedimiento para calibrar el modelo $P-k-C^{*}$ sería realizar el mejor ajuste de los datos experimentales simultáneamente para los tres parámetros $P, k$ y $C^{*}$. Sin embargo si gran parte de los datos de concentración de salida son similares al valor de concentración de fondo $\left(C^{*}\right)-$ como ocurre en el caso de la planta a escala piloto - no es posible realizar una buena estimación de $k$. En estos casos el mejor procedimiento es estimar $P$ para obtener los parámetros $k$ y $C^{*}$ (Kadlec y Wallace, 2009).

El parámetro $P$ representa una combinación de los efectos de la eficiencia hidráulica del sistema y la distribución de las constantes de eliminación para mezclas de contaminantes. Para un único compuesto químico, $P$ es igual al número de tanques en serie $(N)$ determinados mediante el uso de una sustancia trazadora inerte; mientras que para una mezcla, $P$ es siempre menor que $N$ (Kadlec y Wallace, 2009). Cuando $P$ es igual a $N$ se considera que el sistema está actuando en condiciones de flujo pistón lo que quiere decir que el modelo $P-k-C^{*}$ se comporta exactamente igual que el modelo $k-C^{*}$.

En sus trabajos Kadlec suele utilizar valores de $P$ de 1 y 3 (Kadlec y Wallace, 2009; Kadlec y col., 2010; Kadlec y col., 2012). La utilización de valores de $P$ más elevados proporciona resultados similares a los obtenidos en condiciones de flujo pistón mediante el modelo $k$ - $C^{*}$ (valores no mostrados), por lo que en este trabajo se utilizará el mismo criterio.

Para un contaminante consistente en una mezcla de compuestos existe una distribución de las constantes de eliminación entre las diferentes fracciones. Estas distribuciones pueden ser discretas, en el caso de un número contable de compuestos individuales o pueden ser continuas en el caso de un número incontable de compuestos. Combinaciones de ambos tipos de distribución son las variables NT y PT. Para estas variables se ha elegido el valor $P=3$. No se han calibrado los modelos $P-k-C^{*}$ y $P k C T$ para la variable $\mathrm{NH}_{4}{ }^{+}$puesto que se trata de un compuesto individual incluido en la mezcla de compuestos representados en la variable NT. Se ha elegido un valor de $P=1$ para las variables $\mathrm{SST}, \mathrm{DBO}_{5}$ y DQO puesto que se trata de mezclas de compuestos con amplias distribuciones en sus constantes de eliminación.

\subsubsection{Calibración de los modelos}

Los resultados de la calibración de los modelos $k-C^{*}$ y $k C T$ para todo el periodo de estudio se muestran en la Tabla 4.2. El coeficiente de temperatura $\theta$ para cada variable indica la relación entre las constantes de eliminación $k$ y $k_{20}$. El coeficiente de temperatura de SST es cercano a la unidad por lo que $k$ y $k_{20}$ son similares. Las variables $\mathrm{DBO}_{5}, \mathrm{DQO}, \mathrm{NH}_{4}{ }^{+}$y $\mathrm{NT}$ tienen un coeficiente de temperatura inferior a la unidad por lo que $k>k_{20}$, mientras que la variable PT posee un coeficiente de temperatura superior a la unidad por lo que $k<k_{20}$. No se aprecian diferencias importantes entre las concentraciones de fondo de ambos modelos.

La Tabla 4.3 resume la información disponible en otros estudios para su comparación con los resultados obtenidos en la calibración de los modelos $k-C^{*}$ y $k C T$. En el caso de la variable SST los parámetros obtenidos son similares a los calculados por Knight y col. (2000). El valor de $C^{*}$ para la variable SST es similar al comentado en el apartado 3.4.2.1. Los resultados de $k$ de la variable $\mathrm{DBO}_{5}$ se encuentran en el extremo inferior del rango de valores de la Tabla 4.3 para esta variable y la concentración de fondo es similar al valor promedio calculado por Knight y col. (2000). Esta concentración de fondo también se encuentra en el extremo inferior del rango de valores 0 - $25 \mathrm{mg} \mathrm{L}^{-1}$ para la $\mathrm{DBO}_{5}$ al que se hace referencia en el apartado 3.4.2.2. No se han 
encontrado parámetros de la variable DQO en otros estudios sobre humedales artificiales para el tratamiento de agua residual ganadera, sin embargo los valores del coeficiente de temperatura se encuentran muy por debajo del rango de valores 0,958 - 1,029 proporcionado por Stein y col. (2006) para humedales tipo HFSH.

Tabla 4.2. Parámetros $C^{*}, k, k_{20}$ y $\theta$ obtenidos para los modelos $k-C^{*}$ y $k C T$ para el sistema a escala piloto. $\mathbf{n}$ indica el número de muestreos.

\begin{tabular}{|c|c|c|c|c|c|c|}
\hline \multirow{2}{*}{ Variables } & \multirow{2}{*}{$\mathrm{n}$} & \multicolumn{2}{|c|}{ Modelo $k-C^{*}$} & \multicolumn{3}{|c|}{ Modelo $k C T$} \\
\hline & & $C^{*}, \mathrm{mg} \mathrm{L}^{-1}$ & $k, \mathrm{~m}$ año ${ }^{-1}$ & $C^{*}, \mathrm{mg} \mathrm{L}^{-1}$ & $k_{20}, \mathrm{~m} \mathrm{año}^{-1}$ & $\theta$ \\
\hline SST & 49 & 27,88 & 25,57 & 27,96 & 25,05 & 0,993 \\
\hline $\mathrm{DBO}_{5}$ & 46 & 8,52 & 14,09 & 7,26 & 10,58 & 0,966 \\
\hline DQO & 46 & 116,79 & 19,77 & 113,71 & 12,42 & 0,868 \\
\hline $\mathrm{NH}_{4}^{+}$ & 52 & 16,06 & 4,67 & 19,18 & 4,20 & 0,940 \\
\hline NT & 46 & 32,63 & 5,82 & 32,79 & 4,73 & 0,931 \\
\hline PT & 47 & 7,29 & 5,17 & 7,61 & 8,43 & 1,069 \\
\hline
\end{tabular}

Las constantes de eliminación de $\mathrm{NH}_{4}{ }^{+}$y $\mathrm{NT}$ en el sistema han sido muy similares entre sí puesto que la mayor parte del NT se ha encontrado en forma de amonio a lo largo del humedal artificial. Para ambas variables los valores de $k$ se encuentran en el extremo inferior del rango de valores presente en la bibliografía con unos valores muy similares a los obtenidos por Stone y col. (2004). Las concentraciones de fondo sin embargo son muy superiores a las mostradas en la Tabla 4.3, debido a la reducida capacidad de tratamiento de los compuestos de nitrógeno que permite la existencia de unas concentraciones de los contaminantes elevadas en la salida del humedal. Los coeficientes de temperatura son muy inferiores a la información encontrada en otros estudios, que suele ser superior a la unidad.

Las constantes de eliminación y el coeficiente de temperatura de la variable PT son muy similares a los valores promedio calculados por Knight y col. (2000). La concentración de fondo es superior a estos valores promedio aunque se encuentra en el rango encontrado en la bibliografía.

Tabla 4.3. Parámetros $C^{*}, k, k_{20}$ y $\theta$ de humedales artificiales para el tratamiento de agua residual de origen ganadero disponibles en la bibliografía. ${ }^{a}$ indica que el parámetro $C^{*}$ ha sido estimado. b indica que la referencia no procede de un estudio de agua residual de origen ganadero. Los valores entre paréntesis indican el rango de valores calculado para el parámetro.

\begin{tabular}{|c|c|c|c|c|c|}
\hline Referencia & Modelo & Variables & $C^{*}, \mathrm{mg} \mathrm{L}^{-1}$ & $k, \mathrm{~m}$ año ${ }^{-1}$ & $\theta$ \\
\hline \multirow[t]{5}{*}{ Knight y col. (2000) } & $k C T$ & SST & $20^{\mathrm{a}}$ & $21(3-51)$ & 1,01 \\
\hline & & $\mathrm{DBO}_{5}$ & $8^{\mathrm{a}}$ & $22(7-68)$ & $1,03(0,94-1,07)$ \\
\hline & & $\mathrm{NH}_{4}^{+}$ & $3^{\mathrm{a}}$ & $10(-1-26)$ & 1,05 \\
\hline & & NT & $10^{\mathrm{a}}$ & $14(5-32)$ & 1,06 \\
\hline & & PT & $2^{a}$ & $8(2-18)$ & $1,05(0,99-1,14)$ \\
\hline \multirow[t]{3}{*}{ Stone y col. (2002) } & $k C T$ & $\mathrm{NH}_{4}^{+}$ & $4,32-7,73$ & $8,98-9,39$ & $0,98-1,03$ \\
\hline & & NT & $5,81-10,99$ & $8,66-8,85$ & $0,98-1,02$ \\
\hline & & PT & 14,9 & 1,79 & 1,00 \\
\hline \multirow[t]{3}{*}{ Stone y col. (2004) } & $k C T$ & $\mathrm{NH}_{4}^{+}$ & $3^{\mathrm{a}}$ & 4,53 & 1,06 \\
\hline & & NT & $10^{\mathrm{a}}$ & 4,45 & 1,04 \\
\hline & & PT & $2^{\mathrm{a}}$ & 1,67 & 1,03 \\
\hline \multirow[t]{4}{*}{ Jamieson y col. (2007) } & $k-C^{*}$ & SST & $2^{a}$ & $8,7(0,58-66,2)$ & \\
\hline & & $\mathrm{DBO}_{5}$ & $2^{\mathrm{a}}$ & $9,7(0,5-73,8)$ & \\
\hline & & $\mathrm{NH}_{4}^{+}$ & $0,05^{\mathrm{a}}$ & $7,0(0,54-52,3)$ & \\
\hline & & PT & $0,01^{\mathrm{a}}$ & $4,3(5,8-38,4)$ & \\
\hline Stein y col. (2006) & $k C T$ & DQO & & & $0,958-1,029^{b}$ \\
\hline
\end{tabular}

Los resultados de la calibración de los modelos $P-k-C^{*}$ y $P k C T$ se muestran en la Tabla 4.4. En comparación con los parámetros calibrados de los modelos $k-C^{*}$ y $k C T$ (Tabla 4.2), las concentraciones de fondo calculadas para los modelos $P-k-C^{*}$ y $P k C T$ son ligeramente inferiores 
y las constantes de eliminación son superiores para todas las variables, aunque existen importantes diferencias según el valor de $P$ utilizado en la calibración. Aquellas variables calibradas con un valor de $P=1$ presentan unos valores de $k$ y $k_{20}$ muy superiores a los de los modelos $k-C^{*}$ y $k C T$, mientras que las constantes de degradación de los modelos calibrados con $P=3$ son ligeramente superiores.

Estos resultados indican que la elección del valor de tanques aparentes $P$ para las variables NT y PT se aproxima al número de tanques en serie $N$. Cuanto más se aproxime $P$ al valor de $N$, más se acercan las condiciones hidráulicas al flujo pistón, y por tanto más se asemejan las constantes de eliminación a las calculadas mediante la calibración de los modelos $k-C^{*}$ y $k C T$. Los coeficientes de temperatura del modelo $P k C T$ se han mantenido en niveles similares para SST, DQO y PT, y han disminuido para $\mathrm{DBO}_{5}$ y NT en comparación con los del modelo $k C T$.

Tabla 4.4. Parámetros $C^{*}, k, k_{20}$ y $\theta$ obtenidos para los modelos $P-k-C^{*}$ y $P k C T$ para el sistema a escala piloto. $n$ indica el número de muestreos.

\begin{tabular}{lcccc|ccc}
\hline \multirow{2}{*}{ Variables } & \multirow{n}{*}{} & \multirow{2}{*}{$P$} & \multicolumn{2}{c|}{ Modelo $P-k-C^{*}$} & \multicolumn{3}{c}{ Modelo $P k C T$} \\
\cline { 4 - 8 } & & & $C^{*}, \mathrm{mg} \mathrm{L}^{-1}$ & $k, \mathrm{~m} \mathrm{año} \mathrm{N}^{-1}$ & $C^{*}, \mathrm{mg} \mathrm{L}^{-1}$ & $k_{20}, \mathrm{~m} \mathrm{año}^{-1}$ & $\theta$ \\
\hline SST & 49 & 1 & 24,13 & 178,88 & 24,14 & 182,03 & 1,003 \\
DBO $_{5}$ & 46 & 1 & 5,95 & 47,44 & 4,76 & 30,18 & 0,939 \\
DQO & 46 & 1 & 100,62 & 55,17 & 93,52 & 26,90 & 0,887 \\
NT & 46 & 3 & 31,96 & 7,29 & 32,43 & 5,76 & 0,918 \\
PT & 47 & 3 & 7,03 & 6,07 & 7,36 & 10,47 & 1,077 \\
\hline
\end{tabular}

Los coeficientes de determinación $\left(R^{2}\right)$ para cada uno de los modelos y los resultados del análisis AIC se muestran en la Tabla 4.5. Los coeficientes de determinación son muy bajos en el caso de las variables SST, $\mathrm{DBO}_{5}$, DQO y PT lo que indica una baja capacidad de predicción de las concentraciones de salida por parte de los modelos. Los coeficientes de determinación de SST son siempre muy bajos; la capacidad de tratamiento de los SST en el humedal a escala piloto no es dependiente de la concentración de entrada y tiene lugar fundamentalmente en la primera etapa del sistema, por lo que su predicción no es posible en función de las concentraciones de entrada y salida. Los coeficientes de determinación mejoran en el caso de las variables que representan compuestos de nitrógeno, aunque son muy superiores para la variable $\mathrm{NH}_{4}{ }^{+}$en comparación con la variable NT debido a la mayor dificultad que entraña predecir el comportamiento de una mezcla de contaminantes en comparación con un único contaminante.

Tabla 4.5. Coeficientes de determinación y resultados del análisis AIC.

\begin{tabular}{lcccc|cccc}
\hline \multirow{2}{*}{ Variable } & \multicolumn{3}{c|}{ Coeficiente de determinación $\left(R^{2}\right)$} & \multicolumn{3}{c}{ Criterio de Información de Akaike (AIC) } \\
\cline { 2 - 8 } & $k-C^{*}$ & $k C T$ & $P-k-C^{*}$ & $P k C T$ & $k-C^{*}$ & $k C T$ & $P-k-C^{*}$ & $P k C T$ \\
\hline SST & 0,05 & 0,05 & 0,06 & 0,06 & $\mathbf{4 2 4 , 5 9}$ & 426,58 & 426,38 & - \\
DBO $_{5}$ & 0,11 & 0,17 & 0,23 & 0,30 & 325,42 & 324,06 & 324,39 & $\mathbf{3 2 2 , 2 9}$ \\
DQO & 0,03 & 0,12 & 0,14 & 0,28 & 481,86 & 479,12 & 481,93 & $\mathbf{4 7 7 , 5 9}$ \\
$\mathrm{NH}_{4}^{+}$ & 0,61 & 0,70 & - & - & 455,10 & $\mathbf{4 4 2 , 4 2}$ & - & - \\
$\mathrm{NT}$ & 0,36 & 0,50 & 0,40 & 0,53 & 439,95 & 430,62 & 438,58 & $\mathbf{4 2 9 , 3 7}$ \\
$\mathrm{PT}$ & 0,27 & 0,31 & 0,27 & 0,32 & 289,32 & $\mathbf{2 8 8 , 4 6}$ & 290,78 & 289,95 \\
\hline
\end{tabular}

El modelo que mejor se ajusta a los datos experimentales es aquel que obtiene un resultado menor en el análisis AIC. El modelo $P k C T$ es el que mejor describe el comportamiento de las variables $\mathrm{DBO}_{5}$, DQO y NT, sin embargo los valores de $\theta$ para estas variables son difícilmente interpretables biológicamente al compararlos con los calculados en otros sistemas que son muy superiores. Para estas variables sería más apropiado utilizar un modelo que no esté ajustado a la temperatura, como son los modelos $k-C^{*}$ y $P-k-C^{*}$. 

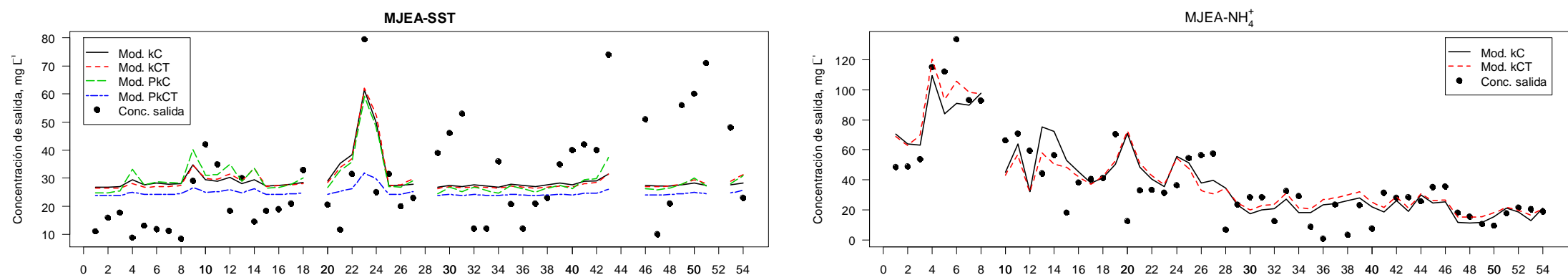

$$
\begin{aligned}
& \text { Número de muestreo } \\
& \text { MJEA-DBO }_{5}
\end{aligned}
$$

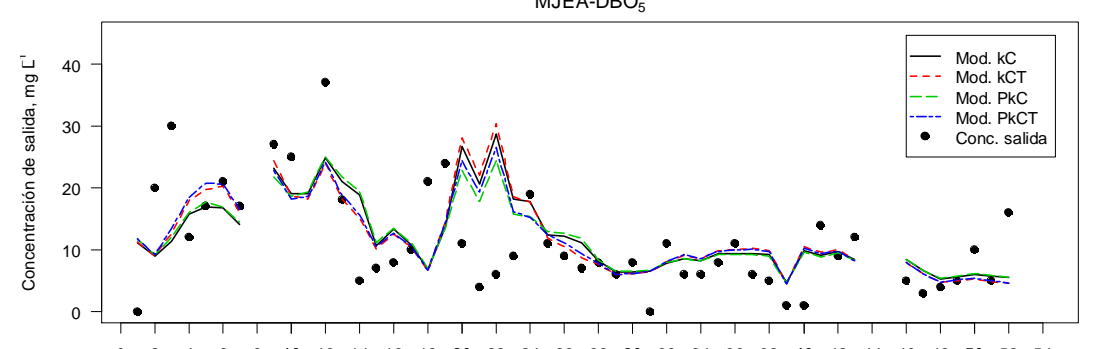

Número de muestreo
MJEA-NT

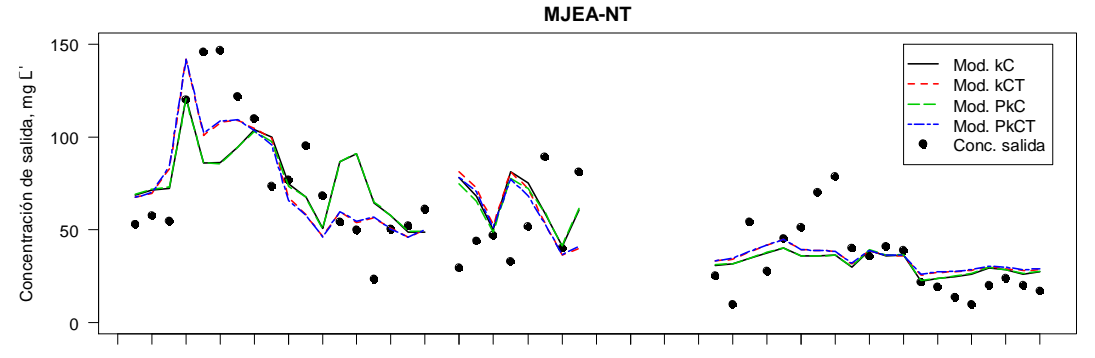

$\begin{array}{llllllllllllllllllllllllllll}0 & 2 & 4 & 6 & 8 & 10 & 12 & 14 & 16 & 18 & 20 & 22 & 24 & 26 & 28 & 30 & 32 & 34 & 36 & 38 & 40 & 42 & 44 & 46 & 48 & 50 & 52 & 54\end{array}$ Número de muestreo
MJEA-PT

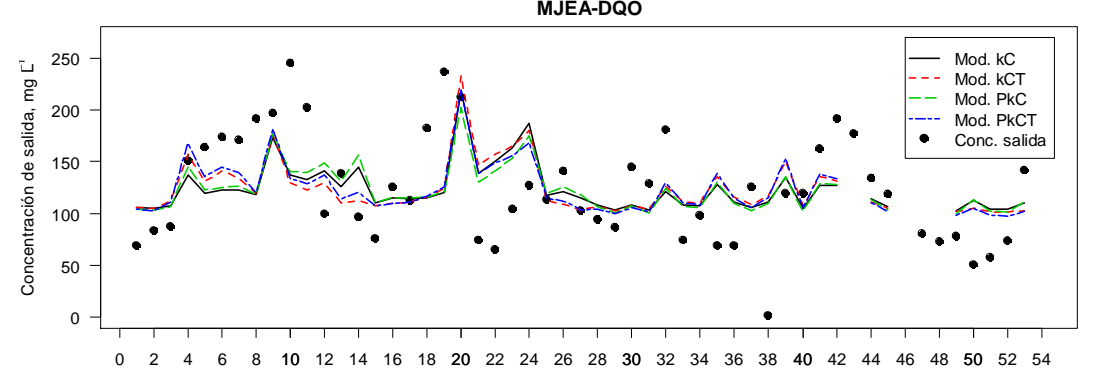

Número de muestreo

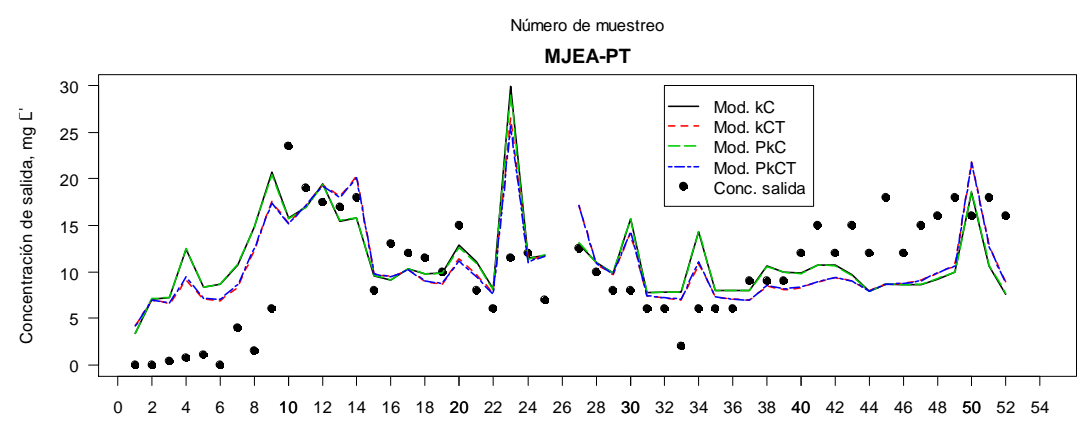

Número de muestreo

Figura 4.4. Concentraciones de salida esperadas mediante el ajuste de los modelos $k-C^{*}, k C T, P-k-C^{*}$ y $P k C T$ frente a los datos de concentración de salida. 
El modelo $k C T$ es el que mejor describe el comportamiento de $\mathrm{NH}_{4}{ }^{+}$y PT lo que indica la influencia de la temperatura sobre estas variables. El modelo $k-C^{*}$ es el que mejor describe la variable SST, sin embargo su capacidad predictiva es muy baja tal y como indican los coeficientes de determinación. El ajuste de los datos a los modelos para cada variable está representado en la Figura 4.4.

\subsubsection{Influencia de la hidrología}

Los parámetros obtenidos tras la calibración de los modelos deben ser aplicados con cautela si la intención es emplearlos para el dimensionado de otros humedales artificiales. Los modelos utilizados no incorporan la variación de componentes hidrológicos externos al sistema, los cuales pueden tener un gran impacto en la hidráulica y el rendimiento del humedal artificial (Jamieson y col., 2007). El caudal a lo largo de un humedal artificial puede ser modificado por componentes hidrológicos externos como precipitación y evapotranspiración, que pueden alterar la calidad del agua. La pérdida de agua debido a la evapotranspiración excesiva reduce la velocidad del agua, incrementa el tiempo de contacto y produce un incremento de la concentración de los contaminantes. Un incremento de la cantidad de agua debido a una precipitación excesiva tiene el efecto contrario; se incrementa la velocidad del agua, se reduce el tiempo de contacto y se diluye la concentración de los contaminantes (Headley y col., 2012).

En general los valores de las constantes de eliminación publicadas en la bibliografía no han sido corregidas para incluir las ganancias o pérdidas de agua en el sistema; en algunos casos la información sobre el balance hídrico no ha sido recogida, mientras que en otros casos las pérdidas o ganancias no se han considerado significativas. Parte de la variación de las constantes de eliminación disponibles en la bibliografía ha de ser atribuida a la falta de ajuste con respecto al balance hídrico (Kadlec y Wallace, 2009). Tales parámetros pueden utilizarse únicamente para predecir el comportamiento de aquellos humedales artificiales cuya eficiencia hidráulica sea similar a la del sistema original (Knight y col., 2000).

La tasa de carga hidráulica $q$ no es un factor tan importante en humedales artificiales como lo es en sistemas convencionales, puesto que los microorganismos que intervienen en los mecanismos de eliminación están asociados con material en suspensión, sustrato y macrófitos en vez de estar distribuidos de forma uniforme en la columna de agua. La importancia de ajustar los parámetros con respecto al balance hídrico se aprecia en la dependencia del modelo con el TRH que condiciona el tiempo de contacto de la población microbiana y el sustrato con el contaminante (Kincanon y McAnally, 2004).

Es posible que la influencia de la hidrología en las constantes de eliminación sea la responsable de los bajos coeficientes de temperatura obtenidos tras la calibración de los modelos. Los bajos valores de $q$ de entrada en el sistema a escala piloto hacen que éste sea muy sensible frente a componentes hidrológicos externos, particularmente la evapotranspiración que es máxima en los meses de verano.

\subsubsection{Influencia de la hidrología en el tratamiento de nitrógeno}

El tratamiento de nitrógeno es particularmente sensible a la temperatura por lo que su análisis permite determinar si existe una influencia de la hidrología en las constantes de eliminación.

La Figura 4.5 muestra las constantes mensuales de eliminación $(k)$ para NT frente a la pérdida de agua en la unidad FS (medida como la diferencia mensual promedio de la evapotranspiración menos la precipitación). Los valores de $k$ han sido calculados mediante el modelo $k$ - $C^{*}$ (Ecuación 4.5) con un valor de $C^{*}=68 \mathrm{mg} \mathrm{L}^{-1}$, que es el resultado de la calibración de los datos mensuales de la unidad FS para todo el periodo de estudio. 
Las constantes de eliminación de NT son mínimas entre los meses de junio y agosto cuando la evapotranspiración y la pérdida de agua en el sistema son máximas, y se recuperan cuando aumentan las precipitaciones y disminuye la pérdida de agua (Figura 4.5).

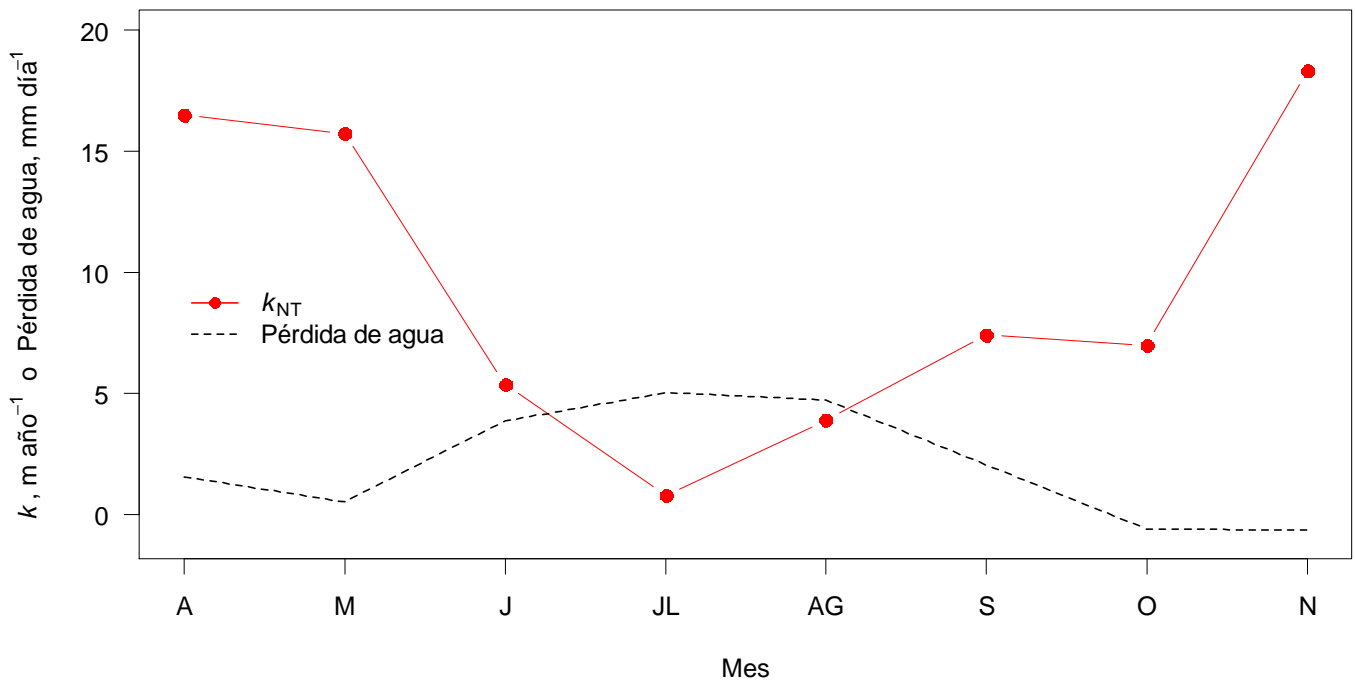

Figura 4.5. Relación entre la Pérdida de agua y la constante de eliminación de NT $\left(k_{\mathrm{NT}}\right)$ en la unidad FS. $C^{*}=68 \mathrm{mg} \mathrm{L}^{-1}$.

Kadlec y Wallace (2009) identifican el perfil de la Figura 4.5 como el correspondiente a los humedales artificiales controlados agronómicamente, aquellos sistemas cuyo comportamiento con respecto a los nutrientes está regulado por la asimilación de nutrientes durante el periodo de crecimiento de los macrófitos y la liberación de nutrientes durante su periodo de senescencia. La asimilación de nutrientes por parte de los macrófitos tiene lugar en primavera y principios de verano cuando la temperatura del agua es menor y cesa cuando la temperatura del agua aumenta en los meses siguientes. Bajos coeficientes de temperatura son indicativos de este tipo de comportamiento.

Sin embargo no es probable que este tipo de regulación de nutrientes tenga lugar en el sistema. De acuerdo con Kadlec y Wallace (2009) los humedales artificiales están controlados agronómicamente cuando la carga de nitrógeno en el sistema es inferior a $120 \mathrm{~g} \mathrm{~N} \mathrm{~m}^{-2}$ año $^{-1}$ lo que supondría una concentración de entrada de unos $8 \mathrm{mg} \mathrm{L} \mathrm{día}^{-1}$ de NT en la unidad FS, valor que se encuentra muy por debajo de las concentraciones de entrada mínimas registradas en la planta piloto.

Posiblemente los bajos valores de $k$ mensuales durante el periodo junio - agosto se deben a la influencia de la evapotranspiración en la carga hidráulica $(q)$. La pérdida de agua durante los periodos de máxima evapotranspiración produce un incremento de la concentración de los contaminantes y reduce el caudal de salida que afecta al valor de $q$ calculado utilizando el promedio de los caudales de entrada y salida del sistema. Todo ello influye en los bajos valores obtenidos para la constante de eliminación $k$ y el coeficiente de temperatura $\theta$.

La influencia de la hidrología también puede apreciarse en los resultados obtenidos en las unidades FSS. La Figura 4.6 muestra la concentración de $\mathrm{NO}_{\mathrm{x}}{ }^{-}$nitrificado y no consumido en las unidades FSS (medido como la diferencia entre la concentración de salida y de entrada de $\mathrm{NO}_{\mathrm{x}}{ }^{-}$en las unidades FSS) frente a la evapotranspiración del sistema para cada muestreo. Las mayores concentraciones de $\mathrm{NO}_{\mathrm{x}}^{-}$producto de la nitrificación en las unidades FSS tienen lugar cuando la evapotranspiración es superior a los $10 \mathrm{~mm} \mathrm{día}^{-1}$ durante los meses de verano. 
Altas temperaturas afectan de forma positiva a la nitrificación, pero no es probable que las altas concentraciones de $\mathrm{NO}_{x}{ }^{-}$se deban únicamente a este proceso. Es posible que la pérdida de agua por evapotranspiración durante estos meses haya provocado un incremento de las concentraciones de $\mathrm{NO}_{\mathrm{x}}{ }^{-}$en el agua residual y un incremento del tiempo de contacto entre el agua residual y los microorganismos, facilitando la acumulación de $\mathrm{NO}_{\mathrm{x}}{ }^{-}$tras su transformación por las bacterias nitrificantes a partir de $\mathrm{NH}_{4}{ }^{+}$.

Esta transformación puede haber sido favorecida particularmente en los muestreos en los que la evapotranspiración haya sido tan fuerte que el lecho de las unidades FSS haya estado expuesto a la atmósfera tal y como ocurre en humedales artificiales de tipo vertical. Periodos de drenaje prolongados permiten la transferencia de oxígeno a través del biofilm adherido al lecho de las unidades FSS. Estas condiciones aerobias permiten la nitrificación del amonio que se ha adsorbido en el lecho cuando las unidades FSS han estado saturadas de agua residual. Cuando el agua residual vuelve a fluir por el lecho los productos de la nitrificación son incorporados a la columna de agua y pasan a estar disponibles para su transformación por las bacterias desnitrificantes (Gregory y col., 2012).

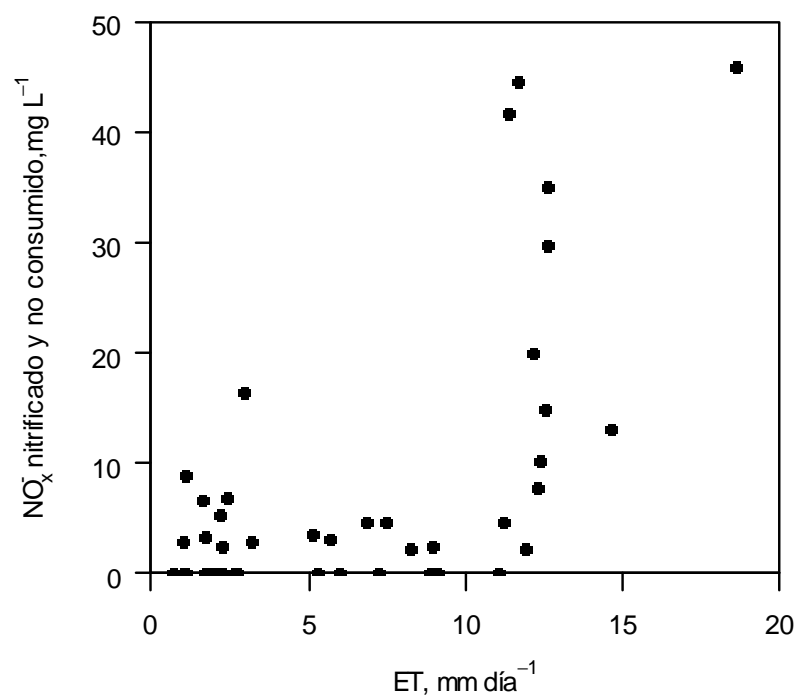

Figura 4.6. Concentración de $\mathrm{NO}_{\mathrm{x}}{ }^{-}$nitrificado y no consumido en las unidades FSS frente a la evapotranspiración en el sistema para cada muestreo.

Es posible que la presencia de altas concentraciones de $\mathrm{NO}_{\mathrm{x}}{ }^{-}$en el efluente también se deba a un proceso de desnitrificación limitado por los elevados tiempos de retención hidráulicos (TRH) en los periodos de máxima evapotranspiración. Elevados TRH favorecen el consumo de la materia orgánica fácilmente biodegradable mientras que la materia orgánica recalcitrante se acumula en el sistema (Jamieson y col., 2007). Esto dificulta la disponibilidad de carbono orgánico para las bacterias desnitrificantes e impide que éstas puedan eliminar los óxidos de nitrógeno acumulados en el sistema.

La disponibilidad de materia orgánica puede apreciarse en los coeficientes de temperatura $\theta$ de $\mathrm{DBO}_{5}$ y DQO (Tabla 4.2). Los coeficientes de temperatura de $\mathrm{DBO}_{5}$ están cercanos a la unidad lo que indica que la evapotranspiración no ha tenido efecto en su degradación, mientras que $\theta$ ha sido muy inferior a los valores presentes en la bibliografía para DQO (Tabla 4.3), lo que indica una fuerte limitación de su degradación durante los periodos de máxima evapotranspiración.

\subsubsection{Calibración de los modelos con los datos corregidos}

Para tener en cuenta los efectos de dilución y concentración causados por influencias meteorológicas es necesario corregir las concentraciones de salida en función del caudal (Reed 
y Brown, 1993). Las concentraciones de salida corregidas han sido utilizadas para calibrar los modelos de nuevo. Los nuevos parámetros han sido denominados $C^{*}{ }_{-}^{*}$ cor,$k_{-}$cor, $k_{20 \_c o r}$ y $\theta_{\text {_cor }}$ para distinguirlos de los previamente calculados.

Los resultados de la calibración de los modelos $k-C^{*}$ y $k C T$ con los datos corregidos se muestra en la Tabla 4.6. La principal diferencia con los datos sin corregir (Tabla 4.2) es una reducción de los valores de la concentración de fondo y un incremento de los coeficientes de temperatura para todas las variables que son más similares a los publicados por otros estudios, particularmente en el caso de DQO, $\mathrm{NH}_{4}{ }^{+}$y NT. El descenso de las concentraciones de fondo se debe a que la corrección ha provocado una disminución de los valores de las concentraciones de salida en los muestreos con bajos valores de caudal de salida. Las constantes de eliminación no han variado de forma importante con la excepción de $k_{-}$cor para DQO que ha descendido desde 19,77 a 11,19 para el modelo $k-C^{*}$.

Tabla 4.6. Parámetros $C_{\text {_cor, }}^{*} \boldsymbol{k}_{\text {_cor }}, \boldsymbol{k}_{20}$ cor $\mathbf{y} \boldsymbol{\theta}_{\text {_cor }}$ obtenidos para los modelos $\boldsymbol{k}$ - $\boldsymbol{C}^{*}$ y $\boldsymbol{k} C T$ utilizando los datos corregidos por los efectos de dilución y concentración para el sistema a escala piloto. $n$ indica el número de muestreos.

\begin{tabular}{|c|c|c|c|c|c|c|}
\hline \multirow{2}{*}{ Variables } & \multirow{2}{*}{$\mathrm{n}$} & \multicolumn{2}{|c|}{ Modelo $k-C^{*}$} & \multicolumn{3}{|c|}{ Modelo $k C T$} \\
\hline & & $C_{\text {cor }}^{*}, \mathrm{mg} \mathrm{L}^{-1}$ & $k_{\text {cor }}, \mathrm{m} \mathrm{año}^{-1}$ & $C_{\text {cor }}^{*} \mathrm{mg} \mathrm{L}^{-1}$ & $k_{20 \_ \text {cor }}, \mathrm{m} \mathrm{año}^{-1}$ & $\theta_{\text {cor }}$ \\
\hline SST & 49 & 18,57 & 23,59 & 17,22 & 26,37 & 1,036 \\
\hline $\mathrm{DBO}_{5}$ & 46 & 1,96 & 10,71 & 1,31 & 9,58 & 0,985 \\
\hline DQO & 46 & 57,35 & 11,19 & 57,89 & 11,49 & 1,004 \\
\hline $\mathrm{NH}_{4}^{+}$ & 52 & 5,19 & 5,24 & 5,59 & 5,19 & 0,995 \\
\hline NT & 46 & 6,45 & 5,58 & 7,27 & 5,41 & 0,988 \\
\hline PT & 47 & $-2,84$ & 3,06 & 0,78 & 7,20 & 1,116 \\
\hline
\end{tabular}

Con respecto a los valores procedentes de otros trabajos (Tabla 4.3) los parámetros de la variable SST siguen siendo similares a los calculados por Knight y col. (2000) y los de la variable $\mathrm{DBO}_{5}$ para el modelo $k-C^{*}$ se asemejan a los calculados por Jamieson y col. (2007). El valor de $\theta_{\text {ccor }}$ para DQO se encuentra en el rango propuesto por Stein y col. (2006). Los parámetros de $\mathrm{NH}_{4}{ }^{+}$y NT se encuentran en el rango de valores de Stone y col. (2002) y Stone y col. (2004). Por último, los valores de los parámetros de PT para el modelo $k C T$ se asemejan a los calculados por Knight y col. (2000).

Los resultados de la calibración de los modelos $P-k-C^{*}$ y $P k C T$ con los datos corregidos se muestran en la Tabla 4.7. Las concentraciones de fondo y las constantes de eliminación fueron en general inferiores a las obtenidas mediante la calibración de los modelos con los datos originales (Tabla 4.4) y muy superiores en el caso de los coeficientes de temperatura.

Tabla 4.7. Parámetros $C^{*}{ }_{-}$cor, $k_{-}$cor, $k_{20}$ cor $\mathbf{y} \theta_{-}$cor obtenidos para los modelos $P-k-C^{*}$ y $P k C T$ utilizando los datos corregidos por los efectos de dilución y concentración para el sistema a escala piloto. $\mathbf{n}$ indica el número de muestreos.

\begin{tabular}{lcccc|ccc}
\hline \multirow{2}{*}{ Variables } & \multirow{2}{*}{} & \multirow{2}{*}{$P$} & \multicolumn{2}{c|}{ Modelo $P-k-C^{*}$} & \multicolumn{3}{c}{ Modelo $P k C T$} \\
\cline { 4 - 8 } & & & $C_{\text {cor }}^{*}, \mathrm{mg} \mathrm{L}^{-1}$ & $k_{\text {cor }}, \mathrm{m} \mathrm{año}^{-1}$ & $C_{\text {cor }}^{*} \mathrm{mg} \mathrm{L}^{-1}$ & $k_{20}$ cor, $\mathrm{m} \mathrm{año}^{-1}$ & $\theta_{\text {cor }}$ \\
\hline SST & 49 & 1 & 13,46 & 134,69 & 13,41 & 194,43 & 1,064 \\
DBO $_{5}$ & 46 & 1 & 0,08 & 33,14 & $-0,31$ & 29,34 & 0,983 \\
DQO & 46 & 1 & 45,19 & 31,55 & 45,87 & 33,50 & 1,009 \\
NT & 46 & 3 & 5,99 & 6,73 & 6,69 & 6,53 & 0,989 \\
PT & 47 & 3 & $-3,59$ & 3,28 & 0,28 & 8,62 & 1,129 \\
\hline
\end{tabular}

Los coeficientes de determinación $R^{2}$ aumentaron al corregir los datos originales frente a los efectos de dilución y concentración, aunque todavía siguen siendo menores de 0,5 para las variables $\mathrm{SST}_{2} \mathrm{DBO}_{5}$ y DQO (Tabla 4.8).

Tabla 4.8. Coeficientes de determinación y Criterio de Información Akaike para los datos corregidos por los efectos de dilución y concentración. 


\begin{tabular}{lcccc|cccc}
\hline \multirow{2}{*}{ Variable } & \multicolumn{3}{c|}{ Coeficiente de determinación $\left(R^{2}\right)$} & \multicolumn{4}{c}{ Criterio de Información de Akaike (AIC) } \\
\cline { 2 - 8 } & $k-C^{*}$ & $k C T$ & $P-k-C^{*}$ & $P k C T$ & $k-C^{*}$ & $k C T$ & $P-k-C^{*}$ & $P k C T$ \\
\hline SST & 0,08 & 0,12 & 0,13 & 0,18 & 415,86 & 415,30 & 414,77 & $\mathbf{4 1 4 , 1 8}$ \\
DBO $_{5}$ & 0,44 & 0,47 & 0,42 & 0,43 & 306,67 & $\mathbf{3 0 6 , 5 3}$ & 307,98 & 308,61 \\
$\mathrm{DQO}^{+}$ & 0,29 & 0,29 & 0,29 & 0,29 & 478,42 & 480,36 & $\mathbf{4 7 8 , 2 4}$ & 480,04 \\
$\mathrm{NH}_{4}^{+}$ & 0,72 & 0,72 & - & - & $\mathbf{4 2 4 , 3 8}$ & 426,23 & - & - \\
$\mathrm{NT}$ & 0,59 & 0,59 & 0,59 & 0,59 & $\mathbf{4 1 4 , 1 3}$ & 415,51 & 415,39 & 417,07 \\
$\mathrm{PT}$ & 0,58 & 0,76 & 0,57 & 0,75 & 274,07 & $\mathbf{2 5 2 , 8 9}$ & 277,33 & 256,39 \\
\hline
\end{tabular}

El efecto de la temperatura en la predicción de los modelos se puede apreciar en el incremento de los coeficientes de determinación entre los modelos $k-C^{*}$ y $k C T$ y $P-k-C^{*}$ y $P k C T$, lo cual ocurre únicamente para las variables SST y PT, aquellas que no estaban influenciadas por la hidrología del humedal (Tabla 4.8).

Los procesos de eliminación de SST en humedales artificiales son procesos físicos que no tienen relación con la temperatura o la estacionalidad (Kadlec, 2003b). Sin embargo las concentraciones de SST en el efluente dependen de procesos físicos y biológicos que intervienen en la generación y el ciclo de sólidos de los humedales artificiales y que están influidos por temperatura y estacionalidad lo que puede llegar a explicar hasta un $50 \%$ de la variación de las concentraciones de salida (Kadlec y Wallace, 2009).

Los coeficientes de temperatura obtenidos para PT pueden atribuirse a la estacionalidad del proceso de descomposición de la biomasa (Akratos y Tsihrintzis, 2007). El resto de variables muestran unos coeficientes de determinación similares para todos los modelos lo que indica que no se observa una influencia de la temperatura en la degradación de estos contaminantes en el humedal artificial.

Los resultados del criterio AIC muestran que tras la corrección de los datos originales los modelos que mejor describen el comportamiento de las variables son modelos menos complejos, con la excepción de la variable SST. La temperatura no mejora la predicción de las variables DQO y NT que están mejor descritos por los modelos $P-k-C^{*}$ y $k-C^{*}$ respectivamente, ni la de la variable $\mathrm{NH}_{4}{ }^{+}$, cuyos datos están mejor ajustados al modelo $k$ - $C$. Sin embargo los datos corregidos para la variable PT están mejor representados por el modelo $k C T$. El ajuste de los datos a los modelos para cada variable está representado en la Figura 4.7.

\subsubsection{Dimensionado de un sistema de flujo combinado tipo MJEA ${ }^{\circledR}$}

Las constantes de eliminación obtenidas en la calibración de los modelos se han utilizado para estimar la superficie requerida por un sistema de flujo combinado tipo MJEA ${ }^{\circledR}$ para alcanzar un nivel determinado de tratamiento de agua residual. La superficie se ha calculado reordenando las ecuaciones de los distintos modelos para resolver la incógnita área $A$. Las constantes de eliminación utilizadas para calcular $A$ se pueden encontrar en las Tablas 4.2, 4.4, 4.6 y 4.7.

Las superficies se han calculado asumiendo un caudal de entrada de $150 \mathrm{~L}$ día $^{-1}$ para un habitante equivalente, que según el Real Decreto - Ley 11/1995 equivale a una carga de $60 \mathrm{~g} \mathrm{DBO}_{5}$ día $^{-1}$ y según Grizzetti y Bouraoui (2006) equivale a una carga de $12 \mathrm{~g} \mathrm{~N}$ día ${ }^{-1}$ y $2,5 \mathrm{~g} \mathrm{P}$ día $^{-1}$. El valor de temperatura del agua elegido equivale al promedio de todo el periodo de estudio y las concentraciones de fondo son las asumidas por Knight y col. (2000) (Tabla 4.9). Las variables SST y DQO no han sido utilizadas para calcular las dimensiones del humedal debido a la baja capacidad de ajuste de los datos a los modelos. 


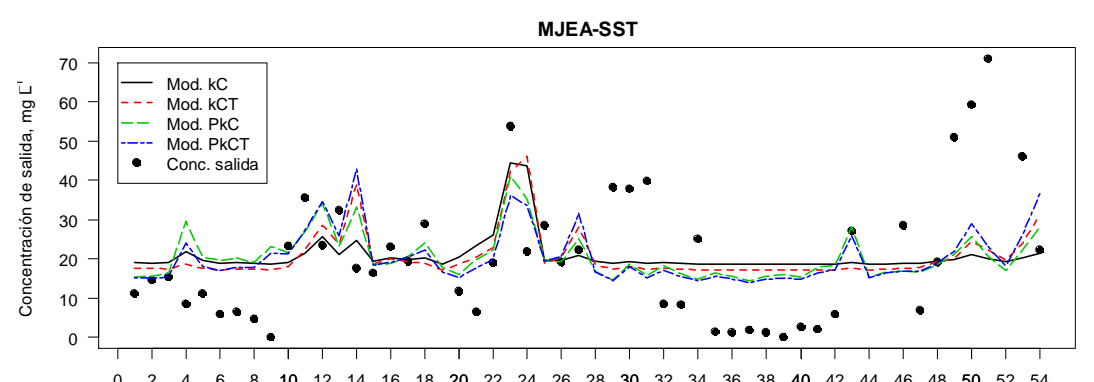

$\begin{array}{llllllllllllllllllllllllllll}0 & 2 & 4 & 6 & 8 & 10 & 12 & 14 & 16 & 18 & 20 & 22 & 24 & 26 & 28 & 30 & 32 & 34 & 36 & 38 & 40 & 42 & 44 & 46 & 48 & 50 & 52 & 54\end{array}$

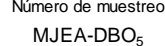

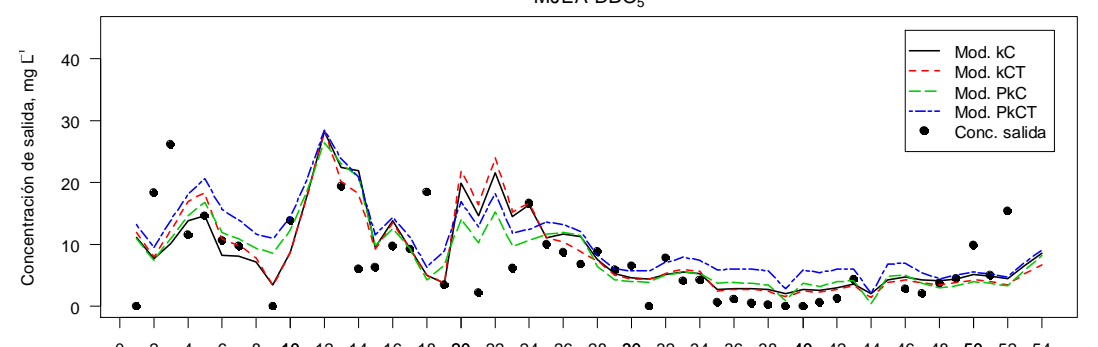

$\begin{array}{llllllllllllllllllllllllllll}0 & 2 & 4 & 6 & 8 & 10 & 12 & 14 & 16 & 18 & 20 & 22 & 24 & 26 & 28 & 30 & 32 & 34 & 36 & 38 & 40 & 42 & 44 & 46 & 48 & 50 & 52 & 54\end{array}$ MJEA-DQO

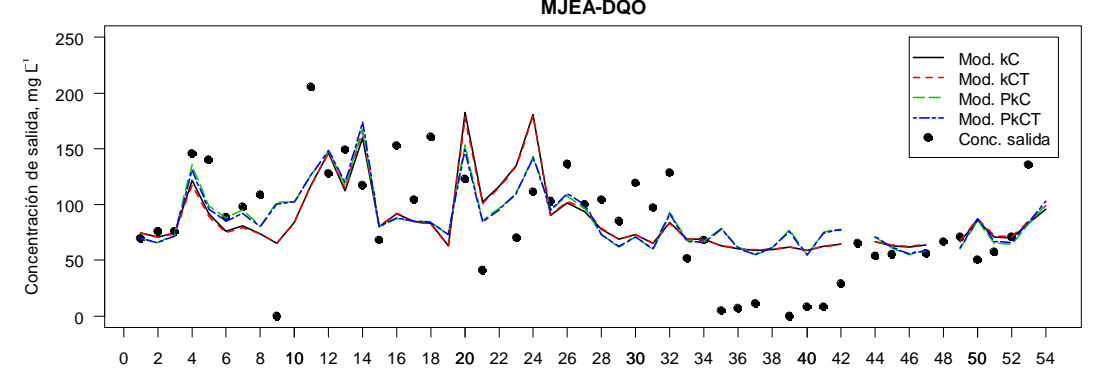

Número de muestreo

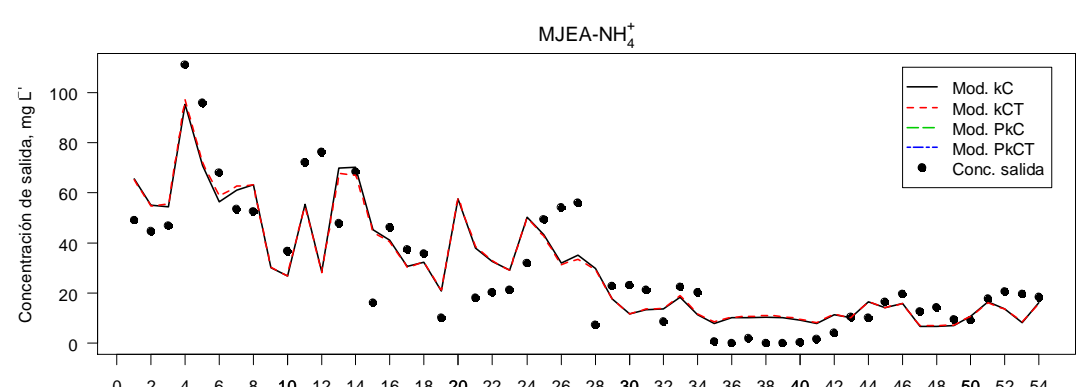

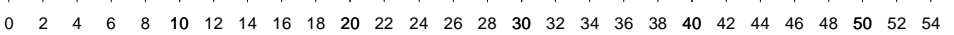
Número de muestreo
MJEA-NT

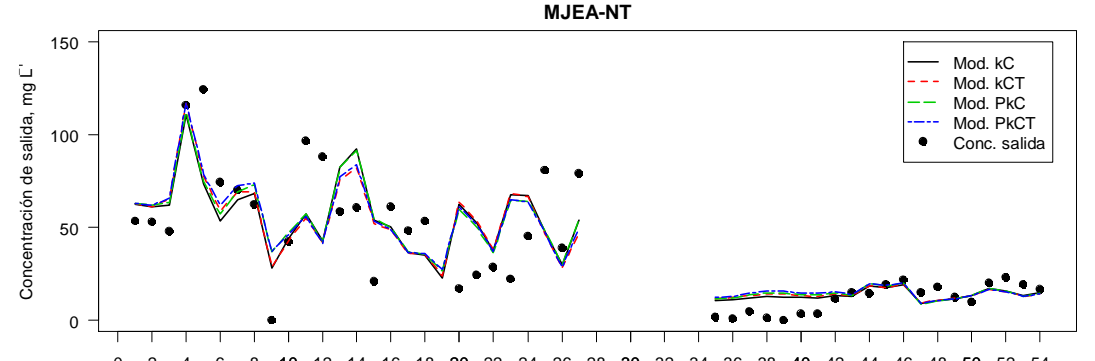
Número de muestreo
MJEA-PT

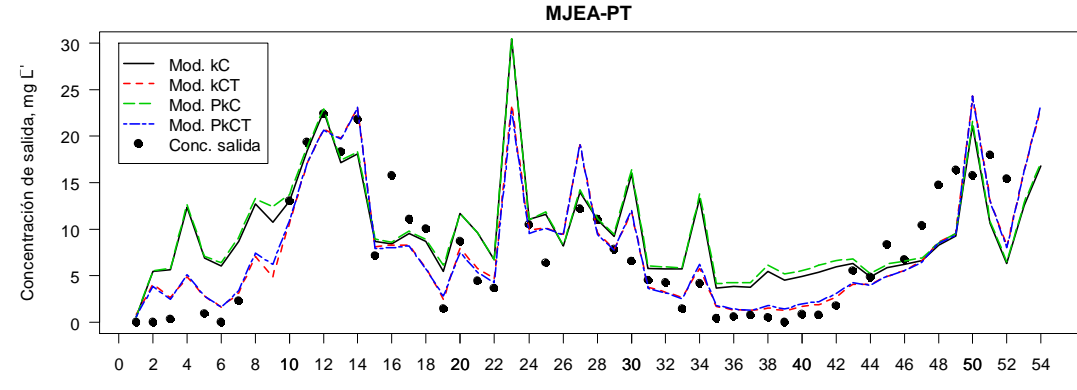

Número de muestreo

Figura 4.7. Concentraciones de salida esperadas mediante el ajuste de los modelos $k-C^{*}, k C T, P-k-C^{*}$ y $P k C T$ con los datos corregidos frente a los datos de concentración de salida corregidos. 
Tabla 4.9. Parámetros utilizados para calcular las dimensiones de un sistema de flujo combinado tipo MJEA $^{\circledR}$.

\begin{tabular}{lcc}
\hline Variables & Valor de entrada & $C^{*}$ \\
\hline $\mathrm{T},{ }^{\circ} \mathrm{C}$ & 16 & - \\
$\mathrm{Caudal}^{3} \mathrm{~m}^{3} \mathrm{dí}^{-1}$ & 0,15 & - \\
$\mathrm{DBO}_{5}, \mathrm{mg} \mathrm{L}^{-1}$ & 400 & 8 \\
$\mathrm{NT}, \mathrm{mg} \mathrm{L}^{-1}$ & 80 & 10 \\
$\mathrm{PT}, \mathrm{mg} \mathrm{L}^{-1}$ & 16,6 & 2 \\
\hline
\end{tabular}

El área de un sistema de flujo combinado tipo MJEA $^{\circledR}$ calculado para cada modelo con los datos originales y corregidos frente a la concentración de salida de cada contaminante se muestra en la Figura 4.8. La curva que define el área requerida decrece con una pendiente suave hasta cambiar de forma asintótica cuando se alcanzan las concentraciones de salida próximas a la concentración de fondo.
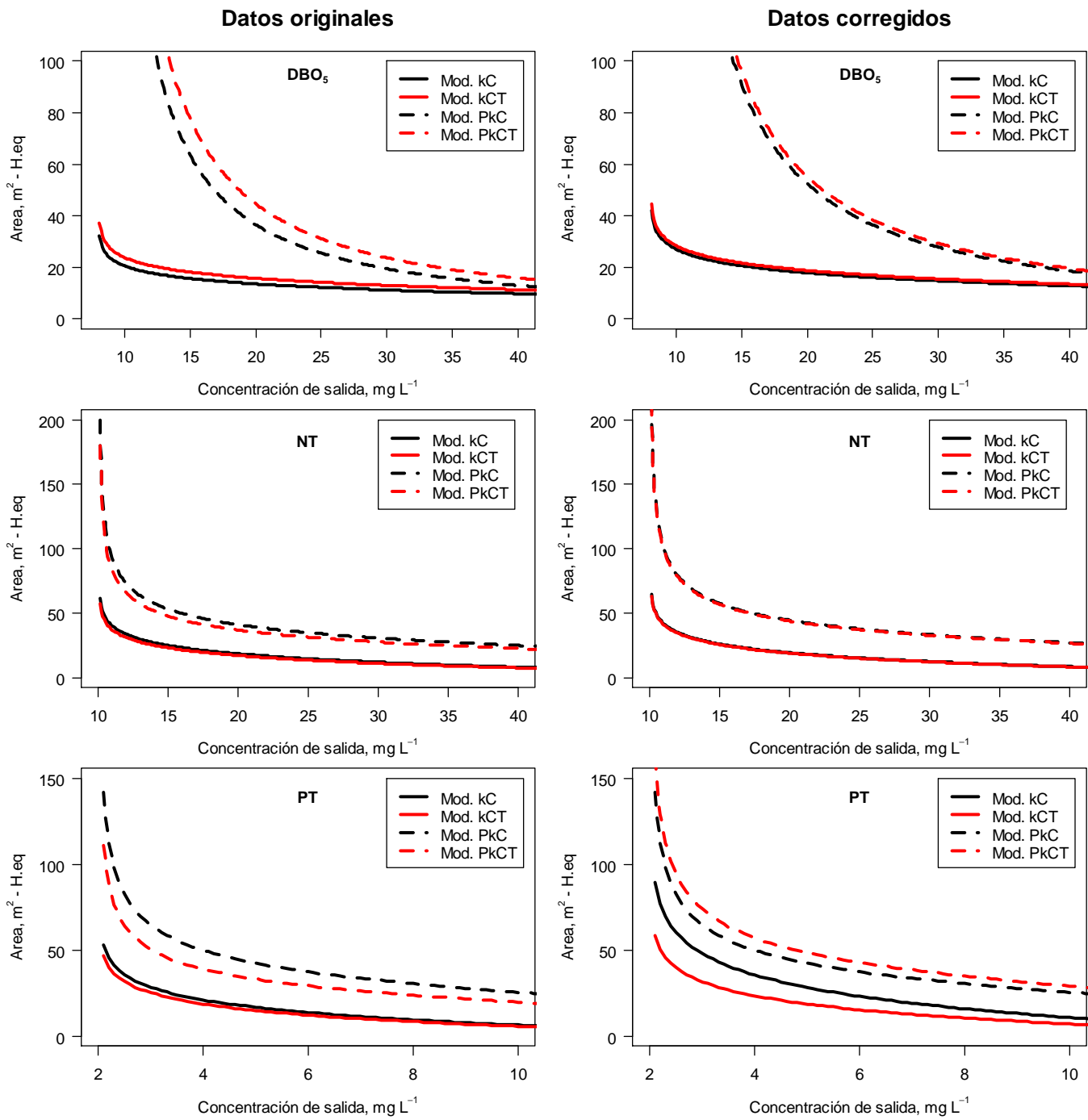

Figura 4.8. Área por habitante equivalente de un sistema de flujo combinado tipo $\mathrm{MJEA}^{\circledR}$ calculada $^{\circledR}$ con las constantes de eliminación de los datos originales y corregidos para los modelos $k-C^{*}, k C T$, $P-k-C^{*}$ y $P k C T$ frente a una concentración de salida objetivo.

El área requerida para reducir la concentración de entrada de $\mathrm{DBO}_{5}$ en un $90 \%$ según el modelo $k-C^{*}$ es de $7,8 \mathrm{~m}^{2} \mathrm{H}_{\text {eq }}{ }^{-1}$ dentro del rango de superficie de $5-10 \mathrm{~m}^{2} \mathrm{H}_{\text {.eq }}{ }^{-1}$ utilizada en otros humedales en Europa para el mismo modelo (Babatunde y col., 2008). Vymazal (1996) indica 
que la eliminación de nutrientes es insuficiente en aquellos humedales artificiales dimensionados como $5 \mathrm{~m}^{2} \mathrm{H}_{\mathrm{eq}}{ }^{-1}$. Según Schierup y col. (1990) un área de entre 15 y $30 \mathrm{~m}^{2}$ H.eq ${ }^{-1}$ sería necesaria para alcanzar una concentración de nitrógeno en el efluente por debajo de $8 \mathrm{mg} \mathrm{L}{ }^{-1}$, mientras que un área de entre 40 y $70 \mathrm{~m}^{2} \mathrm{H}_{\text {.eq }}{ }^{-1}$ sería necesaria para obtener un efluente con una concentración de fósforo inferior a $1,5 \mathrm{mg} \mathrm{L}^{-1}$. El tratamiento de nutrientes en el sistema en estudio es deficiente; alcanzar estos límites de vertido requeriría una superficie muy superior a las recomendadas en estos trabajos.

El área calculada para el tratamiento de cada contaminante varía según el modelo utilizado, aunque es siempre inferior para los modelos $k-C^{*}$ y $k C T$ en comparación con los modelos $P-k-C^{*}$ y $P k C T$. Kadlec y Wallace (2009) indican que no hay gran diferencia entre los resultados de los modelos $k-C^{*}$ y $P-k-C^{*}$ cuando los rendimientos de eliminación se encuentran por debajo del $50 \%$ y la diferencia entre los resultados de los modelos aumenta cuando aumentan los rendimientos de eliminación, llegando a alcanzarse un factor de 10 de diferencia cuando se alcanzan rendimientos del $99 \%$.

Esta relación se cumple para los contaminantes calibrados con los datos originales para un valor de $P=1$, como es el caso de la $\mathrm{DBO}_{5}$, en la que se aprecia una diferencia de un $25 \%$ entre las áreas calculadas mediante los modelos $k-C^{*}$ y $P-k-C^{*}$ para una eficiencia de tratamiento del $90 \%$ (correspondiente a una concentración de salida de $40 \mathrm{mg} \mathrm{L}^{-1}$ ). Sin embargo la relación es muy diferente para los contaminantes calibrados con un valor de $P=3$ como es el caso de NT y PT. Para estas mezclas de contaminantes las diferencias entre las áreas calculadas con los modelos $k-C^{*}$ y $P-k-C^{*}$ alcanzan hasta un $70 \%$ cuando el nivel de tratamiento es todavía del $50 \%$.

Las diferencias de los resultados entre los modelos originales $\left(k-C^{*}\right.$ y $\left.P-k-C^{*}\right)$ y los modelos correspondientes que incorporan la temperatura ( $k C T$ y $P k C T$ respectivamente) no son importantes tal y como puede apreciarse en la Figura 4.8.

La corrección de los datos originales ha generado unos coeficientes de temperatura cercanos a la unidad para las variables $\mathrm{DBO}_{5}$ y NT, por lo que no hay diferencias importantes entre los modelos originales y los que incorporan la ecuación de Arrhenius. En el caso de la variable PT la corrección de los datos si ha tenido un efecto en el área calculada entre los dos tipos de modelos. Según el modelo $k C T$, el hecho de tener en cuenta la temperatura permite utilizar una menor superficie para el tratamiento del PT. La influencia de la temperatura en el modelo PkCT tiene el efecto contrario; se requiere una mayor superficie que la estimada por el modelo $P-k-C^{*}$ para alcanzar un mismo nivel de tratamiento.

El modelo $P-k-C^{*}$ es muy sensible al parámetro $P$. Para mezclas de contaminantes como $\mathrm{DBO}_{5}$ en los que $P=1$, se puede utilizar cualquiera de los modelos siempre y cuando el objetivo de tratamiento del sistema se encuentre por encima del $90 \%$. En este caso por simplicidad es recomendable utilizar los modelos $k-C^{*}$ o $k C T$.

La utilización del modelo $P-k-C^{*}$ para estimar el área requerida para el tratamiento de contaminantes como NT y PT puede dar como resultado áreas de un tamaño superior al $70 \%$ de las calculadas por el modelo $k-C^{*}$ según el nivel de tratamiento que se desea alcanzar. Por motivos económicos es aconsejable utilizar los modelos $k-C^{*}$ o $k C T$ aunque el análisis AIC haya identificado al modelo $P k C T$ como el que mejor se ajusta a los datos originales.

Se han de tener en cuenta las limitaciones del modelo $k-C^{*}$ antes de calcular el área requerida para alcanzar el nivel de tratamiento objetivo. Los parámetros de calibración obtenidos tras la corrección de los datos permiten estimar la superficie de sistemas en los que se ignoran los efectos de las componentes hidrológicas. 


\subsection{CONCLUSIONES}

El sistema de flujo combinado tipo MJEA $^{\circledR}$ para el tratamiento de purines de cerdo está caracterizado por un bajo caudal de entrada y un elevado tiempo de retención hidráulico por lo que está muy influenciado por la hidrología, que está dominada por un periodo de fuerte evapotranspiración entre los meses de junio y agosto. La corrección de los datos experimentales con respecto al caudal de salida del sistema permite utilizar los parámetros obtenidos para el dimensionado de otros sistemas de flujo combinado tipo $\mathrm{MJEA}^{\circledR}$ sin influencia de la hidrología.

La calibración de los modelos $k-C^{*}$ y $k C T$ con los datos del Capítulo 3 corregidos han proporcionado unas constantes de eliminación en el rango inferior de los valores disponibles en la bibliografía para los contaminantes $\mathrm{DBO}_{5}$, NT y PT, lo que indica un bajo rendimiento del sistema de flujo combinado tipo MJEA $^{\circledR}$ para estos contaminantes en comparación con otros sistemas. La influencia de la temperatura ha sido escasa para aquellos contaminantes en los que el coeficiente de temperatura se encontraba próximo a 1, pero muy elevada en el caso del PT que presenta un coeficiente de temperatura superior a la unidad.

El modelo $P-k-C^{*}$ es muy sensible al parámetro $P$. Los valores de las constantes de eliminación para este modelo calibrado con los datos corregidos son muy superiores a las obtenidas para el modelo $k-C^{*}$. Los coeficientes de temperatura indican una baja influencia de la temperatura en la eliminación de $\mathrm{DBO}_{5}$, DQO y NT; y una elevada influencia para PT. La utilización de los modelos $P-k-C^{*}$ y $P k C T$ no consigue un mejor ajuste a los datos experimentales frente a los modelos $k-C^{*}$ y $k C T$.

Las variables que mejor se ajustan a los modelos son $\mathrm{NH}_{4}{ }^{+}$y NT, por lo que es recomendable utilizar los parámetros de calibración obtenidos para estas variables al realizar el dimensionado de un sistema de flujo combinado tipo MJEA $^{\circledR}$. Para los datos de estas variables corregidas frente a la hidrología, el análisis AIC ha identificado el modelo $k-C^{*}$ como el más adecuado para realizar el dimensionado de un sistema de este tipo.

El área calculada con el modelo $k-C^{*}$ para el tratamiento del agua residual generada por un habitante equivalente mediante un sistema de flujo combinado tipo MJEA ${ }^{\circledR}$ es similar a la de otros sistemas para la $\mathrm{DBO}_{5}$, pero requiere de una superficie muy superior en el caso de NT y PT. Las superficies calculadas por modelos $k-C^{*}$ y $P-k-C^{*}$ difieren de forma importante cuando el tratamiento objetivo de $\mathrm{DBO}_{5}$ supera el $90 \%$ o el tratamiento de NT o PT supera el $50 \%$. 




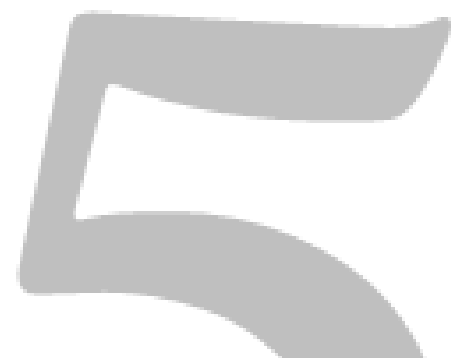

\section{ANÁLISIS FILOGENÉTICO DE LA COMUNIDAD BACTERIANA ASOCIADA A LA RIZOSFERA DE MACRÓFITOS DE SISTEMAS DE FLUJO COMBINADO TIPO MJEA ${ }^{\circledR}$}

\subsection{INTRODUCCIÓN}

\subsubsection{La comunidad microbiana en los humedales artificiales}

El tratamiento del agua residual en los humedales artificiales se basa en la acción combinada de microorganismos, plantas y sustrato. La diversa comunidad microbiana presente en los humedales artificiales puede encontrarse en zonas aerobias, anóxicas y anaerobias y está compuesta por una amplia variedad de bacterias, hongos, algas y protozoos (Scholz, 2003).

Los microorganismos juegan un papel fundamental en la degradación de contaminantes en los humedales artificiales. La degradación biológica mediada por microorganismos en condiciones aerobias o anaerobias es el principal mecanismo de eliminación de la materia orgánica (Vymazal y col., 1998), mientras que la eliminación de nitrógeno depende en gran medida de la actividad microbiana asociada con la nitrificación y la desnitrificación, aunque el descubrimiento de nuevas rutas metabólicas tales como la oxidación anaerobia del amonio (anammox) pueden tener una influencia importante en el tratamiento del nitrógeno (Paredes y col., 2007). Finalmente, los microorganismos también juegan un papel importante en la mineralización del fósforo orgánico ya sea ésta biológica (degradación de la materia orgánica) o bioquímica (hidrólisis enzimática mediante enzimas extracelulares) (Oehl y col., 2004).

Tradicionalmente el estudio de los humedales artificiales se ha centrado exclusivamente en su capacidad de eliminación de nutrientes y patógenos, por lo que se ha tratado estos sistemas como "cajas negras", tecnologías en las que sólo se conocen los datos de entrada y salida y de los que se desconoce su funcionamiento interno (Tietz y col., 2007). Debido a la falta de evidencias directas sobre la composición de la comunidad microbiana presente en los humedales artificiales, un gran número de publicaciones científicas se ha servido de evidencias circunstanciales para atribuir cambios en la composición del agua residual a conocidos procesos microbiológicos que tienen lugar en humedales naturales y sistemas convencionales de tratamiento de agua residual (Faulwetter y col., 2009). 
Es importante determinar la composición y diversidad de las comunidades microbianas así como la identificación específica de los microorganismos activos metabólicamente con el fin de poder comprender los procesos biológicos que tienen lugar en los humedales artificiales (Nogales y col., 2001). Los avances relativamente recientes de los métodos moleculares permiten el estudio de la composición de las comunidades microbianas.

\subsubsection{Técnicas para el estudio de las comunidades microbianas en humedales artificiales}

Existe una gran variedad de técnicas utilizadas para la caracterización de las comunidades microbianas en los humedales artificiales. Cada método proporciona una información específica, por lo que la selección del método juega un papel crucial en los resultados finales de cualquier estudio (Faulwetter y col., 2009).

El método clásico para determinar la abundancia microbiana en muestras de humedales artificiales ha sido la utilización de medios de cultivo generales o selectivos sólidos para el crecimiento de microorganismos en condiciones controladas y el posterior recuento de las colonias formadas o la utilización de medios de cultivo líquidos para la evaluación de la abundancia como número más probable (NMP) (Most Probable Number o MPN). Junto a los métodos de cultivo también se ha utilizado epifluorescencia u observación al microscopio para contar el número de bacterias en las muestras ambientales aunque estas técnicas no han sido utilizadas ampliamente debido al gran esfuerzo requerido y a la limitada información obtenida (Truu y col., 2009). Los métodos de cultivo permiten la evaluación de la abundancia de menos de un $1 \%$ de todos los microorganismos de una muestra ambiental ya que la mayor parte de los microorganismos no pueden cultivarse en condiciones de laboratorio (Sharma y col., 2005). Las limitaciones de estos métodos pueden deberse a la ausencia de algunos nutrientes en el medio de cultivo, a la toxicidad del medio de cultivo para algunos microorganismos o a la producción de sustancias inhibidoras por parte de otros microorganismos presentes en la muestra (Wade, 2002). Independientemente del motivo, la utilización de estos métodos subestima la riqueza real de las comunidades en su ambiente natural (Torsvik y Ovreas, 2002).

La aplicación de métodos moleculares en la ecología microbiana permite la identificación de nuevas especies pertenecientes a linajes de los que no se dispone aún de ningún representante cultivado. Los métodos moleculares más utilizados pueden operar directamente sobre las bacterias o sobre el ADN para la identificación de los microorganismos (Figura 5.1).

El método de hibridación in situ con sondas fluorescentes o FISH (Fluorescence In Situ Hybridization) es un método de tinción celular que permite la identificación y cuantificación de ciertos grupos microbianos a diferentes niveles de resolución taxonómica (Amann y col., 1990). Esta técnica consiste en la fijación química de los microorganismos con paraformaldehído y etanol seguida de una hibridación in situ con sondas fluorescentes (secuencias de entre 10 y 20 nucleótidos marcadas en su extremo con una sustancia fluorescente) que reconocen secuencias del gen ribosomal 16S (ARNr 16S) u otros genes específicos. Una vez hibridados, los microorganismos pueden observarse mediante microscopía de fluorescencia o con citometría de flujo. Este método ha sido utilizado con éxito para determinar la estructura de la población y la dinámica de comunidades bacterianas en diferentes sistemas de tratamiento de agua residual (Schleifer, 2004), sin embargo está limitado a grupos específicos de microorganismos y no permite conocer la estructura de la comunidad microbiana presente en una muestra ambiental.

Los métodos que operan sobre el ADN se basan en la reacción en cadena de la polimerasa o PCR (Polymerase Chain Reaction) para la amplificación de marcadores genéticos utilizando diferentes sets de primers para genes de operones ribosomales y genes funcionales. En el estudio de las interacciones que tienen lugar en los ecosistemas las comunidades bacterianas se comparan en base al ARNr 16S mediante la utilización de técnicas de clonación y secuenciación o de huella genética (también denominadas técnicas fingerprinting) (Truu y col., 2009). 


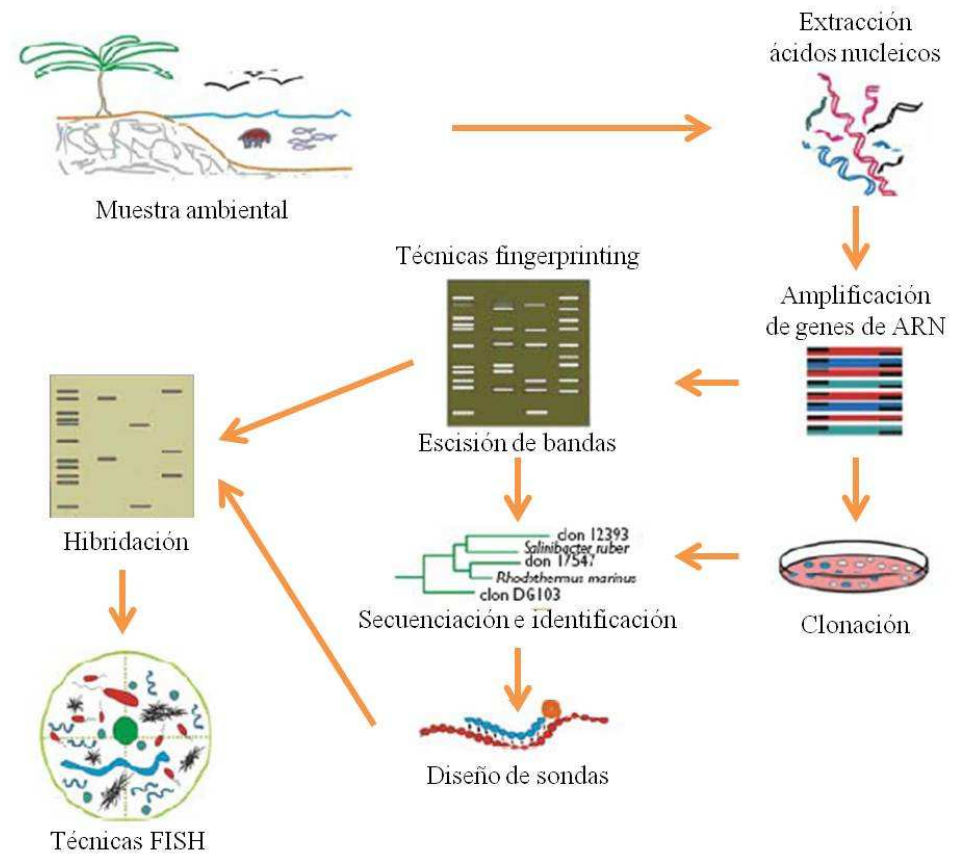

Figura 5.1. Métodos moleculares comunes para el estudio de las comunidades bacterianas en humedales artificiales. Adaptado de Roselló-Mora y Antón (2012).

Las técnicas fingerprinting se basan en la generación de un perfil único para cada comunidad microbiana mediante la separación electroforética de un grupo de productos de la PCR amplificados a partir de ADN o ARN (Oros-Sichler y col., 2007). En general estas técnicas moleculares permiten un análisis rápido y simultáneo de múltiples muestras y son utilizadas para demostrar diferencias entre comunidades microbianas o el efecto de ciertas variables en la composición de estas comunidades. De entre todas las técnicas fingerprinting utilizadas para la caracterización de comunidades bacterianas de humedales artificiales, la electroforesis en gel con gradiente de desnaturalización o DGGE (Denaturing Gradient Gel Electrophoresis) es la técnica más utilizada (Faulwetter y col., 2009). Se trata de un método en el que los productos de la PCR son obtenidos utilizando primers para un marcador molecular específico (por ejemplo ARNr 16S) y sometidos a una separación electroforética en un gel de poliacrilamida que contiene un gradiente linear de un compuesto desnaturalizante como puede ser una mezcla de urea y formamida (Muyzer y col., 1993).

El método más utilizado para analizar los productos amplificados de una PCR de una muestra ambiental es la clonación y posterior secuenciación de los fragmentos de genes individuales. Las secuencias obtenidas son incluidas en librerías de genes y comparadas con secuencias conocidas almacenadas en bases de datos tales como GenBank, Ribosomal Database Project (RDP) o Greengenes (Rastogi y Sani, 2011) lo que permite la identificación filogenética de las muestras. Los avances tecnológicos de los últimos 6 años han permitido el desarrollo de la secuenciación de nueva generación (next generation sequencing o NGS), que permite secuenciar millones de fragmentos de ADN de forma paralela (Rodríguez-Santiago y Armengol, 2012).

Todas las técnicas presentan ventajas y limitaciones, particularmente en el proceso de secuenciación. La DGGE permite obtener un perfil único para cada comunidad microbiana pero su utilización no permite la identificación taxonómica directa (Rastogi y Sani, 2011) aunque con frecuencia se recurre a la secuenciación de las bandas y a su análisis filogenético. La mayor limitación de esta técnica es la corta longitud de los fragmentos amplificados (entre 400 y 500 pares de bases) lo que dificulta los análisis filogenéticos (una secuencia ribosomal 16S se compone de 1.500 pares de bases) y por tanto la correcta caracterización de la comunidad. 
Además los resultados pueden subestimar la composición de la comunidad puesto que la diversidad de las secuencias ARNr 16S es generalmente demasiado baja para distinguir entre grupos de especies relacionadas genéticamente (Truu y col., 2009).

La técnica de clonación y secuenciación tradicional obtiene unos fragmentos amplificados de entre 900 y 1.500 pares de bases, que permiten la secuenciación completa directa. El problema es que se trata de un método que requiere tiempo, recursos económicos y esfuerzo de trabajo para ser utilizado de forma rutinaria en el análisis de la diversidad microbiana de grandes cantidades de muestras (Oros-Sichler y col., 2007). La principal limitación de este método es que tan sólo permite un análisis inicial de la diversidad microbiana de una muestra ambiental. Las muestras ambientales de suelos pueden llegar a requerir alrededor de 40.000 clones para documentar el 50\% de la riqueza (Dunbar y col., 2002), mientras que las bibliotecas de clones de ARNr 16S contienen menos de 1.000 secuencias y por tanto revelan únicamente una pequeña porción de la diversidad microbiana presente en la muestra (Rastogi y Sani, 2011). A pesar de ello las librerías de genes se siguen considerando como el método estándar para los estudios preliminares de diversidad microbiana (DeSantis y col., 2007).

Las técnicas NGS o de secuenciación masiva paralela permiten analizar hasta 10.000 clones por muestra, lo que ha permitido reducir el coste de secuenciación del número de bases (RodríguezSantiago y Armengol, 2012). Su mayor limitación es la corta longitud de los fragmentos amplificados (entre 250 y 300 pares de bases) y el coste económico que supone debido al elevado número de pares de bases que se han de secuenciar.

\subsubsection{Distribución de las comunidades microbianas en los humedales artificiales}

La comunidad microbiana de los humedales artificiales está formada por microorganismos autóctonos y alóctonos. Los microorganismos autóctonos exhiben características adaptativas, son capaces de sobrevivir y crecer en estos ecosistemas y su actividad metabólica les permite participar en los procesos de tratamiento de contaminantes. Los microorganismos alóctonos, que incluyen los patógenos que entran con el agua residual, no suelen sobrevivir o no tienen una importancia funcional en los humedales artificiales (Vymazal, 2005).

La presencia de una comunidad microbiana autóctona estable es considerada un factor decisivo para mantener la estabilidad del ecosistema, la eficiencia del ciclo de nutrientes, la sostenibilidad en el tratamiento de contaminantes y la resiliencia del sistema frente a episodios de contaminación (Torsvik y Ovreas, 2002). La estabilización de las comunidades microbianas en los humedales artificiales a partir de inóculos o de la propia comunidad bacteriana presente en el agua residual es un proceso que puede requerir entre 75 y 100 días para las comunidades presentes en el agua intersticial o el sedimento (Weber y Legge, 2011; Ramond y col., 2012). Una vez estabilizada, la distribución espacial de la comunidad microbiana en los humedales artificiales depende de los potenciales de reducción-oxidación (redox) del agua residual que determinan las condiciones en las que tienen lugar los procesos bioquímicos (aerobias, anóxicas $\mathrm{o}$ anaerobias), mientras que $\mathrm{pH}$ y temperatura influyen en el rango en el que sucede una reacción bioquímica en particular (Paredes y col., 2007).

Los humedales artificiales pueden ser diseñados para favorecer un amplio rango de potenciales redox - permitiendo la presencia de una variedad de procesos biológicos y la eliminación de múltiples contaminantes - o para favorecer un rango limitado de potenciales redox que permita la actividad de un grupo de microorganismos específico. Además del tipo de humedal artificial, otros factores tales como el modo de operación, el tipo de macrófito y la estación del año pueden alterar el potencial redox (Faulwetter y col., 2009).

Las comunidades microbianas de los humedales artificiales de flujo superficial (HFS) son más complejas que las de los sistemas subsuperficiales ya que los microorganismos pueden desarrollarse en diferentes compartimentos como son el sustrato, el agua, los sedimentos o la 
superficie de macrófitos y detritos (Sundberg y col., 2007). La mayor parte de la biomasa microbiana en un HFS está localizada en los sedimentos (81-95\%), pero la abundancia relativa de la biomasa heterótrofa en los diferentes compartimentos depende de la carga de materia orgánica. En condiciones limitantes de aporte de materia orgánica en el agua residual las bacterias se desarrollan sobre las superficies de sedimentos donde su crecimiento está favorecido por una mayor disponibilidad de materia orgánica, mientras que condiciones de alta carga de materia orgánica $\left(32-396 \mathrm{~g}\right.$ DQO día $\left.\mathrm{a}^{-1} \mathrm{~m}^{-3}\right)$ permiten el crecimiento de bacterias en la columna de agua y el biofilm epifítico (Tao y col., 2007). La influencia de la temperatura no es importante en la actividad de la biomasa heterótrofa en HFS debido a la diversidad de la comunidad que incluye numerosas poblaciones de microorganismos que pueden continuar su metabolismo a diferentes temperaturas (Tao y col., 2007).

Los HFS son considerados anóxicos y presentan un gradiente de oxígeno disuelto y potencial redox que disminuye con la profundidad desde una fina capa aerobia en la superficie hasta unas condiciones muy reductoras en la matriz del sustrato (Kadlec y col., 2000; Szogi y col., 2004; Tao y col., 2006). Pueden encontrarse zonas profundas con un alto potencial redox lo cual puede explicarse por una baja difusión de los contaminantes a través de la matriz del lecho (Fox y Doner, 2003) y por la oxigenación de la rizosfera por las plantas (Brix, 1997). La superficie de los detritos de macrófitos y la rizosfera son los lugares en los que se encuentra la mayor capacidad de oxidación de amonio y nitrito por parte de las bacterias oxidadoras del amonio en HFS para el tratamiento de lixiviados de vertedero (Sundberg y col., 2007).

Los principales factores que influyen en las condiciones redox de los humedales artificiales de flujo subsuperficial horizontal (HFSH) son la longitud y la profundidad del sistema. El potencial de reducción-oxidación generalmente aumenta desde la entrada hasta la salida del humedal artificial debido a la progresiva biodegradación de los contaminantes y a la filtración mecánica de los sólidos en suspensión (Faulwetter y col., 2009). La mayor parte de las bacterias (hasta el $78 \%$ ) que entran formando parte del agua residual están muertas o dañadas y son eliminadas fácilmente. En un estudio de cuatro humedales artificiales Decamp y Warren (2001) estimaron que la reducción de la abundancia de bacterias totales desde la entrada a la salida del humedal alcanza el $67 \%$ en HFSH para el tratamiento secundario y entre el 15 y el $39 \%$ en un HFSH utilizado para el tratamiento terciario de agua residual urbana.

La profundidad tiene una influencia mayor que la longitud en la distribución de las poblaciones microbianas en HFSH (Krasnits y col., 2009). El potencial redox en HFSH es más elevado en la superficie $(5-20 \mathrm{~cm})$ posiblemente debido a la difusión pasiva de oxígeno y a la liberación de oxígeno por las plantas, y se reduce con la profundidad (Allen y col., 2002) pudiendo ser alterado por cambios en el nivel del agua que a su vez afectan considerablemente la estructura y la distribución espacial de la comunidad microbiana (Nurk y col., 2005). El perfil vertical del gradiente redox varía de acuerdo con la longitud del humedal artificial y presenta una menor variación vertical cerca de la entrada en comparación con la salida (Kadlec y Knight, 1996). Existe una tendencia general para la reducción de la actividad metabólica microbiana de la biomasa autóctona entre la superficie $(0-10 \mathrm{~cm})$ y las capas más profundas, probablemente debido a cambios en la composición de la materia orgánica a lo largo del gradiente de profundidad (Nurk y col., 2005). Los microorganismos cuyo metabolismo depende de la presencia de oxígeno y que llevan a cabo procesos tales como nitrificación y respiración aerobia están más presentes en las capas superiores de estos sistemas, mientras que la ausencia de oxígeno en las capas más profundas favorece la presencia de microorganismos que intervienen en procesos tales como desnitrificación y metanogénesis (Kern, 2003).

\subsubsection{Efecto de los macrófitos en las comunidades microbianas de los humedales artificiales}

La rizosfera de los macrófitos es el compartimento de los humedales artificiales donde los procesos de tratamiento fisicoquímico y biológico tienen lugar inducidos por la acción combinada de microorganismos, plantas y sustrato con los contaminantes. El área de la rizosfera 
en la que se espera una mayor interacción entre la planta y los microorganismos en un humedal artificial es aquella que se encuentra entre la superficie de la raíz y sus alrededores (Stottmeister y col., 2003). Tanto macrófitos como sustrato proporcionan hábitats favorables para el desarrollo y la supervivencia de las bacterias en la rizosfera al permitir la exclusión de depredadores por el tamaño de poro (Postma y van Veen, 1990). El tipo de sustrato puede condicionar el establecimiento de comunidades microbianas específicas (Vacca y col., 2005), sin embargo los macrófitos son probablemente más beneficiosos para el crecimiento bacteriano que los sustratos debido al transporte de oxígeno hacia la raíz que permite el mantenimiento de la actividad de la biomasa aerobia ( $\mathrm{Li} \mathrm{y} \mathrm{col.,} \mathrm{2008).}$

La liberación de oxígeno genera una capa de condiciones oxidadas alrededor de la raíz con un gradiente redox entre $500 \mathrm{mV}$ muy cerca de la raíz hasta $-250 \mathrm{mV}$ a una distancia de entre 1 y $20 \mathrm{~mm}$ de distancia de la superficie de la raíz. Como resultado, la rizosfera exhibe un mosaico de fuertes gradientes redox (Figura 5.2) que permite la formación de nichos ecológicos que promueven una multitud de procesos microbianos (Faulwetter y col., 2009). Además los macrófitos también liberan exudados de carbono a través de las raíces en el proceso conocido como rizodeposición. Entre los compuestos de carbono identificados que se liberan en la rizodeposición se incluyen azúcares, vitaminas (tiamina, riboflavina y piridoxina) ácidos orgánicos (malato, citrato, aminoácidos, ácidos benzoicos y fenol) y otros compuestos orgánicos (Stottmeister y col., 2003).

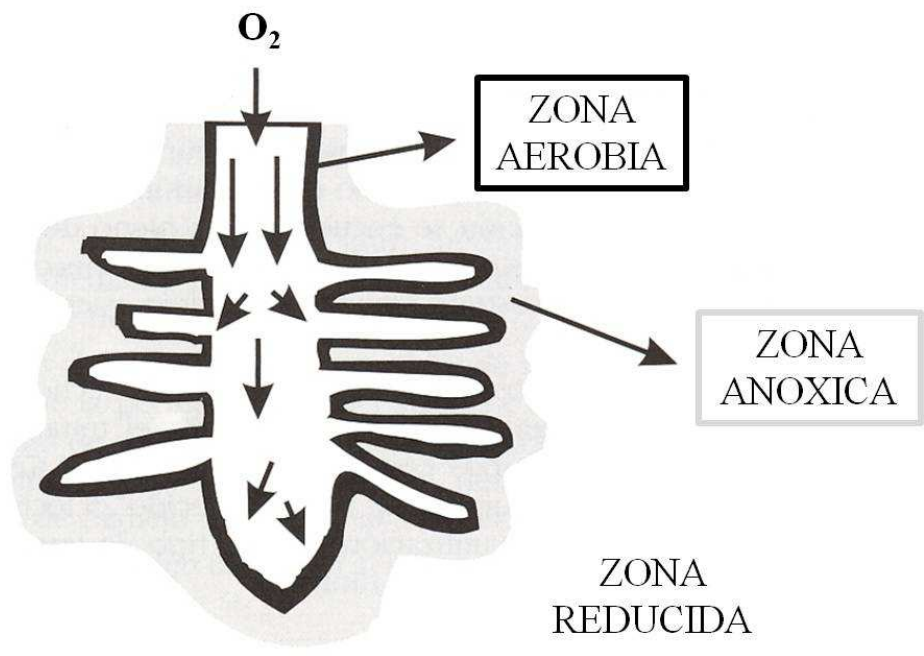

Figura 5.2. Condiciones de reducción-oxidación en la rizosfera de macrófitos de humedales artificiales. Adaptado de Brix (1993).

El efecto de la vegetación en la estructura de la comunidad microbiana se ha analizado en numerosos estudios mediante la comparación de humedales artificiales plantados y no plantados. Algunos autores no han encontrado diferencias significativas entre ambos tipos de sistemas con respecto a la biomasa microbiana (Larsen y Greenway, 2004; Tietz y col., 2007) aunque en general las publicaciones confirman que la presencia de macrófitos mejora la densidad, actividad y diversidad microbiana (Vacca y col., 2005; Gagnon y col., 2007; Weber y col., 2008; Calheiros y col., 2009; Sleytr y col., 2009; Zhang y col., 2010; Weber y Legge, 2011), lo que sugiere que la presencia de plantas favorece el establecimiento de microorganismos responsables de la eliminación de contaminantes (Faulwetter y col., 2009).

Además la rizosfera permite el desarrollo de una comunidad más estable ecológicamente y más robusta frente a cambios en la composición del agua residual de entrada al sistema en comparación con los sistemas no plantados, en los que la composición de la comunidad microbiana varía significativamente como respuesta a perturbaciones externas (Weber y col., 
2008; Zhao y col., 2010). La gran masa radicular desarrollada y su contenido en materia orgánica puede ayudar también a que la composición de la comunidad microbiana resista a los efectos desfavorables de la variación estacional (Zhao y col., 2010). Cambios en la densidad de los macrófitos en un humedal artificial pueden afectar a la diversidad de la comunidad microbiana (Ibekwe y col., 2006) mientras que la diversidad de las especies de macrófitos afecta a la biomasa de la comunidad microbiana aunque no promueve el desarrollo de su estructura (Zhang y col., 2010). Otros estudios demuestran que la presencia de plantas no tiene un efecto importante sobre la estructura de las comunidades microbianas de grupos funcionales específicos en humedales artificiales (Ahn y col., 2007; DeJournett y col., 2007; Gorra y col., 2007; Zhu y col., 2007), aunque el objetivo de estos estudios no es la caracterización ecológica de estos ecosistemas (Baptista y col., 2008).

El tipo de macrófito también tiene un efecto importante en la composición, diversidad y riqueza de las comunidades bacterianas establecidas en la rizosfera de un humedal artificial (RuizRueda y col., 2009; Calheiros y col., 2010; Arroyo y col., 2013). Las tasas de liberación de oxígeno varían según la especie de macrófito (Brix, 1997; Stottmeister y col., 2003). Por ejemplo Typha latifolia $\left(1,41 \mathrm{mg} \mathrm{O}_{2} \mathrm{~h}^{-1}\right.$ planta $\left.^{-1}\right)$ presenta la mayor de estas tasas seguida por Phragmites australis $\left(1 \mathrm{mg} \mathrm{O}_{2} \mathrm{~h}^{-1}\right.$ planta $\left.^{-1}\right)$, Juncus effusus $\left(0,69 \mathrm{mg} \mathrm{O}_{2} \mathrm{~h}^{-1}\right.$ planta $\left.^{-1}\right)$ e Iris pseudacorus $\left(0,34 \mathrm{mg} \mathrm{O}_{2} \mathrm{~h}^{-1}\right.$ planta $^{-1}$ ) (Wießner y col., 2002). Además de la tasa de liberación de oxígeno, la morfología de las raíces, el crecimiento de la biomasa aérea o los exudados liberados en la rizodeposición son característicos de cada especie de planta por lo que cada especie de macrófito permitirá el desarrollo de una comunidad microbiana específica en su rizosfera (Bürgmann y col., 2005; Gagnon y col., 2007; Ge y col., 2011).

\subsubsection{Comunidades bacterianas asociadas a la rizosfera de humedales artificiales para el tratamiento de agua residual porcina}

Las comunidades microbianas de agua residual porcina han sido caracterizadas ampliamente tanto en las fosas de almacenamiento de purines (Ziemer y col., 2004), como en sistemas de tratamiento convencional de agua residual (Whang y col., 2009; Kim y col., 2010) o en sistemas de lagunaje (Cook y col., 2010; Ducey y Hunt, 2013). Sin embargo es difícil encontrar información relacionada con el estudio de la estructura de las comunidades microbianas en humedales artificiales para el tratamiento de agua residual porcina.

La escasa información disponible analiza la estructura de las comunidades microbianas de muestras de suelos o de la columna de agua de humedales artificiales tipo Marsh-Pond-Marsh (Dong y Reddy, 2010, 2012). Únicamente Arroyo y col. (2010) estudian las comunidades presentes en la rizosfera de los macrófitos. El presente estudio pretende analizar las comunidades de bacterias asociadas a la rizosfera de los macrófitos de dos sistemas de flujo combinado tipo MJEA $^{\circledR}$, así como las comunidades asociadas al sedimento de estos sistemas. Parte de este análisis se ha publicado en Arroyo y col. (2010). 


\subsection{OBJETIVOS}

El análisis filogenético de la comunidad bacteriana asociada a la rizosfera de macrófitos de sistemas de flujo combinado tipo MJEA ${ }^{\circledR}$ tiene como objetivos:

a. Caracterizar las comunidades bacterianas del lodo de una balsa de purines y de la rizosfera de Typha latifolia y Salix atrocinerea de un sistema de flujo combinado tipo MJEA $^{\circledR}$ para el tratamiento de agua residual porcina.

b. Caracterizar las comunidades bacterianas del sedimento de la etapa de lagunaje y de la rizosfera de Typha latifolia y Salix atrocinerea de un sistema de flujo combinado tipo MJEA $^{\circledR}$ para el tratamiento de agua residual urbana.

c. Realizar un análisis comparativo de las comunidades bacterianas de ambos sistemas de tratamiento.

d. Analizar los metabolismos de las secuencias de referencia para confirmar la presencia de organismos relacionados con la transformación y eliminación de nitrógeno en el sistema de tratamiento de agua residual porcina. 


\subsection{MATERIALES Y MÉTODOS}

En este capítulo se comparan las comunidades bacterianas asociadas al sedimento y a la rizosfera de macrófitos de dos sistemas de flujo combinado tipo MJEA ${ }^{\circledR}$. Los datos obtenidos experimentalmente proceden de la planta a escala piloto para el tratamiento de purines de cerdo descrita previamente (véase apartado 3.3.1). Estos datos se han comparado con información disponible de estudios previos procedente de una planta a escala real para el tratamiento de agua residual urbana.

\subsubsection{Planta a escala real para el tratamiento de agua residual urbana}

El sistema de tratamiento a escala real depura el agua residual de la localidad de Bustillo de Cea

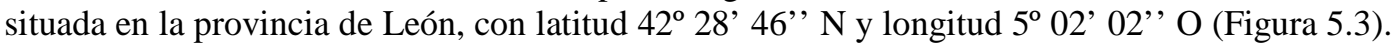
Bustillo de Cea es una pequeña población de 115 habitantes empadronados en 2012 (INE, 2013) y 450 habitantes equivalentes en su máximo estacional (Arroyo, 2011).

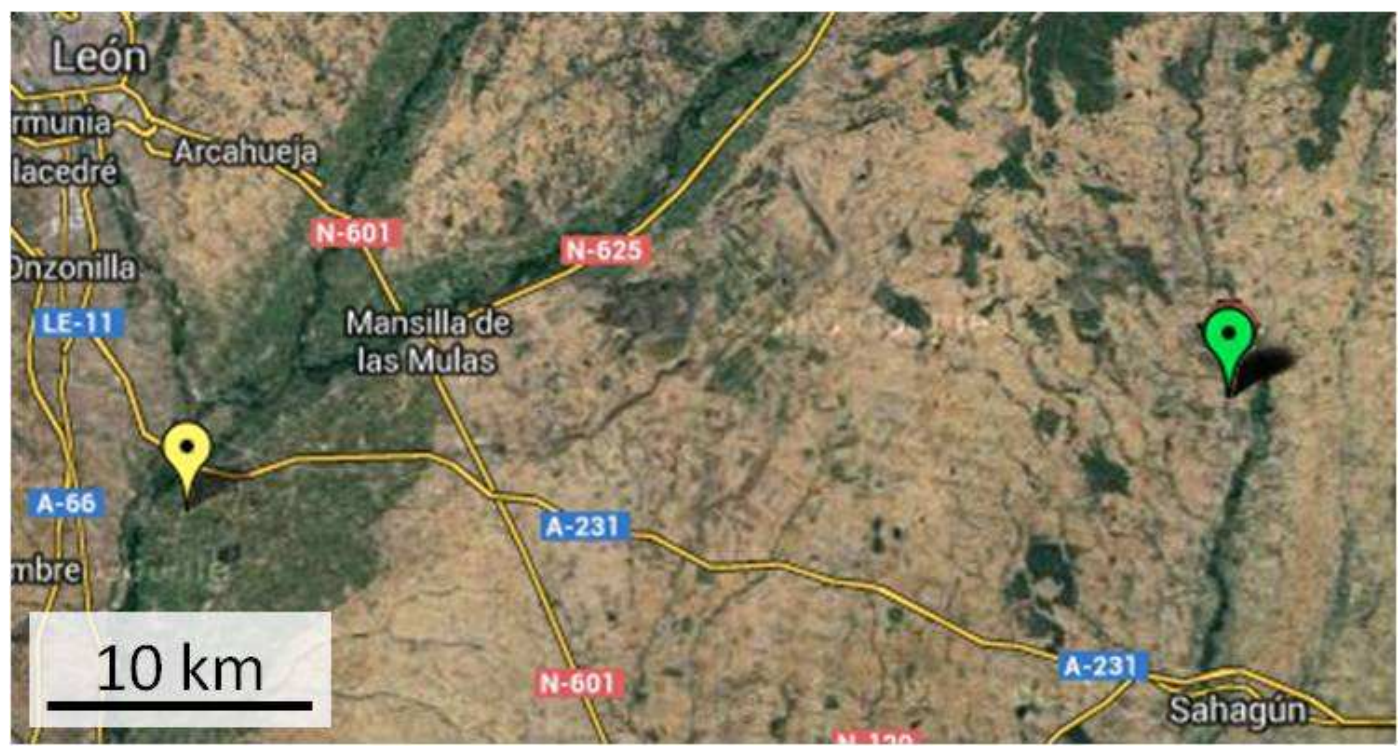

Figura 5.3. Localización de Bustillo de Cea (etiqueta verde) y de CENTROTEC (etiqueta amarilla) en la provincia de León. Adaptado de Google (2013).

La planta a escala real ha estado en funcionamiento desde 1999 hasta la actualidad. La instalación consta de una etapa de pretratamiento constituida por una balsa de decantación y unas rejillas de desbaste y un humedal artificial que está constituido por tres etapas que ocupan una superficie total de $890 \mathrm{~m}^{2}$, tienen un caudal de entrada promedio de $4,28 \mathrm{~m}^{3} \mathrm{~h}^{-1}$ y un tiempo de retención hidráulico (TRH) promedio de 13 días (Figura 5.4).

La primera etapa de depuración del sistema es un sistema de lagunaje que simula un ecosistema acuático con micrófitos. La profundidad de la laguna es variable, oscila entre $1,5 \mathrm{~m}$ en la zona de entrada, $0,5 \mathrm{~m}$ en la zona central y $1 \mathrm{~m}$ en la zona de salida del agua. La superficie de la etapa es de $230 \mathrm{~m}^{2}$, el volumen en la cota normal de funcionamiento es de $156,5 \mathrm{~m}^{3}$ y el TRH promedio es de 5 días.

La segunda etapa es una unidad de flujo superficial horizontal plantada con Typha latifolia (15 plantas $\mathrm{m}^{-2}$ ). El lecho de la unidad está ocupado por grava hasta una altura de $30 \mathrm{~cm}$ y la lámina de agua se encuentra $20 \mathrm{~cm}$ por encima en condiciones normales para una profundidad total de $50 \mathrm{~cm}$. La superficie de la etapa es de $210 \mathrm{~m}^{2}$, el volumen en la cota normal de funcionamiento es de $100,9 \mathrm{~m}^{3}$ y el TRH promedio es de 3,2 días. 

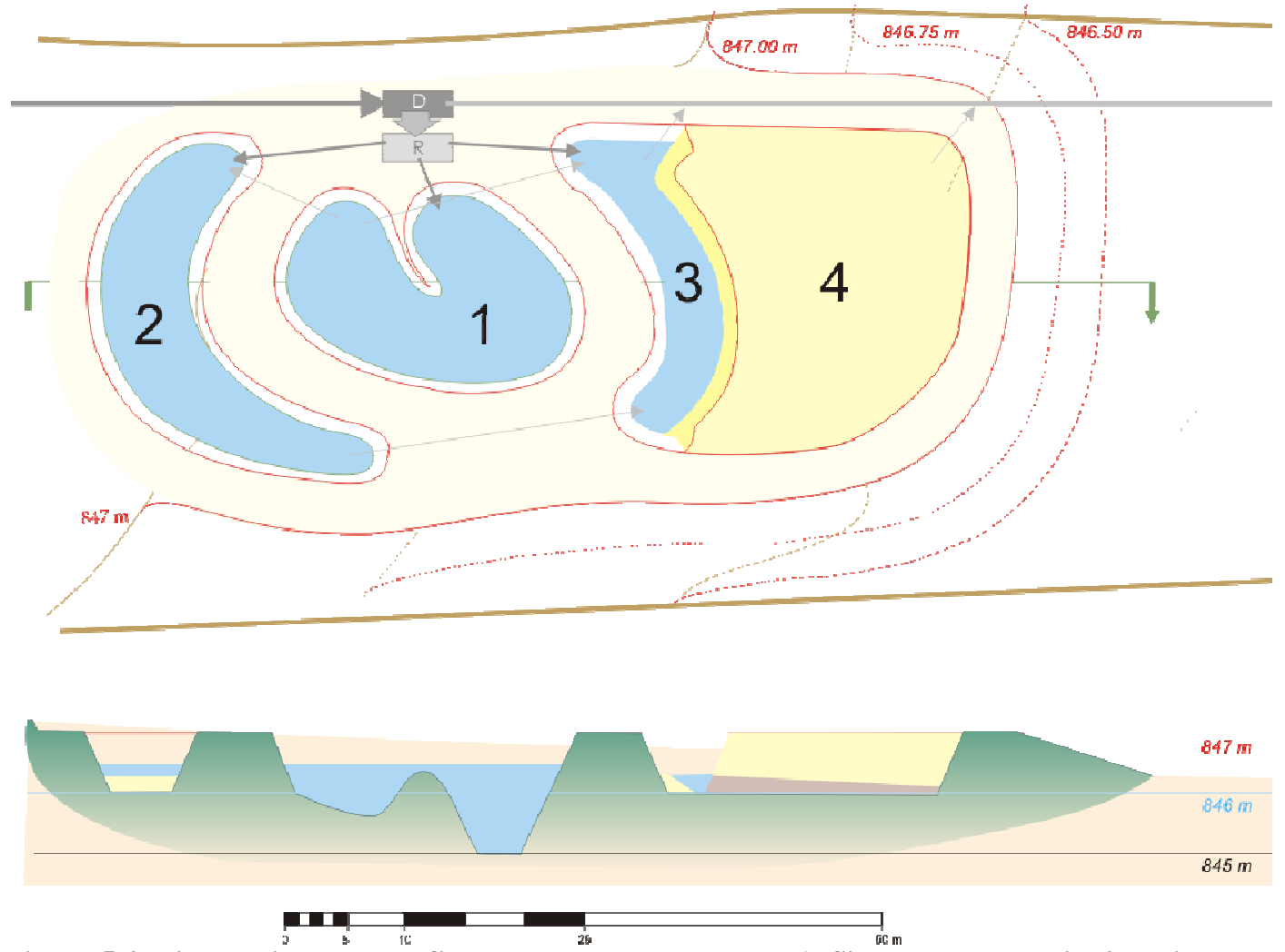

Figura 5.4. Vista cenital y de perfil de la planta a escala real. 1: Sistema de lagunaje. 2: Unidad de flujo superficial horizontal plantada con Typha latifolia. 3: Unidad de flujo superficial horizontal plantada con Iris pseudacorus. 4: Unidad de flujo subsuperficial horizontal plantada con Salix atrocinerea. Adaptado de Ansola y col. (2003).

La tercera etapa es una unidad de flujo superficial horizontal plantada con Iris Pseudacorus (15 plantas $\mathrm{m}^{-2}$ ) seguida de una unidad de flujo subsuperficial horizontal plantada con Salix atrocinerea sobre un sustrato de grava de tamaño entre 20 y $60 \mathrm{~mm}$. La superficie total de esta etapa es de $440 \mathrm{~m}^{2}$ y el TRH promedio es de 3,3 días.

\subsubsection{Toma de muestras}

La toma de muestras se ha realizado en otoño, después del periodo de senescencia de los macrófitos. En la planta a escala piloto para el tratamiento de purines de cerdo se han tomado 3 muestras: una muestra de sedimento de la balsa de purines (denominada como Centrotec-Fosa o CF), una muestra de la rizosfera de Typha latifolia (denominada como Centrotec-Typha o CT) y una muestra de la rizosfera de Salix atrocinerea (denominada como Centrotec-Salix o CS).

La muestra CF se ha tomado en el extremo de la balsa de purines más cercano a la planta piloto. Se ha utilizado un core cilíndrico de $5,3 \mathrm{~cm}$ de diámetro y $100 \mathrm{~cm}$ de largo que se ha introducido en el sedimento hasta una profundidad de $15 \mathrm{~cm}$.

Para la muestra CT se recogieron aleatoriamente 5 individuos de Typha latifolia. Una vez extraída la planta se separaron los rizomas y raíces junto con el sustrato adherido y se llevaron al laboratorio para su análisis.

Para la muestra CS se han elegido aleatoriamente 2 ejemplares de Salix atrocinerea correspondientes a cada una de las dos unidades de flujo subsuperficial. La muestra está formada por raíces y rizomas arrancados de forma parcial así como por el sustrato adherido. 
En la planta a escala real para el tratamiento de agua residual urbana la muestra de sedimento se ha tomado de la etapa de lagunaje o primera etapa de depuración (denominada como BustilloLodo o BL), la muestra de Typha latifolia (denominada como Bustillo-Typha o BT) se ha tomado de la segunda etapa de depuración (flujo superficial), mientras que la muestra de Salix atrocinerea (denominada como Bustillo-Salix o BS) se ha tomado de la última etapa de depuración (flujo subsuperficial). La toma de muestras se ha realizado de forma análoga a la de la planta piloto ubicada en CENTROTEC y los detalles quedan reflejados en Arroyo (2011).

\subsubsection{Clonación}

\subsubsection{Extracción de ADN genómico}

Para la extracción de ADN genómico se ha utilizado el Power Soil ${ }^{\mathrm{TM}}$ DNA Isolation Kit (MoBio Inc., Solana, CA, USA) para extracción de ADN de suelo. El kit de extracción se ha utilizado directamente con las muestras de sedimento mientras que las muestras de rizosfera han requerido la obtención previa de un pellet de bacterias. Para ello se ha realizado un lavado de las raíces y el sustrato asociado con solución salina (agua destilada con $0,9 \%$ de cloruro de sodio). Se han eliminado los restos de sustrato y raíces por filtración y se han tomado $8 \mathrm{ml}$ de lavado. Finalmente se ha obtenido un pellet de bacterias por centrifugación a $4.000 \mathrm{rpm}$ durante 10 minutos. Cuando la cantidad de pellet era escasa se ha repetido este procedimiento.

Cada muestra (los pellet de bacterias de las muestras de rizosfera y 0,10 gramos de las muestras de sedimento) se ha introducido en tubos Powerbead en los que se realiza un rápido mezclado. La lisis celular se produce mecánica y químicamente utilizando las diferentes soluciones incluidas en el Kit comercial. El ADN extraído se recoge en una matriz, siendo finalmente eluido de la misma.

El ADN extraído en cada muestra se ha cuantificado por medio de espectrofotometría a 260nm (Spectophotometer ND 1000, NanoDrop). Se ha comprobado mediante electroforesis la calidad y cantidad del ADN usando un gel a una concentración del 1\% de agarosa en tampón TAE $1 \mathrm{X}$ (40 $\mathrm{mM}$ tris (hidroximetil) aminometano, $1,14 \mu \mathrm{L} \mathrm{L}{ }^{-1}$ ácido acético glacial, $1 \mathrm{mM}$ EDTA, pH $7,8)$. Las muestras se han cargado con glicerol $(0,025 \%)$ y azul de bromofenol $(50 \%)$ y los geles se han visualizado en un transiluminador de luz ultravioleta tras su revelado en bromuro de etidio (10 $\mu \mathrm{l}$ de bromuro de etidio por cada $500 \mathrm{ml}$ de agua destilada).

\subsubsection{Reacción en cadena de la polimerasa (PCR)}

La PCR permite obtener un gran número de copias a partir de un fragmento de ADN. Los fragmentos de ADN codificante para el ARNr 16S han sido amplificados utilizando los cebadores o primers universales $27 \mathrm{f}$ y $907 \mathrm{r}$ del gen ribosomal $16 \mathrm{~S}$ en un termociclador modelo Applied Biosystems ${ }^{\circledR}$ GeneAmp ${ }^{\circledR}$ PCR System 9700.

Para realizar las reacciones de polimerización de $25 \mu \mathrm{l}$ se ha preparado la siguiente mezcla: 2,5 $\mu \mathrm{l}$ de Buffer DNA polimerasa 10x sin magnesio, 2,5 $\mu \mathrm{l}$ de mezcla de nucleótidos (dNTP) con una concentración $0,2 \mathrm{mM}, \quad 2,5 \mu \mathrm{l}$ de primer $\mathrm{ARNr} 16 \mathrm{~S} 27 \mathrm{f}$ (5'-AGAGTTTGATCMTGGCTCAG-3') en concentración 50 pM, 2,5 $\mu$ l de primer ARNr 16S 907f (5'-CCGTCAATTCMTTTRAGTTT-3') en concentración $50 \mathrm{pM}, 1,5 \mu \mathrm{l}$ de cloruro de magnesio $50 \mathrm{mM}$ y $0,625 \mu \mathrm{l}$ de Taq DNA polimerasa (Promega, Taq DNA plymerase in Storage Buffer A). La muestra se ha completado con agua destilada hasta los $25 \mu \mathrm{l}$ se le han añadido 100ng de ADN extraído de la muestra.

La PCR se ha iniciado con una desnaturalización a $80^{\circ} \mathrm{C}$ durante 5 minutos seguida por 28 ciclos con la siguiente rampa de temperaturas: desnaturalización del $\mathrm{ADN}$ a $94^{\circ} \mathrm{C}$ durante 45 segundos, hibridación de las cadenas de $\mathrm{ADN}$ a $53^{\circ} \mathrm{C}$ durante 60 segundos y a una temperatura de polimerización de $72^{\circ} \mathrm{C}$ durante 90 segundos. Tras los 28 ciclos de amplificación la muestra 
se ha mantenido a una temperatura de $72^{\circ} \mathrm{C}$ durante 7 minutos para finalizar la extensión de las cadenas.

El éxito de las reacciones se ha comprobado mediante electroforesis en geles de agarosa al $1 \%$ en tampón TAE. Como control se ha utilizado el marcador sintético 1kb Plus DNA Ladder.

\subsubsection{Reacciones de ligación}

Para la ligación de los fragmentos amplificados se ha utilizado el kit pGEM $^{\circledR}$-T-easy de Promega. Este kit está especialmente diseñado para la clonación directa de productos de PCR. Se realizaron mezclas con un volumen total de $10 \mu \mathrm{l}$ con los siguientes componentes y cantidades: $5 \mu$ l Rapid Ligation Buffer; $1 \mu$ vector pGEM $^{\circledR}$ - (50ng); $1 \mu \mathrm{l}$ T4 DNA Ligase (3 Weiss units $\mu 1^{-1}$ ) y $3 \mu \mathrm{l}$ de producto de PCR. La mezcla se incuba durante 12 horas a temperatura ambiente.

\subsubsection{Experimentos de transformación}

Una vez aislados los fragmentos amplificados por su inclusión en el vector pGEM-T, los vectores recombinantes se han utilizado para la transformación de células competentes de la cepa DH5a de Escherichia coli. Las células competentes se obtuvieron según el protocolo INOUE, mediante el empleo de cloruro de calcio (Inoue y col., 1990) y volúmenes de 50-100 $\mu \mathrm{l}$ se conservan en tubos congelados a $-80^{\circ} \mathrm{C}$.

Los tubos de células competentes DH5 $\alpha$ se descongelan durante 5 minutos en hielo y se mezclan con los $10 \mu \mathrm{l}$ de la reacción de ligación. Esta mezcla se incuba en hielo durante 20 minutos. Luego la muestra se somete a un choque térmico a $42^{\circ} \mathrm{C}$ durante $45-50$ segundos, seguida de una incubación en hielo durante 2 minutos. Se agrega $1 \mathrm{ml}$ de medio LB líquido (medio Luria-Betani: $10 \mathrm{~g}$ Bactotriptona, $5 \mathrm{~g}$ extracto de levadura, $10 \mathrm{~g} \mathrm{NaCl}, \mathrm{y} \mathrm{pH} \mathrm{7,5)} \mathrm{y} \mathrm{se}$ incuba durante 1 hora y 30 minutos a $37^{\circ} \mathrm{C}$ con agitación constante a $150 \mathrm{rpm}$. Finalmente se agrega $75 \mu \mathrm{l}$ del IPTG (Isopropil-Beta-DTiogalactopiranosa, 0,1M) y $75 \mu \mathrm{l}$ de X-Gal (5-Bromo-4Cloro-3-Indol-B-D Galactopiranosa, 5\% en N,N-dimetilformamida p/v) y se siembra en placas con medio sólido LB (se agrega $15 \mathrm{~g}$ de agar por cada litro de medio líquido LB) suplementado con ampicilina (concentración final $100 \mathrm{mg}^{1^{-1}}$ ). Las placas se incuban a $37^{\circ} \mathrm{C}$ durante 24 horas.

Las colonias transformadas serán aquellas que hayan adquirido resistencia a la ampicilina. Las colonias azules no recombinantes corresponden a las células transformadas con el vector que lleva el gen de la $\beta$-galactosidasa funcional y produce por inducción con IPTG dicha enzima capaz de hidrolizar al X-Gal y generar color azul. Las colonias blancas recombinantes corresponden a las células transformadas con el vector que lleva un gen de la $\beta$-galactosidasa no funcional por inserción de un fragmento de ADN procedente de la PCR dentro del mismo. Es en la reacción de ligación y en la posterior transformación cuando se produce la individualización de cada componente de la comunidad bacteriana.

\subsubsection{Análisis rápido de plásmidos}

Esta técnica es utilizada para comprobar qué colonias blancas obtenidas por el método de transformación llevan un producto de la PCR de tamaño esperado y cuáles no.

Cada colonia se resuspende en $50 \mu \mathrm{l}$ de EDTA $(0,01 \mathrm{M}, \mathrm{pH} 8)$ y se mezcla en agitación en vortex. Se mezcla con $50 \mu \mathrm{l}$ de Cracking Buffer $\left(0,2\right.$ g sacarosa, $900 \mu \mathrm{l} \mathrm{H}_{2} \mathrm{O}, 40 \mu \mathrm{l} \mathrm{NaOH} 5 \mathrm{M}$, $50 \mu \mathrm{l}$ SDS $10 \%$ ) y se le somete a incubación a $70^{\circ} \mathrm{C}$ durante 5 minutos. Se deja reposar la muestra a temperatura ambiente durante 5 minutos. Se añade $1,5 \mu \mathrm{KCl}(4 \mathrm{M})$ y $2 \mu \mathrm{l}$ de Bromofenol $(0,4 \%)$ y se mezcla por agitación en vortex. La muestra se incuba en hielo durante 5 
minutos y se somete posteriormente a centrifugación a 14.000 rpm durante 4 minutos. Finalmente se incuba en hielo durante 5 minutos o más.

Se observa el tamaño de los plásmidos para su selección mediante electroforesis en geles de agarosa al $1 \%$ en tampón TAE, utilizando como control negativo plásmidos sin inserto (procedentes de colonias azules).

\subsubsection{Secuenciación y análisis filogenético}

\subsubsection{Secuenciación}

La secuenciación de los insertos de los clones seleccionados se ha realizado utilizando los servicios de secuenciación automática del Laboratorio de Técnicas Instrumentales de la Universidad de León.

Se secuenciaron un total de 50 clones para cada una de las muestras estudiadas en ambas direcciones, utilizando el Kit Thermo SequenaseY Fluorescent Labelled Primer Cycle Sequencing Kit (Amersham Pharmacia Biotech) de acuerdo con las especificaciones indicadas por el fabricante, en un secuenciador automático (MEGABACE 500, Amersham Bioscience). Para evitar que una misma bacteria esté artificialmente sobrerrepresentada en el análisis, se ha evitado seleccionar más de 10 clones de una misma PCR, de este modo los clones estudiados pueden considerarse una muestra de la composición de las comunidades presentes en las muestras. Esto permite encontrar una relación entre el número de clones de una especie o taxón con su frecuencia relativa en la comunidad.

Las secuencias de ADN obtenidas fueron revisadas y editadas con ayuda del editor de alineamientos del programa informático MEGA5 (Molecular Evolutionary Genetics Análisis versión 5) (Tamura y col., 2011).

\subsubsection{Análisis comparativo de las secuencias con las bases de datos}

Una vez revisadas y editadas, las secuencias se compararon con las depositadas en la base de datos GenBank del NCBI (National Center for Biotechnology Information), utilizando el método BLAST (Basic Local Alignment Search Tool) (Altschul y col., 1997). La búsqueda de secuencias similares en la base de datos se realizó mediante el algoritmo BLASTN que permite comparar las secuencias de nucleótidos obtenidas con las de la base de datos (McGinnis y Madden, 2004). Aquellas secuencias de la base de datos que han guardado una mayor similitud con la secuencia original han sido guardadas y utilizadas como secuencias de referencia. En el caso de que las secuencias se identificaran como quimeras (mezcla de secuencias de especies distintas) o como cloroplastos, se procedió a la secuenciación de un nuevo clon.

\subsubsection{Alineamiento}

Se ha realizado un alineamiento múltiple de todas las secuencias junto con las secuencias de referencia obtenidas en la base de datos del NCBI (procedentes de bacterias aisladas e identificadas a nivel de especie o de muestras ambientales y por lo tanto no identificadas). Estos alineamientos permiten asegurar que las posiciones nucleotídicas comparadas son homólogas en todas las secuencias. Se ha realizado el alineamiento mediante la herramienta incluida en el Ribosomal Database Project (Cole y col., 2008; MSU, 2013) que utiliza un método de inferencia de alineamientos de ARN ("INFERence of RNA ALignement" o Infernal) (Nawrocki y col., 2009).

Con el objetivo de conseguir un alineamiento de todas las secuencias estudiadas se ha decidido realizar de forma conjunta el alineamiento de las secuencias obtenidas en el estudio de la planta piloto a pequeña escala para el tratamiento de agua residual porcina junto con la colección de 
secuencias obtenidas en el estudio de la planta piloto a escala real para el tratamiento de agua residual urbana.

\subsubsection{Análisis de la información filogenética}

\subsubsection{Reconstrucción filogenética}

Para la clasificación de las secuencias estudiadas se ha realizado un análisis filogenético con el programa informático MEGA5. Con la finalidad de obtener un mejor resultado, en este análisis se han incluido todas las secuencias de ADN que se desean estudiar, tanto de la planta piloto a pequeña escala como de la planta piloto a escala real, así como secuencias de referencia de la base de datos GenBank del NCBI.

El método escogido para el análisis filogenético ha sido un cálculo de distancias entre parejas de secuencias siguiendo el modelo evolutivo de sustitución no estacionario LogDet (Lake, 1994), diseñado para corregir la desigualdad en la frecuencia de bases de las secuencias (Felsenstein, 2004). La distancia LogDet se define como menos el logaritmo neperiano del determinante de la matriz de divergencia obtenida de la comparación de bases entre cada dos secuencias.

La construcción de árboles filogenéticos se ha realizado de acuerdo con el algoritmo Neighbour-Joining implementado en el programa MEGA5. Este algoritmo representa una buena aproximación heurística para encontrar el árbol de evolución mínima más corto. Secuencialmente encuentra vecinos que minimizan la longitud total del árbol. Es un método rápido que proporciona un único árbol filogenético.

La robustez de los árboles obtenidos (árbol filogenético con toda la colección de secuencias y árboles para cada Filo de bacterias) se ha evaluado por medio de la técnica de remuestreo bootstrap (Felsenstein, 1985), con 1.000 réplicas. Esta técnica indica si el árbol obtenido está soportado por el conjunto de datos estudiados o si ese árbol es un resultado marginal casi igual a otros posibles árboles (Baldauf, 2003). Se realiza eligiendo aleatoriamente submuestras del conjunto de secuencias, con las que se construyen diferentes árboles y se calcula la frecuencia con la que aparecen los nodos en el conjunto de estas submuestras aleatorias.

\subsubsection{Riqueza y diversidad a}

Para estudiar la riqueza y diversidad de las comunidades bacterianas se ha utilizado el software MOTHUR desarrollado para estudios de ecología microbiana (Schloss y col., 2009).

En primer lugar se han definido unidades taxonómicas operativas (OTUs) en base a cinco distancias genéticas diferentes: 0,$01 ; 0,05 ; 0,10 ; 0,20$ y 0,40 . Los OTUs funcionan como unidades de clasificación y permiten agrupar en un mismo OTU todas las secuencias situadas a una distancia filogenética inferior a la determinada, sin considerar si ese OTU es una especie, un género o cualquier otra entidad taxonómica. $\mathrm{Al}$ aumentar la distancia filogenética disminuye el número de OTUs.

Una vez definidos los OTUs se ha evaluado la calidad del muestreo realizado. Para ello se han realizado curvas de rarefacción que muestran el número de OTUs estadísticamente esperado según se incrementa el esfuerzo de muestreo. Representan la expectativa estadística para las correspondientes curvas de acumulación.

En este trabajo las curvas de rarefacción se han calculado para 1.000 submuestreos aleatorios utilizando la siguiente fórmula: 


$$
E(S)=\sum 1-\frac{\left(N-N_{i}\right)}{N}
$$

donde

$$
\begin{aligned}
& E(S)=\text { número esperado de OTUs } \\
& N=\text { número total de OTUs en una muestra } \\
& N_{i}=\text { número de bacterias del iésimo OTU } \\
& n=\text { tamaño de la muestra estandarizado }
\end{aligned}
$$

El estudio de la diversidad alfa (riqueza, diversidad y uniformidad de una comunidad particular que se considera homogénea) de las comunidades de bacterias estudiadas se ha realizado mediante el empleo de índices de riqueza y de índices estructurales de la comunidad.

La riqueza se basa únicamente en el número de OTUs presentes, sin tener en cuenta la abundancia de los mismos. Esta riqueza se ha estudiado mediante las curvas de rarefacción y el estimador no paramétrico Chao1. Mientras que la rarefacción realiza una interpolación sobre los resultados, los estimadores no paramétricos extrapolan el "verdadero" número de OTUs a partir de los OTUs identificados en la muestra (Colwell y Coddington, 1994). Estos estimadores utilizan el número de OTUs raros o poco representados que se encuentran en una muestra para calcular la probabilidad de que haya más OTUs sin descubrir en la muestra. El modelo no paramétrico Chao1 utiliza la relación marcaje-liberación-recaptura para estimar la riqueza total de OTUs al agregar un factor de corrección al número observado de especies mediante la ecuación (Chao, 1984; Chao y col., 1993):

$$
S_{1}=S_{o b s}+\frac{F_{1}^{2}}{2 F_{2}}
$$

donde

$S_{1}=$ número total de OTUs estimado

$S_{o b s}=$ número de OTUs en la muestra

$F_{1}=$ número de OTUs presentes una única vez en la muestra ("singletons")

$F_{2}=$ número de OTUs presentes exactamente dos veces en la muestra ("doubletons")

La idea detrás del estimador es que si una comunidad está siendo muestreada y los OTUs raros ("singletons") se siguen encontrando, es probable que aún existan nuevos OTUs por encontrar. En cuanto todos los OTUs hayan sido recuperados al menos dos veces ("doubletons"), es probable que no puedan encontrarse nuevos OTUs.

El índice de Shannon-Wiener combina la medida de la riqueza y la equitabilidad de una comunidad para determinar la diversidad de la misma. La equitabilidad se refiere a cómo la abundancia se distribuye entre los OTUs de la comunidad. Este índice mide el grado promedio de incertidumbre en predecir a qué OTU pertenecerá un individuo escogido al azar de una colección asumiendo que los individuos son seleccionados al azar y que todos los OTUs están representados en la muestra (Magurran, 1988). Este índice se calcula mediante la ecuación:

$$
H^{\prime}=-\sum\left[\left(\frac{n_{i}}{N}\right) \times \ln \left(\frac{n_{i}}{N}\right)\right]
$$

donde

$$
\begin{aligned}
& H^{\prime}=\text { índice de Shannon } \\
& n_{i}=\text { número de individuos de cada OTU } \\
& N=\text { número total de individuos }
\end{aligned}
$$

En un contexto ecológico, el índice de Shannon-Wiener será igual a cero cuando la muestra contenga sólo un OTU y será máximo cuando todos los OTUs estén representados por el mismo número de individuos $n_{i}$, es decir, que la comunidad tenga una distribución de abundancias 
perfectamente equitativa. Los valores del índice generalmente varían entre 1,5 y 3,5 y solamente en raras ocasiones rebasan la cifra de 4,5 (Margalef, 1972).

El índice de dominancia de Simpson mide la probabilidad de encontrar dos individuos de un mismo OTU en dos "extracciones" sucesivas al azar de la muestra sin "reposición" (Brown y Bowman, 2001). Al igual que el índice de Shannon-Wiener, el índice de Simpson incorpora en un solo valor la riqueza y la equitabilidad de la comunidad bacteriana. El índice de Simpson se calcula mediante la ecuación:

$$
D=\sum_{i=1}^{S} p_{i}^{2}
$$

donde

$$
\begin{aligned}
& D=\text { índice de Simpson } \\
& p_{i}=\text { frecuencia de cada OTU en la muestra }
\end{aligned}
$$

$p_{i}$ representa la probabilidad de que un individuo del OTU $i$ esté presente en la muestra, siendo entonces el sumatorio de $p_{i}$ igual a 1. $p_{i}$ puede calcularse como:

$$
p_{i}=\frac{n_{i}}{N}
$$

donde

$$
\begin{aligned}
& n_{i}=\text { número de individuos del OTU } i \\
& N=\text { número total de individuos para todos los OTUs presentes en la comunidad }
\end{aligned}
$$

Este índice es menos sensible a la riqueza y le da un peso mayor a los OTUs infrecuentes subestimando las especies abundantes. Si la dominancia es grande el valor de probabilidad será bajo, mientras que si las abundancias relativas de los OTUs son iguales la probabilidad será máxima.

\subsubsection{Análisis comparativo (diversidad $\beta$ )}

Las diferencias de riqueza y estructura entre las comunidades de bacterias se han analizado mediante los estimadores Jest y Thetayc y el algoritmo UniFrac (unweighted y weighted) presentes en el software MOTHUR (Schloss y col., 2009).

El estimador Jest devuelve el índice tradicional de Jaccard utilizando el estimador de riqueza Chao1 para la riqueza individual de cada muestra y la riqueza de los OTUs compartidos entre las muestras. La fórmula utilizada es (Schloss y col., 2009):

$$
C_{\text {Jaccard }}=1-\frac{S_{A B, \text { Chao }}}{S_{A, \text { Chao }}+S_{B, \text { Chao }}-S_{A B, \text { Chao }}}
$$

donde

$C_{\text {Jaccard }}=$ valor del estimador Jest

$S_{A B, \text { Chao }}=$ número de OTUs estimado compartido entre las comunidades A y B

$S_{A, \text { Chao }}=$ número de OTUs estimado en la comunidad A

$S_{B, \text { Chao }}=$ número de OTUs estimado en la comunidad B

El estimador Thetayc devuelve la medida de disimilaridad de Yue y Clayton entre las estructuras de dos comunidades. Mientras que el estimador Jest compara las distintas comunidades en función de la riqueza, el estimador Thetayc las compara en función de la abundancia relativa. La fórmula utilizada es (Schloss y col., 2009): 


$$
D_{\theta Y C}=1-\frac{\sum_{i=1}^{S_{T}} a_{i} b_{i}}{\sum_{i=1}^{S_{T}\left(a_{i}-b_{i}\right)^{2}+\sum_{i=1}^{S_{T}} a_{i} b_{i}}}
$$

donde

$$
\begin{aligned}
& D_{\theta Y C}=\text { índice de disimilaridad de Yue y Clayton } \\
& S_{T}=\text { número total de OTUs en las comunidades A y B } \\
& a_{i}=\text { abundancia relativa del OTU i en la comunidad A } \\
& b_{i}=\text { abundancia relativa del OTU i en la comunidad B }
\end{aligned}
$$

El algoritmo UniFrac unweighted es una extensión filogenética del índice de Jaccard que define la distancia entre dos comunidades como la proporción de evolución que es única para cada comunidad. Este método utiliza un árbol filogenético para calcular la fracción de longitud de las ramas del árbol que corresponde a los descendientes de cada comunidad. El algoritmo UniFrac mide la cantidad de divergencia evolutiva entre dos comunidades dividiendo la longitud correspondiente a cada comunidad por el total de la longitud de las ramas del árbol mediante la siguiente fórmula (Schloss y col., 2009):

$$
u=\frac{\sum_{i=1}^{N} l_{i}\left|A_{i}-B_{i}\right|}{\sum_{i=1}^{N} l_{i} \max \left(A_{i}, B_{i}\right)}
$$

donde

$u=$ valor UniFrac unweighted

$N=$ número de nodos en el árbol

$l_{i}=$ longitud de la rama entre el nodo $i$ y su ancestro

$A_{i}, B_{i}=$ indicador de ausencia o presencia $\left(\begin{array}{lll}0 & \text { o } & 1\end{array}\right)$ en las comunidades $\mathrm{A}$ o $\mathrm{B}$ de los descendientes del nodo $i$

Puesto que la presencia de secuencias duplicadas no supone un incremento de la longitud del árbol, el algoritmo UniFrac unweighted no tiene en cuenta las abundancias relativas, que pueden proporcionar información adicional sobre cambios en las comunidades. El algoritmo UniFrac weighted incorpora la abundancia relativa y pondera las ramas del árbol en función de la abundancia de información que éstas poseen, lo que permite detectar cambios acerca de cuántos organismos de cada comunidad están presentes, además de detectar cambios en la presencia o ausencia de los organismos (Lozupone y Knight, 2005). La fórmula utilizada es:

$$
u=\sum_{i}^{n} b_{i} \times\left|\frac{A_{i}}{A_{T}}-\frac{B_{i}}{B_{T}}\right|
$$

donde

$$
\begin{aligned}
& u=\text { valor UniFrac weighted } \\
& n=\text { número total de ramas en el árbol } \\
& b_{i}=\text { longitud de la rama i } \\
& A_{i}, B_{i}=\text { número de descendientes de la rama i de las comunidades A o } \mathrm{B} \\
& A_{T}, B_{T}=\text { número total de secuencias de las comunidades A o } \mathrm{B}
\end{aligned}
$$

El valor UniFrac puede ser utilizado para medir si existen diferencias significativas entre las comunidades bacterianas. Las comunidades son significativamente diferentes si el valor UniFrac para el árbol real es mayor del que podría esperarse si las secuencias estuviesen distribuidas aleatoriamente entre las comunidades. Para determinar si existen diferencias significativas entre comunidades, se realiza un remuestreo tomando 100 veces las secuencias de forma aleatoria. Un nuevo valor UniFrac se calcula para cada remuestreo. El valor de significación se corresponde a la fracción de árboles permutados que tienen valores UniFrac mayores o iguales al del árbol real (Lozupone y Knight, 2005). Para considerar la probabilidad de obtener resultados significativos por azar se ha aplicado la corrección de Bonferroni que 
permite reducir la probabilidad de cometer un error tipo I en el conjunto de pruebas (LópezGonzález y Márquez-Linares, 2004).

Tanto los estimadores Jest y Thetayc como los algoritmos UniFrac unweighted y weighted generan matrices de distancias cuya estructura se ha analizado mediante Análisis de Coordenadas Principales (PCoA). Un PCoA es una técnica clásica de escalamiento multidimensional que permite mostrar la estructura de una matriz de disimilitud (matriz que muestra las distancias entre cada posible par de objetos) de un espacio de múltiples dimensiones en un espacio de pocas dimensiones con la menor pérdida de información posible. La elección del vector de los autovalores permite rotar la matriz de datos; no cambia las posiciones de los puntos relativos entre sí, sino que cambia el sistema de coordenadas (Zuur y col., 2007).

Los PCoAs y Heatmaps de los OTUs de cada comunidad se han realizado con el paquete estadístico R 2.15.1 (RCoreTeam, 2012) para Windows. 


\subsection{RESULTADOS Y DISCUSIÓN}

\subsubsection{Composición de las comunidades bacterianas}

De acuerdo con la clasificación de todas las secuencias mediante la base de datos RDP, la mayoría de los 292 clones iniciales $(84,9 \%)$ están clasificados en tres filos "principales": Proteobacteria (177 clones, 60,6\%), Bacteroidetes (53 clones, 18,2\%) y Firmicutes (18 clones, $6,2 \%)$; mientras que el resto de secuencias $(15,1 \%)$ están clasificadas en 18 filos "secundarios" de los cuales Actinobacteria ( 9 clones, 3,1\%) y Acidobacteria (5 clones, 1,7\%) han sido los únicos que cuentan con una representación superior al 1,5\% en el conjunto de las las secuencias bacterianas.

Estos resultados coinciden con los de diversos reactores biológicos de plantas de tratamiento de agua residual en China y USA que sitúan a Proteobacteria como filo dominante frente a Bacteroidetes, Firmicutes y Actinobacteria como filos subdominantes (Xia y col., 2010). También se asemejan a la composición de las comunidades bacterianas en diferentes humedales artificiales que suele estar dominada por el filo Proteobacteria, seguido por los filos CytophagaFlavobacterium, Actinobacteria y Firmicutes (Truu y col., 2009). Los detalles del número de secuencias pertenecientes a cada filo para cada muestra se encuentran en la Tabla 5.1.

La Figura 5.5 muestra los principales filos del árbol filogenético formado por las secuencias de las comunidades de bacterias muestreadas junto con secuencias externas utilizadas como referencia del NCBI. Algunas de las secuencias no han podido ser asignadas a ningún filo. El tamaño de los triángulos es proporcional al número de secuencias comprendidas en la rama (incluyendo las secuencias de referencia).

Tabla 5.1. Afiliación a nivel de filo de las secuencias de las comunidades de bacterias muestreadas de acuerdo con la base de datos RDP. Los acrónimos indican: CF, Centrotec-Fosa; BL, BustilloLodo; CT, Centrotec-Typha; BT, Bustillo-Typha; CS, Centrotec-Salix; BS, Bustillo-Salix.

\begin{tabular}{lccccccc}
\hline Filo & CF & BL & CT & BT & CS & BS & TOTAL \\
\hline Proteobacteria & 23 & 22 & 39 & 26 & 34 & 33 & 177 \\
Bacteroidetes & 10 & 13 & 6 & 6 & 11 & 7 & 53 \\
Firmicutes & 8 & 4 & 4 & - & 1 & 1 & 18 \\
Actinobacteria & - & - & 2 & 4 & - & 3 & 9 \\
Acidobacteria & - & 2 & - & 1 & - & 2 & 5 \\
Spirochaetes & 3 & 1 & - & - & - & - & 4 \\
Synergistetes & 2 & 1 & - & - & - & - & 3 \\
Verrucomicrobia & 1 & - & - & 2 & - & 1 & 4 \\
Chlorobi & - & 1 & - & - & 2 & 1 & 4 \\
OP11 & - & 3 & - & - & - & - & 3 \\
Elusimicrobia & - & 1 & 1 & - & - & - & 2 \\
TM7 & - & - & - & 1 & - & 1 & 2 \\
Caldiserica & - & 1 & - & - & - & - & 1 \\
Gemmatimonadetes & - & 1 & - & - & - & - & 1 \\
BRC1 & 1 & - & - & - & - & - & 1 \\
Cyanobacteria/Chloroplast & 1 & - & - & - & - & - & 1 \\
OD1 & 1 & - & - & - & - & - & 1 \\
Nitrospira & - & - & - & 1 & - & - & 1 \\
Tenericutes & - & - & 1 & - & - & - & 1 \\
Chloroflexi & - & - & - & - & - & 1 & 1 \\
\hline TOTAL & 50 & 50 & 53 & 41 & 48 & 50 & 292 \\
\hline
\end{tabular}




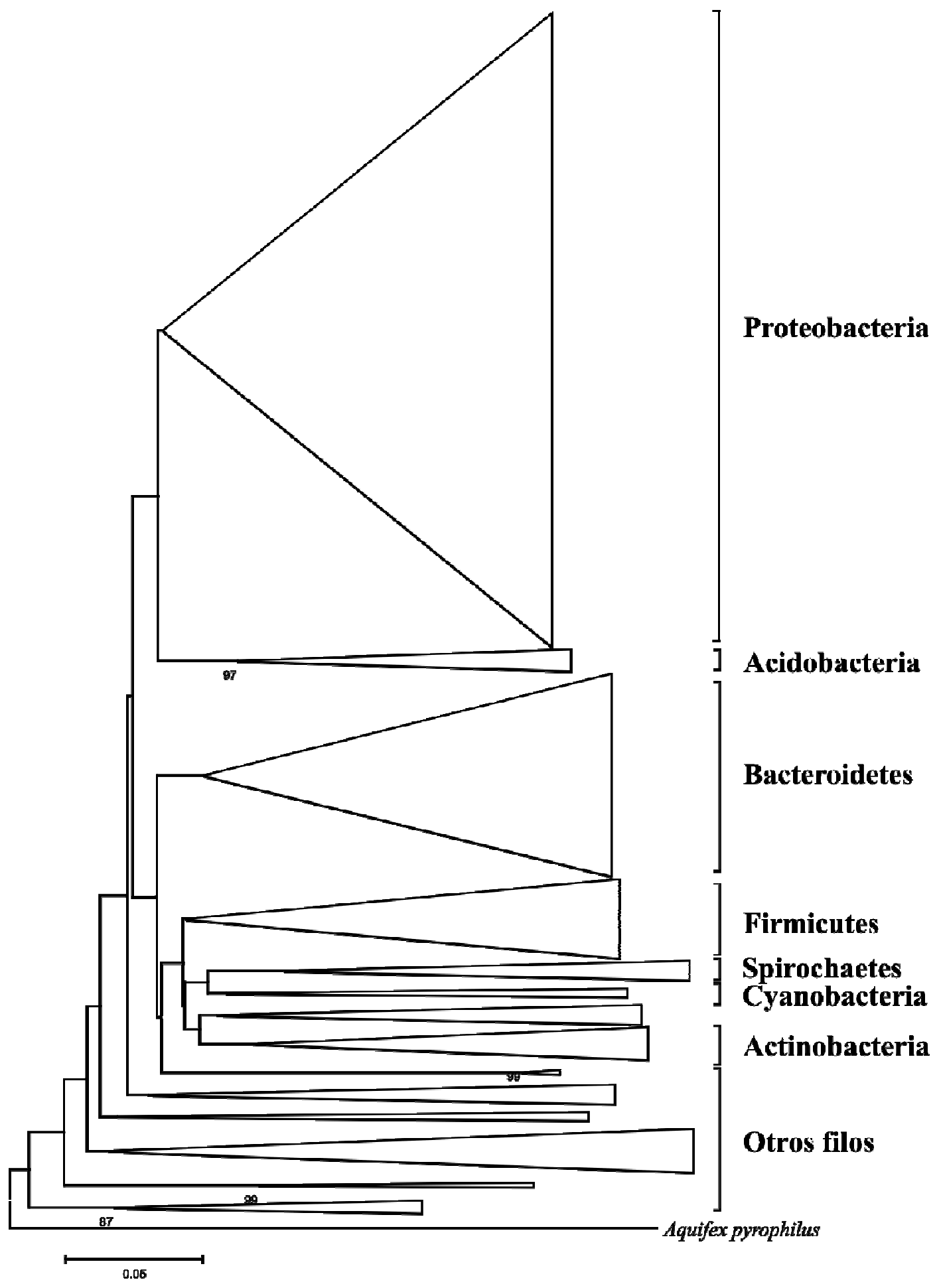

Figura 5.5. Árbol filogenético esquemático de las secuencias indicando los filos Proteobacteria, Bacteroidetes, Firmicutes, Actinobacteria y Acidobacteria. El árbol se ha construido de acuerdo con el algoritmo Neighbour-Joining. Los valores de bootstrap (1.000 réplicas) superiores al $80 \%$ se indican en los nodos. El tamaño de los triángulos es proporcional al número de secuencias pertenecientes a las muestras y de referencia comprendidas en la rama. Algunos grupos no son monofiléticos. La raíz del árbol se ha situado en la especie Aquifex pyrophilus incluida como outgroup. 


\subsubsection{Filo Proteobacteria}

Las secuencias relacionadas con el filo Proteobacteria forman la fracción más importante de la biblioteca de clones e incluye las clases Beta-, Gamma- Alpha-, y Delta-Proteobacteria. El peso relativo de las secuencias de este filo con respecto al total de secuencias de cada muestra de acuerdo con la base de datos RDP es menor en el sedimento de los sistemas de ambos tipos de agua residual (CF 46,0\%; BL 44,0\%) en comparación con la rizosfera del tratamiento de agua residual porcina (CT $73,6 \%$; CS $70,8 \%$ ) y la rizosfera del tratamiento de agua residual urbana (BT 63,4\%; BS 66,0\%).

Según la clasificación de la base de datos RDP, de los 177 clones afiliados a Proteobacteria, 68 $(38,4 \%)$ exhiben una gran similaridad con la clase Beta-Proteobacteria, $50(28,2 \%)$ con la clase Gamma-Proteobacteria, $30(17,0 \%)$ con la clase Alpha-Proteobacteria y $29(16,4 \%)$ con la clase Delta-Proteobacteria (Tabla 5.2).

El peso relativo de las clases del filo Proteobacteria en las muestras de Typha latifolia y Salix atrocinerea difiere según el tipo de agua residual utilizada, estando más presente la clase BetaProteobacteria en el sistema alimentado con agua residual porcina $(61,5$ y $70,6 \%$ para CT y CS respectivamente), mientras que las clases Alpha-Proteobacteria y Gamma-Proteobacteria son más abundantes en el tratamiento de agua residual urbana (un total para las dos clases de $76,9 \%$ y $69,4 \%$ para BT y BS respectivamente).

La composición de las muestras de la rizosfera de los macrófitos es muy diferente de la de las muestras de sedimento para ambos sistemas de agua residual. En el caso de la muestra de lodo del sistema de tratamiento de agua residual porcina (CF) las clases Beta-Proteobacteria y Gamma-Proteobacteria son las más abundantes (un total de 73,9\%), mientras que en la muestra de sedimento del sistema de tratamiento de agua residual urbana (BL) la clase DeltaProteobacteria ha sido la de mayor peso relativo $(81,8 \%)$ (Tabla 5.2). La Figura 5.6 muestra el segmento del árbol filogenético correspondiente al filo Proteobacteria.

Tabla 5.2. Afiliación a nivel de clase de las secuencias de las comunidades de bacterias muestreadas correspondientes al filo Proteobacteria de acuerdo con la base de datos RDP.

\begin{tabular}{lccccccc}
\hline Clase & CF & BL & CT & BT & CS & BS & TOTAL \\
\hline Beta-Proteobacteria & 8 & 2 & 24 & 4 & 24 & 6 & 68 \\
Gamma-Proteobacteria & 9 & 2 & 7 & 14 & 8 & 10 & 50 \\
Alpha-Proteobacteria & 2 & - & 8 & 6 & 1 & 13 & 30 \\
Delta-Proteobacteria & 4 & 18 & - & 2 & 1 & 4 & 29 \\
\hline TOTAL & 23 & 22 & 39 & 26 & 34 & 33 & 177 \\
\hline
\end{tabular}

En la bibliografía se describen composiciones de comunidades bacterianas de la rizosfera de Typha latifolia y Salix atrocinerea de humedales artificiales que tratan agua residual urbana que se asemejan a las encontradas en las muestras CT y CS (dominancia de Beta-Proteobacteria seguida por Gamma-Proteobacteria) (Criado y Bécares, 2005; Ibekwe y col., 2006; Li y col., 2011), mientras que las comunidades de la rizosfera de otros sistemas de agua residual urbana están dominados por Alpha-Proteobacteria (Ahn y col., 2007; Bouali y col., 2013). La composición de las comunidades bacterianas de la rizosfera de macrófitos depende de factores tales como la especie de macrófito, el tipo de humedal artificial o la naturaleza y las características físico-químicas del agua residual. Cada humedal artificial presenta unas características únicas, lo que dificulta la comparación de las comunidades de bacterias entre distintos sistemas. 


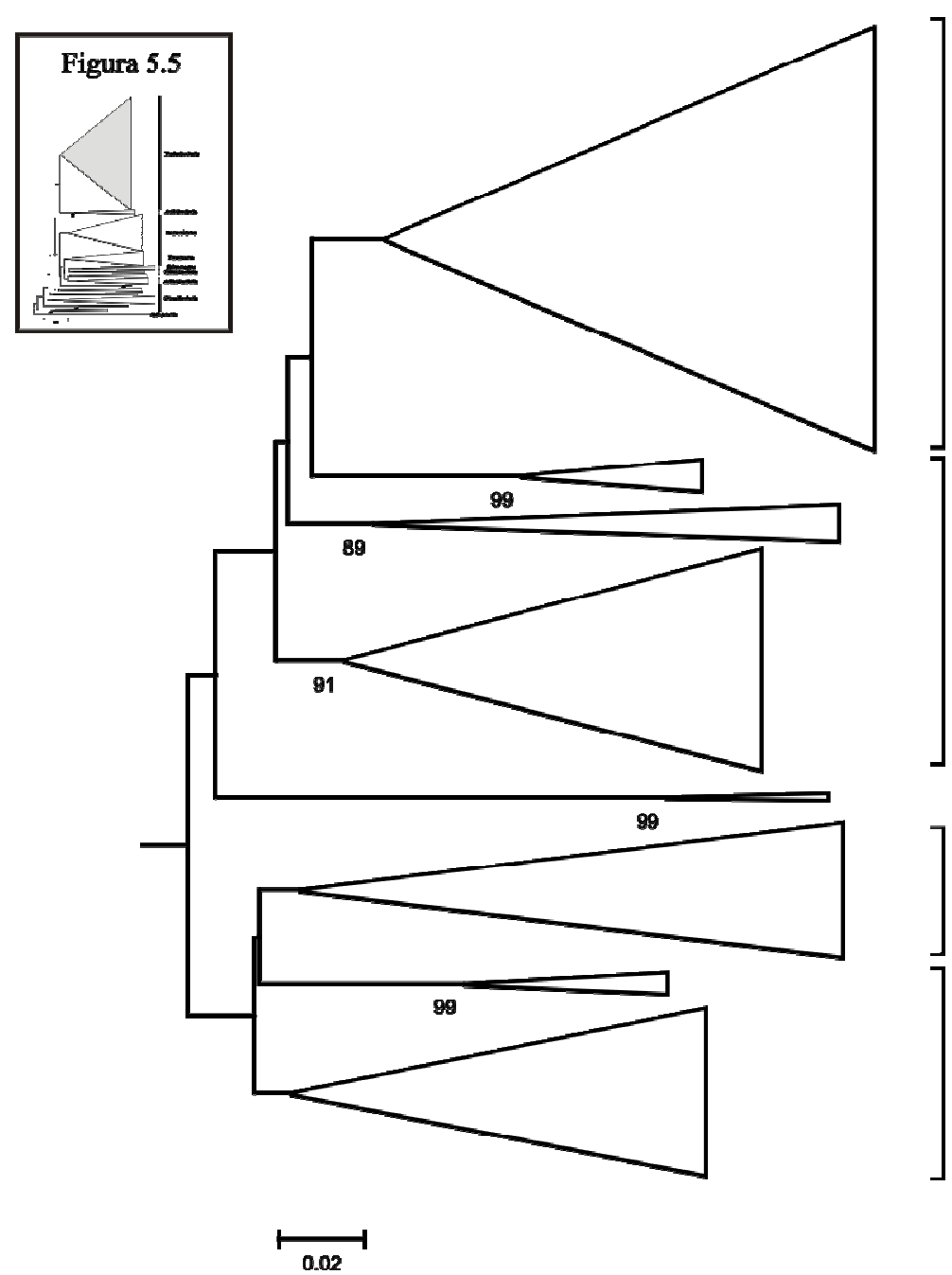

Beta-Proteobacteria

Gamma-Proteobacteria

Delta-Proteobacteria

Alpha-Proteobacteria

Figura 5.6. Segmento del árbol filogenético correspondiente al filo Proteobacteria. El árbol se ha construido de acuerdo con el algoritmo Neighbour-Joining. Los valores de bootstrap (1.000 réplicas) superiores al $\mathbf{8 0 \%}$ se indican en los nodos. Alpha- y Gamma-Proteobacteria forman grupos parafiléticos. La raíz del árbol se ha situado en la especie Aquifex pyrophilus incluida como outgroup (Figura 5.5).

\subsection{Clase Beta-Proteobacteria}

El segmento del árbol filogenético que incluye las secuencias afiliadas a la clase BetaProteobacteria se muestra en la Figura 5.7. Los 68 clones pertenecientes a la clase BetaProteobacteria están relacionados con seis órdenes de bacterias, de entre los cuales Burkholderiales y Rhodocyclales engloban el 89,7\% de las secuencias (34 y 27 clones respectivamente) de acuerdo con la clasificación de la base de datos RDP. De estas 61 secuencias, 50 clones $(82,0 \%)$ pertenecen al sistema de agua residual de origen porcino (Tabla 5.3). Estos dos órdenes son especialmente conocidos por participar en el proceso de desnitrificación de los sistemas de tratamiento de aguas residuales (Wagner y Loy, 2002; Lim y col., 2005).

Los resultados de la clasificación de la base de datos RDP pueden diferir de los resultados que se muestran en los árboles filogenéticos que se han realizado con las secuencias de referencia obtenidas en la base de datos GenBank del NCBI. Un ejemplo concreto es el orden 
Methylophilales incluido en la Tabla 5.3 (base de datos RDP) que no se encuentra en el árbol filogenético de la Figura 5.7 (base de datos GenBank, NCBI).

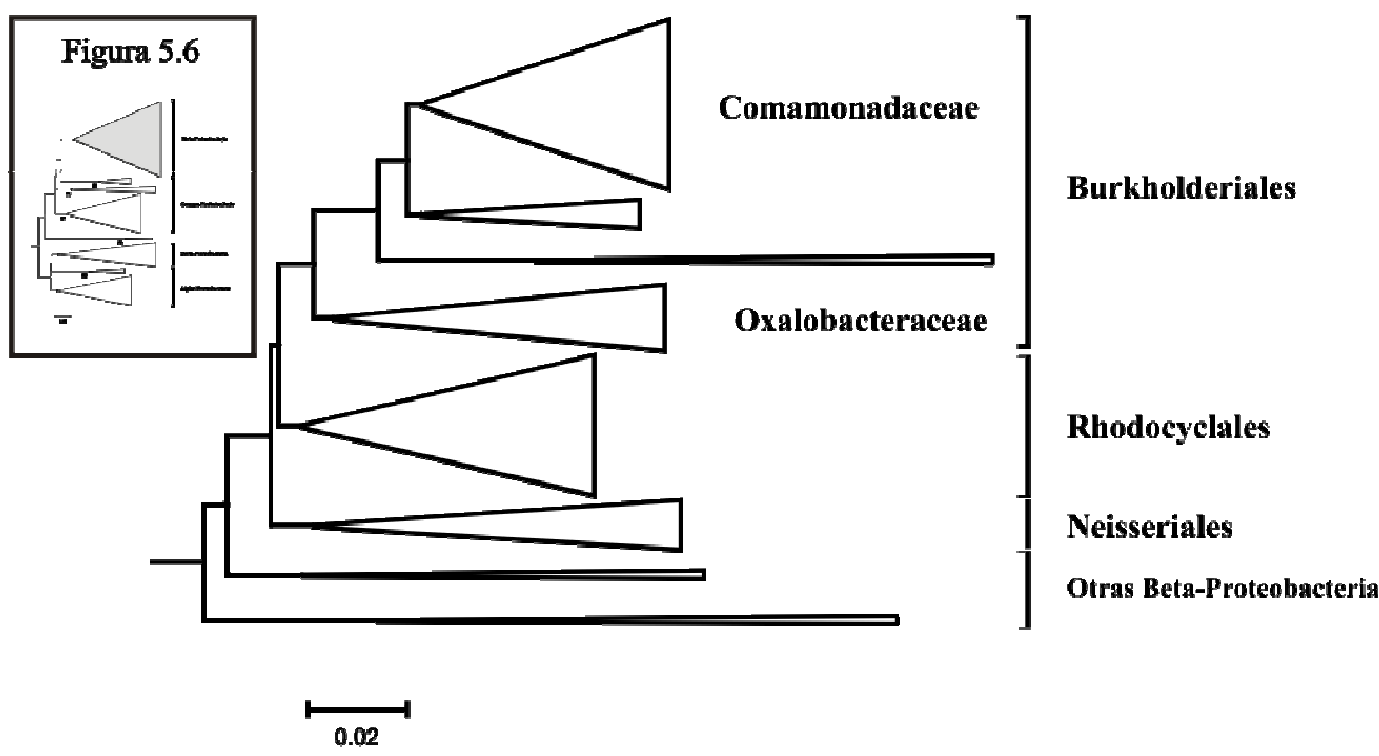

Figura 5.7. Segmento del árbol filogenético correspondiente a la clase Beta-Proteobacteria. El árbol se ha construido de acuerdo con el algoritmo Neighbour-Joining. La raíz del árbol se ha situado en la especie Aquifex pyrophilus incluida como outgroup (Figura 5.5).

Tabla 5.3. Afiliación a nivel de orden de las secuencias de las comunidades de bacterias muestreadas correspondientes a la clase Beta-Proteobacteria de acuerdo con la base de datos RDP.

\begin{tabular}{lccccccc}
\hline Orden & CF & BL & CT & BT & CS & BS & TOTAL \\
\hline Burkholderiales & 2 & - & 13 & 4 & 12 & 3 & 34 \\
Rhodocyclales & 5 & 1 & 7 & - & 11 & 3 & 27 \\
Neisseriales & 1 & - & 3 & - & - & - & 4 \\
Hydrogenophilales & - & 1 & - & - & - & - & 1 \\
Methylophilales & - & - & 1 & - & - & - & 1 \\
Nitrosomonadales & - & - & - & - & 1 & - & 1 \\
\hline \multicolumn{1}{c}{ TOTAL } & 8 & 2 & 24 & 4 & 24 & 6 & 68 \\
\hline
\end{tabular}

El árbol filogenético de las secuencias afiliadas a la familia Comamonadaceae del orden Burkholderiales y a otras Burkholderiales se muestra en la Figura 5.8. Los clones de la muestra $\mathrm{CF}$ se encuentran estrechamente relacionados con bacterias anaerobias del género Acidovorax, capaces de reducir nitrato (Hallin y col., 2006) y con la bacteria Brachymonas denitrificans, bacteria aerobia capaz de realizar la desnitrificación anaerobia y la reducción de hierro (Pervin y col., 2013).

Entre las secuencias pertenecientes a la muestra CT algunas están estrechamente relacionadas con géneros que incluyen especies que intervienen en el proceso de desnitrificación como son Acidovorax o Comamonas (Hallin y col., 2006; Chon y col., 2010) o con especies de conocida capacidad desnitrificante como Rhodoferax fermentans y Rubrivivax gelatinosus (Hougardy y Klemme, 1995; Pei y col., 2010); mientras que otras están relacionadas con Limnohabitans parvus, especie quimioorganótrofa aerobia o facultativa anaerobia (Kasalicky y col., 2010) o con especies del género Hydrogenophaga sp., género que incluye especies quimioorganótrofas o quimiolitoautótrofas que oxidan $\mathrm{H}_{2}$ como fuente de energía y utilizan $\mathrm{CO}_{2}$ como fuente de carbono (Kämpfer y col., 2005). 


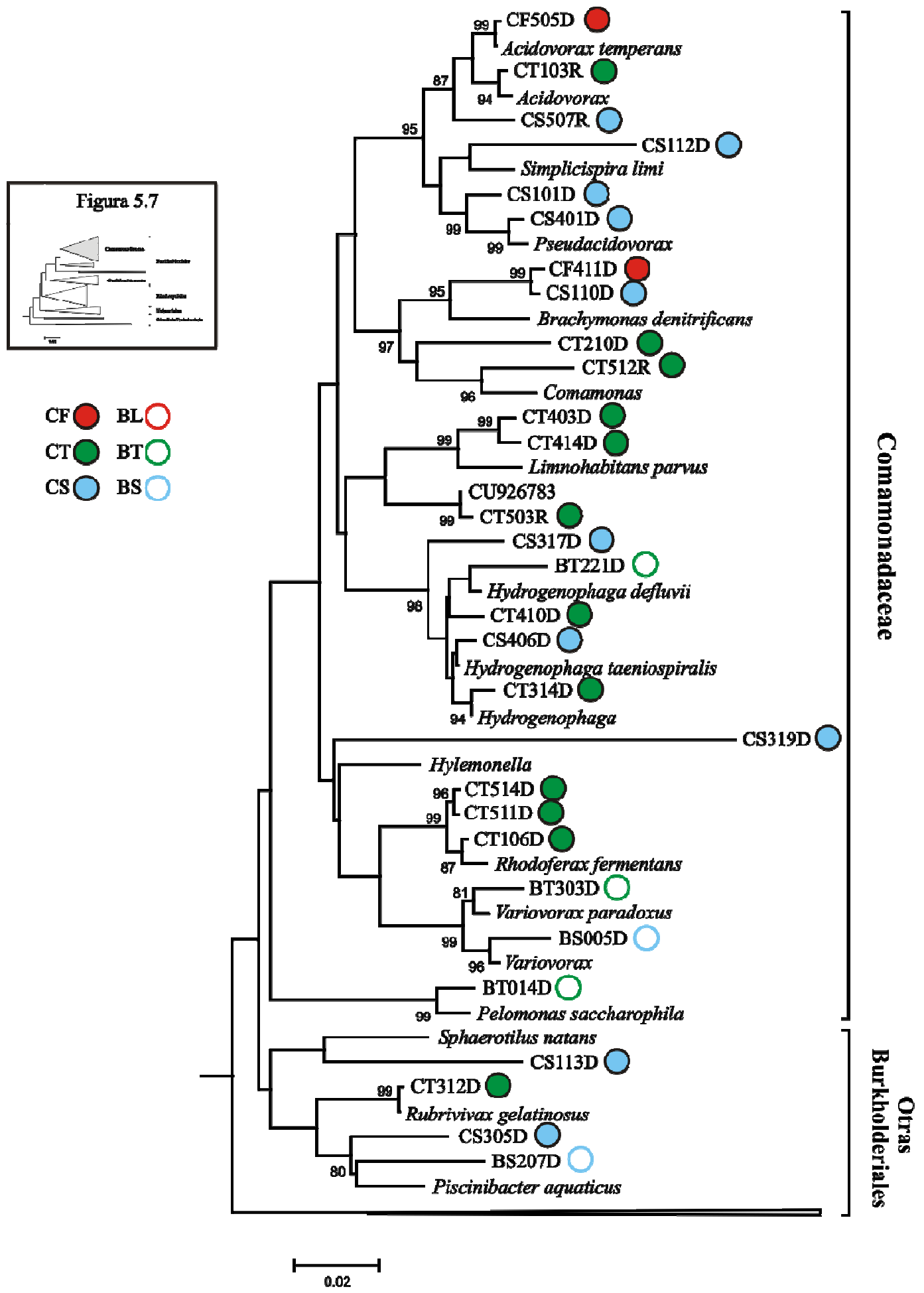

Figura 5.8. Segmento del árbol filogenético correspondiente a la clase Beta-Proteobacteria, orden Burkholderiales, familia Comamonadaceae y otras secuencias sin afiliar a familias, así como las secuencias de bacterias más similares obtenidas del GenBank. El árbol se ha construido de acuerdo con el algoritmo Neighbour-Joining. Los valores de bootstrap (1.000 réplicas) superiores al $80 \%$ se indican en los nodos. La raíz del árbol se ha situado en la especie Aquifex pyrophilus incluida como outgroup (Figura 5.5). 
Los clones del orden Burkholderiales en la muestra CS están relacionados con géneros o especies de metabolismos diversos. Mientras algunos clones están relacionados con géneros conocidos por su actividad desnitrificante como Acidovorax o la especie Brachymonas denitrificans, otros están relacionados con Pseudacidovorax, género de bacterias aerobias facultativas que incluye Pseudacidovorax intermedius como única especie con capacidad para fijar nitrógeno (Kämpfer y col., 2008), con especies del género Simplicispira que poseen un potencial nitrificante (Park y col., 2011) o con especies oxidadoras del hidrógeno como Hydrogenophaga taeniospiralis que puede metabolizar diclorobifenilos y bifenilos policlorados y degradar estos contaminantes orgánicos en el agua residual (Lambo y Patel, 2006). Otras secuencias del orden Burkholderiales están relacionadas con las especies Piscinibacter aquaticus, especie quimioheterótrofa y aerobia facultativa (Stackebrandt y col., 2009), y Sphaerotilus natans, con capacidad para crecer en condiciones de bajo contenido de oxígeno y consumir una gran variedad de compuestos orgánicos para su metabolismo (Pellegrin y col., 1999).

El segmento del árbol filogenético correspondiente a las secuencias afiliadas a la familia Oxalobacteraceae del orden Burkholderiales y a las secuencias afiliadas al orden Rhodocyclales se muestra en la Figura 5.9. En la familia Oxalobacteraceae se encuentra el mayor número de secuencias de muestras de agua residual urbana afiliadas a la clase Beta-Proteobacteria. Un buen número de las secuencias afiliadas a esta familia está estrechamente relacionado con bacterias no cultivadas. La única bacteria correspondiente a la muestra BT está afiliada con Janthinobacterium, género relacionado con la producción de hidrógeno en condiciones anaerobias (Ning y col., 2013) y capaz de generar $\mathrm{N}_{2} \mathrm{O}$ probablemente como resultado de un proceso de desnitrificación incompleto (Hashidoko y col., 2008).

Los clones de la muestra BS están relacionados con Massilia, género aerobio típico de la rizosfera (Ofek y col., 2012) que tiene capacidad antifúngica y es capaz de degradar fenol (Tani y col., 2011), y la especie Sulfuritalea hydrogenivorans, quimiolitótrofo facultativo que crece en condiciones anóxicas mediante la oxidación de azufre e hidrógeno y es capaz de reducir nitrato (Kojima y Fukui, 2011). La única secuencia de agua residual porcina en la familia Oxalobacteraceae corresponde a la muestra CT y está relacionada con Duganella, género de quimiorganótrofos aerobios frecuentes en ambientes de aguas residuales (Hiraishi y col., 1997).

Prácticamente todas las secuencias afiliadas al orden Rhodocyclales, familia Rhodocyclaceae proceden de las muestras del sistema de tratamiento de agua residual porcina. Las 5 secuencias de la muestra CF están estrechamente relacionadas con especies del género Thauera que poseen una capacidad de desnitrificación heterótrofa en presencia de carbono orgánico, aunque también pueden realizar el proceso de desnitrificación a través de rutas autotróficas utilizando sustratos inorgánicos, tales como As(III), como donador de electrones (Sun y col., 2012).

Entre las secuencias de la muestra CT algunas están relacionadas con las especies Dechloromonas hortensis y Dechloromonas aromatica, bacterias anaerobia facultativa y anaerobia respectivamente capaces de utilizar nitrato y perclorato como aceptores de electrones (Wolterink y col., 2005; Salinero y col., 2009). Otras están relacionadas con el género Rhodocyclus, que incluye especies de bacterias púrpuras no del azufre capaces de realizar la actividad fotosintética con nitrato como aceptor de electrones, con el género Propionivibrio, que son bacterias quimioautótrofas aerotolerantes o anaerobias estrictas típicas de sedimentos de agua dulce (Haller y col., 2011), o la especie Azovibrio restrictus, organismo fijador de nitrógeno cuyo nicho ecológico es la rizosfera de las plantas (Reinhold-Hurek y Hurek, 2000). Las secuencias de la muestra CS están relacionadas con bacterias capaces de utilizar nitrato como aceptor de electrones tales como Dechloromonas, Rhodocyclus y Azospira oryzae (Hunter, 2007). 


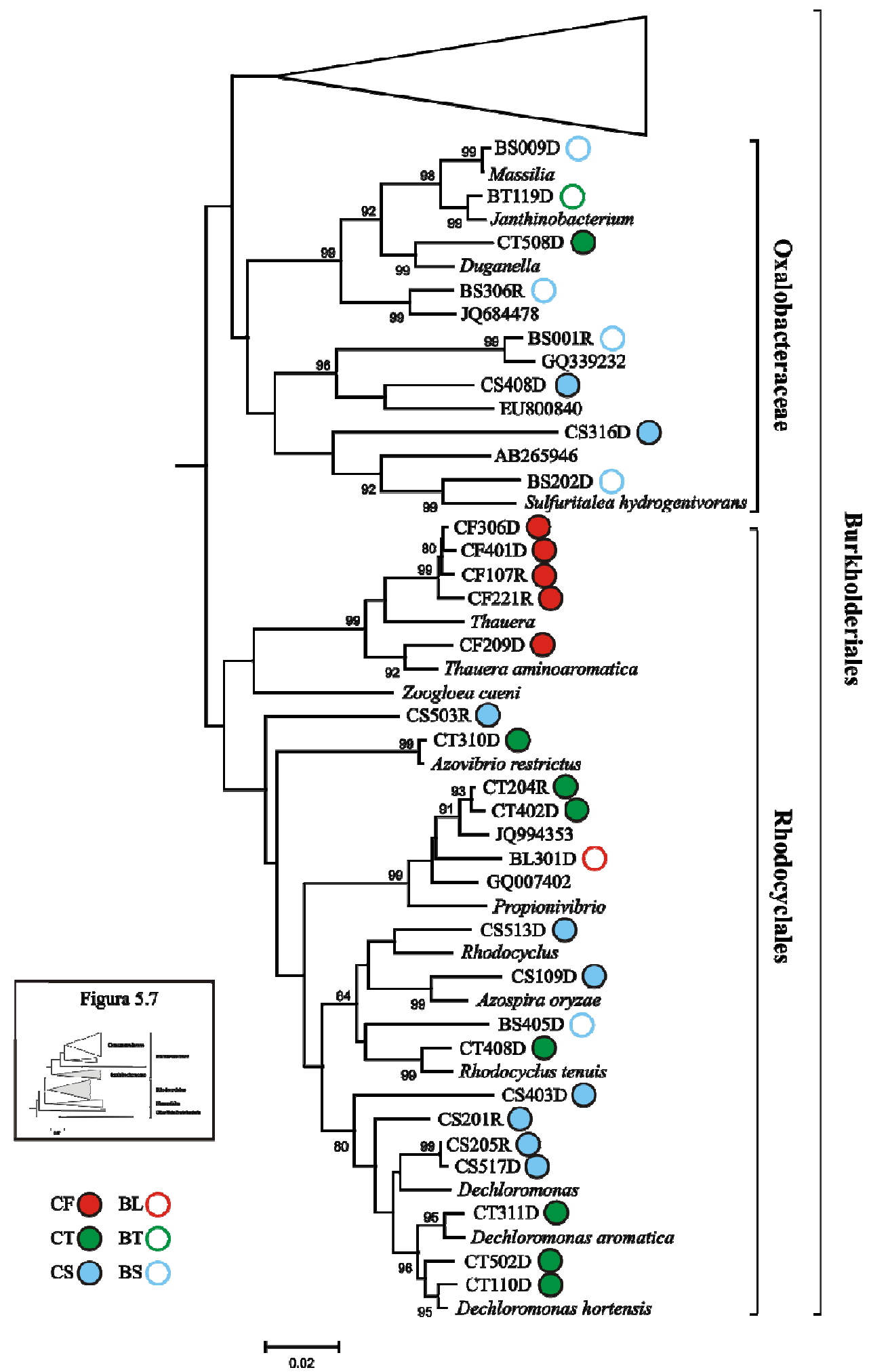

Figura 5.9. Segmento del árbol filogenético correspondiente a la clase Beta-Proteobacteria, orden Burkholderiales, familia Oxalobacteraceae y orden Rhodocyclales, familia Rhodocyclales, así como las secuencias de bacterias más similares obtenidas del GenBank. El árbol se ha construido de acuerdo con el algoritmo Neighbour-Joining. Los valores de bootstrap (1.000 réplicas) superiores al $80 \%$ se indican en los nodos. La raíz del árbol se ha situado en la especie Aquifex pyrophilus incluida como outgroup (Figura 5.5). 


\subsection{Clase Gamma-Proteobacteria}

La clase Gamma-Proteobacteria es el segundo subgrupo más abundante del filo Proteobacteria en el presente estudio. Está compuesta principalmente por bacterias comunes en la etapa aerobia de los sistemas de tratamiento de aguas residuales donde son capaces de oxidar amonio a nitrito en el proceso de nitrificación (Ferrero y col., 2012).

Los 50 clones identificados como Gamma-Proteobacteria según la base de datos RDP se encuentran ampliamente distribuidos entre varios órdenes (Tabla 5.4). En la Figura 5.10 puede verse que la clase Gamma-Proteobacteria forma un grupo parafilético, ya que el ancestro de las Gamma- es también ancestro de las Beta-Proteobacteria. El orden Xanthomonadales es el que se encuentra más próximo a la clase Beta-Proteobacteria según la filogenia obtenida en este trabajo, aunque los valores bootstrap no lo confirman. Xanthomonadales y Pseudomonadales son los dos órdenes que incluyen más secuencias, aunque entre los dos representan únicamente el 44\% del total de clones identificados como Gamma-Proteobacteria. Estos dos órdenes, junto con el orden Enterobacteriales incluyen fundamentalmente secuencias pertenecientes a las rizosferas del sistema de tratamiento de agua residual urbana (BT y BS), mientras que las secuencias de los órdenes Chromatiales, Methylococcales y Alteromonadales proceden exclusivamente de las muestras alimentadas con agua residual porcina (CF, CT y CS) y de la muestra de lodos del sistema de tratamiento de agua residual urbana (BL) (Tabla 5.4).

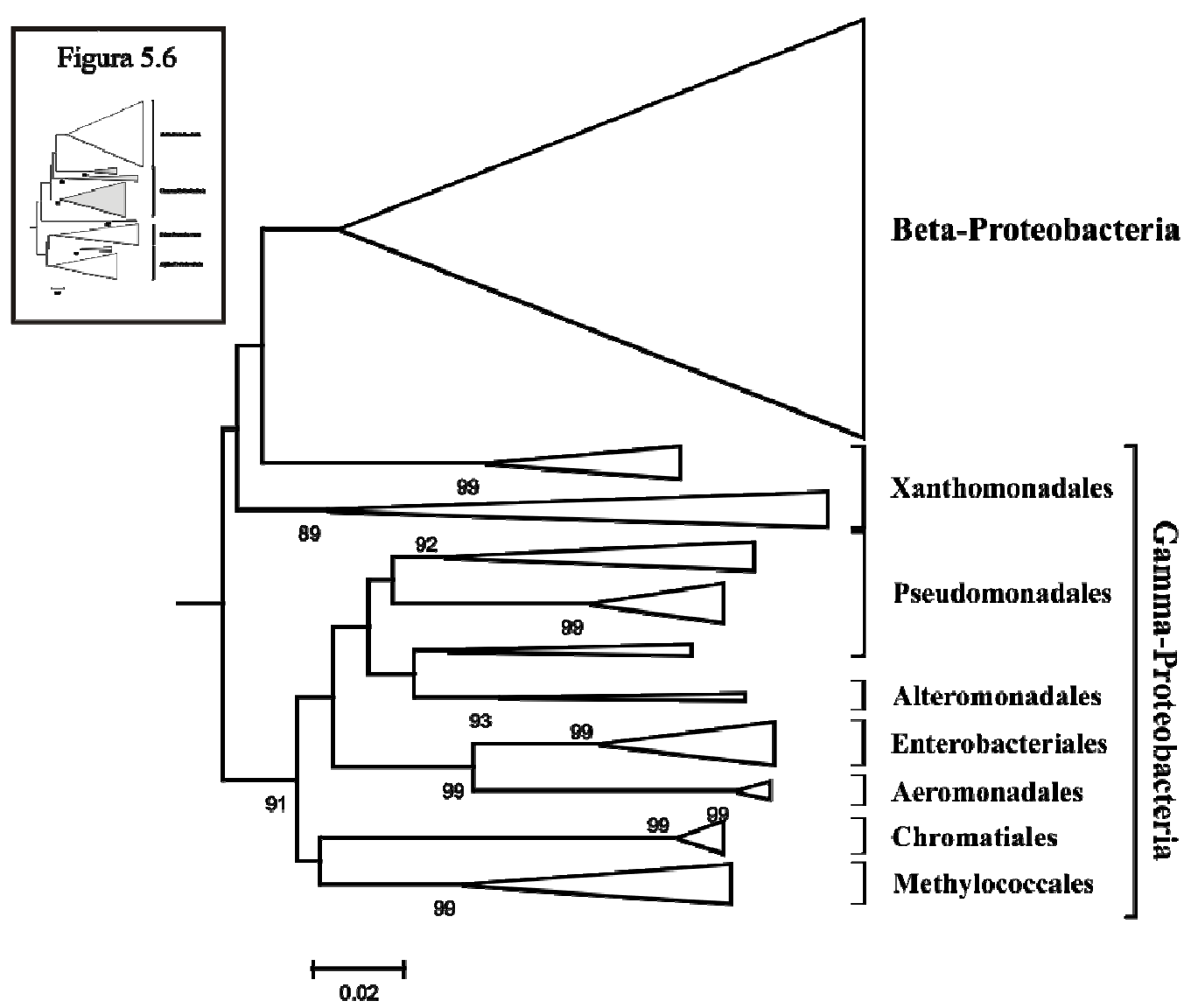

Figura 5.10. Segmento del árbol filogenético correspondiente a la clase Gamma-Proteobacteria. El árbol se ha construido de acuerdo con el algoritmo Neighbour-Joining. Los valores de bootstrap (1.000 réplicas) superiores al $\mathbf{8 0 \%}$ se indican en los nodos. La raíz del árbol se ha situado en la especie Aquifex pyrophilus incluida como outgroup (Figura 5.5). 
Tabla 5.4. Afiliación a nivel de orden y familia de las secuencias de las comunidades de bacterias muestreadas correspondientes a la clase Gamma-Proteobacteria de acuerdo con la base de datos RDP.

\begin{tabular}{lccccccc}
\hline Orden & CF & BL & CT & BT & CS & BS & TOTAL \\
\hline Xanthomonadales & - & - & 2 & 3 & - & 5 & 10 \\
Pseudomonadales & 1 & - & 1 & 6 & 1 & 3 & 12 \\
Enterobacteriales & 1 & - & 1 & 4 & - & 2 & 8 \\
Chromatiales & 7 & - & - & - & - & - & 7 \\
Methylococcales & - & 1 & 1 & - & 4 & - & 6 \\
Alteromonadales & - & 1 & 2 & - & 1 & - & 4 \\
Incertae & - & - & - & 1 & 2 & - & 3 \\
\hline TOTAL & 9 & 2 & 7 & 14 & 8 & 10 & 50 \\
\hline
\end{tabular}

El orden Xanthomonadales, mostrado en la Figura 5.11, es frecuente en los sistemas de tratamiento de agua residual y algunos de sus componentes son capaces de llevar a cabo el proceso de desnitrificación (Chon y col., 2010).

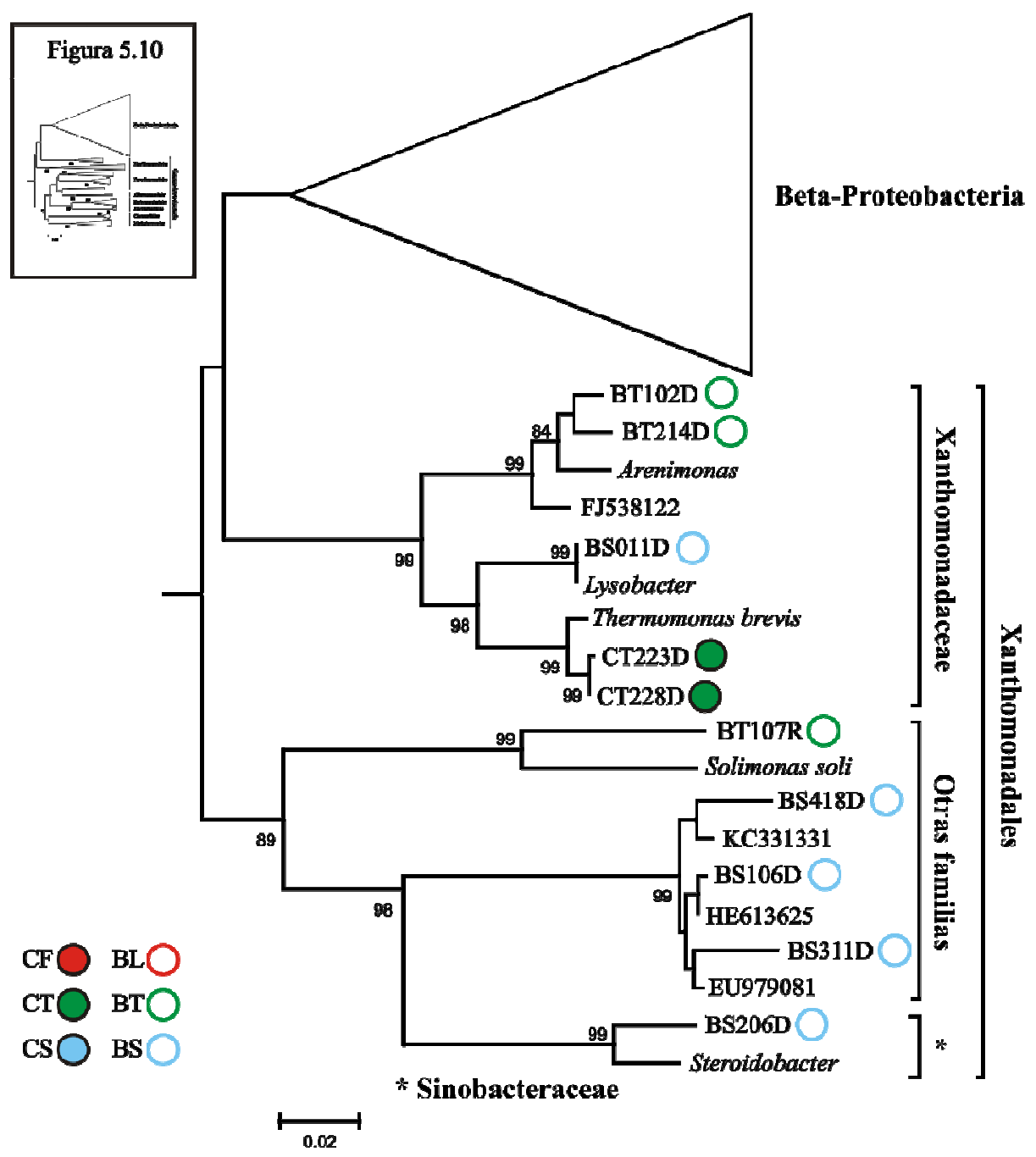

Figura 5.11. Segmento del árbol filogenético correspondiente a la clase Gamma-Proteobacteria, orden Xanthomonadales, así como las secuencias de bacterias más similares obtenidas del GenBank. El árbol se ha construido de acuerdo con el algoritmo Neighbour-Joining. Los valores de bootstrap (1.000 réplicas) superiores al $80 \%$ se indican en los nodos. La raíz del árbol se ha situado en la especie Aquifex pyrophilus incluida como outgroup (Figura 5.5). 
Las dos secuencias de la muestra CT están relacionadas con Thermomonas brevis, bacteria aerobia que puede encontrarse en condiciones anóxicas utilizando nitrato como aceptor de electrones (Mergaert y col., 2003). Las secuencias de la muestra BT están estrechamente relacionadas con especies del género Arenimonas o con Solinomonas soli, todas ellas bacterias aerobias estrictas (Kim y col., 2007; Kwon y col., 2007). Los clones de la muestra BS están relacionados con especies del género Lysobacter, bacterias aerobias estrictas cuya presencia puede deberse a su capacidad lítica que supone una ventaja competitiva en medios ricos en materia orgánica particulada (Ferrero y col., 2012), o del género Steroidobacter, quimioorganótrofos capaces de reducir nitrato (Fahrbach y col., 2008).

El orden Pseudomonadales incluye secuencias de las muestras tomadas en los sistemas de tratamiento de agua residual porcina y urbana (Figura 5.12). De entre los clones procedentes de las muestras alimentadas con agua residual porcina, una corresponde a la muestra CF y está estrechamente relacionada con Pseudomonas aeruginosa, bacteria capaz de realizar la desnitrificación en condiciones aerobias y anaerobias (Davies y col., 1989), otra a la muestra CT relacionada con Acinetobacter y las demás a la muestra CS relacionadas con la bacteria nitrificante Pseudomonas putida (Kouki y col., 2011) y Cellvibrio japonicus, quimioorganótrofo que participa en la reducción de nitrato a nitrito (Humphry y col., 2003), aunque la inclusión de esta especie en la familia Pseudomonadaceae convierte al grupo en un taxón polifilético como puede verse en la Figura 5.12.

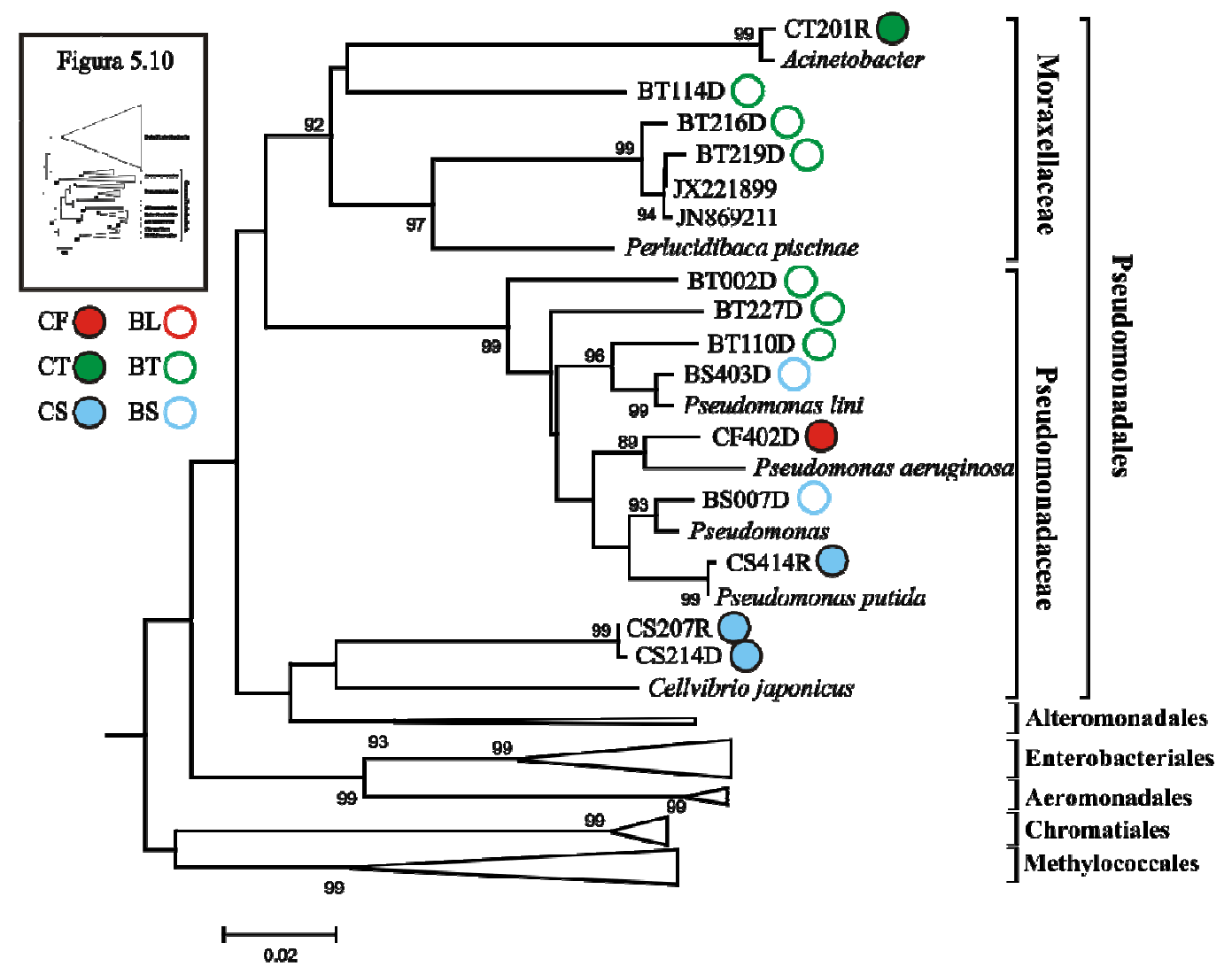

Figura 5.12. Segmento del árbol filogenético correspondiente a la clase Gamma-Proteobacteria, orden Pseudomonadales, así como las secuencias de bacterias más similares obtenidas del GenBank. El árbol se ha construido de acuerdo con el algoritmo Neighbour-Joining. Los valores de bootstrap (1.000 réplicas) superiores al $80 \%$ se indican en los nodos. La raíz del árbol se ha situado en la especie Aquifex pyrophilus incluida como outgroup (Figura 5.5). 
Las secuencias de la muestra BS y alguna de la muestra BT están estrechamente relacionadas con especies del género Pseudomonas, capaces de utilizar un gran número de sustancias como fuente de energía o de carbono, tolerar compuestos tóxicos y promover el crecimiento de las plantas al facilitar la disponibilidad de los nutrientes (Li y col., 2011). Dos secuencias están más relacionadas con Pseudomonas lini, bacteria presente tanto en ambientes aerobios como anaerobios en los que es capaz de reducir nitrato (Delorme y col., 2002).

Las secuencias de la muestra BT incluidas en la familia Moraxellaceae están lejanamente relacionadas con Acinetobacter, género de bacterias aerobias que intervienen en la degradación de hidrocarbonos aromáticos policíclicos (Gao y col., 2006) y en la transformación de nitrato en amonio (Ji y col., 2012), y Perlucidibaca piscinae, bacteria aerobia facultativa capaz de realizar una débil desnitrificación (Song y col., 2008).

La Figura 5.13 muestra la clasificación del árbol filogenético que incluye las secuencias afiliadas a los órdenes Enterobacteriales, Aeromonadales, Alteromonadales, Chromatiales y Methylococcales. La mayoría de las secuencias afiliadas a la familia Enterobacteriaceae del orden Enterobacteriales corresponden a muestras tomadas en el sistema de tratamiento de agua residual urbana aunque también las hay correspondientes a muestras del sistema de tratamiento de agua residual porcina. La presencia de organismos correspondientes a esta familia es común en la rizosfera de macrófitos de humedales artificiales puesto que en este grupo se encuentran la mayor parte de las bacterias alóctonas y potencialmente patógenas de las aguas residuales tales como Escherichia coli o especies pertenecientes al género Shigella (Vacca y col., 2005).

Las secuencias asociadas a la familia Aeromonadaceae del orden Aeromonadales pertenecen a las muestras CT y CS. El crecimiento de las especies del género Aeromonas puede ser influenciado por las concentraciones de amonio, nitrato y/o fosfato en el medio (Pianetti y col., 2006). Además se trata de especies anaerobias facultativas capaces de reducir nitrato a nitrito (Miñana-Galbis y col., 2007), por lo que este género puede jugar un papel importante en el ciclo del nitrógeno en la rizosfera de los humedales artificiales.

Las siete secuencias asociadas a la familia Chromatiaceae del orden Chromatiales pertenecen exclusivamente a la muestra CF. Las especies del género Thiocapsa utilizan compuestos de azufre como donadores de electrones y pueden crecer tanto fototrófica como quimiotróficamente (Guyoneaud y col., 1998). En concreto Thiocapsa roseopersicina es una bacteria anoxigénica fotosintética que pertenece a las bacterias púrpuras del azufre (Gitelson y col., 1999).

Las secuencias del orden Methylococcales pertenecen principalmente a la muestra CS. Las bacterias metanótrofas están categorizadas en tres grupos de bacterias diferentes en base a la estructura de las membranas internas y a las rutas de asimilación de carbono. Los géneros Methylomonas, Methylomicrobium y Methylobacter son metanótrofos que se caracterizan por la producción de una enzima metano monooxigenasa ligada a la membrana y que proliferan en condiciones de alto contenido en oxígeno y bajo contenido en metano (Hanson y Hanson, 1996). La rizosfera de macrófitos es un ambiente favorable para el crecimiento de las bacterias metanótrofas que pueden utilizar el oxígeno liberado por las raíces para catabolizar el metano generado durante la descomposición de la materia orgánica. La presencia de bacterias metanótrofas también puede favorecer la biodegradación de contaminantes xenobióticos debido a la enzima metano monooxigenasa que puede oxidar numerosos contaminantes (DeJournett y col., 2007). 


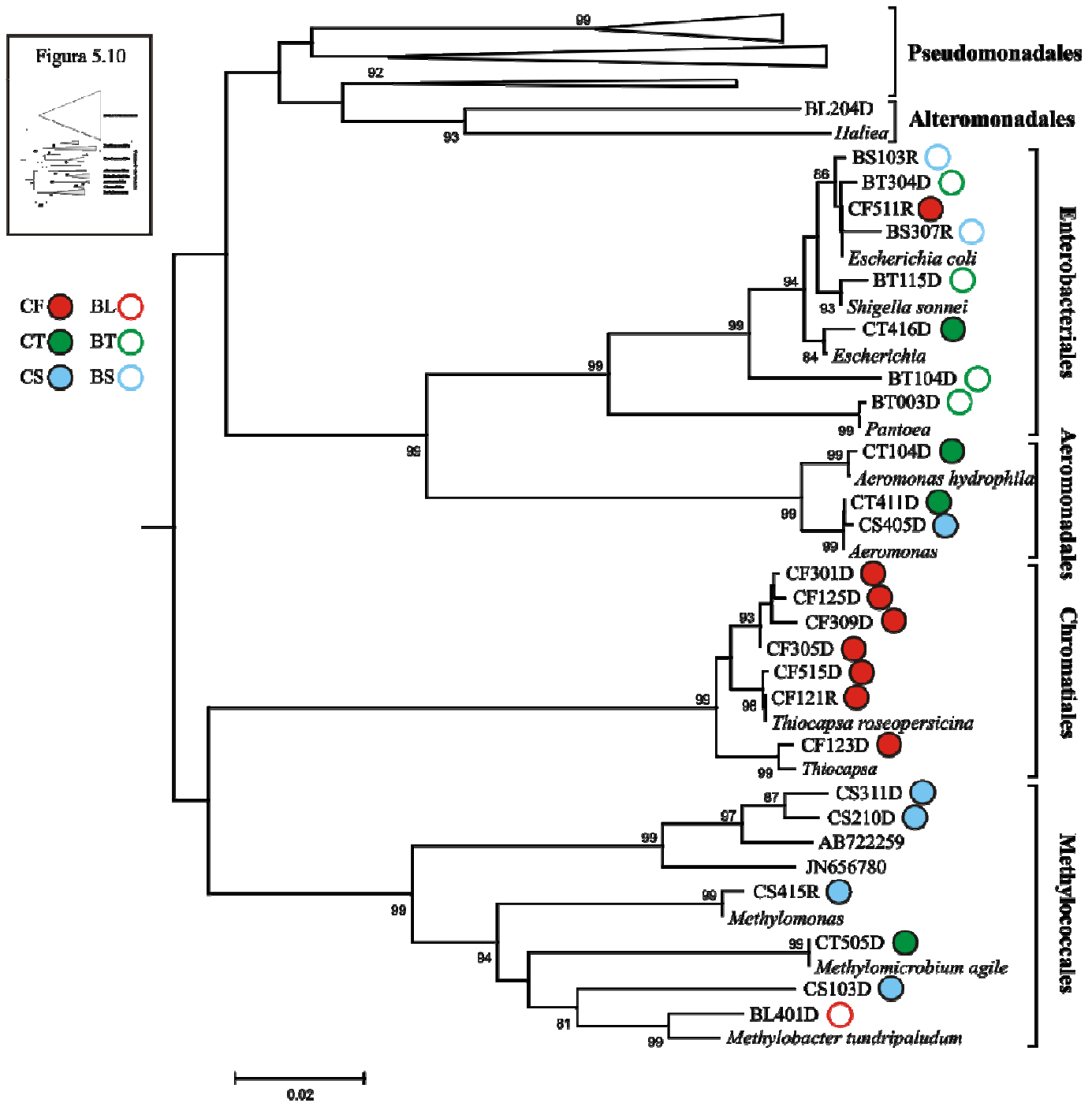

Figura 5.13. Segmento del árbol filogenético correspondiente a la clase Gamma-Proteobacteria, órdenes Alteromonadales, Enterobacteriales, Aeromonadales, Chromatiales y Methylococcales, así como las secuencias de bacterias más similares obtenidas del GenBank. El árbol se ha construido de acuerdo con el algoritmo Neighbour-Joining. Los valores de bootstrap (1.000 réplicas) superiores al $80 \%$ se indican en los nodos. La raíz del árbol se ha situado en la especie Aquifex pyrophilus incluida como outgroup (Figura 5.5).

\subsection{Clase Alpha-Proteobacteria}

La clase Alpha-Proteobacteria alberga un grupo variado de metabolismos e incluye géneros fototróficos, simbiontes de plantas, patógenos de animales y plantas y metabolizadores de metano (Pini y col., 2011). Los 30 clones asignados a este subgrupo se encuentran repartidos entre cinco órdenes representados en la Figura 5.14. La posición de la clase DeltaProteobacteria dentro del árbol es muy próxima a la de la clase Alpha-Proteobacteria. Éstas forman un grupo parafilético ya que las Delta-Proteobacteria descienden de un ancestro que podría calificarse como Alpha-Proteobacteria según la filogenia obtenida (los valores bootstrap no confirman este detalle). Los órdenes Rhodospirillales y Rhizobiales agrupan el 70\% del total de las secuencias identificadas como Alpha-Proteobacteria según la clasificación realizada 
utilizando la base de datos RDP. La muestra más representada en este subgrupo es BS, seguida por las muestras BT y CT (Tabla 5.5; Figura 5.14).

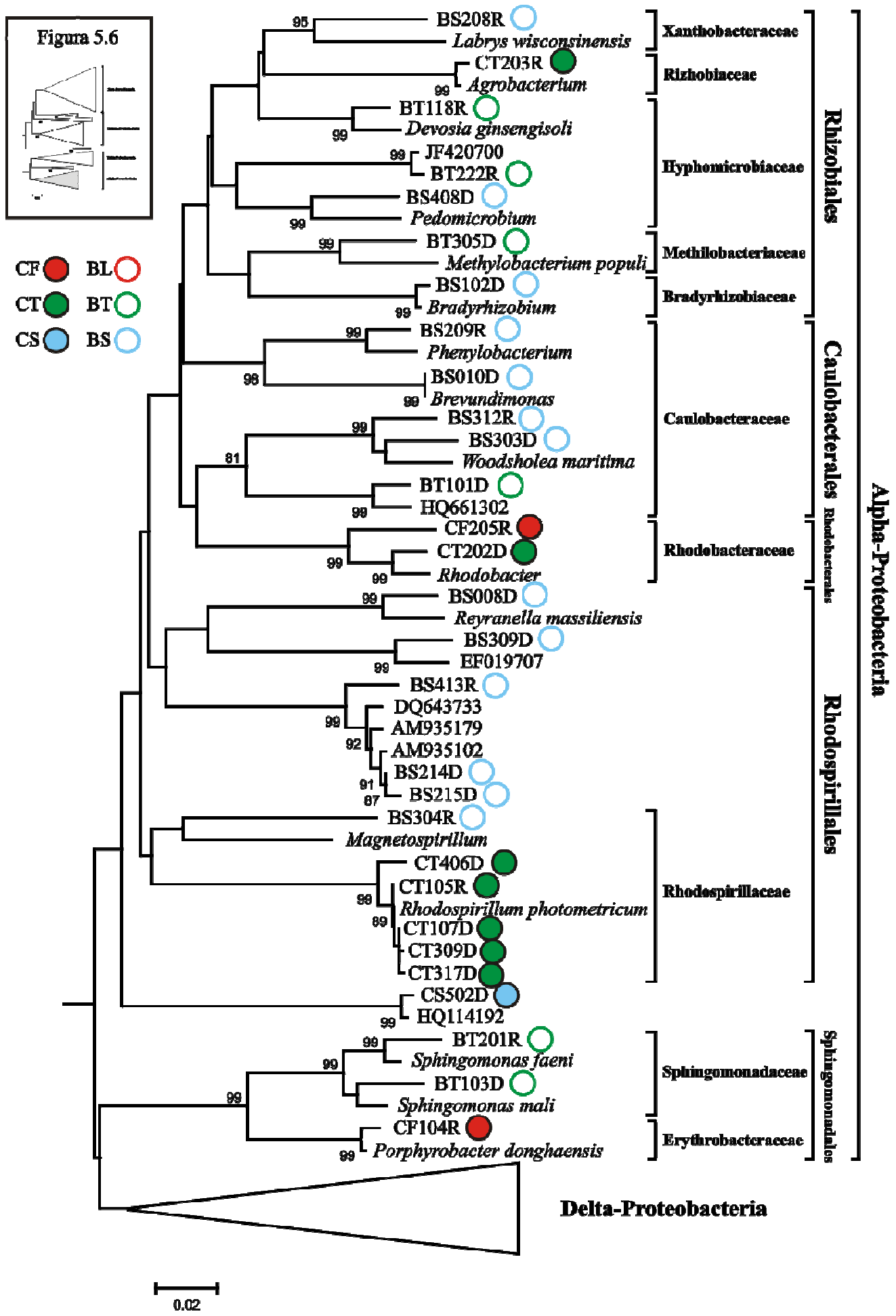

Figura 5.14. Segmento del árbol filogenético correspondiente a la clase Alpha-Proteobacteria. El árbol se ha construido de acuerdo con el algoritmo Neighbour-Joining. Los valores de bootstrap (1.000 réplicas) superiores al $\mathbf{8 0 \%}$ se indican en los nodos. La raíz del árbol se ha situado en la especie Aquifex pyrophilus incluida como outgroup (Figura 5.5). 
De acuerdo con el árbol filogenético construido a partir de secuencias del NCBI, el orden con un mayor número de secuencias es Rhodospirillales que incluye clones de la rizosfera de Typha latifolia del sistema de tratamiento de agua residual porcina (CT) estrechamente relacionados con Rhodospirillum, género de bacterias fotótrofas púrpuras no del azufre capaces de producir hidrógeno a partir de compuestos de carbono en condiciones de anaerobiosis (Lazaro y col., 2012). El resto de clones corresponden exclusivamente a la muestra BS y se encuentran relacionados fundamentalmente con especies no cultivadas o con especies de los géneros Magnetospirillum y Reyranella capaces de reducir nitrato (Pagnier y col., 2011).

Tabla 5.5. Afiliación a nivel de orden y familia de las secuencias de las comunidades de bacterias muestreadas correspondientes a la clase Alpha-Proteobacteria de acuerdo con la base de datos RDP.

\begin{tabular}{lccccccc}
\hline Orden & CF & BL & CT & BT & CS & BS & TOTAL \\
\hline Rhodospirillales & - & - & 5 & - & - & 5 & 10 \\
Rhizobiales & - & - & 2 & 4 & - & 5 & 11 \\
Rhodobacterales & 1 & - & 1 & - & - & - & 2 \\
Caulobacterales & - & - & - & - & - & 2 & 2 \\
Sphingomonadales & 1 & - & - & 2 & - & - & 3 \\
Incertae & - & - & - & - & 1 & 1 & 2 \\
\hline TOTAL & 2 & 0 & 8 & 6 & 1 & 13 & 30 \\
\hline
\end{tabular}

En el orden Rhizobiales se encuentran secuencias de las muestras de rizosfera de Typha latifolia y Salix atrocinerea del sistema de tratamiento de agua residual urbana (BT y BS respectivamente) relacionadas con géneros y especies de hasta seis familias diferentes con metabolismos diversos. Las secuencias están relacionadas con Methylobacterium populi, bacteria aerobia facultativa metilótrofa (Van Aken y col., 2004), Bradyrhizobium, género que incluye bacterias simbióticas fijadoras de nitrógeno (Rivas y col., 2009), Pedomicrobium, género involucrado en la precipitación u oxidación de hierro y/o manganeso (Braun y col., 2009), Devosia ginsengisoli, bacteria aerobia típica de rizosferas (Min-Ho y col., 2007) y Labrys wisconsinensis, bacteria aerobia o facultativa anaerobia (Albert y col., 2010).

El resto de órdenes que incluyen secuencias de muestras de la rizosfera del sistema de tratamiento de agua residual urbana (BT y BS) son Sphingomonadales y Caulobacterales que incluyen géneros de especies aerobias estrictas o facultativas anaerobias como Sphingomonas, Phenylobacterium o Brevundimonas (Segers y col., 1994; Takeuchi y col., 1995; Busse y col., 2003; Kanso y Patel, 2004). El orden Rhodobacterales incluye secuencias de muestras tomadas en el sistema de tratamiento de agua residual porcina (CF y CT) y está caracterizado por la presencia de especies fotótrofas anoxigénicas del género Rhodobacter (Allen y col., 2010).

\subsection{Clase Delta-Proteobacteria}

De acuerdo con la clasificación de la base de datos RDP, las secuencias identificadas dentro de la clase Delta-Proteobacteria están repartidas entre diversos órdenes de entre los cuales Syntrophobacterales y Myxococcales engloban el 65\% de las secuencias. Un 62\% de los clones pertenecen a la muestra de sedimento de agua residual urbana (BL) (Tabla 5.6).

La taxonomía de las Delta-Proteobacteria no está demasiado clara y existen varias discrepancias entre la clasificación de los clones por medio de la herramienta del RDP y la posición filogenética utilizando secuencias de referencia del NCBI.

La mayor parte de las bacterias Delta-Proteobacteria son reductoras de sulfato, hierro o protones que tienen un papel principal en los ambientes anóxicos de lagos meromícticos y sedimentos (Haller y col., 2011). Esta descripción coincide con las secuencias de las muestras CF y BL las cuales constituyen el orden Syntrophobacterales en el árbol filogenético (Figura 5.15) y se encuentran estrechamente relacionadas con los géneros Smithella y Syntrophus, géneros 
sintróficos que actúan como intermediarios en la descomposición metanogénica de la materia orgánica en condiciones anaerobias (Janssen y col., 2009; Narihiro y col., 2012). Con la excepción de una secuencia relacionada con Desulfomicrobium baculatum que es una bacteria estrictamente anerobia reductora de sulfato (Copeland y col., 2009), el resto de secuencias de la muestra BL están relacionadas con bacterias no cultivadas.

Tabla 5.6. Afiliación a nivel de orden y familia de las secuencias de las comunidades de bacterias muestreadas correspondientes a la clase Delta-Proteobacteria de acuerdo con la base de datos RDP.

\begin{tabular}{lccccccc}
\hline Orden & CF & BL & CT & BT & CS & BS & TOTAL \\
\hline Syntrophobacterales & 2 & 11 & - & - & - & 1 & 14 \\
Myxococcales & - & 1 & - & 2 & 1 & 1 & 5 \\
Syntrophorhabdales & 1 & 3 & - & - & - & - & 4 \\
Desulfobacterales & 1 & 1 & - & - & - & - & 2 \\
Desulfovibrionales & - & 2 & - & - & - & - & 2 \\
Bdellovibrionales & - & - & - & - & - & 1 & 1 \\
Desulfuromonadales & - & - & - & - & - & 1 & 1 \\
\hline TOTAL & 4 & 18 & 0 & 2 & 1 & 4 & 29 \\
\hline
\end{tabular}

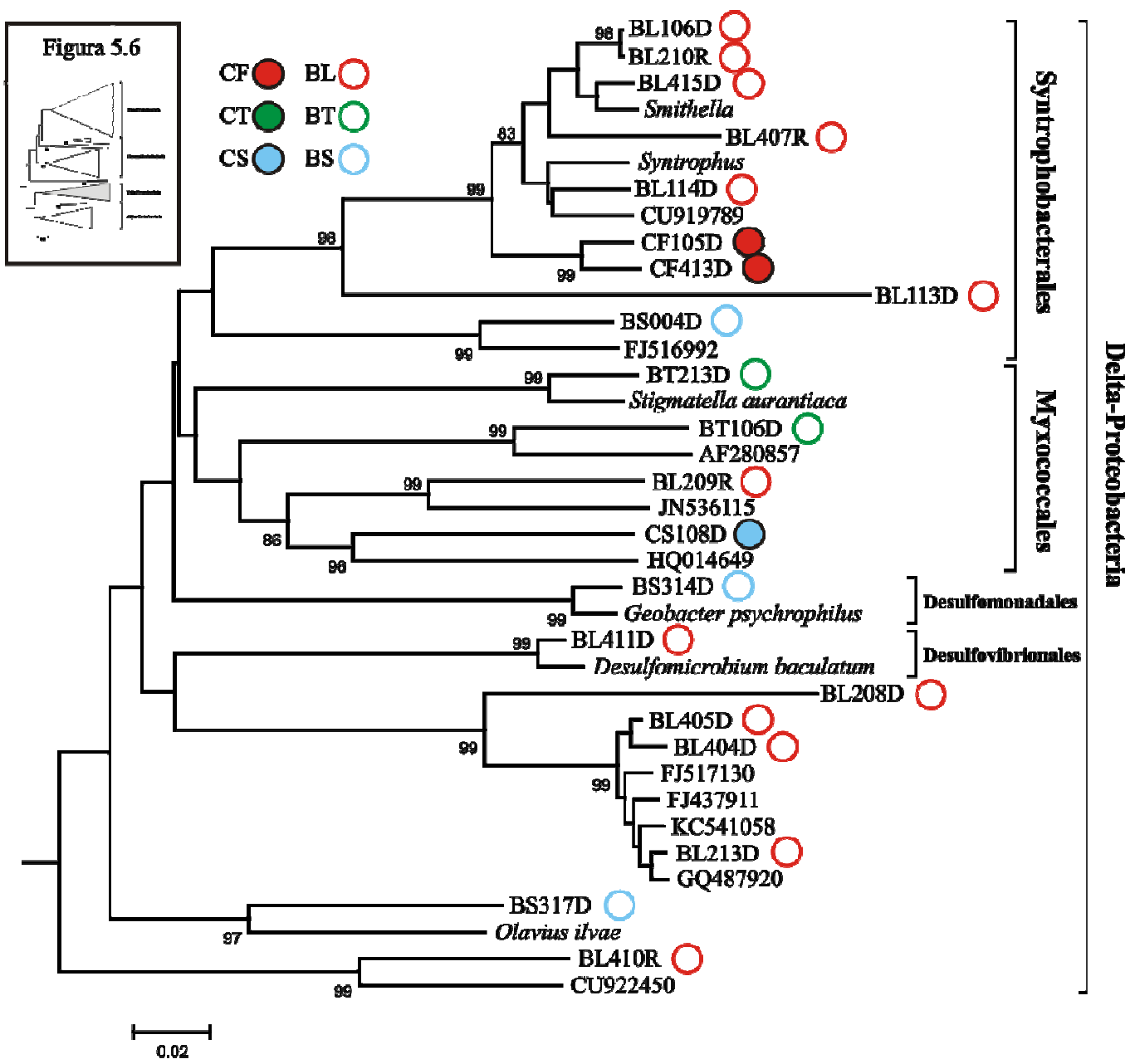

Figura 5.15. Segmento del árbol filogenético correspondiente a la clase Delta-Proteobacteria, órdenes Syntrophobacterales, Myxococcales, Desulfomonadales y Desulfovibrionales así como las secuencias de bacterias más similares obtenidas del GenBank. El árbol se ha construido de acuerdo con el algoritmo Neighbour-Joining. Los valores de bootstrap (1.000 réplicas) superiores al $80 \%$ se indican en los nodos. La raíz del árbol se ha situado en la especie Aquifex pyrophilus incluida como outgroup (Figura 5.5). 
Aparte de una secuencia estrechamente relacionada con Geobacter psychrophilus (bacteria reductora de hierro (III) (Gault y col., 2011)), el resto de secuencias pertenecientes a las muestras BL, BT, BS y CS están agrupadas en los órdenes Syntrophobacterales y Myxococcales. Este último contiene bacterias que intervienen en el ciclo del carbono en suelos y también bacterias "microdepredadoras" capaces de degradar otros organismos mediante exoenzimas hidrolíticas (Lueders y col., 2006; Liu y col., 2012).

El análisis filogenético sitúa a las bacterias del orden Syntrophorhabdales junto al filo Actinobacteria, por lo que la clase Delta-Proteobacteria formaría un grupo polifilético. Esta situación taxonómica queda reflejada en la clasificación del RDP. La Figura 5.16 muestra un segmento perteneciente a la clase Delta-Proteobacteria que no se agrupa con el resto de DeltaProteobacteria en la construcción del árbol filogenético, en el que se encuentran secuencias correspondientes fundamentalmente a la muestra BL estrechamente relacionadas con especies del género Syntrophorhabdus, bacterias anaerobias obligatorias capaces de llevar a cabo la oxidación sintrófica de compuestos aromáticos (Qiu y col., 2008).

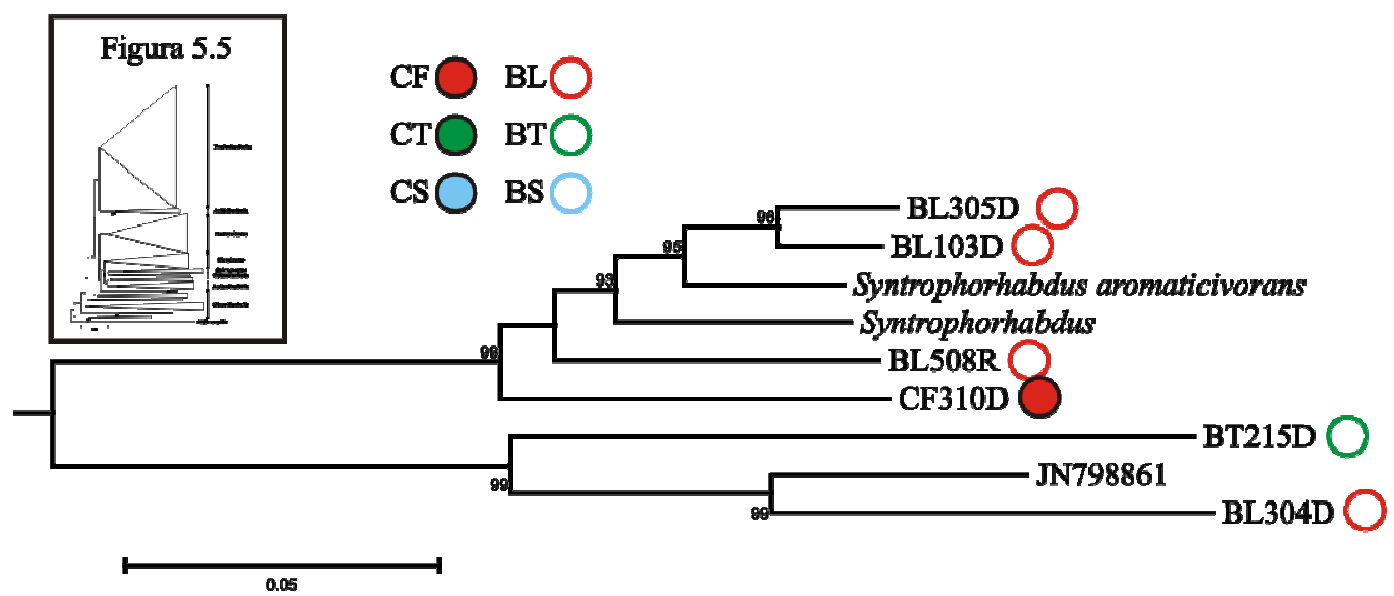

Figura 5.16. Segmento del árbol filogenético correspondiente a la clase Delta-Proteobacteria, orden Syntrophorhabdales así como las secuencias más similares obtenidas del GenBank. El árbol se ha construido de acuerdo con el algoritmo Neighbour-Joining. Los valores de bootstrap (1.000 réplicas) superiores al $80 \%$ se indican en los nodos. La raíz del árbol se ha situado en la especie Aquifex pyrophilus incluida como outgroup (Figura 5.5).

\subsubsection{Filo Bacteroidetes}

Las 53 secuencias relacionadas con el filo Bacteroidetes se distribuyen entre las clases Flavobacteria, Sphingobacteria y Bacteroidia según la metodología que utiliza la base de datos RDP. El número de secuencias perteneciente a cada muestra es relativamente homogéneo para el conjunto de este Filo (Tabla 5.7), pero se pueden apreciar diferencias en la composición de las muestras a nivel de clase (Figura 5.17). En las clases Flavobacteria y Sphingobacteria del árbol filogenético predominan las secuencias de la rizosfera de Typha latifolia y Salix atrocinerea de los sistemas de tratamiento de ambos tipos de agua residual (CT, CS, BT y BS), aunque también incluyen alguna secuencia procedente de las muestras de lodo o sedimento (CF y BL). El género que contiene un mayor número de clones afiliados es Flavobacterium, de la clase Flavobacteria, que incluye especies con potencial desnitrificante (Dong y Reddy, 2010; Saeed y Sun, 2012). Sin embargo no es probable que muchas de las secuencias intervengan en el proceso de desnitrificación puesto que las especies más próximas filogenéticamente que se han encontrado dentro de este género son bacterias aerobias incapaces de reducir nitrato, como es el caso de Flavobacterium terrigena, Flavobacterium cheniae o Flavobacterium caeni (Yoon y col., 2007; Qu y col., 2008; Liu y col., 2010). Lo mismo ocurre con Fluviicola taffensis, otra especie identificada dentro del orden Flavobacteriales (O'Sullivan y col., 2005). 


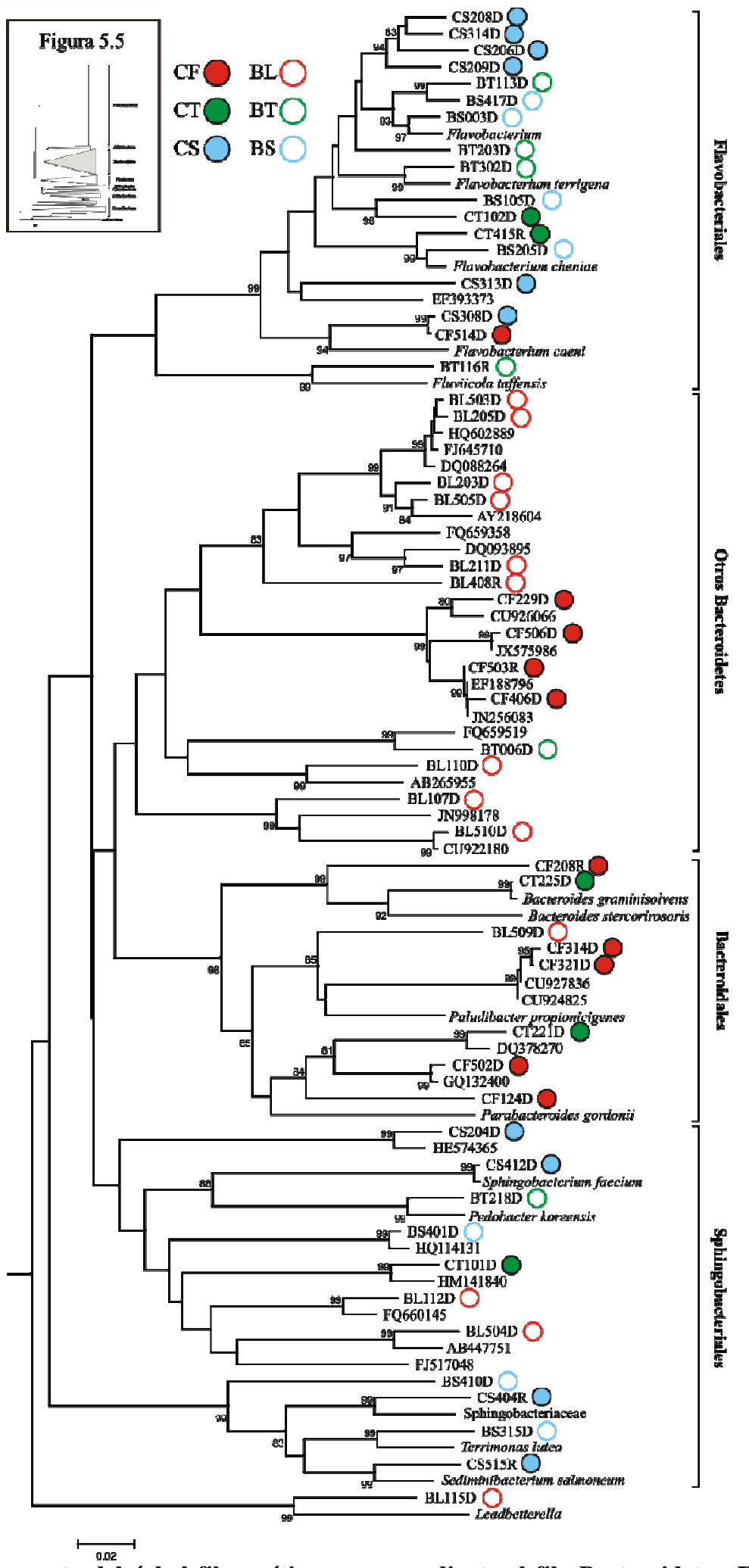

Figura 5.17. Segmento del árbol filogenético correspondiente al filo Bacteroidetes. El árbol se ha construido de acuerdo con el algoritmo Neighbour-Joining. Los valores de bootstrap (1.000 réplicas) superiores al $80 \%$ se indican en los nodos. La raíz del árbol se ha situado en la especie Aquifex pyrophilus incluida como outgroup (Figura 5.5). 
En la clase Sphingobacteria las secuencias también se encuentran estrechamente relacionadas con bacterias aerobias de los géneros Sphingobacterium, Pedobacter, Sediminibacterium y Terrimonas, este último fermentativo acidógeno (Xie y Yokota, 2006; Baik y col., 2007; Qu y Yuan, 2008; Burgos-Díaz y col., 2011; Lu y col., 2012). El grupo parece polifilético en el árbol filogenético con las discrepancias en la clasificación que eso supone.

Tabla 5.7. Afiliación a nivel de orden y familia de las secuencias de las comunidades de bacterias muestreadas correspondientes al filo Bacteroidetes de acuerdo con la base de datos RDP.

\begin{tabular}{llccccccc}
\hline Clase & Orden & CF & BL & CT & BT & CS & BS & TOTAL \\
\hline Flavobacteria & Flavobacteriales & 1 & - & 2 & 4 & 7 & 4 & 18 \\
Sphingobacteria & Sphingobacteriales & - & 7 & 1 & 1 & 4 & 3 & 16 \\
Bacteroidia & Bacteroidales & 9 & 1 & 3 & 1 & - & - & 14 \\
Incertae & & - & 5 & - & - & - & - & 5 \\
\hline TOTAL & & 10 & 13 & 6 & 6 & 11 & 7 & 53 \\
\hline
\end{tabular}

En la clase Bacteroidia se concentran las secuencias pertenecientes a las muestras tomadas en el sistema de tratamiento de agua residual porcina (CF y CT fundamentalmente). Las especies más próximas filogenéticamente a los clones son anaerobias estrictas como Paludibacter propionicigenes, bacteria fermentativa acidógena productora de propionato (Ueki y col., 2006; Lu y col., 2012), Parabacteroides gordonii (Sakamoto y col., 2009) y Bacteroides (Nishiyama y col., 2009; Kitahara y col., 2012).

En este filo también se encuentran hasta 14 clones pertenecientes fundamentalmente a las muestras CF y BL estrechamente relacionados con bacterias no cultivadas que se encuentran agrupados en "Otros Bacteroidetes" en la Figura 5.17.

\subsubsection{Filo Firmicutes}

De acuerdo con la base de datos RDP, las 18 secuencias relacionadas con el filo Firmicutes están distribuidas entre las clases Clostridia, Negativicutes y Erysipelotrichia (Tabla 5.8). La clasificación del árbol filogenético difiere ligeramente al incluir la clase Mollicutes, pero en esencia se trata de un filo en el que se concentran secuencias procedentes del sistema de tratamiento de muestras de agua residual porcina (principalmente CF y CT) y de sedimento del sistema de tratamiento de agua residual urbana (BL) (Figura 5.18). En este filo existen numerosas discrepancias entre las clasificaciones filogenética y de la base de datos RDP.

Tabla 5.8. Afiliación a nivel de orden y familia de las secuencias de las comunidades de bacterias muestreadas correspondientes al filo Firmicutes de acuerdo con la base de datos RDP.

\begin{tabular}{llccccccc}
\hline Clase & Orden & CF & BL & CT & BT & CS & BS & TOTAL \\
\hline Clostridia & Clostridiales & 6 & 2 & 2 & - & - & - & 10 \\
& Thermoanaerobacterales & - & - & - & - & - & 1 & 1 \\
Negativicutes & Selenomonadales & 1 & 2 & 1 & - & 1 & - & 5 \\
Erysipelotrichia & Erysipelotrichales & 1 & - & 1 & - & - & - & 2 \\
\hline TOTAL & & 8 & 4 & 4 & 0 & 1 & 1 & 18 \\
\hline
\end{tabular}

El filo Firmicutes engloba un grupo diverso de bacterias que ocupan una amplia variedad de hábitats (Haakensen y col., 2008) entre los que se encuentran los reactores anaerobios de aguas residuales (Ma y col., 2013). Todas las bacterias identificadas en el árbol filogenético son anaerobias y se conoce la capacidad fermentativa de gran parte de ellas. Las especies de la clase Clostridia son responsables de los procesos de hidrólisis y fermentación de la materia orgánica (Ma y col., 2013) como es el caso de especies de la familia Peptococcaceae, del género Clostridium o la especie Anaerovorax odorimutans (Rogosa, 1971; Matthies y col., 2000). También son anaerobias las especies de los géneros Asteroleplasma y Acholeplasma pertenecientes a la clase Mollicutes (Robinson y Freundt, 1987; Angulo y col., 2000) y las del 
género Anaeromusa pertenecientes a la clase Negativicutes que además son capaces de fermentar aminoácidos (Baena y col., 1999).

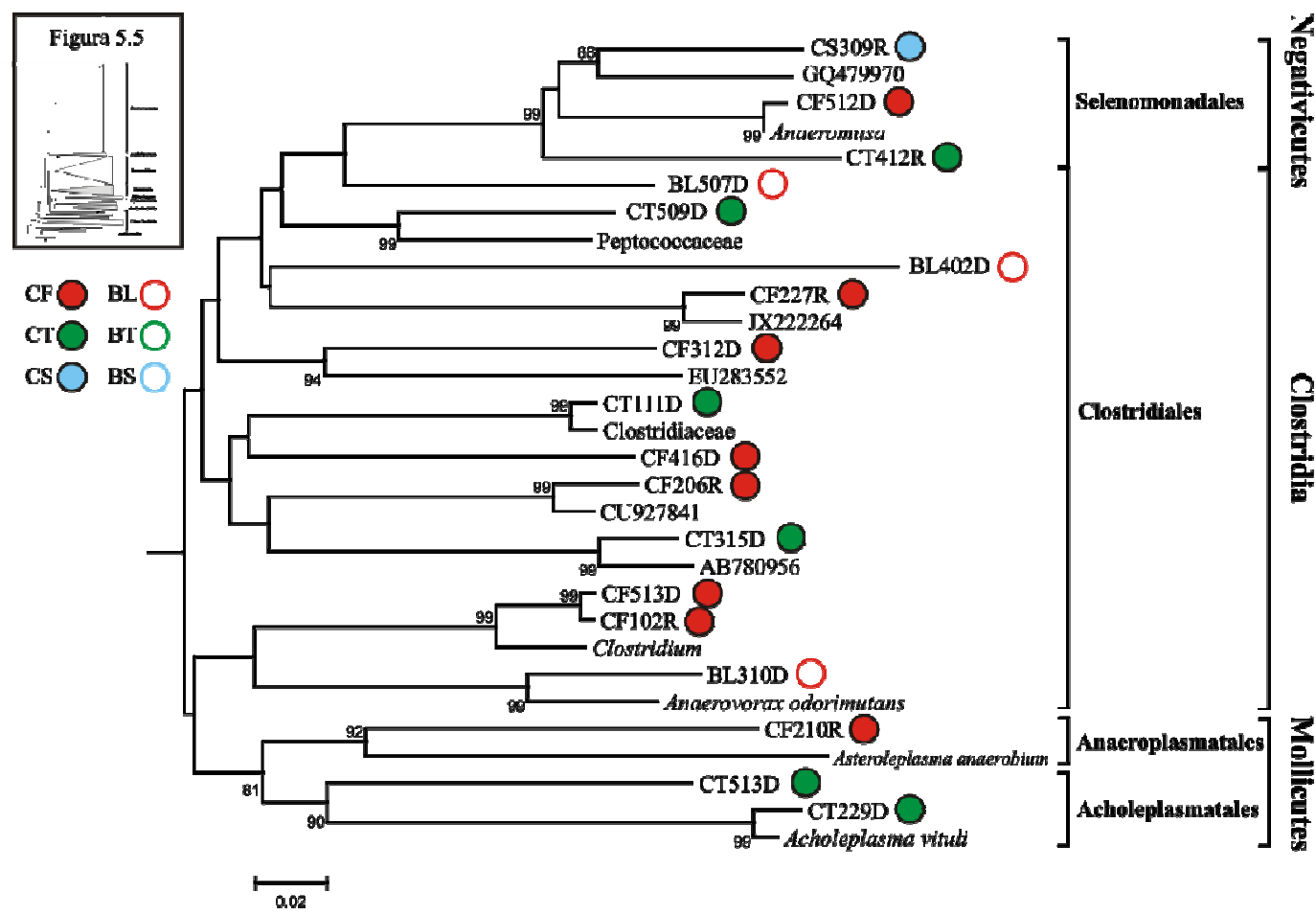

Figura 5.18. Segmento del árbol filogenético correspondiente al filo Firmicutes. El árbol se ha construido de acuerdo con el algoritmo Neighbour-Joining. Los valores de bootstrap (1.000 réplicas) superiores al $\mathbf{8 0 \%}$ se indican en los nodos. La raíz del árbol se ha situado en la especie Aquifex pyrophilus incluida como outgroup (Figura 5.5).

\subsubsection{Filos "secundarios"}

Además de los filos "principales", 17 filos "secundarios" quedan representados por las secuencias obtenidas (Tabla 5.1). Dentro del filo Actinobacteria es destacable la estrecha relación de las secuencias de las muestras de Typha latifolia (CT y BT) con bacterias aerobias de los géneros Actinoplanes y Frondihabitans (Goodfellow y col., 1990; Greene y col., 2009), mientras que secuencias de la muestra de rizosfera de Salix atrocinerea del sistema de tratamiento de agua residual urbana (BS) están relacionadas con bacterias anaerobias estrictas tales como el patógeno humano Propionibacterium acnes.

El filo Acidobacteria está presente particularmente en hábitats de suelos, incluye una importante diversidad filogenética y una extensa versatilidad metabólica (Quaiser y col., 2003). Las secuencias asociadas a este filo pertenecen principalmente a las muestras de agua residual urbana BL y BS y están prácticamente relacionadas con bacterias no cultivadas con la excepción de Geothrix fermentans, bacteria anaerobia estricta que oxida acetato con reducción de Fe(III) (Coates y col., 1999).

De entre los 15 filos restantes merece una mención especial el filo Spirochaetes que incluye fundamentalmente secuencias de la fosa de purines (CF) estrechamente relacionadas con bacterias anaerobias estrictas como Treponema lecithinolyticum (Wyss y col., 1999) o bacterias anaerobias fermentativas pertenecientes al género Sphaerochaeta (Mäkinen y col., 2013). 


\subsubsection{Riqueza y diversidad $\alpha$ de las comunidades bacterianas}

Con el fin de analizar los índices de riqueza y diversidad de las comunidades bacterianas, las secuencias genéticas han sido asignadas a unidades taxonómicas operativas (OTUs) que se definen en función de la similaridad que existe entre las secuencias de cada comunidad bacteriana (Schloss y Westcott, 2011). Un OTU se establece en base a una distancia genética $(D)$ determinada que permite definir la divergencia genética entre las secuencias. Aunque no existen umbrales claros para definir niveles taxonómicos en los OTUs, se considera que las distancias genéticas inferiores o iguales a 0,05 aunque no representan especies, permiten definir de un modo más aproximado las comunidades a nivel de especie o género en comparación con distancias genéticas superiores (Schloss y Westcott, 2011). La distancia genética 0,10 equivale al nivel taxonómico entre familia y orden aproximadamente. Los OTUs han sido establecidos en base a cinco distancias genéticas $(0,03 ; 0,05 ; 0,10 ; 0,20$ y 0,30$)$ para definir la riqueza y diversidad de las comunidades bacterianas del modo más aproximado posible a los diferentes niveles taxonómicos.

La Figura 5.19 muestra las curvas de rarefacción para las distintas distancias genéticas que representan el número de secuencias analizadas frente al número de OTUs observados para cada comunidad bacteriana. Una curva asintótica indica que el esfuerzo de muestreo realizado es suficiente para estimar la riqueza de la comunidad e indica que muestreos adicionales aportarán poca información sobre la composición de la comunidad.
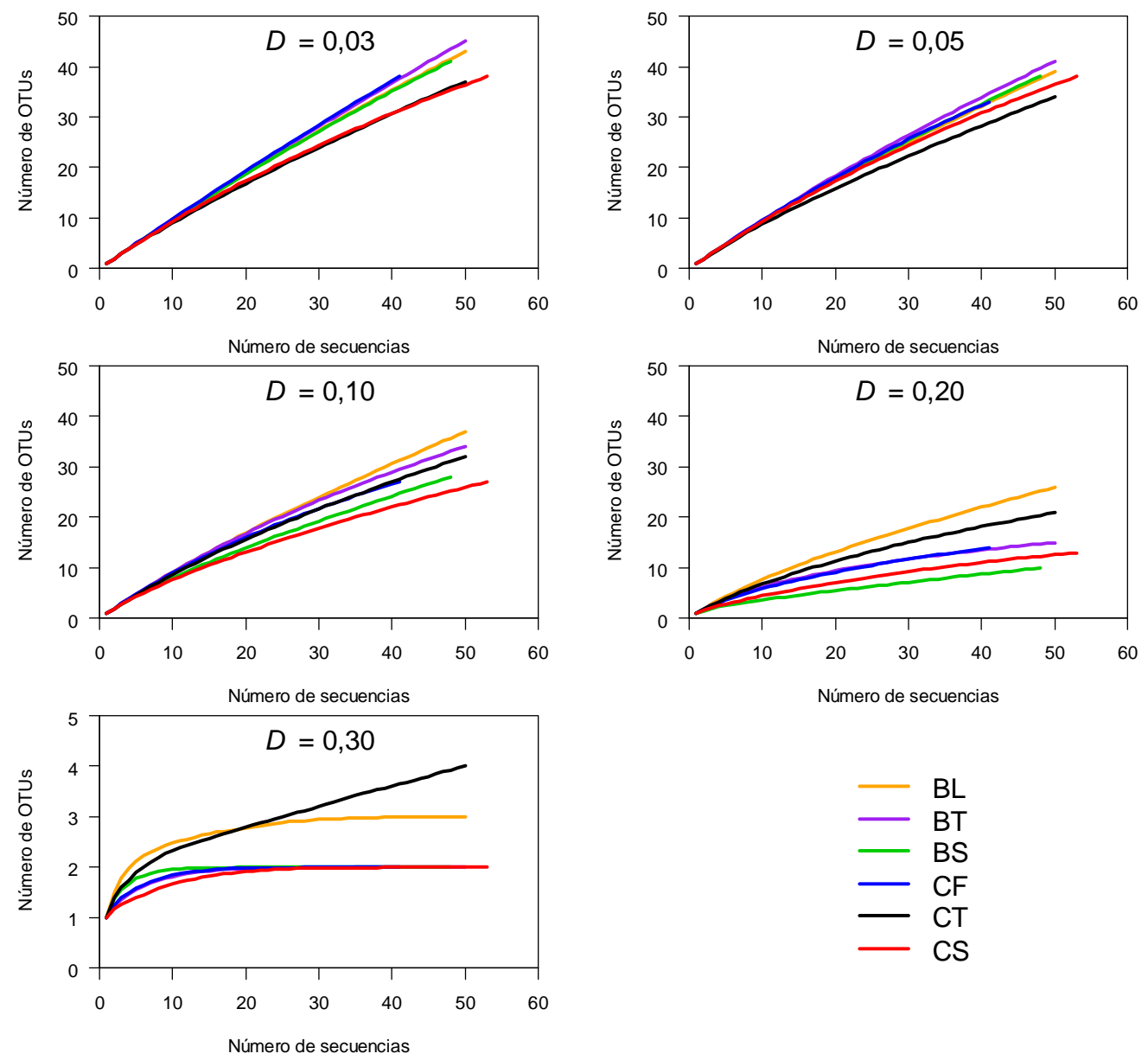

Número de secuencias

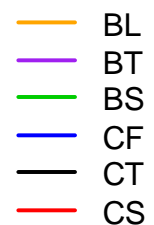

Figura 5.19. Curvas de rarefacción de las comunidades bacterianas muestreadas para cada distancia genética considerada. 
Los resultados muestran que para valores de $D$ pequeños $(0,03 ; 0,05$ y 0,10$)$ las curvas de rarefacción no tienden a estabilizarse, lo que indica un esfuerzo de muestreo insuficiente. Las curvas de las muestras del sistema de tratamiento de agua residual urbana tienen una pendiente más pronunciada en comparación con las del sistema de agua residual porcina, lo que sugiere que la diversidad de bacterias es mayor para estas comunidades a un nivel taxonómico entre especie y familia.

El número de OTUs disminuye al aumentar la distancia genética y se encuentra entre 10 y 26 cuando $D$ es igual a 0,20 (Tabla 5.9). Las curvas de las comunidades de las rizosferas de Typha latifolia y Salix atrocinerea (CT, CS, BT y BS) comienzan a estabilizarse para esta distancia genética a diferencia de las comunidades CF y BL, lo cual indica una mayor diversidad para estas comunidades para un nivel taxonómico aproximado de clase y orden. La estabilización de las curvas de rarefacción se alcanza claramente a una distancia genética de 0,30 . Sin embargo el escaso número de OTUs observados sugiere que esta distancia genética hace referencia a un nivel taxonómico incluso superior a filo, lo que proporciona escasa información.

La estimación de riqueza, diversidad y dominancia para cada comunidad bacteriana se ha realizado para las cinco distancias genéticas mediante los índices Chao1, Shannon-Wiener y Simpson respectivamente (Tabla 5.9).

El índice no paramétrico Chaol permite estimar la riqueza de una muestra (número de OTUs) mediante la extrapolación de la información obtenida (OTUs definidos en la muestra) (Colwell y Coddington, 1994). A una distancia genética de 0,03 - la más próxima a la definición de especie - la riqueza estimada ha sido muy superior al número de OTUs observados para todas las comunidades bacterianas, lo que indica un esfuerzo de muestreo insuficiente. Las mayores riquezas estimadas se han obtenido para las comunidades del sistema de tratamiento de agua residual urbana en el orden $\mathrm{BS}>\mathrm{BL}>\mathrm{BT}$, en comparación con las comunidades del sistema de tratamiento de agua residual porcina con orden $\mathrm{CS}>\mathrm{CF}>\mathrm{CT}$.

Al incrementar la distancia genética, la diferencia entre el número de OTUs observados y la riqueza estimada se ha ido reduciendo para todas las comunidades, lo que indica que la información proporcionada por la estimación de la riqueza pierde importancia a altas distancias genéticas.

La diversidad y la dominancia de las comunidades bacterianas son conceptos opuestos que están representados por los índices de Shannon y Simpson respectivamente. Por lo general las comunidades bacterianas del humedal artificial de agua porcina tienen una diversidad algo menor y una dominancia mayor que las comunidades del sistema de agua residual urbana (Tabla 5.9), aunque las diferencias no son significativas.

Al aumentar las distancias genéticas el índice de Shannon disminuye, mientras que el índice de Simpson aumenta para todas las comunidades bacterianas. Esta variación se debe al menor número de OTUs que son definidos al aumentar la distancia genética.

En ambos sistemas de tratamiento la comunidad de la rizosfera de Salix atrocinerea (CS y BS) es la de mayor diversidad y menor dominancia para distancias genéticas iguales o menores a 0,05 , mientras que las muestras de fosa o sedimento (CF y BL) tienen una mayor diversidad y menor dominancia que las muestras de rizosfera al incrementar las distancias genéticas $(D=$ $0,10$ y $D=0,20)$. 
Tabla 5.9. Número de OTUs observados (OTUs), riqueza estimada (Chao1), índice de diversidad de Shannon-Wiener (Shannon) e índice de dominancia de Simpson (Simpson) para las comunidades de bacterias estudiadas. Los OTUs se han definido en función de las distancias genéticas 0,$03 ; 0,05 ; 0,10 ; 0,20$ y $0,30 .{ }^{*}$ La ausencia de “doubletons" no permite calcular el índice de Chao1 para estas distancias genéticas en la comunidad BL.

\begin{tabular}{|c|c|c|c|c|c|c|c|}
\hline & & $\mathrm{CF}$ & $\mathrm{BL}$ & $\mathrm{CT}$ & BT & $\mathrm{CS}$ & $\mathrm{BS}$ \\
\hline & No.secuencias & 50 & 50 & 53 & 41 & 48 & 50 \\
\hline \multirow[t]{4}{*}{0,03} & OTUs & 37 & 43 & 38 & 38 & 41 & 45 \\
\hline & Chao1 & $130(71-292)$ & $219(107-524)$ & $85(56-163)$ & $187(92-451)$ & $140(79-298)$ & $250(121-598)$ \\
\hline & Shannon & $3,42(3,16-3,68)$ & $3,70(3,49-3,91)$ & $3,51(3,29-3,73)$ & $3,61(3,39-3,83)$ & $3,66(3,45-3,87)$ & $3,76(3,56-3,97)$ \\
\hline & Simpson $\left(\times 10^{-3}\right)$ & $25(2-48)$ & $7(0-15)$ & $17(4-29)$ & $4(-2-9)$ & $7(0-14)$ & $5(-1-11)$ \\
\hline \multirow[t]{4}{*}{0,05} & OTUs & 34 & 39 & 38 & 33 & 38 & 41 \\
\hline & Chao1 & $129(66-309)$ & - * & $85(56-163)$ & $79(50-160)$ & $162(82-389)$ & $190(95-454)$ \\
\hline & Shannon & $3,29(3,02-3,55)$ & $3,53(3,30-3,76)$ & $3,51(3,29-3,73)$ & $3,43(3,21-3,66)$ & $3,53(3,31-3,76)$ & $3,63(3,42-3,85)$ \\
\hline & Simpson $\left(\times 10^{-3}\right)$ & $33(8-57)$ & $16(3-28)$ & $17(4-29)$ & $11(2-20)$ & $13(2-25)$ & $10(1-18)$ \\
\hline \multirow[t]{4}{*}{0,10} & OTUs & 32 & 37 & 27 & 27 & 28 & 34 \\
\hline & Chao1 & $78(48-164)$ & - - & $56(36-115)$ & $53(35-108)$ & $86(47-207)$ & $80(50-166)$ \\
\hline & Shannon & $3,23(2,97-3,49)$ & $3,44(3,20-3,69)$ & $2,87(2,57-3,17)$ & $3,17(2,93-3,40)$ & $2,99(2,69-3,28)$ & $3,40(3,18-3,61)$ \\
\hline & Simpson $\left(\times 10^{-3}\right)$ & $34(10-58)$ & $20(5-36)$ & $74(30-118)$ & $24(9-40)$ & $55(21-89)$ & $19(8-30)$ \\
\hline \multirow[t]{4}{*}{0,20} & OTUs & 21 & 26 & 13 & 14 & 10 & 15 \\
\hline & Chao1 & $37(25-79)$ & $-{ }^{*}$ & $17(14-35)$ & $23(16-59)$ & $21(12-64)$ & $22(16-52)$ \\
\hline & Shannon & $2,50(2,16-2,84)$ & $2,87(2,57-3,17)$ & $1,60(1,22-1,98)$ & $2,09(1,74-2,44)$ & $1,28(0,91-1,65)$ & $2,24(1,96-2,52)$ \\
\hline & Simpson $\left(\times 10^{-3}\right)$ & $130(52-207)$ & $68(26-109)$ & $356(216-495)$ & $178(82-274)$ & $438(287-589)$ & $134(78-190)$ \\
\hline \multirow[t]{4}{*}{0,30} & OTUs & 4 & 3 & 2 & 2 & 2 & 2 \\
\hline & Chao1 & $5(4-17)$ & $3(3-3)$ & $2(2-2)$ & $2(2-2)$ & $2(2-2)$ & $2(2-2)$ \\
\hline & Shannon & $0,69(0,45-0,93)$ & $0,80(0,62-0,98)$ & $0,31(0,13-0,49)$ & $0,42(0,22-0,61)$ & $0,56(0,42-0,70)$ & $0,40(0,23-0,58)$ \\
\hline & Simpson $\left(\times 10^{-3}\right)$ & $611(470-751)$ & $508(395-620)$ & $826(699-953)$ & $744(592-896)$ & $617(495-739)$ & $754(616-892)$ \\
\hline
\end{tabular}


La Figura 5.20 representa la distribución proporcional de las secuencias en las comunidades bacterianas analizadas. Sólo están representados aquellos filos, clases, órdenes y familias con una abundancia igual o mayor a dos secuencias. Mediante esta representación se pueden visualizar las diferencias de diversidad y dominancia entre las distintas muestras a partir del nivel taxonómico de familia.
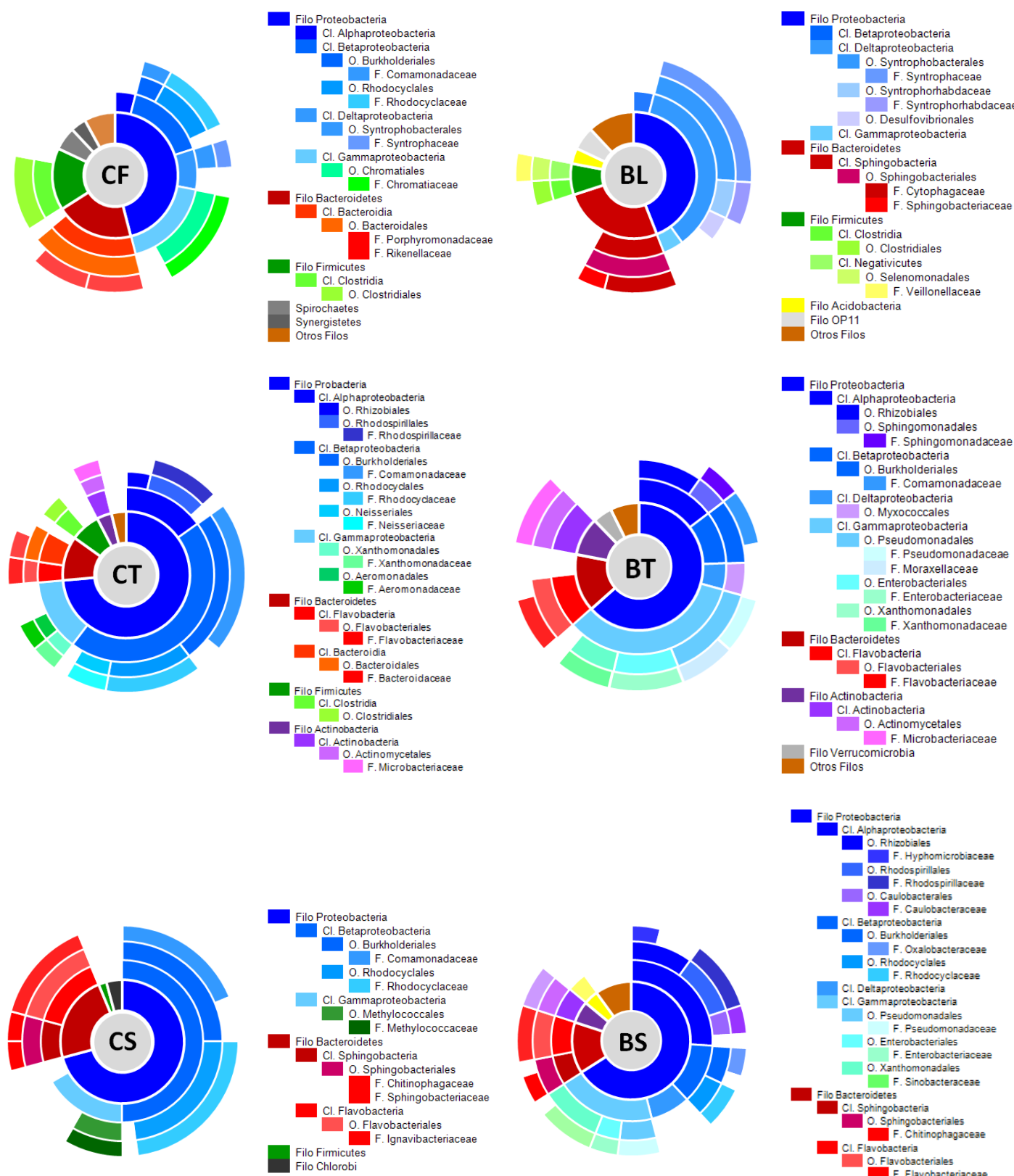

Filo Chlorobi

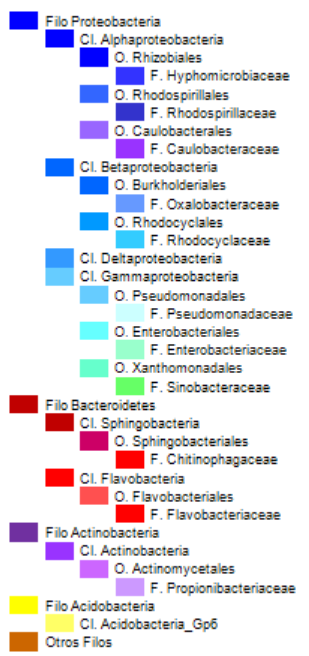

Figura 5.20. Representación proporcional de las comunidades bacterianas analizadas con respecto al total de secuencias de cada muestra. Solo se muestran aquellos filos, clases, órdenes y familias con una abundancia igual o superior a dos secuencias. La afiliación de las secuencias se ha realizado de acuerdo con la base de datos RDP. 
Las muestras de fosa o sedimento (CF y BL) se caracterizan por tener un elevado número de filos y clases con menos de dos secuencias y que por tanto no están representadas en la Figura 5.20. Las muestras de la rizosfera de macrófitos (CT, CS, BT y BS), por el contrario, se caracterizan por presentar un menor número de filos de entre los cuales Proteobacteria incluye la mayor parte de las secuencias.

Esta representación permite apreciar visualmente la mayor diversidad y menor dominancia de las muestras de sedimento o lodo frente a las muestras de rizosfera para las distancias genéticas 0,10 y 0,20 , equivalentes aproximadamente al nivel taxonómico entre familia y clase.

\subsubsection{Diversidad $\beta$. Análisis comparativo de las comunidades de bacterias}

Las diferencias de riqueza y estructura entre las comunidades de bacterias se han estudiado mediante los estimadores Jest, Thetayc y Unifrac. Las matrices de distancias resultantes se han analizado mediante análisis de coordenadas principales (PCoA).

Los PCoAs del estimador Jest permiten agrupar aquellas comunidades bacterianas que comparten los mismos OTUs (Figura 5.21). Los dos primeros ejes permiten explicar entre un 42,7 y un $55,3 \%$ de la variación entre comunidades.

0.03

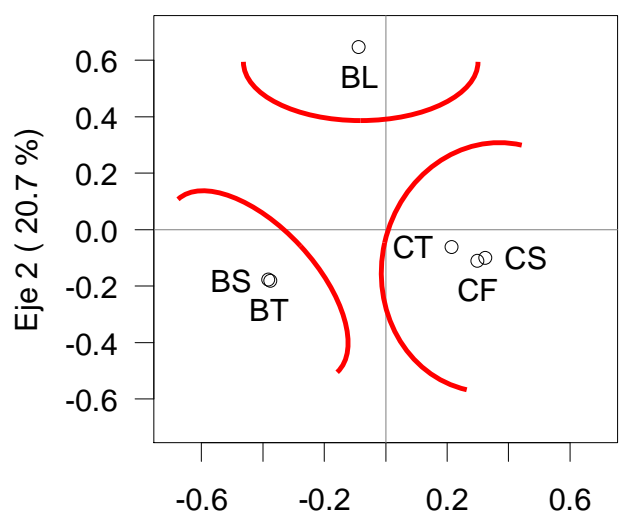

Eje 1 ( $22 \%)$

0.10

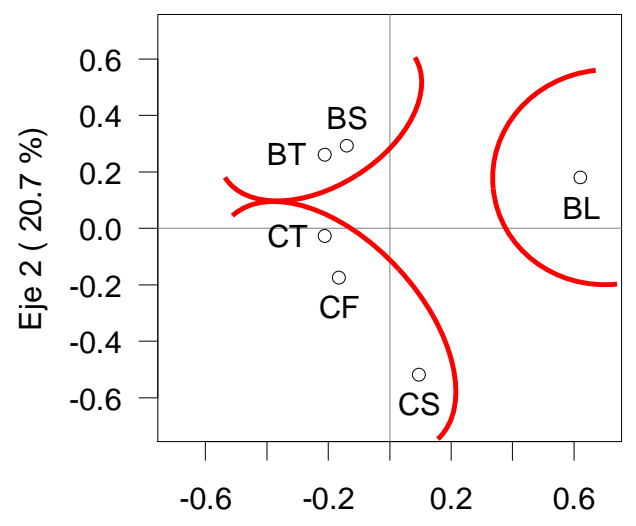

Eje 1 ( $22.6 \%)$
0.05

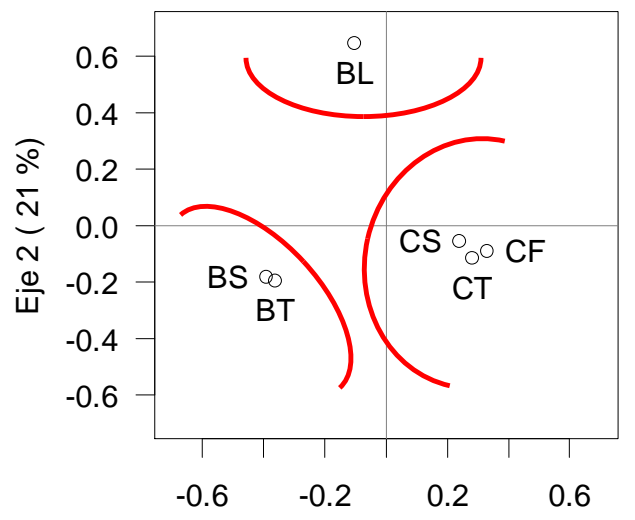

Eje $1(22.1 \%)$

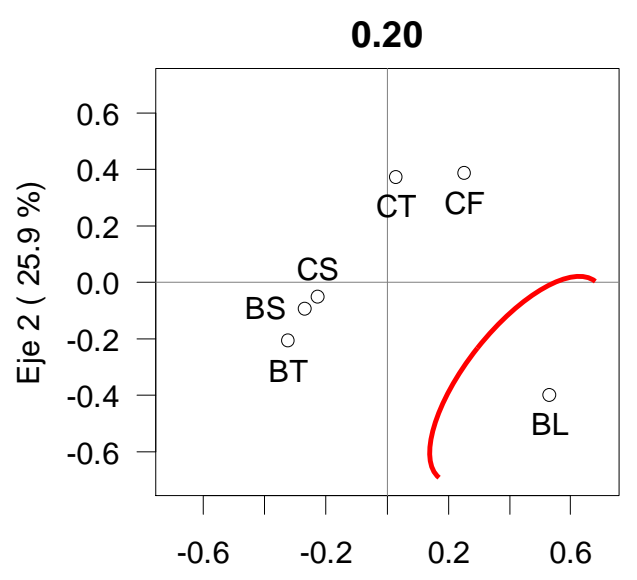

Eje 1 ( $29.4 \%)$

Figura 5.21. Diagramas biplot con los ejes 1 y 2 del Análisis de Coordenadas Principales (PCoA) de la matriz de distancias generada por el estimador Jest para las distancias genéticas 0,$03 ; 0,05 ; 0,10$ y 0,20 . 
La muestra BL es la que menos OTUs comparte con el resto de comunidades y se encuentra separada por el Eje 2 cuando $D$ es igual a 0,03 y 0,05 y por el Eje 1 cuando $D=0,10$. La distancia genética 0,20 proporciona poca información adicional, pero ambos ejes permiten separar claramente la muestra BL del resto de comunidades. El Eje 1 también permite separar las comunidades del sistema de tratamiento de agua residual urbana de las del sistema de agua residual porcina cuando $D$ es igual a 0,03 y 0,05 , mientras que el Eje 2 permite separarlas cuando $D=0,10$. Esto indica que las comunidades bacterianas comparten más OTUs con las comunidades de su mismo sistema de tratamiento.

Los resultados del estimador Thetayc son similares para las dos distancias genéticas mostradas en los PCoA de la Figura 5.22. Los tres primeros ejes permiten explicar una variación de 67,4 $(D=0,05)$ y $82,2 \%(D=0,10)$.

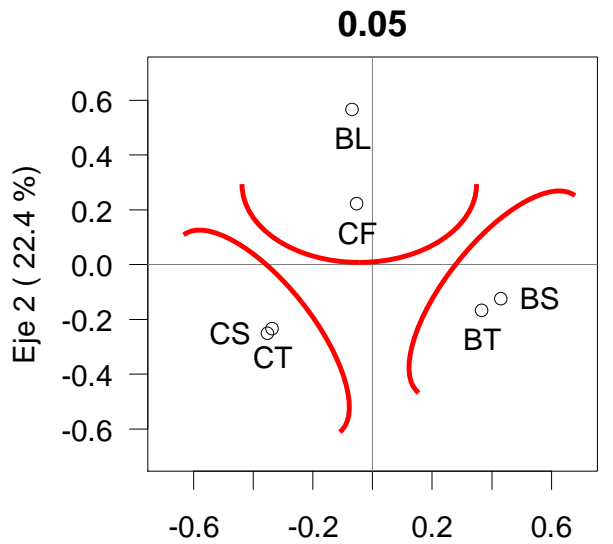

Eje $1(23.9 \%)$

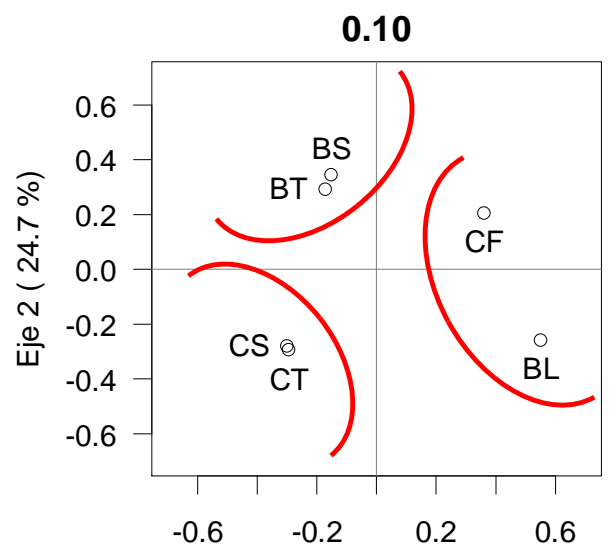

Eje 1 ( $34.4 \%)$

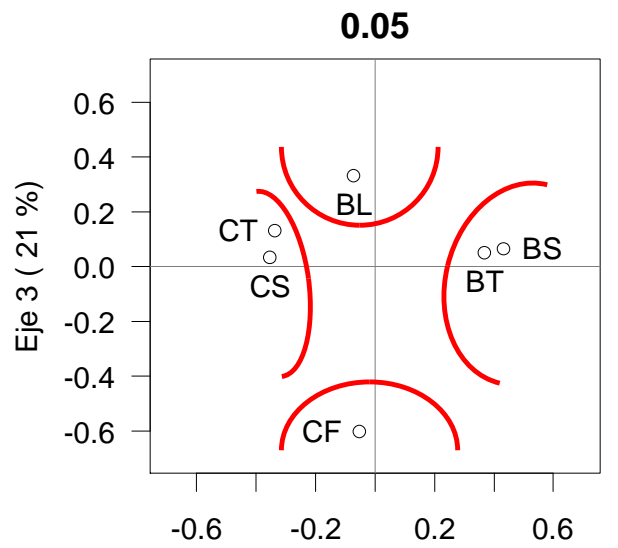

Eje $1(23.9 \%)$

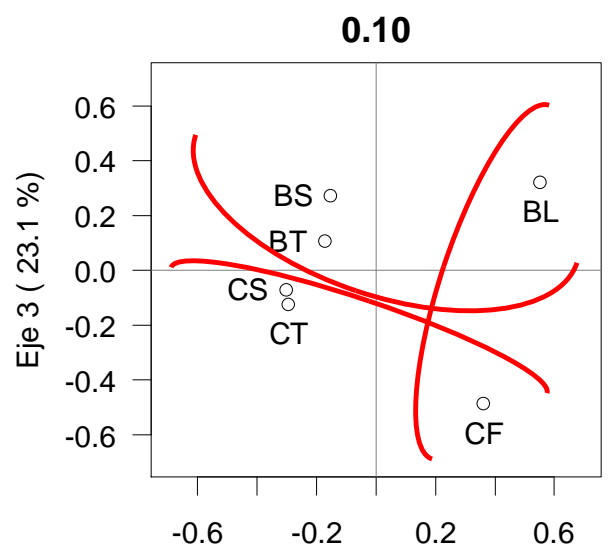

Eje 1 ( $34.4 \%)$

Figura 5.22. Diagramas biplot con los ejes 1, 2 y 3 del Análisis de Coordenadas Principales (PCoA) de la matriz de distancias generada por el estimador Thetayc para las distancias genéticas 0,05 y $\mathbf{0 , 1 0}$.

Para la distancia genética 0,05 el Eje 1 permite separar las muestras de rizosfera de los dos sistemas de tratamiento (CT y CS frente a BT y BS), el Eje 2 separa las muestras de rizosfera de las de sedimento o fosa (CF y BL frente al resto) y el Eje 3 separa CF de BL. En el caso de la distancia genética 0,10 es el Eje 1 el que distingue entre sedimento o fosa frente a las comunidades de rizosfera, el Eje 2 el que separa las rizosferas de los dos sistemas de tratamiento y el Eje 3 el que separa las comunidades de los dos sistemas de tratamiento, aunque la mayor distancia se encuentra entre CF y BL. 
En ambos casos las muestras de rizosfera de cada sistema de tratamiento se encuentran muy próximas entre sí, lo que indica la similaridad en la abundancia relativa de los OTUs de estas comunidades.

Los resultados del método UniFrac son similares a los obtenidos con el estimador Jest. Los dos primeros ejes de los PCoA de la Figura 5.23 para los análisis UniFrac unweighted y UniFrac weighted permiten explicar una variación de 45,7 y 58,2\% respectivamente. En ambos casos el Eje 1 separa BL del resto de comunidades y el Eje 2 separa las comunidades de los dos sistemas de tratamiento entre sí.

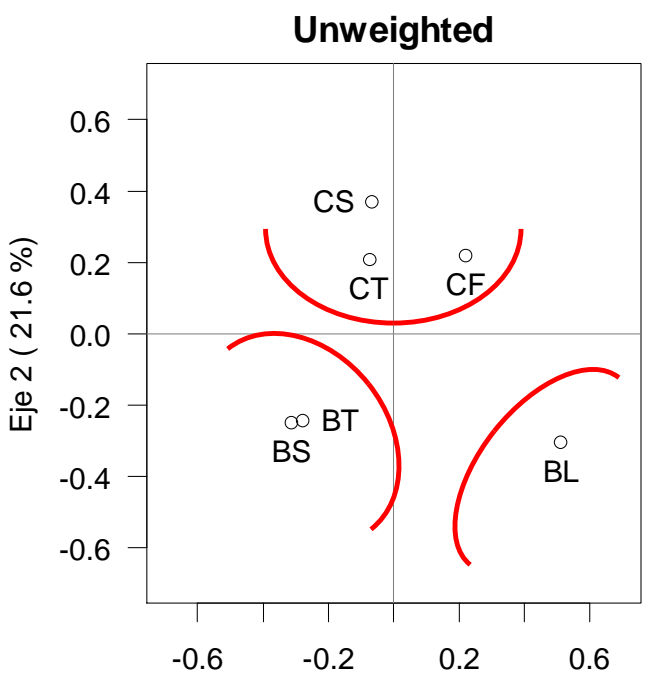

Eje 1 ( $24.1 \%)$

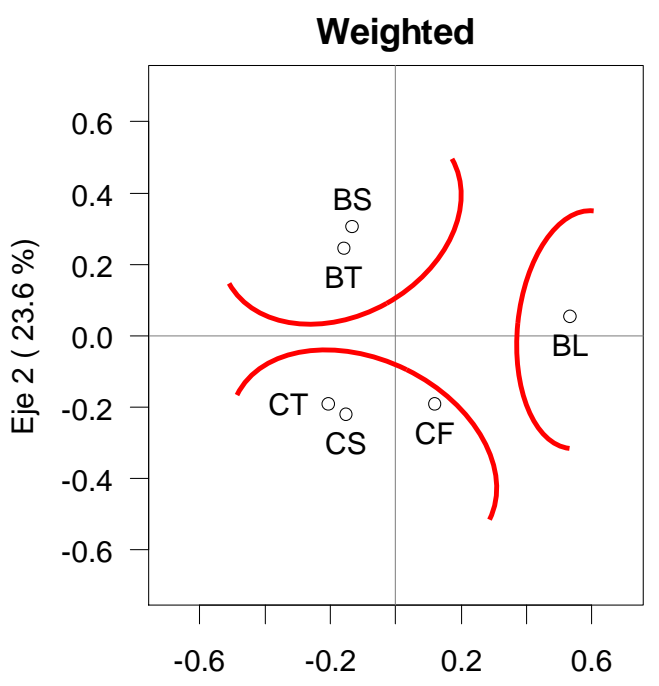

Eje 1 ( $34.6 \%)$

Figura 5.23. Diagramas biplot con los ejes 1 y 2 del Análisis de Coordenadas Principales (PCoA) de la matriz de distancias generada por los algoritmos UniFrac unweighted y weighted.

El análisis individual de la comunidad de bacterias frente al conjunto del resto de comunidades indica que únicamente las comunidades $\mathrm{CF}$ y $\mathrm{BL}$ son significativamente diferentes en comparación con el resto de comunidades $(\mathrm{p}<0,05)$ (Tabla 5.10). Estos resultados coinciden con los análisis de coordenadas principales e indican la singularidad de los ambientes anaerobios (lodo y sedimento) en comparación con el resto de ambientes muestreados (rizosfera de Typha latifolia y Salix atrocinerea).

Tabla 5.10. Valor de significancia (p) del análisis comparativo de cada comunidad con el resto de comunidades estudiadas mediante los algoritmos UniFrac unweighted y UniFrac weighted con corrección de Bonferroni.

\begin{tabular}{lcccccc}
\hline & CF & BL & CT & BT & CS & BS \\
\hline Unweighted & $\mathbf{0 , 0 2}$ & $\mathbf{< 0 , 0 1}$ & 0,91 & 0,72 & 0,86 & 0,20 \\
Weighted & $\mathbf{0 , 0 1}$ & $\mathbf{< 0 , 0 1}$ & 0,90 & 0,68 & 0,82 & 0,23 \\
\hline
\end{tabular}

La comparación de comunidades de bacterias mediante el método UniFrac unweighted confirma que la comunidad $\mathrm{CF}$ es significativamente diferente $(\mathrm{p}<0,01)$ de las comunidades de la rizosfera de Salix atrocinerea de ambos sistemas de tratamiento (CS y BS), mientras que la comunidad BL difiere significativamente de todas las comunidades de rizosfera para ambos métodos UniFrac (Tabla 5.11).

No se han encontrado diferencias significativas entre las comunidades de las rizosferas de los dos sistemas de tratamiento. Estos resultados se asemejan a los obtenidos por Sleytr y col. (2009) y Arroyo (2011) que tampoco encuentran diferencias importantes entre las comunidades 
bacterianas presentes en dos sistemas de tratamiento que reciben agua residual de distinta composición.

Tabla 5.11. Valor de significancia (p) del análisis por parejas de las comunidades de bacterias mediante los algoritmos UniFrac unweighted y UniFrac weighted con corrección de Bonferroni.

\begin{tabular}{lccccc|cccccc}
\hline \multicolumn{5}{c|}{ UniFrac Unweighted } & \multicolumn{5}{c}{ UniFrac Weighted } \\
\hline & BL & CT & BT & CS & BS & & BL & CT & BT & CS & BS \\
\hline CF & 0,6 & 1 & 0,3 & $<\mathbf{0 , 0 1}$ & $<\mathbf{0 , 0 1}$ & CF & 0,15 & 0,75 & 0,9 & 0,45 & 0,15 \\
BL & & $<\mathbf{0 , 0 1}$ & $<\mathbf{0 , 0 1}$ & $<\mathbf{0 , 0 1}$ & $<\mathbf{0 , 0 1}$ & BL & & $<\mathbf{0 , 0 1}$ & $<\mathbf{0 , 0 1}$ & $<\mathbf{0 , 0 1}$ & $<\mathbf{0 , 0 1}$ \\
CT & & & 1 & 0,15 & 1 & CT & & & 1 & 1 & 1 \\
BT & & & & 1 & 1 & BT & & & & 1 & 1 \\
CS & & & & & 1 & CS & & & & 1 \\
\hline
\end{tabular}

La Figura 5.24 muestra el mapa de frecuencias relativas o Heatmap de los OTUs que poseen una abundancia de tres o más secuencias. Los OTUs de mayor frecuencia relativa de la muestra BL son exclusivos de esta comunidad (OTUs 151, 136, 141 y 153), lo que explica las diferencias significativas existentes con el resto de comunidades (Tabla 5.11). La muestra CF comparte OTUs con diferentes comunidades de las rizosferas de Typha latifolia y Salix atrocinerea (OTUs 115, 116, 113 y 102), otros OTUs son exclusivos de esta comunidad (OTUs 013 y 019) y sólo uno está compartido con la comunidad del lodo de Bustillo (BL, OTU 147). La muestra de rizosfera de Salix atrocinerea de Bustillo también presentan OTUs exclusivos (080, 085, 088 y 091) al igual que la muestra de Typha latifolia en el sistema de Centrotec que presenta en exclusividad el OTU 060. Hay cinco OTUs compartidos entre las rizosferas de los dos macrofitos y ambas plantas piloto (115, 114, 113, 107 y 101). Los OTUs 132 y 61 se han encontrado exclusivamente en las rizosferas de la planta piloto de Centrotec.
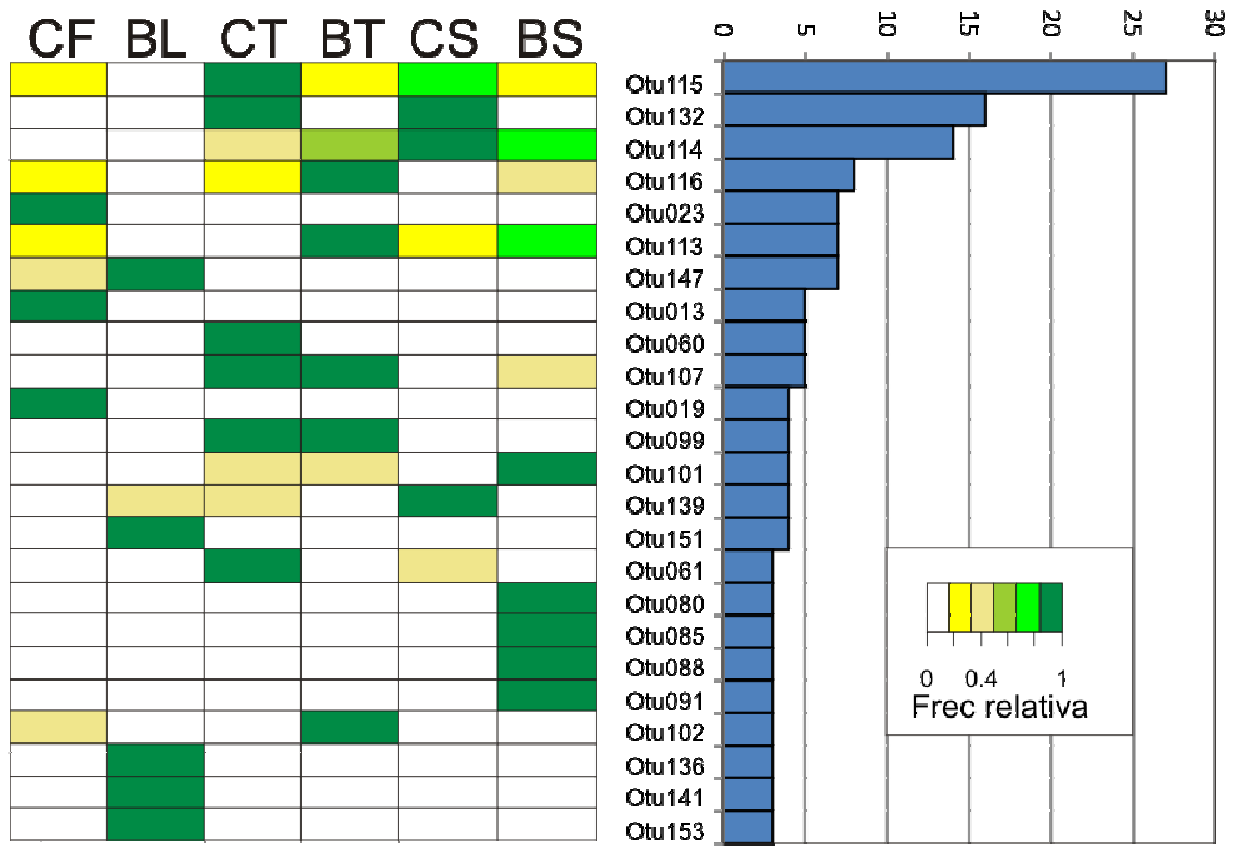

Figura 5.24. Mapa de frecuencias relativas para cada comunidad e histograma de abundancias de las secuencias asignadas para cada OTU. Los OTUs están definidos para una distancia genética de $\mathbf{0 , 1 0}$. Solo se muestran aquellos OTUs con una abundancia superior a dos secuencias. 


\subsubsection{Diversidad metabólica de las comunidades bacterianas}

Los principales metabolismos de las bacterias identificadas positivamente a nivel de especie y género en el análisis filogenético se han resumido en las Tablas 5.12 y 5.13 para poder comparar la estructura de las comunidades bacterianas de las distintas muestras. Es importante resaltar que muchas de estas especies pueden realizar múltiples procesos metabólicos; los incluidos en las Tablas 5.12 y 5.13 son los metabolismos de mayor interés para describir las condiciones de las comunidades bacterianas en los humedales artificiales y su relación particular con los procesos de transformación y eliminación de nitrógeno.

Según el análisis comparativo de las comunidades de bacterias las mayores diferencias se encuentran entre las muestras de lodo de agua residual porcina y sedimento de agua residual urbana (CF y BL) frente a las de la rizosfera de macrófitos. También se han encontrado diferencias entre las muestras del sistema de tratamiento de agua residual porcina (CF, CT y CS) frente a las muestras del sistema de tratamiento de agua residual urbana (BL, BT y BS).

Tabla 5.12. Procesos metabólicos de las especies y géneros de referencia de las secuencias de las muestras CF y BL.

\begin{tabular}{|c|c|c|}
\hline Metabolismo & $\mathrm{CF}$ & $\mathrm{BL}$ \\
\hline Desnitrificación & $\begin{array}{l}\text { Acidovorax temperans } \\
\text { Brachymonas denitrificans } \\
\text { Thauera } \mathrm{sp} \\
\text { Thauera aminoaromatica } \\
\text { Microvirgula aerodenitrificans } \\
\text { Pseudomonas aeruginosa }\end{array}$ & \\
\hline Fermentación & $\begin{array}{l}\text { Paludibacter propionicigenes } \\
\text { Anaeromusa } \mathrm{sp} \\
\text { Syntrophus } \mathrm{sp} \\
\text { Syntrophorhabdus } \mathrm{sp} \\
\text { Clostridium } \mathrm{sp} \\
\text { Sphaerochaeta } \mathrm{sp}\end{array}$ & $\begin{array}{l}\text { Paludibacter propionicigenes } \\
\text { Anaerovorax odorimutans } \\
\text { Syntrophus } \mathrm{sp} \\
\text { Syntrophorhabdus } \mathrm{sp} \\
\text { Syntrophorhabdus aromaticivorans } \\
\text { Smithella } \mathrm{sp}\end{array}$ \\
\hline Fotosíntesis anoxigénica & $\begin{array}{l}\text { Rhodobacter } \mathrm{sp} \\
\text { Thiocapsa } \mathrm{sp} \\
\text { Thiocapsa roseopersicina }\end{array}$ & \\
\hline $\begin{array}{l}\text { Reducción sulfato } \\
\text { Reducción hierro } \\
\text { Metanotrofía }\end{array}$ & & $\begin{array}{l}\text { Desulfomicrobium baculatum } \\
\text { Geothrix fermentans } \\
\text { Methylobacter tundripaludum }\end{array}$ \\
\hline Otros metabolismos anaerobios & $\begin{array}{l}\text { Parabacteroides gordonii } \\
\text { Bacteroides stercorirosoris } \\
\text { Asteroplasma anaerobium } \\
\text { Treponema lecithinolyticum }\end{array}$ & Propionivibrio sp \\
\hline Metabolismos aerobios & Porphyrobacter donghaensis & $\begin{array}{l}\text { Thiobacillus thioparus } \\
\text { Haliea } \mathrm{sp} \\
\text { Flavobacterium caeni } \\
\text { Leadbetterella } \mathrm{sp}\end{array}$ \\
\hline
\end{tabular}

La muestra CF se caracteriza por la presencia de un grupo numeroso de secuencias próximas a bacterias capaces de participar en los procesos de desnitrificación y de fermentación anaerobia entre los que se incluyen organismos sintróficos como Syntrophus y Syntrophorhabdus, que actúan como intermediarios en la descomposición de la materia orgánica. Las principales diferencias con la muestra BL radican en la presencia de numerosos organismos capaces de participar en el proceso de desnitrificación y de un elevado número de secuencias estrechamente relacionados con organismos fotosintéticos anoxigénicos (bacterias púrpuras del azufre), lo cual sugiere un elevado contenido de azufre y nitrógeno en forma de nitrato en el lodo de la balsa de purines. El resto de organismos identificados tienen metabolismos anaerobios, lo cual indica que las condiciones reductoras han dominado en esta muestra. 
Tabla 5.13. Procesos metabólicos de las especies y géneros de referencia de las secuencias de las muestras CT, BT, CS y BS.

\begin{tabular}{|c|c|c|c|c|}
\hline Metabolismo & CT & BT & $\mathrm{CS}$ & BS \\
\hline Desnitrificación & $\begin{array}{l}\text { Acidovorax } \mathrm{sp} \\
\text { Comamonas } \mathrm{sp} \\
\text { Rhodoferax fermentans } \\
\text { Dechloromonas hortensis } \\
\text { Dechloromonas aromatica } \\
\text { Aquitalea denitrificans } \\
\text { Rubrivivax gelatinosus } \\
\text { Thermomonas brevis } \\
\text { Aeromonas sp } \\
\text { Aeromonas hydrophila } \\
\end{array}$ & $\begin{array}{l}\text { Janthinobacterium sp } \\
\text { Pseudomonas lini } \\
\text { Perlucidibaca piscinae } \\
\text { Flavobacterium sp }\end{array}$ & $\begin{array}{l}\text { Brachymonas denitrificans } \\
\text { Dechloromonas } \mathrm{sp} \\
\text { Azospira oryzae } \\
\text { Cellvibrio japonicus } \\
\text { Aeromonas } \mathrm{sp} \\
\text { Flavobacterium } \mathrm{sp}\end{array}$ & $\begin{array}{l}\text { Steroidobacter } \mathrm{sp} \\
\text { Pseudomonas lini } \\
\text { Magnetospirillum } \mathrm{sp} \\
\text { Flavobacterium } \mathrm{sp} \\
\text { Reyranella massiliensis }\end{array}$ \\
\hline Fermentación & $\begin{array}{l}\text { Aquitalea magnusonii } \\
\text { Bacteroides graminisolvens } \\
\text { Anaeromusa sp } \\
\text { Peptococcaceae }\end{array}$ & & & Terrimonas lutea \\
\hline Fotosíntesis anoxigénica & $\begin{array}{l}\text { Rhodocyclus tenuis } \\
\text { Rhodobacter } \mathrm{sp}\end{array}$ & & Rhodocyclus $\mathrm{sp}$ & Rhodocyclus tenuis \\
\hline Reducción hierro & & & & $\begin{array}{l}\text { Pedomicrobium } \mathrm{sp} \\
\text { Geobacter psychrophilus }\end{array}$ \\
\hline Otros metabolismos anaerobios & $\begin{array}{l}\text { Propionivibrio } \mathrm{sp} \\
\text { Acholeplasma vituli } \\
\text { Rhodospirillum photometricum }\end{array}$ & & & \\
\hline Metanotrofía & Methylomicrobium agile & & Methylomonas sp & \\
\hline Fijación nitrógeno & Azovibrio restrictus & Pelomonas saccharophila & Pseudacidovorax $\mathrm{sp}$ & Bradyrhizobium sp \\
\hline Nitrificación & & & $\begin{array}{l}\text { Simplicispira limi } \\
\text { Pseudomonas putida }\end{array}$ & \\
\hline Otros metabolismos aerobios & $\begin{array}{l}\text { Hydrogenophaga } \mathrm{sp} \\
\text { Limnohabitans parvus } \\
\text { Deefgea chitinilytica } \\
\text { Frondihabitans } \mathrm{sp} \\
\text { Acinetobacter } \mathrm{sp}\end{array}$ & $\begin{array}{l}\text { Hydrogenophaga defluvii } \\
\text { Variovorax paradoxus } \\
\text { Arenimonas sp } \\
\text { Solimonas soli } \\
\text { Sphingomonas faeni } \\
\text { Sphingomonas mali } \\
\text { Methylobacterium populi } \\
\text { Devosia ginsengisoli } \\
\text { Labrys wisconsinensis } \\
\text { Flavobacterium terrigena } \\
\text { Fluviicola taffensis } \\
\text { Pedobacter koreensis } \\
\text { Actinoplanes violaceus } \\
\text { Actinoplanes digitatis } \\
\text { Frondihabitans } \mathrm{sp}\end{array}$ & $\begin{array}{l}\text { Hydrogenophaga taeniospiralis } \\
\text { Variovorax } \mathrm{sp} \\
\text { Piscinibacter aquaticus } \\
\text { Sphaerotilus natans } \\
\text { Sphingobacterium faecium } \\
\text { Sediminibacterium salmoneum }\end{array}$ & $\begin{array}{l}\text { Piscinibacter aquaticus } \\
\text { Massilia } \mathrm{sp} \\
\text { Sulfuritalea hydrogenivorans } \\
\text { Lysobacter } \mathrm{sp} \\
\text { Woodsholea maritima } \\
\text { Phenylobacterium } \mathrm{sp} \\
\text { Brevundimonas } \mathrm{sp} \\
\text { Flavobacterium cheniae } \\
\text { Flavobacterium caeni } \\
\text { Frondihabitans } \mathrm{sp}\end{array}$ \\
\hline
\end{tabular}


La muestra BL también presenta un importante grupo de bacterias fermentadoras anaerobias entre las cuales el mayor número de secuencias se ha encontrado estrechamente relacionado con los géneros de actividad sintrófica Syntrophus, Syntrophorhabdus y Smithella. El número de secuencias asociadas a especies pertenecientes a los géneros sintróficos sugiere que la presencia de organismos metanotróficos podría ser superior a la representada por metanótrofos como Methylobacter tundripaludum.

Las condiciones del sedimento han sido predominantemente reductoras tal y como indican el resto de organismos anaerobios y reductores de sulfato y hierro, aunque la presencia de organismos aerobios indica también la presencia de condiciones oxidadoras. Gao y col. (2000) estudiaron el potencial redox del sedimento de humedales artificiales de flujo superficial y concluyeron que el potencial es menor en la zona de contacto entre agua y sedimento $(5 \mathrm{~cm}$; $\mathrm{Eh}=-200 \mathrm{mV}$ ), pero puede incrementarse hasta valores tan elevados como $300 \mathrm{mV}$ a una profundidad de $15 \mathrm{~cm}$ debajo de la superficie del sedimento. El menor potencial redox de la superficie del sedimento es causado probablemente por la sedimentación de la materia orgánica particulada, que crea una zona de alta demanda de oxígeno debido a la gran actividad microbiana, mientras que el incremento del potencial redox con la profundidad puede ser explicado por una baja difusión de los contaminantes a través de la matriz del sustrato (Fox y Doner, 2003).

Los procesos de oxidación y reducción pueden tener lugar simultáneamente en la rizosfera de los macrófitos de los humedales artificiales lo que explica la presencia de bacterias de metabolismos aerobios y anaerobios en las muestras de rizosfera (Tabla 5.13). Los valores del potencial redox dependerán de la disponibilidad de aceptores de electrones tales como nitrato, nitrito, sulfato, etc. y donadores de electrones tales como compuestos orgánicos del agua residual o exudados de las raíces y productos de la rizodeposición (Gonzalias y col., 2007).

La principal diferencia entre las comunidades bacterianas de la rizosfera de Typha latifolia de ambos sistemas de tratamiento de agua residual es la identificación de un número muy superior de organismos que pueden presentar metabolismo anaerobio (desnitrificantes y fermentadores principalmente) en la muestra del sistema de tratamiento de agua residual porcina (CT) en comparación con la muestra tomada en el sistema de tratamiento de agua residual urbana (BT) que presenta muchos más organismos con un posible metabolismo aerobio. Esta diferencia sugiere que las condiciones de la muestra CT han sido más reductoras que las presentes en la muestra BT.

La presencia de tantas especies con potencial para la desnitrificación coincide con la mayor concentración de nitrógeno en la entrada del sistema de tratamiento de agua residual porcina en comparación con el de agua residual urbana (promedio de 113 frente a $62 \mathrm{mg} \mathrm{NTK} \mathrm{L}^{-1}$ respectivamente en el periodo de muestreo) y sugiere la presencia de bacterias nitrificantes que hayan transformado el nitrógeno amoniacal en nitrato que será utilizado por los organismos desnitrificantes tal y como se ha observado en la rizosfera de Typha latifolia de otros humedales artificiales (Ruiz-Rueda y col., 2009).

La muestra tomada en las unidades de tratamiento de agua residual porcina plantadas con Salix atrocinerea (CS) presenta un menor número de especies identificadas con capacidad para participar en el proceso de desnitrificación, mientras que han aumentado los organismos de metabolismo aerobio, entre los que se incluyen organismos nitrificantes. La presencia de los organismos nitrificantes confirma la hipótesis de un proceso de nitrificación en la etapa de tratamiento con flujo subsuperficial horizontal. La ausencia de organismos con metabolismo fermentativo en comparación con la muestra CT puede ser debido al bajo contenido en materia orgánica biodegradable del agua residual en las unidades FSS.

En el caso de la muestra BS se ha producido un descenso del número de especies y géneros con metabolismo aerobio, y un incremento de bacterias púrpuras del azufre y organismos 
fermentadores y reductores del hierro y del azufre en comparación con la muestra BT. Este cambio en la estructura de la comunidad es debido probablemente al carácter anaerobio de los humedales de flujo subsuperficial horizontal. 


\subsection{CONCLUSIONES}

El análisis de las muestras de lodo o sedimento y de rizosfera de Typha latifolia y Salix atrocinerea de dos sistemas de tratamiento de flujo combinado tipo MJEA ${ }^{\circledR}$ de agua residual porcina y urbana ha permitido la caracterización de las comunidades microbianas presentes en las muestras. El análisis filogenético ha revelado que la mayor parte de las secuencias pertenecen a uno de los tres filos principales: Proteobacteria, Bacteroidetes o Firmicutes.

De entre las secuencias asociadas al filo Proteobacteria, las secuencias pertenecientes a las clases Beta- y Gamma-Proteobacteria son las más abundantes en las muestras de rizosfera y de lodo del sistema de tratamiento de agua residual porcina. En el sistema de tratamiento de agua residual urbana las secuencias pertenecientes a las clases Gamma- y Alpha- Proteobacteria son más abundantes en las muestras de rizosfera, mientras que las Delta-Proteobacteria lo son en la muestra de sedimento.

Las muestras del sistema de agua residual porcina tienen menor riqueza, menor diversidad y mayor dominancia que las del sistema de agua residual urbana, aunque la diferencia de riqueza deja de ser apreciable al incrementarse la distancia genética. La comunidad bacteriana de la rizosfera de Salix atrocinerea de ambos sistemas de tratamiento es la de mayor riqueza, mayor diversidad y menor dominancia para una distancia genética cercana al nivel taxonómico de especie, mientras que las muestras del sedimento o foso son las de mayor diversidad y menor dominancia para las distancias genéticas más próximas al nivel taxonómico de familia.

El análisis de la diversidad $\beta$ ha permitido identificar diferencias significativas entre las muestras de rizosfera y las de sedimento o lodo a través de los algoritmos UniFrac, lo que indica la singularidad de los ambientes anaerobios. Los estimadores Jest y Thetayc han permitido además identificar las muestras de rizosfera de cada sistema de tratamiento como aquellas que comparten un mayor número de OTUs de similar riqueza y abundancia relativa.

Los metabolismos de las secuencias de referencia indican la existencia de un amplio rango de condiciones redox que permiten la presencia de organismos aerobios y anaerobios en ambos sistemas de tratamiento. Las condiciones del sistema de tratamiento de agua residual porcina son más reductoras lo que se deduce del mayor número de organismos con posible metabolismo desnitrificante y menor número de organismos aerobios. El análisis filogenético confirma la presencia de organismos con metabolismo nitrificante en la rizosfera de Salix atrocinerea.

Las curvas de rarefacción indican que el esfuerzo de muestreo ha sido insuficiente, por lo que este análisis resulta exploratorio; no se ha podido realizar una caracterización completa de las comunidades bacterianas. 



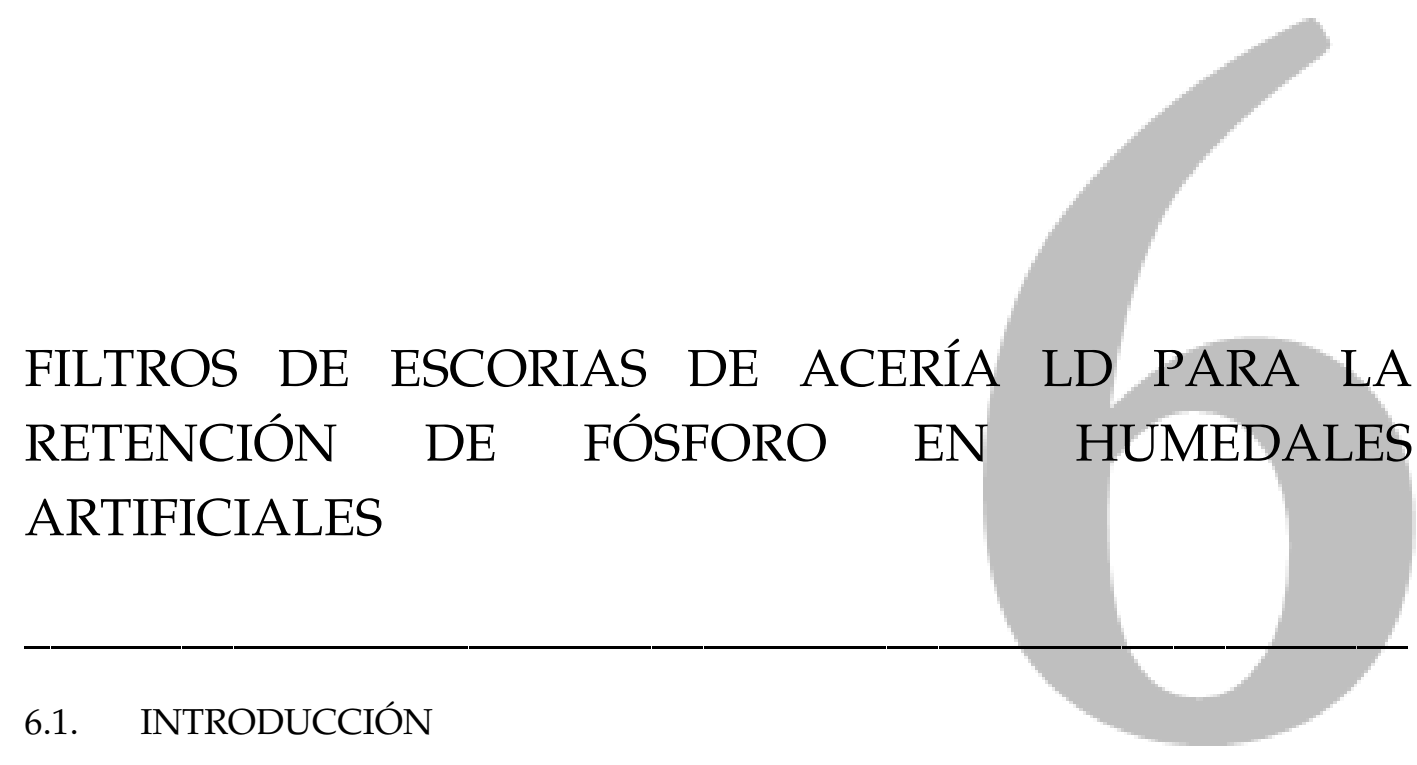

\subsubsection{Mecanismos de retención de fósforo en humedales artificiales}

El fósforo $(\mathrm{P})$ presente en el agua residual se encuentra principalmente en forma de fosfatos, polifosfatos y fósforo orgánico. La forma fosfato está fácilmente disponible para los procesos de precipitación química, adsorción y eliminación biológica, por lo que su proporción con respecto al fósforo total (PT) del agua residual es un parámetro de gran importancia al evaluar la eficiencia de las técnicas convencionales de eliminación.

La eliminación de $\mathrm{P}$ en los sistemas convencionales de tratamiento de agua residual está basada en los procesos biológicos y de precipitación química, cuya aplicación presenta importantes limitaciones en los humedales artificiales.

La precipitación química por medio de la adición de sales metálicas de $\mathrm{Al}, \mathrm{Fe}$ o $\mathrm{Ca}$ al agua residual requiere un control estricto de los parámetros químicos, tales como $\mathrm{pH}$ y alcalinidad, que permiten la precipitación de P. Además, el lodo generado tras la precipitación ha de ser gestionado posteriormente, lo que incrementa los costes económicos de la explotación. La eliminación mediante procesos biológicos requiere mano de obra cualificada y altos costes energéticos debido al estricto control requerido para mantener las fases aerobio-anaerobias (Barca, 2013).

El método más prometedor para mejorar la eliminación de $\mathrm{P}$ en los humedales artificiales es la filtración del agua residual a través de materiales con una alta capacidad para la retención de P. Los principales mecanismos involucrados en esta retención son los procesos de adsorción y precipitación química.

\subsubsection{Adsorción}


La adsorción es el proceso por el cual átomos, iones o moléculas (adsorbato o soluto) se extraen de una fase gaseosa o líquida y se concentran sobre la superficie de otra fase sólida (adsorbente). La mayor parte de los fenómenos de adsorción son combinaciones de procesos de adsorción de tipo electrostático, físico o químico según sea el tipo de atracción entre el soluto y el adsorbente.

La adsorción de tipo electrostático tiene lugar cuando los iones del soluto se concentran en una superficie como resultado de la atracción electrostática en los lugares cargados de la superficie adsorbente. Esto ocurre en materiales arcillosos cuando la sustitución parcial de cationes puede producir un cambio en la carga de la superficie de las partículas. En este caso la carga de la superficie puede ser equilibrada mediante iones y/o moléculas de agua (Das y col., 2006). Si el proceso de adsorción de una o varias especies iónicas está acompañado por una desorción simultánea de una cantidad equivalente de especies iónicas, este proceso es considerado como un intercambio iónico (Dabrowski, 2001).

La adsorción física o fisisorción es una interacción relativamente débil entre soluto y adsorbente mediante fuerzas de Van der Waals por lo que es fácilmente reversible. Puede tener lugar en cualquier superficie siempre y cuando las condiciones de presión y temperatura sean adecuadas. Las moléculas adsorbidas pueden dispersarse por la superficie del adsorbente y no están ligadas a ninguna localización específica pudiendo formar múltiples capas (Webb, 2003).

A diferencia de la fisisorción, la adsorción química o quimisorción consiste en la formación de enlaces químicos fuertes cuya reversibilidad dependerá de su naturaleza. Es un proceso altamente selectivo que tiene lugar únicamente entre ciertas especies de soluto y adsorbente y sólo si la superficie químicamente activa está libre de moléculas previamente adsorbidas. La quimisorción es un proceso monocapa que puede tener lugar simultáneamente con la fisisorción siempre y cuando la capa de moléculas adsorbidas físicamente se encuentre por encima de la capa adsorbida químicamente (Webb, 2003).

El proceso de adsorción se describe generalmente mediante el uso de isotermas de adsorción que relacionan la concentración del soluto en una solución en equilibrio frente a la cantidad adsorbida sobre la fase sólida a temperatura constante. Los modelos de Langmuir y Freundlich son los más utilizados para describir las isotermas de adsorción de fosfato en diferentes adsorbentes.

El modelo de Langmuir se desarrolló inicialmente para describir los mecanismos de adsorción de gases sobre sólidos, aunque se utiliza ampliamente para sistemas difásicos líquido-sólido. El caso más sencillo descrito por el modelo es la adsorción de un único adsorbato sobre una superficie homogénea sobre la que hay un número constante y finito de lugares de adsorción idénticos entre sí. El proceso de adsorción descrito por Langmuir es reversible y en él cada lugar de adsorción puede adsorber únicamente un ión (monocapa) y los iones adsorbidos no pueden interaccionar entre sí (Masel, 1996). La ecuación de Langmuir es descrita como:

$$
q_{e}=\frac{q_{\max } K_{L} C_{e}}{1+K_{L} C_{e}}
$$

donde

$$
\begin{aligned}
& q_{e}=\text { capacidad de adsorción en equilibrio, } \mathrm{mg} \mathrm{g}^{-1} \\
& q_{\max }=\text { máxima capacidad de adsorción en equilibrio, } \mathrm{mg} \mathrm{g}^{-1} \\
& K_{L}=\text { constante de la isoterma de Langmuir, } \mathrm{L} \mathrm{mg}^{-1} \\
& C_{e}=\text { concentración de soluto en equilibrio, } \mathrm{mg} \mathrm{L}^{-1}
\end{aligned}
$$

El modelo de Freundlich se utiliza ampliamente para describir las características de adsorción de una superficie heterogénea (Dada y col., 2012). Mediante la isoterma de Freundlich se describe cómo la afinidad entre soluto y adsorbente disminuye exponencialmente al aumentar la 
saturación de la superficie. A diferencia del modelo de Langmuir, el modelo de Freundlich no incluye la capacidad de adsorción máxima en equilibrio. La ecuación que describe el modelo es:

$$
q_{e}=K_{F} C_{e}^{1 / n}
$$

donde

$$
\begin{aligned}
& q_{e}=\text { capacidad de adsorción en equilibrio, } \mathrm{mg} \mathrm{g}^{-1} \\
& K_{F}=\text { constante de la isoterma de Freundlich, } \mathrm{mg} \mathrm{g}^{-1} \\
& C_{e}=\text { concentración de soluto en equilibrio, } \mathrm{mg} \mathrm{L}^{-1} \\
& n=\text { intensidad de adsorción }
\end{aligned}
$$

\subsubsection{Precipitación química}

La precipitación química en una disolución tiene lugar a partir del momento en que ésta se encuentra sobresaturada por un compuesto. La reacción de disolución-precipitación para un sólido se escribe:

$$
A_{a} B_{b}(s) \leftrightarrow a A(a q)+b B(a q)
$$

donde

$$
\begin{aligned}
& \mathrm{A}_{\mathrm{a}} \mathrm{B}_{\mathrm{b}}=\text { soluto precipitado } \\
& \mathrm{S}=\text { estado sólido } \\
& \mathrm{aA}=\text { ión } \mathrm{A} \text { en disolución } \\
& \mathrm{bB}=\text { ión } \mathrm{B} \text { en disolución } \\
& \mathrm{aq}=\text { estado líquido }
\end{aligned}
$$

Se considera que una disolución está saturada cuando se ha alcanzado la concentración máxima de soluto en la disolución (no puede disolverse más soluto) a temperatura constante. El equilibrio entre disolución y precipitación está controlado por la constante del producto de solubilidad $\left(\mathrm{K}_{\mathrm{PS}}\right)$, que se determina generalmente en condiciones estándar $\left(25^{\circ} \mathrm{C}\right)$ :

$$
\mathrm{K}_{\mathrm{PS}}=\frac{[\mathrm{A}]_{\mathrm{eq}}^{\mathrm{a}}[\mathrm{B}]_{\mathrm{eq}}^{\mathrm{b}}}{\left[\mathrm{A}_{\mathrm{a}} \mathrm{B}_{\mathrm{b}}\right]_{\mathrm{eq}}}
$$

La constante $\mathrm{K}_{\mathrm{PS}}$ puede compararse con el producto iónico (PI) para determinar el estado de saturación de una disolución. El PI de una disolución es el producto de las concentraciones de los iones en cualquier momento, incluso en condiciones de no equilibrio:

$$
\mathrm{PI}=\frac{[\mathrm{A}]^{\mathrm{a}}[\mathrm{B}]^{\mathrm{b}}}{\left[\mathrm{A}_{\mathrm{a}} \mathrm{B}_{\mathrm{b}}\right]}
$$

Al comparar $\mathrm{K}_{\mathrm{PS}}$ y PI:

Si $K_{P S}>$ PI la solución no ha alcanzado la saturación.

Si $K_{\mathrm{PS}}=\mathrm{PI}$ la solución está saturada y no se produce ninguna reacción.

Si $K_{\mathrm{PS}}<$ PI la solución esta sobresaturada y tiene lugar la precipitación.

La solubilidad de las formas de fosfatos y sus precipitados está controlada fuertemente por el $\mathrm{pH}$ de la disolución. Los ortofosfatos son las sales del ácido fosfórico $\left(\mathrm{H}_{3} \mathrm{PO}_{4}\right)$. El ácido fosfórico se disocia en disolución produciendo las formas de fosfato $\mathrm{H}_{2} \mathrm{PO}_{4}{ }^{-}, \mathrm{HPO}_{4}{ }^{2-}$ y $\mathrm{PO}_{4}{ }^{3-}$. El equilibrio químico entre las diferentes formas de ortofosfatos depende del $\mathrm{pH}$ de la disolución (Figura 6.1). La forma $\mathrm{H}_{2} \mathrm{PO}_{4}{ }^{-}$es la dominante para el rango de $\mathrm{pH}$ de 2,2 a 7,2; mientras que la forma $\mathrm{HPO}_{4}{ }^{2-}$ domina cuando el $\mathrm{pH}$ se encuentra entre 7,2 y 12,4 y la forma $\mathrm{PO}_{4}{ }^{3-}$ domina cuando el pH es mayor de 12,4 (Stumm y Morgan, 1996). 


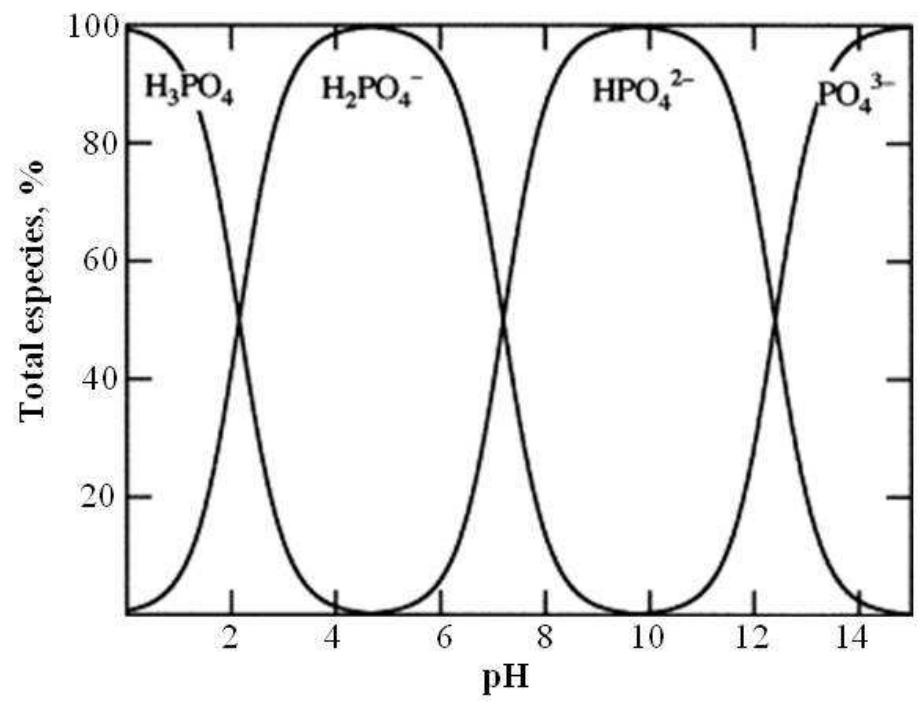

Figura 6.1. Efecto del pH en las diferentes formas de fósforo. Adaptado de Stumm y Morgan (1996).

En los sistemas de tratamiento convencional se añaden varias sales metálicas al agua residual tales como sulfato de aluminio $\left(\mathrm{Al}_{2}\left(\mathrm{SO}_{4}\right)_{3}\right)$, cloruro de hierro (III) $\left(\mathrm{FeCl}_{3}\right)$ o cal $(\mathrm{CaO})$ para favorecer la eliminación de $\mathrm{P}$ por precipitación de fosfatos de $\mathrm{Al}$, Fe y Ca respectivamente. La solubilidad de estos precipitados depende de varios parámetros, incluyendo el $\mathrm{pH}$ como puede apreciarse en la Figura 6.2. Los fosfatos de $\mathrm{Al}$ y Fe son las formas más estables cuando el pH de la disolución es menor de 6, mientras que los fosfatos de Ca son las formas más estables cuando el pH es mayor de 8 (Stumm y Morgan, 1996).

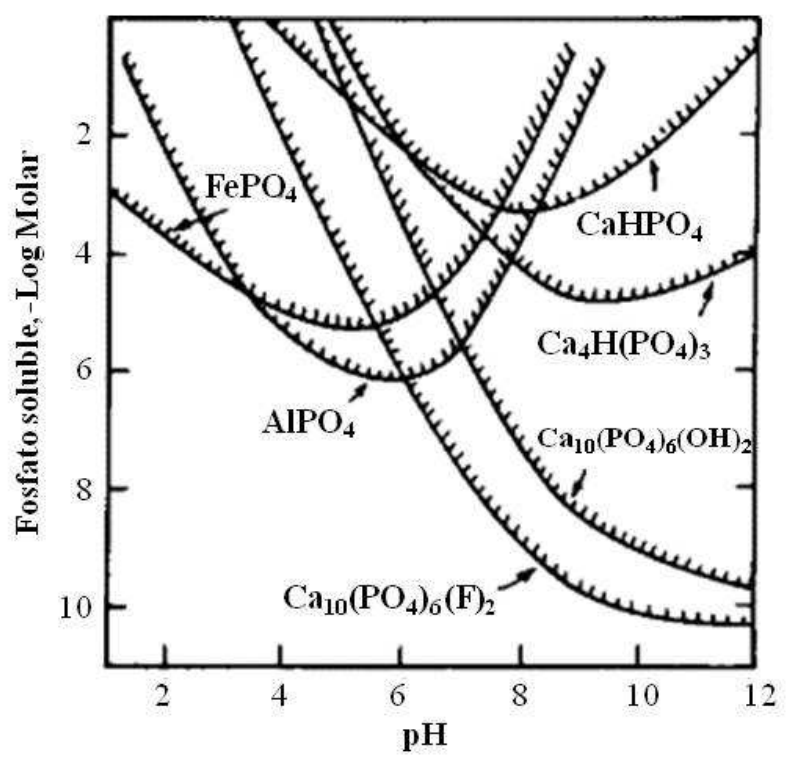

Figura 6.2. Diagrama de solubilidad de diversos fosfatos de Fe, Al y Ca en función del pH calculados para una concentración de $\mathrm{Ca}^{2+}$ de $1^{-3}$ M. Adaptado de Stumm y Morgan (1996).

\subsection{Precipitación de fosfatos de aluminio y hierro}


Cuando una sal de aluminio o hierro se añade al agua residual se produce una reacción de hidrólisis entre los iones metálicos y las moléculas de agua. Si los productos de la hidrólisis se encuentran próximos a una molécula de ortofosfato u otra especie cargada, se producirá una reacción entre ambos compuestos. En caso contrario los productos de la hidrólisis continuarán reaccionando con moléculas de agua para formar hidróxidos metálicos (Thistleton y col., 2001).

Los iones de aluminio $\left(\mathrm{Al}^{3+}\right)$ pueden precipitar en forma de variscita $\left(\mathrm{AlPO}_{4} \cdot 2 \mathrm{H}_{2} \mathrm{O}\right)$ al reaccionar con los ortofosfatos presentes en el agua residual o en forma de hidróxido de aluminio $\left(\mathrm{AlOH}_{3}\right)$ al reaccionar con moléculas de agua. La competencia en el consumo de $\mathrm{Al}^{3+}$ puede limitar la precipitación de $\mathrm{Al}$ como fosfato.

En condiciones anaerobias el ión $\mathrm{Fe}^{2+}$ puede reaccionar con los ortofosfatos presentes en el agua residual para precipitar en forma de vivianita $\left(\mathrm{Fe}_{3}\left(\mathrm{PO}_{4}\right)_{2} \cdot 8 \mathrm{H}_{2} \mathrm{O}\right)$, o con las moléculas de agua para precipitar en forma de hidróxido de hierro (II) $\left(\mathrm{Fe}\left(\mathrm{OH}_{2}\right)\right)$. La oxidación de $\mathrm{Fe}$ (II) a $\mathrm{Fe}$ (III) depende del $\mathrm{pH}$, de la concentración de oxígeno, la actividad catalítica o la inhibición por la presencia de sulfatos o carbonatos (Yeoman y col., 1988). El proceso de conversión es muy lento para valores de $\mathrm{pH}$ inferiores a 6 y óptimo para valores de $\mathrm{pH}$ superiores a 8 , concentraciones de oxígeno disuelto superiores a $3,5 \mathrm{mg} \mathrm{L}^{-1}$ y valores positivos del potencial redox (Thistleton y col., 2001).

El ión $\mathrm{Fe}^{3+}$ puede reaccionar con los ortofosfatos presentes en el agua residual para precipitar en forma de estrengita $\left(\mathrm{FePO}_{4} \cdot 2 \mathrm{H}_{2} \mathrm{O}\right)$ o con las moléculas de agua para precipitar en forma de hidróxido de hierro (III) $\left(\mathrm{Fe}(\mathrm{OH})_{3}\right)$. Aunque el rango de precipitación óptimo para las sales de Fe (III) se encuentra entre 4,5 y 5 se puede seguir produciendo una eliminación significativa de ortofosfatos a mayores valores de $\mathrm{pH}$. El valor de $\mathrm{pH}$ también es importante en la competición entre los aniones $\mathrm{PO}_{4}^{3-}$ y $\mathrm{OH}^{-}$por el $\mathrm{Fe}^{3+}$. La probabilidad de la formación de hidróxidos mediante las reacciones con aniones $\mathrm{OH}^{-}$aumenta al incrementarse el valor de $\mathrm{pH}$ (Thistleton y col., 2002).

\subsection{Precipitación de fosfatos de calcio}

La precipitación de fosfatos de calcio se debe a la reacción entre los fosfatos presentes en el agua y el ión calcio $\left(\mathrm{Ca}^{2+}\right)$, que generalmente proviene de la hidrólisis de óxido de calcio $(\mathrm{CaO})$ o hidróxido de calcio $\left(\mathrm{Ca}(\mathrm{OH})_{2}\right)$. En el proceso de hidrólisis además se producen aniones $\mathrm{OH}^{-}$lo que incrementa el $\mathrm{pH}$ de la disolución:

$$
\begin{aligned}
& \mathrm{CaO}+\mathrm{H}_{2} \mathrm{O} \leftrightarrow \mathrm{Ca}^{2+}+2 \mathrm{OH}^{-} \\
& \mathrm{Ca}(\mathrm{OH})_{2} \leftrightarrow \mathrm{Ca}^{2+}+2 \mathrm{OH}^{-} \quad \mathrm{K}_{\mathrm{PS}}=7,9 \times 10^{-6}
\end{aligned}
$$

La precipitación de los fosfatos de calcio depende fuertemente de las condiciones físico-químicas de la disolución. Valores de $\mathrm{pH}$ básicos favorecen el proceso de precipitación que puede dar lugar a distintos tipos de fosfatos de calcio en función de los valores de $\mathrm{pH}$ y las concentraciones de $\mathrm{Ca}^{2+}$ y ortofosfatos de la disolución (Tabla 6.1, Figura 6.2). La teoría de Ostwald-Gay Lussac, establece que frecuentemente la forma termodinámica menos estable - y por tanto la más soluble -es la más fácilmente precipitable. De acuerdo a sus constantes $\mathrm{K}_{\mathrm{PS}}$, el orden de formación de precipitados de fosfatos de calcio si no hay impurezas que perturben el sistema sería: fosfato cálcico amorfo, fosfato dicálcico, fosfato tricálcico, fosfato octocálcico, hidroxiapatita (HAP) y fluorapatita (FAP) (Tabla 6.1).

Tabla 6.1. Relación de Ca y $P$ y constantes de producto de solubilidad $\left(K_{\mathrm{PS}}\right)$ a $25^{\circ} \mathrm{C}$ de diferentes fosfatos de calcio (Stumm y Morgan, 1996; Valsami-Jones, 2001).

\begin{tabular}{llll}
\hline Compuesto & Fórmula & Relación molar $\mathrm{Ca} / \mathrm{P}$ & $\mathrm{K}_{\mathrm{PS}}\left(25^{\circ} \mathrm{C}\right)$ \\
\hline
\end{tabular}




\begin{tabular}{lccc}
\hline Fosfato cálcico amorfo & $\mathrm{Ca}_{3}\left(\mathrm{HPO}_{4}\right)_{2}$ & $\sim 1,5$ & $\begin{array}{c}\text { Variable, más } \\
\text { soluble que el resto }\end{array}$ \\
Fosfato dicálcico & $\mathrm{CaHPO}_{4}$ & 1 & $10^{-6,6}$ \\
Fosfato tricálcico & $\mathrm{Ca}_{3}\left(\mathrm{PO}_{4}\right)_{2}$ & 1,5 & $10^{-26}$ \\
Fosfato octocálcico & $\mathrm{Ca}_{4} \mathrm{H}_{\left(\mathrm{PO}_{4}\right)_{3}}$ & 1,33 & $10^{-46,9}$ \\
Hidroxiapatita (HAP) & $\mathrm{Ca}_{10}\left(\mathrm{PO}_{4}\right)_{6}(\mathrm{OH})_{2}$ & 1,67 & $10^{-114}$ \\
Fluorapatita (FAP) & $\mathrm{Ca}_{10}\left(\mathrm{PO}_{4}\right)_{6} \mathrm{~F}_{2}$ & 1,67 & $10^{-118}$ \\
\hline
\end{tabular}

Tras la deposición de los precipitados amorfos, los fosfatos de calcio pueden reorganizar su estructura interna para producir cristales con estructuras internas regulares y caras externas planas. Este proceso conocido como cristalización es importante ya que asegura una retención permanente del $\mathrm{P}$ en formas más estables. De este modo cualquier precipitado de fosfato de calcio se terminará transformando en la forma HAP, que es la más estable termodinámicamente (Valsami-Jones, 2001). En el proceso de formación de un precipitado estable influirán el pH, el grado de saturación de la disolución y la relación molar $\mathrm{Ca} / \mathrm{P}$. La relación molar $\mathrm{Ca} / \mathrm{P}$ es útil para predecir qué fosfatos de calcio precipitan en la disolución. Por ejemplo, los compuestos HAP y FAP se podrán formar cuando la relación molar $\mathrm{Ca} / \mathrm{P}$ en la disolución sea superior a 1,67 (Tabla 6.1).

Kim y col. (2006) identifican las condiciones de pH óptimas para la cristalización de fosfatos de calcio en disoluciones con elevadas concentraciones de ortofosfatos mediante el estudio de las curvas de solubilidad y supersolubilidad. En la Figura 6.3 se pueden distinguir tres zonas: la zona estable que se sitúa por debajo de la curva de solubilidad y en la que no tiene lugar la precipitación de fosfatos de calcio; la zona inestable que se encuentra localizada por encima de la curva de supersolubilidad y en la que se forman cristales rápidamente (nucleación); y la zona metaestable - situada entre las dos curvas - en la que no se forman nuevos núcleos, sino que las partículas existentes crecen hasta que la concentración de ortofosfatos alcanza la de la solución saturada. Tal y como se muestra en la Figura 6.3, la curva de supersolubilidad indica que al aumentar la concentración de ortofosfatos la nucleación puede producirse a valores de $\mathrm{pH}$ más ácidos. Para una concentración de $72,9 \mathrm{mg} \mathrm{L}^{-1}$ el rango de $\mathrm{pH}$ para la cristalización de HAP se sitúa entre 6,6 y 7 , mientras que para concentraciones menores a $5 \mathrm{mg} \mathrm{L}^{-1}$ el rango de $\mathrm{pH}$ se encuentra entre 8 y 9,5 (Kim y col., 2006).

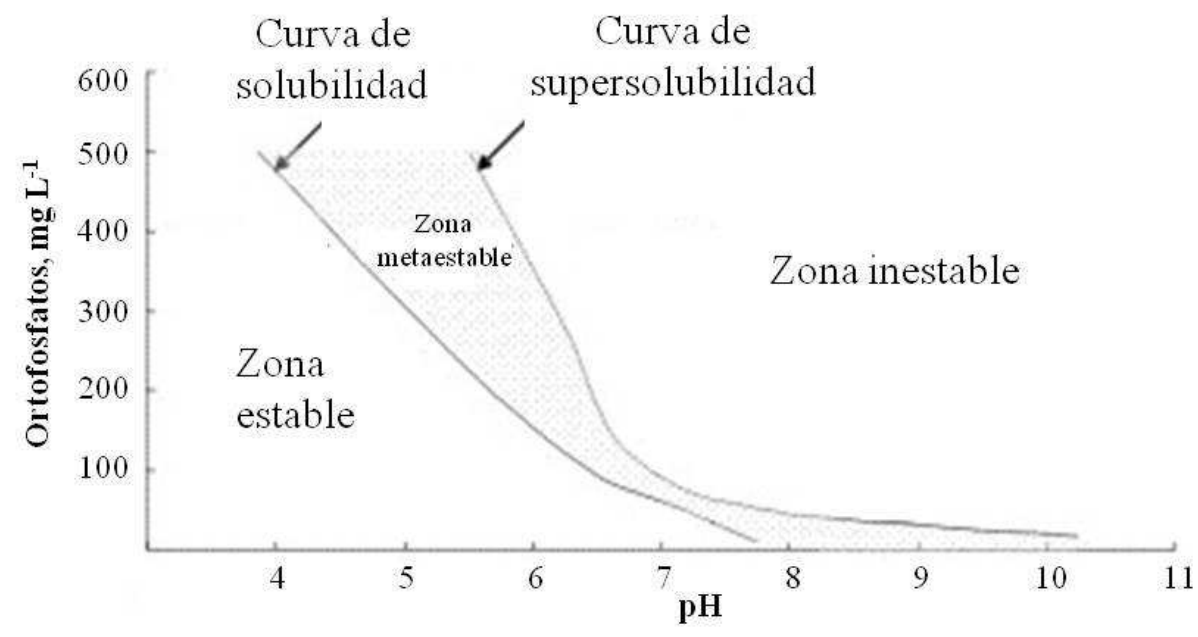

Figura 6.3. Zona estable, metaestable e inestable para la cristalización de los fosfatos de calcio en función del pH y la concentración de ortofosfatos. Adaptado de Kim y col. (2006).

Otros factores influyen en el proceso de precipitación de los fosfatos de calcio. El aumento de la fuerza iónica tiene tendencia a disminuir la constante de saturación, mientras que el aumento de la temperatura favorece la saturación de la disolución. Los ácidos húmicos, fúlvicos y tánicos, el 
citrato o los iones $\mathrm{Mg}^{2+}$ inhiben el proceso de cristalización de $\mathrm{HAP}$, mientras que núcleos de HAP o iones $\mathrm{F}^{-}$y $^{2+}$ lo promueven (Barca, 2013).

La inhibición de la precipitación de fosfatos de calcio es particularmente fuerte debido a a la presencia de carbonatos $\left(\mathrm{CO}_{3}{ }^{2-}\right)$ en el agua. Estos aniones compiten con los ortofosfatos por los iones $\mathrm{Ca}^{2+}$ para formar carbonato de calcio $\left(\mathrm{CaCO}_{3}\right)$ a valores de $\mathrm{pH}$ superiores a 8,3:

$$
\mathrm{CaCO}_{3} \leftrightarrow \mathrm{Ca}^{2+}+\mathrm{CO}_{3}^{2-}
$$

Las fuentes de carbonatos más habituales en el agua residual son el $\mathrm{CO}_{2}$ procedente de la respiración y la disolución de $\mathrm{CO}_{2}$ atmosférico, que forman ácido carbónico $\left(\mathrm{H}_{2} \mathrm{CO}_{3}\right)$ tras reaccionar con las moléculas de agua. $\mathrm{El}_{2} \mathrm{CO}_{3}$ se disocia en disolución a pH 6,4 liberando el anión $\mathrm{HCO}_{3}{ }^{-}$y éste a su vez se disocia a pH 10,3 liberando $\mathrm{CO}_{3}{ }^{2-}$ (Figura 6.4).

Elevados valores de $\mathrm{pH}$ favorecen la precipitación tanto de fosfatos de calcio como de $\mathrm{CaCO}_{3}$. Por lo tanto, a valores de $\mathrm{pH}$ elevados la concentración de iones $\mathrm{Ca}^{2+}$ que deben ser aportados a la disolución ha de ser lo bastante alta para neutralizar los carbonatos presentes en el agua mediante la precipitación de $\mathrm{CaCO}_{3}$ y permitir la precipitación de fosfatos de calcio.

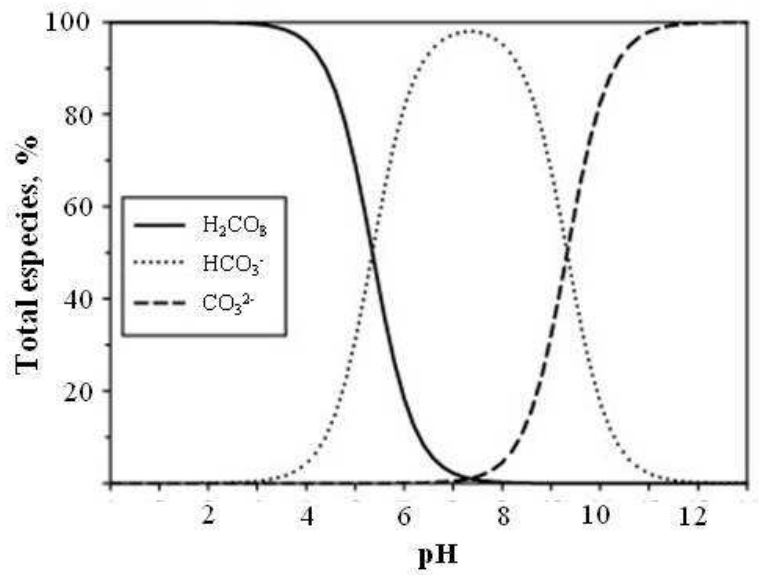

Figura 6.4. Distribución en equilibrio de las especies $\mathrm{H}_{2} \mathrm{CO}_{3}, \mathrm{HCO}_{3}^{-}$y $\mathrm{CO}_{3}{ }^{2-}$ en disolución. $\mathrm{H}_{2} \mathrm{CO}_{3}$ incluye tanto $\mathrm{H}_{2} \mathrm{CO}_{3}$ molecular como $\mathrm{CO}_{2}$ molecular disuelto. Adaptado de Steel y col. (2013).

\subsubsection{Filtros para la retención de fósforo en humedales artificiales}

\subsubsection{Propiedades de los materiales}

La capacidad de un material para eliminar $\mathrm{P}$ del agua residual depende de sus propiedades químicas y físicas. La composición química es determinante en la interacción del material con el $\mathrm{P}$ presente en el agua residual. Las mejores capacidades de retención de $\mathrm{P}$ están relacionadas con altos contenidos de Al, Fe y/o Ca (Reddy y col., 1980). Las propiedades físicas también son importantes puesto que intervienen en la capacidad de retención de $\mathrm{P}$ y condicionan su longevidad (Dunne y Reddy, 2005).

La capacidad del agua para pasar por un filtro depende de las características físicas del material filtrante y está representado mediante el concepto de conductividad hidráulica. La conductividad hidráulica es una constante única para cada material definida en la Ley de Darcy que establece que el caudal que atraviesa un permeámetro es linealmente proporcional a la sección y al gradiente hidráulico: 


$$
\frac{Q}{\text { Sección }}=-K\left(\frac{d h}{d l}\right)
$$

donde

$$
\begin{aligned}
& Q=\text { caudal }, \mathrm{m}^{3} \mathrm{~s}^{-1} \\
& \text { Sección = sección del permeámetro, } \mathrm{m}^{2} \\
& K=\text { conductividad hidráulica, } \mathrm{m} \mathrm{s}^{-1} \\
& d h / d l=\text { gradiente hidráulico, sin unidades }
\end{aligned}
$$

La conductividad hidráulica será menor cuanto menor sea el tamaño de las partículas del material, lo que incrementará el tiempo de contacto entre el agua y el material y facilitará la retención de P. Las partículas pueden agruparse en clases en función de su tamaño y su proporción define la textura del material (Tabla 6.2).

Tabla 6.2. Tipo de partículas de un suelo en función de su tamaño (USDA, 1993).

\begin{tabular}{cc}
\hline Partícula & Diámetro, $\mathrm{mm}$ \\
\hline Grava & $2-76$ \\
Arena & $0,05-2$ \\
Limo & $0,002-0,05$ \\
Arcilla & $<0,002$ \\
\hline
\end{tabular}

El contacto entre las fases sólida y líquida también viene determinado por la superficie específica, que relaciona el área superficial frente a la masa o volumen del material. Esta superficie específica se puede determinar mediante una curva granulométrica que representa la fracción acumulada de la masa de las partículas en función de su diámetro. La uniformidad de los granos del material se puede evaluar mediante el coeficiente de uniformidad (CU) que se expresa como:

$$
\mathrm{CU}=\frac{d_{60}}{d_{10}}
$$

donde

$\mathrm{CU}=$ coeficiente de uniformidad

$d_{60}=$ diámetro por debajo del cual se acumula el $60 \%$ de la masa de los granos

$d_{10}=$ diámetro por debajo del cual se acumula el $10 \%$ de la masa de los granos

Si todas las partículas presentan un tamaño similar, $d_{60}$ y $d_{10}$ no difieren demasiado, CU es un valor pequeño y el material se considera uniforme $(\mathrm{CU}=2$, Figura 6.5$)$. Si por el contrario existe abundancia de tamaños intermedios entre el máximo y el mínimo, $d_{60}$ y $d_{10}$ difieren sustancialmente, $\mathrm{CU}$ es un valor grande y el material se considera no uniforme $(\mathrm{CU}=10$, Figura $6.5)$.

La longevidad del material depende de la textura, puesto que la presencia de partículas de pequeño tamaño reduce la porosidad del filtro al ocuparse los poros existentes entre las partículas de mayor tamaño lo que aumenta el riesgo de colmatación. Además la presencia de materia orgánica, sólidos retenidos o compuestos químicos precipitados sobre el material favorece la cohesión de las partículas, lo que juega un papel determinante en la hidráulica del filtro. 


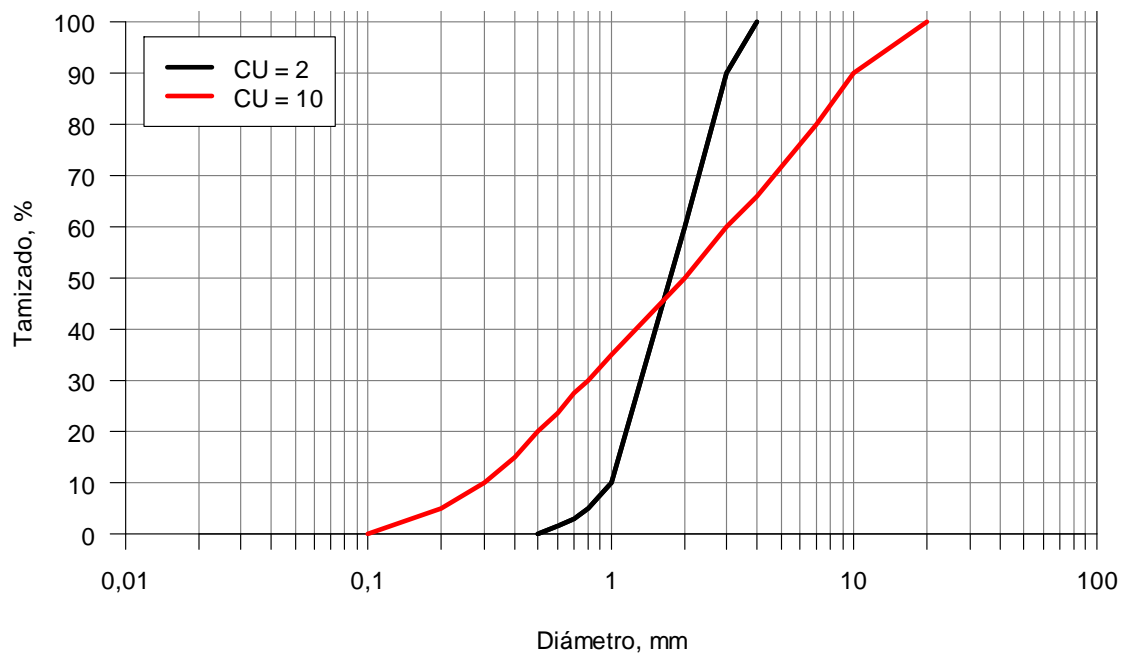

Figura 6.5.Curvas granulométricas de dos materiales con distinto coeficiente de uniformidad.

\subsubsection{Sustratos para la retención de fósforo}

La elección de un sustrato adecuado en los humedales artificiales influye en el tratamiento del agua residual debido a la importancia de los procesos de adsorción y precipitación en la eliminación de $\mathrm{P}$. Tradicionalmente se han utilizado materiales fácilmente disponibles localmente como arena o grava a pesar de su limitada capacidad de retención de P (Mann y Bavor, 1993; Arias y col., 2001). Existe una gran variedad de materiales que han sido objeto de estudio con el propósito de mejorar la eliminación de $\mathrm{P}$ en los humedales artificiales mediante su uso como sustrato para macrófitos (fundamentalmente en HFSH) o en unidades cuyo objetivo exclusivo es el tratamiento de P (Sharma y col., 2012). Estos materiales pueden clasificarse en tres grandes grupos en función de su origen: productos naturales, productos sintéticos y subproductos industriales (Johansson, 2006).

Los productos naturales incluyen rocas minerales (apatita, bauxita, caliza, dolomita, esquisto, marga, mármol, wollastonita, zeolita, etc), suelos (laterita, espodosol, turba, etc) y sedimentos marinos (opoka, conchas, etc) con altos contenidos de Al, Fe y/o Ca. Estos sustratos pueden ser sometidos a un pretratamiento previo (mediante molienda, ácido, calor, etc) para mejorar la capacidad de retención de P (Johansson, 2006; Vohla y col., 2011).

Los productos sintéticos para la retención de P (Alunite, Filtra P, Filtralite ${ }^{\circledR}$, LECA, Norlite, Polonite, ostra koreana, etc) se obtienen generalmente a partir de materiales naturales tales como minerales arcillosos o hidróxidos metálicos con alto contenido en $\mathrm{Al}, \mathrm{Fe}, \mathrm{Ca}$ o $\mathrm{Mg}$ sometidos a temperaturas muy elevadas (Vohla y col., 2011).

Los subproductos industriales con capacidad para la retención de $\mathrm{P}$ proceden de actividades industriales muy diversas. La industria del aluminio utiliza bauxita como materia prima y genera lodo rojo en el proceso que debe su color a un alto contenido en óxidos de Fe. El calentamiento de esquisto bituminoso para producir petróleo genera un residuo rico en Al. Las cenizas generadas en la combustión de carbón en la industria térmica son ricas en óxidos de $\mathrm{Si}$, $\mathrm{Al}$ y Fe. Las escorias generadas en la industria del acero son utilizadas para la retención del $\mathrm{P}$ debido a su alto contenido en óxidos de Al, Fe, Ca y Mg (Johansson, 2006; Vohla y col., 2011).

\subsubsection{Escorias de acería}

Las escorias de acería son subproductos generados en la industria del acero cuya composición puede variar de forma importante dependiendo del proceso de manufactura. Existen tres tipos de escorias de acería denominadas según el proceso en el que son producidas: escorias de horno 
alto (EHA), escorias de horno de arco eléctrico (EHAE) y escorias de horno de oxígeno básico denominadas comúnmente escorias de acería LD debido al proceso de manufactura Linz-Donawitz. Los hornos altos son utilizados en la producción de hierro, mientras que los demás hornos se utilizan en la producción de acero (Proctor y col., 2000).

En el proceso de manufactura de hierro llevado a cabo en hornos altos, la ganga (mineral de hierro y coque) es fundida junto con la $\mathrm{cal}(\mathrm{CaO})$ como agente fluidizante para formar escoria de hierro. Las diferentes gravedades específicas permiten separar la escoria fundida del hierro fundido. Un proceso de enfriamiento posterior permite la solidificación de las EHA. El proceso es similar a grandes rasgos en los hornos de oxígeno básico. El hierro fundido procedente de los hornos altos se convierte en acero al añadir oxígeno en un proceso en el que también se requieren materiales fluidizantes para generar la escoria que recoge las impurezas. Después de solidificarse, la escoria generada en el proceso se denomina escoria de acería LD (Motz y Geiseler, 2001). El proceso de formación del acero en los hornos de arco eléctrico es más complejo y requiere de dos etapas en las que se generan dos tipos de escoria EHAE: escorias negras y escorias blancas (CEDEX, 2011a).

La escoria de acería LD es un material heterogéneo compuesto por distintas proporciones de óxidos. Tanto los compuestos que forman la escoria de acería LD como sus proporciones cambiarán en función del proceso de manufactura del acero, los materiales brutos y los métodos de enfriamiento y choque (Xue y col., 2009). La principal característica de las escorias de acería $\mathrm{LD}$ en comparación con el resto de escorias es su menor contenido de alúmina $\left(\mathrm{Al}_{2} \mathrm{O}_{3}\right)$ y mayor contenido de óxido de manganeso (MnO) (Tabla 6.3). Tanto las escorias de acería LD como las escorias EHAE negras tienen un menor contenido de sílice $\left(\mathrm{SiO}_{2}\right)$ y un mayor contenido en $\mathrm{Fe}$, tanto en su forma libre como formando parte de óxidos (CEDEX, 2007), en comparación con las escorias de alto horno y las escorias EHAE blancas. El contenido de cal $(\mathrm{CaO})$, parcialmente en forma libre, es superior en las escorias de acería LD y EHAE blancas en comparación con el resto. Desde el punto de vista mineralógico las escorias de acería LD presentan en su composición diferentes fases: silicatos bi, tricálcico, wustita - combinación de $\mathrm{FeO}$ y $\mathrm{MnO}$ ferrito bicálcico y cal, más o menos impregnada de óxidos metálicos, responsable de la presencia de cal libre (CEDEX, 2007).

La escoria LD acumulada como residuo es inestable debido a que la cal libre (cuyo contenido en la escoria puede variar entre un $1 \mathrm{y}$ un $15 \%$ ) y la magnesia $(\mathrm{MgO})$ tienden a hidratarse desprendiendo calor y produciendo un hinchamiento que provoca la disgregación del material y modifica la granulometría de la escoria hacia menores tamaños. Por ello se favorece un proceso de envejecimiento de la escoria con agua para conseguir hidratar los elementos inestables. Esta alta higroscopicidad es una propiedad particularmente interesante en la revalorización de las escorias para la construcción de carreteras (CEDEX, 2007).

Tabla 6.3. Composición química promedio de las escorias de horno alto (EHA), de horno de arco eléctrico (EHAE) y de horno de oxígeno básico (LD) (CEDEX, 2007, 2011b, 2011a).

\begin{tabular}{lcccc}
\hline Compuesto & EHA & EHAE - negra & EHAE - blanca & LD \\
\hline $\mathrm{CaO}$ & $38-42$ & $23-32$ & $45,3-62,1$ & 48 \\
$\mathrm{SiO}_{2}$ & $32-37$ & $8-15$ & $17,4-19,3$ & 16 \\
$\mathrm{MgO}$ & $7-9$ & $4,8-6,6$ & $4,5-17,2$ & 5,2 \\
$\mathrm{Al}_{2} \mathrm{O}_{3}$ & $10-14$ & $3,5-7$ & $3,2-10,4$ & 1,2 \\
$\mathrm{FeO}$ & $0,4-0,8$ & $7-35$ & $0-0,9$ & \\
$\mathrm{Fe}_{2} \mathrm{O}_{3}$ & & $11-40$ & $1,1-3,6$ & \\
$\mathrm{Fe} \mathrm{Total}_{\mathrm{MnO}}$ & & & 16,04 \\
$\mathrm{TiO}_{2}$ & $0,2-0,6$ & $2,5-4,5$ & $0-1,2$ & 5,9 \\
\hline
\end{tabular}

\subsubsection{Escorias de acería en humedales artificiales}


Las propiedades físicas y químicas de las escorias de acería han provocado que su capacidad de retención de fósforo haya sido objeto de numerosos estudios. El experimento en batch agitación en suspensión de la escoria en una disolución de concentración conocida durante un tiempo determinado - es el método más documentado debido a su simplicidad y a que requiere cortos periodos de tiempo para su realización. A la hora de comparar la capacidad de retención de las escorias entre sí o con diferentes materiales, los resultados de estos experimentos pueden utilizarse como criterio para la elección del material más adecuado para retener fósforo. Las escorias EHA son las primeras escorias de acería cuya capacidad de retención de fósforo se estudió mediante este tipo de experimentos (Yamada y col., 1986; Sakadevan y Bavor, 1998; Johansson y Gustafsson, 2000), aunque también se han realizado experimentos con escorias EHAE y de acería LD (Drizo y col., 2002; Xue y col., 2009; Barca y col., 2012).

Las condiciones experimentales de los estudios en batch son establecidos arbitrariamente, por lo que los resultados son difícilmente comparables entre sí y pueden dar lugar a confusión (Cucarella y Renman, 2009). Además, la utilización de la ecuación de Langmuir con este tipo de datos experimentales puede provocar estimaciones poco realistas de los parámetros de adsorción, por lo que estos resultados deben ser utilizados con cautela para extrapolarlos a estudios de retención de fósforo en humedales artificiales (Drizo y col., 2002). Por ello es recomendable que los experimentos en batch se realicen acompañados de experimentos en columnas que permitan estimar la capacidad de retención de fósforo a largo plazo (Drizo y col., 2002). El estudio de la capacidad de retención de fósforo en columnas se puede encontrar en la bibliografía para las escorias EHA (Lee y Moon, 1997; Johansson, 1999), EHAE (Drizo y col., 2002; Drizo y col., 2006; Claveau-Mallet y col., 2013) y de acería LD (Barca, 2013).

A pesar del elevado número de publicaciones centradas en la capacidad de retención de fósforo mediante experimentos en batch y columna de las escorias de acería, existen pocos casos documentados sobre la aplicación de estos materiales a humedales artificiales a escala real (Shilton y col., 2006) debido al largo tiempo de experimentación requerido, la complejidad del estudio de las interacciones de los mecanismos de eliminación de fósforo con las variables ambientales y los altos costes de explotación. Sin embargo, se encuentran algunos ejemplos de la utilización de escorias EHA (Korkusuz y col., 2005), EHAE (Lee y col., 2010a) y de acería LD (Barca, 2013) en humedales artificiales.

La elección de un material adecuado para el tratamiento de fósforo en humedales artificiales es específico para cada localización y depende de las características físico-químicas del material, la capacidad de retención de fósforo, el potencial de reciclaje, el coste y la disponibilidad local del material (Drizo y col., 2006). Puesto que la variedad de los procesos y materias primas utilizadas en la manufactura del acero hacen que la composición física y química de las escorias sea diferente en cada planta industrial, resulta interesante reproducir los experimentos realizados en otros estudios para caracterizar la capacidad de retención de fósforo de las escorias de acería LD procedentes de factorías cercanas a la localidad de la planta piloto experimental. 


\subsection{OBJETIVOS}

El estudio de los filtros de escorias de acería LD para la retención de fósforo en humedales artificiales tiene como principales objetivos:

a. Evaluar la capacidad de retención de fósforo de las escorias de acería LD de la planta industrial LD-II y compararla con la obtenida en otros trabajos.

b. Determinar qué mecanismos intervienen en la retención de fósforo en los filtros de escorias de acería LD.

c. Determinar el volumen necesario de escorias de acería LD actuando como filtro para tratar el fósforo generado por un habitante equivalente. 


\subsection{MATERIALES Y MÉTODOS}

\subsubsection{Origen de las escorias de acería $L D$}

Las escorias estudiadas en este capítulo proceden de la acería LD-II localizada en Gijón (Asturias) que junto con la de Avilés (LD-III) son los dos únicos hornos de oxígeno básico existentes en España, ambos pertenecientes a la empresa ARCELOR ESPAÑA S.A. (Figura 6.6). La escoria utilizada es escoria envejecida procedente del área de almacenamiento.

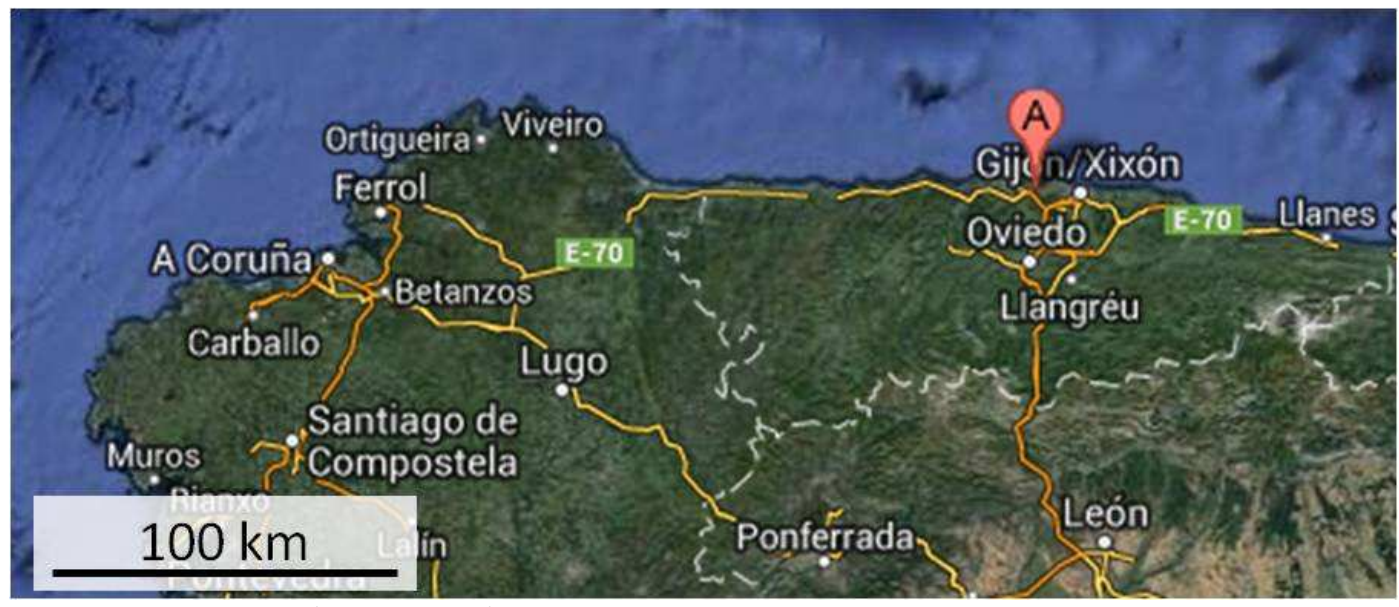

Figura 6.6. Localización de la acería LD-II en España. Adaptado de Google (2013).

6.3.2. Análisis de las propiedades físicas

\subsubsection{Granulometría}

El análisis granulométrico se ha realizado de acuerdo a la norma UNE-EN 933-1:1998 Ensayos para determinar las propiedades geométricas de los áridos. Parte 1: Deteminación de la granulometría de las partículas. La escoria previamente secada a una temperatura inferior a $60^{\circ} \mathrm{C}$ se ha hecho pasar por una columna de tamices (Tabla 6.4). La columna de tamices se ha sometido a vibración y movimientos rotatorios intensos durante varios minutos hasta asegurar que todo el material ha sido tamizado. Posteriormente se ha pesado la fracción retenida en cada tamiz. Los tamizados se han realizado con una cantidad mínima de muestra de $750 \mathrm{~g}$ según se especifica en la norma UNE.

Tabla 6.4. Luz de los tamices UNE utilizados en el análisis granulométrico.

\begin{tabular}{lcccccccccccccc}
\hline Tamiz & $1 / 2 ”$ & $3 / 8 ”$ & $1 / 4 ”$ & 3,50 & 8 & 12 & 16 & 30 & 40 & 50 & 70 & 80 & 100 & 200 \\
\hline $\begin{array}{l}\text { Luz, } \\
\mathrm{mm}\end{array}$ & 12,50 & 9,50 & 6,30 & 5,60 & 2,36 & 1,60 & 1,18 & 0,600 & 0,425 & 0,300 & 0,212 & 0,180 & 0,150 & 0,075 \\
\hline
\end{tabular}

\subsubsection{Densidad real y aparente}

La determinación de la densidad real de cada material se ha realizado con muestras de $200 \mathrm{ml}$ de volumen. La diferencia de volumen producido por la introducción de una cantidad conocida de material en una probeta con un volumen de agua conocido permite determinar su densidad. La densidad real $(\rho)$ en $\mathrm{g} \mathrm{cm}^{-3}$ se obtiene mediante la expresión:

$$
\rho=\frac{\text { masa sustrato }}{\Delta \text { volumen agua }}
$$

La densidad aparente $\left(\rho_{\text {ap }}\right)$ es una magnitud aplicada en materiales porosos que incluyen intersticios de aire, por lo que la densidad total del material es menor que la densidad del 
material poroso si se compactase. La densidad aparente se ha calculado como el cociente de la masa de una muestra de sustrato entre el volumen que ocupa.

$$
\rho_{a p}=\frac{\text { masa sustrato }}{\text { volumen sustrato }}
$$

\subsubsection{Porosidad}

La porosidad se mide saturando el material de agua. Se ha anotado el volumen de agua necesario para saturar un volumen determinado de material en un recipiente cilíndrico prestando especial atención a no dejar aire atrapado durante la inmersión. La porosidad $(f)$ se obtiene mediante la relación:

$$
f=\frac{\text { Volumen de material saturado }}{\text { Volumen de agua necesario para la saturación }}
$$

\subsubsection{Superficie específica}

La superficie específica de un material corresponde a la superficie total de las partículas por unidad de volumen de material. Generalmente en su cálculo se adopta la hipótesis de que las partículas tienen formas esféricas. Si además se tiene en cuenta la distribución granulométrica y el diámetro geométrico promedio de las mallas de dos tamices consecutivos y se rechaza la fracción residual del tamizado, la superficie específica se puede calcular mediante la expresión (Molle, 2003):

$$
S=(1-f) \sum_{i=1}^{n-1} \frac{12}{\left(d_{i+1}+d_{i}\right)} \cdot \frac{m_{i}}{M}
$$

donde

$$
\begin{aligned}
& S=\text { superficie específica, } \mathrm{m}^{-1} \\
& f=\text { porosidad del material } \\
& n=\text { número de tamices utilizados } \\
& d_{\mathrm{i}}=\text { diámetro de malla del tamiz iésimo, } \mathrm{m} \\
& m_{\mathrm{i}}=\text { masa de tamizado recuperado entre los tamizes iésimo e iésimo }+1, \mathrm{~kg} \\
& M=\text { masa total de muestra, } \mathrm{kg}
\end{aligned}
$$

\subsubsection{Análisis químicos y propiedades físicas del agua residual}

Las propiedades físicas del agua $\left(\mathrm{pH}\right.$, conductividad eléctrica $(\mathrm{CE})$ y temperatura $\left(\mathrm{T}^{\mathrm{a}}\right)$ ) se han medido in situ mediante el uso de una sonda YSI 556 MPS Multiprobe calibrada periódicamente.

El análisis del fósforo en forma de ortofosfato se ha realizado inmediatamente después del muestreo. Las muestras se han centrifugado y filtrado antes de ser analizadas por espectrofotometría mediante el método del ácido ascórbico 4500-P-E (APHA-AWWA-WEF, 2005).

Para el análisis químico de las escorias de acería se ha molido una muestra representativa de acuerdo a la norma UNE-EN 932-2 Ensayos para determinar las propiedades generales de los áridos. Parte 2: Métodos para la reducción de muestras de laboratorio. $\mathrm{El}$ análisis químico de los elementos $\mathrm{Al}, \mathrm{Fe}, \mathrm{Ca}, \mathrm{Mg}$ y $\mathrm{P}$ se ha llevado a cabo en el Laboratorio de Técnicas Instrumentales (LTI) de la Universidad de León. Las muestras han sido digeridas y diluidas adecuadamente según el elemento. El análisis se ha realizado por espectroscopía de emisión atómica en un ICP-AES, previa adición de $5 \mathrm{ppm}$ de Sc utilizado como patrón interno. El mismo método se ha utilizado para el análisis de $\mathrm{Ca}$ en muestras de agua. 


\subsubsection{Análisis morfológico}

Se ha estudiado la superficie de la escoria original y de los precipitados formados en el experimento mediante un microscopio electrónico de barrido o SEM (Scanning Electron Microscope) en el LTI de la Universidad de León. Para el análisis se requiere el pretratamiento de la muestra que se recubre con una capa de carbono u oro para darle propiedades conductoras. En este modelo de microscopio la luz se sustituye por un haz de electrones, y las lentes se sustituyen por electroimanes. El haz de electrones, enfocado por las lentes electromagnéticas a través de una columna con alto vacío, barre la superficie de la muestra donde los electrones rebotan o provocan la emisión de electrones secundarios de la muestra. Un detector mide la cantidad de electrones dispersados o emitidos y proporciona información sobre la intensidad de la zona estudiada, lo que permite generar una imagen tridimensional de la muestra.

La emisión de radiaciones en el microscopio SEM comprende un amplio espectro de rayos X que son evaluados por un detector específico para informar sobre la composición química de los objetos. Este análisis espectométrico de rayos $\mathrm{X}$ (denominado microanálisis de rayos $\mathrm{X} o$ MRX), simultáneo con la observación estructural, proporciona una información cualitativa y cuantitativa de la composición elemental de la muestra.

\subsubsection{Análisis mineralógico}

Se ha estudiado la naturaleza de los compuestos cristalinos que forman parte de las muestras de escoria antes y después de los experimentos de columna mediante difracción de rayos X (DRX). Las muestras han sido tomadas de acuerdo a la norma UNE-EN 932-2 Ensayos para determinar las propiedades generales de los áridos. Parte 2: Métodos para la reducción de muestras de laboratorio. Una vez molidas, las muestras han sido analizadas en el servicio de difracción de rayos X de la Universidad de Salamanca.

Los rayos $\mathrm{X}$ tienen longitudes de onda similares a las distancias interatómicas en los materiales cristalinos, por lo que pueden interactuar con los electrones que rodean los átomos. El haz de rayos $\mathrm{X}$ emergente tras esta interacción contiene información sobre la posición y tipo de átomos encontrados en su camino. Los cristales, gracias a su estructura periódica, dispersan elásticamente los haces de rayos $\mathrm{X}$ en ciertas direcciones y los amplifican por interferencia constructiva, originando un patrón de difracción. Con esta información, dirección e intensidad de cada rayo se ha podido determinar la estructura molecular más probable de cada muestra.

\subsubsection{Experimentos en batch}

En los experimentos en batch se favorece el contacto en agitación entre la escoria y una disolución de ortofosfatos durante un tiempo determinado para permitir al sistema alcanzar el equilibrio de la reacción de adsorción. Se han realizado dos tipos de experimentos en batch; en uno de ellos se ha estudiado la cinética de la reacción de adsorción con concentraciones de ortofosfatos constantes $\left(30 \mathrm{mg} \mathrm{L}^{-1}\right)$ en función del tiempo $(0,5-48 \mathrm{~h})$, mientras que el segundo se ha realizado para determinar las isotermas de adsorción con un tiempo constante ( $48 \mathrm{~h}$ ) en función de concentraciones de ortofosfatos en incremento hasta alcanzar el límite de la reacción de adsorción $\left(5,10,25,50,100,200,300\right.$ y $\left.400 \mathrm{mg} \mathrm{L}^{-1}\right)$. Las concentraciones de fósforo y calcio, y el valor de $\mathrm{pH}$ se han analizado antes y después del desarrollo de ambos tipos de ensayos.

Para asegurar su representatividad, ambos tipos de experimentos se han realizado por triplicado con una proporción de escoria:disolución en masa de 1:25. La cantidad de muestra correspondiente se ha tomado de acuerdo a la norma UNE-EN 932-2 Ensayos para determinar las propiedades generales de los áridos. Parte 2: Métodos para la reducción de muestras de laboratorio. La escoria se ha introducido en matraces Erlenmeyer y se ha sometido a una agitación de $120 \mathrm{rpm}$ en agitadores orbitales dentro de una cámara de incubación que asegura 
unas condiciones de temperatura constantes de $25^{\circ} \mathrm{C}$. Se ha utilizado una solución tampón de $\mathrm{NaOH}$ para asegurar un valor inicial de $\mathrm{pH} 7$ en la disolución.

\subsubsection{Experimentos en columna}

Se han utilizado dos columnas de PVC de $35 \mathrm{~cm}$ de altura y $12 \mathrm{~cm}$ de diámetro para analizar la capacidad de retención de $\mathrm{P}$ de los materiales en condiciones de saturación hidráulica. El fondo de cada columna se ha rellenado con $5 \mathrm{~cm}$ de grava inerte a la reacción con los ortofosfatos; a continuación se han rellenado $20 \mathrm{~cm}$ con escorias de dos muestras de textura diferente para cada columna y finalmente se han añadido otros $5 \mathrm{~cm}$ de grava inerte. Cada columna tiene 4 salidas utilizadas como puntos de muestreo verticales localizados a una distancia de 2,5; 5,10 y $15 \mathrm{~cm}$ a partir de los primeros $5 \mathrm{~cm}$ de grava inerte (Figura 6.7).
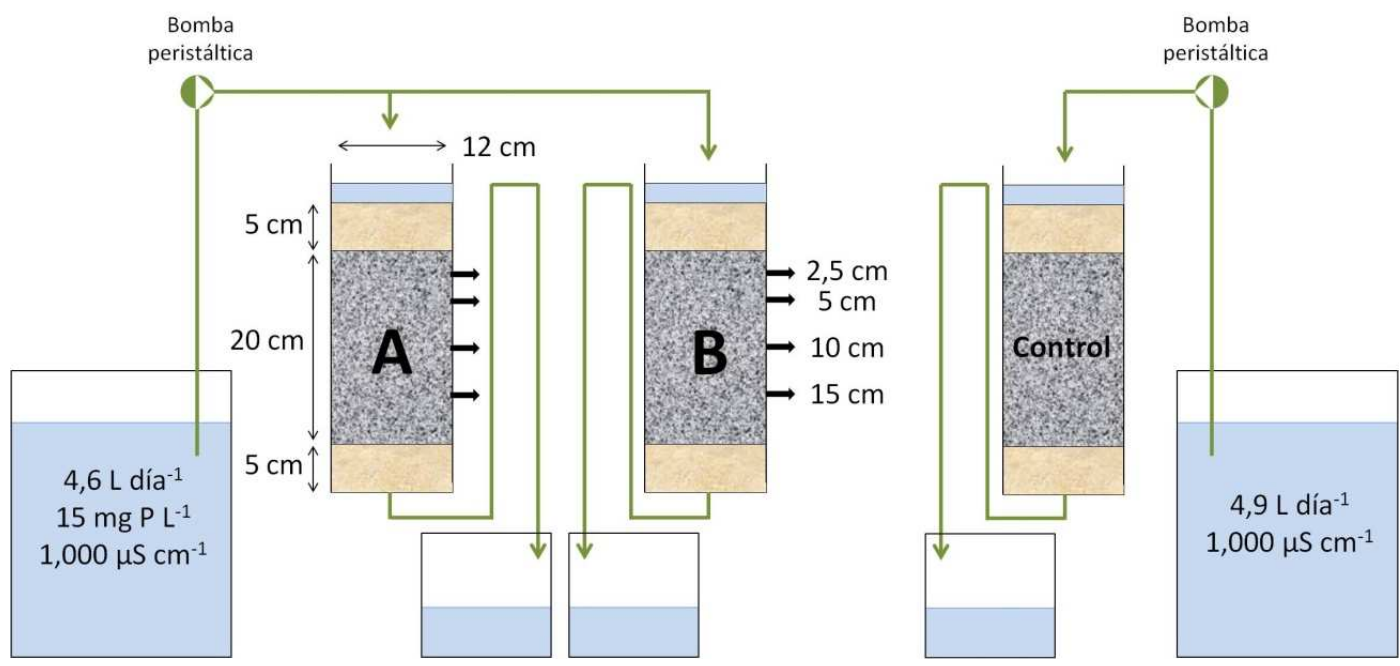

Figura 6.7. Esquema del experimento en columnas para la retención de fósforo.

Durante el periodo de estudio una bomba peristáltica con un caudal promedio de 4,6 $\mathrm{L}_{\text {día }}{ }^{-1}$ ha permitido la alimentación continua de las columnas con una disolución sintética de $\mathrm{P}$ (agua de grifo y $\mathrm{KH}_{2} \mathrm{PO}_{4}$ ) de $15 \mathrm{mg} \mathrm{L}^{-1}$ de $\mathrm{P}$ de concentración objetivo a la que se le ha añadido $\mathrm{NaCl}$ para asegurar una conductividad de $1,000 \pm 100 \mu \mathrm{S} \mathrm{cm}^{-1}$. Las condiciones de temperatura han sido las de la habitación en las que ha tenido lugar el experimento $\left(20 \pm 6{ }^{\circ} \mathrm{C}\right)$. Se ha almacenado la disolución sintética que ha pasado por las columnas en unos tanques para medir su volumen en función del tiempo transcurrido entre dos medidas. La toma de muestras ha sido diaria en la entrada, la salida y los 4 puntos de muestreo verticales.

Una tercera columna (columna Control) idéntica a las anteriores con un caudal promedio de 4,9 $\mathrm{L} \mathrm{día}^{-1}$ y sometida a las mismas condiciones de temperatura se ha utilizado para estudiar la liberación de los iones $\mathrm{Ca}^{2+}$ y su relación con el $\mathrm{pH}$ y la conductividad eléctrica. Para la alimentación del sistema se ha utilizado agua de grifo ajustada con $\mathrm{NaCl}$ para asegurar una conductividad de $1,000 \pm 100 \mu \mathrm{S} \mathrm{cm}^{-1}$. La toma de muestras se ha realizado de forma diaria en la entrada y la salida de la columna. Se han analizado los parámetros concentración de $\mathrm{Ca}^{2+}, \mathrm{pH}$ y conductividad eléctrica.

\subsubsection{Estimación de la concentración de calcio}

La concentración de calcio se ha estimado en función de la concentración de iones hidroxilo calculados a partir del valor de $\mathrm{pH}$ de la muestra. La concentración de iones $\mathrm{Ca}^{2+}$ se ha calculado atendiendo a la relación estequiométrica entre los moles de iones $\mathrm{OH}^{-}$y $\mathrm{Ca}^{2+}$ en la reacción de disociación de la portlandita (Ecuación 6.7). 


\subsection{RESULTADOS Y DISCUSIÓN}

\subsubsection{Propiedades físicas}

Las dos muestras de escoria estudiadas se encuentran en el mismo rango de diámetro de partículas (entre 0,07 y $11 \mathrm{~mm}$ ), aunque presentan unos perfiles de sus curvas granulométricas muy diferentes, particularmente en el rango de diámetro de partícula entre 0,3 y $6 \mathrm{~mm}$ (Figura 6.8). La mayor diferencia de porcentaje de partículas acumulado (tamizado) entre ambas muestras se encuentra en el diámetro de partícula de $2 \mathrm{~mm}$. El $50 \%$ de las partículas de la muestra A tienen un diámetro igual o inferior a $2 \mathrm{~mm}$, mientras que para la muestra $\mathrm{B}$ esta cantidad es de aproximadamente el $20 \%$.

Los valores de $d_{10}$ y $d_{60}$ junto con la curva granulométrica indican que para un mismo porcentaje de material tamizado, la muestra A presenta un menor diámetro de partícula en comparación con la muestra B, lo que resulta en una mayor superficie específica $(S)$ (Tabla 6.5, Figura 6.8). Los coeficientes de uniformidad $(C U)$ superan el valor de 15 , lo que informa de un amplio rango de diámetros de partículas para ambas muestras. Sin embargo, el menor $C U$ de la muestra $\mathrm{B}$ indica una mayor uniformidad o similitud entre los diámetros de las partículas de este sustrato. Aunque ligeramente inferiores en el caso de la muestra A, no hay diferencias importantes en las densidades de ambos sustratos.

Dada su mayor uniformidad, se ha escogido la muestra B para los experimentos en batch de retención de fósforo.

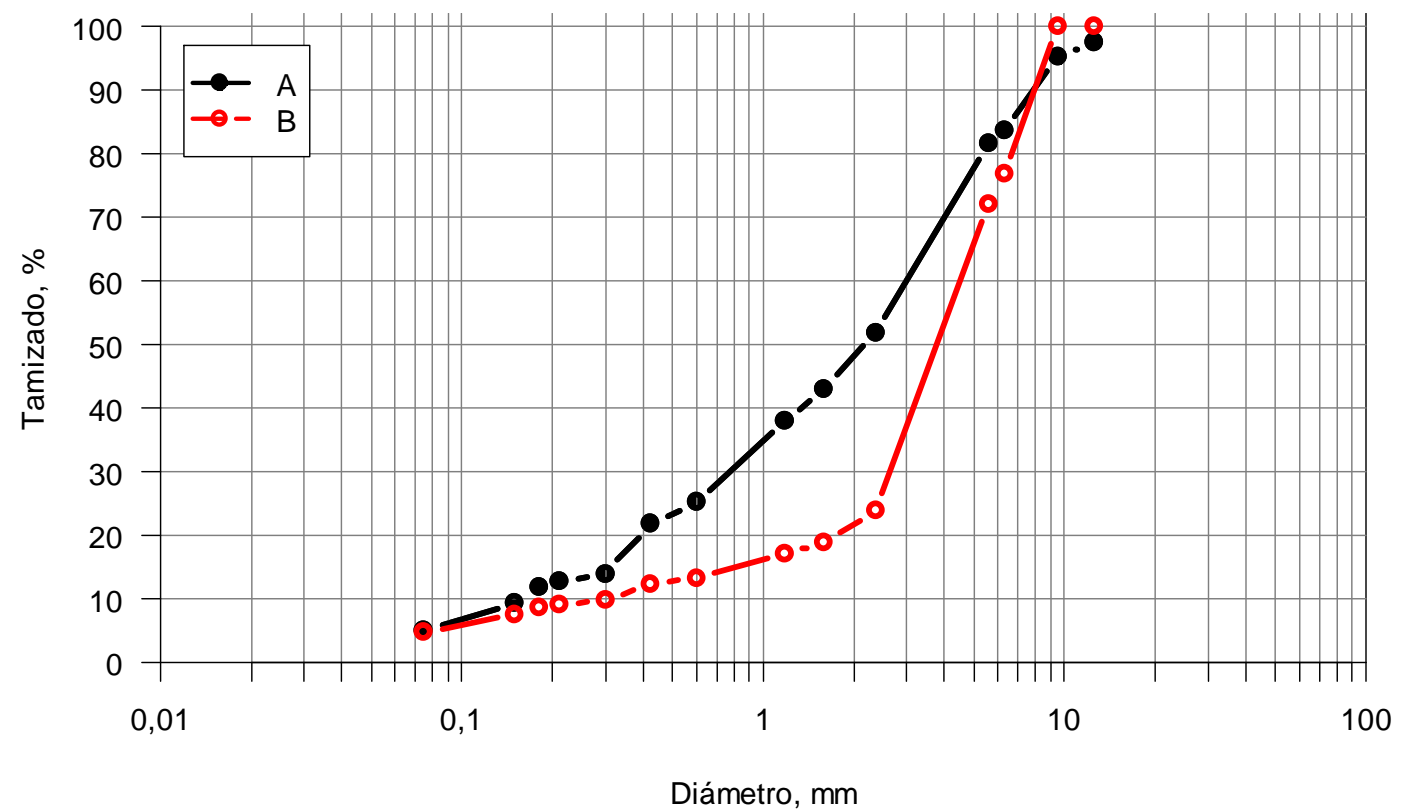

Figura 6.8. Curvas granulométricas de las muestras estudiadas.

Tabla 6.5. Propiedades físicas de las muestras estudiadas.

\begin{tabular}{lccccccc}
\hline Textura & $d_{10}$ & $d_{60}$ & $C U$ & $S$ & $\rho, \mathrm{g} \mathrm{cm}^{-3}$ & $\rho_{\mathrm{ap}}, \mathrm{g} \mathrm{cm}^{-3}$ & $f$ \\
\hline A & 0,16 & 3,04 & 19,41 & 394,56 & 2,80 & 1,42 & 0,49 \\
B & 0,30 & 4,67 & 15,43 & 218,47 & 2,94 & 1,49 & 0,49 \\
\hline
\end{tabular}

6.4.2. Composición química y mineralógica de las escorias de acería $L D$

La composición química de la escoria con respecto a los elementos de mayor interés debido a su relevancia en la retención de $\mathrm{P}$ se muestra en la Tabla 6.6. Fe y Ca son los elementos que más 
van a interaccionar con el fósforo debido a sus cantidades relativas que pueden llegar a alcanzar el $60 \%$ en masa de la composición de la muestra de escoria. Las escorias de acería LD contienen de forma típica más de un $80 \%$ de $\mathrm{CaO}, \mathrm{MgO}, \mathrm{SiO}_{2}$ y $\mathrm{FeO}$ aunque su composición química puede variar dependiendo de la materia prima, la temperatura del proceso, la factoría en la que se manufactura el acero o incluso dentro de la misma factoría a lo largo del día (Xie y col., 2012). Además de Fe, Al y Ca, el MRX de la superficie de la escoria muestra la presencia de Si y Mn en cantidades apreciables (Figura 6.9).

Tabla 6.6. Composición química de la escoria de acería LD.

\begin{tabular}{lccccc}
\hline Elemento & $\mathrm{Al}$ & $\mathrm{Fe}$ & $\mathrm{Ca}$ & $\mathrm{Mg}$ & $\mathrm{P}$ \\
\hline$\%$ masa & 1,05 & 26,17 & 33,92 & 3,27 & 0,52 \\
\hline
\end{tabular}
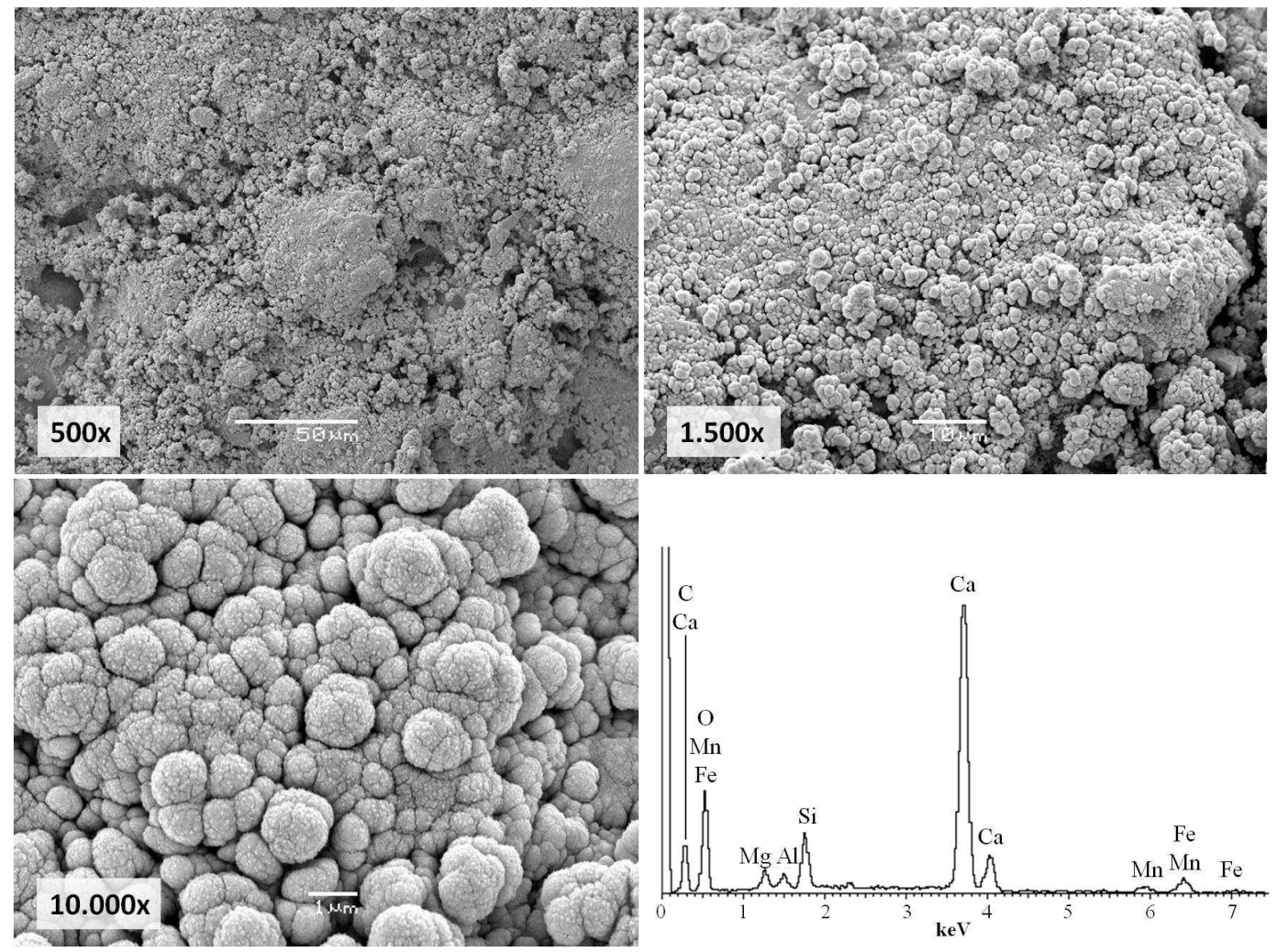

Figura 6.9. De arriba hacia abajo y de izquierda a derecha. Observación SEM a 500, 1.500 y 10.000 aumentos y espectro de elementos obtenidos mediante un MRX de la superficie de una partícula de escoria antes de los experimentos de retención de $\mathbf{P}$.

La superficie de las partículas de escoria de tamaño de grava puede presentar una estructura sólida con formas subangulares y subredondeadas, una estructura heterogénea y porosa o estar formada por aglomerados de partículas en función de la tasa de enfriamiento utilizada para la formación de las escorias (Xie y col., 2012). Se ha analizado la morfología de un grano de escoria de $5 \mathrm{~mm}$ mediante SEM antes de su utilización en los experimentos en batch y en columna (Figura 6.9). La apariencia de la superficie de la escoria a pocos aumentos puede ser atribuida al proceso de envejecimiento durante el cual la cal $(\mathrm{CaO})$ entra en contacto con agua y genera compuestos hidratados como $\mathrm{Ca}(\mathrm{OH})_{2}$ (portlandita). La portlandita tiene una menor densidad que la cal, por lo que la hidratación de $\mathrm{CaO}$ libre resulta en un incremento del volumen y una disgregación de la escoria en partículas de menor diámetro (Yildirim y Prezzi, 2011). En la zona de almacenamiento la escoria está acumulada en contacto directo con el aire por lo que los compuestos hidratados pueden reaccionar con $\mathrm{CO}_{2}$ atmosférico formando calcita $\left(\mathrm{CaCO}_{3}\right)$. 
La presencia de la textura nubosa que puede apreciarse en la imagen SEM a 10.000 aumentos de la Figura 6.9 se puede atribuir a procesos de carbonatación en escorias envejecidas (Yildirim y Prezzi, 2009).

El análisis mineralógico de la escoria revela un patrón de DRX muy complejo, con numerosos picos superpuestos resultado del elevado número de fases cristalinas presentes en la muestra (Figura 6.10). La formación de estas fases depende tanto de las características químicas de la escoria como de la tasa de enfriamiento, que a mayores valores permitirá la formación de cristales bien definidos (Yildirim y Prezzi, 2011). Debido a la compleja composición mineralógica la identificación de las fases minerales es muy difícil, por lo que han sido clasificadas como principales, secundarias o de presencia incierta dependiendo de la intensidad de los picos.

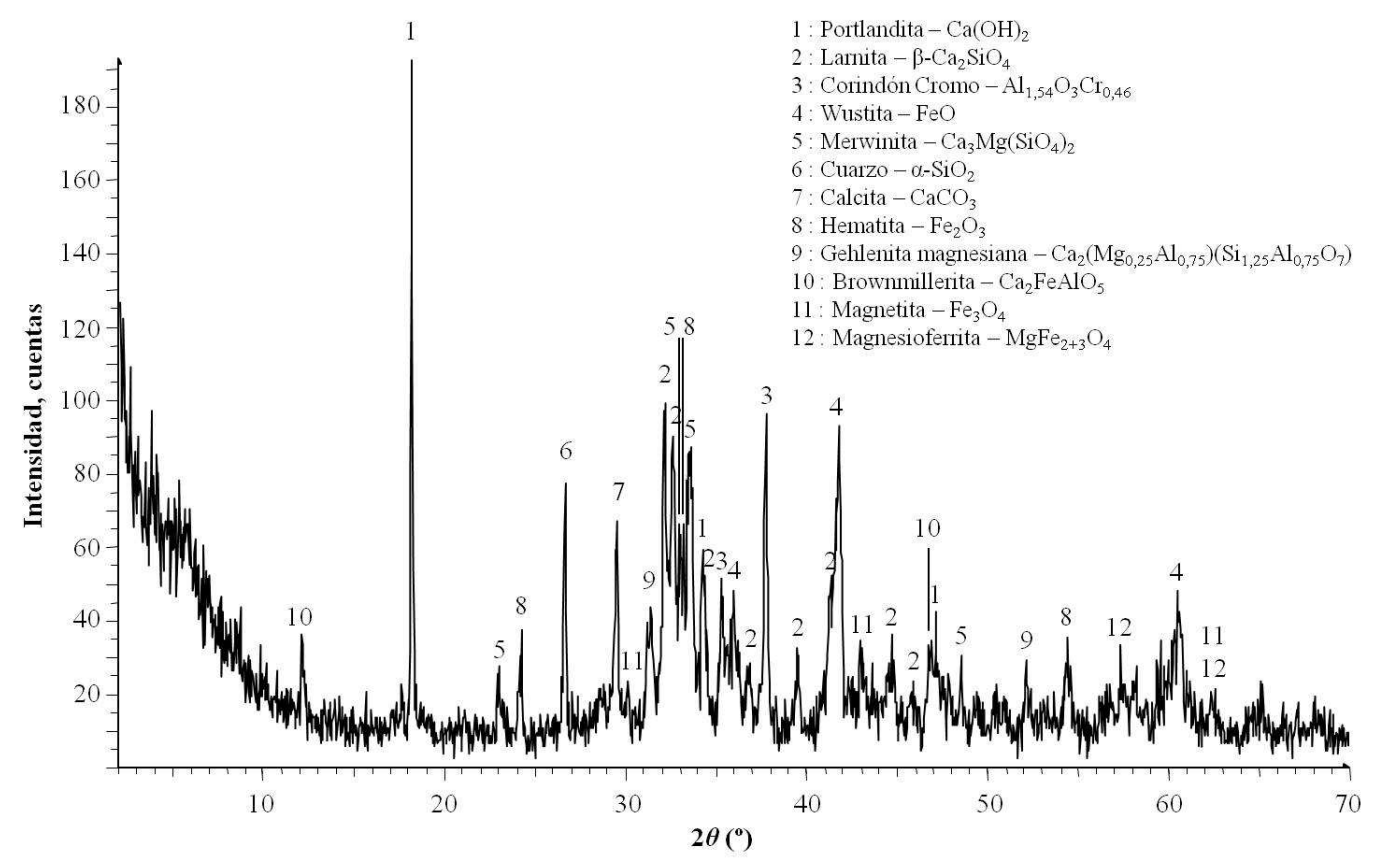

Figura 6.10. Difractograma del análisis de DRX para la muestra de escoria.

El análisis de DRX (Figura 6.10) ha mostrado un pico de difracción agudo y de gran intensidad cercano a $2 \theta=18^{\circ}$ correspondiente a la portlandita $\left(\mathrm{Ca}(\mathrm{OH})_{2}\right)($ Pico 1$)$, la principal fase mineral de la muestra. La presencia de este mineral junto con la presencia de calcita $\left(\mathrm{CaCO}_{3}\right)$ (Pico 7$)$ como una de las fases secundarias permite atribuir la textura nubosa de la morfología de escorias de acería $\mathrm{LD}$ envejecidas a la hidratación de $\mathrm{CaO}$ y a la formación de calcita con $\mathrm{CO}_{2}$ atmosférico. Larnita $\left(\beta-\mathrm{Ca}_{2} \mathrm{SiO}_{4}\right)$ (Pico 2), componente fundamental del cemento Portland, es la fase secundaria más frecuente en los picos del difractograma. La wustita $(\mathrm{FeO})$ (Pico 4) se encuentra como fase secundaria en el análisis y es frecuente en escorias de acería. Su presencia evita junto a otras impurezas la ruptura de los cristales de escoria y la formación de polvo durante el enfriamiento de la escoria (Shi, 2002; Yildirim y Prezzi, 2011). Otras fases secundarias identificadas son corindón cromo $\left(\mathrm{Al}_{1,54} \mathrm{O}_{3} \mathrm{Cr}_{0,46}\right)$, merwinita $\left(\mathrm{Ca}_{3} \mathrm{Mg}\left(\mathrm{SiO}_{4}\right)_{2}\right)$ y cuarzo $\left(\mathrm{SiO}_{2}\right)$ (Picos 3, 5 y 6 respectivamente), cuya presencia es frecuente en este tipo de escorias.

Los óxidos de $\mathrm{Fe}$ son abundantes en la muestra. Además de wustita, el difractograma indica la presencia de hematita $\left(\mathrm{Fe}_{2} \mathrm{O}_{3}\right)$, brownmillerita $\left(\mathrm{Ca}_{2} \mathrm{FeAlO}_{5}\right)$, magnetita $\left(\mathrm{Fe}_{3} \mathrm{O}_{4}\right)$ o magnesioferrita $\left(\mathrm{MgFe}_{2+3} \mathrm{O}_{4}\right)$ (Picos 8, 10, 11 y 12 respectivamente). La presencia de magnetita y magnesioferrita explicaría el comportamiento magnético observado en la muestra de escoria y la dificultad en el proceso de molienda (Belhadj y col., 2012). La última fase clasificada como 
incierta es la gehlenita con impurezas de magnesio (Pico 9). En general, la composición mineralógica de la escoria es similar a los patrones de DRX presentados por otros autores para escorias de acería (Yildirim y Prezzi, 2009).

\subsubsection{Experimentos en batch}

\subsubsection{Cinética de la retención de fósforo y liberación de iones $\mathrm{Ca}^{2+} \mathrm{y} \mathrm{OH}^{-}$}

Los resultados de los experimentos en batch en función del tiempo se muestran en la Figura 6.11. La concentración inicial de $30 \mathrm{mg} \mathrm{L}^{-1}$ de fósforo se reduce rápidamente a niveles inferiores a $1 \mathrm{mg} \mathrm{L}^{-1}$ en presencia de $20 \mathrm{~g}$ de escorias de acería LD durante la primera media hora del ensayo. La rapidez de la reacción sugiere que el estudio de la cinética de la retención de fósforo mediante escorias de acería LD en experimentos tipo batch puede realizarse en un periodo de tiempo muy inferior a las 48 horas.

La concentración de iones $\mathrm{Ca}^{2+}$ aumenta con el tiempo hasta alcanzar un valor con una gran desviación estándar que indica que el equilibrio de la concentración de $\mathrm{Ca}^{2+}$ no se ha alcanzado en la disolución. Los resultados dispares a las 48 horas pueden ser debidos a la reducción de la concentración de calcio en algunas réplicas debido a la precipitación de $\mathrm{CaCO}_{3}$ por la difusión de $\mathrm{CO}_{2}$ atmosférico en la disolución. Estudios similares sugieren que un pseudo-equilibrio se puede alcanzar después de 7 días (Barca y col., 2012).

El valor de $\mathrm{pH}$ de la disolución también aumenta rápidamente hasta alcanzar el equilibrio en torno a las 12 unidades de $\mathrm{pH}$ (Figura 6.11). El elevado coeficiente de correlacion $\left(R^{2}=0,96\right)$ entre las concentraciones de los iones $\mathrm{Ca}^{2+}$ y los iones $\mathrm{OH}^{-}$obtenidos a partir del valor de $\mathrm{pH}$ de la disolución indica que el incremento de $\mathrm{pH}$ e iones $\mathrm{Ca}^{2+}$ puede atribuirse a la disociación de la portlandita $\left(\mathrm{Ca}(\mathrm{OH})_{2}\right)$ en la disolución de acuerdo con la Ecuacion 6.7.

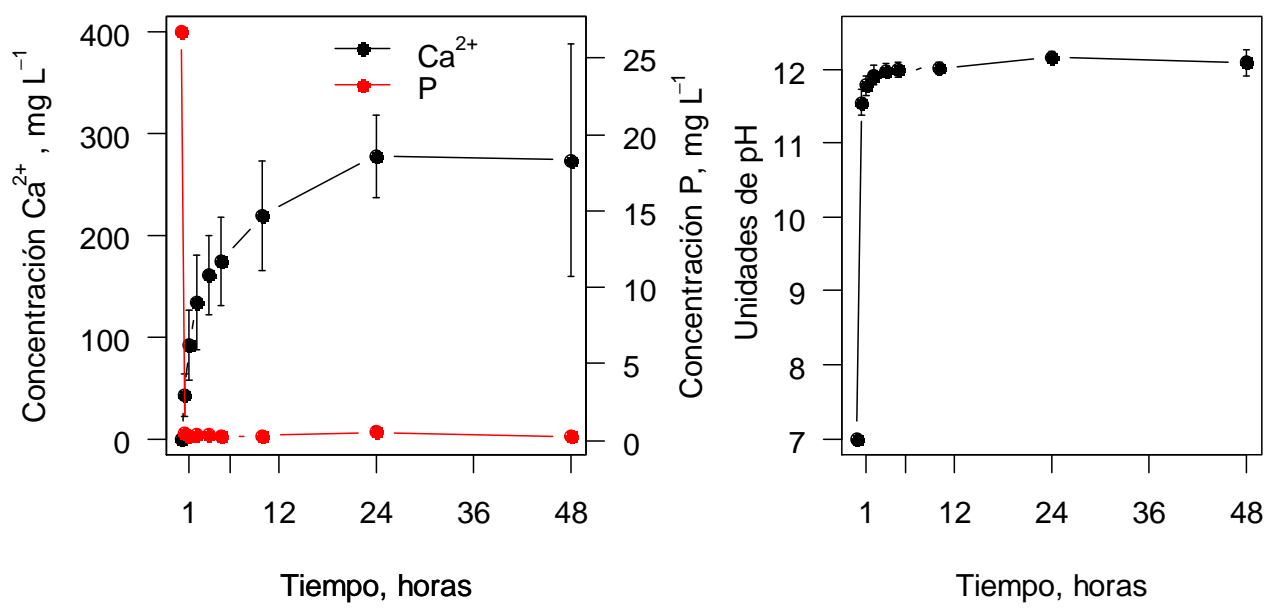

Figura 6.11. Cinética de la retención de fósforo, liberación de iones $\mathrm{Ca}^{2+}$ y cambio del valor de $\mathrm{pH}$.

\subsubsection{Capacidad de retención de fósforo}

Los resultados de los experimentos muestran una gran capacidad de retención de fósforo por las escorias de acería LD, llegando a alcanzar un índice de eliminación promedio superior al $99 \%$ para concentraciones iniciales de $\mathrm{P}$ entre 5 y $300 \mathrm{mg} \mathrm{L}^{-1}$. A partir de una concentración inicial de $400 \mathrm{mg} \mathrm{L}^{-1}$ la eliminación de fósforo en el sistema se reduce hasta un índice de eliminación promedio del $84 \%$. Esta pérdida de capacidad de tratamiento parece estar relacionada con el descenso del suministro de iones $\mathrm{Ca}^{2+}$ a la disolución por parte de la escoria e indíca que la 
capacidad máxima de retención de ortofosfatos se alcanza entre los 330 y $350 \mathrm{mg} \mathrm{L}^{-1}$ de fósforo aproximadamente (Figura 6.12).

Es probable que en la eliminación de ortofosfatos hayan intervenido tanto procesos de adsorción sobre el sustrato como la precipitación de fosfatos de calcio tal y como han descrito Bowden y col. (2009) para escorias de acería LD. Esto explicaría la elevada presencia de ortofosfatos en la disolución para la concentración inicial de $400 \mathrm{mg} \mathrm{L}^{-1}$ con respecto del resto de concentraciones iniciales, e identifica al ión $\mathrm{Ca}^{2+}$ como el factor limitante de la reacción.

De entre los diferentes fosfatos de calcio que pueden precipitar, la hidroxiapatita (HAP) es el compuesto con mayor posibilidad de formarse debido a que el valor de $\mathrm{pH}$ y las concentraciones de ortofosfatos y $\mathrm{Ca}^{2+}$ se encuentran en el rango de valores que favorecen su formación (Stumm y Morgan, 1996; Valsami-Jones, 2001; Kim y col., 2006). Además, el incremento de ortofosfatos está acompañado por un descenso del pH en la disolución (Figura 6.12) ya mostrado por Barca y col. (2012) que puede atribuirse al consumo de iones $\mathrm{OH}^{-}$en el proceso de precipitación de HAP:

$$
10 \mathrm{Ca}^{2+}+6 \mathrm{PO}_{4}^{3-}+2 \mathrm{OH}^{-} \rightarrow \mathrm{Ca}_{10}\left(\mathrm{PO}_{4}\right)_{6}(\mathrm{OH})_{2} \downarrow
$$

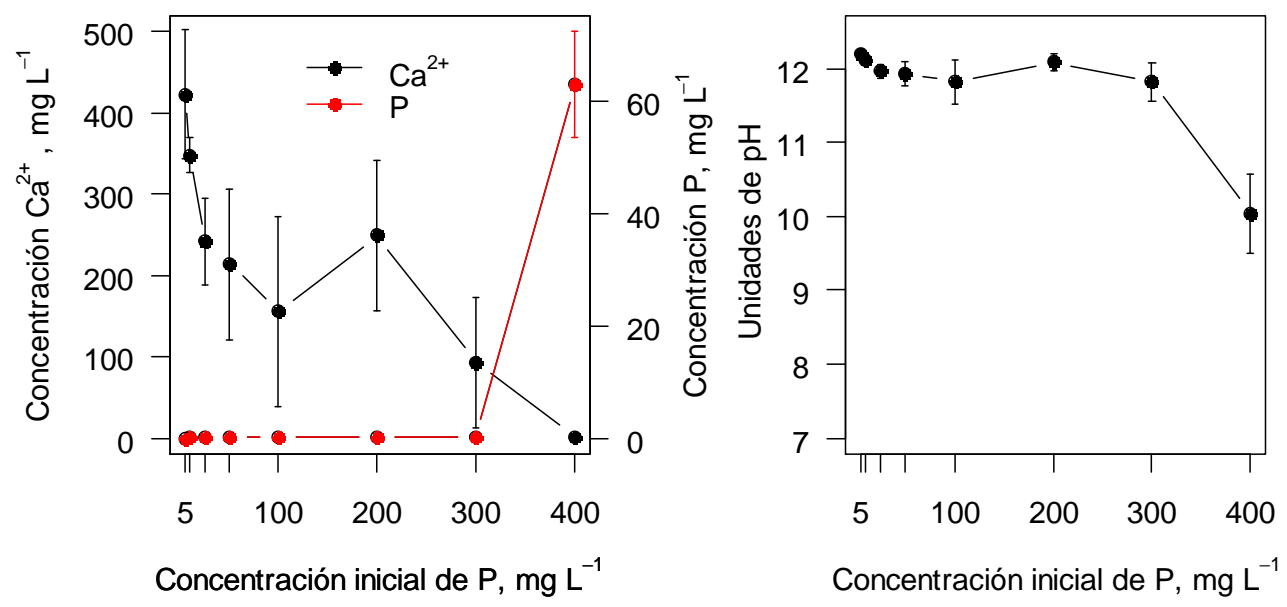

Figura 6.12. Concentraciones de $\mathrm{Ca}^{2+}$ y $\mathbf{P}$ y valores de pH para disoluciones con diferentes concentraciones iniciales de $P$.

La escoria de acería LD utilizada muestra una capacidad muy superior a la de otros materiales (Cucarella y Renman, 2009), aunque bastante inferior a la de otros experimentos en batch realizados con escorias de acería LD que pueden llegar a alcanzar capacidades de retención de $89,9 \mathrm{mg} \mathrm{g}^{-1}$ (Bowden y col., 2009; Xue y col., 2009). La comparación con los resultados de otros estudios es complicada debido a las diferentes condiciones experimentales. Los principales parámetros que afectan al proceso de retención en batch son el tamaño de particula, la relación material:disolución, la concentración inicial de ortofosfatos, la agitación y el tiempo de contacto (Cucarella y Renman, 2009).

La capacidad máxima de retención es importante para realizar el ajuste de las isotermas de adsorción a los datos experimentales. Con la información disponible, el modelo que mejor describe el proceso de eliminación de fósforo en experimentos en batch es el modelo de Langmuir $\left(R^{2}=0,51 ; K_{\mathrm{L}}=2,04 ;\right.$ qmax $\left.=8,3\right)$ frente al de Freundlich $\left(R^{2}=0,45 ; K_{\mathrm{F}}=3,45\right.$; $1 / \mathrm{n}=2,16$ ) aunque en ambos casos no se ha producido un buen ajuste de los modelos a los datos experimentales de acuerdo con los valores de los coeficientes de determinación (Figura 6.13). Esto puede deberse a que el rápido aumento de $\mathrm{pH}$ haya favorecido los procesos de precipitación en detrimento de los de adsorción (Molle, 2003). Un mejor ajuste se podría 
obtener con información adicional en el rango de concentraciones iniciales $300-400 \mathrm{mg} \mathrm{L}^{-1}$ y un menor tiempo de experimentación ya que, de acuerdo con la cinética de eliminación de fósforo, menores tiempos de contacto proporcionan una información más adecuada para estudiar el proceso de adsorción y tiempos de contacto elevados favorecen la precipitación de fosfatos de calcio.

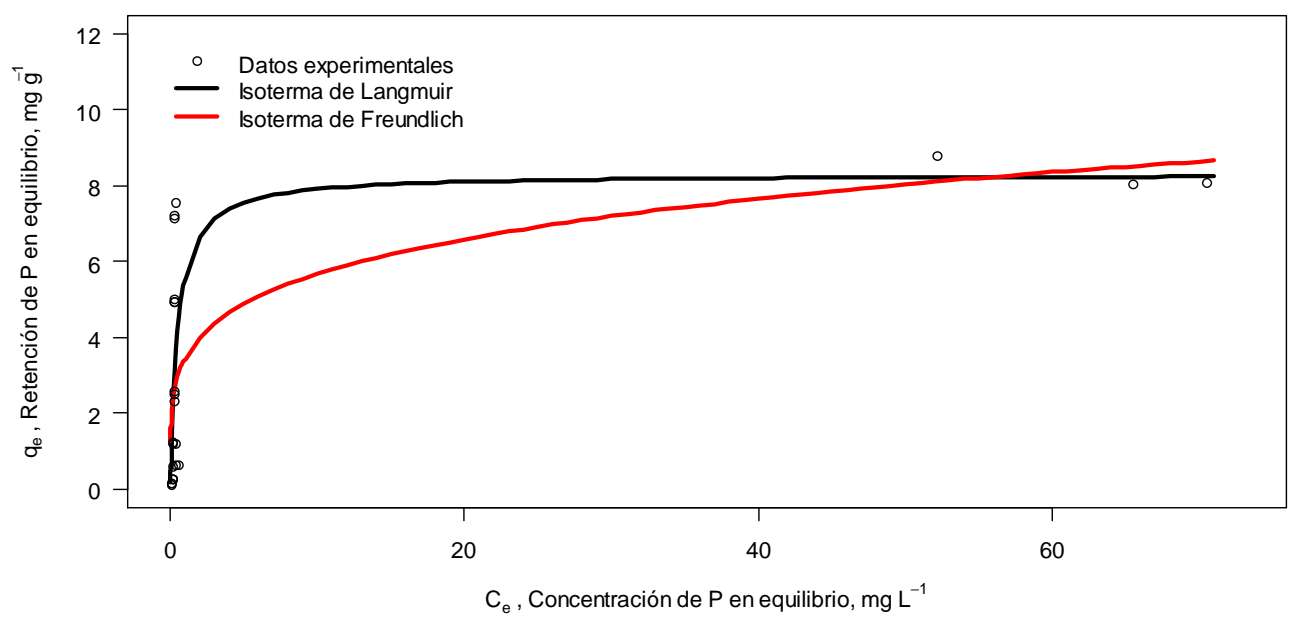

Figura 6.13. Isotermas de Langmuir y Freundlich frente a los datos experimentales.

\subsubsection{Experimentos en columnas}

\subsubsection{Comportamiento hidráulico de las columnas A y B para retención de P}

El caudal promedio de alimentación $\left(4,6 \mathrm{~L} \mathrm{día}^{-1}\right)$ ha proporcionado un tiempo de retención hidráulico teórico de las columnas A y B de 7,6 horas. La Figura 6.14 muestra el caudal promedio que ha transcurrido por cada una de las columnas a lo largo del periodo de experimentación.

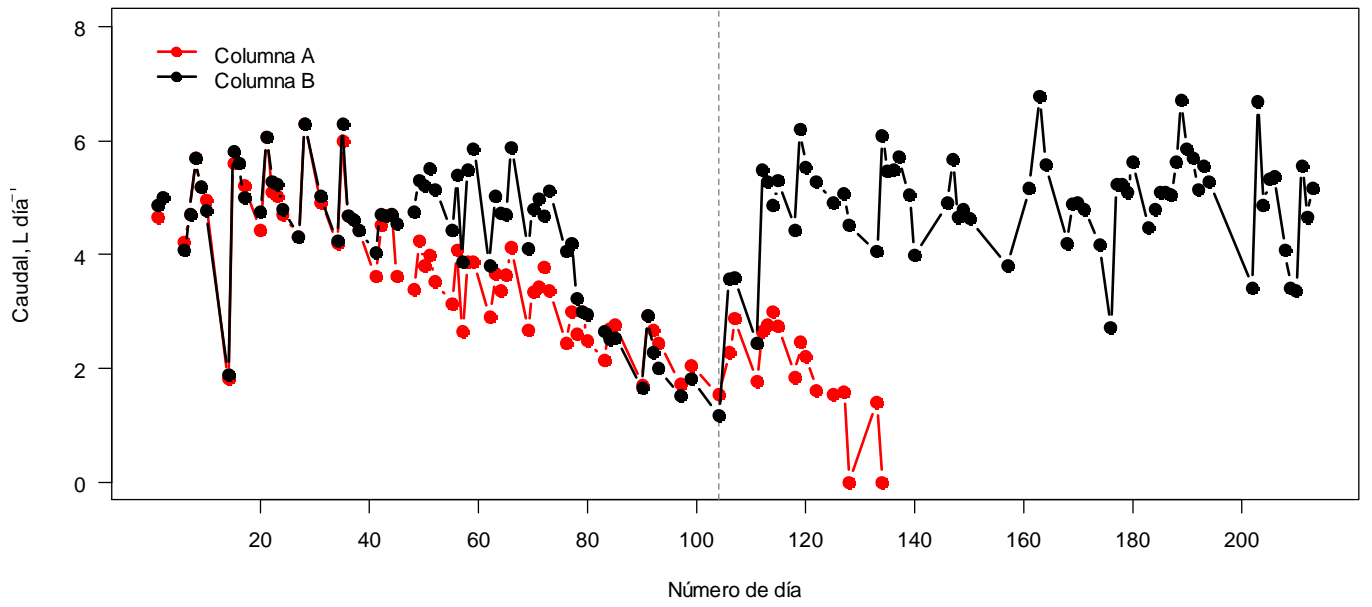

Figura 6.14. Caudal de salida de las dos columnas a lo largo del periodo de estudio. La línea vertical corresponde al día 104.

El caudal de salida de la columna A se ha ido reduciendo progresivamente hasta el día 135, momento en el que se ha detenido el experimento para esa columna. La causa más probable de la reducción de caudal es la formación de precipitados de fosfatos de calcio y $\mathrm{CaCO}_{3}$ que han cortado los caminos preferenciales del agua y reducido las secciones de paso del fluido entre las 
partículas de escoria hasta su colmatación. La Figura 6.15 muestra una fotografía del fondo de la columna A una vez vaciada tras el periodo de experimentación. En ella se puede apreciar cómo un precipitado de color blanco ha ocupado los poros y cohesionado los granos de grava de la parte inferior de la columna hasta impedir el paso del agua.
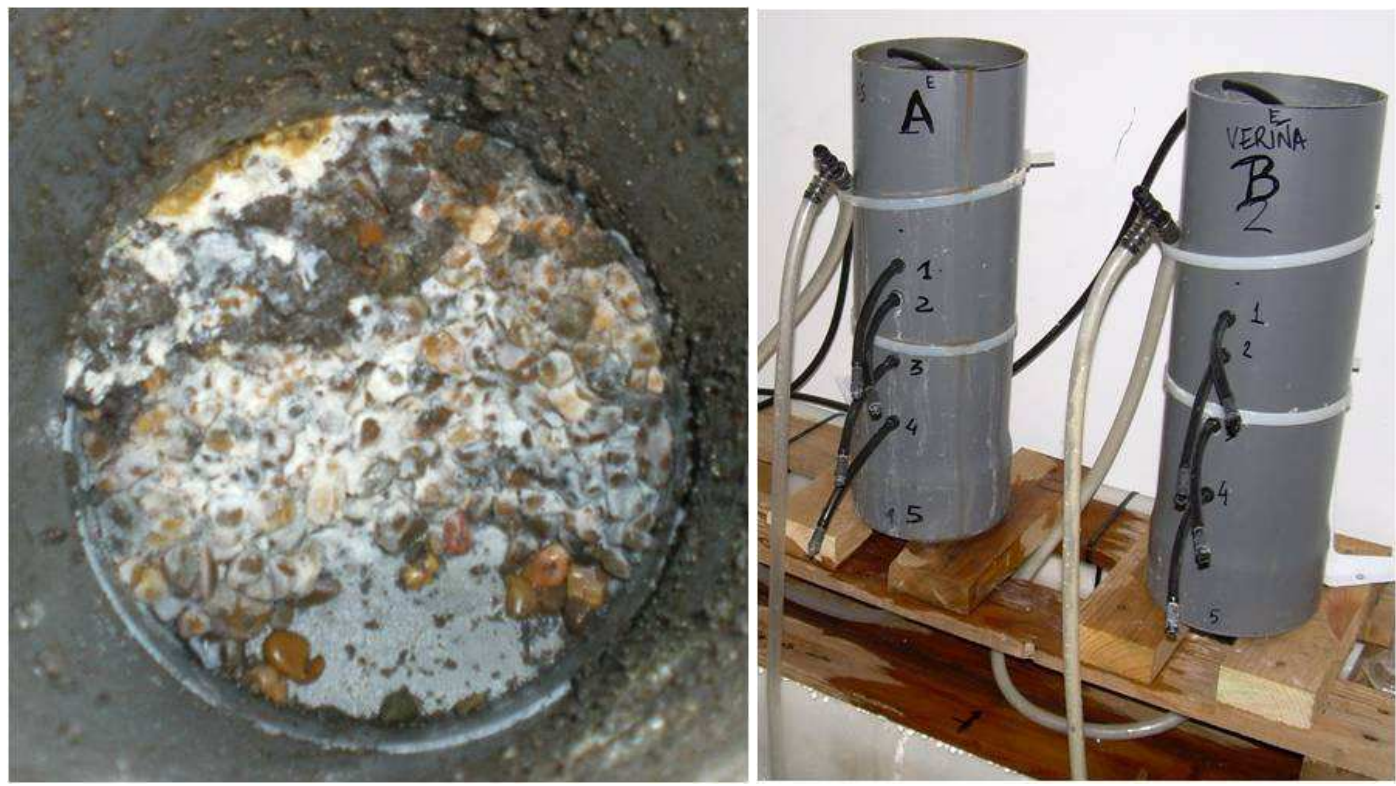

Figura 6.15. Fotografía del fondo de la columna A al finalizar el experimento (izquierda) y foto de las columnas experimentales y sus conductos de vertido (derecha).

La columna B ha mostrado un comportamiento hidráulico relativamente estable durante todo el experimento con la excepción del periodo transcurrido entre los días 78 y 111 durante el cual se ha comportado de forma análoga a la columna A. Es posible que los precipitados de fosfatos de calcio y $\mathrm{CaCO}_{3}$ hayan cortado los caminos preferenciales del agua hasta ese momento para luego favorecer una mejor distribución del flujo a lo largo de la superficie de las escorias. Las diferencias en el comportamiento hidráulico de ambos filtros se deben probablemente a las diferentes texturas de las escorias. Suliman y col. (2006) también observan una reducción de los caminos preferenciales debido a la reducción de la porosidad del sustrato en filtros de tipo subsuperficial y sugiere la utilización de un material de mayor tamaño para evitar la colmatación del filtro. La Figura 6.15 muestra las dos columnas experimentales. En la columna B se aprecia la presencia de un precipitado de color blanco en el conducto de salida. Es posible que el mayor diámetro de las partículas de la escoria $\mathrm{B}$ haya permitido el paso de los fosfatos de calcio y los cristales de $\mathrm{CaCO}_{3}$ evitando así la colmatación del filtro.

Se ha estudiado la morfología y mineralogía del precipitado de color blanco procedente del conducto de salida de la columna B con el fin de identificar su naturaleza. Es necesario indicar que la muestra analizada se ha obtenido después de la sedimentación de los precipitados, lo que ha influido en su morfología. El análisis SEM a 30 aumentos muestra los dos tipos de morfologías a izquierda y derecha del material adhesivo que sujeta la muestra. Ambos tipos muestran una estructura cristalina que puede estar disgregada en pequeños cristales (izquierda) o formando parte de un cristal de mayor tamaño (derecha) (Figura 6.16).

Las imágenes a 500 aumentos permiten apreciar estas morfologías con mayor detalle. Resulta particularmente interesante la superficie del precipitado más uniforme cuya estructura es el resultado de la unión entre cristales de menor tamaño. Según el espectro del análisis MRX, el precipitado está compuesto principalmente de $\mathrm{Ca}, \mathrm{C}$ y $\mathrm{O}$ (Figura 6.16), lo que coincide con el análisis químico (Tabla 6.7). 


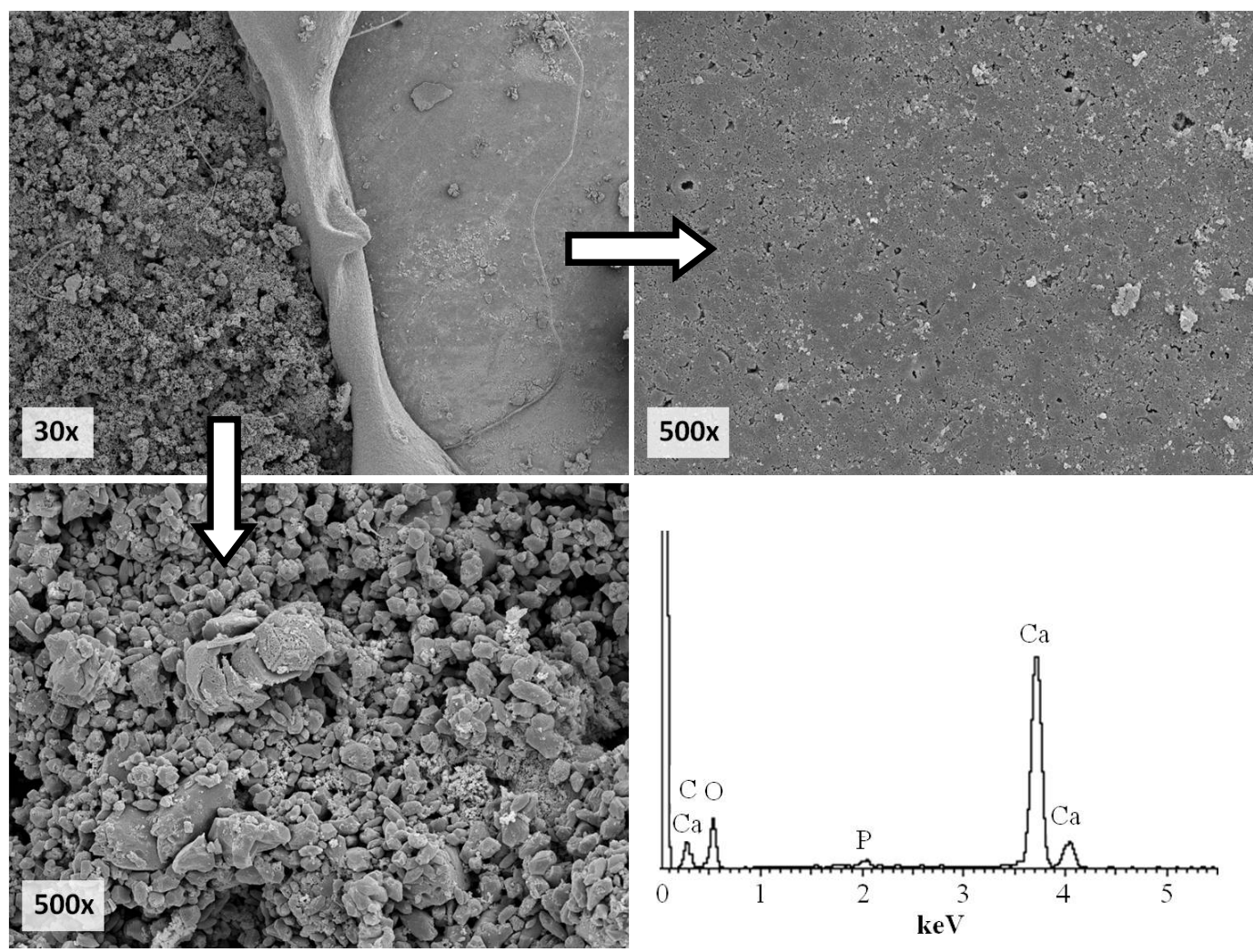

Figura 6.16. De arriba hacia abajo y de izquierda a derecha. Observación SEM a 30, y 500 aumentos de cristales de pequeño y gran tamaño y espectro de elementos obtenidos mediante un MRX de la superficie del precipitado procedente del conducto de vertido de la columna $B$.

Tabla 6.7. Composición centesimal de $\mathbf{P}$ y distintos elementos metálicos del precipitado del conducto de salida de la Columna $B$.

\begin{tabular}{lccccc}
\hline Elemento & $\mathrm{Al}$ & $\mathrm{Fe}$ & $\mathrm{Ca}$ & $\mathrm{Mg}$ & $\mathrm{P}$ \\
\hline$\%$ masa & 0,08 & 0,04 & 40,59 & 0,45 & 1,28 \\
\hline
\end{tabular}

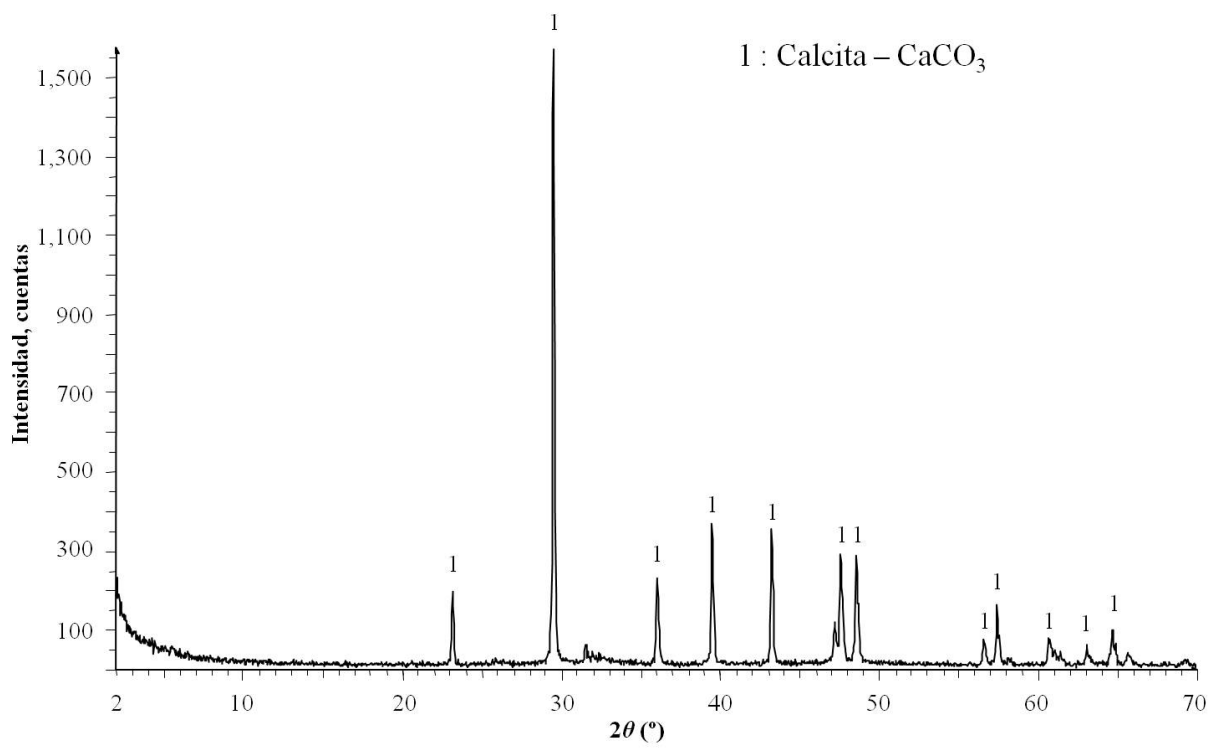

Figura 6.17. Difractograma del análisis DRX para la muestra de precipitado procedente del conducto de vertido de la columna $B$. 
El análisis de DRX indica que el precipitado está compuesto exclusivamente por calcita $\left(\mathrm{CaCO}_{3}\right.$ ) (Figura 6.17). Los cristales de $\mathrm{CaCO}_{3}$ pueden proporcionar lugares de sorción para la eliminación de P (Freeman y Rowell, 1981) lo que explicaría la presencia de este elemento en cantidades traza en el espectro del MRX.

\subsubsection{Liberación de iones $\mathrm{Ca}^{2+}$ en la columna Control}

La concentración de salida de $\mathrm{Ca}^{2+}$ se ha monitorizado durante los 13 primeros días del experimento en la columna Control (Figura 6.18). Las concentraciones en la salida de la columna han disminuido rápidamente desde $548,9 \mathrm{mg} \mathrm{L}^{-1}$ el día 1 hasta $84,7 \mathrm{mg} \mathrm{L}^{-1}$ el día 13 , aunque siempre han sido superiores a las concentraciones de entrada (en torno a los $27,7 \pm 0,79 \mathrm{mg} \mathrm{L}^{-1}$ ). La estimación de las concentraciones de $\mathrm{Ca}^{2+}$ a partir de los iones hidroxilo se ha ajustado bien a los datos experimentales $\left(R^{2}=0,97\right)$, por lo que no se ha continuado con el análisis directo de la concentración de $\mathrm{Ca}^{2+}$ a partir del día 13 .

La concentración de salida de $\mathrm{Ca}^{2+}$ se ajusta bien al proceso de disociación de la portlandita y disminuye de forma asintótica hasta igualar la concentración de entrada. Los resultados de $\mathrm{pH}$ y conductividad también guardan una fuerte relación positiva con los datos de $\mathrm{Ca}^{2+}$ muestreados $\left(R^{2}=0,86\right.$ y $R^{2}=0,98$ respectivamente) lo que permite relacionar el comportamiento de los resultados de $\mathrm{pH}$ y conductividad con la especies iónicas $\mathrm{OH}^{-}$y $\mathrm{Ca}^{2+}$ procedentes de la disociación de la portlandita.
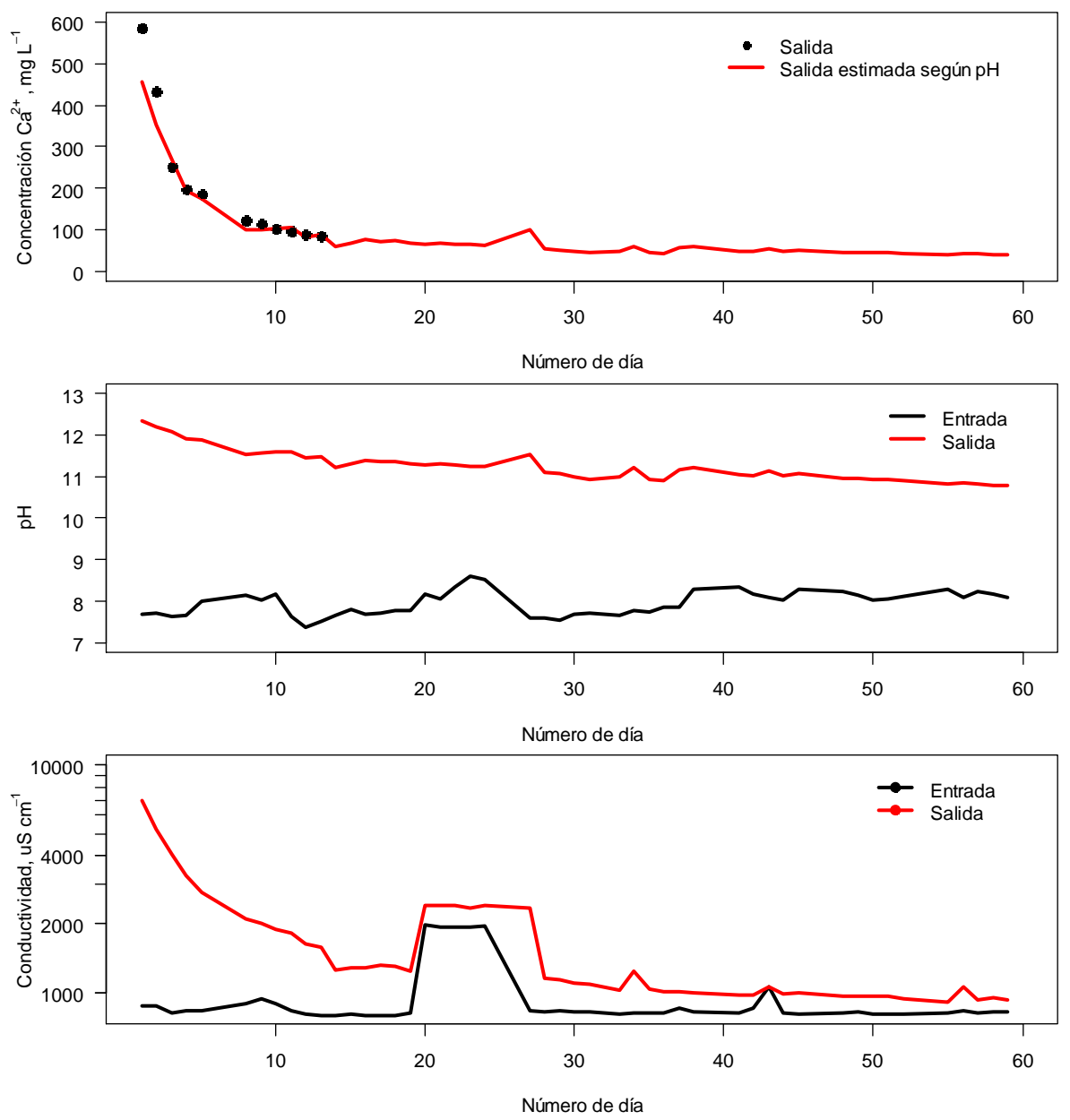

Figura 6.18. Concentración de $\mathrm{Ca}^{2+}$ y valores de $\mathrm{pH}$ y conductividad en la entrada y salida de la columna Control. 


\subsubsection{Resultados de la columna B}

\subsection{Retención de fósforo}

Los resultados de la retención de $\mathrm{P}$ en la columna $\mathrm{B}$ durante el experimento se muestran en la Figura 6.19. Las concentraciones de $\mathrm{P}$ comienzan a aumentar en cada punto de muestreo al saturarse la capacidad de retención de P del volumen de escoria de la sección inmediatamente anterior. Esto se puede apreciar el día 9 y, de forma particularmente clara el día 29, cuando se colmata la sección de columna Entrada $-5 \mathrm{~cm}$ y comienza a observarse la salida de $\mathrm{P}$ en el punto $10 \mathrm{~cm}$.

La presencia de $\mathrm{P}$ en el punto $15 \mathrm{~cm}$ comienza mucho antes de que se alcanze la saturación de la sección anterior (día 45), lo que indica la posible presencia de caminos preferenciales en la sección 5-15 cm. La saturación de la sección Entrada - $15 \mathrm{~cm}$ se alcanza el día 104 coincidiendo con el cambio de comportamiento hidráulico, lo que sugiere que es en esta sección donde han precipitado los fosfatos de calcio y los cristales de $\mathrm{CaCO}_{3}$ que han estado a punto de provocar la colmatación de la columna. A partir de ese momento las concentraciones de los puntos 10 y $15 \mathrm{~cm}$ son muy similares a las de la concentración de entrada. Las concentraciones de $\mathrm{P}$ en la salida de la columna permanecen próximas a 0 durante todo el experimento lo que ha permitido alcanzar un índice de eliminación promedio de 98,3\% para todo el periodo de experimentación.

La capacidad de retención de la sección $15 \mathrm{~cm}$ - Salida es significativamente elevada en comparación con el resto de las secciones. Esto puede deberse a que las partículas de menor tamaño han sedimentado, almacenándose en la base de la columna, lo cual habría reducido la porosidad y aumentado la superficie específica de la escoria presente en esta sección. Otro factor que ha podido contribuir al proceso de retención de $\mathrm{P}$ es la acumulación de fosfatos de calcio y/o cristales de $\mathrm{CaCO}_{3}$ procedentes de secciones anteriores de la columna que han sido observados en el conducto de salida. La precipitación de los fosfatos de calcio sigue la regla de Ostwall: primero precipitan los compuestos menos estables que finalmente recristalizan en la forma de hidroxiapatita (HAP), compuesto más estable termodinámicamente (Valsami-Jones, 2001). Los cristales de HAP recristalizados pueden utilizarse como núcleos para cristalizaciones de HAP adicionales (Kim y col., 2006) mejorando la capacidad de retención de P.

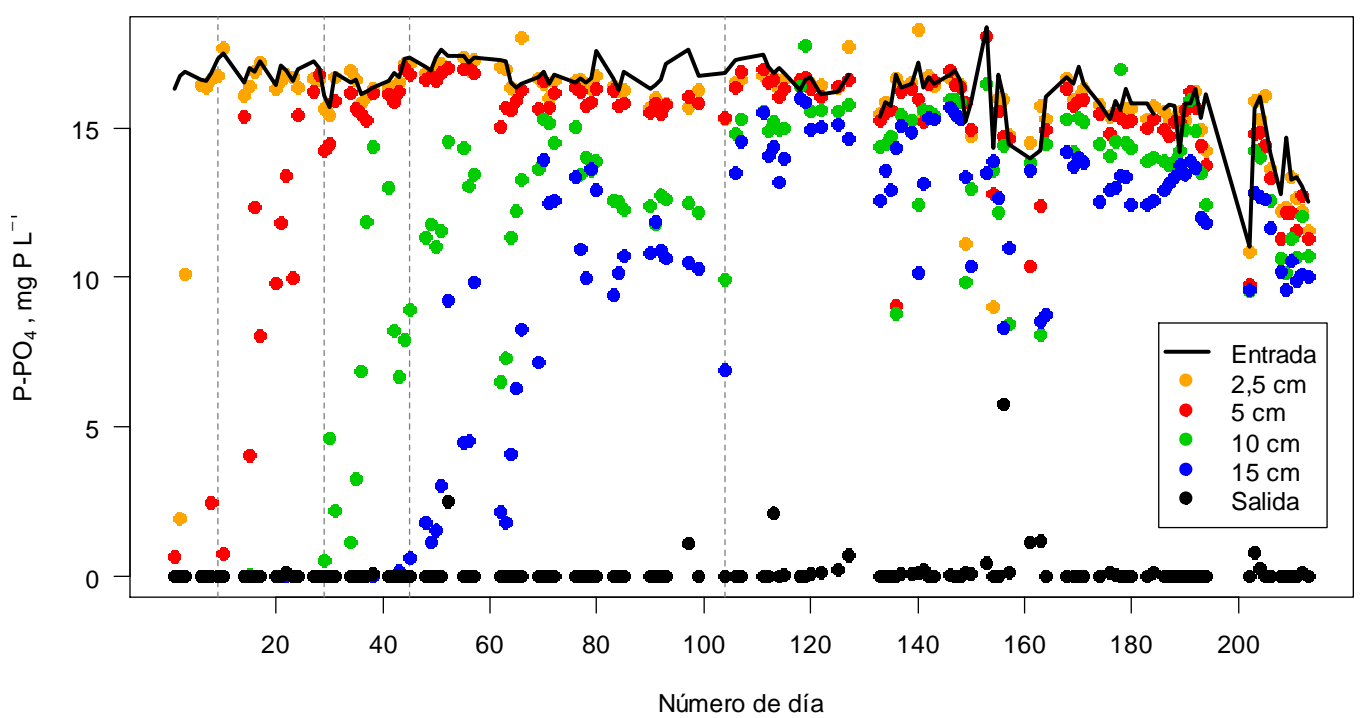

Figura 6.19. Concentraciones de ortofosfatos de entrada, puntos de muestreo y salida de la columna B. Las líneas verticales corresponden a los días 9, 29, 45 y 104. 
La capacidad de retención de $\mathrm{P}$ de la columna B para todo el experimento ha sido de $3,1 \mathrm{mg} \mathrm{g}^{-1}$ de escoria, superior a los valores encontrados para distintos tipos de escorias de acería aunque inferiores a los valores obtenidos por Claveau-Mallet y col. (2012) y también por Bowden y col. (2009) quienes también utilizan escorias de acería LD de similar rango de tamaños de partícula (Tabla 6.8). Las diferencias con los resultados proporcionados por Barca (2013) pueden deberse a los diferentes tamaños de partícula utilizados en el experimento, mientras que las diferencias con otros tipos de escorias de acería pueden estar relacionadas con el mayor contenido en Ca de las escorias de acería LD.

Tabla 6.8. Características y fósforo acumulado en la columna B y otros experimentos en columna con escorias de acería presentes en la bibliografía. Adaptado de Barca (2013).

\begin{tabular}{lcccl}
\hline Tipo Escoria & $\begin{array}{c}\text { Tamaño, } \\
\mathrm{mm}\end{array}$ & $\mathrm{Ca}, \%$ & $\begin{array}{c}\mathrm{P} \mathrm{acumulado}^{-1} \\
\mathrm{mg} \mathrm{g}^{-1} \text { escoria }\end{array}$ & \multicolumn{1}{c}{ Referencia } \\
\hline LD & $<10$ & 33,92 & 3,1 & Presente estudio, Columna B \\
LD & $<20$ & $42-44(\mathrm{CaO})$ & 8,4 & Bowden y col. (2009) \\
LD & $6-12$ & $44,1(\mathrm{CaO})$ & 1,9 & Barca (2013) \\
LD & $20-50$ & $44,1(\mathrm{CaO})$ & 1,3 & Barca $(2013)$ \\
EHA & $0-4$ & 21,6 & $1,0-3,1$ & Gustafsson y col. (2008) \\
EHAE & $2,5-10$ & 21,7 & 1,4 & Drizo y col. (2002) \\
EHAE & $2,5-10$ & $30,4(\mathrm{CaO})$ & 2,2 & Drizo y col. (2006) \\
EHAE & $2-5$ & $27,7(\mathrm{CaO})$ & 0,3 & Chazarenc y col. (2007) \\
EHAE & $5-10$ & $30(\mathrm{CaO})$ & 6 & Claveau-Mallet y col. $(2012)$ \\
\hline
\end{tabular}

Dentro de la columna, las distintas secciones han mostrado capacidades de retención de $\mathrm{P}$ variables dentro del rango $1,14-6,5 \mathrm{mg} \mathrm{g}^{-1}$ (Tabla 6.9). La capacidad de retención mínima se ha obtenido en la sección Entrada $-2,5 \mathrm{~cm}$ que ha mostrado una rápida saturación. Las secciones $2,5-5 \mathrm{~cm}, 5-10 \mathrm{~cm}$ y $10-15 \mathrm{~cm}$ han mostrado resultados en el rango $1-3 \mathrm{mg} \mathrm{g}^{-1}$ mucho más similares a los presentes en la Tabla 6.8, mientras que la sección $15 \mathrm{~cm}$ - Salida ha mostrado la capacidad de retención máxima de $6,5 \mathrm{mg} \mathrm{g}^{-1}$. Los resultados de las secciones superiores se asemejan a los obtenidos por columnas de mayor granulometría, mientras que los de la última sección, en la que han sedimentado las partículas de menor tamaño, son más similares a los resultados presentes en los estudios de escorias de acería LD que utilizan columnas de menor granulometría (Bowden y col., 2009).

Tabla 6.9. Fósforo acumulado en función de la masa de material en las diferentes secciones de la columna B.

\begin{tabular}{lccccc}
\hline Sección & Entrada $-2,5 \mathrm{~cm}$ & $2,5-5 \mathrm{~cm}$ & $5-10 \mathrm{~cm}$ & $10-15 \mathrm{~cm}$ & $15 \mathrm{~cm}-$ Salida \\
\hline $\begin{array}{l}\mathrm{P} \text { acumulado, } \\
\mathrm{mg} \mathrm{g}^{-1}\end{array}$ & 1,14 & 2,68 & 2,51 & 1,71 & 6,50 \\
\hline
\end{tabular}

\subsection{Variación de $\mathrm{pH}$ y conductividad eléctrica}

Los valores de salida de $\mathrm{pH}$ y conductividad eléctrica al comienzo del experimento han sido muy superiores a los de la disolución de entrada (Figura 6.20). Estos resultados son consecuencia de la liberación de los iones $\mathrm{Ca}^{2+}$ y $\mathrm{OH}^{-}$debido a la disociación de la portlandita $\left(\mathrm{Ca}(\mathrm{OH})_{2}\right)$ en la disolución. En los estudios en los que se introducen escorias de acería LD en disolución los iones $\mathrm{OH}^{-}$liberados incrementan el $\mathrm{pH}$ de la disolución hasta valores de 13 unidades (Mayes y col., 2008) y la concentración de $\mathrm{Ca}^{2+}$ liberado está fuertemente relacionada con la conductividad (Barca, 2013).

A medida que avanza el ensayo se produce una reducción progresiva de $\mathrm{pH}$ y conductividad eléctrica acompañada de un incremento de los ortofosfatos para todos los puntos de muestreo. Una elevada concentración de $\mathrm{Ca}^{2+}$ en las condiciones iniciales habría permitido la precipitación de fosfatos de calcio. A medida que la portlandita se disocia se va perdiendo paulatinamente la 
capacidad de liberar iones $\mathrm{Ca}^{2+}$ hasta el punto en que la concentración de $\mathrm{Ca}^{2+}$ no es suficiente para precipitar todos los ortofosfatos en la disolución.

La concentración de $\mathrm{P}$ en los puntos de muestreo 5,10 y $15 \mathrm{~cm}$ aumenta los días 9,29 y 45 (Figura 6.19), justo cuando el $\mathrm{pH}$ disminuye hasta $10 \mathrm{y}$ la conductividad se asemeja a la de la entrada (Figura 6.20). Este proceso continúa hasta que no se disocia más portlandita, momento en el que los valores de pH y de concentración de P son iguales a los de la entrada. En el día 104 se puede además apreciar el efecto del cambio hidráulico en los valores de $\mathrm{pH}$ y conductividad eléctrica.
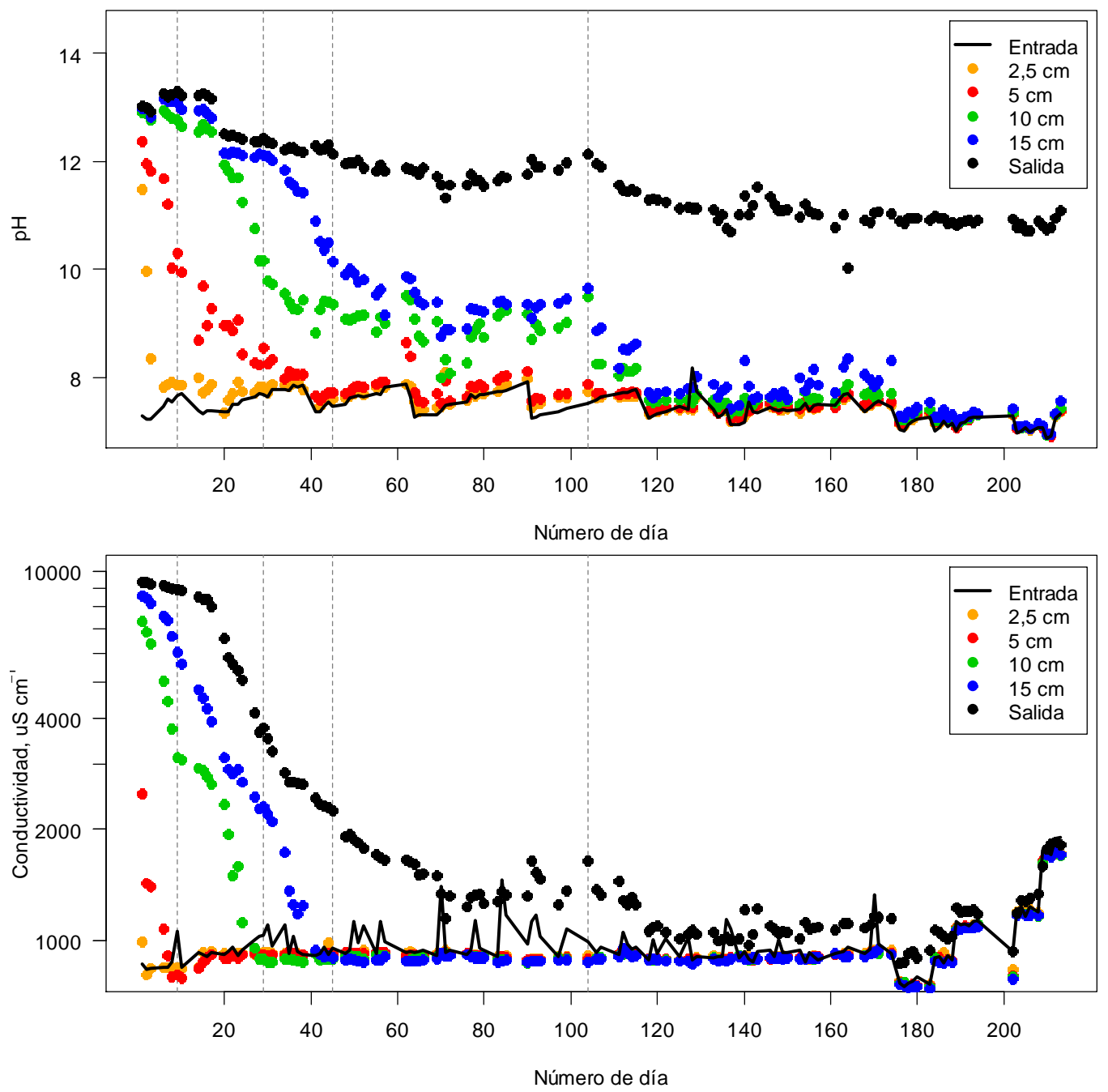

Figura 6.20. Concentraciones de ortofosfatos de entrada, puntos de muestreo y salida de la columna B. Las líneas verticales corresponden a los días 9, 29, 45 y 104.

\subsubsection{Formación de precipitados}

La relación molar $\mathrm{Ca} / \mathrm{P}$ para cada sección de la columna $\mathrm{B}$ en función del tiempo se muestra en la Figura 6.21. Los moles de $\mathrm{Ca}^{2+}$ se han calculado a partir de los valores de $\mathrm{pH}$ de salida de cada puno de muestreo y la reacción de disociación de la portlandita, mientras que los moles de $\mathrm{P}$ son los correspondientes al $\mathrm{P}$ añadido en cada sección de columna, es decir, las correspondientes al fósforo de salida de la sección inmediatamente anterior. Para calcular esta 
relación no se ha tenido en cuenta el contenido en $\mathrm{Ca}^{2+}$ del agua utilizada para preparar la disolución sintética, que ha presentado un valor promedio de $64,9 \pm 14,8 \mathrm{mg} \mathrm{Ca} \mathrm{L}^{-1}(n=13)$.

Inicialmente la relación molar $\mathrm{Ca} / \mathrm{P}$ en disolución ha alcanzado valores elevados cercanos a 500, que han disminuido rápidamente hasta valores de 0,1 en el caso de las tres primeras secciones. El momento en el que la relación $\mathrm{Ca} / \mathrm{P}$ presente en la disolución para estas secciones se aproxima a 0,1 coincide con los días 9, 29 y 45, momentos en los que la disolución alcanza valores de $\mathrm{pH}$ cercanos a 10 y comienza a incrementarse la concentración de ortofosfatos en los puntos de muestreo de las secciones: Entrada $-5 \mathrm{~cm}, 5-10 \mathrm{~cm}$ y $10-15 \mathrm{~cm}$. La reducción de la relación $\mathrm{Ca} / \mathrm{P}$ en la sección $15 \mathrm{~cm}$ - Salida ha sido mucho más gradual y se ha estabilizado en torno a los valores $1-1,67$ hacia el final del experimento (días 120 -213) periodo en el que el valor de $\mathrm{pH}$ se ha encontrado en el rango 10,7 - 11,3.

La relación $\mathrm{Ca} / \mathrm{P}$ indica que la eliminación de ortofosfatos se ha basado principalmente en la precipitación de fosfatos de calcio (Bowden y col., 2009). A partir del momento en el que se ha disociado la mayor parte de la portlandita, los iones de $\mathrm{Ca}^{2+}$ limitan el proceso de precipitación, lo que explica el incremento de $\mathrm{P}$ en los puntos de muestreo. Sin descartar la formación de otras fases (Tabla 6.1), los principales precipitados formados en el sistema son los fosfatos tricálcico, octocálcico e hidroxiapatita (HAP) debido fundamentalmente a que los valores de $\mathrm{pH}$, y las concentraciones de $\mathrm{Ca}^{2+}$ y ortofosfatos de la disolución se encuentran en los rangos de valores que permiten la formación de estos compuestos (Stumm y Morgan, 1996). Los fosfatos tricálcico y octocálcico juegan un papel importante como precursores que eventualmente cristalizan en forma de HAP (Valsami-Jones, 2001), por lo que este último es el compuesto de mayor interés en el sistema.

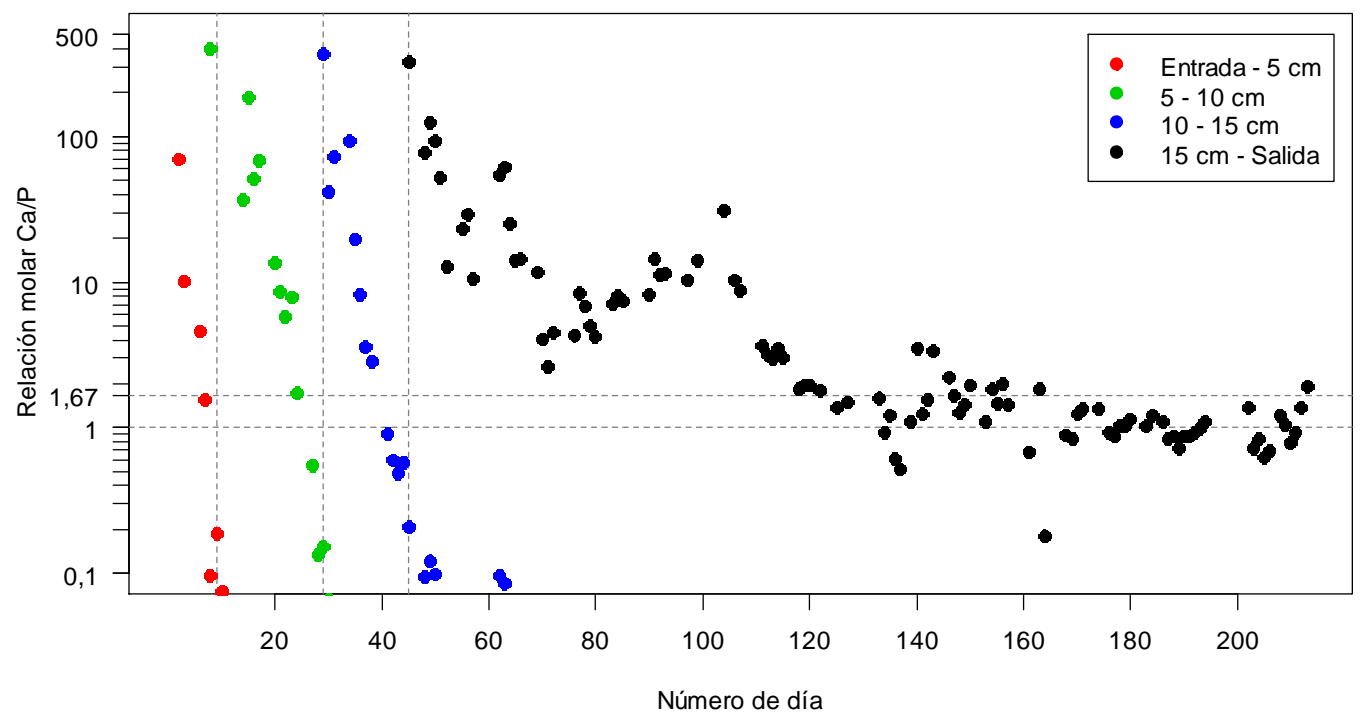

Figura 6.21. Relación molar $\mathrm{Ca} / \mathrm{P}$ para diferentes secciones de la columna durante el experimento.

La formación del precipitado de HAP requiere una relación molar $\mathrm{Ca} / \mathrm{P}$ teórica de 1,67 y el consumo de aniones $\mathrm{OH}^{-}$, lo que puede haber contribuido de forma adicional al descenso del $\mathrm{pH}$ en la disolución de acuerdo con la Ecuacion 6.15.

$$
10 \mathrm{Ca}^{2+}+6 \mathrm{PO}_{4}^{3-}+2 \mathrm{OH}^{-} \rightarrow \mathrm{Ca}_{10}\left(\mathrm{PO}_{4}\right)_{6}(\mathrm{OH})_{2} \downarrow
$$

Aquellos periodos en los que la relación $\mathrm{Ca} / \mathrm{P}$ ha sido igual o superior a 1,67 se ha podido producir la coprecipitación de $\mathrm{HAP}$ y $\mathrm{CaCO}_{3}$. La presencia de carbonatos en la disolución como resultado de la difusión del $\mathrm{CO}_{2}$ atmosférico puede afectar la precipitación de HAP, bloqueando 
los lugares de nucleación de fosfatos o induciendo la precipitación de $\mathrm{CaCO}_{3}$ (House, 1999). Kapolos y Koutsoukos (1999) muestran cómo el efecto de los carbonatos puede variar dependiendo de la sobresaturación de la disolución y la concentración de carbonatos; una sobresaturación relativamente alta puede acelerar la formación de HAP, mientras que en condiciones de baja sobresaturación los carbonatos inhiben el crecimiento de los cristales de HAP. La coprecipitación de P con calcita es un proceso que ha sido observado en diferentes estudios (Kim y col., 2006; Liira y col., 2009).

En los casos en los que la relación $\mathrm{Ca} / \mathrm{P}$ ha sido inferior a 1,67, las concentraciones de $\mathrm{Ca}^{2+}$ han limitado la precipitación de HAP y la eliminación de $\mathrm{P}$ ha podido producirse por la precipitación de otros fosfatos de calcio o por la adsorción específica de ortofosfatos sobre la superficie de la escoria (Barca y col., 2012). La formación de precipitados se puede apreciar en la superficie de la parte superior de la columna B después del experimento (Figura 6.22).

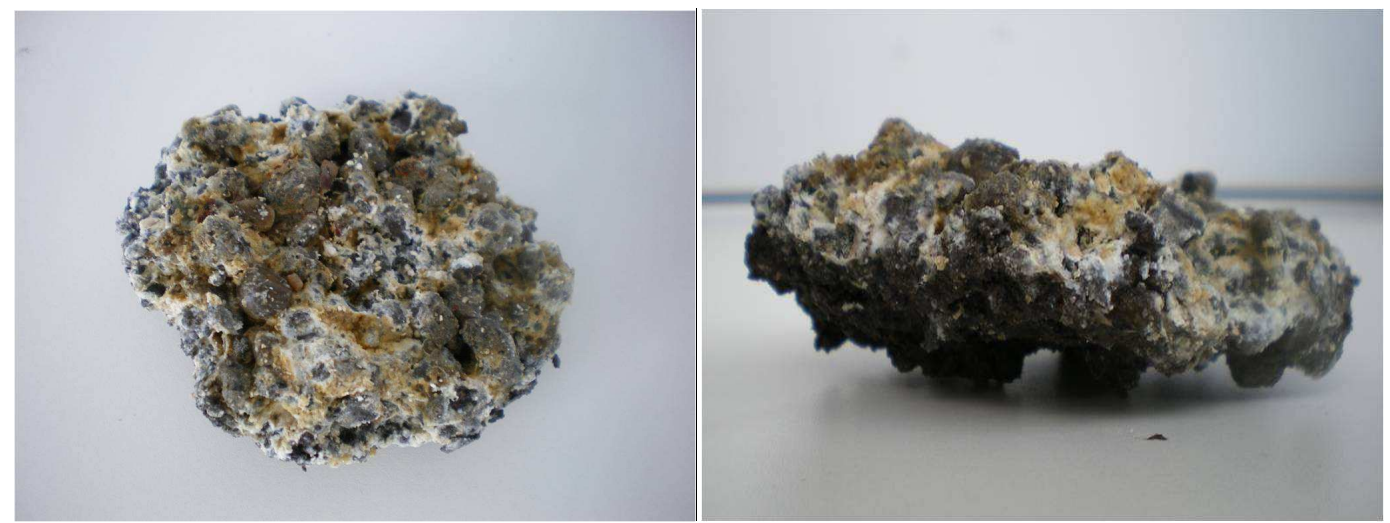

Figura 6.22. Fotografía cenital (izquierda) y lateral (derecha) de la parte superior de la columna B después del experimento.

El estudio de la morfología de la superficie de las escorias de acería LD de la parte superior de la columna B después del experimento revela la presencia de dos tipos de precipitados que incluyen cristales regulares y agregados esferoidales (Figura 6.23). El cristal que se aprecia en la imagen (particularmente nítido a 1.500 aumentos) puede tratarse de calcita, mientras que según el espectro los agregados esferoidales están compuestos principalmente por $\mathrm{Ca}, \mathrm{P}$ y $\mathrm{O}$, por lo que se trataría de fosfatos de calcio. En el espectro no se observa $\mathrm{Al}, \mathrm{Fe}$ o $\mathrm{Mn}$ lo que se puede deber a que los fosfatos de calcio forman una capa sobre la superficie de la escoria que impide distinguir estos elementos.

La superficie de las escorias de la sección Entrada $-5 \mathrm{~cm}$ también ha sido estudiada (Figura 6.24). En las imágenes se puede apreciar los dos tipos de estructuras a 500 aumentos aunque los cristales se identifican más fácilmente a 1.500 aumentos, lo que confirma la precipitación de $\mathrm{CaCO}_{3}$ y su posterior cristalización como calcita sobre la superficie de la escoria de acuerdo con los principales elementos identificados en el espectro ( $\mathrm{Ca}, \mathrm{O}$ y $\mathrm{C}$ fundamentalmente). Se observan cantidades traza de $\mathrm{P}$ lo que indica la presencia residual de fosfatos de calcio o $\mathrm{P}$ coprecipitado con los cristales de $\mathrm{CaCO}_{3}$ en la superficie estudiada.

Los resultados de los análisis SEM y MRX de la superficie de las escorias antes y después de los experimentos son similares a los encontrados por otros estudios (Bowden y col., 2009; Barca, 2013) en los que se ha mostrado la formación de una capa de fosfatos de calcio, HAP y cristales de $\mathrm{CaCO}_{3}$ cubriendo la superficie de escorias de acería LD después de un año de experimentos en columnas. 


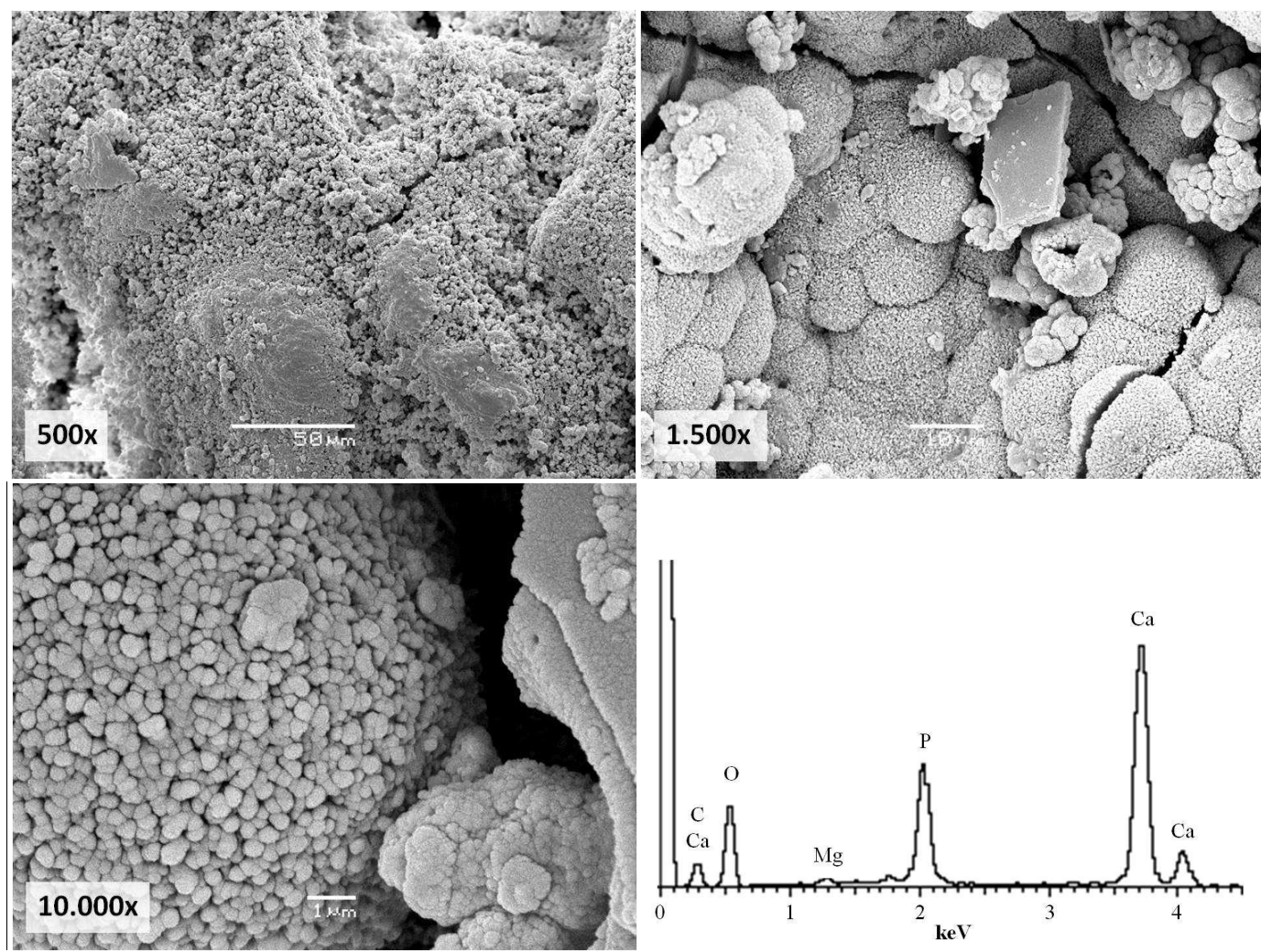

Figura 6.23. De arriba hacia abajo y de izquierda a derecha. Observación SEM a 500, 1.500 y 10.000 aumentos de la superficie de la escoria de la columna $B$ después de los experimentos y espectro de elementos obtenidos mediante un MRX del aglomerado esferoidal.
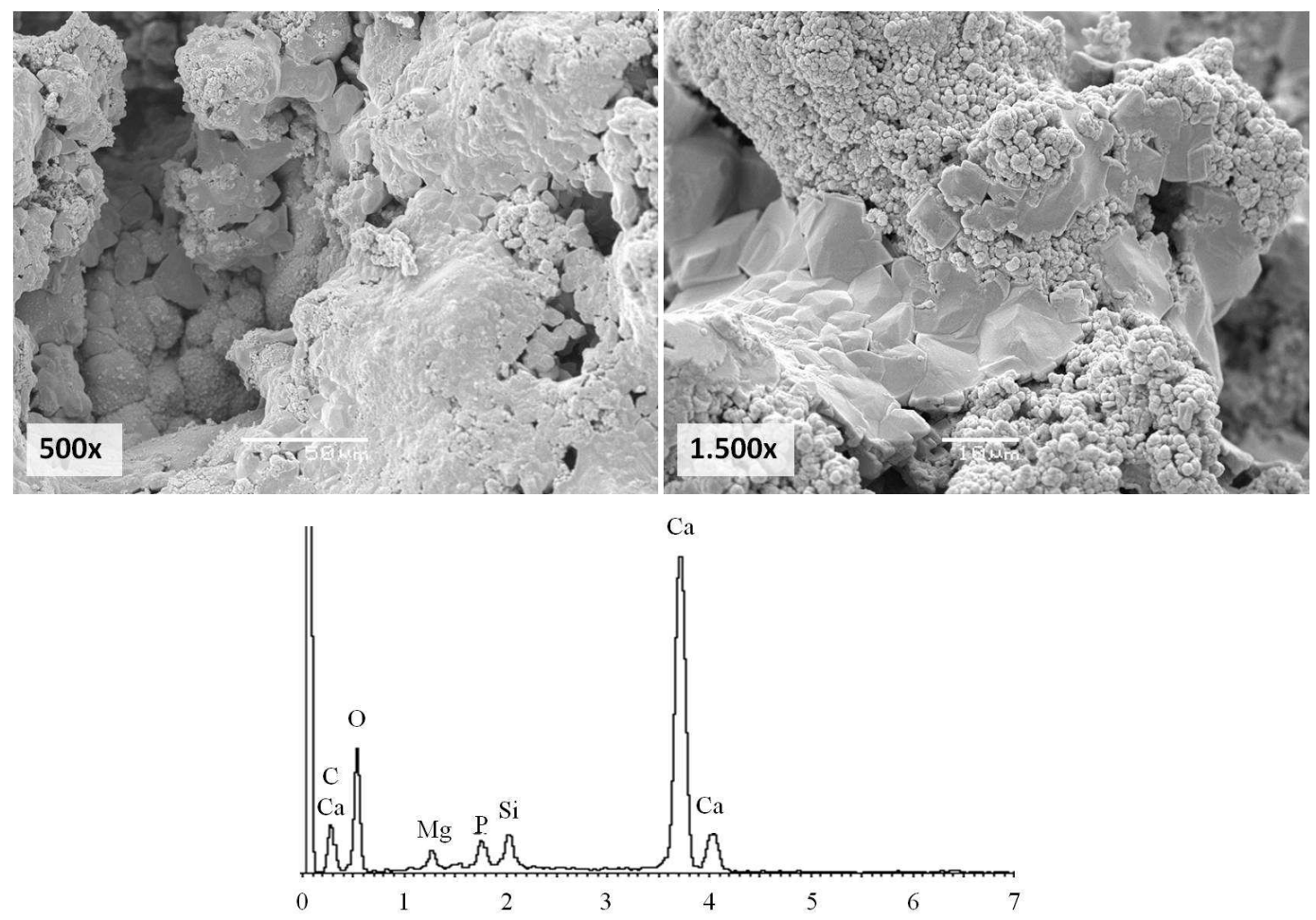

Figura 6.24. De izquierda a derecha y de arriba hacia abajo. Observación SEM a 500 y 1.500 aumentos de la superficie de la escoria de la sección Entrada $\mathbf{- 5} \mathbf{~ c m}$ de la columna B después de los experimentos y espectro de elementos obtenidos mediante análisis MRX de los cristales. 


\subsubsection{Volumen de un filtro de escorias de acería $L D$}

El estudio de la capacidad de retención de $\mathrm{P}$ y el potencial de saturación de un material permite determinar la longevidad de un sustrato que es un parámetro clave en el dimensionado y coste económico de los humedales artificiales. Los experimentos en batch utilizan los modelos de adsorción de Langmuir y Freundlich para caracterizar la capacidad de retención de P de un material en función de su estructura, textura, composición química y pH (Sakadevan y Bavor, 1998); pero son demasiado sencillos para tener en cuenta otros factores que pueden influir en los procesos de eliminación de fósforo en condiciones ambientales: hidráulica, materia orgánica, salinidad, fuerza iónica, potencial redox, competencia entre iones, temperatura y actividad microbiológica entre otros (Cucarella y Renman, 2009).

Los experimentos en columna son más efectivos que los experimentos en batch para estimar la longevidad de un sustrato. Estos experimentos también permiten estudiar la capacidad de retención de $\mathrm{P}$ de los materiales en condiciones de laboratorio pero son más similares a los sistemas de filtración utilizados a escala real y permiten el estudio de los materiales durante un mayor periodo de tiempo (Drizo y col., 2002; Cucarella y Renman, 2009).

Sin embargo los resultados deben ser tratados con precaución. A diferencia del agua sintética utilizada en los experimentos en condiciones de laboratorio, el contenido en fósforo del agua residual no está limitado exclusivamente a ortofosfatos, por lo que la capacidad de retención de $\mathrm{P}$ del filtro puede ser diferente a la esperada. Otros componentes del agua residual pueden competir con el $\mathrm{P}$ por el calcio y la capacidad de retención de $\mathrm{P}$ puede verse afectada por la colmatación del filtro debido a la retención de sólidos en suspensión o al crecimiento del biofilm que es favorecido por la presencia de materia orgánica y nutrientes en el agua residual (Drizo y col., 2002). Los sistemas a escala real están expuestos a condiciones ambientales que pueden modificar el tiempo de retención hidraúlico del humedal artificial y someterlo a oscilaciones térmicas que afectan de forma importante la eliminación de P.

El volumen de un filtro de escorias de acería LD se ha estimado de acuerdo a los resultados experimentales obtenidos en la columna B. Para ello se han utilizado los valores de P acumulado por volumen de las distintas secciones hasta el momento en el que se observa la liberación de $\mathrm{P}$ en los puntos de muestreo de la columna o hasta el último día de experimentación en el caso de la columna al completo (Tabla 6.10). No se ha tenido en cuenta la porosidad de la escoria para el cálculo del volumen de cada sección.

Tabla 6.10. Fósforo acumulado por volumen de sección desde la entrada hasta el punto de muestreo hasta el momento de liberación de $P$.

\begin{tabular}{lcccc}
\hline Sección & Entrada $-5 \mathrm{~cm}$ & Entrada $-10 \mathrm{~cm}$ & Entrada $-15 \mathrm{~cm}$ & Entrada $-20 \mathrm{~cm}$ \\
\hline $\begin{array}{l}\mathrm{P} \text { acumulado, } \\
\mathrm{mg} \mathrm{cm}^{-3}\end{array}$ & 2,59 & 3,07 & 2,82 & 4,46 \\
\hline
\end{tabular}

Se ha asumido una eliminación completa del fósforo de entrada, una concentración de fósforo de entrada de $15 \mathrm{mg} \mathrm{L}^{-1}$ y un caudal de $150 \mathrm{~L}_{\text {día }}{ }^{-1}$ por habitante equivalente. Estos valores equivalen a un total de $0,82 \mathrm{~kg}$ de fósforo por habitante equivalente y año.

Teniendo en cuenta el rango de valores de la Tabla 6.10; eliminar 0,82 $\mathrm{kg}$ de fósforo por habitante equivalente y año requeriría un volumen de escoria de acería LD entre 0,18 y $0,32 \mathrm{~m}^{3}$.

Es necesario remarcar que la disociación de la portlandita y liberación $\mathrm{de} \mathrm{Ca}_{2}{ }^{+}$dependerá del caudal de entrada. Caudales elevados producirán una rápida disociación reduciendo la capacidad de retención de P por parte del filtro de escorias de acería LD. Debido a la limitada longevidad de las escorias, su utilización en humedales artificiales requerirá la sustitución periódica del material. Para optimizar el uso de los iones $\mathrm{Ca}_{2}{ }^{+}$disociados, este tipo de material debería ser 
utilizado para el tratamiento de aguas residuales con una elevada concentración de fósforo, ya que en el caso de bajas concentraciones se desperdiciaría el potencial de retención de fósforo.

Un experimento a escala piloto permitiría obtener unos datos más aproximados al comportamiento real de estos sistemas frente a condiciones reales, sin embargo este tipo de estudios son escasos. Shilton y col. (2006) registraron un índice promedio de eliminación de PT del $77 \%$ durante 5 años en filtros a escala real de escoria de fundición hasta alcanzar la saturación con 1,23 $\mathrm{g} \mathrm{kg}^{-1}$, mientras que Barca (2013) alcanzó un índice de eliminación de PT del $62 \%$ durante 2 años en filtros a escala piloto de escoria de acería LD hasta alcanzar la saturación con $0,61 \mathrm{~g} \mathrm{~kg}^{-1}$. Nuevos ensayos a escala piloto y real serían muy valiosos para ayudar a comprender el comportamiento de estos sistemas en condiciones ambientales. 


\subsection{CONCLUSIONES}

Las escorias de acería LD de la planta LD-II han mostrado una capacidad de retención de fósforo superior a la de otro tipo de escorias de acería. Las diferencias de los resultados de este experimento con los obtenidos en otros estudios sobre escorias de acería LD pueden atribuirse a la utilización de escorias de diferente granulometría y contenido en Ca.

La eliminación de fósforo ha sido completa para concentraciones inferiores a los $300 \mathrm{mg} \mathrm{L}^{-1}$ en los experimentos en batch y no se ha podido apreciar un incremento en las concentraciones de fósforo en la salida de la columna de experimentación durante el periodo de estudio. El estudio de la cinética en los experimentos en batch indica que la eliminación de $\mathrm{P}$ se produce rápidamente y se aconseja utilizar periodos de tiempo cortos o concentraciones iniciales más elevadas para este tipo de experimentos.

En el interior de la columna los resultados son variables, siendo la retención de fósforo de la última sección hasta cuatro veces superior a la de las demás secciones debido a que las partículas de menor tamaño han sedimentado en el fondo de la columna y aumentado la superficie especifica de esta sección. La hidráulica del sistema indica que son preferibles las partículas de mayor tamaño para evitar problemas de colmatación en el filtro.

La elevada retención de fósforo se debe al contenido en calcio de la escoria que se encuentra principalmente en forma de portlandita. La disociación de la portlandita incrementa el contenido de calcio en la disolución e incrementa el $\mathrm{pH}$ y la conductividad eléctrica de la misma. La relación molar $\mathrm{Ca} / \mathrm{P}$ y el $\mathrm{pH}$ favorecen la formación de fosfatos de calcio tricálcico, octocálcico e hidroxiapatita. Tambien se produce la coprecipitación de $\mathrm{CaCO}_{3}$ que compite por los iones $\mathrm{Ca}^{2+}$ cuando el contenido de estos se reduce en la disolución.

La capacidad de retención de fósforo se reduce cuando la disociación de la portlandita alcanza un límite. En ese momento el pH alcanza el valor de 10 y la conductividad eléctrica se asemeja a los valores de entrada, por lo que estos parámetros son unos indicadores que pueden ser utilizados para determinar la longevidad de este tipo de sistemas.

El volumen de escoria requerido para el tratamiento del fósforo generado por un habitante equivalente es inferior a un metro cúbico por año. Se recomienda el estudio de la capacidad de eliminación de fósforo de las escorias de acería LD en un sistema a escala piloto alimentado por agua residual en condiciones ambientales naturales. 




\section{DISCUSIÓN GENERAL - RECOMENDACIONES DE DISEÑO PARA EL TRATAMIENTO DE PURINES DE CERDO CON HUMEDALES ARTIFICIALES}

Los resultados analizados en el Capítulo 3 muestran un sistema de tratamiento capaz de eliminar sólidos y materia orgánica eficientemente, con unos índices de eliminación promedio de 83, 82 y $64 \%$ para los contaminantes $\mathrm{SST}_{1} \mathrm{DBO}_{5}$ y DQO respectivamente. La capacidad de tratamiento de nitrógeno y fósforo en el sistema ha sido limitada, aunque similar a la publicada por otros estudios que utilizan sistemas de humedales artificiales para el tratamiento de agua residual ganadera, con unos índices de eliminación promedio para todo el periodo de experimentación de 44 y $45 \%$ para los contaminantes NT y PT respectivamente. La elevada concentración de estos contaminantes en el agua residual de origen porcino junto con su limitada capacidad de tratamiento hace que estos contaminantes sean prioritarios en el dimensionado de un sistema de estas características a escala real.

Los parámetros de calibración obtenidos tras la corrección de los datos en el Capítulo 4 permiten estimar la superficie de sistemas de flujo combinado tipo MJEA ${ }^{\circledR}$ que no están controlados por los efectos de la evapotranspiración sobre el tiempo de retención hidráulico. Además de ignorar los efectos de las componentes hidrológicas, la corrección de los datos permite aproximar las condiciones hidraúlicas del sistema a las de flujo pistón que son las condiciones ideales de un humedal artificial para la aplicación del modelo $k-C^{*}$.

En el caso de realizar el dimensionado de un sistema de flujo combinado tipo MJEA ${ }^{\circledR}$ en las condiciones climáticas de la zona de estudio, sería necesario corregir el caudal de entrada al sistema para mantener el tiempo de retención hidráulico durante los periodos de máxima evapotranspiración. La Figura 7.1 muestra el porcentaje mensual del caudal de entrada que necesitaría ser modificado para corregir los efectos de la evapotranspiración en el sistema de acuerdo a los datos meteorológicos del periodo de estudio. El porcentaje ha sido calculado como la relación promedio mensual entre la pérdida de agua y el caudal de entrada. 


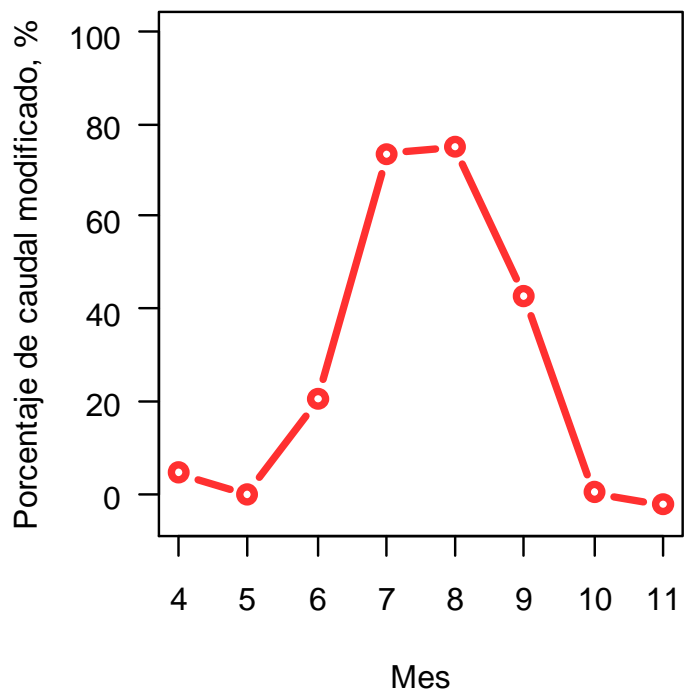

Figura 7.1. Porcentaje de caudal de entrada afectado por la influencia de evapotranspiración y precipitación.

\subsection{RECOMENDACIONES DE DISEÑO PARA EL TRATAMIENTO DE NITRÓGENO}

La Figura 7.2 muestra la superficie requerida por un sistema de flujo combinado tipo MJEA ${ }^{\circledR}$ para alcanzar un nivel de tratamiento objetivo determinado de NT. El dimensionado se ha realizado para una explotación porcina de 150 verracos que equivalen a un volumen de purín anual aproximado de $6,12 \mathrm{~m}^{3}$ plaza $^{-1}$ año ${ }^{-1}$ (Campos y col., 2004) para el cual se ha asumido una dilución con el agua de limpieza de 1:3 para un total de $24,5 \mathrm{~m}^{3}$ plaza $^{-1}$ año $^{-1}$.

El agua residual de la superficie de la balsa de purines ha presentado unas concentraciones promedio de NT de $400 \mathrm{mg} \mathrm{L}^{-1}$. Se ha de tener en cuenta que estas concentraciones corresponden a un purín diluido con agua de limpieza y lluvia y con un contenido de sólidos en suspensión reducido debido a la sedimentación en el fondo de la fosa. Esto explica que las concentraciones de nitrógeno sean muy inferiores a las estimadas para un verraco según el Real Decreto 324/2000 (18 $\left.\mathrm{kg}_{\text {plaza }}{ }^{-1} \mathrm{año}^{-1}\right)$. Los parámetros de calibración para NT se corresponden con los de la Tabla 4.6 para los datos corregidos (modelo $k-C^{*} ; C^{*}=6,45 ; k=5,58 \mathrm{~m}$ año ${ }^{-1}$ ).

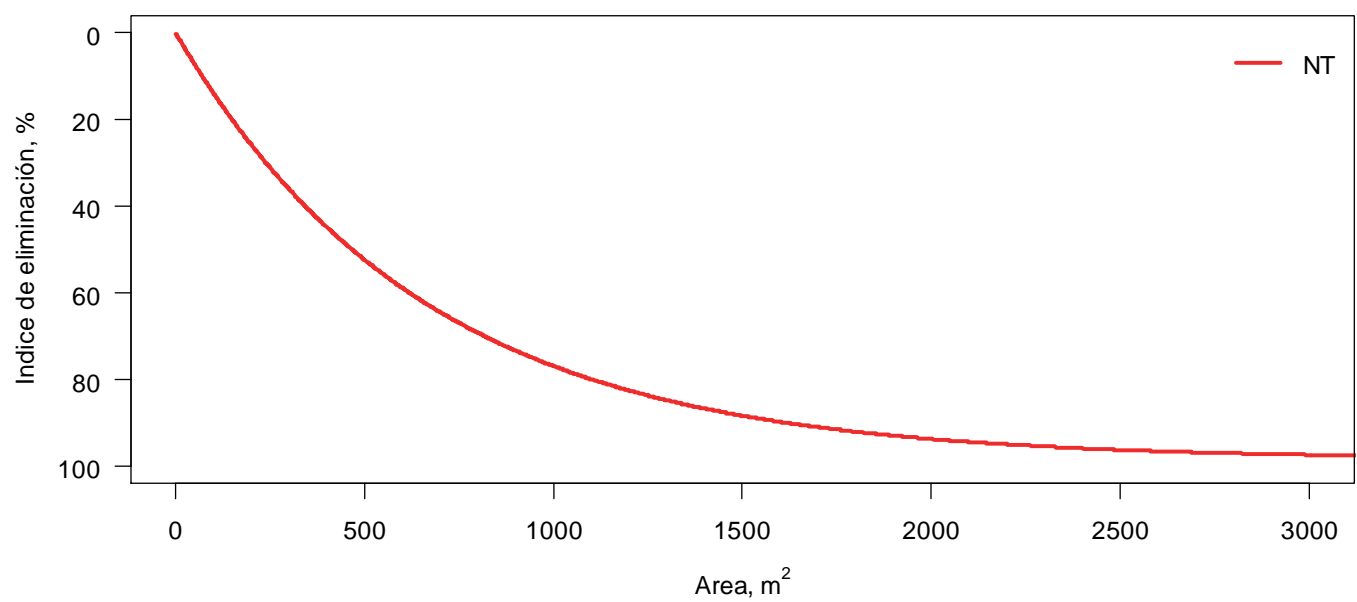

Figura 7.2. Area de un sistema de flujo combinado tipo MJEA $^{\circledR}$ frente al índice de eliminación. El área se ha calculado con las constantes de eliminación de los datos corregidos de NT para el modelo $k-C^{*}$. 
El área requerida por un sistema de flujo combinado tipo MJEA ${ }^{\circledR}$ para el tratamiento de NT aumenta de forma asintótica (Figura 7.2). Según los parámetros de calibración calculados en el Capítulo 4, alcanzar un índice de eliminación del 90\% requeriría un área de $1.600 \mathrm{~m}^{2}$, equivalente a $10,7 \mathrm{~m}^{2}$ plaza $^{-1}$ y permitiría un efluente de $41 \mathrm{mg} \mathrm{L}^{-1}$. La limitada información encontrada limita la comparación de estos resultados con los de otros sistemas de humedales artificiales para el tratamiento de agua residual porcina, aunque si pueden ser comparados con la información disponible de sistemas para el tratamiento de agua residual bovina.

Los resultados se asemejan a los obtenidos en un humedal de flujo subsuperficial horizontal (HFSH) en Alemania que requiere $10 \mathrm{~m}^{2}$ plaza $^{-1}$ para una reducción del 86\% de NT (Kern, 2003) y a los obtenidos en Italia para una reducción del 50\% de NT en un HFSH dimensionado como $1,84 \mathrm{~m}^{2}$ plaza $^{-1}$ para un volumen de $80 \mathrm{~L} \mathrm{día}^{-1}$ plaza $^{-1}$ (Mantovi y col., 2003). Otros humedales artificiales de flujo superficial (HFS) requieren superficies de un promedio de 120 $\mathrm{m}^{2}$ plaza $^{-1}$, muy superiores a las obtenidas en la planta piloto, aunque la elevada superficie permite obtener una calidad del efluente excelente, en torno a $0,5 \mathrm{mg} \mathrm{L}^{-1}$ de $\mathrm{NH}_{4}{ }^{+}($Kadlec y Wallace, 2009).

El tratamiento de nitrógeno en la planta a escala piloto se ha visto limitado debido a unos procesos de nitrificación y desnitrificación incompletos tal y como se ha explicado en el Capítulo 3. El análisis filogenético del Capítulo 5 ha revelado la presencia de un elevado número de secuencias asociadas a organismos capaces de participar en el proceso de desnitrificación en las muestras de rizosfera de Typha latifolia y Salix atrocinerea lo que indica la predominancia de condiciones reductoras en estas unidades de tratamiento. La presencia de organismos nitrificantes ha sido demostrada únicamente en la rizosfera de Salix atrocinerea en las unidades FSS, en las que el potencial redox ha aumentado respecto a la entrada. El proceso de nitrificación en las unidades FSS y la limitada desnitrificación debido a la baja biodegradabilidad de la materia orgánica presente en el agua residual son responsables de la presencia de altas concentraciones de nitratos en la salida del sistema. Sería recomendable modificar el diseño del sistema a fin de evitar posibles vertidos de nitratos a los cauces receptores y asegurar el cumplimiento de la Directiva 91/676/CEE.

La principal dificultad para la eliminación de nitrógeno del agua residual de la superficie de la balsa de purines es la baja relación C:N, lo que limita el proceso de desnitrificación. Se plantean dos alternativas de sistemas de flujo combinado de HFSH con humedales artificiales de flujo vertical (HFSV) para mejorar el tratamieno de nitrógeno: el sistema HFSH - HFSV con recirculación y el sistema HFSV - HFSH con adición de carbono.

\subsubsection{Sistema HFSH - HFSV con recirculación}

Una etapa de flujo horizontal colocada en primer lugar permite la eliminación de la materia orgánica y los sólidos en suspensión y proporciona las condiciones para que tenga lugar la desnitrificación. La etapa de flujo vertical alimentada de forma intermitente permite una eliminación adicional de la materia orgánica y sólidos en suspensión y facilita la nitrificación de amonio en nitrato. Para poder eliminar el nitrógeno es necesario recircular el efluente nitrificado a la cabecera del sistema (unidad HFSH) (Vymazal, 2007).

Los pasos a seguir para el diseño de este tipo de sistemas combinados están descritos en Brix y Johansen (1999) y se resumen a continuación:

a. Estimar el área requerida por un humedal artificial tipo HFSH para reducir la concentración de entrada de $\mathrm{DBO}_{5}$ hasta $30 \mathrm{mg} \mathrm{L}^{-1}$ mediante el uso de la Ecuación 4.5 del modelo $k-C^{*}$.

b. Calcular las concentraciones de salida de $\mathrm{NH}_{4}{ }^{+}$de la unidad HFSH mediante el uso de la Ecuación 4.5 del modelo $k-C^{*}$. 
c. Estimar el área requerida por un humedal artificial tipo HFSV en función de las concentraciones de $\mathrm{DBO}_{5}$ y amonio $\left(\mathrm{NH}_{4}{ }^{+}\right)$. La demanda de oxígeno se puede calcular asumiendo una demanda de $1 \mathrm{~g} \mathrm{O}_{2}$ por $\mathrm{g} \mathrm{DBO}_{5}$ y $4,3 \mathrm{~g} \mathrm{O}_{2}$ por $\mathrm{g} \mathrm{NH}_{4}{ }^{+}$. La tasa de transferencia de oxígeno de un HFSV es como mínimo de $28 \mathrm{~g} \mathrm{~m}^{-2}$ día $^{-1}$ (Cooper, 2005) una estimación conservativa que asegura una buena nitrificación incluso durante el invierno. El área de un HFSV se calcula mediante la expresión (Cooper, 2005):

$$
A=\frac{Q\left[\left(\mathrm{DBO}_{5 e n t}-\mathrm{DBO}_{5 \text { sal }}\right)+4,3\left(\mathrm{NH}_{4 e n t}^{+}-\mathrm{NH}_{4 s a l}^{+}\right)\right]}{T O}
$$

donde

$$
\begin{aligned}
& A=\text { area, } \mathrm{m}^{2} \\
& Q=\text { caudal, } \mathrm{m}^{3} \text { día } \\
& \mathrm{DBO}_{5 \text { ent }}=\text { concentración de } \mathrm{DBO}_{5} \text { en el afluente, } \mathrm{mg} \mathrm{L}^{-1} \\
& \mathrm{DBO}_{5 \text { sal }}=\text { concentración de } \mathrm{DBO}_{5} \text { en el efluente, } \mathrm{mg} \mathrm{L}^{-1} \\
& \mathrm{NH}_{4}^{+} \text {ent }=\text { concentración de amonio en el afluente, } \mathrm{mg} \mathrm{L}^{-1} \\
& \mathrm{NH}_{4}^{+} \text {sal }=\text { concentración de amonio en el efluente, } \mathrm{mg} \mathrm{L}^{-1} \\
& T O=\text { tasa de transferencia de oxígeno, } \mathrm{g} \mathrm{O}_{2} \mathrm{~m}^{-2} \text { día }
\end{aligned}
$$

d. Calcular las concentraciones de salida de la unidad HFSV. Si la profundidad de la unidad es de $1 \mathrm{~m}$ se puede esperar una eficiencia de nitrificación del $90 \%$ con una operación adecuada del sistema.

e. Elegir una tasa de recirculación adecuada y calcular la nueva carga en la unidad HFSH.

f. Repetir todos los pasos anteriores con la nueva carga calculada. La tasa de carga hidráulica del sistema y la concentración de los contaminantes cambiará como consecuencia de la recirculación. Se puede asumir que $1 \mathrm{~g}$ de nitrato $\left(\mathrm{NO}_{3}{ }^{-}\right)$contribuye a la degradación de 2,4 a 4 g DBO $_{5}$ (Brix y Johansen, 1999; Brix y col., 2003). Se puede asumir también que la desnitrificación en la unidad HFSH tendrá lugar a una velocidad superior a la de la degradación de la materia orgánica en ausencia de desnitrificación. Cuando la recirculación es incluida en el proceso el dimensionado es un proceso iterativo y los cálculos deberían ser realizados al menos tres veces.

En la Figura 7.3 se muestra el tamaño de un sistema HFSH - HFSV para el tratamiento de 10 $\mathrm{m}^{3}$ día $^{-1}$ (equivalente a los $24,5 \mathrm{~m}^{3}$ plaza $^{-1}$ año $^{-1}$ para 150 plazas) de agua residual de la superficie de la balsa de purines con unas concentraciones de entrada promedio de $355 \mathrm{mg} \mathrm{L}^{-1}$ de $\mathrm{DBO}_{5}$ y $310 \mathrm{mg} \mathrm{L}^{-1}$ de $\mathrm{NH}_{4}{ }^{+}$. El dimensionado se ha realizado para tres sistemas: sin recirculación, con recirculación del 50\% y con recirculación del 75\%.

Se asume que la eliminación de $\mathrm{NO}_{3}{ }^{-}$en la unidad de flujo horizontal de los sistemas con recirculación es completa. El aporte adicional de nitratos favorece el consumo de materia orgánica y permitiría reducir el tamaño de la unidad HFSH, sin embargo se carece de información para determinar en qué medida se produciría esta reducción. En la estimación del área requerida de una unidad tipo HFSH para reducir la concentración de entrada hasta $30 \mathrm{mg} \mathrm{L}^{-1}$ se han utilizado los parámetros obtenidos en la calibración del modelo $k$ - $C^{*}$ con los datos corregidos de entrada y salida de las unidades FSS del Capítulo 3 (Tabla 7.1).

Tabla 7.1. Parámetros obtenidos en la calibración del modelo $k-C^{*}$ para los contaminantes $\mathrm{DBO}_{5} \mathrm{y}$ $\mathrm{NH}_{4}{ }^{+}$en las unidades FSS.

\begin{tabular}{cc|cc}
\hline \multicolumn{2}{c|}{$\mathrm{DBO}_{5}$} & \multicolumn{2}{c}{$\mathrm{NH}_{4}{ }^{+}$} \\
\hline$C^{*}$ & $k$ & $C^{*}$ & $k$ \\
\hline 3,30 & 13,98 & 1,93 & 5,59 \\
\hline
\end{tabular}


Un sistema sin recirculación proporcionaría unos índices de eliminación del $97 \%$ de $\mathrm{DBO}_{5}$ y $64 \%$ de $\mathrm{NH}_{4}{ }^{+}$con un área de $5,6 \mathrm{~m}^{2}$ plaza ${ }^{-1}$ y un efluente fuertemente nitrificado. Si se utilizase una recirculación del 50 o 75\% en el sistema, la eliminación de $\mathrm{DBO}_{5}$ permanecería inmutable, pero la eliminación de amonio se incrementaría hasta el $75-80 \%$, y las concentraciones de $\mathrm{NO}_{3}{ }^{-}$se reducirían entre un 30 y un $50 \%$.

La recirculación del efluente incrementaría el flujo de agua residual a través del sistema y diluiría la concentración de los contaminantes en el afluente. La fuerte influencia del caudal en el dimensionado de los humedales artificiales tipo HFSH y HFSV implica que la superficie del sistema completo se incrementaría desde $5,6 \mathrm{~m}^{2}$ plaza $^{-1}$ sin recirculación hasta $9,4 \mathrm{~m}^{2}$ plaza $^{-1}$ con una recirculación del $75 \%$.

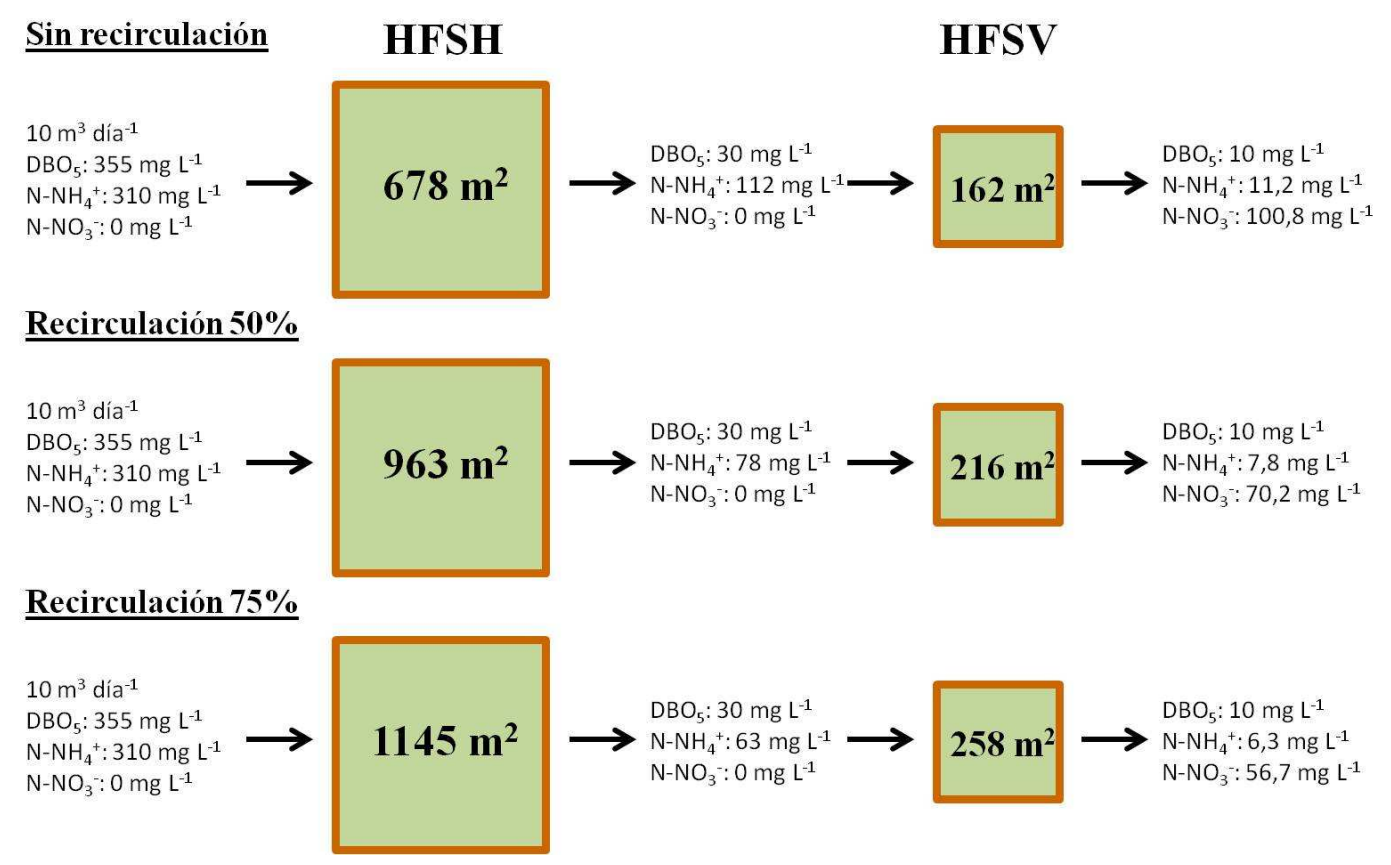

Figura 7.3. Esquema de un sistema de flujo combinado tipo HFSH - HFSV para el tratamiento de agua residual de una explotación porcina de 150 plazas. Las profundidades de las unidades HFSH y HFSV son de $0,5 \mathrm{~m}$ y $1 \mathrm{~m}$ respectivamente.

\subsubsection{Sistema HFSV - HFSH con adición de carbono}

La etapa de flujo vertical permitiría la transformación del amonio en nitrato aunque al mismo tiempo se produciría el consumo de la materia orgánica necesaria para llevar a cabo el proceso de desnitrificación en la unidad HFSH. Un aporte externo de $\mathrm{DBO}_{5}$ a la entrada de la etapa HFSH en las cantidades adecuadas permitiría a las bacterias desnitrificantes completar eficientemente la eliminación del $\mathrm{NO}_{3}{ }^{-}$sin comprometer la capacidad de tratamiento de la $\mathrm{DBO}_{5}$.

Fuentes de carbono externo típicamente utilizadas en la desnitrificación del agua residual en sistemas convencionales de tratamiento son el etanol, el ácido acético, la fructosa o la glucosa (Lin y col., 2002; Songliu y col., 2009), sin embargo el coste económico asociado a su utilización resulta demasiado elevado para los humedales artificiales cuyo propósito es la reducción del coste económico del proceso de tratamiento. 
Una alternativa de fuente de carbono es la biomasa cosechada durante el periodo de senescencia de los macrófitos emergentes debido a su bajo coste y disponibilidad. La degradación de la biomasa vegetal condiciona la disponibilidad de carbono en el sistema y depende de la proporción de celulosa, hemicelulosa y lignina (Ding y col., 2012). La eficiencia de la eliminación de nitrato mediante la incorporación de trozos de espadaña seca en un humedal artificial aumenta a medida que la relación C:N incrementa hacia 5:1. Para una relación C:N superior a 5:1, la eliminación de nitrato es prácticamente completa (Ingersoll y Baker, 1998). La adición de biomasa vegetal como fuente de carbono externa puede suponer un incremento de hasta un 58\% de la eficiencia de la eliminación de nitrato, aunque puede dar lugar a la liberación de compuestos de nitrógeno en el agua residual (Wen y col., 2010).

El dimensionado de un sistema de estas características requeriría determinar las constantes de eliminación del $\mathrm{NO}_{3}{ }^{-}$en un HFSH. Este tipo de sistemas requiere de un pretratamiento para reducir el contenido de sólidos en suspensión en el afluente y evitar una posible colmatación de la superficie del HFSV.

\subsection{RECOMENDACIONES DE DISEÑO PARA EL TRATAMIENTO DE FÓSFORO}

La Figura 7.4 muestra la superficie requerida por un sistema de flujo combinado tipo MJEA ${ }^{\circledR}$ para alcanzar un nivel de tratamiento objetivo determinado de PT. El dimensionado se ha realizado para una explotación porcina de 150 verracos con un volumen de purín anual aproximado de $24,5 \mathrm{~m}^{3}$ plaza $^{-1}$ año $^{-1}$ tal y como se especifica en el apartado 7.1. La concentración promedio de PT en la superficie de la balsa de purines ha sido de $80 \mathrm{mg} \mathrm{L}^{-1}$. Los parámetros obtenidos en la calibración del modelo $k C T$ para PT se corresponden con los de la Tabla 4.6 para los datos corregidos (modelo $k C T ; C^{*}=0,78 ; k_{20}=7,20 \mathrm{~m} \mathrm{año}^{-1} ; \theta=1,116 ; \mathrm{T}=$ $\left.16^{\circ} \mathrm{C}\right)$.

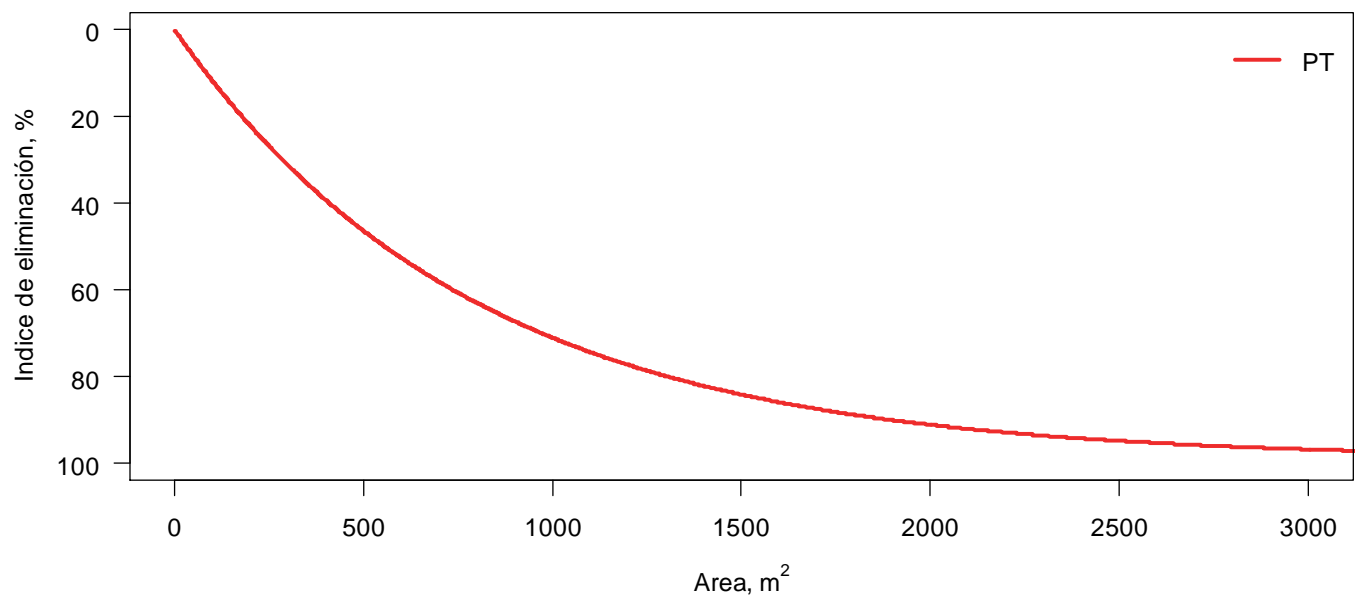

Figura 7.4. Area de un sistema de flujo combinado tipo MJEA $^{\circledR}$ frente al índice de eliminación. El área se ha calculado con las constantes de eliminación de los datos corregidos de PT para el modelo $k C T$.

La curva asintótica que se muestra en la Figura 7.4 es muy similar a la de la Figura 7.2 para el NT, aunque alcanzar el mismo nivel de tratamiento requiere de una superficie ligeramente superior en el caso del PT. El sobredimensionado del humedal artificial no soluciona el problema de la eliminación de PT a largo plazo, particularmente frente a altas concentraciones de entrada como son las del agua residual porcina. Tal y como se ha explicado en el Capitulo 3 la eliminación de fósforo en el sistema no es sostenible, sino que depende de los mecanismos de adsorción y precipitación sobre el sustrato que han alcanzado la saturación en la planta a escala piloto. 
La sustitución del sustrato una vez alcanzada la saturación no es una solución debido al trastorno que supone para los macrófitos y la comunidad bacteriana establecidos en el lecho. La opción más interesante para el tratamiento de fósforo es la incorporación al sistema de una unidad de tratamiento adicional rellena de un material con una alta capacidad de adsorción de fósforo. Una vez saturada esta unidad, el material puede ser reemplazado, por lo que no es necesario alterar el funcionamiento del sistema de tratamiento original.

La elección de un sustrato capaz de retener una elevada cantidad de ortofosfatos ha sido estudiada en el Capitulo 6 para un volumen de escoria de acería LD entre 0,18 y 0,32 $\mathrm{m}^{3}$ por habitante equivalente y año. Teniendo en cuenta que la mayor parte del fósforo presente en el agua residual porcina se encuentra en forma inorgánica (Levasseur, 1998), se puede asumir que la mayor parte del fósforo presente en el agua residual será transformado eventualmente en ortofosfatos, por lo que el volumen de un filtro para el tratamiento de PT debería ser semejante al diseñado para tratar ortofosfatos.

Teniendo en cuenta una concentración de entrada de PT de $80 \mathrm{mg} \mathrm{L}^{-1}$ para una explotación porcina de 150 verracos que generan $24,5 \mathrm{~m}^{3}$ plaza $^{-1}$ año $^{-1}$ de purín (véase apartado 7.1) y los volúmenes de escoria de acería LD estimados en el Capítulo 6 (véase apartado 6.4.5); sería necesario un volumen de filtro de acería LD entre 66 y $114 \mathrm{~m}^{3}$ para evitar el vertido de $\mathrm{P}$ durante un año.

La continuidad de la liberación de iones $\mathrm{Ca}_{2}{ }^{+}$, clave en la retención de fósforo, dependerá del caudal de agua residual que pase por el filtro. Para evitar una pérdida prematura de la capacidad de retención de fósforo será necesario utilizar un menor volumen de escorias que podrán ser sustituidas periódicamente. Sería necesario un volumen de filtro de acería LD entre 5,5 y 9,5 m3 para evitar el vertido de $\mathrm{P}$ durante un mes, lo que equivaldría a 12 sustituciones anuales.

La estimación de volumen se realiza a partir de información experimental en condiciones controladas y no tiene en cuenta las condiciones ambientales a las que está expuesto un humedal artificial ni los efectos de la composición del agua residual que puede interaccionar con la escoria o generar caminos preferenciales del agua a través del filtro debido a su contenido en solidos en suspensión o la creación de biofilm por la presencia de materia orgánica y nutrientes. Es aconsejable realizar experimentos a escala piloto en condiciones ambientales con agua residual para obtener una información experimental que permita un dimensionado adecuado de este tipo de sistemas.

Tal y como se ha expuesto en el Capítulo 6, en el proceso de disociación de la portlandita se liberan aniones $\mathrm{OH}^{-}$que pueden aumentar el $\mathrm{pH}$ de la disolución hasta valores de 13 unidades de $\mathrm{pH}$. Periodos prolongados de un vertido de elevado $\mathrm{pH}$ en un cauce receptor pueden producir un incremento de la concentración de amoníaco $\left(\mathrm{NH}_{3}\right)$ que tiene efectos tóxicos en los organismos acuáticos en concentraciones incluso inferiores a los $2 \mathrm{mg} \mathrm{L}^{-1}$. A medida que el $\mathrm{pH}$ se incrementa en el agua la proporción de $\mathrm{NH}_{3}$ respecto al amonio $\left(\mathrm{NH}_{4}{ }^{+}\right)$aumenta. Para un valor de $\mathrm{pH}$ de 9,25 la proporción $\mathrm{NH}_{3} / \mathrm{NH}_{4}{ }^{+}$es de 0,5 mientras que a $\mathrm{pH} 10$ esta relación es aproximadamente de 0,8 .

Además de los efectos indirectos, exposiciones prolongadas entre valores de $\mathrm{pH}$ de 9,5 y 10 pueden producir daños en los ojos, agallas y piel de los peces (USEPA, 2010). Por otro lado los límites de vertido de conductividad para actividades industriales se sitúan en los $6.000 \mu \mathrm{S} \mathrm{cm}^{-1}$ (Morillas, 2000), valor que se supera en los primeros 20 días de funcionamiento de la columna experimental (apartado 6.4.4.3.2., Figura 6.20) y que podrían prolongarse durante más tiempo en un humedal artificial a escala real. Los valores de conductividad eléctrica habituales en un río se encuentran entre 200 y $1.000 \mu \mathrm{S} \mathrm{cm}^{-1}$. El incremento de la conductividad eléctrica de un cauce receptor por encima de estos niveles hace que estos hábitats no sean adecuados para ciertas especies de macroinvertebrados y peces (USEPA, 2012). 
Drizo y col. (2002) sugieren que aquellos humedales artificiales que incorporen filtros de escorias de acería dispongan de al menos tres unidades dispuestas en serie. Las primeras etapas están plantadas con macrófitos, ya que de otro modo su crecimiento sería inhibido por los altos valores de $\mathrm{pH}$ y conductividad eléctrica del efluente del filtro de escorias. A estas etapas le sigue el filtro de escorias de acería cuyo objetivo es la eliminación de $\mathrm{P}$, e inmediatamente después se encontraría una última etapa cuyo objetivo es la estabilización de los valores de pH y conductividad eléctrica antes del vertido. La capacidad de los humedales artificiales para reducir el $\mathrm{pH}$ de aguas extremadamente alcalinas ha sido demostrada en otros estudios (Mayes y col., 2006, 2008). 




\section{CONCLUSIONES GENERALES}

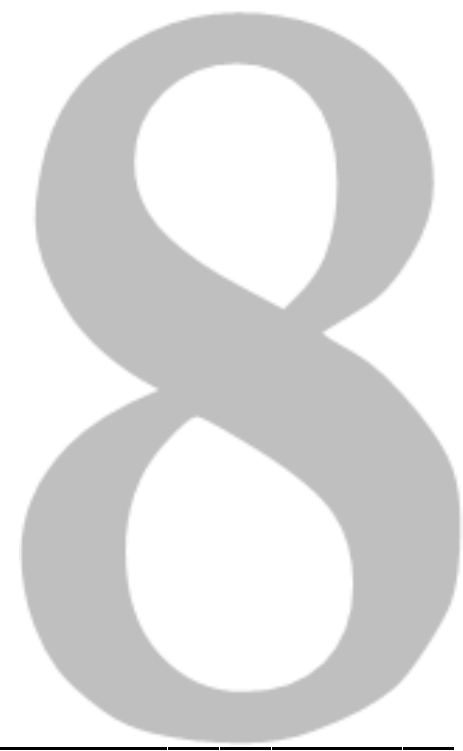

1. Los sistemas de flujo combinado tipo MJEA ${ }^{\circledR}$ para el tratamiento de la fracción líquida de purines de origen porcino son eficientes en el tratamiento de materia orgánica y sólidos en suspensión, sin embargo su capacidad de tratamiento de nitrógeno y fósforo es limitada.

2. La calibración de los modelos de dimensionado ha proporcionado unos parámetros en el rango inferior de los valores presentes en otros estudios para el modelo $k-C^{*}$ y nuevos parámetros de diseño para el modelo $P-k-C^{*}$ no disponibles en la bibliografía para sistemas de tratamiento de agua residual porcina. El ajuste de los datos experimentales a los modelos mejora tras corregir la influencia de la hidrología, mientras que el efecto de la temperatura se aprecia únicamente en la variable PT. Se recomienda la utilización del modelo $k-C^{*}$ para el dimensionado de sistemas de flujo combinado tipo MJEA ${ }^{\circledR}$.

3. Las comunidades bacterianas del sedimento de la balsa de purines se caracterizan por la presencia de metabolismos estrictamente anaerobios, mientras que las de la rizosfera de macrófitos del sistema de flujo combinado tipo MJEA ${ }^{\circledR}$ para el tratamiento de la fracción líquida de purines de origen porcino, se caracterizan por la presencia de metabolismos aerobios, facultativos y anaerobios. Se trata de comunidades menos ricas y diversas que las muestras análogas de un sistema de tratamiento de agua residual urbana, y presentan una menor proporción de organismos con metabolismos aerobios.

4. Los filtros de escorias de acería LD son altamente eficientes en la eliminación de fosfatos del agua residual debido a su elevado contenido en calcio. Su utilización presenta inconvenientes relacionados con la hidráulica y longevidad del filtro y el incremento del valor de $\mathrm{pH}$ y conductividad del efluente que debe ser corregido antes de su vertido a un cauce receptor. 
5. Se recomienda el estudio de dos alternativas para mejorar el tratamiento de nitrógeno: la combinación de un sistema HFSH - HFV con recirculación o la combinación de un sistema HFV - HFSH con aporte externo de carbono al sistema. También se recomienda el estudio a escala piloto de un filtro de acería LD para mejorar el tratamiento de fósforo con el objeto de estudiar su comportamiento frente a un agua residual en condiciones ambientales reales. 




\section{LEGISLACIÓN}

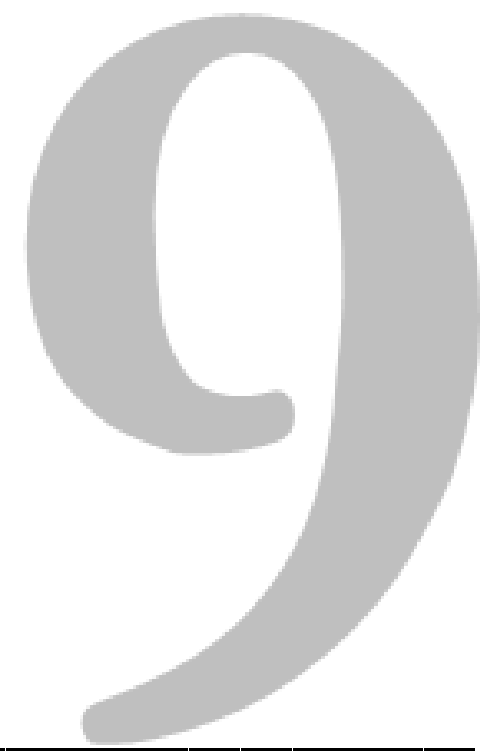

Decreto 109/1998, de 11 de junio, por el que se designan las zonas vulnerables a la contaminación de las aguas por nitratos procedentes de fuentes de origen agrícola y ganadero y se aprueba el Código de buenas prácticas agrarias. BOCYL 112, de 16-06-98.

Directiva 91/676/CEE del Consejo, de 12 de diciembre de 1991, relativa a la protección de las aguas contra la contaminación producida por nitratos utilizados en la agricultura.

Ley 22/2011, de 28 de julio, de residuos y suelos contaminados.

Real Decreto 849/1986, de 11 de abril, por el que se aprueba el Reglamento del Dominio Público Hidráulico que desarrolla los títulos preliminar, I, IV, V, VI, VII y VIII del texto refundido de la Ley de Aguas, aprobado por el Real Decreto Legislativo 1/2001, de 20 de julio.

Real Decreto 261/1996, de 16 de febrero, sobre protección de las aguas contra la contaminación producida por los nitratos procedentes de fuentes agrarias.

Real Decreto 324/2000, de 3 de marzo, por el que se establecen normas básicas de ordenación de las explotaciones porcinas. Revisión vigente desde el 5 de agosto de 2009.

Real Decreto 606/2003, de 23 de mayo, por el que se modifica el Real Decreto 849/1986, de 11 de abril, por el que se aprueba el Reglamento del Dominio Público Hidráulico, que desarrolla los Títulos preliminar, I, IV, V, VI y VIII de la Ley 29/1985, de 2 de agosto, de Aguas.

Real Decreto - Ley 11/1995, de 28 de diciembre, por el que se establecen las normas aplicables al tratamiento de las aguas residuales urbanas. 



\section{BIBLIOGRAFÍA}

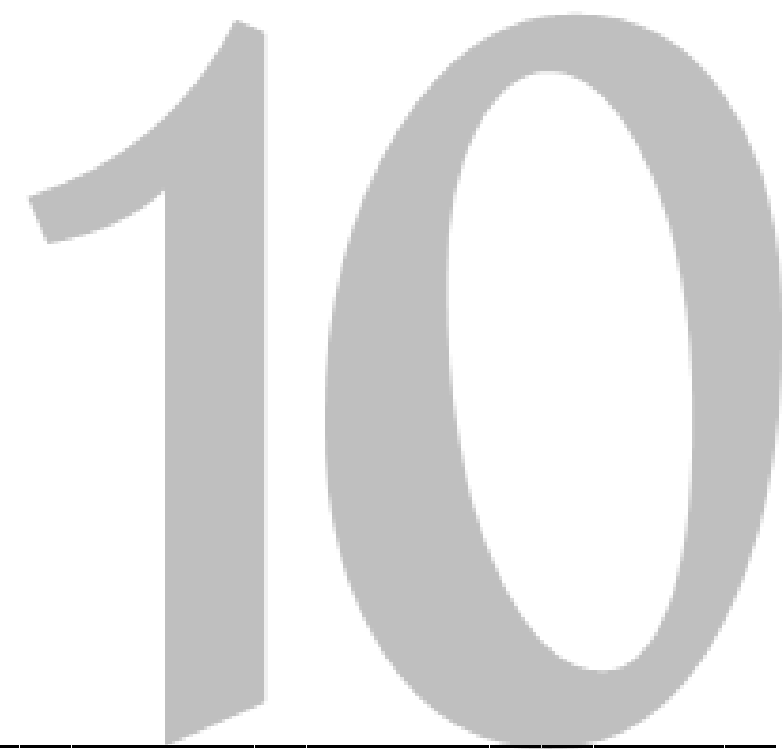

AEMET. 2012. Agencia Estatal de Meteorologia. Estacion meteorologica de Leon (Virgen del Camino). www.aemet.es. Fecha de acceso: 05-02-2012.

Ahn, C., Gillevet, P. M. y Sikaroodi, M. 2007. Molecular characterization of microbial communities in treatment microcosm wetlands as influenced by macrophytes and phosphorus loading. Ecological Indicators. 7: 852-863.

Ahn, Y. 2006. Sustainable nitrogen elimination biotechnologies: A review. Process Biochemistry. 41: 1709-1721.

Akratos, C. S. y Tsihrintzis, V. A. 2007. Effect of temperature, HRT, vegetation and porous media on removal efficiency of pilot-scale horizontal subsurface flow constructed wetlands. Ecological Engineering. 29: 173-191.

Albert, R. A., Waas, N. E., Langer, S., Pavlons, S. C., Feldner, J. L., Rossello-Mora, R. y Busse, H. J. 2010. Labrys wisconsinensis sp. nov., a budding bacterium isolated from Lake Michigan water, and emended description of the genus Labrys. International Journal of Systematic and Evolutionary Microbiology. 60: 1570-1576.

Allen, J. G., Beutel, M. W., Call, D. R. y Fischer, A. M. 2010. Effects of oxygenation on ammonia oxidation potential and microbial diversity in sediment from surface-flow wetland mesocosms. Bioresource Technology. 101: 1389-1392.

Allen, R. G., Pereira, L. S., Raes, D. y Smith, M. 2006. Evapotranspiración del cultivo. FAO. Organización de las Naciones Unidas para la Agricultura y la Alimentación. Roma, Italia.

Allen, W. C., Hook, P. B., Biederman, J. A. y Stein, O. R. 2002. Temperature and Wetland Plant Species Effects on Wastewater Treatment and Root Zone Oxidation. Journal of Environmental Quality. 31: 1010-1016.

Altschul, S. F., Madden, T. L., Shäffer, A. A., Shang, J., Zhang, Z., Miller, W. y Lipman, D. J. 1997. Gappet BLAST and PSIBLAST: a new generation of protein database search program. Nucleic Acids Research. 25: 3389-3402. 
Amann, R. I., Binder, B. J., Olson, R. J., Chisholm, S. W., Devereux, R. y Stahl, D. A. 1990. Combination of $16 \mathrm{~S}$ rRNA-targeted oligonucleotide probes with flow cytometry for analyzing mixed microbial populations. Applied and Environmental Microbiology. 56: $1919-1925$.

Angulo, A. F., Reijgers, R., Brugman, J., Kroesen, I., Hekkens, F. E. N., Carle, P., Bové, J. M., Tully, J. G., Hill, A. C., Schouls, L. M., Schot, C. S., Roholl, P. J. M. y PolakVogelzang, A. A. 2000. Acholeplasma vituli sp. nov., from bovine serum and cell cultures. International Journal of Systematic and Evolutionary Microbiology. 50: 11251131.

Ansola, G., Gonzalez, J. M., Cortijo, R. y de Luis, E. 2003. Experimental and full-scale pilot plant constructed wetlands for municipal wastewaters treatment. Ecological Engineering. 21: 43-52.

APHA-AWWA-WEF. 2005. Standard Methods for the Examination of Water and Wastewater. 21 edition, Baltimore, MD, USA.

Arias, C. A., Del Bubba, M. y Brix, H. 2001. Phosphorus removal by sands for use as media in subsurface flow constructed reed beds. Water Research. 35: 1159-1168.

ARM. 2011. www.armreedbeds.co.uk. Fecha de acceso: 28-08-2013.

Armstrong, J., Armstrong, W. y Beckett, P. M. 1992. Phragmites australis: Venturi and humidity-induced pressure flows enhance rhizome aeration and rhizosphere oxidation. New Phytologist. 120: 197-207.

Arroyo, P., Ansola, G., Blanco, I., Molleda, P., Calabuig, E. y Sáenz de Miera, L. E. 2010. Comparative analysis of the composition of bacterial communities from two constructed wetlands for municipal and swine wastewater treatment. Journal of Water and Health. 8: $147-157$.

Arroyo, P. 2011. Los humedales construidos como sistemas para el tratamiento de agua residual industrial y urbana. Caracterización de las comunidades de bacterias presentes en estos ecosistemas. Universidad de León. León, España.

Arroyo, P., Ansola, G. y Sáenz de Miera, L. E. 2013. Effects of substrate, vegetation and flow on arsenic and zinc removal efficiency and microbial diversity in constructed wetlands. Ecological Engineering. 51: 95-103.

Austin, D. C., Wolf, L. y Strous, M. 2006. Mass transport and microbiological mechanisms of nitrification and denitrification in tidal flow constructed wetlands systems. 10th International Conference on Wetland Systems for Water Pollution Control. Lisboa, Portugal. 209-218.

Ayers, R. S. y Westcot, D. W. 1994. Water quality for agriculture. FAO. Food and Agriculture Organization of the United Nations. Roma, Italia.

Babatunde, A. O., Zhao, Y. Q., O'Neill, M. y O'Sullivan, B. 2008. Constructed wetlands for environmental pollution control: A review of developments, research and practice in Ireland. Environment International. 34: 116-126.

Baena, S., Fardeau, M. L., Woo, T. H. S., Ollivier, B., Labat, M. y Patel, B. K. C. 1999. Phylogenetic relationships of three amino-acid-utilizing anaerobes, Selenornonas acidaminovorans, Selenomonas acidaminophila and Eubacterium acidaminophilum, as inferred from partial 16s rDNA nucleotide sequences and proposal of Thermanaerovibrio acidaminovorans gen. nov., comb. nov. and Anaeromusa acidaminophila gen. nov., comb. nov. International Journal of Systematic Bacteriology. 49: 969-974.

Baik, K. S., Park, Y. D., Kim, M. S., Park, S. C., Moon, E. Y., Rhee, M. S., Choi, J. H. y Seong, C. N. 2007. Pedobacter koreensis sp. nov., isolated from fresh water. International Journal of Systematic and Evolutionary Microbiology. 57: 2079-2083.

Baldauf, S. L. 2003. Phylogeny for the faint of heart: a tutorial. TRENDS in Genetics. 19: 345351.

Baptista, J. C., Davenport, R. J., Donnelly, T. y Curtis, T. P. 2008. The microbial diversity of laboratory-scale wetlands appears to be randomly assembled. Water Research. 42: 3182-3190. 
Barca, C., Gérente, C., Meyer, D., Chazarenc, F. y Andres, Y. 2012. Phosphate removal from synthetic and real wastewater using steel slags produced in Europe. Water Research. 46: 2376-2384.

Barca, C. 2013. Steel slag filters to upgrade phosphorus removal in small wastewater treatment plants. L'Université Nantes Angers Le Mans. Nantes, Francia.

Barrow, N. J. 1983. On the reversibility of phosphate sorption by soils. Journal of Soil Science. 34: 751-758.

Belhadj, E., Diliberto, C. y Lecomte, A. 2012. Characterization and activation of Basic Oxygen Furnace slag. Cement \& Concrete Composites. 34: 34-40.

Bisen, P. S., Debnath, M. y Prasad, G. B. K. S. 2012. Microbes: Concepts and Applications. John Wiley \& Sons, Inc, Hoboken, NJ, USA.

Bohn, H. L. 1971. Redox potential. Soil Science. 112: 39-45.

Borin, M., Politeo, M. y De Stefani, G. 2013. Performance of a hybrid constructed wetland treating piggery wastewater. Ecological Engineering. 51: 229-236.

Bouali, M., Pelletier, E., Chaussonnerie, S., Le Paslier, D., Bakhrouf, A. y Sghir, A. 2013. Characterization of rhizosphere prokaryotic diversity in a horizontal subsurface flow constructed wetland using a PCR cloning-sequencing based approach. Environmental Biotechnology. 97: 4221-4231.

Bowden, L. I., Jarvis, A. P., Younger, P. L. y Johnson, K. L. 2009. Phosphorus Removal from Waste Waters Using Basic Oxygen Steel Slag. Environmental Science \& Technology. 43: 2476-2481.

Braun, B., Richert, I. y Szewzyk, U. 2009. Detection of iron-depositing Pedomicrobium species in native biofilms from the Odertal National Park by a new, specific FISH probe. Journal of Microbiological Methods. 79: 37-43.

Bremner, J. M. y Shaw, K. 1958. Denitrification in soil. II. Factors affecting denitrification. Journal of Agricultural Science. 51: 40-52.

Brix, H. 1990. Gas exchange through the soil-atmosphere interphase and through dead culms of Phragmites australis in a constructed reed bed receiving domestic sewage. Water Research. 24: 259-266.

Brix, H. 1993. Wastewater treatment in constructed wetlands: system design, removal processes and treatment performance. pp. 9 - 22 en G.A., M., editor. Constructed wetalnds for water quality improvement. CRC press. Boca Raton, FL, USA.

Brix, H. 1997. Do macrophytes play a role in constructed treatment wetlands? Water Science \& Technology. 35: 11-17.

Brix, H. y Johansen, N. H. 1999. Treatment of domestic sewage in a two-stage constructed wetland - design principles. pp. 155-163 en Vymazal, J., editor. Nutrient Cycling and Retention in Natural and Constructed Wetlands. Backhuys Publishers. Leiden, Holanda.

Brix, H., Arias, C. A. y Johansen, N. H. 2003. Experiments in a two-stage constructed wetland system: nitrification capacity and effects of recycling on nitrogen removal. pp. 237-258 en Vymazal, J., editor. Wetlands - nutrients, metals and mass cycling. Backhuys Publishers. Leiden, Holanda.

Brix, H. 2003. Plants Used in Constructed Wetlands and their Functions. 1st International Seminar on the Use of Aquatic Macrophytes for Wastewater Treatment in Constructed Wetlands. Lisboa, Portugal. 81-109.

Brown, M. V. y Bowman, J. P. 2001. A molecular phylogenetic survey of sea-ice microbial communities (SIMCO). FEMS Microbial Ecology. 35: 267-275.

Buresh, R. J., Casselman, M. E. y Patrick Jr, W. H. 1980. Nitrogen fixation in flooded soil systems: a review. Advances in Agronomy. 33: 149-192.

Bürgmann, H., Meier, S., Bunge, M., Widmer, F. y Zeyer, J. 2005. Effects of model root exudates on structure and activity of a soil diazotroph community. Environmental Microbiology. 7: 1711-1724.

Burgos-Díaz, C., Pons, R., Espuny, M. J., Aranda, F. J., Teruel, J. A., Manresa, A., Ortiz, A. y Marqués, A. M. 2011. Isolation and partial characterization of a biosurfactant mixture produced by Sphingobacterium sp. isolated from soil. Journal of Colloid and Interface Science. 361: 195-204. 
Burnham, K. P. y Anderson, D. R. 1988. Model Selection and Inference. Springer, Londres, Reino Unido.

Busnardo, M. J., Gersberg, R. M., Langis, R., Sinicrope, T. L. y Zedler, J. B. 1992. Nitrogen and phosphorus removal by wetland mesocosms subjected to different hydroperiods. Ecological Engineering. 1: 287-308.

Busse, H. J., Denner, E. B. M., Buczolits, S., Salkinoja-Salonen, M., Bennasar, A. y Kämpfer, P. 2003. Sphingomonas aurantiaca sp. nov., Sphingomonas aerolata sp. nov. and Sphingomonas faeni sp. nov., air- and dustborne and Antarctic, orangepigmented, psychrotolerant bacteria, and emended description of the genus Sphingomonas. International Journal of Systematic and Evolutionary Microbiology. 53: 1253-1260.

Calheiros, C. S. C., Duque, A. F., Moura, A., Henriques, I. S., Correia, A., Rangel, A. O. S. S. y Castro, P. M. L. 2009. Substrate effect on bacterial communities from constructed wetlands planted with Typha latifolia treating industrial wastewater. Ecological Engineering. 35: 744-753.

Calheiros, C. S. C., Teixeira, A., Pires, C., Franco, A. R., Duque, A. F., Crispim, L. F. C., Moura, S. C. y Castro, P. M. L. 2010. Bacterial community dynamics in horizontal flow constructed wetlands with different plants for high salinity industrial wastewater polishing. Water Research. 44: 5032-5038.

Campos, P. E., Illa, A. J., Magrí, A. A., Palatsi, C. J., Solé, M. F. y Flotats, R. X. 2004. Guía de los tratamientos de las deyecciones ganaderas Área de Ingeniería Ambiental Universidad de Lleida. Departamento de Agricultura, Ganaderia y Pesca. Lérida, España.

Capone, D. G. 2000. The marine microbial nitrogen cycle. p. 525 en Kirchman, D. L., editor. Microbial Ecology of the Oceans. Wiley-Liss. New York.

CEDEX. 2007. Escorias de acería http://www.cedexmateriales.vsf.es/view/ficha.aspx?idresiduo=282\&idmenu=358. Fecha de acceso: 31-07-2013.

CEDEX. 2011a. Escorias de Acería de Horno de Arco Eléctrico. http://www.cedexmateriales.vsf.es/view/ficha.aspx?idresiduo=217\&idmenu=218. Fecha de acceso: 31-07-2013.

CEDEX. 2011b. Escorias de horno alto. http://www.cedexmateriales.vsf.es/view/ficha.aspx?idresiduo=255\&idmenu=259. Fecha de acceso: 31-07-2013.

Chao, A. 1984. Nonparametric estimation of the number of classes in a population. Scandinavian Journal of Statistics. 11: 265-270.

Chao, A., Ma, M. C. y Yang, M. C. K. 1993. Stopping rules and estimation for recapture debugging with unequal failure rates. Biometrika. 80: 193-201.

Chazarenc, F., Brisson, J. y Comeau, Y. 2007. Slag columns for upgrading phosphorus removal from constructed wetland effluents. Water Science \& Technology. 56: 109-115.

Chon, K., Kim, Y., Chang, N. I. y Cho, J. 2010. Evaluating wastewater stabilizing constructed wetland, through diversity and abundance of the nitrite reductase gene nirS, with regard to nitrogen control. Desalination. 264: 201-205.

Claveau-Mallet, D., Wallace, S. y Comeau, Y. 2012. Model of phosphorus precipitation and crystal formation in electric arc furnace steel slag filters. Environmental Science \& Technology. 46: 1465-1470.

Claveau-Mallet, D., Wallace, S. y Comeau, Y. 2013. Removal of phosphorus, fluoride and metals from a gypsum mining leachate using steel slag filters. Water Research. 47: 1512-1520.

Coates, J. D., Ellis, D. J., Gaw, C. V. y Lovley, D. R. 1999. Geothrix fermentans gen. nov., sp. nov., a novel $\mathrm{Fe}(\mathrm{III})$-reducing bacterium from a hydrocarbon-contaminated aquifer. International Journal of Systematic and Evolutionary Microbiology. 49: 1615-1622.

Cole, J. R., Wang, Q., Cardenas, E., Fish, J., Chai, B., Farris, R. J., Kulam-Syed-Mohideen, A. S., McGarrell, D. M., Marsh, T., Garrity, G. M. y Tiedje, J. M. 2008. The Ribosomal Database Project: improved alignments and new tools for rRNA analysis. Nucleic Acids Research. 37: 141-145. 
Colwell, R. K. y Coddington, J. A. 1994. Estimating terrestrial biodiversity through extrapolation. Philosophical Transactions of the Royal Society B: Biological Sciences. 345: 101-118.

Cook, K. L., Rothrock Jr., M. J., Lovanh, N., Sorrell, J. K. y Loughrin, J. H. 2010. Spatial and temporal changes in the microbial community in an anaerobic swine waste treatment lagoon. Anaerobe. 16: 74-82.

Cooper, P. 2005. The performance of vertical flow constructed wetland systems with special reference to the significance of oxygen transfer and hydraulic loading rates. Water Science \& Technology. 51: 81-90.

Cooper, P. F., Job, G. D., Green, M. B. y Shutes, R. B. E. 1996. Reed Beds and Constructed Wetlands for Wastewater Treatment. WRc Publications, Medmenham, Marlow, Reino Unido.

Copeland, A., Spring, S., Göker, M., Schneider, S., Lapidus, A., Del Rio, T. G., Tice, H., Cheng, J. F., Lucas, S., Chen, F., Nolan, M., Bruce, D., Goodwin, L., Pitluck, S., Ivanova, N., Mavromatis, K., Ovchinnikova, G., Pati, A., Chen, A., Palaniappan, K., Land, M., Hauser, L., Chang, Y. J., Jeffries, C. C., Meincke, L., Sims, D., Brettin, T., Detter, J. C., Han, C., Chain, P., Bristow, J., Eisen, J. A., Markowitz, V., Hugenholtz, P., Kyrpides, N. C., Klenk, H. P. y Lucas, S. 2009. Complete genome sequence of Desulfomicrobium baculatum type strain $\left(\mathrm{X}^{\mathrm{T}}\right)$. Standards in Genomic Sciences. 1: 2937.

Criado, C. y Bécares, E. 2005. Characterization of bacterial communities of a constructed wetland in cold conditions. The journal of general and applied microbioloby. 51: 197201.

Cronk, J. K. 1996. Constructed wetlands to treat wastewater from dairy and swine operations. Agriculture Ecosystems \& Environment. 58: 97-114.

Cucarella, V. y Renman, G. 2009. Phosphorus Sorption Capacity of Filter Materials Used for On-site Wastewater Treatment Determined in Batch Experiments - A Comparative Study. Journal of Environmental Quality. 38: 381-392.

D'Angelo, E. M. y Reddy, K. R. 1999. Regulators of heterotrophic microbial potentials in wetland soils. Soil Biology and Biochemistry. 31: 815-830.

Dabrowski, A. 2001. Adsorption - from theory to practice. Advances in Colloid and Interface Science. 93: 135-224.

Dada, A. O., Olalekan, A. P., Olatunya, A. M. y Dada, O. 2012. Langmuir, Freundlich, Temkin and Dubinin-Radushkevich Isotherms Studies of Equilibrium Sorption of $\mathrm{Zn}^{2+}$ Unto Phosphoric Acid Modified Rice Husk. IOSR Journal of Applied Chemistry. 3: 38-45.

Dan, T. H., Quang, L. N., Chiem, N. H. y Brix, H. 2011. Treatment of high-strength wastewater in tropical constructed wetlands planted with Sesbania sesban: Horizontal subsurface flow versus vertical downflow. Ecological Engineering. 37: 711-720.

Das, J., Patra, B. S., Baliarsingh, N. y Parida, K. M. 2006. Adsorption of phosphate by layered double hydroxides in aqueous solutions. Applied Clay Science. 32: 252-260.

Davies, K. J. P., Lloyd, D. y Boddy, L. 1989. The Effect of Oxygen on Denitrification in Paracoccus denitrificans and Pseudomonas aeruginosa. Journal of General Microbiology. 135: 2445-2451.

Decamp, O. y Warren, A. 2001. Abundance, biomass and viability of bacteria in wastewaters: impact of treatment in horizontal subsurface flow constructed wetlands. Water Research. 35: 3496-3501.

DeJournett, T. D., Arnold, A. W. y LaPara, T. M. 2007. The characterization and quantification of methanotrophic bacterial populations in constructed wetland sediments using PCR targeting 16S rRNA gene fragments. Applied Soil Ecology. 35: 648-659.

Delorme, S., Lemanceau, P., Christen, R., Corberand, T., Meyer, J. M. y Gardan, L. 2002. Pseudomonas lini sp. nov., a novel species from bulk and rhizospheric soils. International Journal of Systematic and Evolutionary Microbiology. 52: 513-523.

DeSantis, T. Z., Brodie, E. L., Moberg, J. P., Zubieta, I. X., Piceno, Y. M. y Andersen, G. L. 2007. High-Density Universal 16S rRNA Microarray Analysis Reveals Broader 
Diversity than Typical Clone Library When Sampling the Environment. Microbial Ecology. 53: 371-383.

Ding, Y., Song, X., Wang, Y. y Yan, D. 2012. Effects of dissolved oxygen and influent COD/N ratios on nitrogen removal in horizontal subsurface flow constructed wetland. Ecological Engineering. 46: 107-111.

Dong, X. y Reddy, G. B. 2010. Soil bacterial communities in constructed wetlands treated with swine wastewater using PCR-DGGE technique. Bioresource Technology. 101: 11751182.

Dong, X. y Reddy, G. B. 2012. Ammonia-oxidizing bacterial community and nitrification rates in constructed wetlands treating swine wastewater. Ecological Engineering. 40: 189197.

Drexler, J. Z., Andrson, F. E. y Snyder, R. L. 2008. Evapotranspiration rates and crop coefficients for a restored marsh in the Sacramento-San Joaquin Delta, California, USA. Hydrological processes. 22: 725-735.

Drizo, A., Comeau, Y., Forget, C. y Chapuis, R. P. 2002. Phosphorus Saturation Potential: A Parameter for Estimating the Longevity of Constructed Wetland Systems. Environmental Science \& Technology. 36: 4642-4648.

Drizo, A., Forget, C., Chapuis, R. P. y Comeau, Y. 2006. Phosphorus removal by electric arc furnace steel slag and serpentinite. Water Research. 40: 1547-1554.

Dubbe, D. R., Garver, E. G. y Pratt, D. C. 1988. Production of Cattail (Typha spp.) Biomass in Minnesota, USA. Biomass. 79-104.

Ducey, T. F. y Hunt, P. G. 2013. Microbial community analysis of swine wastewater anaerobic lagoons by next-generation DNA sequencing. Anaerobe. 21: 50-57.

Dunbar, J., Barns, S. M., Ticknor, L. O. y Kuske, C. R. 2002. Empirical and Theoretical Bacterial Diversity in Four Arizona Soils. Applied and Environmental Microbiology. 68: 3035-3045.

Dunne, E. J. y Reddy, K. R. 2005. Phosphorus biogeochemistry of wetlands in agricultural watersheds. pp. 105-119 en Dunne, E. J., Reddy, R. y Carton, O. T., editores. Nutrient management in agricultural watersheds: a wetland solution. Wageningen Academic Publishers. Wageningen, Holanda.

Dunne, E. J., Culleton, N., O'Donovan, G., Harrington, R. y Olsen, A. E. 2005. An integrated constructed wetland to treat contaminants and nutrients from dairy farmyard dirty water. Ecological Engineering. 24: 221-234.

Ezzahri, J., Ennabili, A. y Radoux, M. 2010. Artificial ecosystems for wastewaters treatment under Mediterranean conditions (Morocco). Biological Diversity and Conservation. 3: 145-150.

Fahrbach, M., Kuever, J., Remesch, M., Huber, B. E., Kämpfer, P., Dott, W. y Hollender, J. 2008. Steroidobacter denitrificans gen. nov., sp. nov., a steroidal hormone-degrading gammaproteobacterium. International Journal of Systematic and Evolutionary Microbiology. 58: 2215-2223.

Faulwetter, J. L., Gagnon, V., Sundberg, C., Chazarenc, F., Burr, M. D., Brisson, J., Camper, A. K. y Stein, O. R. 2009. Microbial processes influencing performance of treatment wetlands: A review. Ecological Engineering. 35: 987-1004.

Felsenstein, J. 1985. Confidence limits on phylogenies: an approach using the bootstrap. Evolution. 39: 783-791.

Felsenstein, J. 2004. Inferring Phylogenies, Sunderland, MA, USA.

Fernández, G. J., de Miguel, B. E., de Miguel, M. J. y Curt, F. M. D. 2005. Manual de Fitodepuración. Filtros de macrófitas en flotación. Proyecto LIFE. España.

Ferrero, E. M., de Godos, I., Rodríguez, E. M., García-Encina, P. A., Muñoz, R. y Bécares, E. 2012. Molecular characterization of bacterial communities in algal-bacterial photobioreactors treating piggery wastewaters. Ecological Engineering. 40: 121-130.

Fonder, N. 2010. Hydraulic and removal efficiencies of horizontal flow treatment wetlands. Université de Liege Gembloux. Bélgica.

Fox, P. M. y Doner, H. E. 2003. Accumulation, release, and solubility of arsenic, molybdenum, and vanadium in wetland sediments. Journal of Environmental Quality. 32: 2428-2435. 
Freeman, J. S. y Rowell, D. L. 1981. The adsorption and precipitation of phosphate onto calcite. Journal of Soil Science. 32: 75-84.

Gagnon, V., Chazarenc, F., Comeau, Y. y Brisson, J. 2007. Influence of macrophyte species on microbial density and activity in constructed wetlands. Water Science \& Technology. 56: 249-254.

Gao, S., Tanii, K. K., Peters, D. W. y Herbel, M. J. 2000. Water selenium speciation and sediment fractionation in a California flow-through wetland system. Journal of Environmental Quality. 29: 1275-1283.

Gao, Y., X.Z., Y., Wu, S. C., Cheung, K. C., Tam, N. F. Y., Qian, P. Y. y Wong, M. H. 2006. Interactions of rice (Oryza sativa L.) and PAH-degrading bacteria (Acinetobacter $\mathrm{sp}$.) on enhanced dissipation of spiked phenanthrene and pyrene in waterlogged soil. Science of the Total Environment. 372: 1-11.

García, F. B. 2007. Digestión metanogénica de purines porcinos y "stripping" de N. http://www.3tres3.com/medioambiente/digestion-metanogenica-de-purines-porcinos-ystripping-de-n 2006/. Fecha de acceso: 20-02-2013.

Gault, A. G., Ibrahim, A., Langley, S., Renaud, R., Takahashi, Y., Boothman, C., Lloyd, J. R., Clark, I. D., Ferris, F. G. y Fortin, D. 2011. Microbial and geochemical features suggest iron redox cycling within bacteriogenic iron oxide-rich sediments. Chemical Geology. 281: 41-51.

Ge, Y., Zhang, C., Jiang, Y., Yue, C., Jiang, Q., Min, H., Fan, H., Zeng, Q. y Chang, J. 2011. Soil Microbial Abundances and Enzyme Activities in Different Rhizospheres in an Integrated Vertical Flow Constructed Wetland. CLEAN - Soil, Air, Water. 39: 206-211.

Geary, P. M. y Moore, J. A. 1999. Suitability of a treatment wetland for dairy wastewaters. Water Science Technology. 40: 179-185.

Gersberg, R. M., Elkins, B. V. y Goldman, C. R. 1984. Use of artificial wetlands to remove nitrogen from wastewater. Journal of the Water Pollution Control Federation. 56: 152156.

Gitelson, A., Stark, R., Dor, I., Michelson, O. y Yacobi, Y. Z. 1999. Optical Characteristics of the Phototroph Thiocapsa roseopersicina and Implications for Real-Time Monitoring of the Bacteriochlorophyll Concentration. Applied and Environmental Microbiology. 65: 3392-3397.

González, F. T., Vallejos, G. G., Silveira, J. H., Franco, C. Q., García, J. y Puigagut, J. 2009. Treatment of swine wastewater with subsurface-flow constructed wetlands in Yucatán, Mexico: Influence of plant species and contact time. Water SA. 35: 335-342.

Gonzalias, A. E., Kuschk, P., Wiessner, A., Jank, M., Kästner, M. y Köser, H. 2007. Treatment of an artificial sulphide containing wastewater in subsurface horizontal flow laboratoryscale constructed wetlands. Ecological Engineering. 31: 259-268.

Goodfellow, M., Stanton, L. J., Simpson, K. E. y Minnikin, D. E. 1990. Numerical and chemical classification of Actinoplanes and some related actinomycetes. Journal of General Microbiology. 136: 19-36.

Google. 2013. Google Maps. www.maps.google.es. Fecha de acceso: 30-08-2013.

Gorra, R., Coci, M., Ambrosoli, R. y Laanbroek, H. J. 2007. Effects of substratum on the diversity and stability of ammonia-oxidizing communities in a constructed wetland used for wastewater treatment. Journal of Applied Microbiology. 103: 1442-1452.

Gray, K. R., Biddlestone, A. J., Thayanithy, K., Job, G. D., Bere, S. S. J., Edwards, J., Sun, G. y Cooper, D. J. 1996. Use of reed bed treatment systems for the removal of BOD and ammoniacal-nitrogen from agricultural 'dirty waters '. 5th Int. Conference on Wetland Systems for Water Pollution Control. 2. XII. 1-8. Viena, Austria.

Greene, A. C., Euzéby, J. P., Tindall, B. J. y Patel, B. K. C. 2009. Proposal of Frondihabitans gen. nov. to replace the illegitimate genus name Frondicola Zhang et al. 2007. International Journal of Systematic and Evolutionary Microbiology. 59: 447-448.

Gregory, S. P., Dyson, P. J., Fletcher, D., Gatland, P. y Shields, R. J. 2012. Nitrogen removal and changes to microbial communities in model flood/drain and submerged biofilters treating aquaculture wastewater. Aquacultural Engineering. 50: 37-45. 
Grizzetti, B. y Bouraoui, F. 2006. Assessment of Nitrogen and Phosphorus Environmental Pressure at European Scale. Sustainability, I. E. European Commission - Joint Research Centre. Bruselas, Bélgica.

Guidi, W., Piccioni, E. y Bonari, E. 2008. Evapotranspiration and cropcoefficient of poplar and willow short-rotation coppice used as vegetation filter. Bioresource Technology. 99: 4832-4840.

Gustafsson, J. P., Renman, A., Renman, G. y Poll, K. 2008. Phosphate removal by mineralbased sorbents used in filters for small-scale wastewater treatment. Water Research. 42: 189-197.

Guyoneaud, R., Süling, J., Petri, R., Matheron, R., Caumette, P., Pfennig, N. y Imhoff, J. F. 1998. Taxonomic rearrangements of the genera Thiocapsa and Amoebobacter on the basis of 16s rDNA sequence analyses, and description of Thiolamprovum gen. nov. International Journal of Systematic and Evolutionary Microbiology. 48: 957-964.

Haakensen, M., Dobson, C. M., Deneer, H. y Ziola, B. 2008. Real-time PCR detection of bacteria belonging to the Firmicutes Phylum. International Journal of Food Microbiology. 125: 236-241.

Haller, L., Tonolla, M., Zopfi, J., Peduzzi, R., Wildi, W. y Poté, J. 2011. Composition of bacterial and archaeal communities in freshwater sediments with different contamination levels (Lake Geneva, Switzerland). Water Research. 45: 1213-1228.

Hallin, S., Throbäck, I. N., Dicksved, J. y Pell, M. 2006. Metabolic Profiles and Genetic Diversity of Denitrifying Communities in Activated Sludge after Addition of Methanol or Ethanol. Applied and Environmental Microbiology. 72: 5445-5452.

Hanson, R. S. y Hanson, T. E. 1996. Methanotrophic Bacteria. Microbiological Reviews. 60: 439-471.

Harrington, R. y McInnes, R. 2009. Integrated Constructed Wetlands (ICW) for livestock wastewater management. Bioresource Technology. 100: 5498-5505.

Hashidoko, Y., Takakai, F., Toma, Y., Darung, U., Melling, L., Tahara, S. y Hatano, R. 2008. Emergence and behaviors of acid-tolerant Janthinobacterium sp. that evolves $\mathrm{N}_{2} \mathrm{O}$ from deforested tropical peatland. Soil Biology and Biochemistry. 40: 116-125.

Headley, T. R., Davison, L., Huett, D. O. y Muller, R. 2012. Evapotranspiration from subsurface horizontal flow wetlands planted with Phragmites australis in sub-tropical Australia. Water Research. 46: 345-354.

Hiraishi, A., Shin, Y. K. y Sugiyama, J. 1997. Proposal To Reclassify Zoogloea ramigera IAM 12670 (P.R.Dugan 115) as Duganella zoogloeoides gen. nov., sp. nov. International Journal of Systematic Bacteriology. 47: 1249-1252.

Hougardy, A. y Klemme, J. H. 1995. Nitrate reduction in a new strain of Rhodoferax fermentans. Archives of Microbiology. 164: 358-362.

House, W. A. 1999. The Physico-Chemical Conditions for the Precipitation of Phosphate with Calcium. Environmental Technology. 20: 727-733.

Hu, B., Shen, L., Du, P., Zheng, P., Xu, X. y Zeng, J. 2012. The Influence of Intense Chemical Pollution on the Community Composition, Diversity and Abundance of Anammox Bacteria in the Jiaojiang Estuary (China). PLOS One. 7: e33826.

Humphry, D. R., Black, G. W. y Cummings, S. P. 2003. Reclassification of 'Pseudomonas fluorescens subsp. cellulosa' NCIMB 10462 (Ueda et al. 1952) as Cellvibrio japonicus sp. nov. and revival of Cellvibrio vulgaris sp. nov., nom. rev. and Cellvibrio fulvus sp. nov., nom. rev. International Journal of Systematic and Evolutionary Microbiology. 53: 393-400.

Hunt, P. G. y Poach, M. E. 2001. State of the art for animal wastewater treatment in constructed wetlands. Water Science and Technology. 44: 19-25.

Hunt, P. G., Matheny, T. A. y Szogi, A. A. 2003. Denitrification in Constructed Wetlands Used for Treatment of Swine Wastewater. Journal of Environmental Quality. 32: 727-735.

Hunt, P. G., Poach, M. E., Matheny, T. A., Reddy, G. B. y Stone, K. C. 2006. Denitrification in Marsh-Pond-Marsh Constructed Wetlands Treating Swine Wastewater at Different Loading Rates. Soil Science Society of America. 70: 487-493. 
Hunt, P. G., Stone, K. C., Matheny, T. A., Poach, M. E., Vanotti, M. B. y Ducey, T. F. 2009. Denitrification of nitrified and non-nitrified swine lagoon wastewater in the suspended sludge layer of treatment wetlands. Ecological Engineering. 35: 1514-1522.

Hunter, W. J. 2007. An Azospira oryzae (syn Dechlorosoma suillum) Strain That Reduces Selenate and Selenite to Elemental Red Selenium. Current Microbiology. 54: 376-381.

Ibekwe, A. M., Lyon, S. R., Leddy, M. y Jacobson-Meyers, M. 2006. Impact of plant density and microbial composition on water quality from a free water surface constructed wetland. Journal of Applied Microbiology. 102: 921-936.

INE. 2013. Nomenclátor: Población del Padrón Continuo por Unidad Poblacional. http://www.ine.es/nomen2/index.do. Fecha de acceso: 20-05-2013.

Ingersoll, T. L. y Baker, L. A. 1998. Nitrate removal in wetland microcosms. Water Research. 32: 677-684.

Inoue, H., Nojima, H. y Okayama, H. 1990. High efficiency transformation of Escherichia coli with plasmids. Gene. 96: 23-28.

Jamieson, R., Gordon, R., Wheeler, N., Smith, E., Stratton, G. y Madani, A. 2007. Determination of first order rate constants for wetlands treating livestock wastewater in cold climates. Journal of Environmental Engineering Science. 6: 65-72.

Janssen, A. J. H., Lens, P. N. L., Stams, A. J. M., Plugge, C. M., Soroking, D. Y., Muyzer, G., Dijkman, H., Van Zessen, E., Luimes, P. y Buisman, C. J. N. 2009. Application of bacteria involved in the biological sulfur cycle for paper mill effluent purification. Science of the Total Environment. 407: 1333-1343.

Ji, G., Wang, R., Zhi, W., Liu, X., Kong, Y. y Tan, Y. 2012. Distribution patterns of denitrification functional genes and microbial floras in multimedia constructed wetlands. Ecological Engineering. 44: 179-188.

Johansson, L. 1999. Blast furnace slag as phosphorus sorbents - column studies. The Science of the Total Environment. 229: 89-97.

Johansson, L. y Gustafsson, J. P. 2000. Phosphate removal using blast furnace slags and opokamechanisms. Water Research. 34: 259-265.

Johansson, L. 2006. Substrates for phosphorus removal - Potential benefits for on-site wastewater treatment? Water Research. 40: 23-36.

Kadlec, R. H. y Knight, R. L. 1996. Treatment Wetlands. Lewis Publishers, Boca Raton, FL, USA.

Kadlec, R. H. 2000. The inadequacy of first-order treatment wetland models. Ecological Engineering. 15: 105-119.

Kadlec, R. H., Knight, R., Vymazal, J., Brix, H., Cooper, J. y Haberl, R. 2000. Constructed Wetlands for Pollution Control: Processes, Performance, Design and Operation. IWA Publications, Londres, Reino Unido.

Kadlec, R. H. 2003a. Effect of pollutant speciation in treatment wetlands design. Ecological Engineering. 20: 1-16.

Kadlec, R. H. 2003b. Pond and wetland treatment. Water Science \& Technology. 48: 1-8.

Kadlec, R. H. y Wallace, S. D. 2009. Treatment Wetlands. 2nd edition. Taylor \& Francis Group, LLC, Boca Raton, FL, USA.

Kadlec, R. H., Cuvellier, C. y Stober, T. 2010. Performance of the Columbia, Missouri, treatment wetland. Ecological Engineering. 36: 672-684.

Kadlec, R. H., Bays, J. S., Mokry, L. E., Andrews, D. y Ernst, M. R. 2011. Performance analysis of the Richland-Chambers treatment wetlands. Ecological Engineering. 37: 176-190.

Kadlec, R. H., Pries, J. y Lee, K. 2012. The Brighton treatment wetlands. Ecological Engineering. 47: 56-70.

Kämpfer, P., Schulze, R., Jäckel, U., Malik, K. A., Amann, R. y Spring, S. 2005. Hydrogenophaga defluvii sp. nov. and Hydrogenophaga atypica sp. nov., isolated from activated sludge. International Journal of Systematic and Evolutionary Microbiology. 55: 341-344.

Kämpfer, P., Thummes, K., Chu, H. I., Tan, C. C., Arun, A. B., Chen, W. M., Lai, W. A., Shen, F. T., Rekha, P. D. y Young, C. C. 2008. Pseudacidovorax intermedius gen. nov., sp. 
nov., a novel nitrogen-fixing betaproteobacterium isolated from soil. International Journal of Systematic and Evolutionary Microbiology. 58: 491-495.

Kanso, S. y Patel, B. K. C. 2004. Phenylobacterium lituiforme sp. nov., a moderately thermophilic bacterium from a subsurface aquifer, and emended description of the genus Phenylobacterium. International Journal of Systematic and Evolutionary Microbiology. 54: 2141-2146.

Kapolos, J. y Koutsoukos, P. G. 1999. Formation of Calcium Phosphates in Aqueous Solutions in the Presence of Carbonate Ions. Langmuir. 15: 6557-6562.

Karpiscak, M. M., Freitas, R. J., Gerba, C. P., Sanchez, L. R. y Shamir, E. 1999. Management of dairy waste in the Sonoran desert using constructed wetland technology. Water Science \& Technology. 40: 57-65.

Kasalicky, V., Jezbera, J., Simek, K. y Hahn, M. W. 2010. Limnohabitans planktonicus sp. nov. and Limnohabitans parvus sp. nov., planktonic betaproteobacteria isolated from a freshwater reservoir, and emended description of the genus Limnohabitans. International Journal of Systematic and Evolutionary Microbiology. 60: 2710-2714.

Kato, K., Inoue, T., Ietsugu, H., Koba, T., Sasaki, H., Miyaji, N., Kitagawa, K., Sharma, P. K. y Nagasawa, T. 2013. Performance of six multi-stage hybrid wetland systems for treating high-content wastewater in the cold climate of Hokkaido, Japan. Ecological Engineering. 51: 256-263.

Kern, J. 2003. Seasonal efficiency of a constructed wetland for treating dairy farm wastewater. pp. 197-214 en Mander, U. y Jenssen, P. D., editores. Constructed wetlands for wastewater treatment in cold climates. WITpress. Estonia.

Kickuth, R. 1977. Degradation and incorporation of nutrients from rural wastewaters by plant hydrosphere under limnic conditions. pp. 335-343 Utilization of Manure by Land Spreading. Londres, Reino Unido.

Kim, E. H., Yim, S. B., Jung, H. C. y Lee, E. J. 2006. Hydroxyapatite crystallization from a highly concentrated phosphate solution using powdered converter slag as a seed material. Journal of Hazardous Materials. B136: 690-697.

Kim, M. K., Kim, Y. J., Cho, D. H., Yi, T. H., Soung, N. K. y Yang, D. C. 2007. Solimonas soli gen. nov., sp. nov., isolated from soil of a ginseng field. International Journal of Systematic and Evolutionary Microbiology. 57: 2591-2594.

Kim, W., Lee, S., Shin, S. G., Lee, C., Hwang, K. y Hwang, S. 2010. Methanogenic community shift in anaerobic batch digesters treating swine wastewater. Water Research. 44: 49004907.

Kincanon, R. y McAnally, A. S. 2004. Enhancing commonly used model predictions for constructed wetland performance: as-built design considerations. Ecological Modelling. 174: 309-322.

Kitahara, M., Sakamoto, M., Tsuchida, S., Kawasumi, K., Amao, H., Benno, Y. y Ohkuma, M. 2012. Bacteroides stercorirosoris sp. nov. and Bacteroides faecichinchillae sp. nov., isolated from chinchilla (Chinchilla lanigera) faeces. International Journal of Systematic and Evolutionary Microbiology. 62: 1145-1150.

Knight, R. L., Payne Jr., V. W. E., Borer, R. E., Clarke Jr., R. A. y Pries, J. H. 2000. Constructed wetlands for livestock wastewater management. Ecological Engineering. 15: 41-55.

Kojima, H. y Fukui, M. 2011. Sulfuritalea hydrogenivorans gen. nov., sp. nov., a facultative autotroph isolated from a freshwater lake. International Journal of Systematic and Evolutionary Microbiology. 61: 1651-1655.

Korkusuz, E. A., Beklioglu, M. y Demirer, G. N. 2005. Comparison of the treatment performances of blast furnace slag-based and gravel-based vertical flow wetlands operated identically for domestic wastewater treatment in Turkey. Ecological Engineering. 24: 187-200.

Kouki, S., Saidi, N., M'hiri, F., Nasr, H., Cherif, H., Ouzari, H. y Hassen, A. 2011. Isolation and characterization of facultative mixotrophic ammonia-oxidizing bacteria from constructed wetlands. Journal of Environmental Sciences. 23: 1699-1708. 
Krasnits, E., Friedler, E., Sabbah, I., Beliavski, M., Tarre, S. y Green, M. 2009. Spatial distribution of major microbial groups in a well established constructed wetland treating municipal wastewater. Ecological Engineering. 35: 1085-1089.

Kwon, S. W., Kim, B. Y., Weon, H. Y., Baek, Y. K. y Go, S. J. 2007. Arenimonas donghaensis gen. nov., sp. nov., isolated from seashore sand. International Journal of Systematic and Evolutionary Microbiology. 57: 954-958.

Laanbroek, H. J. 1990. Bacterial cycling of minerals that affect plant growth in waterlogged soils: a review. Aquatic Botany. 38: 109-125.

Lake, J. A. 1994. Reconstructing evolutionary trees from DNA and protein sequences: paralinear distances. Proceedings of the National Academy of Sciences of USA. 91: 1455-1459.

Lambo, A. J. y Patel, T. R. 2006. Cometabolic Degradation of Polychlorinated Biphenyls at Low Temperature by Psychrotolerant Bacterium Hydrogenophaga sp. IA3-A. Current Microbiology. 53: 48-52.

Langergraber, G. 2008. Modeling of processes in subsurface flow constructed wetlands - A review. Vadose Zone Journal. 7: 830-842.

Lansing, S. L. y Martin, J. F. 2006. Use of an ecological treatment system (ETS) for removal of nutrients from dairy wastewater. Ecological Engineering. 28: 235-245.

Larsen, E. I. y Greenway, M. 2004. Quantification of biofilms in a sub-surface flow wetland and their role in nutrient removal. Water Science \& Technology. 49: 115-122.

Larsson, S., Cuingnet, C., Clause, P., Jacobsson, I., Aronsson, P., Perttu, K., Rosenqvist, H., Dawson, M., Wilson, F., Backlund, A., Mavrogianopoulus, G., Riddel-Black, D., Carlander, A., Stenstrom, T. A. y Hasselgren, K. 2003. Short-rotation Willow Biomass Plantations Irrigated and Fertilised with Wastewaters - Results from a 4-year multidisciplinary field project in Sweden, France, Northern Ireland and Greece. Agency, D. E. P. Danish Ministry of the Environment. Dinamarca.

Lazaro, C. Z., Vich, D. V., Hirasawa, J. S. y Varesche, M. B. A. 2012. Hydrogen production and consumption of organic acids by a phototrophic microbial consortium. International Journal of Hydrogen Energy. 37: 11691-11700.

Lee, C., Lee, C. C., Lee, F. Y., Tseng, S. K. y Liao, C. J. 2004. Performance of subsurface flow constructed wetland taking pretreated swine effluent under heavy loads. Bioresource Technology. 92: 173-179.

Lee, C., Fletcher, T. D. y Sun, G. 2009. Nitrogen removal in constructed wetland systems. Engineering in Life Sciences. 9: 11-22.

Lee, M. S., Drizo, A., Rizzo, D. M., Druschel, G., Hayden, N. y Twohig, E. 2010a. Evaluating the efficiency and temporal variation of pilot-scale constructed wetlands and steel slag phosphorus removing filters for treating dairy wastewater. Water Research. 44: 40774086.

Lee, S., Maniquiz, M. C. y Kim, L. H. 2010b. Characteristics of contaminants in water and sediment of a constructed wetland treating piggery wastewater effluent. Journal of Environmental Sciences. 22: 940-945.

Lee, S. H. y Moon, V. H. 1997. Adsorption of phosphorus in saturated slag media columns. Separation and Purification Technology. 12: 109-118.

Levasseur, P. 1998. Composition des lisiers de porc, facteurs de variation et methodes d'evaluation. TechniPorc. 21: 19-25.

Levasseur, P. 2004. Epandage d'eau résiduaire issue d'un traitement biologique. Effet de fortes doses de potassium sur le maïs. TechniPorc. 27: 25-28.

Li, J., Wen, Y., Zhou, Q., Xingjie, Z., Li, X., Yang, S. y Lin, T. 2008. Influence of vegetation and substrate on the removal and transformation of dissolved organic matter in horizontal subsurface-flow constructed wetlands. Bioresource Technology. 99: 49904996.

Li, M. y Gu, J. D. 2011. Advances in methods for detection of anaerobic ammonium oxidizing (anammox) bacteria. Applied Microbiology Biotechnology. 90: 1241-1252. 
Li, Y. H., Liu, Q. F., Liu, Y., Zhu, J. N. y Zhang, Q. 2011. Endophytic bacterial diversity in roots of Typha angustifolia L. in the constructed Beijing Cuihu Wetland (China). Research in Microbiology. 162: 124-131.

Lian-sheng, H., Hong-liang, L., Bei-dou, X. y Ying-bo, Z. 2006. Effects of effluent recirculation in vertical-flow constructed wetland on treatment efficiency of livestock wastewater. Water Science and Technology. 54: 137-146.

Liira, M., Koiv, M., Mander, U., Motlep, R., Vohla, C. y Kirsimät, K. 2009. Active filtration of phosphorus on Ca-rich hydrated oil shale ash: does longer retention time improve the process? Environmental Science \& Technology. 43: 3809-3814.

Lim, S. J. 2008. Swine wastewater treatment by the static granular bed reactor. Iowa State University. Ames, IA, USA.

Lim, Y. W., Lee, S. A., Kim, S. B., Yong, H. Y., Yeon, S. H., Park, Y. K., Jeong, D. W. y Park, J. S. 2005. Diversity of Denitrifying Bacteria Isolated from Daejeon Sewage Treatment Plant. The Journal of Microbiology. 43: 383-390.

Lin, Y. F., Jing, S. R., Wang, T. W. y Lee, D. Y. 2002. Effects of macrophytes and external carbon sources on nitrate removal from groundwater in constructed wetlands. Environmental Pollution. 119: 413-420.

Liu, J., Lu, Z., Yang, J., Xing, M., Yu, F. y Guo, M. 2012. Effect of earthworms on the performance and microbial communities of excess sludge treatment process in vermifilter. Bioresource Technology. 117: 214-221.

Liu, Y., Jin, J. H., Zhou, Y. G., Liu, H. C. y Liu, Z. P. 2010. Flavobacterium caeni sp. nov., isolated from a sequencing batch reactor for the treatment of malachite green effluents. International Journal of Systematic and Evolutionary Microbiology. 60: 417-421.

López-González, C. y Márquez-Linares, M. A. 2004. Corrección secuencial de Bonferroni para el ajuste del nivel de significancia en pruebas estadísticas simultáneas. Vertebrata Mexicana. 14: 21-28.

Lozupone, C. y Knight, R. 2005. UniFrac: a New Phylogenetic Method for Comparing Microbial Communities. Applied and Environmental Microbiology. 71: 8228-8235.

Lu, L., Xing, D. y Ren, N. 2012. Pyrosequencing reveals highly diverse microbial communities in microbial electrolysis cells involved in enhanced $\mathrm{H}_{2}$ production from waste activated sludge. Water Research. 46: 2425-2434.

Lueders, T., Kindler, R., Miltner, A., Friedrich, M. W. y Kaestner, M. 2006. Identification of Bacterial Micropredators Distinctively Active in a Soil Microbial Food Web. Applied and Environmental Microbiology. 72: 5342-5348.

Ma, J., Wang, Z., Zou, X., Feng, J. y Wu, Z. 2013. Microbial communities in an anaerobic dynamic membrane bioreactor (AnDMBR) for municipal wastewater treatment: Comparison of bulk sludge and cake layer. Process Biochemistry. 48: 510-516.

Magurran, A. E. 1988. Ecological diversity and its measurement, Nueva Jersey, NJ, USA.

Mäkinen, A. E., Lay, C. H., Nissilä, M. E. y Puhakka, J. A. 2013. Bioelectricity production on xylose with a compost enrichment culture. International Journal of Hydrogen Energy.

Mann, R. A. y Bavor, H. J. 1993. Phosphorus Removal in Constructed Wetlands Using Gravel and Industrial Waste Substrata. Water Science \& Technology. 27: 107-113.

Mantovi, P., Marmiroli, M., Maestri, E., Tagliavini, S., Piccinini, S. y Marmiroli, N. 2003. Application of a horizontal subsurface flow constructed wetland on treatment of dairy parlor wastewater. Bioresource Technology. 88: 85-94.

MAPA. 2006. Hechos y cifras de la agricultura, la pesca y la alimentación en España. Ministerio de Agricultura, Pesca y Alimentación. Madrid, España.

Margalef, R. 1972. Homage to Evelyn Hutchinson, or why is there an upper limit to diversity. pp. 211-235 en Deevey, E. S., editor. Growth by Intussusception. Ecological Essays in Honor of G.Evelyn Hutchinson. Transcriptions of The Connecticut Academy of Arts and Sciences. Gainesville, FL, USA.

Martín, I. y Fernández, J. 1992. Nutrient Dynamics and Growth of a Cattail Crop (Typha latifolia L.) Developed in an Effluent with High Eutrophic Potential - Application to Wastewater Purification Systems. Bioresource Technology. 42: 7-12. 
Masel, R. I. 1996. Principles of Adsorption and Reaction on Solid Surfaces. Wiley Interscience, Nueva York, NY, USA.

Mateu, J. R. 2005. La cogeneración como alternativa al tratamiento de los purines. http://www.3tres3.com/medioambiente/la-cogeneracion-como-alternativa-altratamiento-de-los-purines_1248/. Fecha de acceso: 20-02-2013.

Matthies, C., Evers, S., Ludwig, W. y Schink, B. 2000. Anaerovorax odorimutans gen. nov., sp. nov., a putrescine-fermenting, strictly anaerobic bacterium. International Journal of Systematic and Evolutionary Microbiology. 50: 1591-1594.

Mayes, W. M., Younger, P. L. y Aumonier, J. 2006. Buffering of alkaline steel slag leachate across a natural wetland. Environmental Science \& Technology. 40: 1237-1243.

Mayes, W. M., Younger, P. L. y Aumonier, J. 2008. Hydrogeochemistry of Alkaline Steel Slag Leachates in the UK. Water Air Soil Pollution. 195: 35-50.

McGechan, M. B., Moir, S. E., Castle, K. y Smit, I. P. J. 2005. Modelling oxygen transport in a reed-bed constructed wetland purification system for dilute effluents. Biosystems Engineering. 91: 191-200.

McGinnis, S. y Madden, T. L. 2004. BLAST: at the core of a powerful and diverse set of sequence analysis tools. Nucleic Acids Research. 32: 20-25.

Meers, E., Rousseau, D. P. L., Blomme, N., Lesage, E., Du Laing, G., Tack, F. M. G. y Verloo, M. G. 2005. Tertiary treatment of the liquid fraction of pig manure with Phragmites australis. Water, Air, and Soil Pollution. 160: 15-26.

Meers, E., Tack, F. M. G., Tolpe, I. y Michels, E. 2008. Application of a Full-scale Constructed Wetland for Tertiary Treatment of Piggery Manure: Monitoring Results. Water Air Soil Pollution. 193: 15-24.

Mergaert, J., Cnockaert, M. C. y Swings, J. 2003. Thermomonas fusca sp. nov. and Thermomonas brevis sp. nov., two mesophilic species isolated from a denitrification reactor with poly(e-caprolactone) plastic granules as fixed bed, and emended description of the genus Thermomonas. International Journal of Systematic and Evolutionary Microbiology. 53: 1961-1966.

Min-Ho, Y., Ten, L. N. y Im, W. T. 2007. Cohnella panacarvi sp. nov., a Xylanolytic Bacterium Isolated from Ginseng Cultivating Soil. Journal of Microbiology and Biotechnology. 17: 913-918.

Miñana-Galbis, D., Farfán, M., Fusté, M. C. y Lorén, J. G. 2007. Aeromonas bivalvium sp. nov., isolated from bivalve molluscs. International Journal of Systematic and Evolutionary Microbiology. 57: 582-587.

Mitsch, W. J. y Gosselink, J. G. 2007. Wetlands. 4th edition. John Wiley \& Sons Inc., Nueva York, NY, USA.

Molle, P. 2003. Filtres plantés de roseaux: limites hydrauliques et rétention du phosphore. Université Montpellier II Sciences et Techniques du Languedoc. Montpellier, Francia.

Molle, P., Liénard, A., Grasmick, A., Iwema, A. y Kabbabi, A. 2005. Apatite as an interesting seed to remove phosphorus from wastewater in constructed wetlands. Water Science \& Technology. 51: 193-203.

Morgan, J. A. y Martin, J. F. 2008. Performance of an ecological treatment system at three strengths of dairy wastewater loading. Ecological Engineering. 33: 195-209.

Morillas, E. P. 2000. Autorizaciones de vertido de aguas residuales. Técnicas de laboratorio. 22: 364-369.

Motz, H. y Geiseler, J. 2001. Products of steel slags an opportunity to save natural resources. Waste Management. 21: 285-293.

MSU. 2013. RDP's Pyrosequencing Pipeline. http://pyro.cme.msu.edu/spring/align.spr. Fecha de acceso: 21-05-2013.

Murray, F. W. 1967. On the computation of saturation vapor pressure. Journal of Applied Meteorology. 6: 203-204.

Muyzer, G., De Waal, E. C. y Uitterlinden, A. G. 1993. Profiling of Complex Microbial Populations by Denaturing Gradient Gel Electrophoresis Analysis of Polymerase Chain Reaction-Amplified Genes Coding for 16S rRNA. Applied and Environmental Microbiology. 59: 695-700. 
Narihiro, T., Terada, T., Ohashi, A., Kamagata, Y., Nakamura, K. y Sekiguchi, Y. 2012. Quantitative detection of previously characterized syntrophic bacteria in anaerobic wastewater treatment systems by sequence-specific rRNA cleavage method. Water Research. 46: 2167-2175.

Nawrocki, E. P., Kolbe, D. L. y Eddy, S. R. 2009. Infernal 1.0: Inference of RNA alignments. Bioinformatics. 25: 1335-1337.

Newman, J. M., Clausen, J. C. y Neafsey, J. A. 2000. Seasonal performance of a wetland constructed to process dairy milkhouse wastewater in Connecticut. Ecological Engineering. 14: 181-198.

Ning, Y. Y., Wang, S. F., Jin, D. W., Harada, H. y Shi, X. Y. 2013. Formation of hydrogenproducing granules and microbial community analysis in a UASB reactor. Renewable Energy. 53: 12-17.

Nishiyama, T., Ueki, A., Kaku, N., Watanabe, K. y Ueki, K. 2009. Bacteroides graminisolvens sp. nov., a xylanolytic anaerobe isolated from a methanogenic reactor treating cattle waste. International Journal of Systematic and Evolutionary Microbiology. 59: 19011907.

Nogales, B., Moore, E. R. B., Llobet-Brossa, E., Rossello-Mora, R., Amann, R. y Timmis, K. N. 2001. Combined Use of 16S Ribosomal DNA and 16S rRNA To Study the Bacterial Community of Polychlorinated Biphenyl-Polluted Soil. Applied and Environmental Microbiology. 67: 1874-1884.

Nurk, K., Truu, J., Truu, M. y Mander, U. 2005. Microbial Characteristics and Nitrogen Transformation in Planted Soil Filter for Domestic Wastewater Treatment. Journal of Environmental Science and Health. 40: 1201-1214.

O'Sullivan, L. A., Rinna, J., Humphreys, G., Weightman, A. J. y Fry, J. C. 2005. Fluviicola taffensis gen. nov., sp. nov., a novel freshwater bacterium of the family Cryomorphaceae in the phylum 'Bacteroidetes'. International Journal of Systematic and Evolutionary Microbiology. 55: 2189-2194.

Oehl, F., Frossard, E., Fliessbach, A., Dubois, D. y Oberson, A. 2004. Basal organic phosphorus mineralization in soils under different farming systems. Soil Biology and Biochemistry. 36: 667-675.

Ofek, M., Hadar, Y. y Minz, D. 2012. Ecology of Root Colonizing Massilia (Oxalobacteraceae). PLOS One. 7: 1-12.

Oros-Sichler, M., Costa, R., Heuer, H. y Smalla, K. 2007. Molecular Fingerprinting Techniques to Analyze Soil Microbial Communities. p. 646 en Van Elsas, J. D., Jansson, J. K. y Trevors, J. T., editores. Modern Soil Microbiology. CRC Press. Boca Raton, FL, USA.

Pagnier, I., Raoult, D. y La Scola, B. 2011. Isolation and characterization of Reyranella massiliensis gen. nov., sp. nov. from freshwater samples by using an amoeba co-culture procedure. International Journal of Systematic and Evolutionary Microbiology. 61: 2151-2154.

Paredes, D., Kuschk, P., Mbwette, T. S. A., Stange, F., Müller, R. A. y Köser, H. 2007. New Aspects of Microbial Nitrogen Transformations in the Context of Wastewater Treatment - A Review. Engineering in Life Sciences. 7: 13-25.

Park, S., Yu, J., Byun, I., Cho, S., Park, T. y Lee, T. 2011. Microbial community structure and dynamics in a mixotrophic nitrogen removal process using recycled spent caustic under different loading conditions. Bioresource Technology. 102: 7265-7271.

Paul, E. A. y Clark, F. E. 1996. Soil microbiology and biochemistry. 2nd edition. Academic Press, San Diego, CA, USA.

Pedescoll, A. 2010. Clogging in Horizontal Subsurface Flow Constructed Wetlands. Measures, design factors and prevention strategies. Universidad Politécnica de Barcelona. Barcelona, España.

Pei, Y. S., Wang, J., Wang, Z. Y. y Yang, Z. F. 2010. Characteristics of Ammonia-oxidizing and Denitrifying Bacteria at the River-sediment Interface. Procedia Environmental Sciences. 2: 1988-1996. 
Pellegrin, V., Juretschko, S., Wagner, M. y Cottenceau, G. 1999. Morphological and Biochemical Properties of a Sphaerotilus sp. Isolated From Paper Mill Slimes. Applied and Environmental Microbiology. 65: 156-162.

Pervin, H. M., Batstone, D. J. y Bond, P. L. 2013. Previously unclassified bacteria dominate during thermophilic and mesophilic anaerobic pre-treatment of primary sludge. Systematic and Applied Microbiology. 36: 281-290.

Pianetti, A., Bruscolini, F., Rocchi, M. B., Sabatini, L. y Citterio, B. 2006. Influence of different concentrations of nitrogen and phosphorous on Aeromonas spp. growth. Igiene e Sanità Pubblica. 62: 609-622.

Pini, F., Galardini, M., Bazzicalupo, M. y Mengoni, A. 2011. Plant-Bacteria Association and Symbiosis: Are There Common Genomic Traits in Alphaproteobacteria? Genes. 2: 1017-1032.

Poach, M. E., Hunt, P. G., Vanotti, M. B., Stone, K. C., Matheny, T. A., Johnson, M. H. y Sadler, E. J. 2003. Improved nitrogen treatment by constructed wetlands receiving partially nitrified liquid swine manure. Ecological Engineering. 20: 183-197.

Poach, M. E., Hunt, P. G., Reddy, G. B., Stone, K. C., Johnson, M. H. y Grubbs, A. 2004. Swine wastewater treatment by marsh-pond-marsh constructed wetlands under varying nitrogen loads. Ecological Engineering. 23: 165-175.

Poach, M. E., Hunt, P. G., Reddy, G. B., Stone, K. C., Johnson, M. H. y Grubbs, A. 2007. Effect of intermittent drainage on swine wastewater treatment by marsh-pond-marsh constructed wetlands. Ecological Engineering. 30: 43-50.

Postma, J. y van Veen, J. A. 1990. Habitable Pore Space and Survival of Rhizobium leguminosarum biovar trifolii Introduced into Soil. Microbial Ecology. 19: 149-161.

Pouliot, F., Godbout, S., Dufour, V., Von Bernuth, R. D. y Hill, J. 2005. Efficacité de la séparation fèces-urine sous caillebotis bilan et sous-produits. TechniPorc. 28: 35-39.

Proctor, D. M., Fehling, K. A., Shay, E. C., Wittenborn, J. L., Green, J. J., Avent, C., Bigham, R. D., Connolly, M., Lee, B., Shepker, T. O. y Zak, M. A. 2000. Physical and Chemical Characteristics of Blast Furnace, Basic Oxygen Furnace, and Electric Arc Furnace Steel Industry Slags. Environmental Science \& Technology. 34: 1576-1582.

Qiu, Y. L., Hanada, S., Ohashi, A., Harada, H., Kamagata, Y. y Sekiguchi, Y. 2008. Syntrophorhabdus aromaticivorans gen. nov., sp. nov., the First Cultured Anaerobe Capable of Degrading Phenol to Acetate in Obligate Syntrophic Associations with a Hydrogenotrophic Methanogen. Applied and Environmental Microbiology. 74: 20512058.

Qu, J. H., Li, H. F., Yang, J. S. y Yuan, H. L. 2008. Flavobacterium cheniae sp. nov., isolated from sediment of a eutrophic reservoir. International Journal of Systematic and Evolutionary Microbiology. 58: 2186-2190.

Qu, J. H. y Yuan, H. L. 2008. Sediminibacterium salmoneum gen. nov., sp. nov., a member of the phylum Bacteroidetes isolated from sediment of a eutrophic reservoir. International Journal of Systematic and Evolutionary Microbiology. 58: 2191-2194.

Quaiser, A., Ochsenreiter, T., Lanz, C., Schuster, S. C., Treusch, A. H., Eck, J. y Schleper, C. 2003. Acidobacteria form a coherent but highly diverse group within the bacterial domain: evidence from environmental genomics. Molecular Microbiology. 50: 563-575.

Radoux, M. y Kemp, D. 1982. Aproche écologique et experimentale des potentialités épuratrices de quelques hélophytes: Phragmites australis (cav.) Trin. Ex Steud. Typha latifolia L. et Carex acuta L. . Trib. Cebedeau. 465-466: 325-340.

Radoux, M., Cadelli, D. y Nemcova, M. 1997. A comparison of purification efficiencies of various constructed ecosystems (aquatic, semi-acuatic and terrestrial) receiving urban wastewaters. Wetlands Ecology and Management. 4: 207-217.

Radoux, M., Cadelli, D., Nemcova, M., Ennabili, A. y Ezzahri, J. 2003. Optimisation of extensive wastewater treatment systems under Mediterranean conditions (Morocco): compared purification efficiency of artificial ecosystems. pp. 143-168 en Vymazal, J., editor. Wetlands-nutrients, metals and mass cycling. Backhuys Publishers. Lieden, Holanda. 
Ramond, J. B., Welz, P. J., Cowan, D. A. y Burton, S. G. 2012. Microbial community structure stability, a key parameter in monitoring the development of constructed wetland mesocosms during start-up. Research in Microbiology. 163: 28-35.

Rastogi, G. y Sani, K. R. 2011. Molecular Techniques to Assess Microbial Community Structure, Function, and Dynamics in the Environment. p. 516 en Ahmad, I., Ahmad, F. y Pichtel, J., editores. Microbes and Microbial Technology: Agricultural and Environmental Applications. Springer New York. Nueva York, NY, USA.

RCoreTeam. 2012. R: A Language and Environment for Statistical Computing. R Foundation for Statistical Computing. 2.15.1:

Reddy, G. B., Hunt, P. G., Phillips, R., Stone, K. C. y Grubbs, A. 2001. Treatment of swine wastewater in marsh-pond-marsh constructed wetlands. Water Science and Technology. 44: 545-550.

Reddy, K. R., Overcash, M. R., Khaleel, R. y Westerman, P. W. 1980. Phosphorus AdsorptionDesorption Characteristics of Two Soils Utilized for Disposal of Animal Wastes. Journal of Environmental Quality. 9: 86-92.

Reddy, K. R. y Patrick, W. H. 1984. Nitrogen transformations and loss in flooded soils and sediments. CRC Crit Rev Environ Control. 13: 273-309.

Reddy, K. R. y D'Angelo, E. M. 1994. Soil process regulating water quality in wetlands. pp. 309-324 en Mitsch, W. J., editor. Global Wetlands. Elsevier. Amsterdam, Holanda.

Reddy, K. R., Kadlec, R. H., Flaig, E. y Gale, P. M. 1999. Phosphorus Retention in Streams and Wetlands: A Review. Critical Reviews in Environmental Science and Technology. 29: 83-146.

Reddy , K. R., D'Angelo, E. M. y Harris, W. G. 2000. Biogeochemistry of Wetlands. pp. 89119 en Sumner, M. E., editor. Handbook of Soil Science. CRC Press. Boca Raton, FL, USA.

Reed, S. C., Middlebrooks, E. J. y Crites, R. W. 1988. Natural Systems for Waste Management and Treatment. 1st edition. McGraw-Hill Book Company, New York, NY, USA.

Reed, S. C. y Brown, D. S. 1993. Constructed wetland design - the first generation. Water Environment Research. 64: 776-781.

Reinhold-Hurek, B. y Hurek, T. 2000. Reassessment of the taxonomic structure of the diazotrophic genus Azoarcus sensu lato and description of three new genera and new species, Azovibrio restrictus gen. nov., sp. nov., Azospira oryzae gen. nov., sp. nov. and Azonexus fungiphilus gen. nov., sp. nov. International Journal of Systematic and Evolutionary Microbiology. 50: 649-659.

Richardson, C. J. 1999. The role of wetlands in storage, release, and cycling of phosphorus on the landscape: a 25-year retrospective. pp. 47-68 en Reddy, K. R., O'Connor, G. A. y Schelske, C. L., editores. Phosphorus biogeochemistry in subtropical ecosystems. CRC Press. Boca Raton, FL, USA.

Rittman, B. E. y McCarty, P. L. 2001. Environmental biotechnology: principles and applications. McGraw-Hill, Nueva York, NY, USA.

Rivas, R., Martens, M., de Lajudie, P. y Willems, A. 2009. Multilocus sequence analysis of the genus Bradyrhizobium. Systematic and Applied Microbiology. 32: 101-110.

Robinson, I. M. y Freundt, E. A. 1987. Proposal for an Amended Classification of Anaerobic Mollicutes. International Journal of Systematic Bacteriology. 37: 78-81.

Rodríguez-Santiago, B. y Armengol, L. 2012. Tecnologías de secuenciación de nueva generación en diagnóstico genético pre- y postnatal. Diagnóstico Prenatal. 23: 56-66.

Rogosa, M. 1971. Peptococcaceae, a New Family To Include the Gram-Positive, Anaerobic Cocci of the Genera Peptococcus, Peptostreptococcus, and Ruminococcus. International Journal of Systematic Bacteriology. 21: 234-237.

Roques, H. 1990. Fondements théoriques du traitement chimique des eaux. Technique et documentation - Lavoisier, París, Francia.

Roselló-Mora, R. y Antón, J. 2012. "Procariotas": arqueas y bacterias. p. 617 en Vargas, P. y Zardoya, R., editores. El Árbol de la Vida: sistemática y evolución de seres vivos. CSIC. Madrid, España. 
Rousseau, D. P. L., Vanrolleghem, P. A. y De Pauw, N. 2004. Model-based design of horizontal subsurface flow constructed treatment wetlands: a review. Water Research. 38: 14841493.

Ruiz-Rueda, O., Hallin, S. y Bañeras, L. 2009. Structure and function of denitrifying and nitrifying bacterial communities in relation to the plant species in a constructed wetland. FEMS Microbial Ecology. 67: 308-319.

Saeed, T. y Sun, G. 2012. A review on nitrogen and organics removal mechanisms in subsurface flow constructed wetlands: Dependency on environmental parameters, operating conditions and supporting media. Journal of Environmental Management. 112: 429-448.

Sakadevan, K. y Bavor, H. J. 1998. Phosphate adsorption characteristics of soils, slags and zeolite to be used as substrates in constructed wetland systems. Water Research. 32: 393-399.

Sakamoto, M., Suzuki, N., Matsunaga, N., Koshihara, K., Seki, M., Komiya, H. y Benno, Y. 2009. Parabacteroides gordonii sp. nov., isolated from human blood cultures. International Journal of Systematic and Evolutionary Microbiology. 59: 2843-2847.

Salas, J. J., Pidre, J. R. y Sánchez, L. 2007. Manual de tecnologías no convencionales para la depuración de aguas residuales. Capítulo IV: Humedales artificiales. Coria Gráfica, Sevilla, España.

Salinero, K. K., Keller, K., Feil, W. S., Feil, H., Trong, S., Di Bartolo, G. y Lapidus, A. 2009. Metabolic analysis of the soil microbe Dechloromonas aromatica str. RCB: indications of a surprisingly complex life-style and cryptic anaerobic pathways for aromatic degradation. BMC Genomics. 10: 1-23.

Schaafsma, J. A., Baldwin, A. H. y Streb, C. A. 2000. An evaluation of a constructed wetland to treat wastewater from a dairy farm in Maryland, USA. Ecological Engineering. 14: 199206.

Schierup, H. H., Brix, H. y Lorenzen, B. 1990. Spildevandsrensning i rodzoneanlog. Spildevandsforskning fra Miljostyrelsen. 8: 1-88.

Schleifer, K. H. 2004. Microbial Diversity: Facts, Problems and Prospects. Systematic and Applied Microbiology. 27: 3-9.

Schloss, D. P., Westcott, S. L., Ryabin, T., Hall, J. R., Hartmann, M., Hollister, E. B., Lesniewski, R. A., Oakley, B. B., Parks, D. H., Robinson, C. J., Sahl, J. W., Stres, B., Thallinger, G. G., Van Horn, D. J. y Weber, C. F. 2009. Introducing mothur: OpenSource, Platform-Independent, Community-Supported Software for Describing and Comparing Microbial Communities. Applied and Environmental Microbiology. 75: 7537-7541.

Schloss, P. D. y Westcott, S. L. 2011. Assessing and Improving Methods Used in Operational Taxonomic Unit-Based Approaches for 16S rRNA Gene Sequence Analysis. Applied and Environmental Microbiology. 77: 3219-3226.

Schmid, B. H., Stephan, U. y Hengl, M. A. 2005. Sediment deposition in constructed wetland ponds with emergent vegetation: laboratory study and mathematical model. Water Science \& Technology. 51: 307-314.

Scholz, M. 2003. Performance predictions of mature experimental constructed wetlands which treat urban water receiving high loads of lead and copper. Water Research. 37: 12701277.

Segers, P., Vancanneyt, M., Pot, B., Torck, U., Hoste, B., Dewettinck, D., Falsen, E., Kersters, K. y de Vos, P. 1994. Classification of Pseudomonas diminuta Leifson and Hugh 1954 and Pseudomonas vesicularis Busing, Doll, and Freytag 1953 in Brevundimonas gen. nov. as Brevundimonas diminuta comb. nov. and Brevundimonas vesicularis comb. nov., Respectively. International Journal of Systematic and Evolutionary Microbiology. 44: 499-510.

Seidel, K. 1953. Pflanzungen zwischen Gewässern und Land. Mitteilungen Mas-Planc Gesselschaft. 17-20. 
Sharma, P. K., Takashi, I., Kato, K., Ietsugu, H., Tomita, K. y Nagasawa, T. 2012. Seasonal efficiency of a hybrid sub-surface flow constructed wetland system in treating milking parlor wastewater at northern Hokkaido. Ecological Engineering. 53: 257-266.

Sharma, R., Ranjan, R., Kapardar, R. K. y Grover, A. 2005. 'Unculturable' bacterial diversity: An untapped resource. Current Science. 89: 72-77.

Shi, C. 2002. Characteristics and cementitious properties of ladle slag fines from steel production. Cement and Concrete Research. 32: 459-462.

Shilton, A. N., Elmetri, I., Drizo, A., Pratt, S., Haverkamp, R. G. y Bilby, S. C. 2006. Phosphorus removal by an 'active' slag filter - a decade of full scale experience. Water Research. 40: 113-118.

Sikora, F. J., Zhu, T., Behrends, L. L., Steinberg, S. L. y Coornod, H. S. 1995. Ammonium removal in constructed wetlands with recirculating subsurface flow: removal rates mechanisms. Water Science \& Technology. 32: 193-202.

Sleytr, K., Tietz, A., Langergraber, G., Haberl, R. y Sessitsch, A. 2009. Diversity of abundant bacteria in subsurface vertical flow constructed wetlands. Ecological Engineering. 35: 1021-1025.

Sliekers, A. O., Derwort, N., Campos Gomez, J. L., Strous, M., Kuenen, J. G. y Jetten, M. S. M. 2002. Completely autotrophic nitrogen removal over nitrite in one single reactor. Water Resources. 36: 2475-2482.

Song, J., Choo, Y. J. y Cho, J. C. 2008. Perlucidibaca piscinae gen. nov., sp. nov., a freshwater bacterium belonging to the family Moraxellaceae. International Journal of Systematic and Evolutionary Microbiology. 58: 97-102.

Songliu, L., Hongying, H., Yingxue, S. y Jia, Y. 2009. Effect of carbon source on the denitrification in constructed wetlands. Journal of Environmental Sciences. 21: 10361043.

Sorensen, D. y Gianola, D. 2002. Likelihood, Bayesian and MCMC Methods in Quantitative Genetics. Springer, Nueva York, NY, U.S.A.

Sorrell, B. K. y Armstrong, W. 1994. On the difficulties of measuring oxygen release by root systems of wetland plants. Journal of Ecology. 82: 177-183.

Stackebrandt, E., Verbarg, S., Frühling, A., Busse, H. J. y Tindall, B. J. 2009. Dissection of the genus Methylibium: reclassification of Methylibium fulvum as Rhizobacter fulvus comb. nov., Methylibium aquaticum as Piscinibacter aquaticus gen. nov., comb. nov. and Methylibium subsaxonicum as Rivibacter subsaxonicus gen. nov., comb. nov. and emended descriptions of the genera Rhizobacter and Methylibium. International Journal of Systematic and Evolutionary Microbiology. 59: 2552-2560.

Steel, K. M., Alizadehhesari, K., Balucan, R. D. y Basic, B. 2013. Conversion of $\mathrm{CO}_{2}$ into mineral carbonates using a regenerable buffer to control solution pH. Fuel. 111: 40-47.

Stein, O. R., Hook, P. B., Biederman, J. A., Allen, W. C. y Borden, D. J. 2003. Does batch operation enhance oxidation in subsurface constructed wetlands? Water Science \& Technology. 48: 149-156.

Stein, O. R., Biederman, J. A., Hook, P. B. y Allen, W. C. 2006. Plant species and temperature effects on the $k-C^{*}$ first-order model for COD removal in batch-loaded SSF wetlands. Ecological Engineering. 26: 100-112.

Stone, K. C., Hunt, P. G., Szogi, A. A., Humenik, F. J. y Rice, J. M. 2002. Constructed Wetland Design and Performance for Swine Lagoon Wastewater Treatment. American Society of Agricultural Engineers. 45: 723-730.

Stone, K. C., Poach, M. E., Hunt, P. G. y Reddy, G. B. 2004. Marsh-pond-marsh constructed wetland design analysis for swine lagoon wastewater treatment. Ecological Engineering. 23: 127-133.

Stottmeister, U., Wießner, A., Kuschk, P., Kappelmeyer, U., Kästner, M., Bederski, O., Müller, R. A. y Moormann, H. 2003. Effects of plants and microorganisms in constructed wetlands for wastewater treatment. Biotechnology Advances. 22: 93-117.

Stumm, W. y Morgan, J. J. 1996. Aquatic Chemistry. Wiley-Interscience, Nueva York, NY, USA. 
Suliman, F., French, H. K., Haugen, L. E. y Sovik, A. K. 2006. Change in flow and transport patterns in horizontal subsurface flow constructed wetlands as a result of biological growth. Ecological Engineering. 27: 124-133.

Sun, G., Zhao, Y. y Allen, S. 2005. Enhanced removal of organic matter and ammoniacalnitrogen in a column experiment of tidal flow constructed wetland system. Journal of Biotechnology. 115: 189-197.

Sun, G., Zhu, Y., Saeed, T., Zhang, G. y Lu, X. 2012. Nitrogen removal and microbial community profiles in six wetland columns receiving high ammonia load. Chemical Engineering Journal. 203: 326-332.

Sundberg, C., Stendahl, J. S. K., Tonderski, K. y Lindgren, P. E. 2007. Overland flow systems for treatment of landfill leachates - Potential nitrification and structure of the ammoniaoxidising bacterial community during a growing season. Soil Biology and Biochemistry. 39: 127-138.

Szogi, A. A. y Hunt, P. G. 2001. Distribution of ammonium-N in the water-soil interface of a surface-flow constructed wetland for swine wastewater treatment. Water Science and Technology. 44: 11-12.

Szogi, A. A., Hunt, P. G., Sadler, E. J. y Evans, D. E. 2004. Characterization of OxidationReduction Processes in Constructed Wetlands for Swine Wastewater Treatment. Applied Engineering in Agriculture. 20: 189-200.

Takeuchi, M., Sakane, T., Yanagi, M., Yamasato, K., Hamana, K. y Yokota, A. 1995. Taxonomic Study of Bacteria Isolated from Plants: Proposal of Sphingomonas rosa sp. nov., Sphingomonas pruni sp. nov., Sphingomonas asaccharolytica sp. nov., and Sphingomonas mali sp. nov. International Journal of Systematic and Evolutionary Microbiology. 45: 334-341.

Tamura, K., Peterson, D., Peterson, N., Stecher, G., Nei, M. y Kumar, S. 2011. MEGA5: Molecular Evolutionary Genetics Analysis Using Maximum Likelihood, Evolutionary Distance, and Maximum Parsimony Method. Molecular Biology and Evolution. 28: 2731-2739.

Tani, A., Akita, M., Murase, H. y Kimbara, K. 2011. Culturable bacteria in hydroponic cultures of moss Racomitrium japonicum and their potential as biofertilizers for moss production. Journal of Bioscience and Bioengineering. 112: 32-39.

Tanner, C. C. y Kloosterman, V. C. 1997. Guidelines for Constructed Wetland Treatment of Farm Dairy Wastewaters in New Zealand. National Institute of Water and Atmospheric Research. Hamilton, Nueva Zelanda.

Tao, W., Hall, K. J. y Duff, S. J. B. 2006. Performance evaluation and effects of hydraulic retention time and mass loading rate on treatment of woodwaste leachate in surfaceflow constructed wetlands. Ecological Engineering. 26: 252-265.

Tao, W., Hall, K. J. y Duff, S. J. B. 2007. Microbial biomass and heterotrophic production of surface flow mesocosm wetlands treating woodwaste leachate: Responses to hydraulic and organic loading and relations with mass reduction. Ecological Engineering. 31: 132-139.

Tchobanoglous, G. 2003. Preliminary treatment in construted wetlands. 1st International seminar on the use of aquatic macrophytes for wastewater treatment in constructed wetlands. Lisboa, Portugal. 13-33.

Tchobanoglous, G., Burton, F. L. y Stensel, H. D. 2003. Wastewater Engineering: Treatment and Reuse. 4th edition. Mc Graw Hill, Nueva York, NY, USA.

Teske, A., Alm, E., Regan, J. M., Toze, S., Rittman, B. E. y Stahl, D. A. 1994. Evolutionary relationship among ammonia and nitrite-oxidizing bacteria. Journal of Bacteriology. 176: 6623-6630.

Tetens, O. 1930. Uber einige meteorologische Begriffe. Zeitschrift fur Geophysik. 6: 297-309.

Thistleton, J., Clark, T., Pearce, P. y Parsons, S. A. 2001. Mechanisms of Chemical Phosphorus Removal 1 - Iron (II) Salts. Process Safety and Environmental Protection. 79: 339-344.

Thistleton, J., Berry, T. A., Pearce, P. y Parsons, S. A. 2002. Mechanisms of Chemical Phosphorus Removal II: Iron (III) Salts. Process Safety and Environmental Protection. 80: 265-269. 
Tietz, A., Kirschner, A., Langergraber, G., Sleytr, K. y Haberl, R. 2007. Characterisation of microbial biocoenosis in vertical subsurface flow constructed wetlands. Science of the Total Environment. 380: 160-172.

Torsvik, V. y Ovreas, L. 2002. Microbial diversity and function in soil: from genes to ecosystems. Current Opinion in Microbiology. 5: 240-245.

Truu, M., Juhanson, J. y Truu, J. 2009. Microbial biomass, activity and community composition in constructed wetlands. Science of the Total Environment. 407: 3958-3971.

Ueki, A., Akasaka, H., Suzuki, D. y Ueki, K. 2006. Paludibacter propionicigenes gen. nov., sp. nov., a novel strictly anaerobic, Gram-negative, propionate-producing bacterium isolated from plant residue in irrigated rice-field soil in Japan. International Journal of Systematic and Evolutionary Microbiology. 56: 39-44.

USDA. 1993. Soil Survey Manual - Soil Survey Division Staff United States Department of Agriculture. USA.

USEPA. 1988. Design Manual. Constructed Wetlands and Aquatic Plant Systems for Municipal Wastewater Treatment Office Research Development. Center for Environmental Research Information. Cincinnati, OH, USA.

USEPA. 1993. Subsurface Flow Constructed Wetlands For Wastewater Treatment. A Technology Assessment. Office Of Water. Washington DC, USA.

USEPA. 2000. Manual. Constructed Wetlands Treatment of Municipal Wastewaters. Cincinnati, OH, USA.

USEPA. 2010. Causal Analysis/Diagnosis Decision Information System (CADDIS). www.epa.gov/caddis. Fecha de acceso: 27-08-2013.

USEPA. 2012. Water: Monitoring \& Assessment. Conductivity. www.water.epa.gov/type/rsl/monitoring/vms59.cfm. Fecha de acceso: 27-08-2013.

Vacca, G., Wand, H., Nikolausz, M., Kuschk, P. y Kästner, M. 2005. Effect of plants and filter materials on bacteria removal in pilot-scale constructed wetlands. Water Research. 39: 1361-1373.

Valsami-Jones, E. 2001. Mineralogical controls on phosphorus recovery from wastewaters. Mineralogical Magazine. 65: 611-620.

Van Aken, B., Peres, C. M., Doty, S. L., Yoon, J. M. y Schnoor, J. L. 2004. Methylobacterium populi sp. nov., a novel aerobic, pink-pigmented, facultatively methylotrophic, methane-utilizing bacterium isolated from poplar trees (Populus deltoides $x$ nigra DN34). International Journal of Systematic and Evolutionary Microbiology. 54: 11911196.

Van Oostrom, A. J. y Russell, J. M. 1994. Denitrification in constructed wastewater wetlands receiving high concentrations of nitrate. Water Science \& Technology. 29: 7-14.

Vanotti, M. B. y Hunt, P. G. 1999. Solids and Nutrient Removal from Flushed Swine Manure using Polyacrylamides. American Society of Agricultural Engineers. 42: 1833-1840.

Vohla, C., Koiv, M., Bavor, H. J., Chazarenc, F. y Mander, U. 2011. Filter materials for phosphorus removal from wastewater in treatment wetlands - A review. Ecological Engineering. 37: 70-89.

Vymazal, J. 1995. Algae and element cycling in wetlands. Lewis Publishers, Chelsea, MI, USA.

Vymazal, J. 1996. The use of subsurface-flow constructed wetlands for wastewater treatment in the Czech Republic. Ecological Engineering. 7: 1-14.

Vymazal, J., Brix, H., Cooper, P. F., Haberl, R., Perfler, R. y Laber, J. 1998. Removal mechanisms and types of constructed wetlands. pp. 17-66 en Vymazal, J., Brix, H., Cooper, P. F., Green, M. B. y Haberl, R., editores. Constructed wetlands for wastewater treatment in Europe. Backhuys Publishers. Leiden, Holanda.

Vymazal, J. 2003a. Removal Mechanisms in Constructed Wetlands. 1st International Seminar on the Use of Aquatic Macrophytes for Wastewater Treatment in Constructed Wetlands. Lisboa, Portugal.

Vymazal, J. 2003b. Types of Constructed Wetlands. Proceedings of the 1st International Seminar on The Use of Aquatic Macrophytes for Wastewater Treatment in Constructed Wetlands. Lisboa, Portugal. 35-79. 
Vymazal, J. 2005. Horizontal sub-surface flow and hybrid constructed wetlands systems for wastewater treatment. Ecological Engineering. 25: 478-490.

Vymazal, J. 2007. Removal of nutrients in various types of constructed wetlands. Science of the Total Environment. 380: 48-65.

Vymazal, J. 2009. The use constructed wetlands with horizontal sub-surface flow for various types of wastewater. Ecological Engineering. 35: 1-17.

Wade, W. 2002. Unculturable bacteria - the uncharacterized organisms that cause oral infections. Journal of the Royal Society of Medicine. 95: 81-83.

Wagner, M. y Loy, A. 2002. Bacterial community composition and function in sewage treatment systems. Current Opinion in Microbiology. 13: 218-227.

Wallace, S. D. y Knight, R. L. 2006. Small Scale Constructed Wetland Treatment Systems: Feasibility, Design Criteria and O\&M Requirements. Water Environment Research Foundation. Londres, Reino Unido.

Webb, P. A. 2003. Introduction to Chemical Adsorption Analytical Techniques and their Applications to Catalysis. http://www.micromeritics.com/repository/files/intro_to_chemical_adsorption.pdf. Fecha de acceso: 23-Julio-2013.

Weber, K. P., Gehder, M. y Legge, R. L. 2008. Assessment of changes in the microbial community of constructed wetland mesocosms in response to acid mine drainage exposure. Water Research. 42: 180-188.

Weber, K. P. y Legge, R. L. 2011. Dynamics in the bacterial community-level physiological profiles and hydrological characteristics of constructed wetland mesocosms during start-up. Ecological Engineering. 37: 666-677.

Wen, Y., Chen, Y., Zheng, N., Yang, D. y Zhou, Q. 2010. Effects of plant biomass on nitrate removal and transformation of carbon sources in subsurface-flow constructed wetlands. Bioresource Technology. 101: 7286-7292.

Whang, L. M., Chien, I. C., Yuan, S. L. y Wu, Y. J. 2009. Nitrifying community structures and nitrification performance of full-scale municipal and swine wastewater treatment plants. Chemosphere. 75: 234-242.

Wieder, R. K. 1989. A survey of constructed wetlands for acid coal mine drainage treatment in the eastern United States. Wetlands. 9: 299-315.

Wießner, A., Kuschk, P., Kästner, M. y Stottmeister, U. 2002. Abilities of Helophyte Species to Release Oxygen into Rhizospheres with Varying Redox Conditions in Laboratory-Scale Hydroponic Systems. International Journal of Phytoremediation. 4: 1-15.

Wolterink, A., Kim, S., Muusse, M., Kim, I. S., Roholl, P. J. M., van Ginkel, C. G., Stams, A. J. M. y Kengen, S. W. M. 2005. Dechloromonas hortensis sp. nov. and strain ASK-1, two novel (per)chlorate-reducing bacteria, and taxonomic description of strain GR-1. International Journal of Systematic and Evolutionary Microbiology. 55: 2063-2068.

Wynn, T. M. y Liehr, S. K. 2001. Development of a constructed subsurface-flow wetland simulation model. Ecological Engineering. 16: 519-536.

Wyss, C., Choi, B. K., Schüpbach, P., Moter, A., Guggenheim, B. y Göbel, U. B. 1999. Treponema lecithinolyticum sp. nov., a small saccharolytic spirochaete with phospholipase $\mathrm{A}$ and $\mathrm{C}$ activities associated with periodontal diseases. International Journal of Systematic and Evolutionary Microbiology. 49: 1329-1339.

Xia, S., Duan, L., Song, Y., Jixiang, L., Piceno, Y. M., Andersen, G. L., Alvarez-Cohen, L., Moreno-Andrade, I., Huang, C. L. y Hermanowicz, S. W. 2010. Bacterial Community Structure in Geographically Distributed Biological Wastewater Treatment Reactors. Environmental Science \& Technology. 44: 7391-7396.

Xie, C. H. y Yokota, A. 2006. Reclassification of [Flavobacterium] ferrugineum as Terrimonas ferruginea gen. nov., comb. nov., and description of Terrimonas lutea sp. nov., isolated from soil. International Journal of Systematic and Evolutionary Microbiology. 56: 1117-1121.

Xie, J., Wu, S., Lin, J., Cai, J., Chen, Z. y Wei, W. 2012. Recycling of basic oxygen furnace slag in asphalt mixture: Material characterization \& moisture damage investigation. Construction and Building Materials. 36: 467-474. 
Xinshan, S., Qin, L. y Denghua, Y. 2010. Nutrient Removal by Hybrid Subsurface Flow Constructed Wetlands for High Concentration Ammonia Nitrogen Wastewater. Procedia Environmental Sciences. 2: 1461-1468.

Xue, Y., Hou, H. y Zhu, S. 2009. Characteristics and mechanisms of phosphate adsorption onto basic oxygen furnace slag. Journal of Hazardous Materials. 162: 973-980.

Yamada, H., Kayama, M., Saito, K. y Hara, M. 1986. A fundamental research on phosphate removal by using slag. Water Research. 20: 547-557.

Yeoman, S., Stephenson, T., Lester, J. N. y Perry, R. 1988. The Removal of Phosphorus During Wastewater Treatment: A Review. Environmental Pollution. 49: 183-233.

Yildirim, I. Z. y Prezzi, M. 2009. Use of Steel Slag in Subgrade Applications. Indiana Department of Transportation and Purdue University. West Lafayette, IN, USA.

Yildirim, I. Z. y Prezzi, M. 2011. Chemical, Mineralogical, and Morphological Properties of Steel Slag. Advances in Civil Engineering. 2011: 1-13.

Yoon, J. H., Kang, S. J., Lee, J. S. y Oh, T. K. 2007. Flavobacterium terrigena sp. nov., isolated from soil. International Journal of Systematic and Evolutionary Microbiology. 57: 947950.

Zhang, C. B., Wang, J., Liu, W. L., Zhu, S. X., Ge, H. L., Chang, S. X., Chang, J. y Ge, Y. 2010. Effects of plant diversity on microbial biomass and community metabolic profiles in a full-scale constructed wetland. Ecological Engineering. 36: 62-68.

Zhao, Y., Liu, B., Zhang, W., Hu, C. y An, S. 2010. Effects of plant and influent C:N:P ratio on microbial diversity in pilot-scale constructed wetlands. Ecological Engineering. 36: 441-449.

Zhu, N., An, P., Krishnakumar, B., Zhao, L., Sun, L., Mizuochi, M. y Inamori, Y. 2007. Effect of plant harvest on methane emission from two constructed wetlands designed for the treatment of wastewater. Journal of Environmental Management. 85: 936-943.

Zhu, W. L., Cui, L. H., Ouyang, Y., Long, C. F. y Tang, X. D. 2011. Kinetic Adsorption of Ammonium Nitrogen by Substrate Materials for Constructed Wetlands. Pedosphere. 21: 454-463.

Ziemer, C. J., Cotta, M. A. y Whitehead, T. R. 2004. Application of group specific amplified rDNA restriction analysis to characterize swine fecal and manure storage pit samples. Anaerobe. 10: 217-227.

Zumft, W. G. 1992. The denitrifying prokaryotes. pp. 554-582 en Balows, A., Trüper, H. G., Dworkin, M., Harder, W. y Schleifer, K. H., editores. The prokaryotes. A handbook on the biology of bacteria: ecophysiology, isolation, identification, applications. Springer. Nueva York, Berlin, Heidelberg.

Zuur, A. F., Leno, E. N. y Smith, G. M. 2007. Analysing Ecological Data. Springer, Nueva York, NY, USA. 